\title{
JUNTAS EM PAVIMENTOS DE CONCRETO: DISPOSITIVOS DE TRANSFERÊNCIA DE CARGA
}

\section{LEZZIR FERREIRA RODRIGUES}

Tese apresentada à Escola de Engenharia de São Carlos, da Universidade de São Paulo, como parte dos requisitos para obtenção do título de Doutor em Engenharia de Estruturas.

Orientador: Prof. Dr. Libânio Miranda Pinheiro Co-Orientador: Prof. Dr. Gilson Natal Guimarães

São Carlos 2008 

À mãe santíssima Nossa Senhora, com muito amor 



\section{AGRADECIMENTOS}

A DEUS, meu querido pai maior e consolador, pelo amparo e força necessários à concretização deste trabalho. Aos meus amados pais, Eliphis Levi e Nadir, cujo amor e dedicação possibilitam esta jornada. Ao meu noivo, Leandro Waidemam, que soube amar e compartilhar como verdadeiro e eterno companheiro. Às minhas queridas irmãs, Lesley e Leízza, pelo carinho. Ao meu querido e também amado amigo Paê, que ante a qualquer adversidade permaneceu sempre a meu lado. Aos familiares e amigos, presentes ou ausentes, que preencheram todos os importantes momentos.

Ao professor, em especial, Libânio Miranda Pinheiro, cuja amizade e apoio incondicional viabilizaram esta pesquisa. Ao também querido professor Gilson Natal Guimarães, amigo constante. Ao professor Jorge Miguel Proença pelo carinho e apoio à pesquisa. Ao professor Reginaldo Teixeira Coelho, conselheiro astuto e grande incentivador.

Aos demais professores do Curso de Pós-Graduação em Engenharia de Estruturas da EESC-USP, que incentivaram e ajudaram a construir formação primorosa. Aos colegas e profissionais pelo auxílio prestado, em especial ao técnico Caio Leonardo, cuja dedicação muito ajudou na pesquisa.

À CAPES e à FAPESP, respectivamente pela Bolsa de Doutorado e pelo Auxílio, que possibilitaram a realização deste trabalho.

Aos Laboratórios de Estruturas da EESC-USP e da UFG, à UCG e à UFSCar, pela realização dos ensaios experimentais, e ao IST-UTL pela realização da análise numérica. Às empresas Perfinasa - Perfilados e Ferros Nossa Senhora Aparecida Ltda. e Carlos Campos Consultoria Ltda. pelo apoio.

A todos os pesquisadores, que com dedicação e renúncia, ajudam a construir a cartilha do saber e promovem a melhoria da educação e da tecnologia, em nosso país. 



\section{RESUMO}

Este trabalho apresenta um estudo experimental do comportamento de juntas transversais em placas de concreto simples, apoiadas sobre fundação elástica. Uma vez sujeita a tensões, provocadas tanto pelo carregamento como por empenamentos e variações volumétricas da placa, as juntas podem provocar uma redução sensível na vida do pavimento, caso não estejam devidamente dimensionadas para suportar as cargas impostas. Devido a isto, a conexão mecânica entre as placas do pavimento é fundamental para garantir uma melhor eficiência na transferência desses esforços e, consequentemente, um aumento na vida útil do pavimento. No trabalho, faixas de concreto, com dimensões de $220 \mathrm{~cm} \times 60 \mathrm{~cm}$ e espessuras de $12 \mathrm{~cm}$ e $16 \mathrm{~cm}$, foram ensaiadas com força monotônica até a ruína, considerando força em um dos lados da junta. O estudo analisou o comportamento do sistema placa-junta para diferentes dispositivos metálicos de transferência, sendo eles: barras de seções circulares e quadradas, placas e discos, adotando dois dispositivos por modelo ensaiado. Dois diferentes tipos de juntas foram analisados, segundo sua tipologia, como juntas serradas e juntas moldadas. Os resultados experimentais mostram que o aumento na espessura do pavimento aumenta sua capacidade resistente, para os dois tipos de junta. Já a tipologia da junta pode influenciar na força de ruína da peça, uma vez que a presença de concreto abaixo do dispositivo causa variação na rigidez vertical do conjunto, conhecida como interação concretobarra, levando o modelo serrado a romper com uma carga superior. Os ciclos de carregamento aumentaram a propagação de fissuras sob o lado carregado, reduziram a força de fissuração em parte dos modelos, mas não reduziram sua força de ruína. O disco metálico, em função dos dados coletados, apresentou o melhor desempenho em relação aos demais, e é sugerido como o dispositivo de transferência de carga preferencial para se obter uma maior eficiência do sistema.

Palavras-chave: pavimentação, pavimentos de concreto, junta transversal, dispositivos de transferência. 


\section{ABSTRACT}

This paper presents an experimental study of the behavior of transverse joints in slabs of plain concrete, under elastic support. Once it subjects to tensions, caused so much by the loading as for warped and volumetric variations of the slap, the joints can cause a sensitive reduction in the life of the pavement, in case they are not properly design to support the loads forced. Due to this, the mechanical connection among the slabs of the pavement is fundamental to guarantee a better efficiency in the transfer of those efforts and, consequently, a prolongation in the useful life of the pavement. In the paper, concrete areas, with dimensions of $220 \mathrm{~cm} \times 60 \mathrm{~cm}$ and thickness of $12 \mathrm{~cm}$ and $16 \mathrm{~cm}$ were loading frame monotonic until the rupture, in one on the sides of the joint. The study analyzed the behavior of the system slab/joint for different metallic devices of transfer, being them: dowels of circular and square sections, plates and disks, adopting two devices for model. Two different types of joints were analyzed, according to the typology, as sawed and molded joints. The tests data show that the increase in the thickness of the pavement increases in resistant capacity, for the two types of joints. Already the typology of the joints can influence in the maximum load of the model, once the concrete presence below the device causes variation in the vertical rigidity of the group, known as interaction concrete-dowel, taking the sawed model rupture with a superior load. The loading cycles increased the cracks propagation under the load side, they reduced the load crack partly of the models, but they didn't reduce ultimate force. The disk plate, in function of the collected data, presented the best performance in relation to the others, and it is suggested as the preferential transfer device of load to obtain a larger efficiency of the system.

Keywords: paving, concrete pavements, transverse joint, transfer devices. 


\section{LISTA DE SIGLAS}

AASHTO American Association of State Highway and Transportation Official ABNT Associação Brasileira de Normas Técnicas

ACPA American Concrete Pavement Association

ASTM American Society for Testing and Materials

CAD Concreto de alto desempenho

CBUQ Concreto Betuminoso Usinado a Quente

CEL Célula de carga

DCP Danley Construction Products

DNIT Departamento Nacional de Infra-Estrutura de Transporte

DNER Departamento Nacional de Estradas e Rodagem

DSA Doublé Shearing Aparatus

ECS Epoxy coated steel

ESAL Equivalente Single Axle Load

EESC Escola de Engenharia de São Carlos

GFRP Glass fiber reinforced polymer

IPR Instituto de Pesquisas Rodoviárias

LVDTs Linear Variable Differential Transformers

MEF Método dos Elementos Finitos

UCG Universidade Católica de Goiás

UFG Universidade Federal de Goiás

UFSCar Universidade Federal de São Carlos

USP Universidade de São Paulo

UTL Universidade Técnica de Lisboa 


\section{LISTA DE SÍMBOLOS}

A Área do plano de corte

$A_{s} \quad$ Área de seção transversal da armadura

a Raio da área de contato da carga

aj Abertura da junta

$b \quad$ Raio de distribuição equivalente de pressões na face inferior da placa

C Taxa de compressão na borracha

$C_{u} \quad$ Leitura na célula de carga do lado não carregado

$C_{L} \quad$ Leitura na célula de carga do lado carregado

c Constante referente à forma de distribuição da resultante

D Diagonal da placa metálica ou o diâmetro do círculo circunscrito

DCI Rigidez vertical

$d_{u} \quad$ Deslocamento vertical do lado não carregado

$d_{L} \quad$ Deslocamento vertical do lado carregado

E Capacidade de transferência de carga medida pela eficiência

$E_{c} \quad$ Módulo de elasticidade do concreto

$E_{s} \quad$ Módulo de elasticidade da barra

$e \quad$ Espessura do dispositivo

F $\quad$ Força aplicada

$F_{u} \quad$ Força última

$F_{\text {fiss }} \quad$ Força cortante de fissuração

$F_{\text {máx }} \quad$ Força máxima

$F_{\text {mín }} \quad$ Força mínima 
$f_{c k} \quad$ Resistência característica à compressão do concreto

$f_{c t, f} \quad$ Resistência do concreto à tração na flexão

$f_{c t m} \quad$ Resistência média do concreto à tração

$f_{y} \quad$ Resistência de escoamento aço

$f_{s} \quad$ Tensão no aço

$f_{u} \quad$ Resistência última do aço

f $\quad$ Frequência de aplicação da força

f $\quad$ Fator de forma para o aço

G Módulo de elasticidade transversal do aço da placa retangular

$h \quad$ Espessura da placa de concreto

I Momento de inércia da barra

$I_{C} \quad$ Momento de inércia da barra circular

$I_{D} \quad$ Momento de inércia do disco metálico

$I_{P L} \quad$ Momento de inércia da placa metálica

$I_{Q} \quad$ Momento de inércia da barra quadrada

$I_{s} \quad$ Momento de inércia da placa retangular

K Módulo de reação da barra

$k \quad$ Coeficiente de recalque da fundação ou módulo de Westergaard

$\mathrm{k} \quad$ Rigidez da mola

$L \quad$ Espaçamento entre as juntas

$L_{L} \quad$ Comprimento de parte da placa apoiada na fundação do lado carregado

$L_{u} \quad$ Comprimento de parte da placa apoiada na fundação do lado não carregado

LTE Porcentagem de carga transferida nos deslocamentos

$\ell \quad$ Raio de rigidez de uma placa de concreto 
$\ell_{Q} \quad$ Lado da seção quadrada

$\ell_{P L} \quad$ Lado da placa metálica

$\log \mathrm{N} \quad$ Logaritmo do número de ciclos à fadiga

l Comprimento da barra

$M_{\max } \quad$ Momento fletor máximo

$M_{0} \quad$ Momento fletor na estrutura à esquerda da face do corpo elástico

$N \quad$ Número de ciclos

$\mathrm{N}_{\mathrm{i}} \quad$ Número de repetições que causaria a ruptura por fadiga

$\mathrm{n}_{\mathrm{i}} \quad$ Número de repetições aplicadas sob condição particular de tensões

$P_{t} \quad$ Proporção de carga transferida

$P_{c} \quad$ Porção de força crítica transferida por uma barra

p Pressão transmitida ao subleito

$p^{\prime} \quad$ Pressão em barra de transferência

$q \quad$ Reação da fundação

$R_{u} \quad$ Resultante experimental do lado não carregado

$R_{L} \quad$ Resultante experimental do lado carregado

$R_{L, \text { teo }} \quad$ Resultante teórica do lado carregado

$R_{u, \text { teo }} \quad$ Resultante teórica do lado não carregado

$R_{1} \quad$ Resultante de pressão em barra de transferência

$R_{2} \quad$ Resultante de pressão em barra de transferência

$t_{i} \quad$ Espessura inicial na borracha

$t_{f} \quad$ Espessura final na borracha

$t_{e} \quad$ Espessura do espaçador utilizado em ensaios na borracha

$V \quad$ Força cortante 
y Deslocamento vertical da área carregada

$y_{n c} \quad$ Deslocamento vertical do lado não carregado

$y_{c} \quad$ Deslocamento vertical do lado carregado

$y_{0} \quad$ Deslocamento localizado sob o ponto de aplicação da força

$\beta \quad$ Rigidez relativa da barra

$\varepsilon \quad$ Deformação

$\varepsilon_{u} \quad$ Deformação na ruptura

$\varepsilon_{y \phi} \quad$ Deformação no escoamento para barra de seção circular

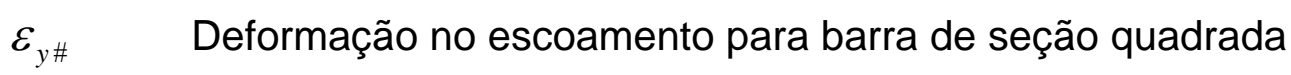

$\varepsilon_{y, \text { chapa }}$ Deformação no escoamento para chapa metálica

$\varepsilon_{c u} \quad$ Deformação última do concreto na compressão

$\varepsilon_{c t} \quad$ Deformação última do concreto na tração

$\varepsilon_{y} \quad$ Deformação no escoamento

$\phi \quad$ Diâmetro da barra

$\gamma \quad$ Constante que leva em conta a existência de vazio

$\mu \quad$ Coeficiente de atrito

$v \quad$ Coeficiente de Poisson do concreto

$\theta \quad$ Ângulo

$\rho \quad$ Taxa de armadura

$\sigma_{n c} \quad$ Tensão na face inferior da placa, no lado não carregado

$\sigma_{c} \quad$ Tensão na face inferior da placa, para o lado carregado

$\sigma_{c, \text { teo }} \quad$ Tensão máxima teórica no canto da placa

$\sigma_{i, t e o} \quad$ Tensão máxima teórica no interior da placa 
$\sigma_{b, t e o} \quad$ Tensão máxima teórica na borda da placa

$\sigma_{e} \quad$ Tensão de esmagamento

$\sigma_{\max } \quad$ Tensão máxima aplicada

$\sigma_{y} \quad$ Resistência do aço ao escoamento

$\tau \quad$ Tensão de cisalhamento

$\Delta E \quad$ Perda em potencial da capacidade de transferir carga

$\Delta_{\text {placa }} \quad$ Deslocamento vertical total da placa de concreto 


\section{SUMÁRIO}

INTRODUÇÃO__ 1

1.1 JUSTIFICATIVA

1.2 OBJETIVOS _ 3

1.3 METODOLOGIA __ 4

1.4 ESTRUTURA DO TRABALHO __ 4

JUNTAS EM PAVIMENTOS _ 7

2.1 JUNTAS EM PAVIMENTOS DE CONCRETO __ 7

2.1.1 Transferência de carga __ 11

2.1.2 Dispositivos de transferência de carga __ 15

2.1.3 Métodos de dimensionamento das juntas ___ 18

2.2 HISTÓRICO DO ESTUDO SOBRE JUNTAS _ 20

2.3 ESTUDOS TEÓRICO-EXPERIMENTAIS EM JUNTAS __ 23

2.3.1 Westergaard (1928) _ 23

2.3.2 Bradbury (1932) __ 25

2.3.3 Friberg, B. F. (1938) e (1940)__ 28

2.3.4 Teller e Cashell (1958)__ 33

2.3.5 Buch e Zollinger (1996) __ 41

2.3.6 Mannava, Bush e Kukreti (1999) ___ 43

2.3.7 Eddi; Shalaby e Rizkalla (2001) __ 46

2.3.8 Silva (2001) _ 50

2.3.9 Murison, Shalaby e Mufti (2004) _ 53

2.3.10 Cervo (2004) _ 58

2.3.11 Tertuliano (2005) _ _ 61

2.3.12 Walker e Holland (1998)___ 64

2.3.13 Danley Construction Products (2000) _ 69

2.3.14 Shaw e Shaw (2005) _ 71

2.4 Cisalhamento em conexões

2.4.1 Hofbeck, Ibrahim e Mattock (1969) __ 72

2.4.2 Mattock e Hawkins (1972) _ 74

2.4.3 Aziz e Jalalifar (2007)__ 75 


\section{MODELOS NUMÉRICOS PARA ANÁLISE DE PAVIMENTOS}

DE CONCRETO

3.1 CONSIDERAÇÕES INICIAIS 77

3.2 HISTÓRICO DO ESTUDO NUMÉRICO _ 78

3.3 MODELOS COMPUTACIONAIS___ 80

3.3.1 Scarpas, Ehrola \& Judycki (1994) __ 80

3.3.2 Davids e Mahoney (1999) __ 82

3.3.3 Murison, Shalaby e Mufti (2002) _ 85

3.3.4 Maggi (2004) _ 87

PROCEDIMENTO EXPERIMENTAL _ 89

4.1 CONSIDERAÇÕES GERAIS _ 89

4.2 ENSAIOS NOS MODELOS__ 90

4.2.1 Características dos modelos _ 90

4.2.2 Dispositivos de transferência ___ 94

4.2.3 Materiais__ 97

4.2.4 Confecção dos modelos e dos corpos-de-prova ___ 98

4.2.5 Montagem dos ensaios _ 104

4.2.6 Sistema de ensaio _ـ 107

4.2.7 Instrumentação___ 109

4.3 ENSAIOS NA FUNDAÇÃO __ 117

SIMULAÇÕES NUMÉRICAS 125

5.1 INTRODUÇÃO _ 125

5.2 PRÉ-PROCESSAMENTO _ 125

5.2.1 Elementos finitos utilizados __ 127

5.2.2 Definição da malha de elementos finitos __ 131

5.2.3 Acoplamentos e vinculações __ 133

5.2.4 Relações constitutivas utilizadas ___ 133

5.3 SOLUÇÃO__ 141

APRESENTAÇÃO DOS RESULTADOS _ 143

6.1 PROPRIEDADE DOS MATERIAIS __ 143

6.1.1 Concreto___ 143

6.1.2 Dispositivos de transferência___ 145

6.1.3 Camada de Borracha __ 147 
6.2 CISALHAMENTO DUPLO 152

6.3 FISSURAÇÃO __ 156

6.3.1 Modelos com junta serrada __ 157

6.3.2 Modelos com junta moldada _ـ 160

6.4 MODOS DE RUÍNA E CRITÉRIO DE PARADA DOS ENSAIOS _ 163

6.4.1 Modos de ruína _ 163

6.4.2 Critério de parada dos ensaios _ـ 164

6.5 FORÇAS E DESLOCAMENTOS___ 167

6.5.1 Juntas serradas - ensaio estático _ـ 167

6.5.2 Juntas serradas - ensaio cíclico __ 178

6.5.3 Juntas moldadas _ـ 188

6.6 EXTENSOMETRIA _ 197

6.6.1 Deformação no concreto ___ 198

6.6.2 Deformação no aço ___ 205

ANÁLISE DOS RESULTADOS__ 233

7.1 PLACAS VERSUS CORPOS-DE-PROVA PRISMÁTICOS ___ 233

7.2 EFICIÊNCIA DAS JUNTAS___ 234

7.3 FORÇAS E DESLOCAMENTOS__ 239

7.4 REAÇÕES DE APOIO____ 246

CONCLUSÕES E RECOMENDAÇÕES __ 253

8.1 CONCLUSÕES __ 253

8.2 RECOMENDAÇÕES __ 256

8.3 SUGESTÕES PARA TRABALHOS FUTUROS __ 257

BIBLIOGRAFIA _ 259

APÊNDICE A $\quad 267$

APÊNDICE B _ 273 



\section{CAPÍTULO 1}

INTRODUÇÃO

\subsection{JUSTIFICATIVA}

Neste item serão considerados aspectos específicos que justifiquem o estudo de juntas transversais com mecanismos de transferência de cargas, em pavimentos de concreto. Serão apresentadas, também, uma breve consideração sobre o estado da arte da pavimentação rodoviária brasileira e a importância do pavimento de concreto no cenário nacional.

\subsubsection{Justificativa geral}

Os pavimentos de concreto, atualmente, vêm se tornando objeto de grande interesse por parte de pesquisadores, por se tornar uma alternativa economicamente viável e de grande durabilidade, para a execução de pavimentos.

No entanto, do ponto de vista estrutural, poucos estudos estão sendo feitos no Brasil. O desenvolvimento de pesquisas se limita às universidades, como a Universidade de São Paulo (USP) e a Universidade Federal de Goiás (UFG).

O Laboratório de Mecânica dos Pavimentos (LMP), criado em 1997 na Escola Politécnica da USP, desenvolve atividades de pesquisa voltadas à interpretação mecanicista da interação das cargas, do ambiente e das estruturas de pavimentos. Desenvolveu mais recentemente o primeiro projeto de pavimentos de concretos instrumentados e monitorados, incluindo uma seção de Whitetopping Ultradelgado (WTUD), para o estudo de gradientes térmicos em placas de concreto.

O Laboratório de Estruturas da UFG, desde o ano de 2001, estuda o comportamento estrutural de pavimentos de concreto por meio de ensaios laboratoriais e análises computacionais. A influência de parâmetros, como espessura, abertura da junta e barras de transferência, é estudada na resposta do pavimento às solicitações. 
Esse conjunto de profissionais atua na divulgação de pesquisas voltadas à pavimentação no país, e visam aumentar a participação dos pavimentos de concreto na malha viária brasileira, que atualmente corresponde a $2 \%$.

O perfil da malha viária federal brasileira é alarmante, segundo o Departamento Nacional de Infra-estrutura de Transportes (DNIT, 2002), do Ministério dos Transportes, para o ano de 2002. Cerca de 24\% das rodovias federais executadas em pavimento flexível não apresentam condições ideais de tráfego seguro, estando em mau ou péssimo estado de conservação, já necessitando de reabilitação ou mesmo reconstrução, em alguns casos.

De acordo com Packard (1994), economicamente, o custo inicial para construção de pavimento de concreto em vias de tráfego médio e pesado é normalmente igual ou um pouco maior que o flexível. Considerando-se o mesmo período de vida útil para um longo prazo, entre os pavimentos de concreto e os pavimentos asfálticos, o custo final será igual ou menor para pavimentos rígidos, quando dimensionados para a mesma condição.

Há então necessidade de melhor atender às exigências do mercado, que cada vez mais prima pela durabilidade, desempenho e pequeno custo de estruturas de concreto, e para isso torna-se fundamental o melhoramento e a inovação técnica, por parte dos profissionais do ramo.

\subsubsection{Justificativa específica}

Os dispositivos de transferência têm o desempenho ditado por dois parâmetros principais: o espaçamento e as dimensões dos dispositivos e, secundariamente, a abertura da junta.

Apesar da importância desses parâmetros, é prática comum o emprego de um espaçamento fixo, geralmente de $30 \mathrm{~cm}$. O diâmetro das barras é fornecido em tabelas, adotado conforme a espessura do pavimento (Rodrigues e Cassaro, 1998).

No entanto, não existe a adoção sistemática de métodos analíticos para determinação numérica de tensões, deformações e deslocamentos verticais; e de métodos mecânicos para previsão da resposta da estrutura, traduzida do cálculo analítico. Sendo assim, Hall (2004) afirma serem necessários: a criação de métodos para dimensionamento de juntas transversais nos pavimentos; metodologia 
mecânica empírica para dimensionamento; e estudo da influência dos tipos de base e de suas propriedades, no comportamento do pavimento.

Segundo Eddie, Shalaby e Rizkalla (2001), não existe uma metodologia para limitação dos deslocamentos verticais nas juntas, além do desconhecimento do comportamento do pavimento frente aos efeitos do carregamento de longa duração. Há uma lacuna no que se refere ao projeto de juntas.

Existem elementos finitos capazes de representar materiais frágeis como o concreto, analisando numericamente o problema e permitindo a visualização da distribuição de tensões, deformações e formação das fissuras. Porém, esses modelos numéricos necessitam de validação experimental, que é uma das propostas desta pesquisa.

É devido a essas disposições e sugestões de pesquisadores, para conhecimento mais detalhado do comportamento desse tipo de estrutura, que se propõe estudar numérica e experimentalmente, neste trabalho, os mecanismos de transferências de carga entre placas de concreto simples, por meio da adoção de dispositivos de transferência com barras de seção circular e quadrada, placas quadradas e discos. Propõe-se estudar, também, a eficiência das juntas transversais nos pavimentos de concreto.

\subsection{OBJETIVOS}

Do ponto de vista da engenharia estrutural, o objetivo desta tese de doutorado é o estudo do comportamento de juntas transversais de pavimentos de concreto simples, quando submetidas a carregamentos monotônicos e cíclicos, em um dos lados da junta. Os modelos ensaiados para carregamento cíclico serão avaliados sob cargas de serviço.

Serão consideradas juntas serradas e moldadas, por meio de ensaios experimentais realizados em placas sobre apoio deformável, avaliando a influência de alguns parâmetros na resposta do pavimento às solicitações.

Como objetivos específicos, podem-se citar:

- Avaliar a variação da seção transversal dos dispositivos de transferência, presentes em juntas serradas e moldadas, utilizando as curvas tensão- 
deformação do aço e do concreto, e as forças e os deslocamentos verticais obtidos;

- Verificar o comportamento do sistema placa-junta, para o mesmo nível de capacidade de suporte da fundação e para duas espessuras dos modelos, por meio do parâmetro da eficiência na transferência de carga;

- Verificar tanto o comportamento das placas de concreto simples, quando submetidas a carregamentos monotônicos e cíclicos, quanto a resposta da fundação a essas solicitações;

- Verificar as reações da fundação na análise teórica, desenvolvida com a formulação proposta, e compará-las com resultados experimentais.

- Comparar o modelo numérico desenvolvido para a placa, com base nos resultados experimentais.

\subsection{METODOLOGIA}

O programa experimental avaliou o comportamento das juntas serradas e moldadas, em placas de concreto simples, apoiadas sobre meio elástico.

O modelo numérico, desenvolvido com auxílio de programa computacional com base no método dos elementos finitos, permitiu a verificação dos deslocamentos verticais no modelo quando submetido a força vertical quase estática. Os parâmetros necessários à modelagem numérica foram obtidos a partir de resultados experimentais.

\subsection{ESTRUTURA DO TRABALHO}

A descrição dos procedimentos para a obtenção dos resultados e das conclusões a respeito do comportamento de juntas em placas de concreto simples utilizadas na pavimentação, será exposta nos capítulos que se seguem.

O Capítulos 2 apresenta uma revisão bibliográfica sobre os tipos de juntas existentes em pavimentos de concreto, notadamente nos de concreto simples, como objeto do estudo. Descreve metodologias para avaliação da capacidade estrutural do pavimento, por meio do parâmetro da transferência de carga, apresenta métodos de 
dimensionamento das juntas e ensaios laboratoriais efetuados. Um breve histórico sobre o estudo das juntas em pavimentos também é apresentado.

O Capítulo 3 fornece uma revisão bibliográfica sobre os estudos desenvolvidos para modelagem numérica, em pavimentos de concreto, e os modelos numéricos propostos.

O Capítulo 4 apresenta a caracterização dos modelos e da fundação analisados, bem como seus processos de preparação, instrumentação e procedimento experimental para os ensaios em laboratório. Destaca, ainda, os materiais empregados na confecção das placas e o detalhamento dos dispositivos de transferência empregados, e expõe alguns resultados dos experimentos.

O Capítulo 5 mostra as etapas de desenvolvimento do modelo numérico que representa o comportamento do sistema placa-junta, apoiado sobre o solo. Sua validação foi estabelecida por meio de comparação com os resultados experimentais, notadamente os deslocamentos verticais.

No Capítulo 6 são apresentados os seguintes resultados experimentais: propriedades mecânicas dos materiais empregados, fissuração dos modelos, modo de ruptura e critério de parada dos ensaios, forças, deslocamentos verticais e deformações no concreto e no aço.

No Capítulo 7 são avaliados os resultados experimentais, verificadas as reações da fundação obtidas na análise teórica e na experimental, e apresentados os custos para manufatura dos dispositivos.

No capítulo 8 são apresentadas as conclusões obtidas no trabalho, bem como as recomendações e as sugestões para trabalhos futuros.

Em seguida são indicadas as Referências Bibliográficas, que permitiram o estudo de assuntos relacionados ao trabalho e auxiliaram no planejamento do programa experimental. 


\section{CAPÍTULO 2}

\section{JUNTAS EM PAVIMENTOS}

\subsection{JUNTAS EM PAVIMENTOS DE CONCRETO}

Uma vez submetido a tensões, provocadas tanto pelo carregamento como por empenamentos e modificações volumétricas da placa, os pavimentos de concreto de cimento Portland podem estar sujeitos ao aparecimento de fissuras transversais e longitudinais. A ausência de controle desse fenômeno pode provocar uma redução sensível na vida do pavimento, caso não esteja devidamente dimensionado para suportar as solicitações.

Muitas vezes, deformações de pavimentos são associadas a variações de temperatura, segundo Severi (2002), sendo que o empenamento de placas de pavimentos de concreto tem uma grande influência na resposta às cargas do tráfego.

Como dispositivo de controle das fissuras, existe o emprego de seções artificialmente enfraquecidas e uniformemente espaçadas, conhecidas como juntas. Essas juntas vão forçar a ocorrência das fissuras em locais previamente determinados e vão permitir a expansão e a contração das placas.

A placa de concreto tem sua maior dimensão no dia de seu assentamento, mas diminui continuamente, à medida que é molhada e secada. Isto se deve ao fato de que o concreto começa a apresentar mudanças em suas dimensões e forma, à medida que endurece, por se contrair de maneira não uniforme, segundo Gulyas (2006). Como a placa apresenta uma diferença de retração entre a parte superior e a inferior, a mudança do perfil faz com que as extremidades se elevem. As juntas levantadas tornam-se os pontos mais vulneráveis da placa, ao permitir que o impacto do tráfego destrua continuamente suas bordas e traga desconforto aos usuários.

À medida que a placa se retrai, a junta tende a abrir, e é preciso introduzir algum tipo de dispositivo de transferência de força, que mantenha a superfície em um plano e 
transfira as forças verticais de uma placa à outra, quando essas forças passam pela junta. Esta transmissão de forças, comumente denominada carga, ocorre na passagem de um eixo de veículo de massa qualquer, sobre a junta.

Há em geral três tipos de juntas transversais, empregadas em pavimentos de concreto, segundo sua função: junta de retração, junta de expansão e junta de construção.

As dimensões das placas de concreto, recomendadas pelo Departamento Nacional de Infra-Estrutura de Transporte (DNIT, 2005) são apresentadas na Figura 2.1. As juntas transversais são construídas no sentido da largura da placa de concreto.

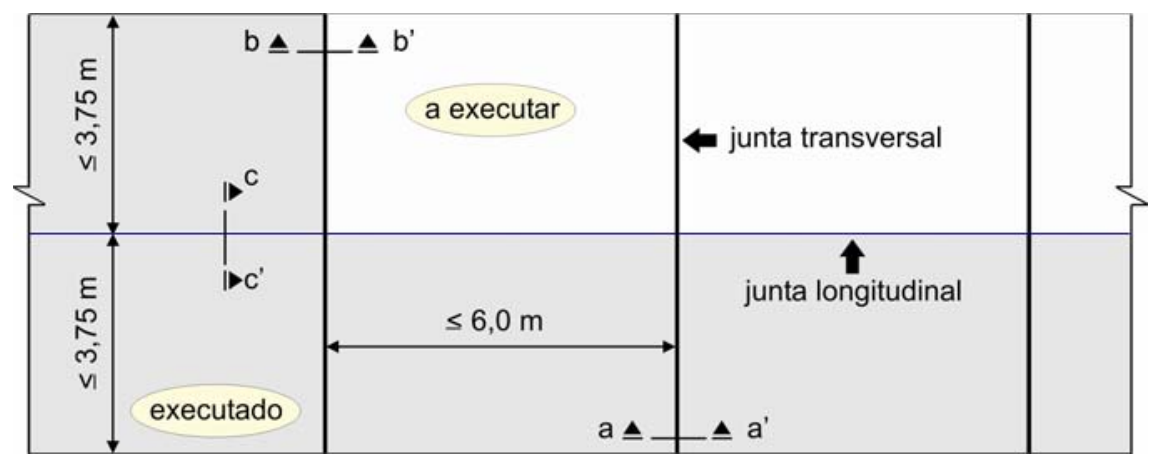

Figura 2.1 - Pavimento de concreto. Fonte: DNIT (2005)

A junta de retração ou serrada corresponde a uma seção enfraquecida formada na placa de concreto, por meio de corte ou ranhura da superfície do pavimento, como apresentado no corte aa', indicado na Figura 2.1 e na Figura 2.2. Sua função é aliviar as tensões de tração geradas pela variação de temperatura e pelo atrito entre na interface placa-fundação, controlando a fissuração. Quando dotada de dispositivos de transferência, como por exemplo barras, apresenta uma função adicional, que é a de proporcionar a transferência de carga entre as placas.

Fissuras devidas à variação inicial do volume de concreto e fissuras adicionais, devidas ao empenamento da placa, podem ocorrer na superfície do pavimento, se as juntas de retração não forem devidamente empregadas e espaçadas. Logo após o processo de acabamento do concreto ou após seu endurecimento inicial, é iniciado o corte dessas juntas. A profundidade da ranhura deve ter, segundo o DNIT (2005) entre 1/4 e 1/6 da espessura da placa, e sua abertura pode variar entre $3 \mathrm{~mm}$ e $10 \mathrm{~mm}$. As barras têm uma das metades pintada e engraxada, de forma a permitir a livre movimentação da junta, quando da variação volumétrica do concreto. 


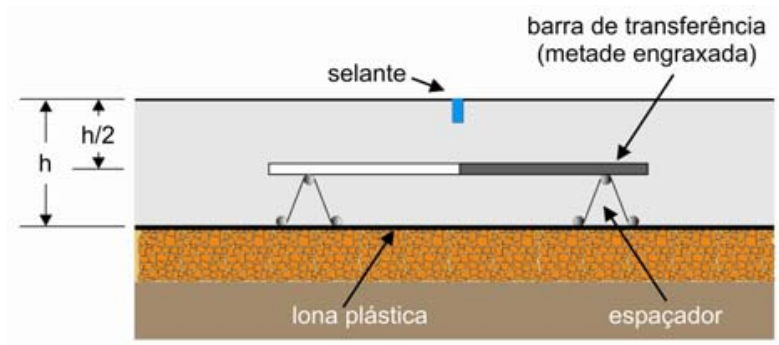

Figura 2.2 - Junta de retração (corte aa')

A junta de construção é utilizada para facilitar a execução do pavimento. O espaçamento entre essas juntas é ditado pela largura da máquina de pavimentação, pela espessura do pavimento, pela interrupção da jornada de trabalho e pela geometria da área a ser obtida. Devem dispor de adequada transferência de carga, com a adoção de barras. A Figura 2.3a apresenta um corte longitudinal do pavimento de concreto mostrado na Figura 2.1. A junta longitudinal é dotada ou de barra de ligação, mostrada na Figura 2.3b, que resiste à força de atrito entre a junta considerada e a junta ou a borda livre mais próxima a ela, e de encaixe tipo machoe-fêmea, mostrada na Figura 2.3c, que une as faces da junta. Ambos os mecanismos asseguram a ligação entre as faixas e evitam possíveis movimentos laterais. No entanto, apenas as barras de ligação resistem às forças de atrito da fundação. 


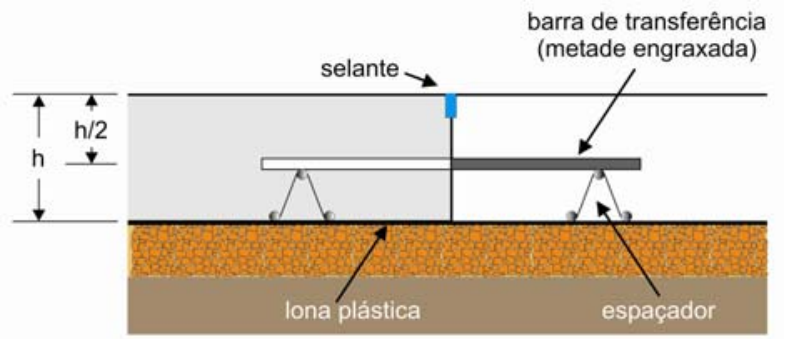

(a)

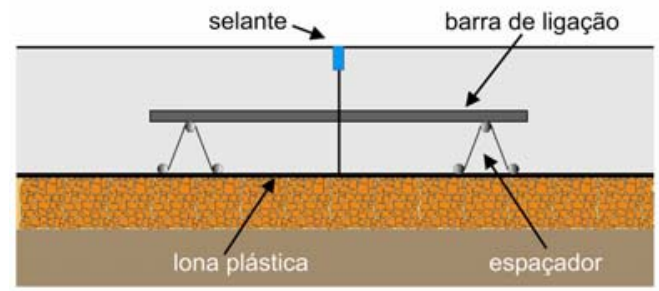

(b)

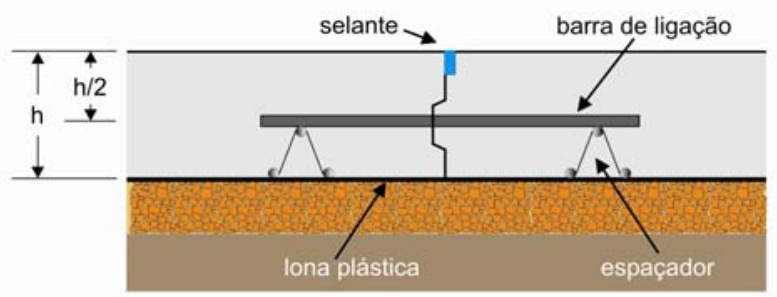

(c)

Figura 2.3 - Junta de construção (a) transversal - corte bb'; (b) e (c) longitudinal - corte cc'.

As juntas longitudinais de construção devem ficar situadas fora das trilhas de tráfego, enquanto que as juntas transversais de construção não deverão coincidir com bueiros, drenos ou estruturas que venham enfraquecer a seção.

A junta de expansão, apresentada na Figura 2.4, propicia espaço para a expansão do pavimento e absorve movimentações da placa, prevenindo assim o desenvolvimento de tensões de compressão, que podem causar o empenamento do pavimento. São empregadas nos encontros com estruturas, como pontes e viadutos, ou em cruzamentos complexos. A junta deve permitir que o pavimento se movimente livremente na direção da estrutura confrontante, sem comprimi-la, de modo a não trazer prejuízos, tanto ao pavimento quanto à estrutura (Pitta, 1998).

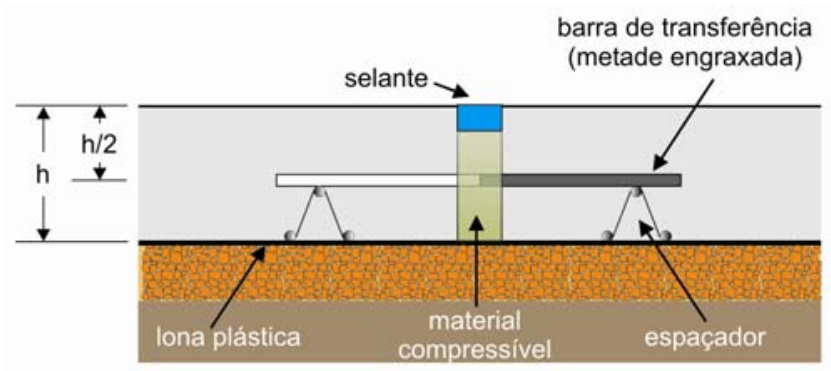

Figura 2.4 - Junta de expansão 
Os pavimentos de concreto estão sujeitos a patologias, decorrentes de problemas na fundação, dimensionamento equivocado ou má execução. A seguir são apresentados alguns defeitos e sua terminologia, no que se refere às juntas, segundo o DNIT (2004):

- Escalonamento ou degrau na junta: caracteriza-se pela ocorrência de deslocamentos verticais diferenciados e permanentes entre uma placa e outra adjacente, na região da junta.

- Esborcinamento das juntas, caracterizado pela quebra das bordas da placa de concreto (quebra em cunha) nas juntas, com comprimento máximo de $60 \mathrm{~cm}$, não atingindo toda a espessura da placa.

- Esborcinamento ou quebra de canto são quebras que aparecem nos cantos das placas, tendo forma de cunha, que ocorrem a distância não superior a $60 \mathrm{~cm}$ do canto.

- Alçamento de placas se caracteriza pelo desnivelamento das placas nas juntas ou nas fissuras transversais e, eventualmente, na proximidade de canaletas de drenagens ou de intervenções feitas no pavimento.

\subsubsection{Transferência de carga}

No item a seguir serão apresentadas metodologias para avaliação da capacidade estrutural do pavimento, por meio do parâmetro da transferência de carga entre placas contíguas dotadas de juntas.

A. American Association of State Highway and Transportation Official (AASHTO, 1993)

A capacidade estrutural do pavimento pode ser avaliada por diferentes parâmetros: inspeção visual, testes não destrutivos ou verificação dos danos provocados por fadiga do pavimento.

A inspeção visual avalia as condições da pista de rolamento, com o levantamento dos defeitos visíveis. Os danos causados pela fadiga são verificados pela quantificação do tráfego vigente, sendo possível estimar a vida útil remanescente do pavimento. 
A análise dos deslocamentos verticais por testes não destrutivos tem sido, por várias décadas, segundo a AASHTO (1993), um método importante na avaliação estrutural, fornecendo dados para pavimentos de concreto novos ou reabilitados. Sua primeira aplicação levava em conta o deslocamento vertical total mensurado para uma dada força, servindo de indicativo direto para sua capacidade estrutural. Com o avanço científico percebeu-se que relações mais corretas do comportamento do pavimento eram obtidas utilizando a porção elástica dos deslocamentos verticais, e não seu deslocamento total.

Este método pode avaliar a capacidade do pavimento tanto em condições estáticas quanto dinâmicas. No entanto, é ressaltado que apenas em condições dinâmicas esta metodologia avalia com segurança e confiabilidade, por se aproximar das cargas reais proporcionadas pelo tráfego.

O coeficiente de transferência de carga é um parâmetro utilizado para quantificar a capacidade do pavimento de concreto em transferir ou distribuir força ao longo de uma descontinuidade, seja uma junta ou uma fissura. A presença de dispositivos de transferência, intertravamento dos agregados (vide item 2.1.2) e acostamentos provocam variações neste valor.

A capacidade de transferência de carga é medida pela eficiência da junta, que é comumente expressa segundo: os deslocamentos verticais, eq. (2.1) ou as tensões, eq.(2.2), para o lado carregado e o não carregado. No entanto, não existem correlações entre esses dois parâmetros.

$$
\begin{gathered}
y_{e j}=\frac{y_{n c}}{y_{c}} \cdot 100 \\
\sigma_{e j}=\frac{\sigma_{n c}}{\sigma_{c}} \cdot 100
\end{gathered}
$$

As variáveis $y_{n c}$ e $\sigma_{n c}$ correspondem respectivamente ao deslocamento vertical da junta e à tensão na face inferior da placa, no lado não carregado; $y_{c}$ e $\sigma_{c}$ correspondem respectivamente ao deslocamento vertical da junta e a tensão na face inferior da placa, para o lado carregado. 
A carga transferida ao longo da junta em um pavimento de concreto influencia diretamente nas tensões surgidas por esforços de tração na flexão, na junta ou nas suas proximidades.

Para o cálculo da tensão teórica na borda livre da placa, a AASHTO (1993) se baseia na análise de Westergaard (1927), que propôs, ao estudar o comportamento de placas de concreto para pavimentos, que as tensões máximas na face inferior da placa diretamente sobre a carga no canto $\left(\sigma_{c, t e o}\right)$, no interior $\left(\sigma_{i, t e o}\right)$ e na borda $\left(\sigma_{b, t e o}\right)$ corresponderiam respectivamente a:

$$
\begin{aligned}
& \sigma_{c, \text { teo }}=\frac{3 \cdot P}{h^{2}} \cdot\left[1-\left(\frac{a \sqrt{2}}{\ell}\right)^{0,6}\right] \\
& \sigma_{i, \text { teo }}=\frac{3 \cdot(1+v) \cdot P}{2 \cdot \pi \cdot h^{2}} \cdot\left[\ln \cdot\left(\frac{\ell}{b}\right)+0,6159\right] \\
& \sigma_{b, \text { teo }}=\frac{3 \cdot(1+v) \cdot P}{2 \cdot \pi \cdot h^{2}} \cdot\left[1,80948 \ln \cdot\left(\frac{\ell}{b}\right)+0,37432\right]
\end{aligned}
$$

Nessas equações, $P$ corresponde à força; $\ell=\sqrt[4]{\frac{E_{c} \cdot h^{3}}{12\left(1-v^{2}\right) \cdot k}}$ ao raio de rigidez de uma placa de concreto; $E_{c}$ é o módulo de elasticidade do concreto; $h$ é a espessura da placa de concreto; $v$ é o coeficiente de Poisson do concreto; $k$ é o coeficiente de recalque da fundação; $b$ é o raio de distribuição equivalente de pressões na face inferior da placa $=\sqrt{1,6 \cdot a^{2}+h^{2}}-0,675 \cdot h$, quando $a<1,724 \cdot h$, ou $b=a$, quando $a \geq 1,724 \cdot h$; $a$ é o raio da área de contato da carga, semicircular no caso de carga na borda e circular no caso de cargas no canto e no interior.

Para se obter a medida de resistência do solo, ou a capacidade de suporte, pode ser realizada uma prova de carga, que determinará o módulo de reação de Westergaard ou coeficiente de recalque, que é expresso por: 


$$
k=\frac{p}{y}
$$

O valor $p$ é a pressão transmitida ao subleito, em MPa; e $y$ é o deslocamento vertical da área carregada, em $\mathrm{m}$.

A norma do DNER-35 (1989) estabelece o procedimento para determinação do coeficiente de recalque do subleito e da sub-base de pavimentos de concreto de cimento Portland.

A Figura 2.5 apresenta as posições da carga de roda para eixos simples. Para espessuras do pavimento de concreto entre $15 \mathrm{~cm}$ e $35 \mathrm{~cm}$, a AASHTO (1993) recomenda a adoção de uma carga de até $40 \mathrm{kN}$, no estudo da eficiência na transferência de carga, porque simula as tensões provocadas pela passagem de um veículo de eixo simples.

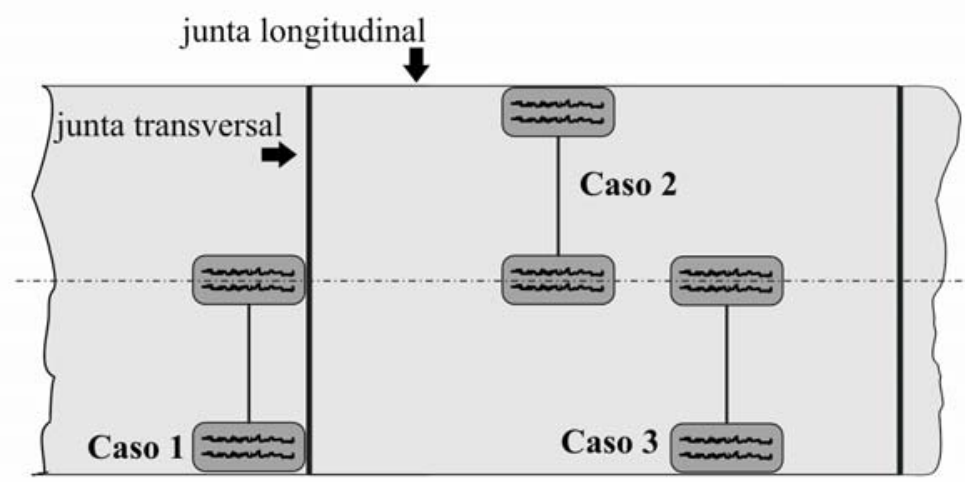

Figura 2.5 - Posições dos eixos segundo Westergaard (1927)

\section{B. American Concrete Pavement Association (ACPA, 1991)}

Uma junta é considerada 100\% efetiva se os deslocamentos verticais são iguais de ambos os lados da junta, ou 0\% efetiva se o lado descarregado não apresentar deslocamentos para qualquer intensidade de força.

A capacidade de transferência de carga medida pela eficiência $E$, é expressa segundo os deslocamentos verticais, e considerada adequada se for superior a $75 \%$. A eq. (2.7) fornece a medida de eficiência de juntas armadas ou não, e corresponde à relação entre o deslocamento vertical do lado não carregado $y_{n c}$ e do lado carregado $y_{c}$. 


$$
E=\frac{2 y_{n c}}{y_{c}+y_{n c}} \times 100
$$

\subsubsection{Dispositivos de transferência de carga}

Uma das funções do dispositivo de transferência é a de reduzir o deslocamento vertical relativo da junta carregada. O termo deflexão é comumente encontrado na terminologia rodoviária fornecida pelo DNER (1997) e se refere a esta deformação vertical sofrida pelo pavimento, em conseqüência de aplicação de cargas sobre ele.

O dispositivo de transferência ajuda na acomodação do movimento restringido e mantém a junta em alinhamento. O movimento horizontal da junta surge devido aos alongamentos e encurtamentos sofridos pelas placas, que tendem a ser restringidos pelo atrito existente entre o pavimento e a fundação. Os dispositivos também são necessários, segundo Friberg (1940), para aliviar as tensões de esmagamento $\sigma_{e}$ no concreto circundante à barra, nas adjacências da junta, surgidas devido ao carregamento.

Os mecanismos de transferência de carga mais comuns são as barras de seção circular, posicionadas horizontalmente na junta transversal (Figura 2.6a), e o próprio intertravamento dos agregados.

Outro dispositivo de transferência de carga é a placa de seção quadrada ou "diamond dowel", mostrada na Figura 2.6b. A placa quadrada corresponde a uma placa metálica de lados iguais, posicionada no plano médio paralelo ao plano horizontal da superfície do pavimento. Sua diagonal é alinhada ao eixo longitudinal da pista. 


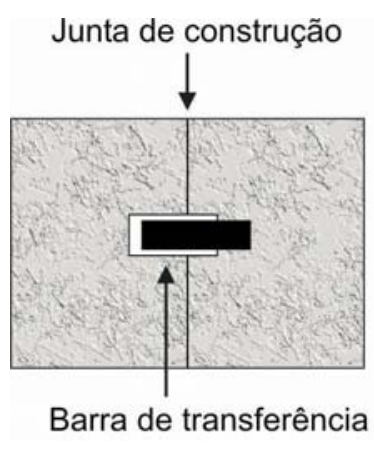

(a)

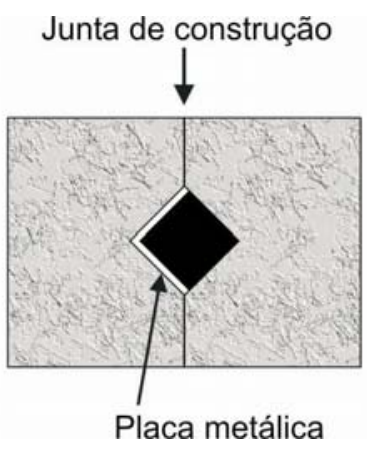

(b)

Figura 2.6 - Vista em planta de dispositivos de transferência (a) seção circular; (b) seção quadrada

As barras de seção circular, conhecidas como barras de transferência, promovem uma conexão mecânica entre as placas do pavimento, sem restringir o movimento horizontal. Elas também mantêm as placas em alinhamento horizontal e vertical. A Figura 2.7 apresenta o detalhe de uma barra de transferência, apoiada sobre espaçadores. Comercialmente apresentam os diâmetros de 12,5mm; 16mm; 20mm; $25 \mathrm{~mm}$ e $32 \mathrm{~mm}$.

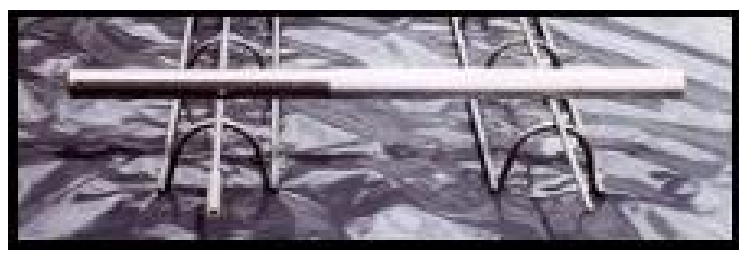

Figura 2.7 - Barra de transferência

O intertravamento dos agregados é o fechamento mecânico que se forma entre as superfícies fraturadas ao longo da fissura, abaixo da junta, conforme apresentado na Figura 2.8, e é aceitável para pequeno volume de tráfego e estradas secundárias. A forma das partículas do agregado influencia na transferência de carga, segundo Colley e Humphrey (1967). O aumento da angularidade do agregado graúdo aumenta a eficiência na transferência de carga. 


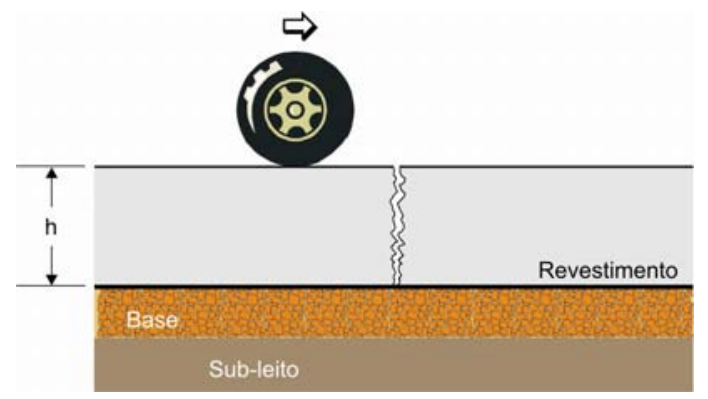

Figura 2.8 - Intertravamento dos agregados

Um outro dispositivo é o disco metálico ou "disk plate". Consiste no posicionamento de discos metálicos no interior de uma junta transversal moldada, conforme apresentado na Figura 2.9.

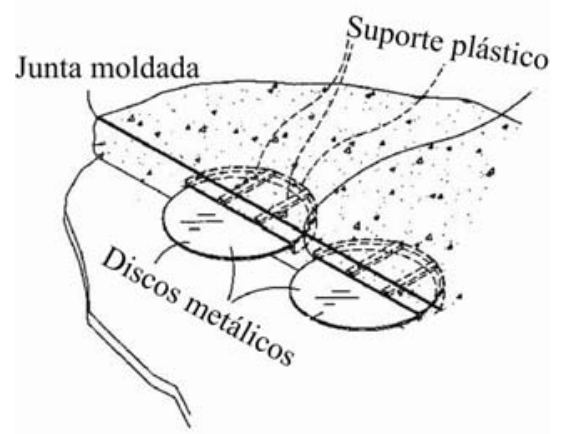

Figura 2.9 - Posicionamento do disco metálico. Fonte: Shaw e Shaw (2005)

Do ponto de vista construtivo, é importante salientar que os dispositivos devem ser propriamente instalados no plano horizontal, paralelos à superfície do pavimento e à junta longitudinal. Também devem ser centralizados na junta, garantindo comprimento de embutimento igual em ambos os lados, carregado e não carregado, além de cobrimento do concreto equivalente no topo e na base da placa. Qualquer variação na posição da barra, ou seu desalinhamento, pode tanto reduzir a eficiência na transferência de carga como contribuir para o lascamento e a fissuração do pavimento, segundo Yu e Tayabji (2007). 


\subsubsection{Métodos de dimensionamento das juntas}

A seguir serão abordados métodos de dimensionamento de pavimentos de concreto, com ênfase na junta. É ressaltada a importância do diâmetro, comprimento e espaçamento dos dispositivos, uma vez que interferem na magnitude das tenções desenvolvidas, tanto no dispositivo quanto na matriz de concreto circundante.

A. American Association of State Highway and Transportation Official (AASHTO, 1993)

A AASHTO (1993) sugere que o diâmetro da barra de transferência em PCS seja igual à espessura da placa de concreto multiplicada por $\frac{1}{8}$. O espaçamento e comprimento da barra são normalmente de $30 \mathrm{~cm}$ e $46 \mathrm{~cm}$, respectivamente. Gráficos interativos fornecem, por meio de parâmetros de entrada, a taxa de armadura $\rho$ necessária para armar as juntas, conforme apresentado na Figura 2.10. Conhecidos o comprimento da placa, superior a 4,5m, o coeficiente de atrito (Tabela 2.1) e a tensão de escoamento do aço de barras ou de telas soldadas, é possível obter $\rho$.

$$
\rho=\frac{L \cdot \mathrm{F}}{2 f_{s}} \times 100
$$

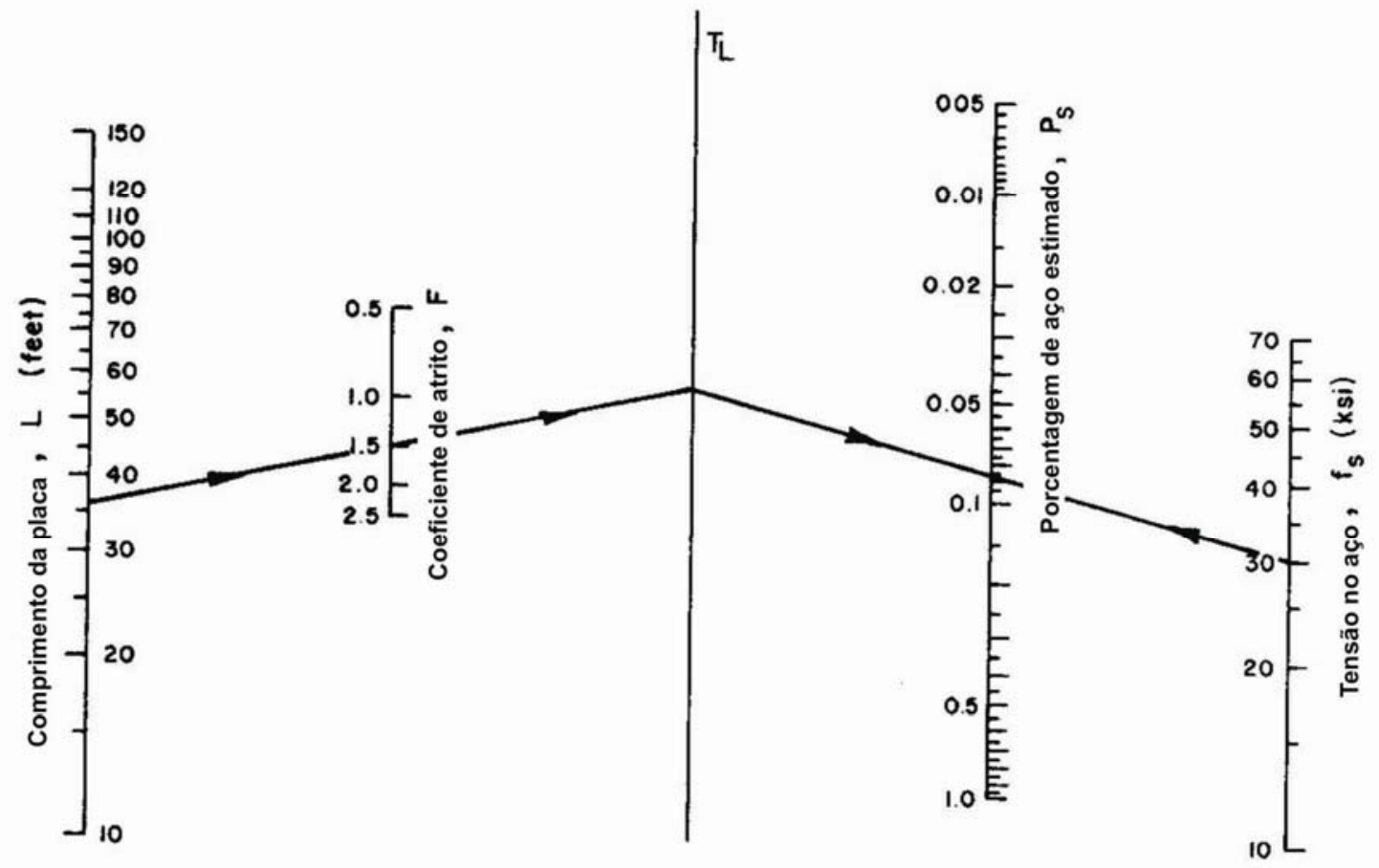

Figura 2.10 - Ábaco para dimensionamento da armadura da junta. Fonte: AASTHO (1993) 
Tabela 2.1 - Coeficientes de atritos na interface placa-fundação. Fonte: AASHTO (1993)

\begin{tabular}{|c|c|}
\hline Tipo de material abaixo da placa & Coeficiente de atrito \\
\hline Solo melhorado & 2,2 \\
\hline Sub-base granular & 1,5 \\
\hline Pedra britada & 1,5 \\
\hline Sub-base natural & 0,9 \\
\hline
\end{tabular}

O espaçamento $L$ entre as juntas corresponderá a:

$$
L=\frac{A_{s}}{\rho \cdot h} \times 100
$$

$A_{s}$ é a área de seção transversal da armadura, em $\mathrm{cm}^{2} ; \rho$ é a taxa de armadura requerida; e $h$ é a espessura do pavimento, em $\mathrm{cm}$.

B. Departamento Nacional de Infra-estrutura de transportes (DNIT, 2005)

Em pavimentos de concreto simples (PCS), o dimensionamento das barras de transferência de carga, segundo o DNIT (2005), obedece a estudos sob a ação de cargas repetidas. Em função da espessura da placa, a Tabela 2.2 fornece, de forma simplificada, as dimensões das barras de transferência lisas, em aço CA-25.

Tabela 2.2 - Dimensões das barras de transferência para PCS. Fonte: DNIT (2005)

\begin{tabular}{|c|c|c|c|}
\hline $\begin{array}{c}\text { Espessura da placa } \\
(\mathrm{cm})\end{array}$ & Diâmetro $(\mathrm{mm})$ & Comprimento $(\mathrm{cm})$ & Espaçamento (cm) \\
\hline Até 17 & 20 & 46 & 30 \\
\hline $17,5-22,0$ & 25 & 46 & 30 \\
\hline $22,5-30,0$ & 32 & 46 & 30 \\
\hline$>30,0$ & 40 & 46 & 30 \\
\hline
\end{tabular}

Em pavimentos de concreto estruturalmente armados (PCEA), que possuem armadura posicionada na face inferior da placa para combater as tensões desenvolvidas pelo carregamento, as barras de transferência aplicadas nas juntas transversais devem ter o diâmetro compatível com a espessura do pavimento, porém 
nunca menor que 16mm. A Tabela 2.3 fornece o diâmetro das barras de transferência de acordo com a normalização do DNIT (2005).

Tabela 2.3 - Diâmetro das barras de transferência para PCEA. Fonte: DNIT (2005)

\begin{tabular}{|c|c|}
\hline Espessura do pavimento $(\mathrm{cm})$ & Diâmetro das barras (mm) \\
\hline$h \leq 12,5$ & 16 \\
\hline $12,5<h \leq 15,0$ & 20 \\
\hline $15,0<h \leq 20,0$ & 25 \\
\hline$h>20,0$ & 32 \\
\hline
\end{tabular}

O DNIT (2005) baseia-se, para a elaboração do projeto geométrico de pavimentos rígidos, dentre eles o de concreto, em trabalhos como os publicados pela Portand Cement Association (PCA), pelo Highway Research Board (HRB), pelo American Concrete Institute $(\mathrm{ACl})$ e pela Associação Brasileira de Cimento Portland (ABCP). As bases são de natureza tanto teórica quanto experimental.

\subsection{HISTÓRICO DO ESTUDO SOBRE JUNTAS}

Desde 1917 as barras de transferência têm sido utilizadas em juntas transversais de pavimentos de concreto, segundo Teller e Cashell (1958). Esse tipo de dispositivo foi utilizado na construção de uma pista de tráfego, entre dois acampamentos militares próximos a Newport News, Virgínia, Estados Unidos. As barras tinham diâmetro de $19 \mathrm{~mm}$, e foram espaçadas em um pavimento de concreto de $6 \mathrm{~m}$ de largura. A justificativa para seu uso vinha do fato de que as tensões na extremidade carregada da placa e os deslocamentos verticais eram maiores do que as respostas para carregamento no interior da placa. Portanto, se a porção da carga aplicada na borda fosse transferida para uma placa adjacente, resultaria em uma redução significativa das tensões e dos deslocamentos.

Barras de grande comprimento, cerca de $120 \mathrm{~cm}$, e pequeno diâmetro, da ordem de $12,5 \mathrm{~mm}$, espaçadas a cada $75 \mathrm{~cm}$, foram originalmente a regra adotada nos Estados Unidos até final da década de 1920. Nos testes de Arlington, conduzidos desde 1930 pela divisão de ensaios do Bureau of Public Roads, barras de $19 \mathrm{~mm}$ de diâmetro e aberturas das juntas transversais de $12,5 \mathrm{~mm}$ e $19 \mathrm{~mm}$ foram utilizadas, segundo a 
prática recomendada na época (Teller e Sutherland, 1935). Os valores de espaçamento aplicados foram de $45 \mathrm{~cm}, 70 \mathrm{~cm}$ e $90 \mathrm{~cm}$. Nas juntas longitudinais, foram utilizadas barras de ligação de $12,5 \mathrm{~mm}$ de diâmetro, $120 \mathrm{~cm}$ de comprimento, e espaçadas entre $60 \mathrm{~cm}$ e $150 \mathrm{~cm}$. Os experimentos realizados não alcançaram uma transferência de carga eficaz. Até então, existiam deficiências sobre a junta, quanto à necessidade ou não de seu emprego e seu dimensionamento detalhado.

Westergaard (1928), em seu estudo analítico sobre a transmissão de forças proporcionada pelas barras de transferência, concluiu que somente duas barras, próximas à força aplicada (carga de roda), eram ativas na transferência de carga. Verificou que existia pouca variação na tensão de tração resultante, para espaçamentos de $60 \mathrm{~cm}$ e $90 \mathrm{~cm}$. Essa tensão é produzida na face inferior da placa, diretamente carregada por uma força sobre a junta armada. No entanto, sugere que o espaçamento entre barras seja o menor possível, da ordem de $60 \mathrm{~cm}$.

A prática emergente em se adotar barras com diâmetros superiores a $19 \mathrm{~mm}$, até então usual, e o espaçamento entre as barras menor do que $70 \mathrm{~cm}$ ganhou força pelos estudos teóricos de Bradbury (1932). Esse pesquisador concluiu que o diâmetro, o comprimento e o espaçamento entre as barras, unicamente de seção circular, eram diretamente influenciados pela magnitude da máxima força aplicada. Verificou-se a necessidade de maiores diâmetros, menores comprimentos e menor espaçamento entre as barras para garantir uma melhor transferência de carga. A redução do comprimento da barra, até então de $120 \mathrm{~cm}$, não afetaria prejudicialmente a transferência de força, porque maiores comprimentos provocavam um aumento nas tensões do concreto circundante à barra, que levava à lascamentos e ruptura. Para investigar a magnitude e a distribuição das pressões, Bradbury aplicou equações de Timoshenko (1925), com algumas modificações. A partir de seus estudos, foi desenvolvida uma fórmula para estimar o comprimento das barras, em função do diâmetro, da tensão no entorno do concreto e da tensão no aço da barra. Considerou-se que o sistema placa-barra estava apoiado sobre fundação elástica.

O tratamento teórico mais conclusivo do comportamento da barra foi apresentado por Friberg $(1938,1940)$. Com base na formulação apresentada por Timoshenko, foi adotado um modelo que tratava a barra como uma viga de comprimento infinito envolvida por um meio elástico. As equações teóricas para obtenção da tensão de 
esmagamento e dos momentos fletores foram comparadas experimentalmente, em placas submetidas a carga na borda. Friberg concluiu que o aumento do diâmetro da barra atenua as tensões no concreto que a envolve, e sugere a diminuição do comprimento da barra de $60 \mathrm{~cm}$ para $30 \mathrm{~cm}$, para que haja pleno aproveitamento do concreto e do aço. Constatou que barras distantes 1,8 vezes o raio de rigidez da placa $\ell$ (vide item 2.3.1) são ineficientes para minimizar as tensões surgidas pela passagem do tráfego.

Experimentos subseqüentes contribuíram para a popularidade da metodologia de Friberg, apresentados por Teller e Cashell (1958), que confirmaram os benefícios do uso de barras de maior diâmetro (acima de 19mm). Essas barras minimizavam os deslocamentos verticais da junta, aumentavam a eficiência na transferência de carga e reduziam lascamentos e ruína do concreto, devido às tensões impostas. Além disso, maiores diâmetros permitiam menor comprimento da barra, sem alterar a capacidade resistente da estrutura, conforme já havia afirmado Friberg. Os pesquisadores admitiram que, para barras de seção circular, espaçadas a cada $30 \mathrm{~cm}$ e com abertura da ranhura de $19 \mathrm{~mm}$, a relação entre a espessura da placa he o diâmetro da barra $\phi$ corresponderia a $(h / \phi)=8$.

Inovações mais recentes, no sentido de criar dispositivos com maior eficiência na transferência de carga, com menor incidência de patologias, como corrosão, e a um baixo custo de execução, vêm conquistado o mercado construtor, conciliando o lugar que até então era ocupado tradicionalmente pela barra circular.

A placa quadrada, ou "diamond dowel", é um dispositivo de transferência de carga, ainda não utilizado no cenário brasileiro, e um dos pontos de estudo desta tese. Inicialmente foi utilizada nos Estados Unidos no final dos anos 1990, e seu desempenho é superior ao da barra de transferência convencional (seção circular), segundo Walker e Holland (1998), por permitir um maior espaçamento entre os dispositivos, uma melhor movimentação horizontal e uma menor tensão no concreto.

Os pesquisadores verificaram numericamente que placas metálicas de seção quadrada permitiam movimento horizontal da placa de concreto em todas as direções, e sem restrições, minimizando deste modo o tamanho e o número de fissuras. Essas placas metálicas possuíam uma significante reserva de resistência, porque eram capazes de redistribuir as tensões, se escoamentos locais ocorressem. 
Sua posição, em diagonal, propiciou um excelente comportamento, já que a parte mais larga (diagonal) resistiu aos máximos momentos fletores, forças cortantes e tensões atuantes, enquanto que a parte mais estreita (arestas) resistiu a menores tensões.

Outro dispositivo de transferência de carga inovador, não somente pelas características geométricas, mas pelo desconhecimento de registros de sua utilização tanto no cenário brasileiro como estrangeiro, é o disco metálico, ou "disk plate". Esse mecanismo foi desenvolvido por Shaw e Shaw (2005), com patente registrada no United States Patent and Trademark Office, EUA. Consiste no posicionamento de discos metálicos no interior de uma junta transversal moldada, com o emprego de suporte plástico. Esses suportes servem para acondicionar o disco através de um compartimento com formato semicircular, visualizado na Figura 2.9. O suporte plástico é fixado na fôrma da placa de concreto, restringindo seus movimentos horizontal e vertical. Segundo os autores, esse dispositivo permite um movimento horizontal relativo entre a porção do piso já concretada, e a nova porção, além de restringir o movimento vertical entre as placas.

\subsection{ESTUDOS TEÓRICO-EXPERIMENTAIS EM JUNTAS}

A seguir serão apresentados ensaios laboratoriais, que investigaram 0 comportamento de pavimentos de concreto dotados de juntas, armadas ou não. A resposta do sistema placa-junta foi obtida para carregamentos estáticos e cíclicos. $\mathrm{O}$ estudo também apresentou caráter analítico, empregando princípios teóricos para dimensionamento dos pavimentos. Todos os gráficos e figuras apresentados apresentam unidades de medidas aproximadas para o Sistema Internacional de Unidades (SI), para o caso de estudos apresentados no sistema inglês.

\subsubsection{Westergaard (1928)}

Westergaard (1928), em seu estudo sobre a transmissão de esforços verticais ao longo da junta do pavimento, verificou que a eficiência do sistema depende da capacidade das barras em aliviar tensões, no caso da Figura 2.11 , sendo que $P$ é a força atuante sobre um lado da junta, à metade da distância entre duas barras. As barras A, B, C e D, com espaçamento $s$, transmitem forças Q e R como 
apresentado nessa figura. Barras posicionadas a distâncias superiores não foram consideradas ativas, e adotou-se comprimento infinito para as placas.

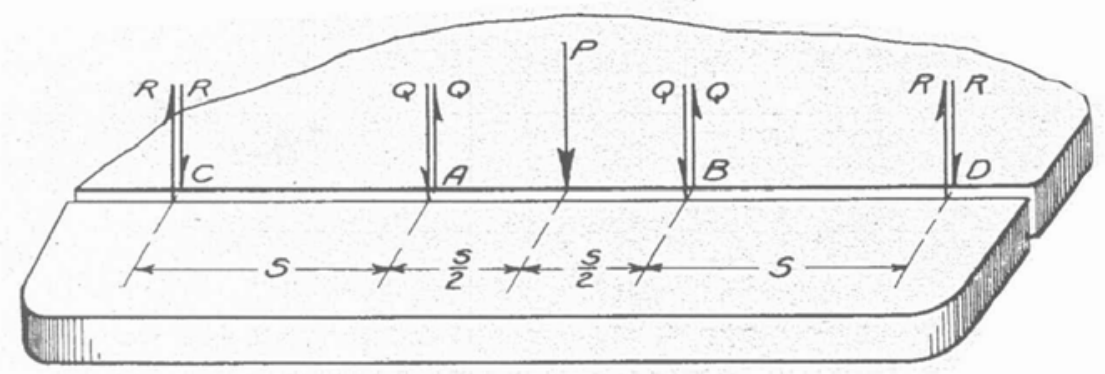

Figura 2.11 - Forças transferidas ao longo das barras. Fonte: Westergaard (1928)

Verificou-se que os deslocamentos verticais dependem da rigidez da placa e da rigidez da fundação. A rigidez da placa depende do modulo de elasticidade do concreto, do coeficiente de Poisson $v$ e da espessura da placa $h$. A rigidez da fundação é, geralmente, expressa em termos do coeficiente de recalque $k$. Esses termos podem determinar a distância, denominada raio de rigidez relativa $\ell$ como sendo:

$$
\ell=\sqrt[4]{\frac{E_{c} \cdot h^{3}}{12 \cdot\left(1-v^{2}\right) k}}
$$

A Figura 2.12 apresenta o diagrama de deslocamentos verticais produzidos na extremidade de uma placa com um carregamento aplicado. A distância $\ell$ aparece como uma unidade da escala horizontal do diagrama. Os deslocamentos verticais $y$ podem ser medidos através do diagrama, convenientemente traçado em termos de $y_{0}$ como unidade, sendo este deslocamento localizado sob o ponto de aplicação da força. 


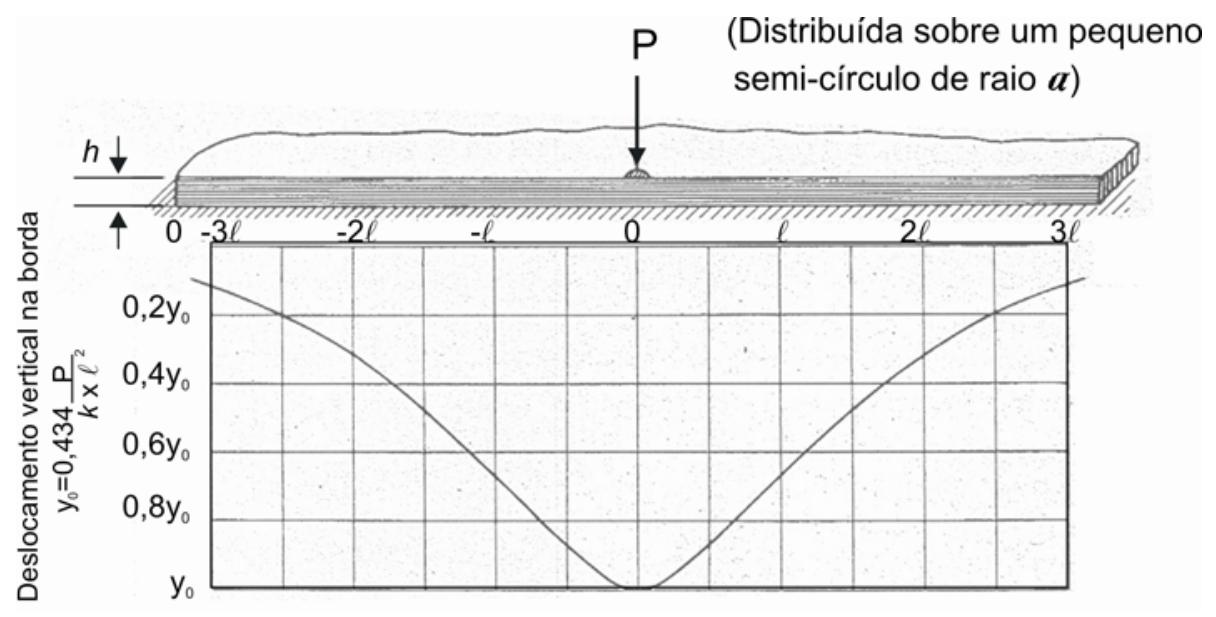

Figura 2.12 - Deslocamentos verticais na borda de placas produzidos por carga pontual na borda. Fonte: Westergaard (1928)

Westergaard concluiu que somente as primeiras duas barras de cada lado da carga são ativas na transferência de força, e cada lado da junta transmitiria a metade da carga $P$ aplicada, ou seja $\frac{P}{2}$, contanto que as barras de transferência sejam rígidas e com resistência suficiente para provocar deslocamentos verticais iguais das duas placas nos seus pontos de conexão.

Para carregamento na borda longitudinal de uma placa, o deslocamento vertical generalizado para uma carga circular de raio $a$ equivale a:

$$
y_{0}=\frac{\sqrt{2+1,2 \cdot v} \cdot P}{\sqrt{E_{c} \cdot h^{3} \cdot k}}\left[1-\frac{(0,76+0,4 \cdot v) \cdot a}{\ell}\right]
$$

\subsubsection{Bradbury (1932)}

Inicialmente, em seu estudo sobre juntas em pavimentos de concreto, Bradbury (1932) descreve e avalia seu emprego, para os diferentes tipos existentes (vide item 2.1). A prática da época dividia o plano de rolamento em faixas de $2,7 \mathrm{~m}$ a $3 \mathrm{~m}$ de largura, e o espaçamento entre juntas transversais de $4,5 \mathrm{~m}$ a $30 \mathrm{~m}$, sendo o mais comum $12 \mathrm{~m}$. O diâmetro e o espaçamento das barras de transferência eram variáveis, sendo recomendados diâmetros entre $12,5 \mathrm{~mm}$ e $19 \mathrm{~mm}$, e espaçamentos entre $25 \mathrm{~cm}$ e $90 \mathrm{~cm}$, sendo o mais comum $70 \mathrm{~cm}$. A abertura das juntas serradas variava entre $9 \mathrm{~mm}$ e $12,5 \mathrm{~mm}$, e sua profundidade correspondia a $1 / 3$ da espessura 
da placa. A escolha desses parâmetros era feita segundo a experiência do construtor. A prática existente mostrava-se ineficiente, e os princípios de dimensionamento utilizados até então, segundo Bradbury apresentavam discordâncias, que refletiam em diferentes detalhamentos nos vários estados norteamericanos. Foi devido a esses fatores que o pesquisador desenvolveu métodos analíticos para o detalhamento racional das juntas.

A partir de análises desenvolvidas por Timoshenko para o caso de barras engastadas, Bradbury fez algumas considerações: a barra foi considerada finita; à medida que a distância da face da junta aumenta ocorre um decréscimo na intensidade das pressões; e a fundação do sistema foi considerada elástica. Não foi avaliado o efeito da pressão imposta ao concreto pela barra, denominado de módulo de reação da barra $(\mathrm{K})$, seja acima ou abaixo da barra.

Considerando o comprimento da barra envolvido pelo concreto, a pressão máxima positiva $p$ ocorre nas proximidades do ponto de aplicação da força $P$ e se estende ao longo de aproximadamente 2/10 de seu comprimento, como mostrado na Figura 2.13.

As resultantes de pressões $R_{1}$ e $R_{2}$ equivalem a:

$$
\begin{aligned}
& R_{1}=\frac{p \cdot l \cdot \phi}{10} \\
& R_{2}=\frac{3 p^{\prime} \cdot l \cdot \phi}{20}
\end{aligned}
$$

onde $p=\frac{25 \cdot P(l+1,5 \cdot a)}{2 \cdot l^{2} \cdot \phi}$ é a pressão positiva; $p^{\prime}=\frac{5 \cdot P(l+7,5 \cdot a)}{3 \cdot l^{2} \cdot \phi}$ é a pressão negativa; $\phi$ é o diâmetro; e $l$ o comprimento da barra.

O momento fletor máximo $M_{\max }$, obtido na posição em que a força cortante $V$ é nula, equivale a:

$$
M_{\max }=\frac{7 \cdot P \cdot(l+8,8 \cdot a)}{146}
$$


O comprimento total da barra de seção circular, obtido limitando-se a resistência da barra à força cortante, corresponde $\mathrm{a}$ :

$$
l=d \sqrt{\frac{20 \cdot f_{s}}{p}}+a j
$$

onde $f_{s}$ é o tensão no aço e $a j$ é a abertura da junta.

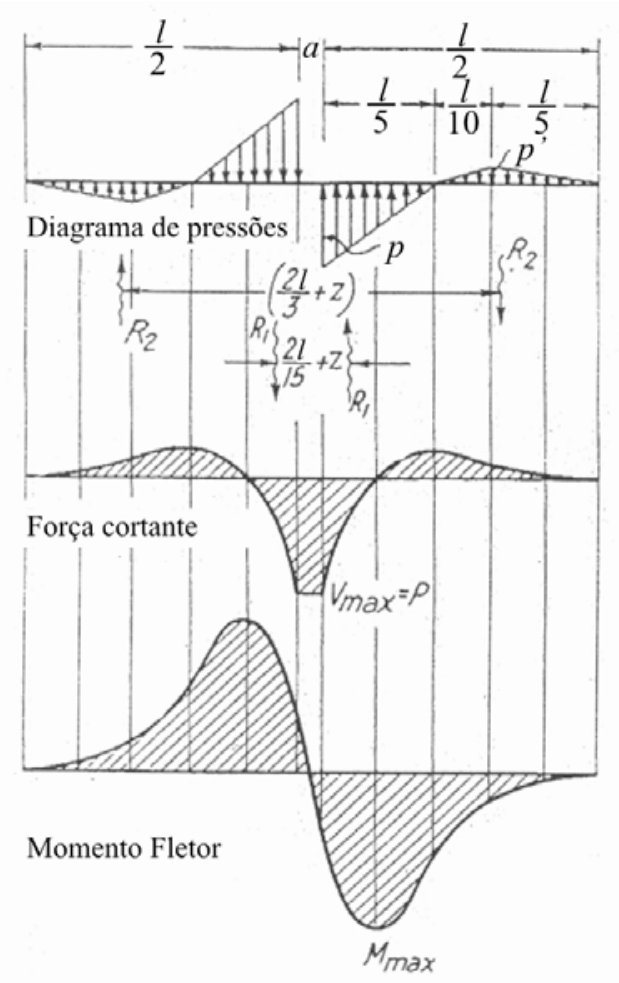

Figura 2.13 - Diagramas de momento fletor e força cortante em barra de transferência. Fonte:

Bradbury (1932)

Bradbury sugeriu que o centro da barra de transferência deveria estar localizado a pelo menos três vezes o diâmetro da barra, partindo do topo da placa. Ainda assim, o diâmetro da barra não deveria exceder $1 / 6$ da espessura da placa. Concluiu também que barras com $19 \mathrm{~mm}$ de diâmetro eram inúteis como dispositivo de transferência de carga, caso não fossem espaçadas em curtos intervalos, da ordem de $20 \mathrm{~cm}$ a $25 \mathrm{~cm}$.

Em seu estudo, Bradbury concluiu que menores comprimentos da barra, inferior a $90 \mathrm{~cm}$, maiores diâmetros, entre $22 \mathrm{~mm}$ e $25 \mathrm{~mm}$, e menor espaçamento eram preferenciais para o aumento da eficiência do sistema. 


\subsubsection{Friberg, B. F. (1938) e (1940)}

Testes em laboratório foram feitos por Friberg (1938) em barras de transferência, envolvidas em concreto e não engraxadas, para observar suas características até a ruptura.

De maneira a ser possível verificar corretamente os dados sobre a ruptura do concreto nas proximidades da barra, parte engastada em um bloco de concreto, foram executados modelos com barras de diferentes tamanhos. O esquema experimental é apresentado na Figura 2.14. Os blocos de concreto tinham $20 \mathrm{~cm}$ de largura e comprimentos de $15 \mathrm{~cm}$ e $25 \mathrm{~cm}$.

Alguns blocos de concreto foram apoiados sobre base metálica e outros sobre borracha, e os modelos eram ensaiados com dois ou três dias de idade. 0 carregamento era aplicado no topo da barra, a uma distância de aproximadamente $1,25 \mathrm{~cm}$ da face do concreto. Os testes permitiam verificar os deslocamentos verticais e as curvaturas da barra ensaiada.
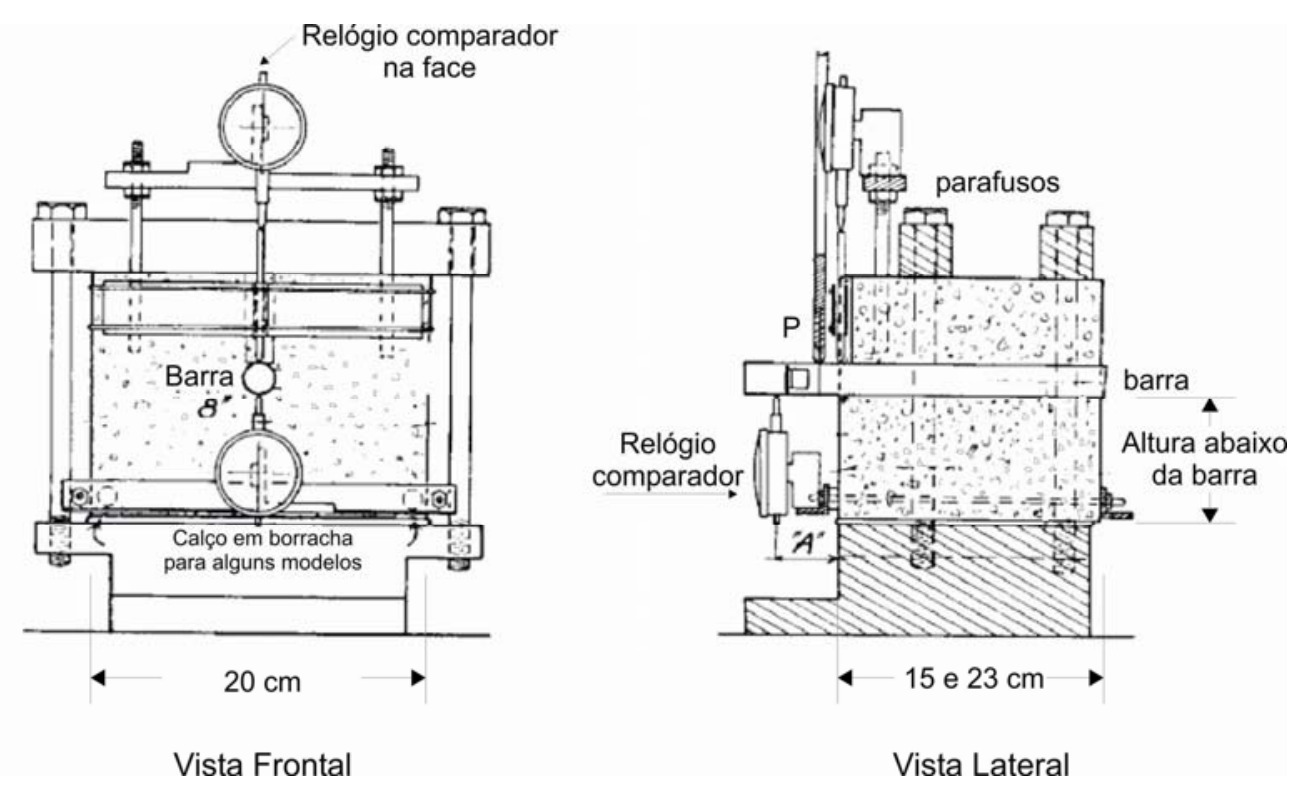

Figura 2.14 - Esquema de ensaio para barra engastada em bloco de concreto. Fonte: Friberg (1938)

A Tabela 2.4 apresenta o programa de ensaios efetuados. Foram ensaiados 30 modelos até sua ruptura, que na sua grande maioria ocorreu por lascamento do concreto, nas proximidades e abaixo da barra. A fissuração ocorreu na direção vertical, acima e abaixo da barra, em modelos apoiados em borracha. Os modelos 
apoiados em base metálica apresentaram fissuras horizontais, para pequenos carregamentos, e radiais, próximas da ruptura.

Tabela 2.4 - Programa de ensaios segundo Friberg (1938)

\begin{tabular}{|c|c|c|c|c|}
\hline $\begin{array}{c}\text { Diâmetro das } \\
\text { barras } \\
(\mathrm{mm})\end{array}$ & $\begin{array}{c}\text { Tensão de } \\
\text { escoamento da } \\
\text { barra } \\
(\mathrm{MPa})\end{array}$ & $\begin{array}{c}\text { Tensão de } \\
\text { ruptura da barra } \\
(\mathrm{MPa})\end{array}$ & $\begin{array}{c}\text { Comprimento de } \\
\text { engaste das barras } \\
(\mathrm{cm})\end{array}$ & $\begin{array}{c}\text { Altura do bloco } \\
\text { abaixo da barra } \\
(\mathrm{cm})\end{array}$ \\
\hline 19 & 417 & 696 & 7,5 & $7,6^{[1]}$ \\
\hline 25 & 334 & 590 & 15,0 & $6,6^{[2]}$ \\
\hline 32 & 372 & 586 & 23 & $6,35^{[3]}$ \\
\hline & & & & $6,10^{[4]}$ \\
\hline & & & & $10,0^{[5]}$ \\
\hline & & & & $21,5^{[6]}$ \\
\hline
\end{tabular}

A Figura 2.15 apresenta o gráfico carga aplicada versus comprimento de embutimento da barra, obtido experimentalmente. É possível observar que diâmetros de $19 \mathrm{~mm}$ e $25,4 \mathrm{~mm}$ ganham pouca eficiência para comprimentos de engaste de $12,5 \mathrm{~cm}$ e $17,5 \mathrm{~cm}$, respectivamente. Para o mesmo comprimento, o aumento do diâmetro propicia um aumento na carga aplicada.

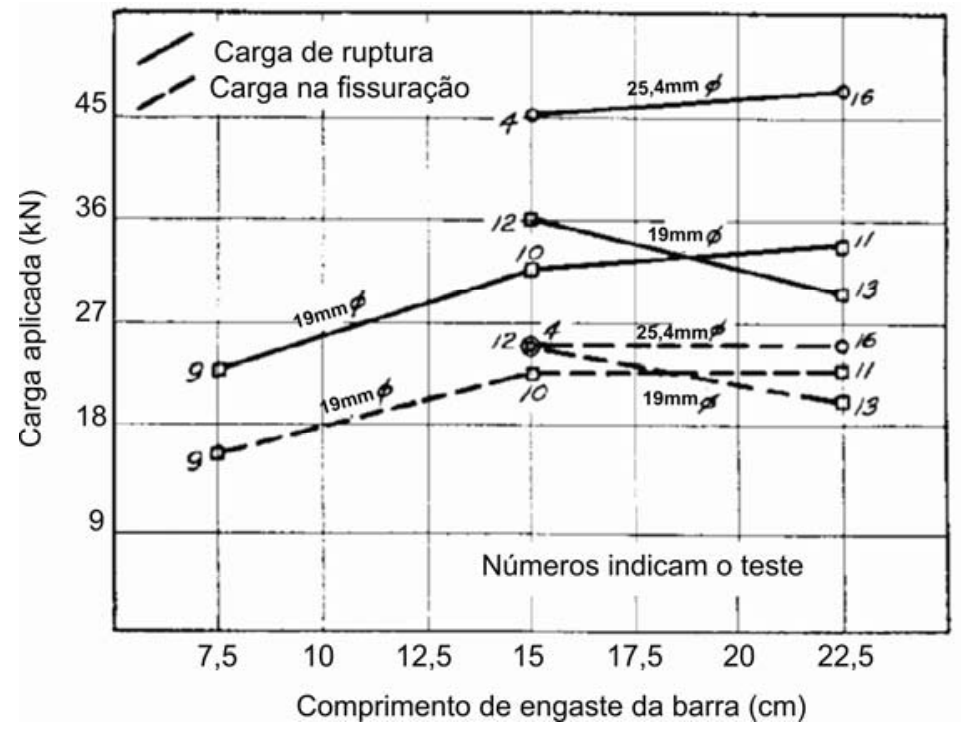

Figura 2.15 - Gráfico carga aplicada versus comprimento de embutimento da barra. Fonte: Friberg (1938) 
Em análises subseqüentes, Friberg (1940) sugere soluções matemáticas, capazes de fornecer os deslocamentos verticais da barra e a distribuição de pressões entre a barra e o concreto, e tanto o comportamento quanto a eficiência das barras foram determinados.

Para uma estrutura elástica (barra) prolongada a uma distância infinita dentro de um corpo elástico com superfície de contorno, Figura 2.16, Timoshenko desenvolveu uma relação entre as propriedades elásticas de duas estruturas e o deslocamento vertical no corpo circundado.

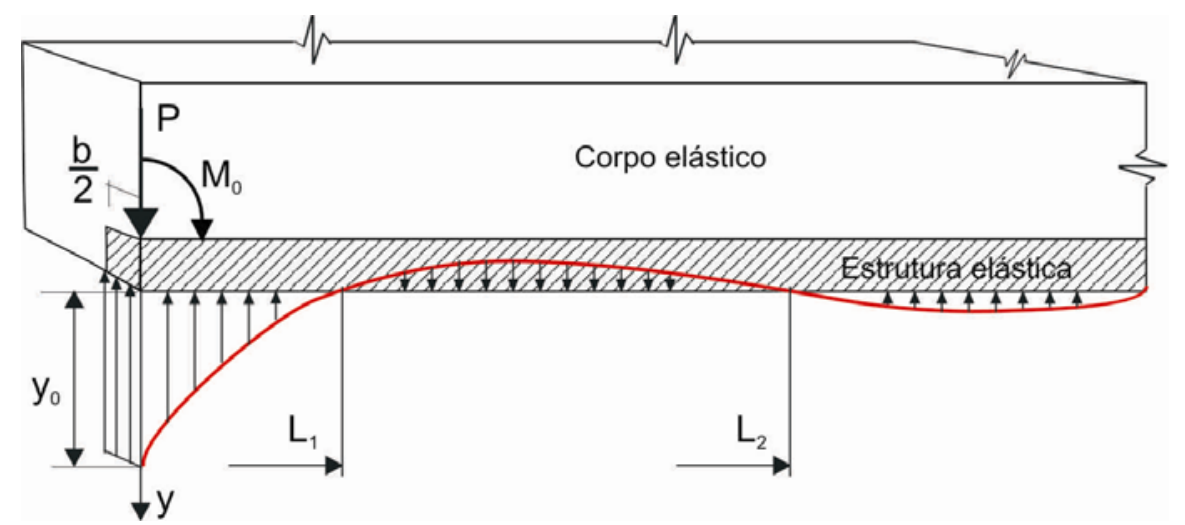

Figura 2.16 - Diagrama de carga e deslocamento mostrando uma barra inserida em um corpo elástico. Fonte: Friberg (1940)

A rigidez relativa da barra e do corpo elástico é expressa pela eq.(2.15).

$$
\beta=\sqrt[4]{\frac{\mathrm{K} \phi}{4 E_{s} I}}
$$

onde $K$ é o módulo de reação ou de suporte da barra; $\phi$ é o diâmetro da barra; $I$ é o momento de inércia da barra; $E_{s}$ é o módulo de elasticidade da barra.

$\mathrm{Na}$ face da estrutura, o deslocamento vertical $y_{0}$ corresponderá a:

$$
y_{0}=\frac{P-\beta M_{0}}{2 \beta^{3} E_{s} I}
$$


onde $P$ é a carga concentrada; $\beta$ é a rigidez relativa da barra; $M_{0}$ é o momento fletor na estrutura à esquerda da face do corpo elástico; I é o momento de inércia da barra; $E_{s}$ é o módulo de elasticidade da barra.

A pressão entre a estrutura elástica e o corpo elástico em qualquer ponto será igual a Ky, ou seja, é diretamente derivada do deslocamento vertical. Nos pontos onde a pressão na estrutura muda de positivo para negativo (vide Figura 2.16), entre $L_{1}$ e $L_{2}$ e à frente de $L_{2}$ será correspondente a:

$$
\tan \beta \cdot L=1-\frac{P}{\beta M_{0}}
$$

onde $L$ é a distância da face do corpo ao ponto desejado.

A Figura 2.17 ilustra o comportamento ao longo da junta de uma barra no interior de uma placa de concreto.

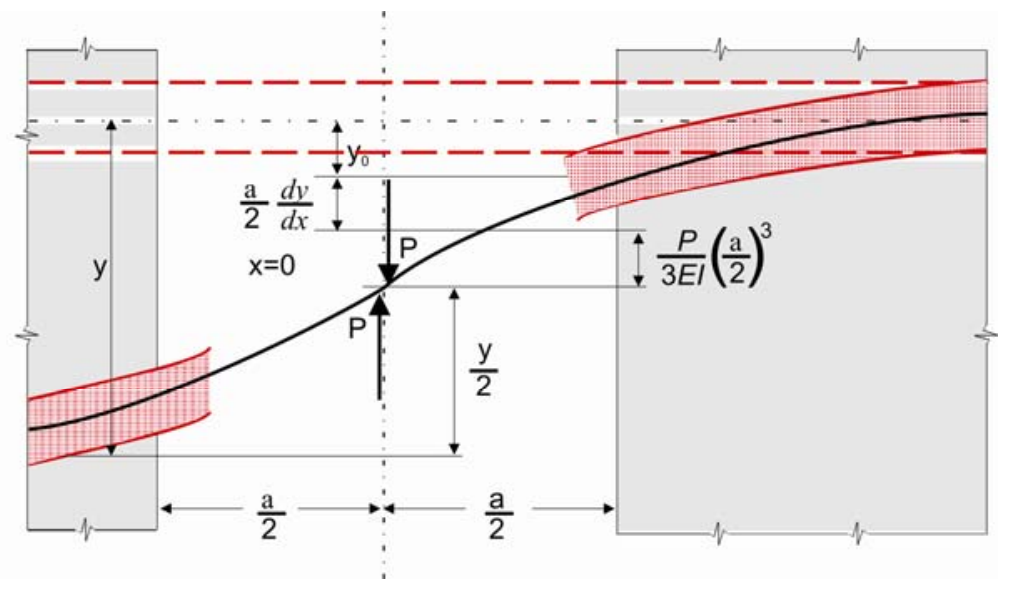

Figura 2.17 - Deslocamento de uma barra ao longo da junta de um pavimento de concreto

O deslocamento vertical $y$ no centro da junta armada depende do deslocamento na face de cada junta $y_{0}$, do deslocamento devido à inclinação da barra na metade superior da junta $\frac{a j}{2} \frac{d y_{0}}{d x}$ e do deslocamento da barra na metade superior da junta, correspondente a $\frac{P}{3 E I}\left(\frac{a j}{2}\right)^{3}$. Portanto, o deslocamento no centro da junta é obtido por: 


$$
y=\frac{P}{2 \cdot E_{s} \cdot I}\left(\frac{1+(1+\beta \cdot a j)^{2}}{\beta^{3}}+\frac{a j^{3}}{6}\right)
$$

onde aj corresponde a abertura da junta.

Friberg (1940) afirmou que barras a distâncias maiores do que 1,8 vez o raio de rigidez relativa do sistema placa-fundação $\ell$ eq.(2.9), medidas do ponto de aplicação da carga, são inativas. Assumiu que a força transferida para cada barra diminui linearmente com a distância do ponto de aplicação da carga.

Algumas considerações puderam ser feitas ao modelo proposto por Friberg (19381940) por diversos autores.

Segundo Grinter (1940), o estudo se refere à utilização de barras somente para o caso de serem utilizadas em placas finas. Essas placas são assentadas sobre uma fundação, que se espera reagir elasticamente nas proximidades da carga vertical aplicada, e de baixo valor. Como mostrado na Figura 2.18, não há somente deformações de compressão no concreto sob a barra, mas a placa apresenta curvatura e afunda dentro da fundação abaulada.

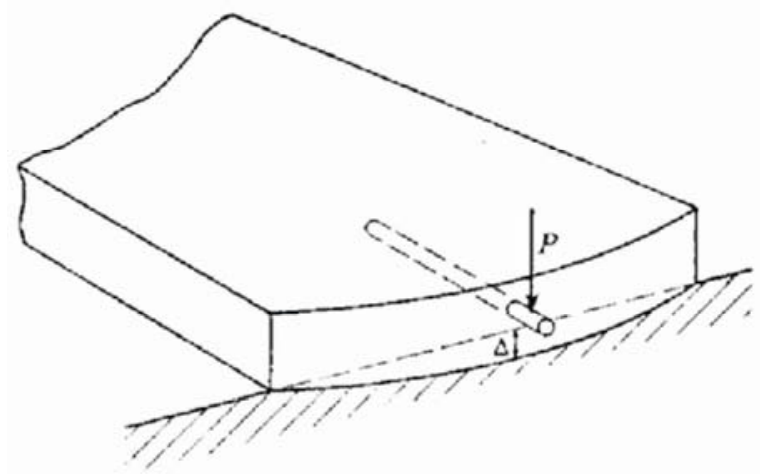

Figura 2.18 - Curvatura da placa e deformação da fundação

Outro fator desconsiderado por Friberg, segundo Grinter (1940), se refere às tensões surgidas devidas ao empenamento do pavimento. O coeficiente de recalque da fundação varia de seção a seção, e a variação de temperatura no pavimento não é uniforme. O resultado é que duas lajes adjacentes não se empenarão da mesma maneira, havendo diferenças na elevação entre as duas placas na junta, que deve ser nivelada pelas barras. Sendo assim, a força cortante na barra é subestimada, o 
que provocará o cálculo de barras mais curtas e valores baixos de transferência de força.

Segundo Fremont (1940), Friberg faz uma aproximação, admitindo que a placa de concreto é absolutamente rígida, representada por colunas conectadas a um apoio rígido, de comprimento constante e características elásticas constantes, apresentado na Figura 2.19. Portanto o subleito acaba não recebendo ação, o que na realidade não ocorre; e logo, as cargas nas barras assim avaliadas acabam sendo maiores do que as calculadas.

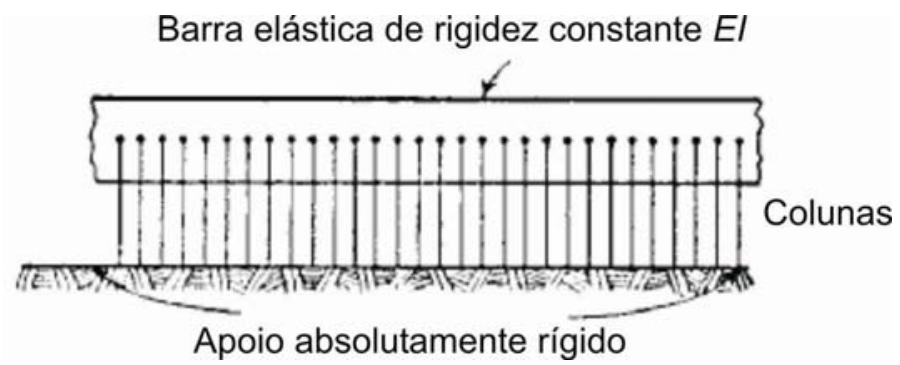

Figura 2.19 - Esboço de colunas conectadas a um apoio rígido. Fonte: Fremont (1940)

\subsubsection{Teller e Cashell (1958)}

Até o ano de 1947, não existiam testes ou publicações que avaliassem o comportamento de um pavimento de concreto submetido a cargas repetidas, seus efeitos e tensões. Isto levou o Bureau of Public Roads, no mesmo ano, a desenvolver uma série de testes, capazes de fornecer informações sobre a influência no comportamento estrutural de barras de transferência em aço sob carregamento repetido.

A pesquisa, conduzida por Teller e Cashell (1958), propunha avaliar: a eficiência inicial de modelos na transferência de carga; o grau com que essa eficiência pode ser mantida a determinado número de ciclos; e o efeito causado na transferência de carga pela variação do diâmetro, do comprimento da barra de seção circular e da abertura da junta.

Preliminarmente foi estudado um modelo, composto por uma placa de concreto com $300 \mathrm{~cm} \times 120 \mathrm{~cm} \times 15 \mathrm{~cm}$, dividida transversalmente por uma junta moldada. 0 esquema de ensaio é apresentado na Figura 2.20. Cada lado da junta era apoiado por uma viga metálica (Figura 2.20g), sendo que os deslocamentos verticais da viga 
metálica simulavam a deformação sofrida por uma fundação de baixo suporte, quando a carga era aplicada ao pavimento, sem no entanto ter sido referenciado seu valor. A carga era aplicada alternadamente nos lados da junta. Quando a carga era aplicada em um lado da junta através do abaixamento da alavanca (Figura 2.20d), o outro lado era automaticamente descarregado. A viga metálica de apoio do lado descarregado sofria deslocamento vertical apenas pelas forças cortantes do sistema interligado, enquanto que a do lado carregado sofria deslocamento vertical pelo carregamento.

A carga era aplicada por blocos (Figura 2.20e) com diâmetro de 25,4cm, e os pesos nos finais das alavancas de carregamento (Figura 2.20f) criavam a carga requerida.

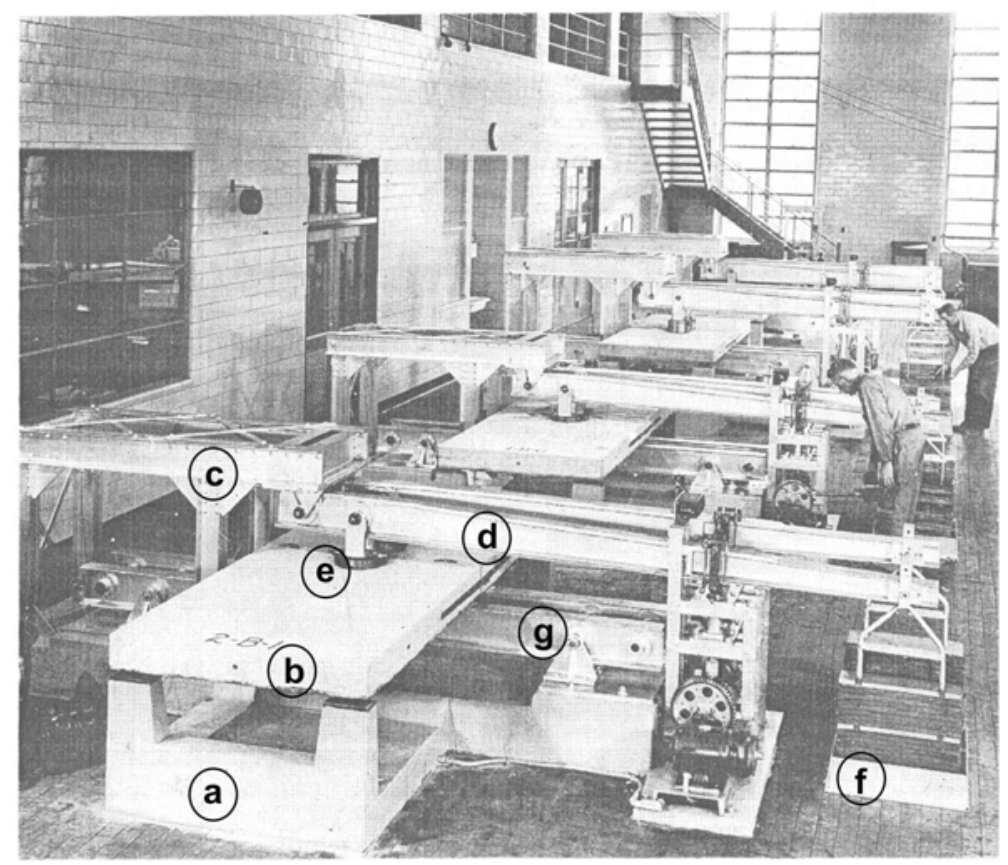

Figura 2.20 - Esquema de ensaio (a) base de concreto armado; (b) modelo; (c) pórtico metálico; (d) alavanca de carregamento; (e) bloco de carregamento; (f) pesos ajustáveis; (g) viga metálica de apoio. Fonte: Teller e Cashell (1958)

Após o estudo preliminar ter sido efetuado, foram construídos 32 modelos, sendo destes 29 ensaiados e dados coletados. A Tabela 2.5 fornece as variáveis adotadas.

Tabela 2.5 - Variáveis adotadas segundo Teller e Cashell (1958)

\begin{tabular}{|c|c|c|c|c|c|c|c|}
\hline Diâmetros das barras & $\mathrm{mm}$ & 16 & 19 & 22 & 25 & 28 & 32 \\
\hline Abertura da junta & $\mathrm{mm}$ & 2 & 12 & 19 & 25 & & \\
\hline Espessura dos modelos & $\mathrm{cm}$ & 15 & 20 & 25 & & & \\
\hline
\end{tabular}


estudo da variação do comprimento as barras foi efetuado para alguns diâmetros, de barra, conforme indicado na Tabela 2.6.

Tabela 2.6 -Comprimento das barras de transferência para alguns diâmetros, segundo Teller e Cashell (1958)

\begin{tabular}{|c|c|c|c|c|}
\hline $\begin{array}{c}\text { Diâmetro das } \\
\text { barras }\end{array}$ & \multicolumn{5}{|c|}{ Comprimento da barra de transferência ${ }^{[1]}$} \\
\hline $\mathrm{mm}$ & $\mathrm{mm}$ & $\mathrm{mm}$ & $\mathrm{mm}$ & $\mathrm{mm}$ \\
\hline 19 & 10 & 17 & 32 & 48 \\
\hline 25 & 12 & 22 & 42 & 63 \\
\hline 32 & 14 & 27 & 52 & - \\
\hline [1] Valores originalmente em polegadas, com arredondamento. \\
\hline
\end{tabular}

As barras de transferência eram de aço carbono, e suas propriedades mecânicas, assim como as do concreto utilizado, podem ser visualizadas na Tabela 2.7.

Tabela 2.7 - Propriedades mecânicas dos materiais segundo Teller e Cashell (1958)

\begin{tabular}{|c|c|c|c|c|c|}
\hline \multicolumn{3}{|c|}{ Concreto $^{[1]}$} & \multicolumn{3}{c|}{ Aço } \\
\hline $\begin{array}{c}\text { Resistência à } \\
\text { compressão do } \\
\text { concreto } \\
f_{c}\end{array}$ & $\begin{array}{c}\text { Resistência à } \\
\text { tração na flexão } \\
\text { do concreto } \\
f_{c t, f}\end{array}$ & $\begin{array}{c}\text { Módulo de } \\
\text { elasticidade do } \\
\text { concreto } \\
E_{c}\end{array}$ & $\begin{array}{c}\text { Resistência à } \\
\text { tração do aço } \\
f_{y}\end{array}$ & $\begin{array}{c}\text { Resistência de } \\
\text { escoamento do } \\
\text { aço } \\
f_{u}\end{array}$ & $\begin{array}{c}\text { Módulo de } \\
\text { elasticidade do } \\
\text { aço } \\
E_{s}\end{array}$ \\
\hline 38 & $\mathrm{MPa}$ & $\mathrm{MPa}$ & $\mathrm{MPa}$ & $\mathrm{MPa}$ & $\mathrm{MPa}$ \\
\hline [1]Propriedades determinadas aos 28 dias & 49.000 & 458 & 305 & 207.000 \\
\hline
\end{tabular}

Os modelos foram confeccionados em fôrma rígida desmontável, e puderam ser movimentados para o canteiro de ensaio por meio de parafusos laterais, presos ao longo de todo o perímetro, sustentando desta forma seu peso próprio. Cada modelo continha quatro barras de transferência, espaçadas a cada $30 \mathrm{~cm}$, com diâmetro de $19 \mathrm{~mm}$. 


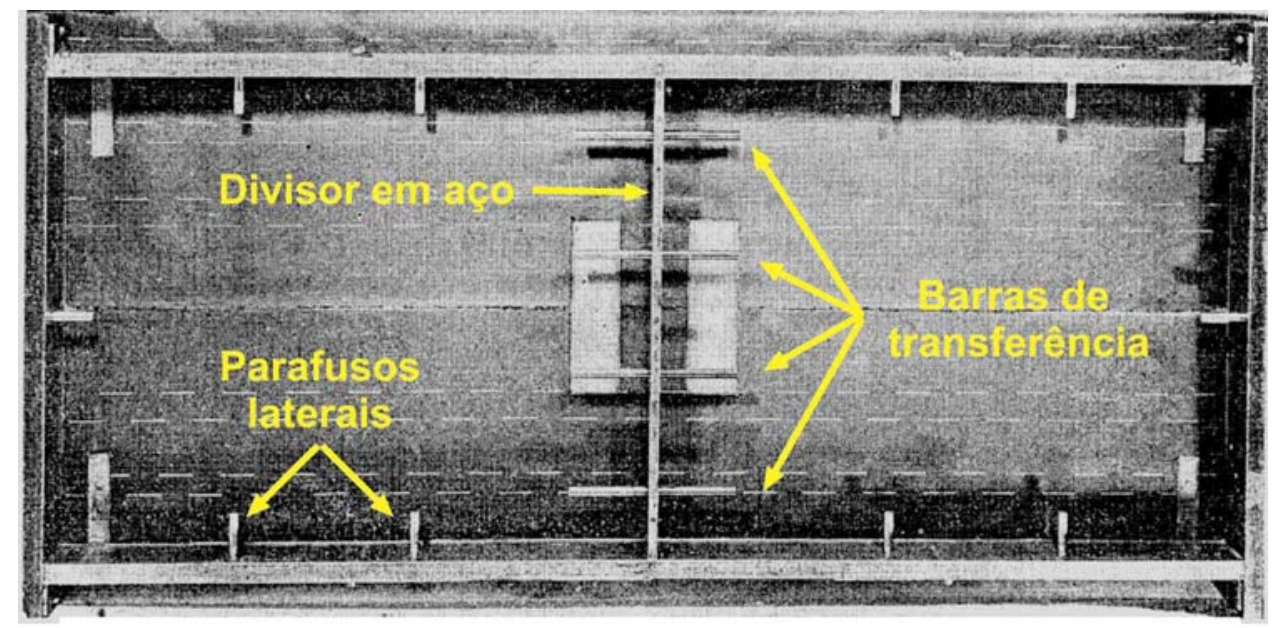

Figura 2.21 - Vista superior da fôrma metálica construída para lançamento do concreto. Fonte: Teller e Cashell (1958)

Metade de cada barra foi engraxada para diminuir a aderência do concreto, simulando a condição crítica de aderência entre barra e concreto, o que provoca um escorregamento da barra. A presença de óleo; água ou bolhas de ar no concreto, particularmente sob a barra; ou mesmo a contração do concreto durante 0 endurecimento, além do desgaste da região compreendida entre as superfícies da barra e do concreto quando submetidas a carregamento cíclico, são situações que contribuem para o seu escorregamento e, conseqüentemente, diminuição das tensões de aderência.

O procedimento experimental contou com três métodos, para as cargas em situação de serviço:

Método 1: Foram aplicadas cargas de 22,5 kN a 45 kN, em incrementos de 4,5 kN. Os deslocamentos verticais foram lidos nas quatro barras de cada modelo. Este método foi utilizado em 19 modelos.

Método 2: As cargas foram aplicadas similarmente ao método 1. Os deslocamentos verticais foram lidos em apenas uma das quatro barras de transferência, localizada próxima ao ponto de aplicação da carga. Este método foi utilizado em 18 modelos.

Método 3: Após a finalização dos testes com modelos de quatro barras, as duas barras de transferência próximas às extremidades foram cortadas em 12 modelos, e apenas a duas barras centrais permaneceram ativas. As cargas foram aplicadas similarmente ao método 1. 
A Figura 2. 22 ilustra a relação entre a carga aplicada e o deslocamento vertical relativo das duas superfícies carregadas $(y)$, em intervalos de leituras com aplicação de cargas estáticas, após vários números de ciclos aplicados. As características de comportamento foram comuns para todos os testes realizados, e y foi obtido por relógios comparadores, posicionados sobre uma barra próxima à força aplicada.

Os sucessivos incrementos de carga causaram, progressivamente, pequenos incrementos em $y$, até a carga aplicada de $22 \mathrm{kN}$. Entre $22 \mathrm{kN}$ e $45 \mathrm{kN}$, a relação entre carga aplicada e deslocamento foi linear. Isto indica que durante a aplicação dos primeiros $22 \mathrm{kN}$ as barras se acomodavam, havendo um rearranjo ou escorregamento inicial.

Com a superposição dos valores do trecho retilíneo do gráfico por uma reta inclinada pontilhada, sobre o eixo $\mathrm{Y}$ é possível estimar quantitativamente o escorregamento sofrido pelas barras para cada número de ciclos aplicados. O escorregamento inicial foi da ordem de $0,09 \mathrm{~mm}$. Após $2 \times 10^{6}$ ciclos, o escorregamento foi da ordem de $0,16 \mathrm{~mm}$.

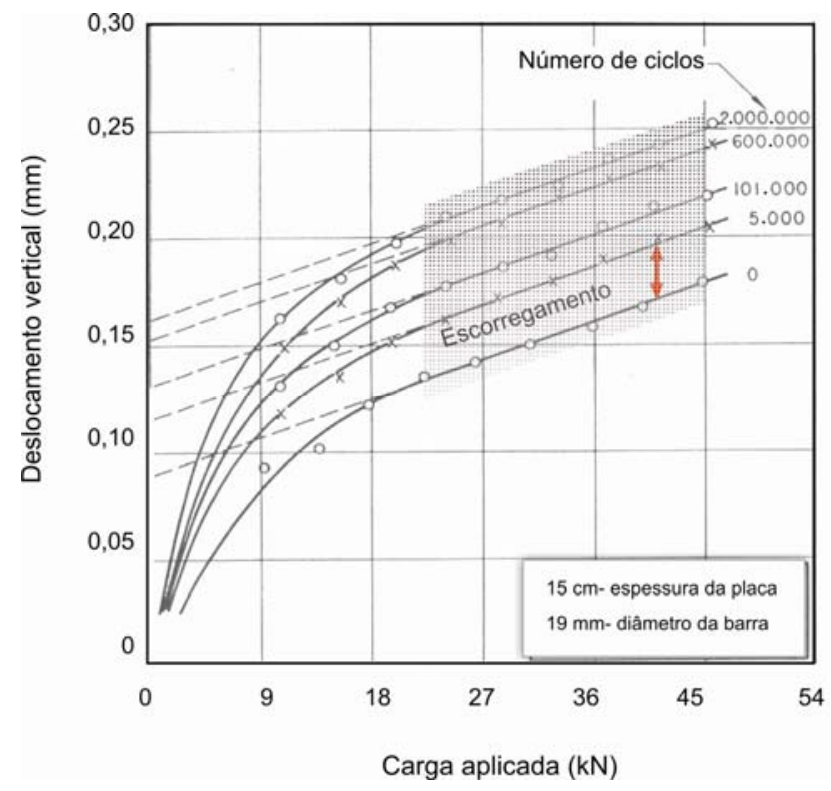

Figura 2. 22 - Gráfico deslocamento vertical x carga aplicada por número de ciclos de carregamento. Fonte: Teller e Cashell (1958)

A maneira pela qual esse escorregamento aumentou, com o acréscimo do número de repetições de carga, é apresentada na Figura 2.23. O aumento do 
escorregamento resultante da aplicação repetida de $45 \mathrm{kN}$ é traçada até os $2 \times 10^{6}$ ciclos. Os valores foram determinados pela intersecção no eixo $Y$ das curvas apresentadas na Figura 2. 22. Verificou-se um rápido aumento no escorregamento durante os primeiros ciclos de carregamento.

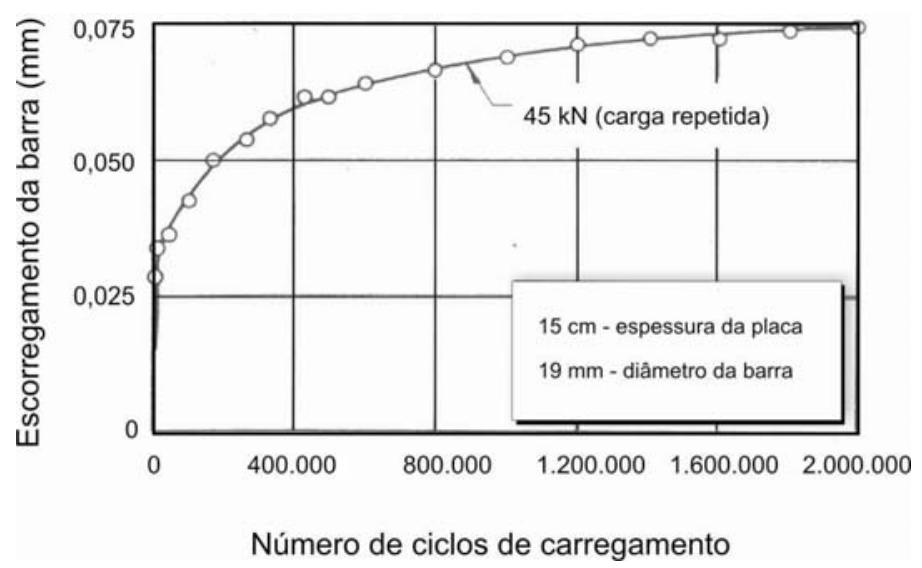

Figura 2.23 - Efeito do carregamento repetido no desenvolvimento do escorregamento. Fonte: Teller e Cashell (1958)

Vale ressaltar que com base nos ensaios preliminares, os modelos seguintes foram testados até 600.000 ciclos, uma vez que até esse valor eram verificadas mudanças no comportamento do sistema. Acima desse valor e até $2 \times 10^{6}$ ciclos, as mudanças foram consideradas pequenas.

A barra de transferência ou um sistema de barras não começa a funcionar na sua máxima eficiência até todo o escorregamento inicial ocorrer, devido ao deslocamento vertical do lado carregado na junta do pavimento. Dessa maneira, Teller e Cashell (1958) afirmam que como efeito do escorregamento há uma redução na transferência de força, de um valor que depende do grau de escorregamento da barra.

A repetição de carga causa um aumento progressivo no escorregamento inicial das barras. Essa mudança ocorrida sob cargas repetidas é atribuída ao esmagamento do concreto acima ou abaixo da barra, particularmente na região próxima à face da junta.

Segundo esses autores, é mais seguro assumir um escorregamento inicial na junta armada na prática das construções e conhecer o seu efeito na transferência de força. A perda em potencial da capacidade de transferência de força, resultante de 
um escorregamento inicial no sistema de transferência, pode ser expressa pela eq. (2.19).

$$
\Delta E=\frac{\mathrm{e}_{i}}{y_{0}} \times 100
$$

onde $\Delta E$ é a perda em potencial da capacidade de transferir carga, em \%; $\mathrm{e}_{i}$ é o escorregamento inicial, em $\mathrm{mm} ; y_{0}$ é o deslocamento da extremidade livre do pavimento, em milímetros, causada pela carga em questão.

O deslocamento vertical da borda do pavimento, sobre a qual a carga é aplicada, deve ser igual ao deslocamento da barra de transferência mais o deslocamento da borda adjacente da placa. Para assegurar esta relação, é implícito que não haja escorregamento da barra.

A parte proporcional da carga aplicada que é transferida à placa adjacente pela barra é obtida pela equação.

$$
P_{t}=\frac{1}{2+\frac{y_{d}}{y_{0}}} \times 100
$$

onde $P_{t}$ se refere à proporção de carga transferida, em \%; $y_{d}$ é o deslocamento vertical da barra causado por uma força cortante unitária, em milímetros; $y_{0}$ é o deslocamento vertical da extremidade livre do pavimento, em milímetros, causado por uma força unitária.

A porcentagem de carga transferida, desta maneira, depende sobremaneira da rigidez relativa da barra e do pavimento $(\beta)$, de modo que esses fatores afetarão a rigidez um do outro.

A Figura 2.24 apresenta um gráfico típico da relação entre a carga estática aplicada no sistema versus a tensão na barra, com $\phi=19 \mathrm{~mm}$ e abertura da junta de $19 \mathrm{~mm}$. A taxa de deslocamento vertical foi de $0,25 \mathrm{~mm}$ por $4,5 \mathrm{kN}$ de carga aplicada. Observou-se que as tensões são essencialmente lineares, entre $9 \mathrm{kN}$ e $45 \mathrm{kN}$. Para carregamentos menores, a não linearidade é devida, provavelmente, aos ajustes iniciais de acomodamento das barras. As tensões nas barras 2 e 3, próximas à área 
carregada, são maiores do que aquelas mais distantes do ponto de carregamento (1 e 4), indicando maior transferência de força.

O ponto na barra em que ocorre a mudança do momento fletor de positivo para negativo (ponto de inflexão da curva elástica) não foi detectado no centro da junta, para os testes efetuados.

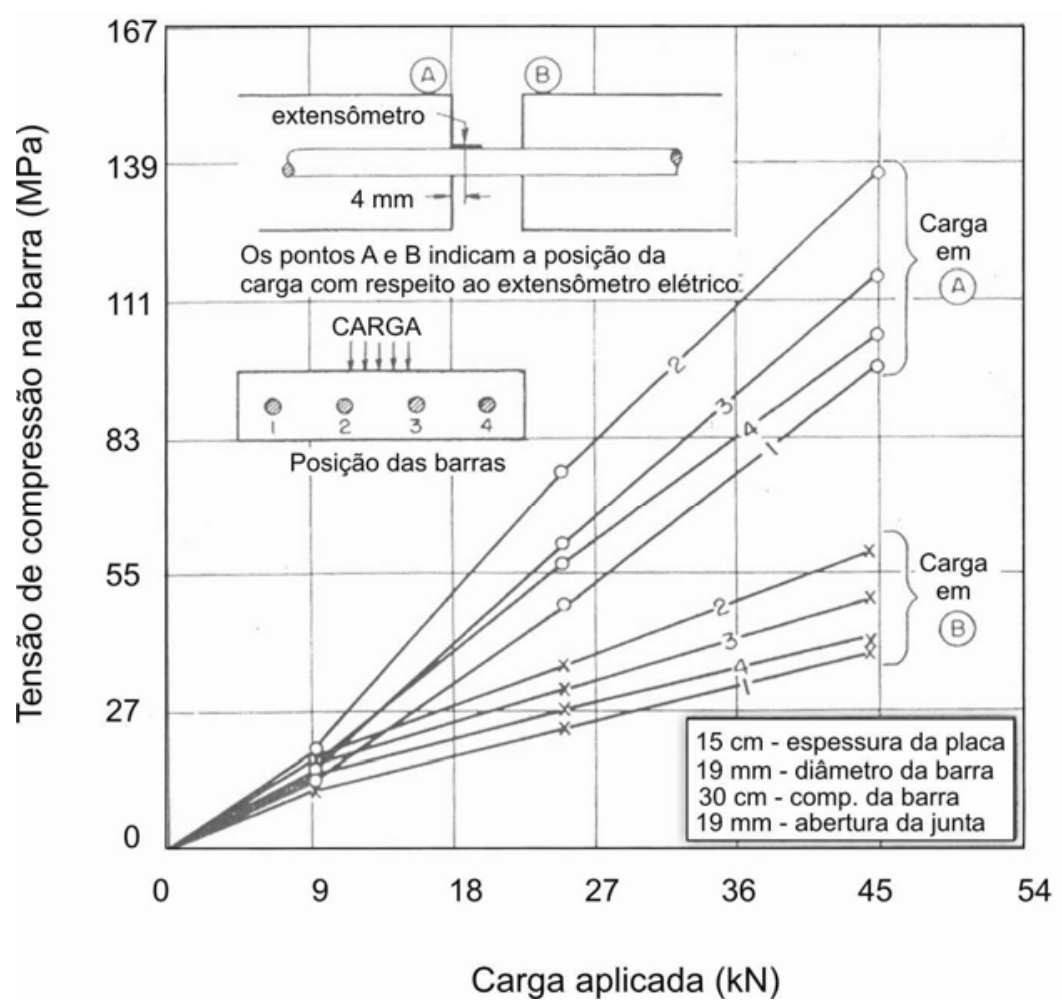

Figura 2.24 - Gráfico tensão de compressão na barra x carga aplicada

A Figura 2.25 apresenta o comportamento da superfície de concreto com 0 posicionamento de extensômetros elétricos nos modelos estudados. Para as condições dos experimentos, o concreto permaneceu elástico, para diferentes espessuras das placas de concreto. 


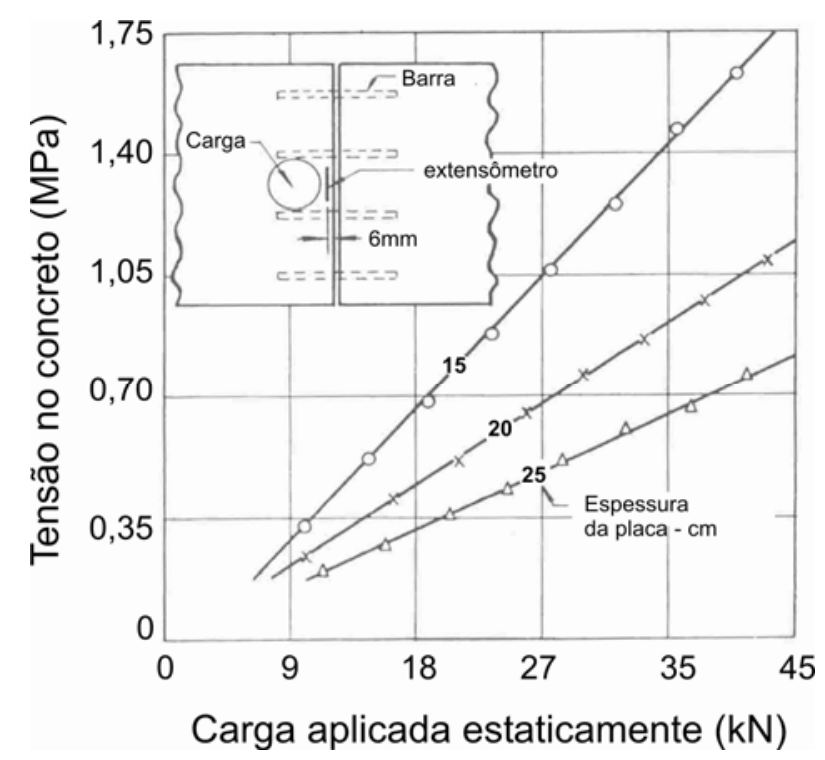

Figura 2.25 - Gráfico carga aplicada versus tensão no concreto ao longo da borda da junta. Fonte: Teller e Cashell (1958)

Teller e Cashell (1958) puderam concluir com os experimentos que:

- Existe uma relação exponencial entre o diâmetro e os deslocamentos das barras;

- Existe uma relação entre a espessura da placa e o diâmetro da barra. Para espaçamentos de $30 \mathrm{~cm}$ e abertura da junta de $19 \mathrm{~mm}$ ou menos, o diâmetro da barra deve ser $1 / 8$ da espessura da placa;

- Quanto maior a rigidez da barra de transferência, devido ao aumento de diâmetro, menor será o comprimento de embutimento necessário para promover uma máxima transferência de carga. Além disso, quanto maior o comprimento de embutimento, menores são os deslocamentos verticais ocorridos na junta;

- A diminuição da abertura da junta reduz as tensões nas barras, que leva a uma diminuição dos deslocamentos na barra e um aumento na porcentagem de carga transferida.

\subsubsection{Buch e Zollinger (1996)}

Aprofundando os estudos iniciados por Teller e Cashell (1958), sobre aumento progressivo do escorregamento das barras, os pesquisadores Buch e Zollinger (1996) conduziram experimentos, que avaliavam os efeitos do tipo de agregado empregado no concreto. Estes efeitos foram analisados em relação ao diâmetro das 
barras, às tensões de esmagamento, à magnitude das forças e ao número de ciclos empregados.

Modelos em concreto de cimento Portland com dimensões de $61 \mathrm{~cm} \times 25,4 \mathrm{~cm} \times$ $91,5 \mathrm{~cm}$ foram moldados, e juntas foram serradas para induzir o surgimento de uma fissura controlada. Os modelos foram ensaiados após 28 dias, com resistência característica à compressão do concreto $f_{c k}$ de $24 \mathrm{MPa}$. O coeficiente de recalque da fundação era $k=28 \mathrm{MPa} / \mathrm{m}$.

Antes de serem aplicados ciclos de carregamento, todos os modelos foram préfissurados sob carga estática. O carregamento era aplicado por um par de atuadores hidráulicos, que pulsavam alternadamente em cada lado da junta, produzindo uma carga que aumentava de zero até $40 \mathrm{kN}$, e depois decrescia até zero. A freqüência de aplicação da carga era de $0,7 \mathrm{~Hz}$.

A segunda fase da pesquisa correspondia ao desenvolvimento de um modelo mecânico-empírico, baseado nos resultados laboratoriais, para a previsão do escorregamento da barra. A eq. (2.21) apresenta o escorregamento $e$ sofrido pela barra, em função do número de ciclos.

$$
e=\left[\beta_{0}+\beta_{1} \cdot \ln (N)+\beta_{2} \cdot\left(\sigma_{e}\right)+\beta_{3} \cdot(P)+\beta_{4} \cdot\left(\mathrm{SiO}_{2}\right) \cdot 0,0254\right]
$$

onde $N$ é o número de ciclos; $\sigma_{e}$ é a tensão provocada pela barra ao concreto circundante, conhecida como tensão de esmagamento; $P$ é a força aplicada; $\mathrm{SiO}_{2}$ é a porcentagem de dióxido de silício ou sílica; $\beta_{0}=-4,36 ; \beta_{1}=0,526 ; \beta_{2}=0,003$; $\beta_{3}=0,001$ e $\beta_{4}=0,011$.

O aumento de $\sigma_{e}$ provoca um aumento na deterioração do concreto circundante à barra, provocando seu escorregamento ou eventual ruptura da junta. Essa tensão, proposta por loannides e Korovesis (1992), é calculada por:

$$
\sigma_{e}=\frac{\mathrm{K}}{D C I} \cdot P_{c}
$$


onde Ké o módulo de suporte da barra; $D C I=\frac{4 \cdot \beta^{3} \cdot E_{s} \cdot I_{s}}{2+\beta \cdot a}$, que corresponde a uma rigidez vertical causada pela interação da barra com a placa e $P_{c}$ é a porção de força transferida por uma barra crítica, tendo em vista que cada barra individualmente transfere uma parcela de força.

A relação entre o escorregamento da barra "e" e a perda da eficiência na transferência de força é fornecida pela eq.(2.23).

$$
L T E=93,094 e^{(-0,0218 \cdot e)}
$$

onde LTE corresponde à porcentagem de carga transferida nos deslocamentos.

O estudo concluiu que o escorregamento da barra aumenta com o aumento no número de ciclos de carregamento. Também verificou que o escorregamento e o deslocamento vertical reduzem com o aumento do diâmetro da barra.

\subsubsection{Mannava, Bush e Kukreti (1999)}

Um programa experimental foi conduzido na Universidade de Oklahoma para determinar as características carga aplicada versus deslocamento vertical de juntas dotadas de barras de transferência. Mannava, Bush e Kukreti (1999) procuravam investigar os efeitos da resistência do concreto, do diâmetro da barra e da abertura da junta transversal no comportamento do pavimento de concreto.

O esquema experimental foi planejado para testar uma barra de transferência lisa posicionada ao longo de uma junta, como apresentado na Figura 2.26. Oito modelos foram carregados estaticamente, até o limite de escoamento do aço, em um pórtico de reação, utilizando para tanto um atuador hidráulico preso na parte superior de um suporte metálico em L. O suporte metálico se conectava a um dos blocos. O ponto de aplicação da força foi centrado sobre da junta.

O comprimento de embutimento da única barra foi de $25 \mathrm{~cm}$ ou $8 \phi$ da barra. Como o foco do estudo era a interação da barra com o concreto, uma fundação rígida (camada metálica) foi utilizada para todos os testes. O bloco de reação tinha dimensões de $38 \mathrm{~cm} \times 38 \mathrm{~cm}$ x $25 \mathrm{~cm}$ e o bloco carregado possuía as dimensões de $38 \mathrm{~cm} \times 33 \mathrm{~cm} \times 22,9 \mathrm{~cm}$. Um espaço de $2,5 \mathrm{~cm}$ de altura foi providenciado para 
permitir deslocamentos verticais durante o carregamento. Os modelos foram executados primeiramente pela concretagem do bloco de reação, contendo metade da barra engastada e engraxada. Nos dias subseqüentes, com a retirada da fôrma do primeiro bloco, o bloco carregado foi concretado. Duas placas metálicas foram utilizadas para formar a abertura da junta. Os deslocamentos verticais foram lidos por LVDTs (Linear Variable Differential Transformers), com hastes estendidas ao longo de pequenos orifícios feitos no concreto, da ordem de 6,4mm de diâmetro, até a barra.

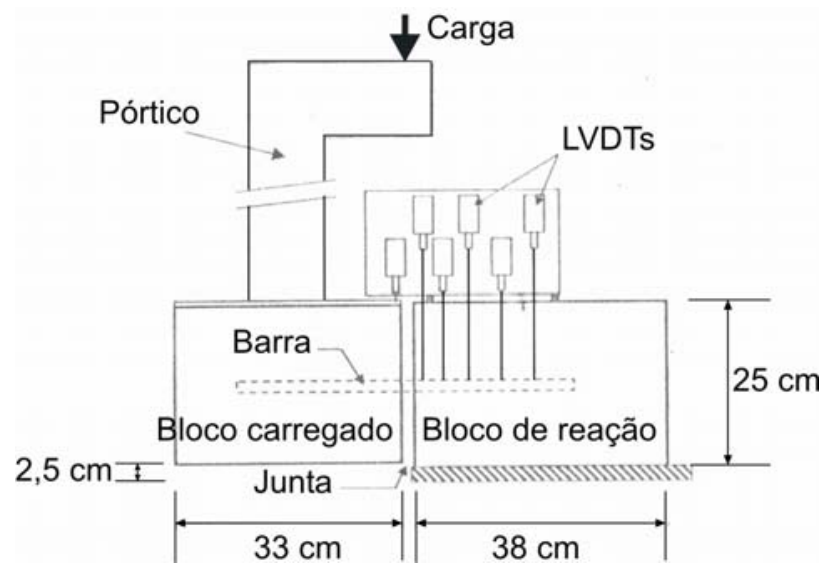

Figura 2.26 - Esquema do ensaio experimental. Fonte: Mannava, Bush e Kukreti (1999)

A Tabela 2.8 fornece as variáveis adotadas no programa experimental. Foram consideradas três resistências à compressão do concreto, três diâmetros para a barra de transferência lisa e duas aberturas da junta. Três letras classificam esses parâmetros, um em relação ao outro, seja L (low = baixa), $\mathrm{M}$ (médium = média) e H (high = alta), segundo, respectivamente, sua resistência, diâmetro e abertura.

Tabela 2.8 - Variáveis adotadas segundo Mannava, Bush e Kukreti (1999)

\begin{tabular}{|c|c|c|c|c|}
\hline $\begin{array}{c}\text { Resistência à compressão do } \\
\text { concreto característica }\end{array}$ & $\mathrm{MPa}$ & $17(\mathrm{~L})$ & $28(\mathrm{M})$ & $45(\mathrm{H})$ \\
\hline Diâmetro das barras & $\mathrm{mm}$ & $19(\mathrm{~L})$ & $25(\mathrm{M})$ & $38(\mathrm{H})$ \\
\hline Abertura da junta & $\mathrm{mm}$ & $9(\mathrm{~L})$ & $20(\mathrm{H})$ & \\
\hline
\end{tabular}

O gráfico deslocamento vertical versus distância da face da junta apresentado na Figura 2.27 foi obtido para $40 \%$ da carga de ruptura dos modelos MML e HHL, em linha cheia. Permanecendo a abertura da junta constante $(9 \mathrm{~mm})$, verifica-se que, 
aumentando a resistência à compressão do concreto e o diâmetro da barra, é possível obter maiores deslocamentos verticais para o mesmo estágio de carregamento.

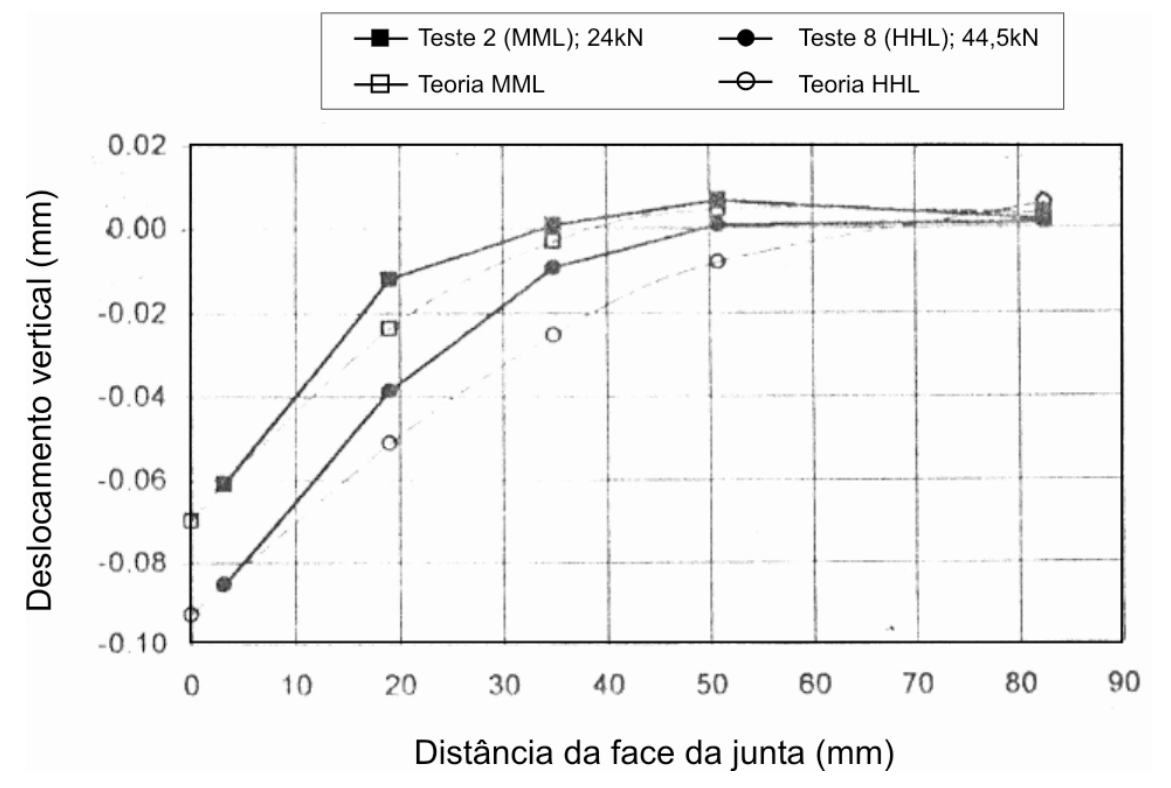

Figura 2.27 - Gráfico deslocamento vertical versus distância da face da junta. Fonte: Mannava, Bush e Kukreti (1999)

Comparando os resultados experimentais obtidos com as previsões analíticas fornecidas por Timoshenko (vide eq.(2.16)), os pesquisadores verificaram que, em geral, a expressão analítica prevê pequena curvatura próximo da face da junta (linha tracejada), menor do que as encontradas nos experimentos. Também a expressão geralmente prevê grandes deslocamentos verticais, no sentido ascendente, para a parte da barra bem distante da face da junta, embora a magnitude desses deslocamentos seja bem menor.

A expressão analítica também não acompanha a suavização da curva da linha elástica da barra, exibida nos testes, em detalhe na Figura 2.28. Fontes locais de não linearidade são evidentes, segundo os pesquisadores. Essas fontes incluem o início e progressivo escoamento da barra, além de tensões locais $\sigma_{e}$, nas imediações da junta entre o concreto e a barra. 


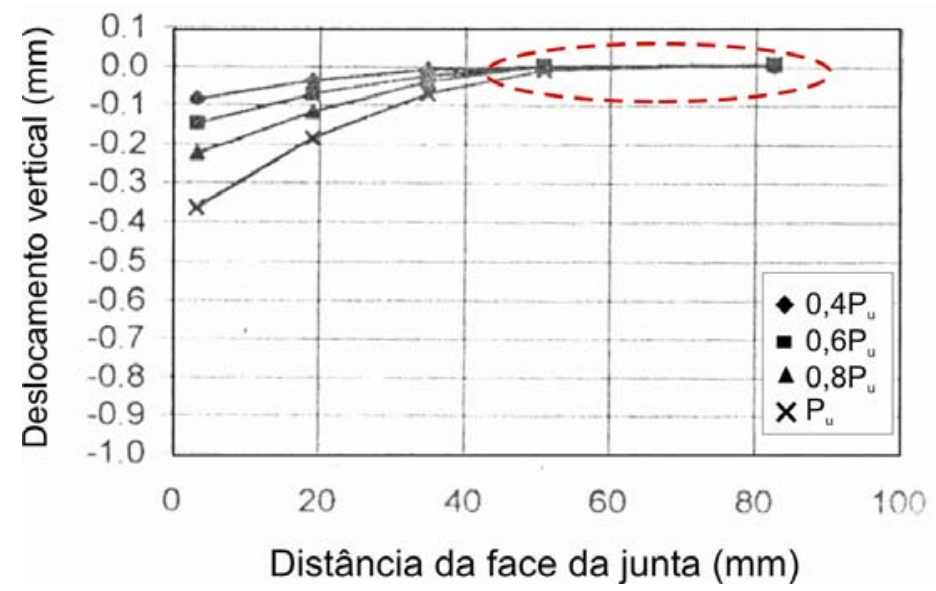

Figura 2.28 - Gráfico deslocamento vertical versus distância da junta para Teste 8 - HHL. Fonte: Mannava, Bush e Kukreti (1999)

Mannava, Bush e Kukreti (1999) verificaram que uma redução de $25 \%$ do diâmetro da barra, de $25 \mathrm{~mm}$ para $19 \mathrm{~mm}$, resultou em uma redução similar da rigidez dos modelos, de aproximadamente $20 \%$ para concretos de baixa resistência (17MPa) e pequena abertura da junta $(9 \mathrm{~mm})$. Concluíram também que a equação de Timoshenko, baseada nos princípios elástico-lineares, não leva em conta o comportamento não-linear associado ao escoamento da barra e às elevadas tensões $\sigma_{b}$ em torno da barra.

\subsubsection{Eddi; Shalaby e Rizkalla (2001)}

Ensaios executados no Laboratório da Universidade de Manitoba, Canadá, avaliaram o comportamento de barras de transferência em fibra de vidro ("Glass fiber reinforced polymer dowels"), ou GFRP, e em aço envolvidas por epóxi ("Epoxy coated steel"), ou ECS, todas utilizadas em juntas transversais de pavimentos de concreto. Os testes verificaram a transferência de força nos pavimentos e a viabilidade da utilização de GFRP nessa aplicação. O estudo incluiu ensaios estáticos e cíclicos em 12 modelos, sendo que cada modelo contou com duas barras de transferência. $O$ detalhe da sua geometria e a configuração do ensaio são mostrados na Figura 2.29.

O carregamento, seja monotônico ou repetido, foi aplicado por um sistema servohidráulico com capacidade para $5.000 \mathrm{kN}$, em um dos lados da junta, sobre uma região de distribuição de carga de $60 \mathrm{~cm} \times 25 \mathrm{~cm}$. Os modelos foram instrumentados 
com LVDTs e relógios comparadores, para medição dos deslocamentos verticais e horizontais.

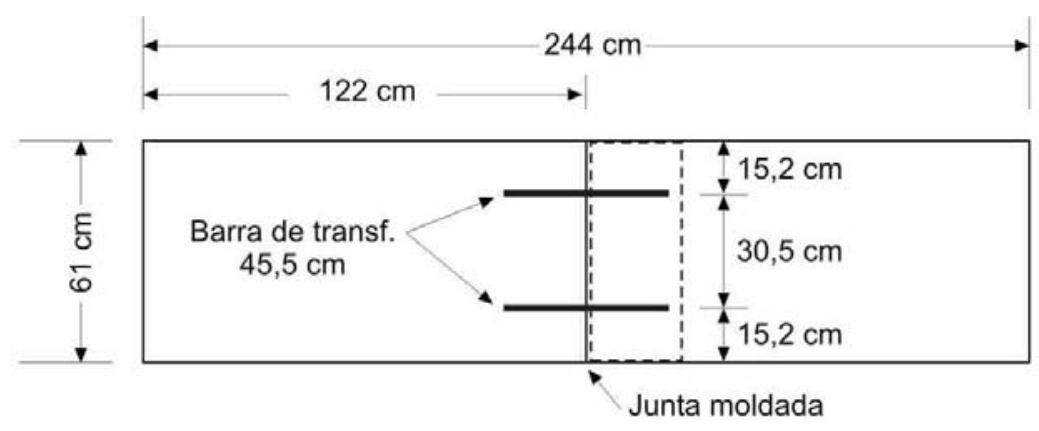

(a)

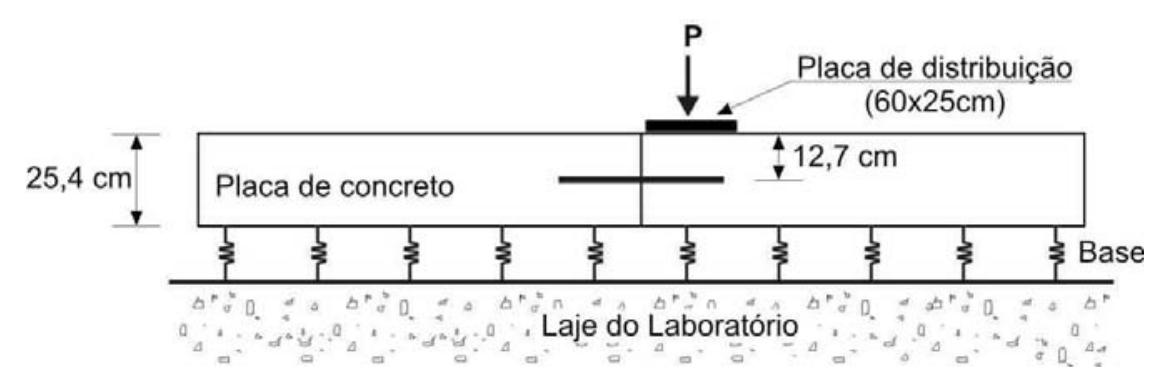

(b)

Figura 2.29 - Configuração de ensaio (a) vista superior; (b) corte transversal. Fonte: Eddi; Shalaby e Rizkalla (2001)

No programa experimental apresentado na Tabela 2.9, foram incluídos dois valores de coeficiente de recalque, que levaram em conta a capacidade de suporte da fundação. O primeiro valor apresentava baixo suporte, constituído por uma matriz de molas de aço e $k=3,6 \mathrm{MPa} / \mathrm{m}$; e o segundo, com elevado suporte, constituído por três camadas de $10 \mathrm{~cm}$ cada, de pedra britada e $k=133,3 \mathrm{MPa} / \mathrm{m}$. Três fases constituíram o procedimento experimental, em função do tipo de carregamento empregado e da resistência da fundação. 
Tabela 2.9 - Programa experimental dos ensaios segundo Eddie; Shalaby e Rizkalla (2001)

\begin{tabular}{|c|c|c|c|}
\hline Etapa & Número de modelos & Base & Método de ensaio \\
\hline \multirow{3}{*}{ Fase 1} & $1 \mathrm{ECS}^{[1]}$ & \multirow{3}{*}{ Molas de aço } & \multirow{3}{*}{ Carregamento monotônico até o colapso } \\
\hline & 1 GFRP - tipo $1^{[2]}$ & & \\
\hline & 1 GFRP - tipo $2^{[3]}$ & & \\
\hline \multirow{3}{*}{ Fase 2} & 2 ECS & \multirow{3}{*}{$\begin{array}{l}\text { Pedra britada } \\
\text { bem graduada }\end{array}$} & \multirow{3}{*}{$\begin{array}{c}\text { Carregamento monotônico até } 300 \mathrm{kN} \text {, } \\
\text { descarregamento, re-carregamento } \\
\text { monotônico até o colapso }\end{array}$} \\
\hline & 2 GFRP - tipo 1 & & \\
\hline & 2 GFRP - tipo 2 & & \\
\hline \multirow{3}{*}{ Fase 3} & $1 \mathrm{ECS}$ & \multirow{3}{*}{$\begin{array}{c}\text { Pedra britada } \\
\text { bem graduada }\end{array}$} & \multirow{3}{*}{ Carregamento cíclico até $10^{6}$ ciclos } \\
\hline & 1 GFRP - tipo 1 & & \\
\hline & 1 GFRP - tipo 2 & & \\
\hline
\end{tabular}

A Fase 1 foi caracterizada pela ruptura do concreto devido às deformações. Foi observado um esmagamento do concreto na região da junta moldada, seguido do fechamento da junta, e fissuração do concreto sob a região de distribuição de carga. O gráfico eficiência da junta versus força aplicada, indicado na Figura 2.30, apresenta os resultados obtidos nesta fase. Os modelos chegaram à ruptura com cargas próximas a $100 \mathrm{kN}$, e eficiência da junta na ordem de $86 \%$ a $100 \%$. A eficiência da junta foi obtida de acordo com as especificações da ACPA (vide item 2.1.1B).

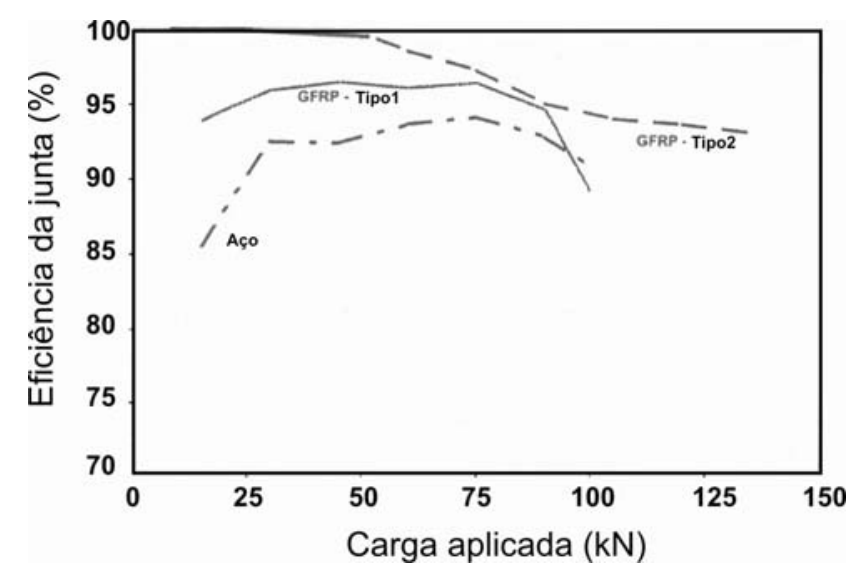

Figura 2.30 - Eficiência da junta: Fase 1. Fonte: Eddi; Shalaby e Rizkalla (2001) 
$\mathrm{Na}$ Fase 2 foi observado esmagamento do concreto seguido de fechamento e fragmentação das faces da junta moldada, a cargas próximas a $200 \mathrm{kN}$. A eficiência no intervalo entre $90 \%$ e $97 \%$ foi obtida até a carga de $300 \mathrm{kN}$, como apresentado no gráfico eficiência da junta versus carga aplicada da Figura 2.31.

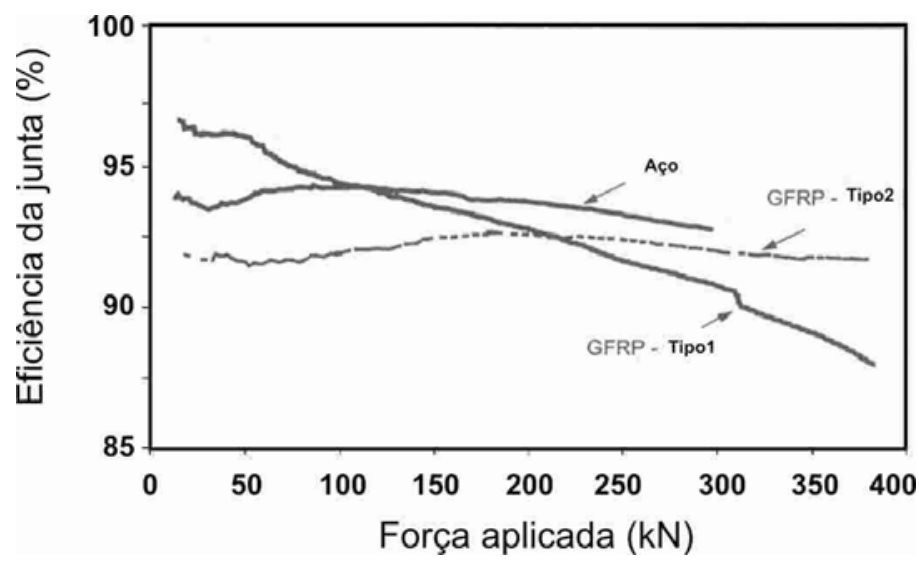

Figura 2.31 - Eficiência da junta: Fase 2. Fonte: Eddi; Shalaby e Rizkalla (2001)

Os resultados sugeriram que as barras de transferência produzidas com fibra de vidro GFRP apresentaram uma eficiência equivalente à da de aço ECS, nos ensaios estáticos, com uma transferência de carga aceitável até a ruptura das peças.

$\mathrm{Na}$ Fase 3, a freqüência do carregamento foi de $6 \mathrm{~Hz}$ em onda senoidal, com forças máxima e mínima de $130 \mathrm{kN}$ e $20 \mathrm{kN}$, tendo sido aplicados $10^{6}$ ciclos. Para todas as barras de transferência, foi verificada uma eficiência maior do que $80 \%$, superior ao valor mínimo recomendado pela ACPA, de $75 \%$, apresentado na gráfico eficiência da junta versus força aplicada, da Figura 2.32.

Os modelos foram ensaiados com cargas no Estado Limite de Serviço, apenas com o surgimento de algumas fissuras, sem no entanto levar à ruptura. A diminuição na eficiência das juntas, em relação às duas fases anteriores, se deve ao fato de que os carregamentos cíclicos levaram à compactação da camada da base, o que contribuiu para essa diminuição. 


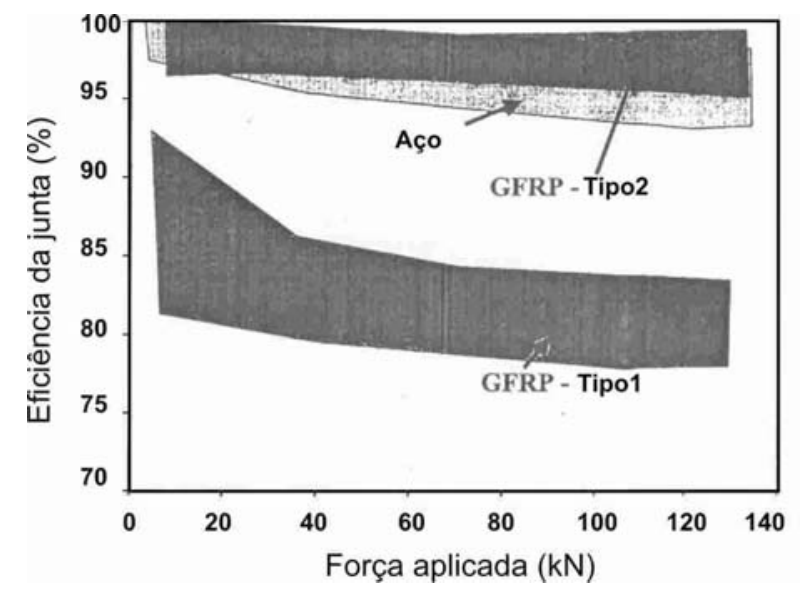

Figura 2.32 - Eficiência da junta: Fase 3. Fonte: Eddi; Shalaby e Rizkalla (2001)

A Figura 2.33 fornece o gráfico eficiência versus força aplicada, em função do número de ciclos empregados. A eficiência inicial, a zero ciclos, excedeu a 98\%. Testes subseqüentes indicaram uma pequena diminuição na eficiência, entre 94\% e 97\%, que pode ser atribuída à compactação da base ou ao escorregamento da barra.

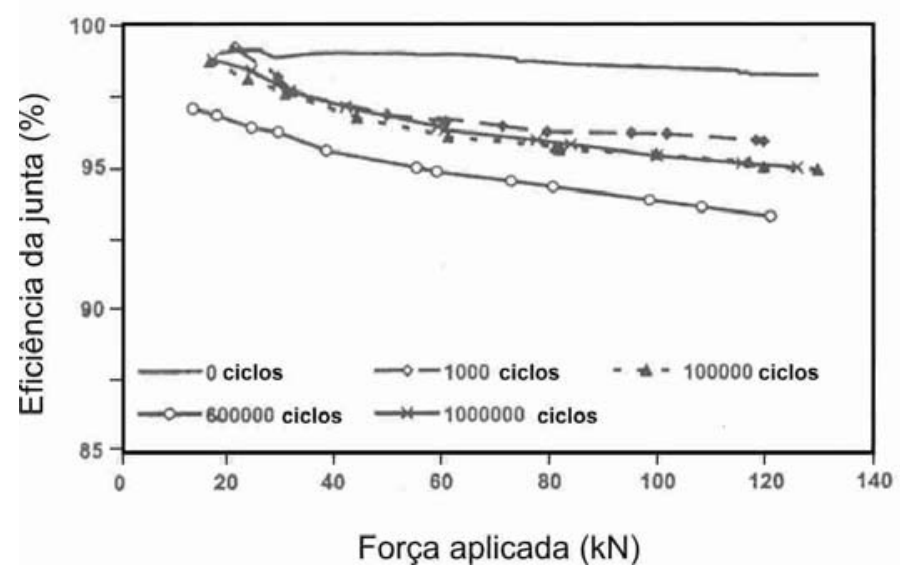

Figura 2.33 - Eficiência da junta com dispositivo ECS. Fonte: Eddi; Shalaby e Rizkalla (2001)

Os pesquisadores concluíram que as barras em GFRP com 38mm de diâmetro são aceitáveis como dispositivos de transferência, em substituição ao ECS.

\subsubsection{Silva (2001)}

O estudo do desempenho estrutural e em serviço de um reforço de pavimento flexível (asfáltico) com placas de concreto (whitetopping) foi o objetivo do trabalho de Silva (2001). O estudo foi feito na Pista Circular Experimental do extinto 
Departamento Nacional de Estradas de Rodagens e atual Departamento Nacional de Infra-Estrutura de Transporte (DNIT), localizado no Instituto de Pesquisas Rodoviárias (IPR), no Rio de Janeiro.

Foram realizados levantamentos na Pista Circular, como: deformações permanentes, deslocamentos verticais, desgaste de pneus, ensaios de placa e instrumentação com seis extensômetros e duas células de carga.

De forma a medir os esforços exercidos pela placa de concreto - WT - sobre a superfície da camada de CBUQ, no centro da pista circular experimental do IPR, Silva (2001) instalou células de carga, dimensionadas para suportar cargas de até $56 \mathrm{kN}$, Figura 2.34.

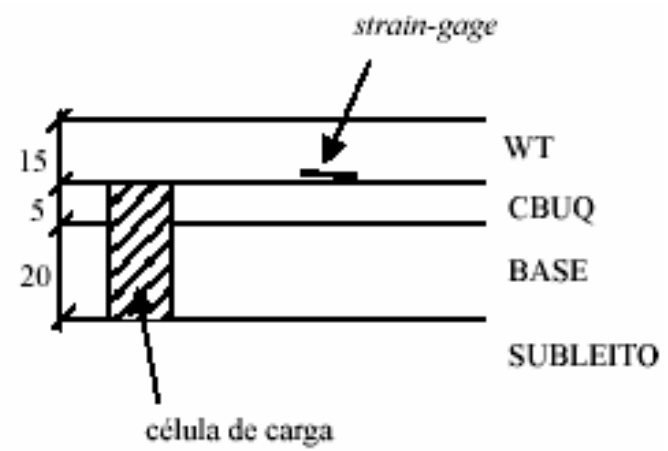

Figura 2.34 - Seção transversal da pista experimental do IPR (unidade em $\mathrm{cm}$ )

A Figura 2.35 apresenta as seqüência de instalação de uma das células de carga.

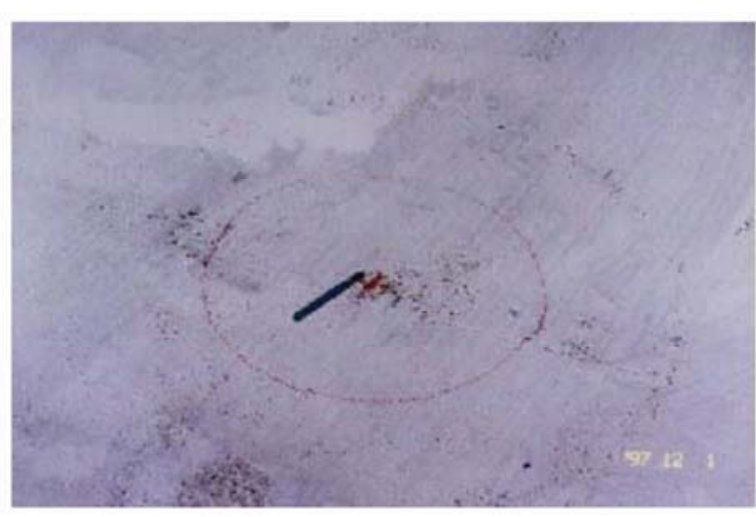

(a)

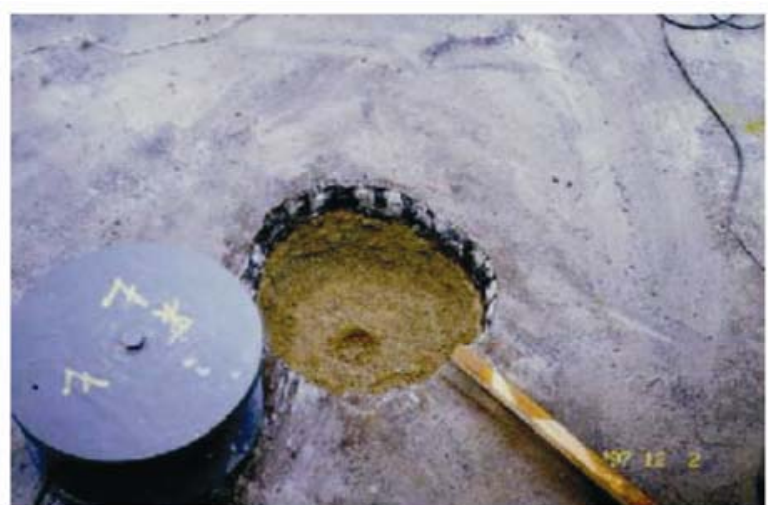

(b)

Figura 2.35 - (a)marcação da localização da célula de carga; (b) execução do buraco no concreto asfáltico e na base para embutir a célula de carga. Fonte: Silva (2001) 
No experimento, a pista foi dividida em dois trechos, sendo um deles constituído de concreto puro e outro de concreto com fibras metálicas. O esquema de instalação dos sensores na pista é apresentado na Figura 2.36.

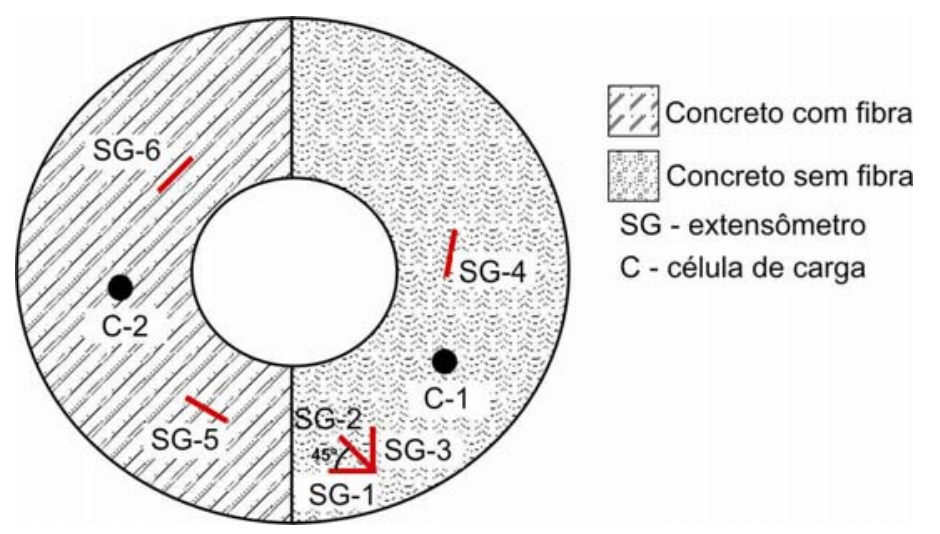

Figura 2.36 - Vista superior da pista experimental. Fonte: Silva (2001)

O citado autor concluiu que as tensões verticais na célula 1 aumentam à medida que as rodas se aproximam dessa célula, atingindo valores de tensões máximos quando estavam sobre elas. Acredita-se que a célula 2 sofreu um deslocamento devido a recalques do subleito, pelo fato dos valores das tensões verticais em pontos simétricos serem tão discrepantes. Já a célula 1 sofreu compressão na passagem das rodas sobre ela, e uma pequena tração, imediatamente antes e após a passagem das rodas.

Silva (2001) propõe o uso de instrumentação em pavimentos flexíveis e rígidos, por acreditar ser esta uma das maneiras de aumentar a credibilidade dos métodos mecanísticos. Ainda assim, destacou a importância da instrumentação embutida em pavimentos, da qual há poucos exemplos no país.

No entanto, adverte que são delicadas as técnicas de instalação e monitoramento de extensômetros elétricos e células de carga, pois requerem habilidade. Há sempre certo número de sensores que se mostram inoperantes, daí a necessidade de se dispor de número maior de sensores, superior, portanto, ao número que se considerou necessário. 


\subsubsection{Murison, Shalaby e Mufti (2004)}

O programa experimental conduzido por Murison, Shalaby e Mufti (2004), na Universidade de Manitoba, estudou o comportamento de diferentes tipos de barras de transferência envolvidas em concreto, quando solicitadas por força cortante.

O principal objetivo do estudo era de quantificar os deslocamentos verticais e obter a linha elástica de cada barra, de maneira a estudar as diferenças de comportamento para cargas que simulavam um tráfego.

A Tabela 2.10 apresenta o programa experimental desenvolvido. Estudou-se quatro tipos de barras de transferência, sendo elas: aço envolvido por epóxi (ECS); barra de transferência em fibra de vidro (GFRP); e dois tubos de GFRP de diferentes diâmetros, preenchidos por concreto.

Tabela 2.10 - Programa experimental dos ensaios, segundo Murison, Shalaby e Mufti (2004)

\begin{tabular}{|c|c|c|c|c|c|}
\hline \multirow[t]{2}{*}{ Etapa } & \multirow[t]{2}{*}{$\begin{array}{l}\text { Número de } \\
\text { modelos }\end{array}$} & $\begin{array}{c}\text { Tensão no } \\
\text { escoamento } \\
\sigma_{y}\end{array}$ & $\begin{array}{l}\text { Módulo de } \\
\text { Elasticidade } \\
\text { do aço }\end{array}$ & $\begin{array}{l}\text { Coeficiente de } \\
\text { Poisson }\end{array}$ & \multirow[t]{2}{*}{ Método de ensaio } \\
\hline & & $\mathrm{MPa}$ & $\mathrm{MPa}$ & & \\
\hline \multirow{4}{*}{ Fase 1} & $1 \mathrm{ECS}^{[1]}$ & 300 & 200.000 & 0,3 & \multirow{4}{*}{$\begin{array}{c}\text { Carregamento monotônico } \\
\text { até } 12 \mathrm{kN} \text { e cíclico a } \\
10^{6} \text { ciclos }\end{array}$} \\
\hline & $\begin{array}{c}1 \text { GFRP - tipo } \\
1^{[2]}\end{array}$ & 177 & 40.000 & {$[5]$} & \\
\hline & $\begin{array}{c}1 \text { GFRP - tipo } \\
2^{[3]}\end{array}$ & 207 & 19.000 & 0,33 & \\
\hline & $\begin{array}{c}1 \text { GFRP - tipo } \\
3^{[4]}\end{array}$ & 207 & 19.000 & 0,33 & \\
\hline \multirow{4}{*}{ Fase 2} & $1 \mathrm{ECS}^{[1]}$ & 300 & 200.000 & $0,3-0,33$ & \multirow{4}{*}{$\begin{array}{l}\text { Carregamento monotônico } \\
\text { até o colapso }\end{array}$} \\
\hline & $\begin{array}{c}1 \text { GFRP - tipo } \\
1^{[2]}\end{array}$ & 177 & 40.000 & [5] & \\
\hline & $\begin{array}{c}1 \text { GFRP - tipo } \\
2^{[3]}\end{array}$ & 207 & 19.000 & 0,33 & \\
\hline & $\begin{array}{l}1 \text { GFRP - tipo } \\
3^{[4]}\end{array}$ & 207 & 19.000 & 0,33 & \\
\hline
\end{tabular}

Um total de oito placas de concreto foram construídas, com dimensões de $61 \mathrm{~cm} x$ $61 \mathrm{~cm} \times 25,4 \mathrm{~cm}$, sendo que cada uma continha duas barras parcialmente embutidas, como apresentado na Figura 2.37. Esse recurso eliminou a necessidade de 
concretagem da placa adjacente e facilitou o monitoramento visual dos danos na face da junta.

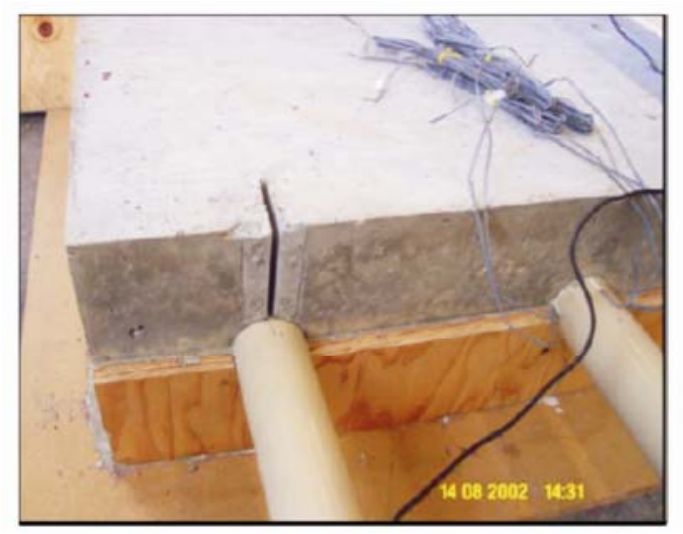

Figura 2.37 - Modelo de concreto com barra de transferência. Fonte: Murison, Shalaby e Mufti (2004)

A metade exposta das barras de $22,9 \mathrm{~cm}$ foi carregada com uma prensa metálica apresentada na Figura 2.38a, e foi instrumentada com LVDTs e extensômetros elétricos de resistência. Foram feitas medições de deslocamento vertical na porção concretada das barras, por meio de hastes proeminentes de orifícios, que foram conectadas tanto nas barras como em LVDTs acoplados na face superior das placas, Figura 2.38b. Em todos os ensaios, as barras e as placas foram instrumentadas para medirem o comportamento carga aplicada versus deslocamento vertical e carga aplicada versus deformação.

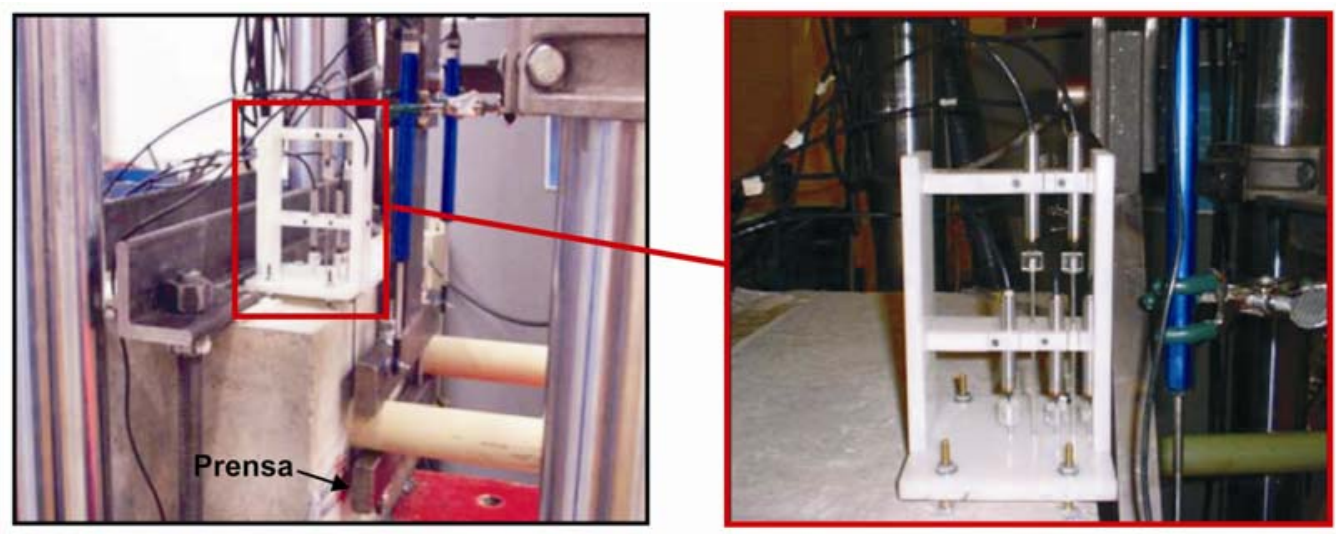

(a)

(b)

Figura 2.38 - Instrumentação (a) prensa metálica distante 1,25 mm da face de concreto; (b) detalhe do posicionamento dos LVDTs no interior da placa. Fonte: Murison, Shalaby e Mufti (2004) 
Os modelos foram ancorados em uma viga rígida, como mostrado na Figura 2.39, que por sua vez foi atirantada na laje de reação do laboratório.

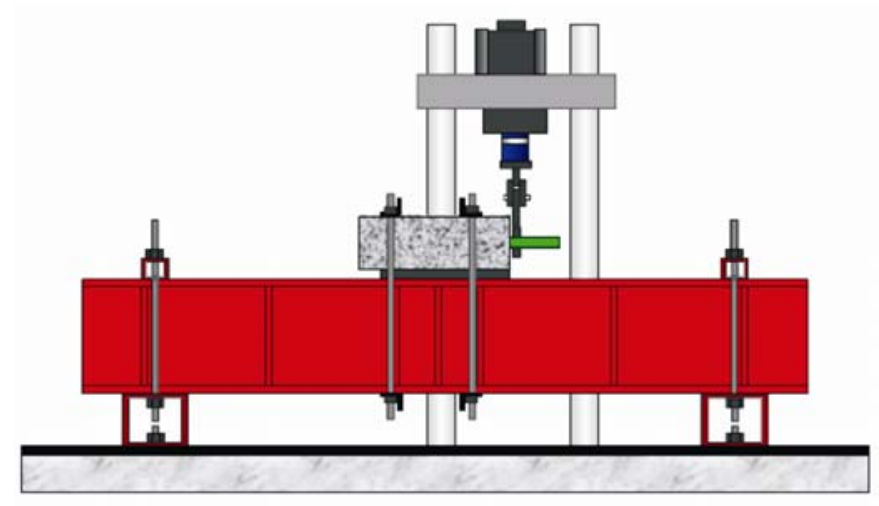

Figura 2.39 - Esquema de ensaio. Fonte: Murison, Shalaby e Mufti (2004)

O estudo compreendeu duas fases:

Fase 1: esta etapa envolveu a aplicação de carregamento estático e cíclico em quatro placas, cada uma com um tipo de barra, com resistência característica do concreto à compressão $f_{c k}$ de $35 \mathrm{MPa}$, especificada aos 28 dias. Os modelos foram carregados até uma carga de serviço de $12 \mathrm{kN}$, que representa a maior carga aplicada a uma barra de transferência sobre uma Carga por Eixo Simples Equivalente (Equivalente Single Axle Load - ESAL) de $80 \mathrm{kN}$. Testes estáticos foram feitos inicialmente e repetidos após cada série de 250.000 ciclos de carregamento, para um total de $10^{6}$ ciclos. Os deslocamentos verticais foram medidos durante intervalos de um segundo, com 160 pontos analisados por segundo. A freqüência inicial do carregamento foi de $5 \mathrm{~Hz}$, que foi posteriormente reduzida para $4,5 \mathrm{~Hz}$ em função de limitações da aparelhagem empregada. A carga mínima de compressão aplicada foi de $10 \%$ da carga de pico, ou seja 1,2 kN. A Figura 2.40 apresenta os deslocamentos verticais na face da junta, durante ciclos de carregamento. 


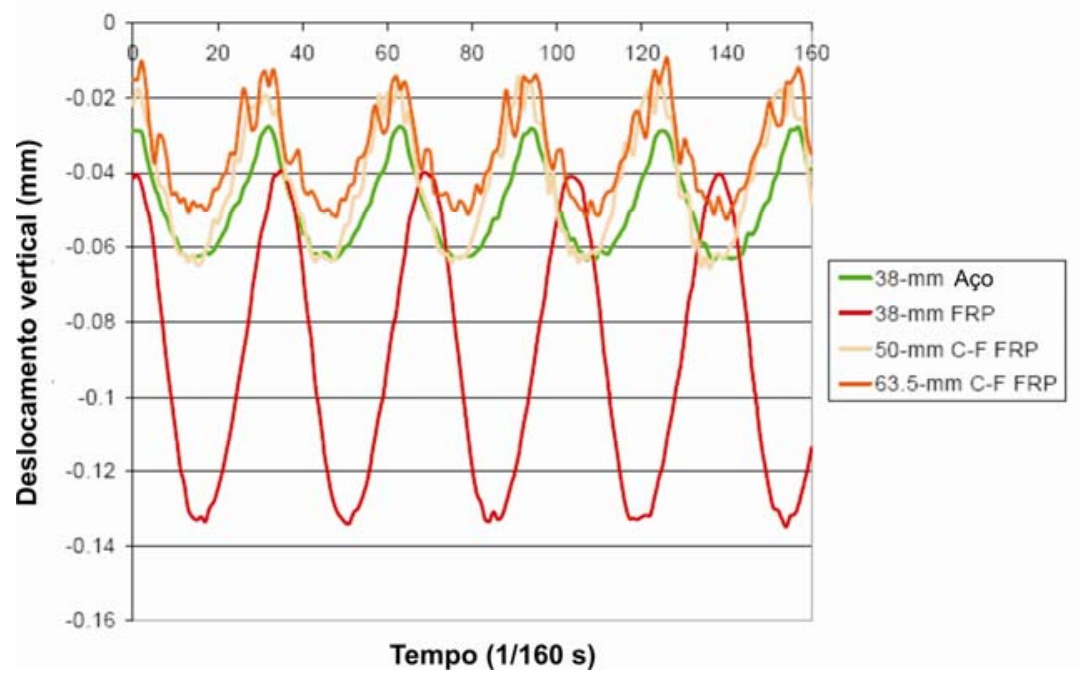

Figura 2.40 - Gráfico deslocamento vertical versus tempo. Fonte: Murison, Shalaby e Mufti (2004)

A Figura 2.41 apresenta o gráfico força aplicada versus deslocamento vertical, para cada tipo de barra estudada, antes e após a aplicação de $10^{6}$ ciclos de repetição de $12 \mathrm{kN}$. Pode ser visualizada uma diferença nos deslocamentos verticais, entre zero ciclos e $10^{6}$ ciclos. Os deslocamentos verticais após a repetição do carregamento foram menores do que aqueles medidos durante o início dos testes. Isto parece que se deve a um aumento nos deslocamentos de parte da barra externa à junta, devido à fissuração no interior do concreto. Isto causaria uma redução nas deformações transversais da barra, resultando em um menor deslocamento vertical, medido do topo da superficie da barra.

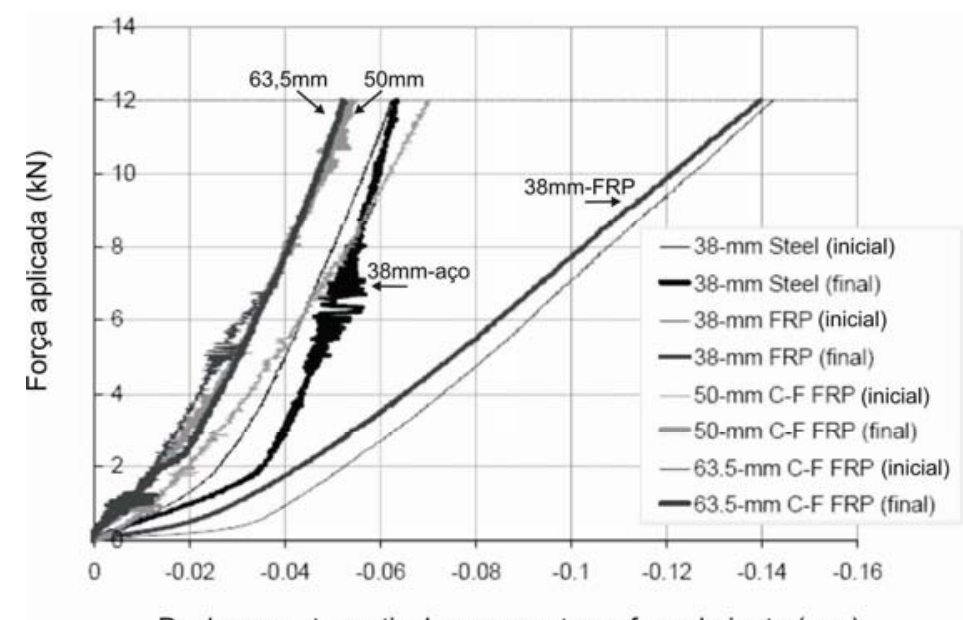

Deslocamento vertical no concreto na face da junta (mm)

Figura 2.41 - Força aplicada versus deslocamento vertical, antes e depois de um milhão de ciclos.

Fonte: Murison, Shalaby e Mufti (2004) 
Fase2: envolveu carregamento estático em quatro placas adicionais, carregadas monotonicamente até a ruptura das barras. As de aço ECS, que possuíam uma rigidez significativamente maior em relação às outras barras, foram carregadas até a deformação alcançar o escoamento. A Figura 2.42 apresenta o gráfico força aplicada versus deslocamento do pistão, para os quatro tipos de barras. A barra de $38 \mathrm{~mm}$ em FRP causou lascamento do concreto abaixo da barra, com uma carga de $24 \mathrm{kN}$. Sua carga de ruptura foi de $39 \mathrm{kN}$. A barra de aço de $38 \mathrm{~mm}$ exibiu fissuração e pequenas lascas de concreto até $80 \mathrm{kN}$, quando a carga foi interrompida, devido ao escoamento da barra de aço. As barras de $50 \mathrm{~mm}$ e de $63,5 \mathrm{~mm}$ tiveram carga de ruptura, respectivamente, de $55 \mathrm{kN}$ e $80 \mathrm{kN}$.

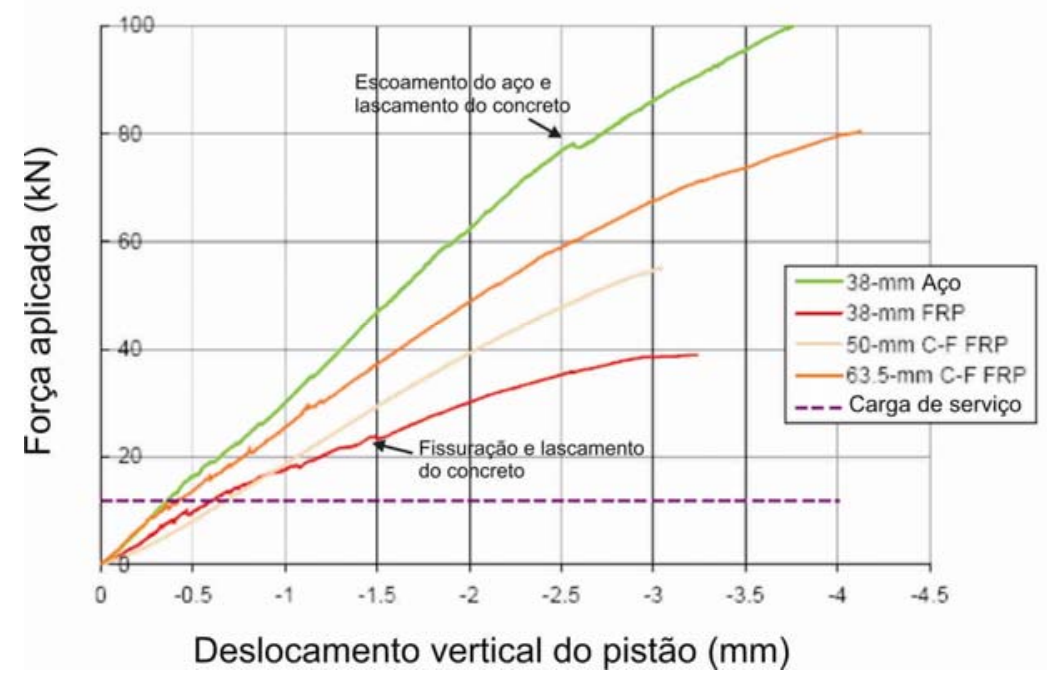

Figura 2.42 - Gráfico força aplicada versus deslocamento vertical do pistão. Fonte: Murison, Shalaby e Mufti (2004)

Concluiu-se que diâmetros maiores, para o caso das GFRP preenchidas por concreto (tipos 2 e 3), apresentaram os menores deslocamentos verticais, com uma melhor distribuição da carga aplicada ao longo de todo o comprimento da barra, reduzindo assim a concentração de forças. Não foram verificados, na Fase 1, sinais de danos depois de $10^{6}$ ciclos, aplicados em todos os modelos. Na Fase 2, foram verificados sinais de danos, como lascamentos e fissuras do concreto, apenas nas barras de 38mm de diâmetro. 


\subsubsection{Cervo (2004)}

Com experimentos laboratoriais, Cervo (2004) estudou o comportamento à fadiga de concretos para pavimentos, por meio de ensaios dinâmicos, o que permitiu a construção de modelos de ruptura por fadiga para concreto.

A deterioração sob carregamento cíclico, segundo a pesquisadora, leva ao surgimento e à evolução de microfissuras e à propragação de microfissuras préexistentes no material, podendo causar a ruptura da estrutura.

A ruptura por fadiga somente ocorre se a carga aplicada fornecer suficiente tensão para o crescimento e propagação das fissuras ou para que alterações significativas ocorram no material, atingindo um estado de instabilidade e afetando a vida útil da estrutura. Essa situação é definida como o limite de fadiga do material, que pode ocorrer quando a soma dos danos, para todos os níveis de tensão, atingir um certo valor crítico e igual a 1, conforme apresentado na eq.(2.24). Essa regra foi estabelecida por Palmgren-Miner, e é adotada pela NBR 6118 (2003).

$$
\sum \frac{\mathrm{n}_{\mathrm{i}}}{\mathrm{N}_{\mathrm{i}}} \leq 1
$$

onde $\mathrm{n}_{\mathrm{i}}$ é o número de repetições aplicadas sob condição particular de tensões; $\mathrm{N}_{\mathrm{i}}$ é o número de repetições que causaria a ruptura por fadiga para a mesma condição de tensões aplicadas.

Os modelos confeccionados em concreto apresentavam traço semelhante ao obtido na Pista Experimental da Universidade de São Paulo (Severi, 2002). Os modelos ensaiados consistiam em corpos-de-prova prismáticos, com dimensões $10 \mathrm{~cm} \mathrm{x}$ $10 \mathrm{~cm} \times 40 \mathrm{~cm}$ e $f_{c t, f}$ de 4,8MPa. Na totalidade 105 unidades foram confeccionadas, sendo que 90 amostras foram utilizadas em ensaios dinâmicos, e o restante ensaiado à tração na flexão estática, conforme apresentado na Figura 2.43. 


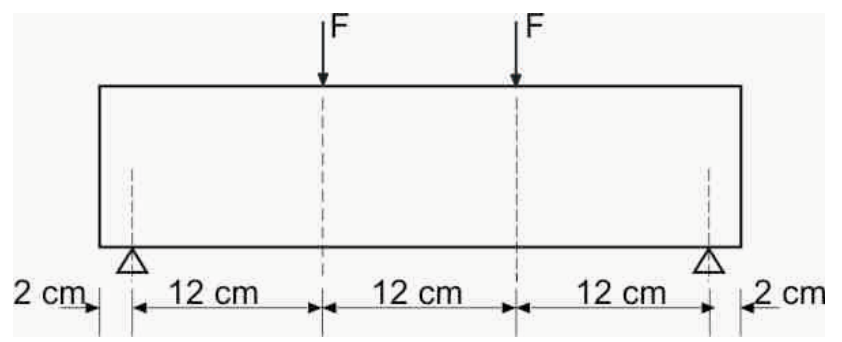

Figura 2.43 - Esquema de ensaio em corpo-de-prova prismático

Foram também moldados 70 corpos-de-prova em concreto de alto desempenho (CAD) para ensaios à fadiga, com a mesma resistência à tração na flexão que o concreto empregado no Whitetopping Ultradelgado da Rodovia Castello Branco, em 1997 (Balbo, 1999). As amostras em CAD apresentaram resistência à tração na flexão entre 5,3MPa e 6,3MPa.

Os ensaios à fadiga, apresentados na Figura 2.44, foram realizados em uma máquina servo-hidráulica com capacidade de $10.000 \mathrm{kN}$, do Laboratório de Metalurgia do Instituto de Pesquisas Tecnológicas do Estado de São Paulo (IPT).

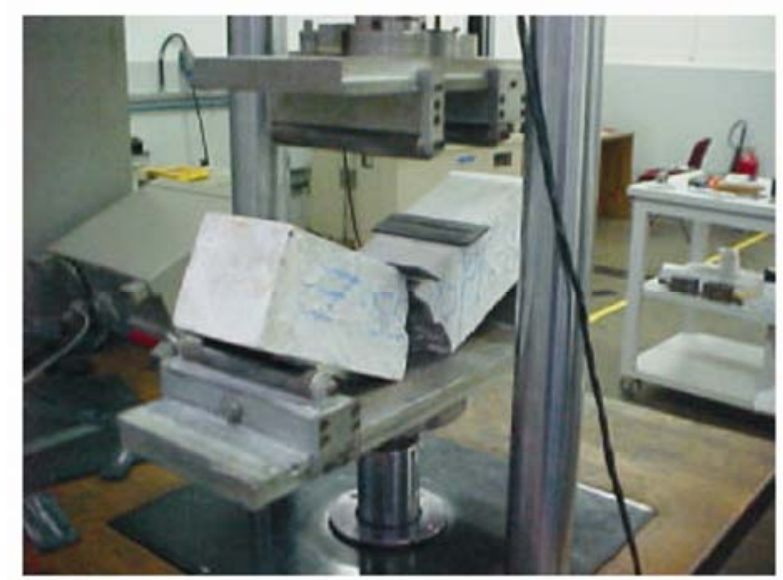

Figura 2.44 - Ensaio à fadiga. Fonte: Cervo (2004)

A Tabela 2.11 fornece um resumo, para diferentes frequências impostas, do número máximo de ciclos $\mathrm{N}$ que levou o concreto convencional seco à ruptura por fadiga, para uma intensidade de tensão constante. A relação de tensões $\mathrm{RT}=\frac{\sigma_{\max }}{f_{c t, f}}\left(\sigma_{\max }\right.$ é a tensão máxima aplicada) indica que, para atingir um determinado número de ciclos como $10^{5}$, foi necessário aplicar uma carga dinâmica com valor de $83 \%$ da carga 
estática que levaria o concreto à ruptura por tração na flexão. Para atingir um número de ciclos de $10^{6}$, foi necessário aplicar uma carga dinâmica com valor de $79 \%$ da carga estática que levaria o concreto à ruptura por tração na flexão. A tensão mínima aplicada, para garantir o contato do sistema, foi de $7 \%$ da tensão de ruptura estática do concreto à tração na flexão.

Tabela 2.11 - Número de ciclos para concreto convencional, segundo Cervo (2005)

\begin{tabular}{|c|c|c|c|}
\hline \multirow{2}{*}{ Frequência $(\mathrm{Hz})$} & $\mathrm{N}$ & $\mathrm{RT}$ & $\begin{array}{c}\text { Número estimado } \\
\text { de ciclos }\end{array}$ \\
\hline 10 & 996.627 & 0,79 & $10^{6}$ \\
\hline 10 & 109.105 & 0,83 & \multirow{2}{*}{$10^{5}$} \\
\hline 5 & 4.311 & 0,83 & \\
\hline 1 & 6.574 & 0,83 & \\
\hline
\end{tabular}

A Tabela 2.12 fornece um resumo, para diferentes frequências impostas, do número máximo de ciclos $\mathrm{N}$ que levou o concreto de alto desempenho seco à ruptura por fadiga, para uma intensidade de tensão constante.

Tabela 2.12 - Número de ciclos para CAD, segundo Cervo (2005)

\begin{tabular}{|c|c|c|c|}
\hline Frequência $(\mathrm{Hz})$ & $\mathrm{N}$ & $\mathrm{RT}$ & $\begin{array}{c}\text { Número de ciclos } \\
\text { estimado }\end{array}$ \\
\hline 10 & 868.486 & 0,65 & $10^{6}$ \\
\hline 10 & 185.738 & 0,73 & $10^{5}$ \\
\hline 5 & 16.603 & 0,73 & \\
\hline
\end{tabular}

O modelo de ruptura por fadiga proposto por Cervo (2005), para concreto convencional, relações entre tensões de 0,79; 0,80; 0,83 e 0,85, frequência de $10 \mathrm{~Hz}$ e a tensão constante, é dado por:

$$
\log \mathrm{N}=25,858-25,142\left(\frac{\sigma_{\max }}{f_{c t, f}}\right)
$$


Considerando as frequências de $1 \mathrm{~Hz}, 5 \mathrm{~Hz}$ e $10 \mathrm{~Hz}$, para valores de RT de 0,83, foi proposto um modelo à fadiga, conforme eq.(2.26).

$$
\log \mathrm{N}=3,144+0,182 \cdot \mathrm{f}
$$

onde $\log \mathrm{N}$ é o logaritmo do número de ciclos à fadiga e $\mathrm{f}$ é a frequência de aplicação das cargas.

Cervo (2004) concluiu que o CAD apresentou resistência à ruptura por fadiga inferior à do concreto convencional. Concluiu também que os ensaios experimentais, que usualmente são empregados para determinar modelos à fadiga de concretos para pavimentação, estariam superestimando a resistência do pavimento à fadiga, uma vez que são realizados à frequência de $10 \mathrm{~Hz}$, que está acima das frequências reais ocorridas na pista.

\subsubsection{Tertuliano (2005)}

Ensaios estáticos foram realizados por Tertuliano (2005) em placas de concreto simples com pontos de transferência de forças. O objetivo era avaliar 0 comportamento de barras de transferência e comparar os valores obtidos experimentalmente com as recomendações de cálculo.

No programa experimental foram ensaiadas oito placas de concreto, com dimensões $220 \mathrm{~cm} \times 60 \mathrm{~cm}$. As espessuras das placas foram de $8 \mathrm{~cm}$ e de $12 \mathrm{~cm}$, e as aberturas da junta, de $6 \mathrm{~mm}$ e $30 \mathrm{~mm}$. O diâmetro das barras lisas foi de $16 \mathrm{~mm}$, e o comprimento de $50 \mathrm{~cm}$, com aço do tipo CA-25, vendidas comercialmente. Cada modelo possuía duas barras e uma junta transversal, que se diferenciava em serrada e moldada. Todos os modelos foram apoiados sobre uma camada de areia de $20 \mathrm{~cm}$.

A Figura 2.45 apresenta o esquema de ensaio adotado para os modelos. A carga aplicada era distribuída por meio de uma viga em perfil de aço tipo I, por toda extensão da junta. Um apoio de segundo gênero foi colocado entre o atuador e o perfil, para possibilitar uma possível rotação da placa. 
Foram medidos deslocamentos verticais nas bordas e nas faces da junta, com relógios comparadores. Ensaios de coeficiente de recalque $k$ foram realizados para se avaliar a capacidade da camada suporte e controlar suas variações.

A Tabela 2.13 fornece os dados dos modelos, que foram ensaiados com pelo menos 13 dias de idade.

Tabela 2.13 - Características físicas dos modelos ensaiados

\begin{tabular}{|c|c|}
\hline Característica & Valor \\
\hline $\begin{array}{c}\text { Resistência à compressão do concreto } \\
\text { média } f_{c} \text { na data do ensaio }\end{array}$ & $20 \mathrm{MPa}$ \\
\hline $\begin{array}{c}\text { Resistência à tração na flexão do concreto } \\
\text { média } f_{c t, f} \text { na data do ensaio }\end{array}$ & $2,5 \mathrm{MPa}$ \\
\hline Tensão de escoamento do aço $f_{y}$ & $424 \mathrm{MPa}$ \\
\hline Coeficiente de recalque $k$ & $48 \mathrm{MPa} / \mathrm{m}$ \\
\hline
\end{tabular}

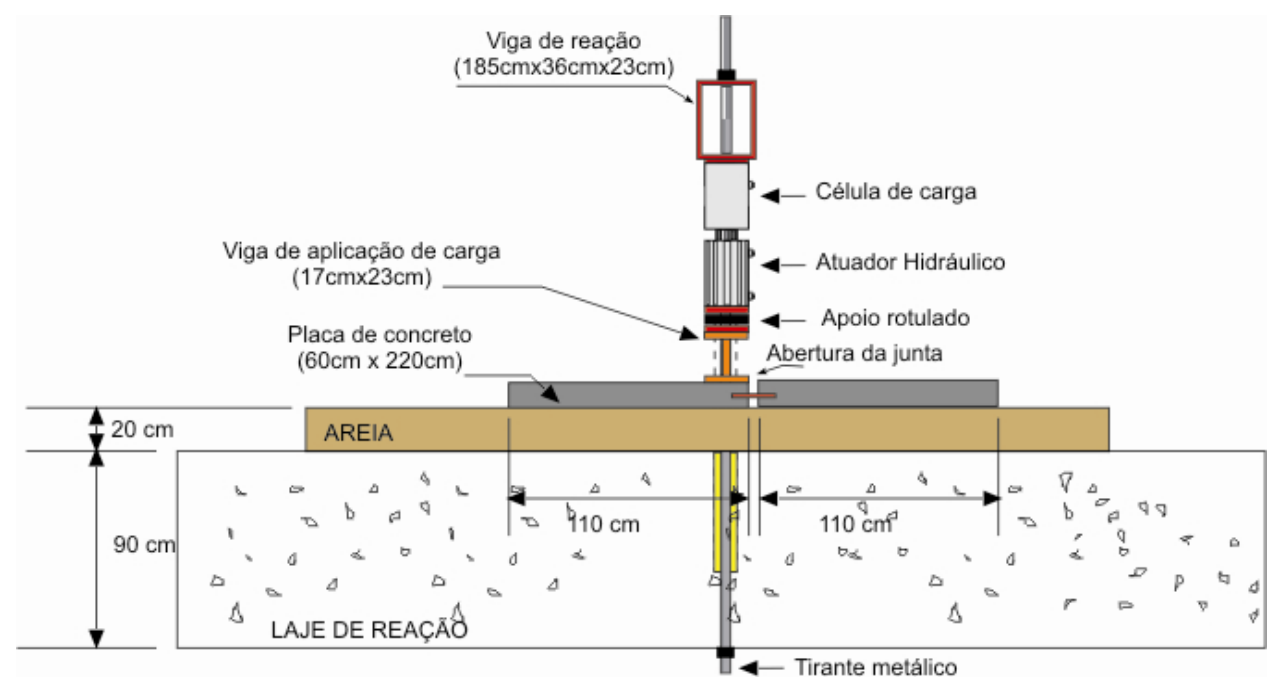

Figura 2.45 - Esquema de ensaio em vista longitudinal. Fonte: Tertuliano (2005)

O parâmetro de eficiência das juntas (vide item 2.1.1.B) foi utilizado para verificar a transferência de forças entre a porção carregada da junta e a não carregada. Para tanto, foram feitas medições de deslocamentos verticais em ambas as porções. Os gráficos eficiência da junta versus força aplicada são mostrados nas Figura 2.46 e Figura 2.47. 


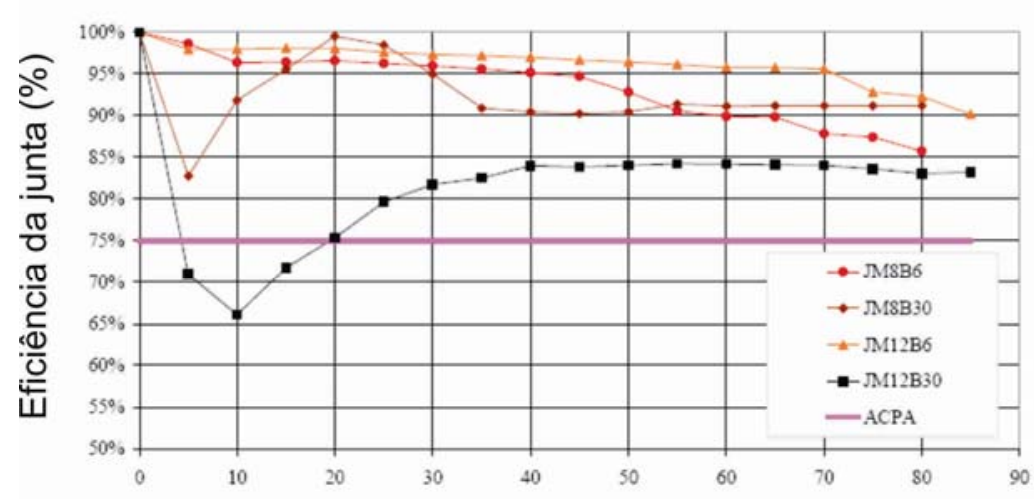

Força aplicada $(\mathrm{kN})$

Figura 2.46 - Gráfico eficiência da junta moldada versus carga aplicada. Fonte: Tertuliano (2005)

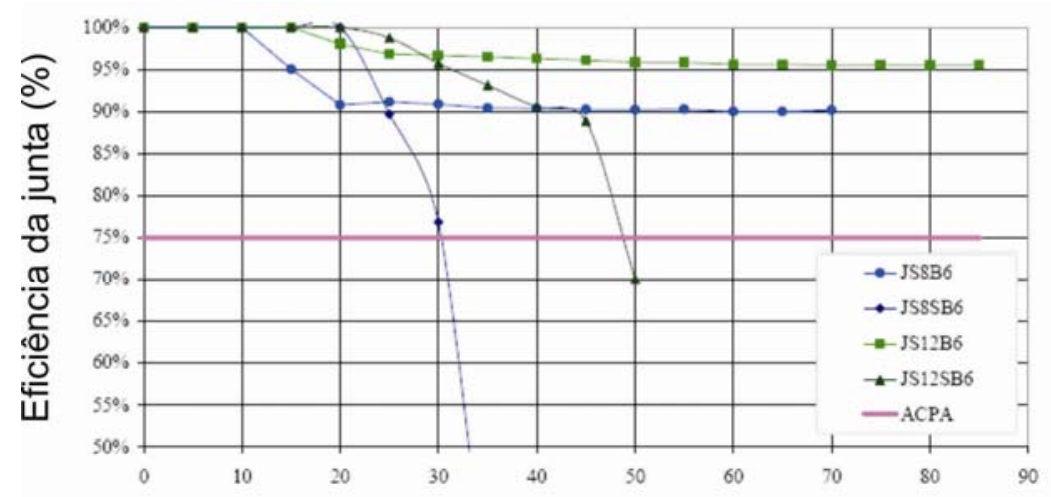

Força aplicada $(\mathrm{kN})$

Figura 2.47 - Gráfico eficiência da junta serrada versus carga aplicada. Fonte: Tertuliano (2005)

Segundo Tertuliano (2005), as placas com juntas de $30 \mathrm{~mm}$ na série moldada apresentaram valores de eficiência decrescentes nas primeiras cargas, sendo que na placa JM12B30 foi registrada eficiência menor que o limite da ACPA (75\%), aumentando após a carga de $40 \mathrm{kN}$, até chegar a valores próximos de $85 \%$. As placas de abertura de $6 \mathrm{~mm}$ tiveram queda de eficiência logo nas primeiras cargas, porém para valores próximos de 90\%, mantiveram-se nesse patamar.

As placas da série serrada mantiveram uma eficiência de 100\% até a fissuração da junta. As dotadas de barras de transferência mantiveram eficiência acima de 90\%. Já as sem barras tiveram suas eficiências diminuídas bruscamente, após a carga de fissuração.

Tertuliano (2005), com seus ensaios, recomenda que a junta serrada e com barras de transferência seja adotada, em comparação com junta moldada, visto que a 
serrada oferece melhor capacidade de transferência de força, apesar de não fornecer a maior força dentre as placas. A utilização desses dispositivos de transferência sempre são benéficos, segundo esse autor, já que possibilitam uma maior transmissão de esforços, em relação a placas de concreto simples sem barras.

Considerou também que as placas de maior espessura tiveram menores deslocamentos verticais, na junta e nas extremidades, tendo sido capazes de promover maior transmissão de esforços. As placas com maiores aberturas de juntas $(30 \mathrm{~mm})$ apresentaram um pior desempenho na transferência de força.

Conclui que os efeitos referentes à camada suporte necessitam de um estudo mais aprofundado para que se possam tirar conclusões a respeito deste componente do experimento, visto ter considerado apenas a análise do $k$. Sugere também o posicionamento de células de carga abaixo das placas, para mensurar as reações na camada suporte e obtenção das reações do solo com melhor precisão.

Por fim, esse pesquisador recomenda realizar um estudo com carga dinâmica, para melhor simulação do comportamento de um pavimento de concreto em situação de serviço.

\subsubsection{Walker e Holland (1998)}

As placas metálicas quadradas ("diamond dowels") foram inicialmente estudadas por Walker e Holland (1998), e até então não existiam recomendações da indústria para seu tamanho e espaçamento. Dois tipos de dispositivos foram avaliados em seus estudos: placas metálicas retangulares, para serem usadas em juntas de contração; e placas metálicas quadradas, para serem usadas em juntas de construção, Figura 2.48a. A Figura 2.48b mostra o detalhe do encaixe entre a fôrma plástica, fixada na junta moldada, e a placa metálica quadrada. Esse sistema foi patenteado pela empresa norte-americana PNA Construction Technologies (1), e tem sido industrializado desde 1999. 


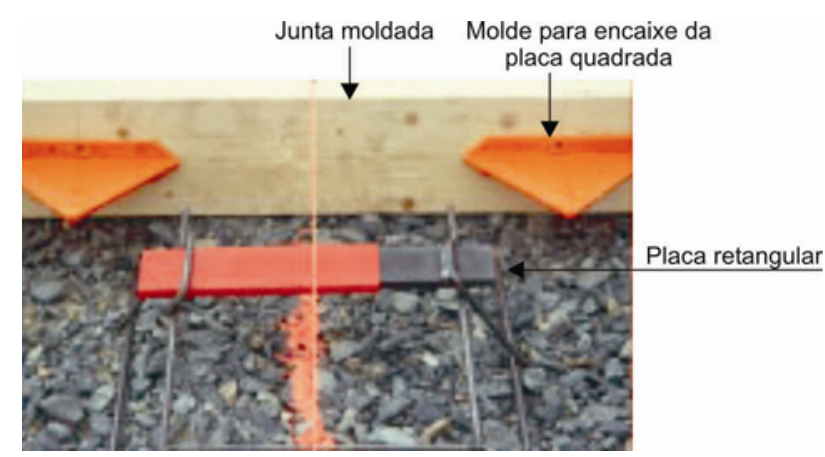

(a)

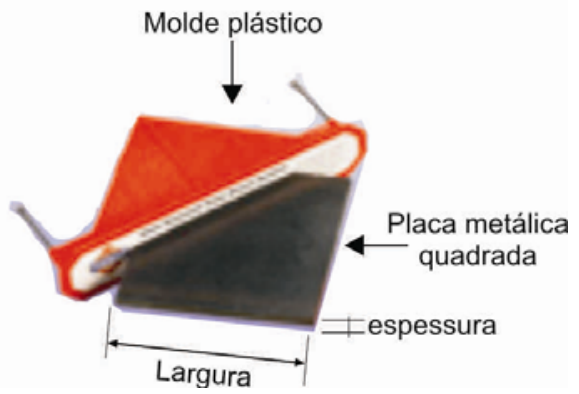

(b)

Figura 2.48 - Dispositivos de transferência: (a) posicionamento da fôrma para a placa quadrada e posicionamento da placa retangular; (b) detalhe da conexão entre fôrma e placa quadrada. Fonte:

PNA Construction Technologies (1)

A Figura 2.49a e a Figura 2.49c mostram os dispositivos quadrado e retangular, instalados na placa e sem qualquer movimento. As Figura 2.49b e Figura 2.49d mostram os dispositivos depois de movimentadas, permitindo movimento irrestrito.

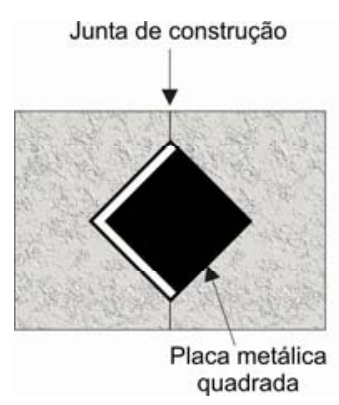

(a)

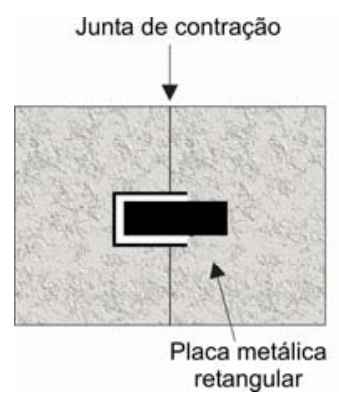

(c)

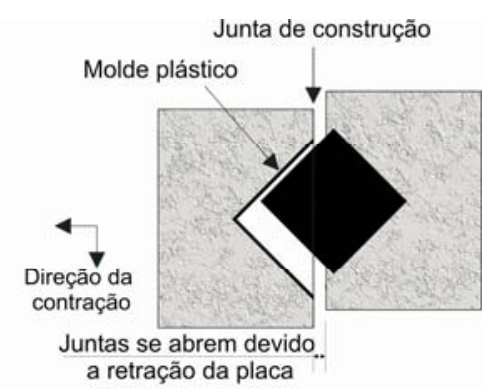

(b)

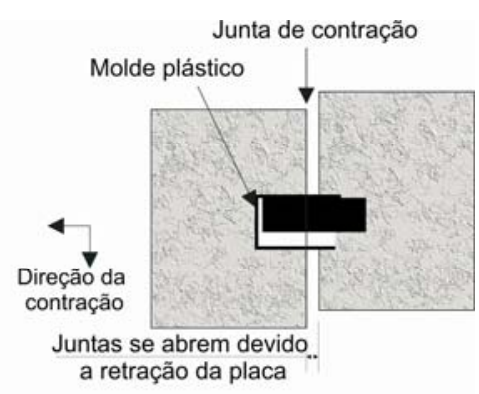

(d)

Figura 2.49 - Comportamento dos dispositivos (a) placa quadrada antes da contração; (b) placa quadrada depois da contração; (c) placa retangular antes da contração; (d) placa retangular depois da contração. Fonte: Walker e Holland (1998) 
A análise do comportamento dos dispositivos foi feita por meio analítico, através do desenvolvimento de equações, e foi utilizada ferramenta computacional, para modelagem dos dispositivos.

O deslocamento vertical da placa retangular $\left(\Delta_{P R}\right)$, apresentado na Figura 2.50, consistirá no somatório dos deslocamentos devidos à força e ao momento, ou seja:

$$
\Delta_{P R}=\frac{P \cdot z^{3}}{24 \cdot E_{s} \cdot I_{s}}+\frac{P \cdot z \cdot f}{2 \cdot G \cdot A}
$$

onde $P$ é a força aplicada; $E_{s}$ é o módulo de elasticidade do aço da placa retangular; $I_{s}$ é o momento de inércia da placa retangular; $G$ é o módulo de elasticidade transversal do aço da placa retangular; $A$ é a área da seção transversal do aço e $f$ é o fator de forma para o aço.

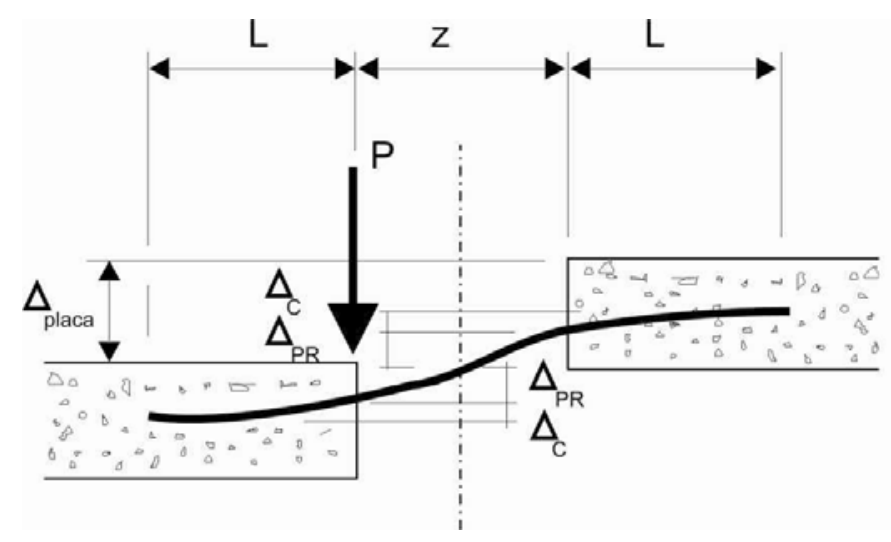

Figura 2.50 - Deslocamento vertical da junta. Fonte: Walker e Holland (1998)

O deslocamento vertical do concreto $\left(\Delta_{C}\right)$ pode ser determinado assumindo que o dispositivo, no caso a placa retangular, atua como uma viga apoiada em fundação elástica, Figura 2.51. Para a carga concentrada, o deslocamento vertical $y_{a p}$ corresponde a:

$$
y_{a p}=\frac{P}{2 \cdot E_{s} \cdot I_{s} \cdot \beta^{3}} \cdot \frac{C_{4} \cdot C_{1}-C_{3} \cdot C_{2}}{C_{11}}
$$


onde $\beta$ é a rigidez relativa da barra; $C_{1}, C_{2}, C_{3}, C_{4}$ e $C_{11}$ são constantes dependentes de $\beta$ e de $\mathrm{L}$.

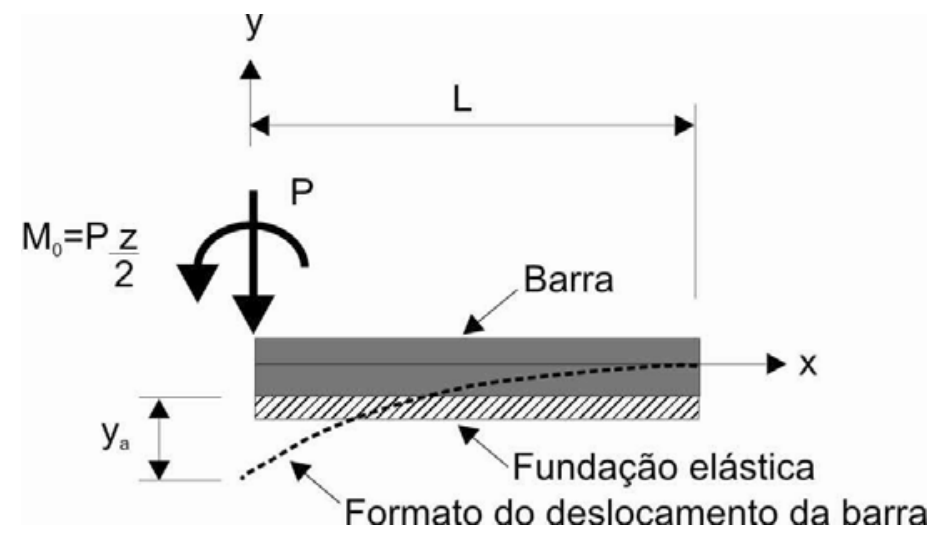

Figura 2.51 - Modelo de viga apoiada em fundação elástica, para placa retangular

Para o momento aplicado, segue-se que:

$$
y_{a m}=\frac{-P \cdot \frac{Z}{2}}{2 \cdot E_{s} \cdot I_{s} \cdot \beta^{2}} \cdot \frac{2 \cdot C 3 \cdot C 1+C 4^{2}}{C 11}
$$

O deslocamento vertical total $\Delta_{\text {placa }}$ da placa de concreto dotada de dispositivo será:

$$
\Delta_{\text {placa }}=2 \cdot\left[y_{a p}+y_{a m}+\left(\frac{P \cdot z^{3}}{24 \cdot E_{s} \cdot I_{s}}+\frac{P \cdot z \cdot F}{2 \cdot G \cdot A}\right)\right]
$$

O módulo de reação ou suporte da barra $\mathrm{K}$ no estudo variou de $80.000 \mathrm{MPa} / \mathrm{m}$ a $400.000 \mathrm{MPa} / \mathrm{m}$. No entanto, como no intervalo entre $80.000 \mathrm{MPa} / \mathrm{m}$ e $267.000 \mathrm{MPa} / \mathrm{m}$ os resultados pouco se alteraram, os autores adotaram o $\mathrm{K}$ igual a $190.000 \mathrm{MPa} / \mathrm{m}$. A abertura adotada da junta foi de $5 \mathrm{~mm}$.

A Tabela 2.14 fornece os espaçamentos entre placas retangulares e quadradas, em relação aos da barra circular, para que se tenha o mesmo desempenho. Por exemplo, uma placa quadrada (PQ) de $6 \mathrm{~mm}$ de espessura e $115 \mathrm{~mm}$ de largura, espaçada por $46 \mathrm{~cm}$ de centro a centro, promoverá o mesmo desempenho de uma barra circular de $\phi=19 \mathrm{~mm}$ e espaçamento de $30 \mathrm{~cm}$, de centro a centro das barras. 
Tabela 2.14 - Relação entre espaçamentos para diferentes dispositivos de transferência de força, segundo Walker e Holland (1998)

\begin{tabular}{|c|c|c|c|c|c|c|c|}
\hline \multicolumn{2}{|c|}{$\begin{array}{c}\text { Dispositivo } \\
\text { Espessura } \times \text { largura }\end{array}$} & $\begin{array}{c}\text { Espaçamento da barra } \\
\text { circular } \\
\phi=19 \mathrm{~mm}\end{array}$ & $\begin{array}{c}\text { Espaçamento da barra } \\
\text { circular } \\
\phi=25 \mathrm{~mm}\end{array}$ & $\begin{array}{c}\text { Espaçamento da barra } \\
\text { circular } \\
\phi=32 \mathrm{~mm}\end{array}$ \\
\cline { 2 - 8 } & $30 \mathrm{~cm}$ & $45 \mathrm{~cm}$ & $30 \mathrm{~cm}$ & $45 \mathrm{~cm}$ & $30 \mathrm{~cm}$ & $45 \mathrm{~cm}$ \\
\hline \multirow{3}{*}{$\mathrm{PQ}$} & $6 \mathrm{~mm} \times 115 \mathrm{~mm}$ & $46 \mathrm{~cm}$ & $60 \mathrm{~cm}$ & $28 \mathrm{~cm}$ & $40 \mathrm{~cm}$ & - & $25 \mathrm{~cm}$ \\
\cline { 2 - 8 } & $9,5 \mathrm{~mm} \times 115 \mathrm{~mm}$ & $61 \mathrm{~cm}$ & $61 \mathrm{~cm}$ & $43 \mathrm{~cm}$ & $61 \mathrm{~cm}$ & $28 \mathrm{~cm}$ & $43 \mathrm{~cm}$ \\
\cline { 2 - 8 } & $12,5 \mathrm{~mm} \times 25 \mathrm{~mm}$ & $61 \mathrm{~cm}$ & $61 \mathrm{~cm}$ & $56 \mathrm{~cm}$ & $61 \mathrm{~cm}$ & $38 \mathrm{~cm}$ & $56 \mathrm{~cm}$ \\
\hline \multirow{2}{*}{$\mathrm{PR}$} & $9,5 \mathrm{~mm} \times 25 \mathrm{~mm}$ & $23 \mathrm{~cm}$ & $36 \mathrm{~cm}$ & - & - & - & - \\
\cline { 2 - 8 } & $12,5 \mathrm{~mm} \times 25 \mathrm{~mm}$ & $33 \mathrm{~cm}$ & $51 \mathrm{~cm}$ & - & $28 \mathrm{~cm}$ & - & - \\
\hline
\end{tabular}

A placa retangular foi modelada como uma viga apoiada em fundação elástica. Para a placa quadrada, foi utilizado na análise um elemento finito de placa sobre uma fundação elástica, conforme apresentado na Figura 2.52.

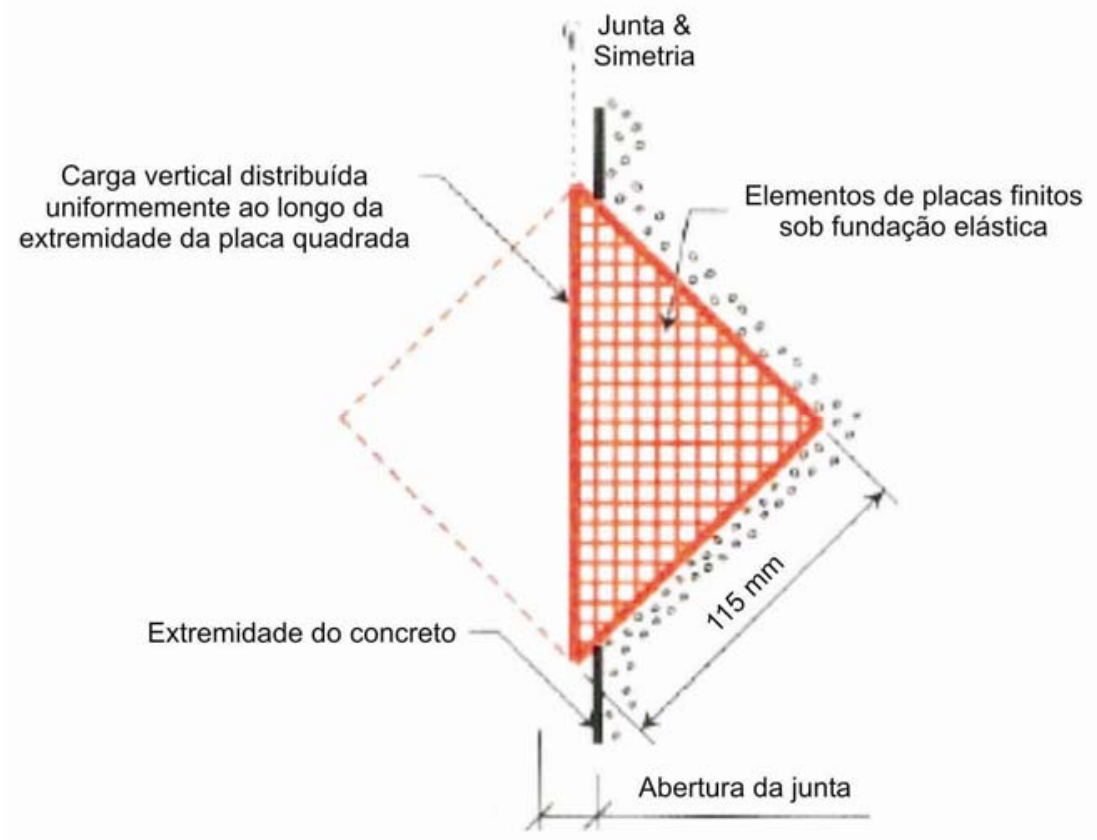

Figura 2.52 - Modelo computacional para placa quadrada. Fonte: Walker e Holland (1998)

Walker e Holland (1998) fazem algumas considerações a respeito de seu estudo, que são apresentadas nos parágrafos seguintes: 
As placas quadradas possuem significante reserva de resistência, porque esse dispositivo pode redistribuir as tensões se escoamentos locais ocorrerem. Além disso, o formato permite que a placa de concreto se mova horizontalmente sem restrição, quando as contrações do concreto abrirem as juntas.

Os autores recomendaram que o espaçamento das placas quadradas e retangulares seja igual a $46 \mathrm{~cm}$, equivalente à performance de barras circulares espaçadas a $30 \mathrm{~cm}$, valor este que segue recomendação do $\mathrm{ACl} 302.1 \mathrm{R}$, uma vez que não existem recomendações industriais para tamanho e espaçamento destes dispositivos.

De maneira controversa, Shaw et al. (2005) afirmam que a placa quadrada pode apresentar desvantagens inerentes, que são resultantes da formação de cantos nas placas, relativamente acentuados, com o uso de moldes plásticos. Esses cantos acentuados criariam pontos de concentração de tensão, que resultariam na fissuração do concreto.

A placa quadrada também poderia unir-se ao molde, segundo Shaw et al. (2005), inibindo o movimento da placa quadrada, na direção lateral da junta ou normal a ela. Segundo os autores, se a placa quadrada não puder se mover dentro do molde, provocará fissuração na placa de concreto.

\subsubsection{Danley Construction Products (2000)}

Algumas empresas, como a Danley Construction Products (DCP, 2000), investiram em projetos para investigação dos seus dispositivos de transferência, dentre eles placas quadradas, placas retangulares, barras circulares e barras quadradas. Ensaios laboratoriais foram efetuados e, dentro do programa experimental, utilizaram para resistência característica à compressão do concreto $f_{c k}=32 \mathrm{MPa}$. As dimensões das placas de concreto ensaiadas eram de $100 \mathrm{~cm} \times 100 \mathrm{~cm} \times 15 \mathrm{~cm}$. A Figura 2.53 apresenta o processo de fabricação e de moldagem dos modelos. 


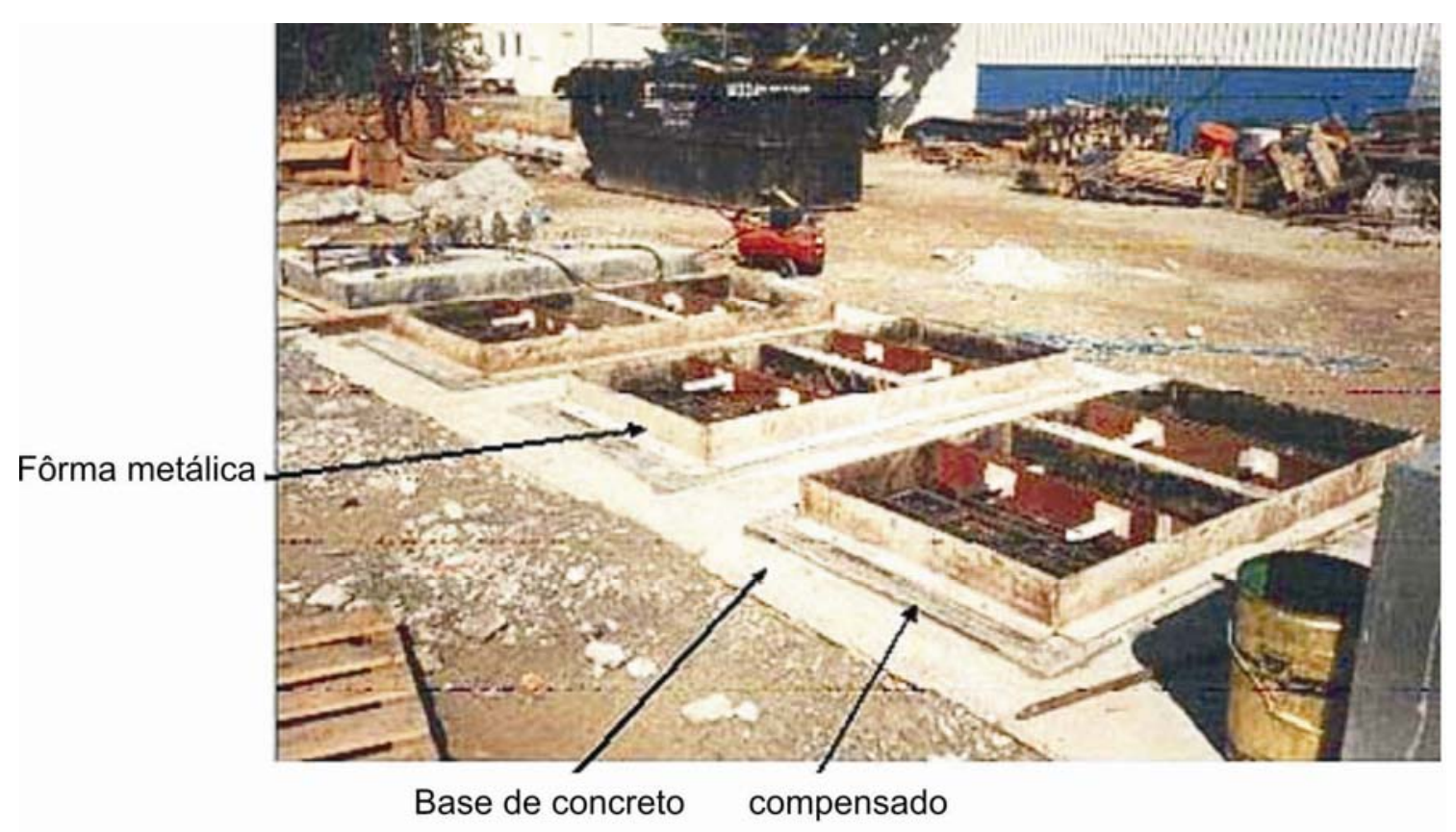

Figura 2.53 - Canteiro de fabricação dos modelos. Fonte: DCP (2000)

A Figura 2.54 apresenta o posicionamento das placas quadradas no interior da placa de concreto. Os dispositivos eram locados com ajuda de um molde plástico (vide Figura 2.48b). Dois atuadores hidráulicos foram posicionados a $28,5 \mathrm{~cm}$ da junta, para simularem a passagem de um veículo (vide Figura 2.56). A abertura das juntas foi de $10 \mathrm{~mm}$.

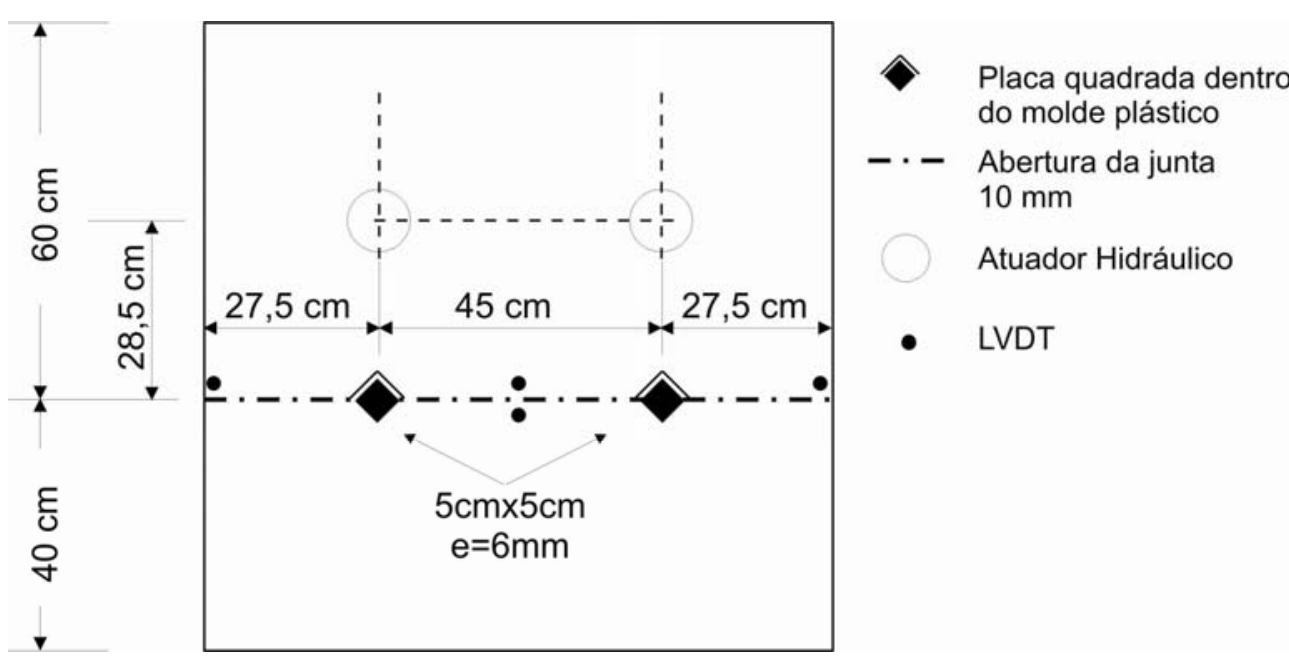

Figura 2.54 - Posicionamento das placas quadradas no interior da placa de concreto. Fonte: DCP (2000) 


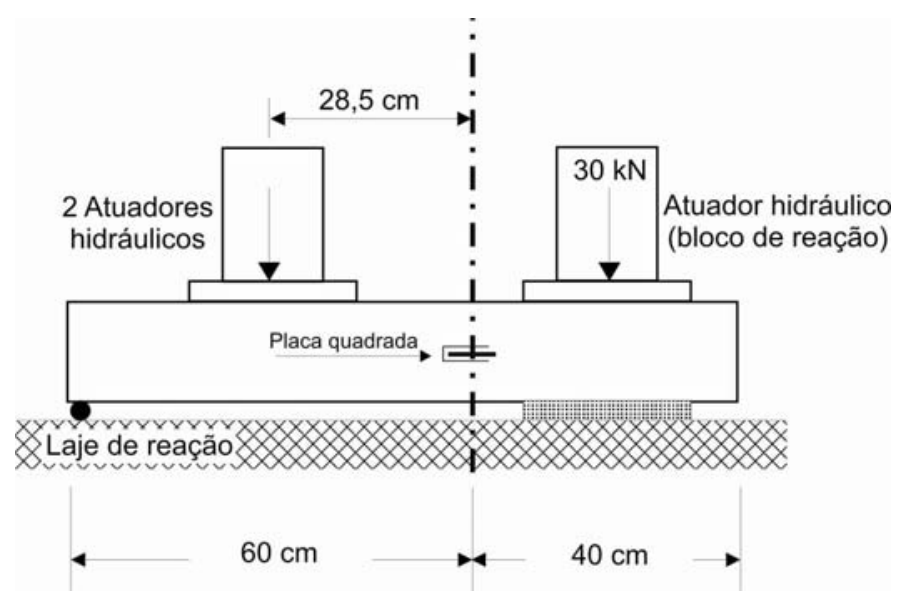

Figura 2.55 - Esquema de ensaio. Fonte: DCP (2000)

Os resultados obtidos mostraram que os ensaios executados com o dispositivo e sua fôrma plástica apresentaram comportamento diferente do verificado com o dispositivo sozinho, e, segundo observações, acredita-se que, para um incremento de carga, a fôrma plástica permite movimento do dispositivo, resultando em um maior deslocamento vertical para menores cargas. Isto também irá interferir na transferência de força, ao longo do comprimento do dispositivo.

Para os dispositivos estudados, foi verificado que as placas quadradas apresentaram deslocamentos verticais inferiores na junta.

\subsubsection{Shaw e Shaw (2005)}

O disco metálico, ou "disk plate", foi desenvolvido por Shaw e Shaw (2005). Esse dispositivo permite um movimento horizontal relativo entre a porção do piso, já concretada, e a nova porção, além de restringir o movimento vertical entre as placas. Consiste no posicionamento do disco metálico no interior de uma junta transversal moldada, conforme apresentado na Figura 2.56.

Os pesquisadores sugerem que para o seu posicionamento serão necessários moldes plásticos em forma de arco, presos à fôrma da junta moldada. Não foram comentados espaçamentos e dimensões para o disco metálico. 


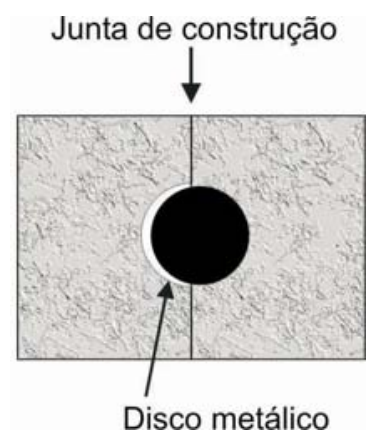

Figura 2.56 - Posicionamento do disco metálico

\subsection{CISALHAMENTO EM CONEXÕES}

A seguir serão descritos ensaios realizados em modelos submetidos a força cortante para determinação da tensão de cisalhamento, segundo o plano cortante delimitado. Uma breve revisão teórica a respeito de cisalhamento duplo também é apresentada.

\subsubsection{Hofbeck, Ibrahim e Mattock (1969)}

Estudos foram efetuados por Hofbeck, Ibrahim e Mattock (1969), na Universidade de Washington, para determinação da transferência de forças cortantes. A transferência de cisalhamento ao longo de um plano definido é frequentemente considerada no dimensionamento de conexões em estruturas pré-moldadas.

No programa experimental, foram moldados 38 corpos-de-prova prismáticos, com ou sem fissura pré-existente, confeccionados para cisalhamento duplo, também denominado "double shear", como mostrados na Figura 2.57.

Ao receberem a força axial $\mathrm{V}$ os modelos devem romper apenas por cisalhamento, ao longo do plano paralelo à direção da força aplicada, sem momento fletor. Os estribos utilizados servem como armadura de montagem do elemento, e se corretamente posicionada, levará à ruptura do modelo ao longo do Plano Cortante. 


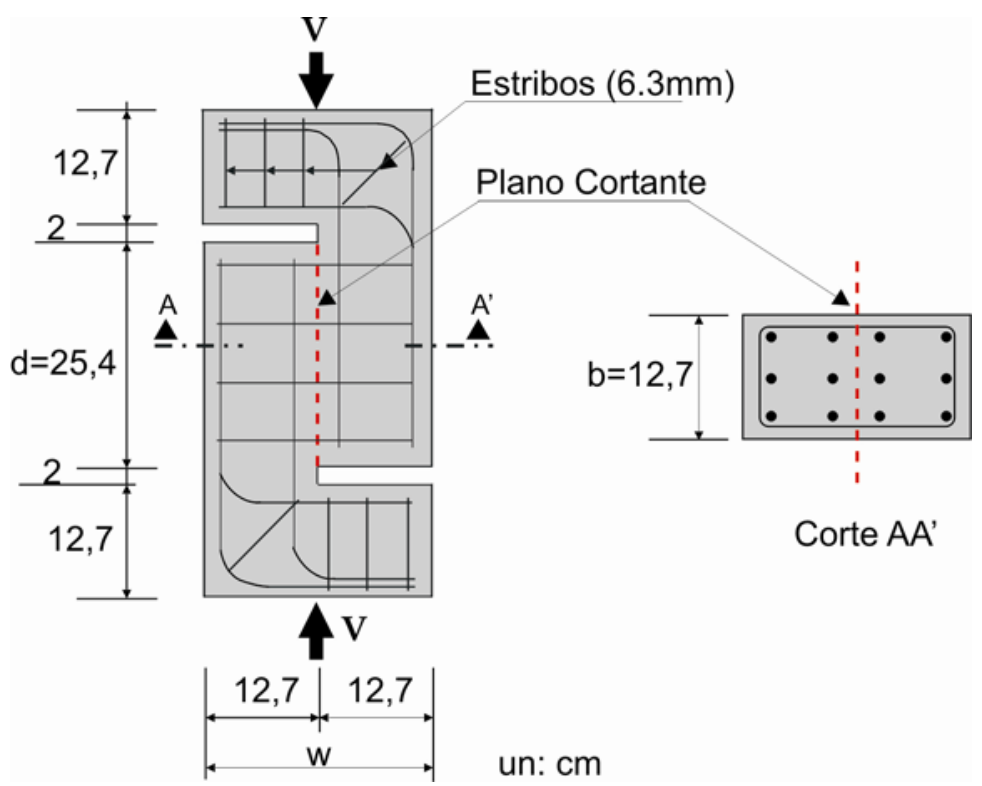

Figura 2.57 - Corpo-de-prova para cisalhamento duplo. Fonte: Hofbeck, Ibrahim e Mattock (1969)

Os pesquisadores concluíram que se a fissura existe em um plano cortante antes da aplicação da força, então ocorrerá um aumento do escorregamento, e também diminuirá a resistência ao cisalhamento.

A tensão de cisalhamento $\tau$ é obtida dividindo-se a força cortante máxima pela área do plano cortante $A$, representada pela largura do modelo e pelo comprimento do plano cortante.

Barras que cruzarem o plano cortante, como as pernas de estribos, tornam-se inativas no concreto inicialmente não fissurado. Contudo elas contribuem na tensão de cisalhamento resistente do concreto com fissuras pré-existentes, agindo como dispositivo de transferência de carga.

A transferência da força cortante é função do parâmetro $\rho \cdot f_{y}$, sendo que:

$$
\rho=\frac{A_{s}}{A}
$$

onde $A_{s}$ é o somatório das seções transversais dos estribos que atravessam o Plano Cortante; e $f_{y}$ é a tensão de escoamento do estribo. 
Isto significa que mudanças no diâmetro, na resistência e no espaçamento da armadura afetarão a resistência ao cisalhamento somente se elas modificarem a taxa de armadura.

\subsubsection{Mattock e Hawkins (1972)}

Estudos mais recentes, desenvolvidos por Mattock e Hawkins (1972), criaram um modelo com plano cortante rotacionado $\theta$ em relação ao eixo vertical, conforme apresentado na Figura 2.58. Os parâmetros $b$ (largura do modelo) e $d$ (comprimento do plano cortante) correspondem respectivamente a $30 \mathrm{~cm}$ e $15 \mathrm{~cm}$. Os 66 modelos foram submetidos a carregamento monotônico até a ruptura.

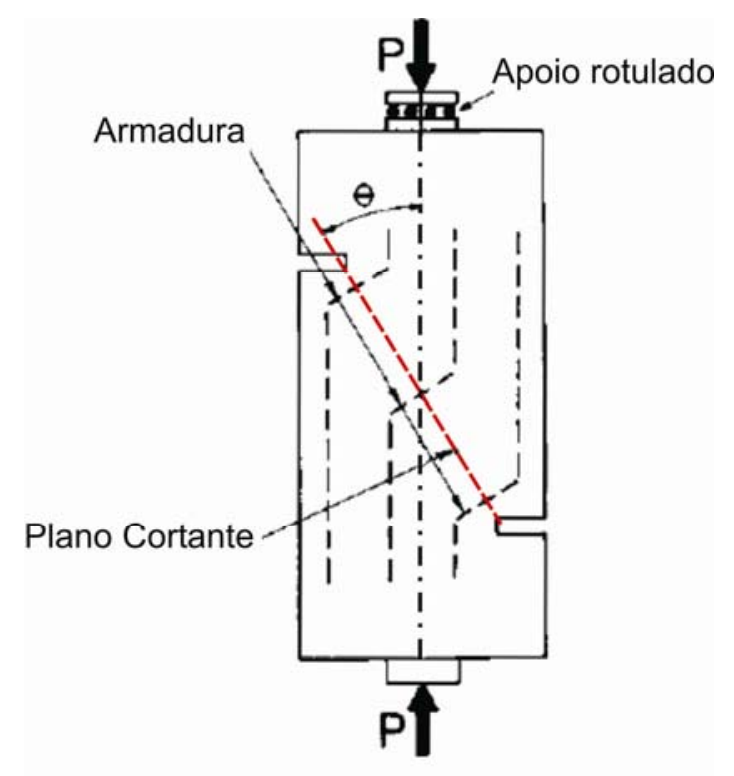

Figura 2.58 - Corpo-de-prova para cisalhamento com plano cortante rotacionado. Fonte: Mattock e Hawkins (1972)

Por várias razões, fissuras podem surgir antes que a força cortante seja aplicada na estrutura. Essas fissuras podem ocorrer, segundo Mattock e Hawkins (1972), por forças de tração causadas por contrações restringidas ou por deformações devidas a gradientes térmicos. Por causa disto, alguns modelos foram previamente fissurados, com a aplicação de forças transversais.

Em todos os casos, o escorregamento ao longo do plano cortante foi medido, e, em alguns casos, a separação lateral do plano cortante também. As fissuras eram 
marcadas nas faces dos modelos à medida que se desenvolviam. Os ângulos variaram, sendo adotados: $0,15^{\circ}, 30^{\circ}, 45^{\circ}, 60^{\circ}$ e $75^{\circ}$.

Os autores puderam concluir que fissuras pré-existentes ao longo do Plano Cortante rotacionado $\theta$ reduzem a tensão de cisalhamento última e aumentam o escorregamento das faces. Mudanças na resistência, no tamanho e no espaçamento da armadura adicionada afetam a resistência ao cisalhamento somente se na relação $\rho f_{y}, f_{y} \leq 455 \mathrm{MPa}$.

\subsubsection{Aziz e Jalalifar (2007)}

Testes de cisalhamento duplo foram estudados em blocos de concreto de resistência à compressão de 20, 40, 50 e 100MPa submetidos a diferentes forças de protensão, por Aziz e Jalalifar (2007), na Universidade de Wollongong, Austrália. Os parâmetros do ensaio foram: resistência ao cisalhamento e deslizamento.

A Figura 2.59 apresenta a máquina de testes empregada, Doublé Shearing Aparatus (DSA), e o modelo proposto depois de ensaiado.

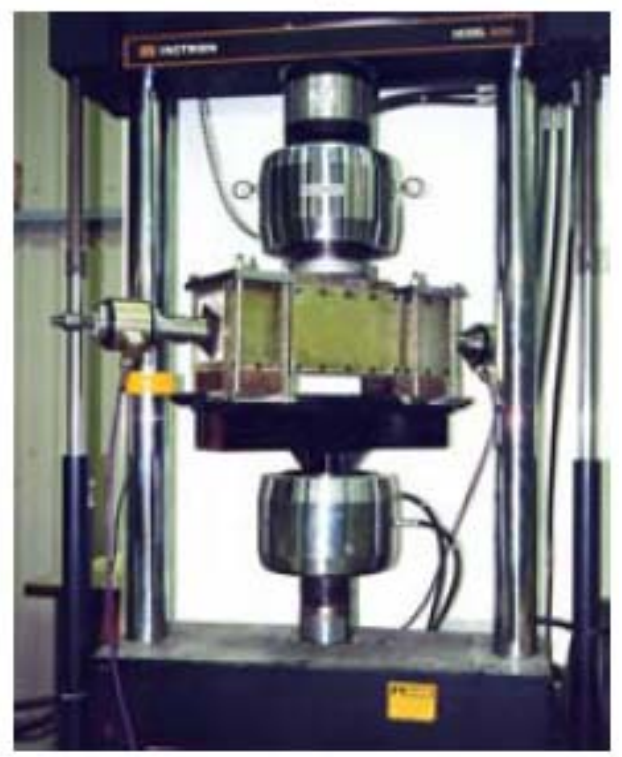

(a)

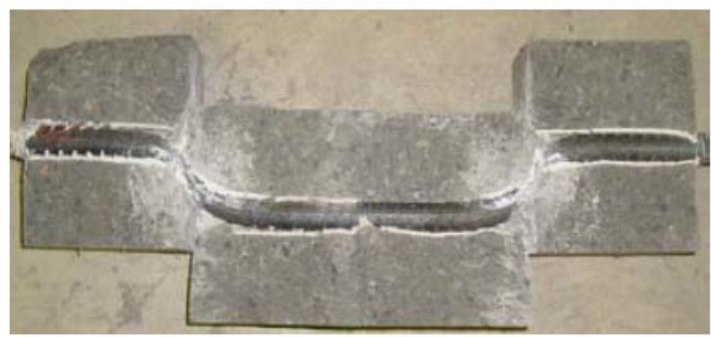

(b)

Figura 2.59 - Ensaio de cisalhamento duplo: (a)máquina DSA; (b) seção de concreto armado após ensaiado. Fonte: Aziz e Jalalifar (2007) 
Em situações de carregamento em que dois planos cortam o elemento, diz se que esse elemento está sujeito a corte duplo, como visto em detalhe na Figura 2.59a.

Uma análise numérica tridimensional foi desenvolvida com os resultados experimentais. Uma malha de elementos finitos foi modelada, como apresentado na Figura 2.60a. No processamento dos resultados numéricos, verificou-se a formação de uma abertura, na vizinhança da junta submetida a força cortante, Figura 2.60b.

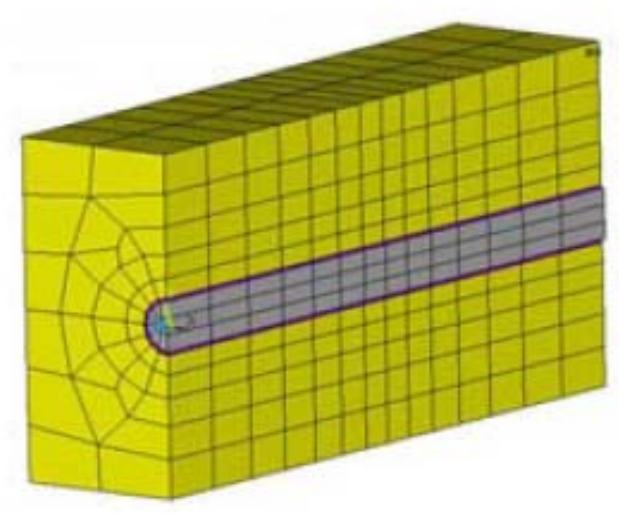

(a)

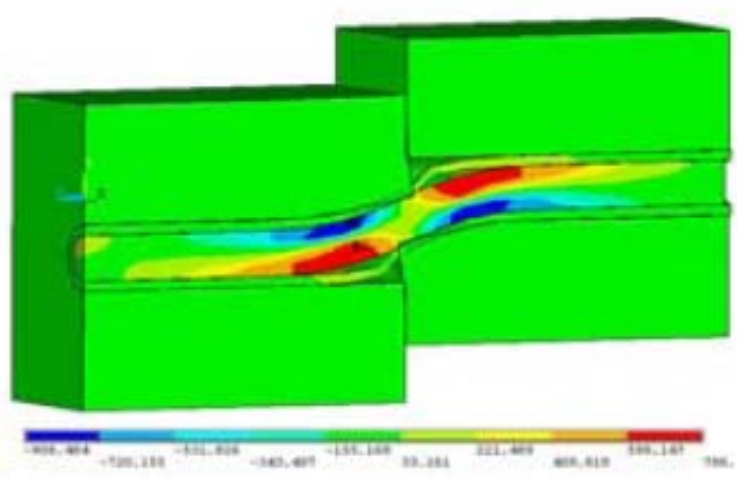

(b)

Figura 2.60 - Análise numérica: (a) malha de elementos finitos; (b) visualização de abertura na junta carregada. Fonte: Aziz e Jalalifar (2007)

Aziz e Jalalifar (2007) concluíram que a resistência da barra de aço ao cisalhamento foi influenciada pela configuração da seção transversal. Também verificaram que a resistência à compressão do concreto influenciou a força produzida na barra, e que o aumento da protensão na barra contribuiu para o aumento da força cortante do meio circundante. 


\section{CAPÍTULO 3}

\section{MODELOS NUMÉRICOS PARA ANÁLISE DE PAVIMENTOS DE CONCRETO}

Este capítulo apresenta um breve estado da arte sobre o desenvolvimento de técnicas numéricas computacionais para a análise do comportamento de pavimentos de concreto, com ou sem juntas. Algumas características serão abordadas, tais como: configuração da malha de elementos finitos, condições de apoio da placa, interfaces placa-fundação e concreto-barra, além dos resultados numéricos encontrados.

\subsection{CONSIDERAÇÕES INICIAIS}

Os pavimentos de concreto são submetidos a uma variedade de carregamentos e de condições de apoio. Eles também são expostos a uma considerável variação climática. Ambos fatores causam condições severas de tensões, em zonas localizadas no pavimento, que podem levar a fissuração, ruptura, defeitos, etc.

Análises estruturais de pavimentos envolveram soluções clássicas de Westergaard, para pavimentos rígidos, e Burmister, para pavimentos flexíveis.

Westergaard (1926) é considerado o pioneiro no desenvolvimento de análise teórica para a determinação de tensões máximas, no interior e na borda de placas de concreto. Idealizou um pavimento de concreto como uma placa elástica apoiada sobre uma fundação de Winkler (ou líquido denso).

Duas décadas depois, Burmister (1943) propôs que, para pavimentos flexíveis, todas as camadas eram compostas por sólidos elásticos. As interfaces das camadas podiam ser unidas ou não, e as cargas advindas de eixos múltiplos (eixo duplo e tandem) eram tratadas como um somatório de efeitos para carga individual.

Embora muitas aproximações tenham sido feitas para a determinação de tensões dos pavimentos de concreto, limitações da matemática convencional restringiam seu 
desenvolvimento. As soluções analíticas limitavam-se a poucos casos de ações e a modelos mais simples dos materiais.

Portanto, a utilização de métodos numéricos possibilita a análise mais realista do comportamento dos pavimentos de concreto. Devido a isso, o Método dos Elementos Finitos (MEF) pode ser utilizado como procedimento analítico, já que ele permite diferentes e variadas simulações, para as condições atuais nos pavimentos.

Para a simulação numérica do comportamento do sistema placa-junta, nesta tese de doutorado, foi escolhido o programa ANSYS 9.0, que utiliza o MEF, sendo que o modelo de concreto leva em conta a fissuração, o comportamento pós-fissuração, o comportamento plástico na compressão e a presença de armadura.

\subsection{HISTÓRICO DO ESTUDO NUMÉRICO}

Huang \& Wang (1973) desenvolveram, a partir do MEF, um programa, capaz de determinar as tensões em um sistema composto por uma série de até três placas conectadas por barras ao longo de uma junta. Os parâmetros utilizados para se avaliar a junta quando dotada de dispositivos de transferência, foram avaliar a eficiência desses dispositivos (vide item 2.1.1) e a perda de contato entre a placa e a base, sob tensão última. A linguagem de programação utilizada foi o FORTRAN IV, versão 65.

Channakeshava, Barzegar e Voyiadjis (1993) consideraram, em suas análises de elementos finitos, a não linearidade do concreto, a fissuração na tração, a ruptura na compressão e a perda de suporte na placa, devida ao empenamento do pavimento, sofrido pelos gradientes de temperatura. Consideraram também a perda de suporte da fundação devida à remoção de material da sub-base, causada pelo bombeamento de material fino.

Scarpas, Ehrola e Judycki (1994), a partir de modelos mecânicos desenvolvidos e da análise cinemática da seção fissurada e armada, fizeram uma implementação utilizando o MEF no programa CAPA-3D, criado pelos próprios autores. Segundo o modelo mecânico do comportamento da placa submetida a forças cortantes, definiram que a formação da fissura em concreto simples, denominada por eles de "vista denteada", especificava a tipologia do processo de fissuração. A idealização 
do modelo consistia no desenho de linhas retas, sendo que o comprimento e a inclinação da fissura denteada dependiam da composição do concreto.

Guo, Sherwood e Snyder (1995) modelaram uma barra de transferência por três segmentos de vigas, sendo dois segmentos de comprimento finito, embebidos no concreto e fletidos, conectados na junta a um segmento de viga, submetido a força cortante e a momento fletor. O modelo considerava a interação barra-concreto.

Buch e Zollinger (1996) desenvolveram um modelo mecânico-empírico que prevê o escorregamento da barra de transferência. Após investigações em laboratório, fatores como o tipo do agregado, o diâmetro da barra e o número de ciclos de carregamento aplicados revelaram suas influências no escorregamento da barra e na perda de eficiência na transferência de carga. Também foi desenvolvida uma relação entre o escorregamento e a perda de eficiência na transferência de carga.

Davids, Turkiyyah e Mahoney (1998) desenvolveram, na Universidade de Washington, um programa de elementos finitos em 3D, para análise de pavimentos rígidos em elementos finitos, incorporando estratégias para modelagem na transferência de carga da junta e no intertravamento dos agregados. A modelagem da barra de transferência é efetuada utilizando-se um novo elemento, desenvolvido para permitir momento fletor, malhas independentes das barras e modelagem do seu escorregamento. O intertravamento dos agregados pode ser modelado utilizando-se elementos de molas lineares ou utilizando-se um modelo de duas fases, que calcula racionalmente, para respostas não lineares da junta e para a variação na força cortante com a abertura da junta. A perda de contato entre a placa e a base pode ser modelada usando-se uma aproximação de contato nodal.

Davids e Mahoney (1999) validaram o programa EverFE, por meio da comparação dos resultados obtidos experimentalmente com os obtidos pelo programa. $O$ deslocamento vertical da junta, em modelos reduzidos, foi o parâmetro utilizado na comparação. Verificaram que as estratégias de modelagem não lineares na transferência de carga da junta, empregadas pelo EverFE, são importantes na previsão da resposta do pavimento.

Murison, Shalaby e Mufti (2002) modelaram a interação da barra de transferência com o concreto utilizando na análise elementos finitos. O modelo foi desenvolvido para investigar tanto o deslocamento vertical de uma barra, submetida a uma carga 
de tráfego, quanto tensões de esmagamento $\sigma_{e}$, produzidas na interface barraconcreto. Dois materiais foram utilizados como componentes das barras: aço e polímero reforçado com fibras ("fibre reinforced polymer") ou FRP. Elementos hexagonais com oito nós foram utilizados nos modelos, e a base de $20 \mathrm{~cm}$ foi modelada usando um material elástico linear, com módulo de 1.400MPa. A discretização da malha foi mais refinada nas proximidades da face da junta.

\subsection{MODELOS COMPUTACIONAIS}

Neste item, serão considerados estudos de quatro grupos de pesquisadores.

\subsubsection{Scarpas, Ehrola \& Judycki (1994)}

Por meio da elaboração de modelos mecânicos do comportamento do concreto submetido à forças cortantes, os pesquisadores definiram que a formação da fissura em concreto simples, por eles denominada por "vista denteada", especificava o processo de fissuração, Figura 3.1a. A idealização do modelo consistia no desenho de linhas retas, sendo que o comprimento e a inclinação da fissura denteada dependem da composição do concreto, Figura 3.1b.

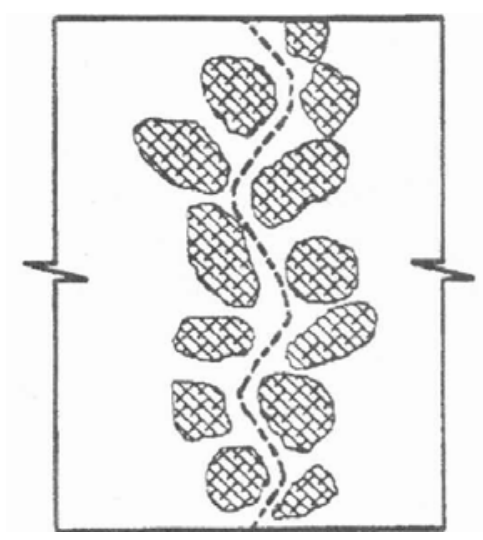

(a)

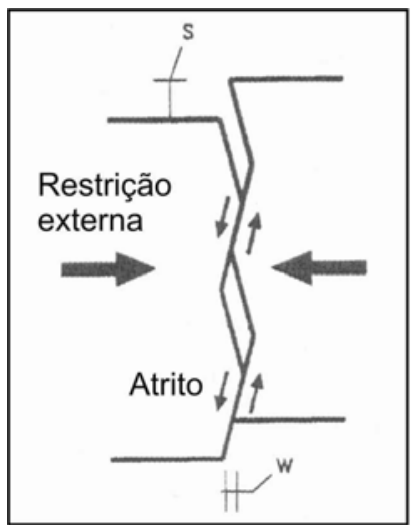

(b)

Figura 3.1 - Modelo mecânico para concreto simples: (a) formação da fissura denteada; (b) transferência de esforços cortantes em uma fissura de abertura w e deslocamentos. Fonte: Scarpas, 
Quando deslocamentos verticais são impostos nas faces opostas da seção fissurada, a fissura denteada tende a empurrar os blocos de concreto em ambos os lados. Pela ação restringida de forças externas, o atrito pode ser desenvolvido.

Para o caso de seção armada por dispositivos, como barras, apresentado na Figura 3.2, não há necessidade de aplicação de forças externas para desenvolver o mecanismo de atrito. No caso, quando os blocos de concreto de ambos os lados são empurrados, a barra posicionada na fissura é solicitada. Para o equilíbrio das tensões de compressão, mecanismos de atrito são desenvolvidos, ao longo da interface. Quanto maior a porcentagem de armadura $\rho$, maior será a resistência e a rigidez do mecanismo apresentado.

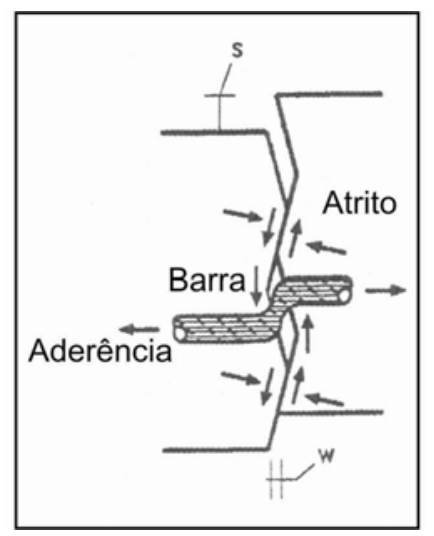

Figura 3.2 - Mecanismo de transferência de esforços cortantes em seção armada. Fonte: Scarpas, Ehrola e Judycki (1994)

Sendo assim, a partir dos modelos mecânicos desenvolvidos e da análise cinemática da seção fissurada e armada, foi feita uma implementação utilizando o Método dos Elementos Finitos (MEF) no programa CAPA-3D, criado pelos próprios autores.

O elemento geométrico tridimensional utilizado para a simulação da interface da fissura tem 16 nós, como apresentado na Figura 3.3a, com espessura bem pequena e próxima de zero. Assumiu-se que a barra se estendia ao longo da direção da espessura do elemento, conforme apresentado na Figura 3.3b, com uma inclinação definida pelo usuário, com respeito ao plano médio do elemento. 


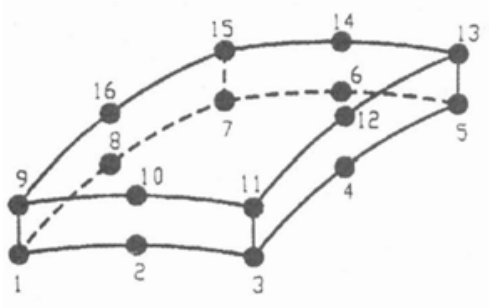

(a)

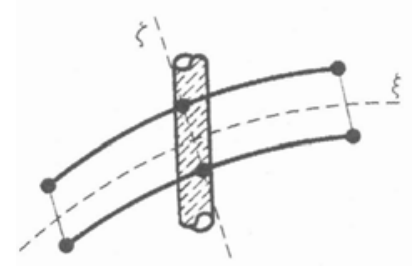

(b)

Figura 3.3 - (a) Geometria do elemento; (b) Simulação da barra

Para testes no programa, foi elaborado um cubo de $100 \mathrm{~mm}$ de aresta, com uma espessura da interface de $4 \mathrm{~mm}$, conforme apresentado na Figura 3.4. Uma pressão normal de 1,0 MPa foi aplicada nas faces opostas da malha, na direção normal ao plano da interface.

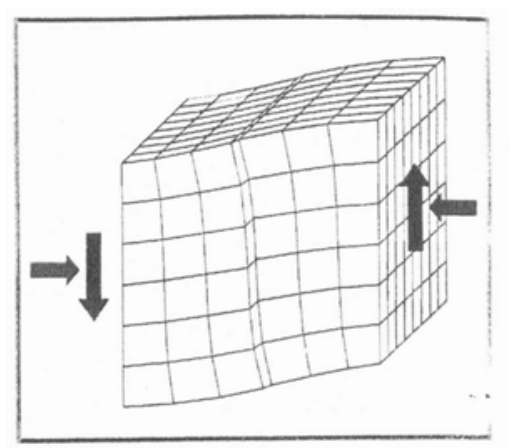

Figura 3.4 - Simulação no CAPA-3D de uma junta armada fissurada. Fonte: Scarpas, Ehrola e Judycki (1994)

Os pesquisadores concluíram que o modelo mecânico desenvolvido simulou as características do mecanismo de transferência de força cortante nas interfaces da junta fissurada. Com base no modelo mecânico, um elemento finito foi formulado e implementado, fornecendo condições para se avaliar pavimentos, sob condições gerais de carregamento e para uma geometria arbitrária.

\subsubsection{Davids e Mahoney (1999)}

Um modelo, criado a partir do programa EverFE, teve seus resultados comparados com resultados laboratoriais, realizados por Hammons (1997) apud Davids e Mahoney (1999), para validar o programa. O EverFE é um programa computacional 
desenvolvido pelos pesquisadores Davids, Turkiyyah e Mahoney (1998), da Universidade de Washington.

O modelo, desenvolvido a partir do MEF, pode ser visualizado na Figura 3.5. As placas e a base apresentavam comportamento elástico e linear, e foram discretizadas com elemento hexaédrico de 20 nós e aproximação quadrática. A fundação adotada foi tipo Winkler e a perda de contato entre a placa e a face superior da base foi considerada utilizando-se contato nodal.

Assume-se que a fundação tipo Winkler é composta por um líquido denso. Esse modelo é composto por uma série de molas independentes, em que a reação da fundação, por unidade de área, é, em qualquer ponto, proporcional ao deslocamento vertical, mas independente dos deslocamentos verticais de qualquer outro ponto.

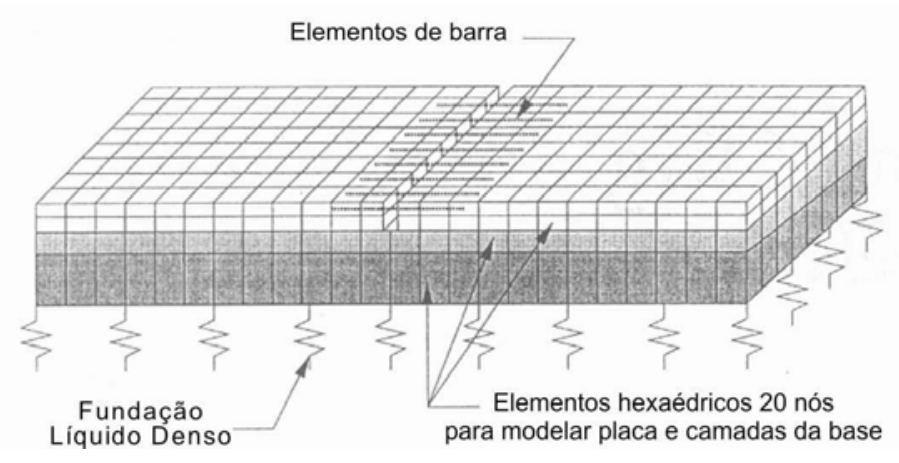

Figura 3.5 - Malha de elementos finitos. Fonte: Davids e Mahoney (1999)

As barras de transferência puderam ser locadas sem relação com a malha das placas, como apresentado na Figura 3.6a. Elementos de viga com três nós, visualizados na Figura 3.6b, e 18 graus de liberdade foram utilizados para representar as porções das barras engastadas no concreto. Para a parte relativa à abertura da junta, foi utilizado um elemento de viga com dois nós e suscetível a força cortante. 


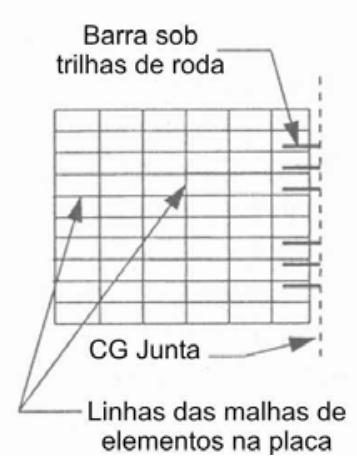

(a)

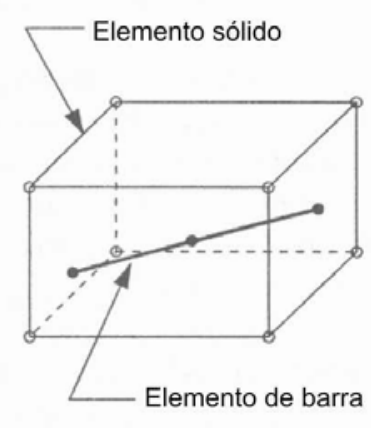

(b)

Figura 3.6 - Elemento de barra engastado no concreto. Fonte: Davids e Mahoney (1999)

Vazios existentes entre as barras e o concreto circundante, provocados por escorregamentos, puderam ser modelados utilizando-se a aproximação por contato nodal. A Figura 3.7 apresenta as dimensões do modelo experimental de Hammons, tendo sido considerada a existência de um vazio, indicado por uma constante $\gamma$. Essa figura apresenta, também, o detalhe da modelagem da barra de transferência. Vale ressaltar que quatro elementos foram localizados próximos à junta, para melhor analisar o potencial contato, com dois elementos utilizados para discretizar as porções remanescentes engastadas da barra, dando um total de 13 potenciais pontos de contato para cada barra.

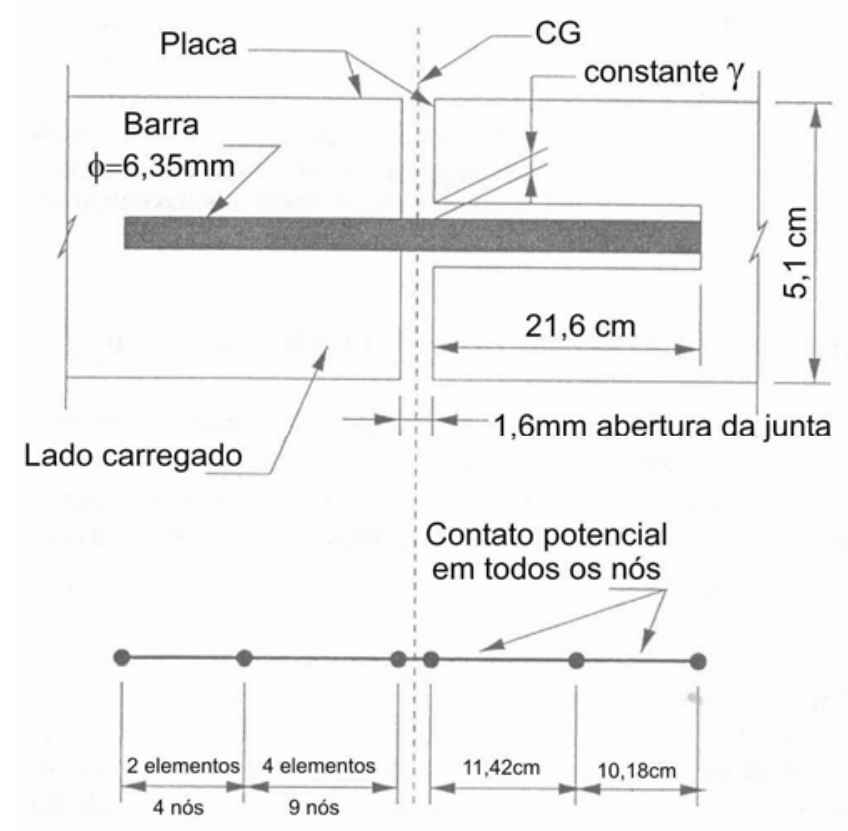

Figura 3.7 - Adoção de vazios entorno das barras. Fonte: Davids e Mahoney (1999) 
Na comparação entre os dados experimentais e aqueles previstos pelo programa, foi considerado um vazio $\gamma=0,08 \mathrm{~mm}$ entre a barra e o lado não carregado da placa de concreto. Duas bases foram modeladas: lençol de borracha, tratado como líquido denso, e base de cimento tratada, modelada como meio contínuo elástico.

Na previsão dos deslocamentos verticais, lidos experimentalmente por transdutores alinhados às barras, foi observado que o maior erro foi da ordem de 17\%, provavelmente por imprecisão da modelagem, nas condições de contorno e na resposta não linear da base de borracha, que não foi computada na modelagem em elementos finitos.

\subsubsection{Murison, Shalaby e Mufti (2002)}

Com a finalidade de verificar as diferenças no comportamento entre barras de aço e de polímero com fibras ("fibre reinforced polymer"), em um sistema barra-concreto, uma modelagem em elementos finitos foi realizada pelos pesquisadores Murison, Shalaby e Mufti (2002). O modelo foi criado utilizando-se o programa ADINA, versão 7.4, para investigar os deslocamentos verticais da barra engastada no concreto e a correspondente tensão de ruptura produzida.

O modelo compreendia uma placa isolada, com uma barra de transferência projetada em um dos lados, onde uma força $F$ era aplicada. A Figura 3.8 apresenta a malha de elementos finitos produzida para barras de $38 \mathrm{~mm}$ e $60 \mathrm{~mm}$ de diâmetro, e comprimento total de $100 \mathrm{~cm}$.

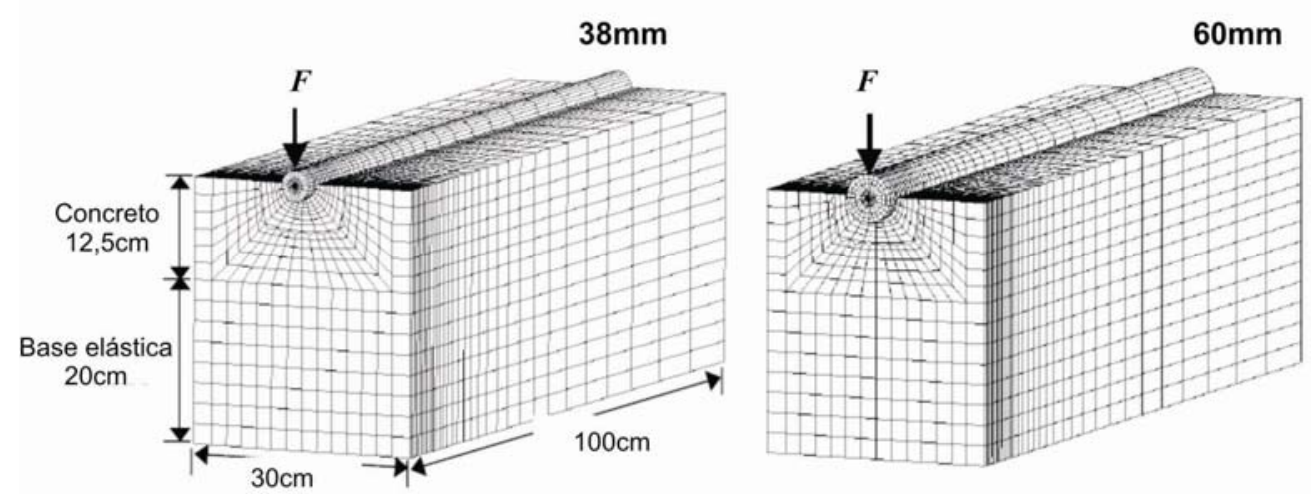

Figura 3.8 - Definição da malha para barras de 38mm e 60mm. Fonte: Murison, Shalaby e Mufti (2002) 
A base do modelo era elástica e fixa, propiciando uma fundação rígida de $20 \mathrm{~cm}$ de espessura. A espessura total da placa de concreto era de $25 \mathrm{~cm}$, mas, para simplificação e redução no número de elementos, foi removida a metade de cima do modelo.

A região onde os deslocamentos verticais e as tensões de esmagamento são mais críticas é próximo da face da junta. Por isso mesmo, uma malha mais refinada foi adicionada nessa região. Elementos hexagonais com oito nós foram utilizados nos modelos. A Tabela 3.1 fornece detalhes das propriedades dos materiais empregados. A resistência do concreto à compressão $\left(f_{c}\right)$ selecionada foi de 30MPa, e a resistência do concreto à tração na flexão $\left(f_{c t, f}\right)$ foi de $5 \mathrm{MPa}$.

Tabela 3.1 - Propriedades dos materiais

\begin{tabular}{|c|c|c|}
\hline Material & $\begin{array}{c}\text { Módulo de Elasticidade } \\
(\mathrm{MPa})\end{array}$ & Coeficiente de Poisson \\
\hline Aço & 200.000 & 0,3 \\
\hline FRP & 40.000 & 0,3 \\
\hline Concreto & 24.600 & 0,2 \\
\hline Base elástica & 1.400 & 0,3 \\
\hline
\end{tabular}

A força máxima $F$ aplicada por barra foi adotada como sendo $12 \mathrm{kN}$, à uma distância teórica de $1,25 \mathrm{~cm}$ da face da junta, que contava com uma abertura total de $2,5 \mathrm{~cm}$. Ao invés de ser aplicada uma força pontual, ela foi aplicada como uma pressão vertical atuante na superfície superior da porção projetada da barra, o que evitaria concentração de tensões.

A formulação utilizada para determinação do deslocamento vertical da barra foi desenvolvida por Friberg (1940), apresentada na eq. 2.15 do item 2.3.3.

Os pesquisadores concluíram que a teoria desenvolvida por Friberg tende a prever maiores deslocamentos positivos (para cima), na porção intermediária da barra, do que nos modelos desenvolvidos em MEF, como apresentado na Figura 3.9. 

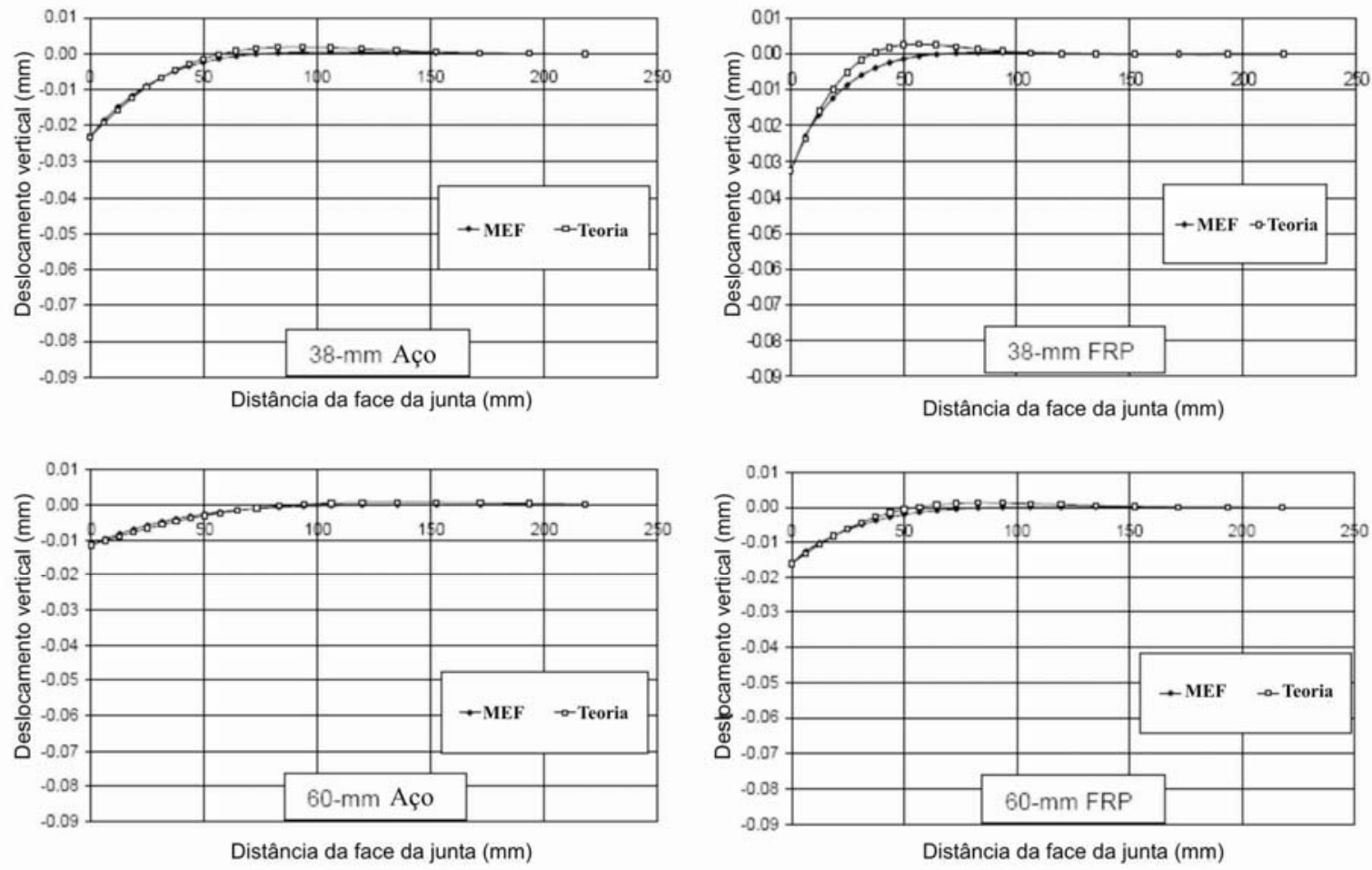

Figura 3.9 - Deslocamentos das barras - MEF versus Teoria segundo Friberg (1940)

\subsubsection{Maggi (2004)}

Maggi (2004) desenvolveu um modelo que representa o comportamento de placas de concreto armado apoiadas sobre EPS. A validação do modelo foi feita pela comparação com resultados experimentais, obtidos dos ensaios realizados pela pesquisadora.

No estudo adotou-se o programa ABAQUS, versão 6.2, para o processamento de modelos de concreto armado apoiados sob meio elástico. Nessa análise, foram avaliadas as possibilidades para modelagem do solo e de sua interface com o pavimento. Uma forma de modelar o solo por meio de molas e permitir o descolamento entre pavimento e fundação foi introduzindo outra placa, de pequena espessura e baixo módulo de elasticidade, tangente à face inferior da placa de concreto, e nesta sim, acoplar as molas que representam o solo, conforme apresentado na Figura 3.10. O modelo de contato era estabelecido entre essas duas placas. 


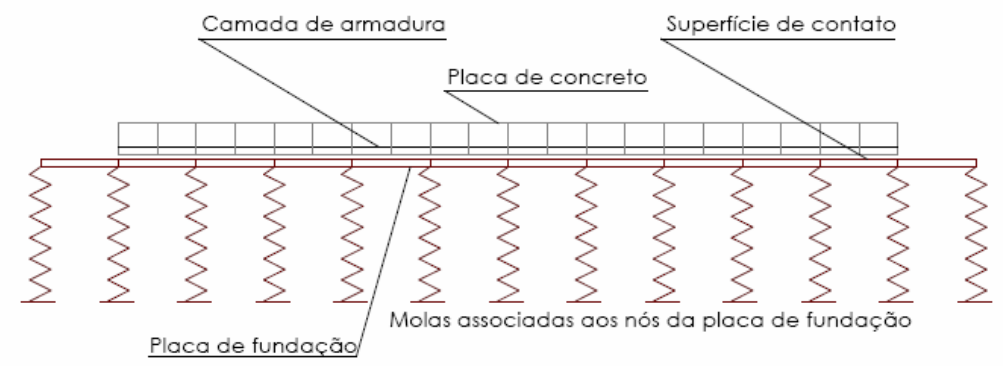

Figura 3.10 - Modelo de placa de concreto armado apoiada sobre o solo. Fonte: MAGGI (2004)

O modelo de concreto do ABAQUS foi projetado para casos em que o material estava sujeito a carregamento monotônico. Dessa forma, não foi possível fazer uma análise direta da fadiga do material.

A armadura em tela, com taxa $\rho=0,17 \%$, das placas ensaiadas de concreto armado de $200 \mathrm{~cm} \times 200 \mathrm{~cm}$ e espessura de $8 \mathrm{~cm}$, foi modelada com elementos de barra. Esses elementos são unidirecionais e podem ser definidos um a um ou embutidos em superfícies orientadas. A armadura foi introduzida como duas superfícies, orientadas nas direções x e y. Para as barras de aço, utilizou-se material elastoplástico.

Na Figura 3.11 foram traçados os deslocamentos no centro da placa, medidos na análise experimental e determinados com a modelagem numérica.

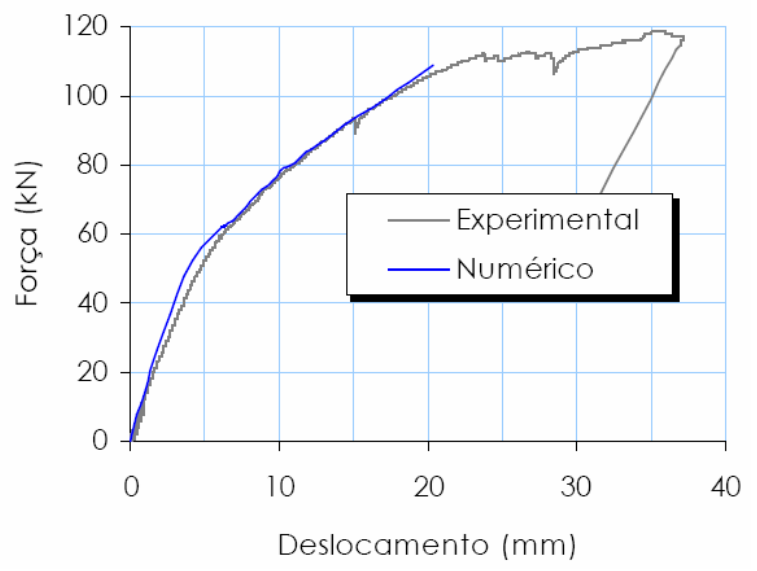

Figura 3.11 - Deslocamento vertical no centro da placa. Fonte: Maggi (2004)

Maggi (2004) conclui que os deslocamentos, as tensões e as deformações estavam compatíveis com os dados medidos em laboratório para um modelo semelhante e verificou que a modelagem desenvolvida poderia ser usada no estudo dos pavimentos de concreto armado. 


\section{CAPÍTULO 4}

\section{PROCEDIMENTO EXPERIMENTAL}

Este capítulo apresenta o procedimento experimental adotado nos ensaios realizados, bem como o detalhamento dos modelos e dos dispositivos de transferência. Também são apresentados os materiais empregados e suas caracterizações, o processo executivo dos modelos e corpos-de-prova, o sistema de ensaio e a instrumentação, utilizados na determinação do comportamento e da resistência das juntas em pavimentos de concreto. Aborda o ensaio do coeficiente de recalque para obtenção da capacidade resistente das borrachas, e ensaios para determinação de suas propriedades mecânicas como deformação constante e dureza.

\subsection{CONSIDERAÇÕES GERAIS}

Os ensaios experimentais realizados tiveram como objetivo principal a análise do comportamento estrutural de placas de concreto contíguas, ligadas por dispositivos de transferência.

O estudo experimental foi dividido em duas etapas, segundo o tipo de carregamento aplicado:

- Primeira etapa: execução de ensaios quase estáticos, sobre um dos lados das juntas de pavimentos de concreto simples;

- Segunda etapa: execução de ensaios repetidos, sobre um dos lados das juntas de pavimentos de concreto simples.

$\mathrm{Na}$ primeira etapa, foram executados ensaios quase estáticos em corpos-de-prova prismáticos, para determinação da força cortante em seções dos dispositivos de transferência de carga.

Foram realizados ensaios em 23 modelos, com dimensões de $220 \mathrm{~cm}$ por $60 \mathrm{~cm}$ e espessuras $h$ de $12 \mathrm{~cm}$ e de $16 \mathrm{~cm}$. Os modelos estavam apoiados em base elástica 
(lençol de borracha natural) com $14 \mathrm{~cm}$ de espessura total, que, por sua vez, estava em contato direto com a laje de reação.

As principais variáveis dos ensaios foram: variação da seção armada do dispositivo de transferência, espessura das placas de concreto simples e tipo de carregamento imposto.

Todas as peças foram ensaiadas até a ruína. Parte da primeira etapa da pesquisa, que se refere à confecção e ao ensaio de modelo preliminar, foi desenvolvida no Laboratório de Estruturas da Escola de Engenharia Civil da Universidade Federal de Goiás. A parte restante da primeira e a segunda etapa foram realizadas no Laboratório de Estruturas da Universidade de São Paulo - São Carlos.

\subsection{ENSAIOS NOS MODELOS}

\subsubsection{Características dos modelos}

Foram confeccionados modelos em concreto simples, que simulavam frações de uma pista trafegável de pavimento de concreto. Essas partes, compostas por duas placas justapostas, eram interligadas por dispositivos que serviam de pontos de transferência de forças, posicionados sob o lugar de junção desses elementos: a junta.

Os modelos tinham as dimensões como mostrado na Figura 4.1, tanto para juntas moldadas quanto para serradas. Foi admitido um espaçamento entre os dispositivos de transferência equivalente a $30 \mathrm{~cm}$, usualmente adotado (Pitta, 1998). Os dispositivos de transferência foram convenientemente dispostos a $h / 2$ da face superior da placa e posicionados para a concretagem por meio de espaçadores metálicos (caranguejos).

A junta serrada teve um corte a uma profundidade de $1 / 4$ da espessura da placa, e a junta moldada foi obtida com um separador metálico, durante concretagem. Todas as juntas, tanto as moldadas quanto as serradas, possuíam uma abertura de $6 \mathrm{~mm}$, aproximadamente. 


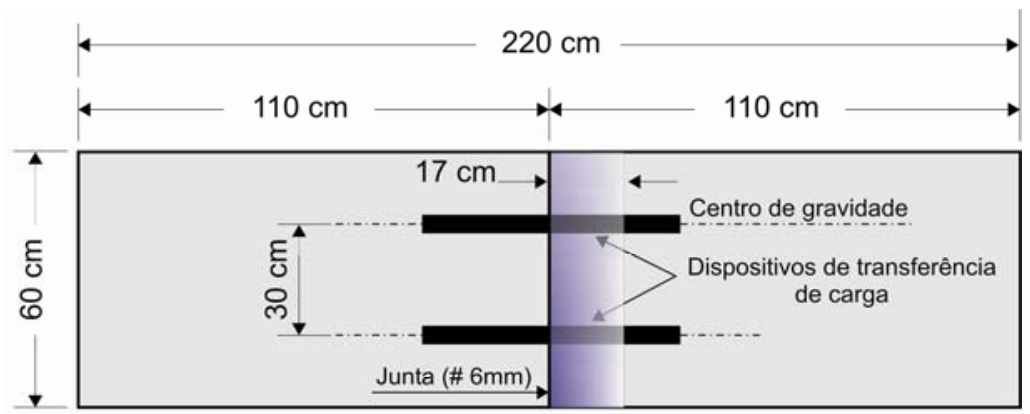

(a)

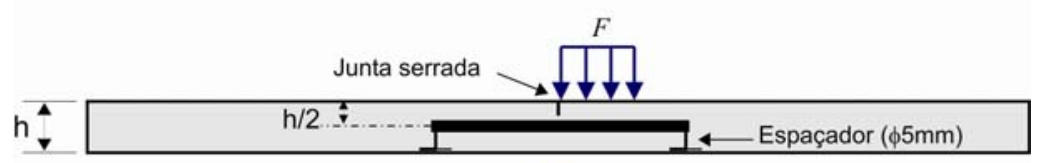

(b)

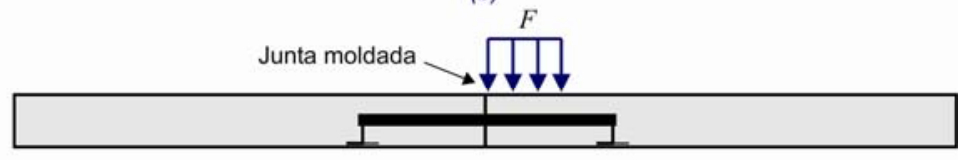

(c)

Figura 4.1 - Dimensões dos modelos de concreto simples: (a) vista superior; (b) corte longitudinal em junta serrada; (c) corte longitudinal em junta moldada

Os parâmetros gerais de projeto, para o dimensionamento dos modelos em concreto simples, são apresentados na Tabela 4.1. Nessa tabela, estão mostradas as características físicas adotadas e as propriedades mecânicas dos materiais utilizados no dimensionamento.

Tabela 4.1 - Parâmetros de projeto para dimensionamento das placas

\begin{tabular}{|l|c|c|}
\hline \multicolumn{1}{|c|}{ Parâmetros de Projeto } & Placas $(\mathrm{P})$ & Unidade \\
\hline Comprimento da placa & 220 & $\mathrm{~cm}$ \\
\hline Largura da placa & 60 & $\mathrm{~cm}$ \\
\hline Espessura do pavimento $(h)$ & $12 / 16$ & $\mathrm{~cm}$ \\
\hline Coeficiente de Poisson do concreto $(v)$ & 0,20 & - \\
\hline Resistência do concreto à tração na flexão $\left(f_{c t, f}\right)$ & 2,5 & $\mathrm{MPa}$ \\
\hline Resistência característica do concreto à compressão $\left(f_{c k}\right)$ & 20 & $\mathrm{MPa}$ \\
\hline
\end{tabular}


$\mathrm{Na}$ execução de pavimentos de concreto, alguns métodos fixam um valor característico para a resistência à tração na flexão $\left(f_{c t, f}\right)$ para o dimensionamento, o recebimento e a aceitação do concreto de um determinado trecho. Porém, nesta pesquisa, foi especificada a resistência característica à compressão $\left(f_{c k}\right)$, tendo em conta os processos de recebimento e de concretagem dos modelos. Foi adotado um valor de $f_{c k}$ considerado ideal para um conjunto de experimentos realizados no Laboratório da UFG.

O valor de projeto para $f_{c t, f}$ foi obtido com o emprego de equações que correlacionam as resistências de compressão, de tração na flexão e na tração direta do concreto. A eq.(4.1) mostra as correlações das resistências, segundo NBR 6118 (2003). A eq.(4.2) apresenta a formulação final para determinação de $f_{c t, f}$, em função de $f_{c k}$.

$$
\begin{aligned}
& f_{c t, m}=0,3 \cdot\left(f_{c k}\right)^{\frac{2}{3}}=0,9 \cdot f_{c t, f} \\
& f_{c t, f}=\frac{0,3}{0,9} \sqrt[3]{f_{c k}^{2}}
\end{aligned}
$$

onde $f_{c t m}$ é a resistência média do concreto à tração; $f_{c t, f}$ é a resistência do concreto à tração na flexão; $f_{c k}$ é a resistência característica do concreto à compressão, as três em MPa.

O valor de projeto adotado para o $f_{c t, f}$ do concreto aos 28 dias foi de 2,5MPa.

A Tabela 4.2 apresenta as principais variáveis adotadas para as placas ensaiadas e o programa de ensaios. Cada modelo dotado de junta (J) foi designado segundo a tipologia da junta - serrada (S) ou moldada (M) -, espessura em centímetros - (12) ou (16), tipo de dispositivo - barra circular (BC); barra quadrada (BQ); placa metálica (PM) ou disco metálico (DM) - e tipo de carregamento - monotônico (M) ou cíclico (C). Por exemplo, um modelo com junta serrada, de espessura fixa em $12 \mathrm{~cm}$, provida de barra circular como dispositivo e submetida a carregamento monotônico 
foi denominado JS12BCM. A nomenclatura do modelo preliminar, ensaiado no Laboratório da UFG, vem precedida pela letra $\mathbf{P}$.

Tabela 4.2 - Programa de ensaio e variáveis adotadas

\begin{tabular}{|c|c|c|c|c|c|}
\hline Modelo & Junta & $\begin{array}{l}\text { Espessura } \\
h \text { da placa } \\
(\mathrm{cm})\end{array}$ & $\begin{array}{l}\text { Dispositivo de } \\
\text { transferência } \\
\text { metálico }\end{array}$ & $\begin{array}{l}\text { Dimensões } \\
\text { nominais do } \\
\text { elemento } \\
(\mathrm{mm})\end{array}$ & Aplicação de carga \\
\hline PJS12BCM & serrada & 12 & Seção circular & 12,5 & \multirow{19}{*}{$\begin{array}{l}\text { Carregamento } \\
\text { monotônico }\end{array}$} \\
\hline JS12SDM & serrada & 12 & - & - & \\
\hline JS16SDM & serrada & 16 & - & - & \\
\hline JS12BCM & serrada & 12 & Seção circular & 12,5 & \\
\hline JS12BQM & serrada & 12 & Seção quadrada & $\# 10,0$ & \\
\hline JS12PMM & serrada & 12 & Placa metálica & \#115 & \\
\hline JS12DMM & serrada & 12 & Disco metálico & $\phi 163$ & \\
\hline JS16BCM & serrada & 16 & Seção circular & 12,5 & \\
\hline JS16BQM & serrada & 16 & Seção quadrada & $\# 10,0$ & \\
\hline JS16PMM & serrada & 16 & Placa metálica & $\# 115$ & \\
\hline JS16DMM & serrada & 16 & Disco metálico & $\phi 163$ & \\
\hline JM12BCM & moldada & 12 & Seção circular & 12,5 & \\
\hline JM12BQM & moldada & 12 & Seção quadrada & $\# 10,0$ & \\
\hline JM12PMM & moldada & 12 & Placa metálica & \#115 & \\
\hline JM12DMM & moldada & 12 & Disco metálico & $\phi 163$ & \\
\hline JM16BCM & moldada & 16 & Seção circular & 12,5 & \\
\hline JM16BQM & moldada & 16 & Seção quadrada & $\# 10,0$ & \\
\hline JM16PMM & moldada & 16 & Placa metálica & \#115 & \\
\hline JM16DMM & moldada & 16 & Disco metálico & $\phi 163$ & \\
\hline JS12BCC & serrada & 12 & Seção circular & 12,5 & \multirow{4}{*}{$\begin{array}{l}\text { Carregamento } \\
\text { cíclico }\end{array}$} \\
\hline JS12PMC & serrada & 12 & Placa metálica & \#115 & \\
\hline JS12DMC & serrada & 12 & Disco metálico & $\phi 163$ & \\
\hline JS16PMC & serrada & 16 & Seção circular & 12,5 & \\
\hline
\end{tabular}

A diferenciação entre os tipos de juntas teve como objetivo observar a variação de comportamento do ponto de vista estrutural quando ensaiadas, visto que tanto a junta serrada quanto a moldada são empregadas em pavimentos de concreto sem descontinuidades ou em encontros com outras estruturas, para o caso de pistas de rolamento. A diferença de espessura das placas permitiu avaliar a influência dessa 
variável no comportamento do sistema placa-junta, tanto para carregamento quase estático quanto cíclico. Finalmente, esperou-se identificar a influência da variação da área e da seção de aço dos dispositivos de transferência de carga, no comportamento global da estrutura.

O modelo preliminar foi ensaiado objetivando-se: avaliar a capacidade resistente da borracha escolhida; verificar o sistema de ensaio e identificar o posicionamento da instrumentação, principalmente no que se refere aos dispositivos metálicos.

A região de distribuição da carga aplicada sobre um dos lados da junta foi selecionada para que a força aplicada uniformemente fosse distribuída em toda a largura do modelo, simulando uma configuração de roda dupla. Essa região correspondeu a um retângulo de $17 \mathrm{~cm} \times 60 \mathrm{~cm}$. A Figura 4.2 apresenta a disposição do carregamento imposto.

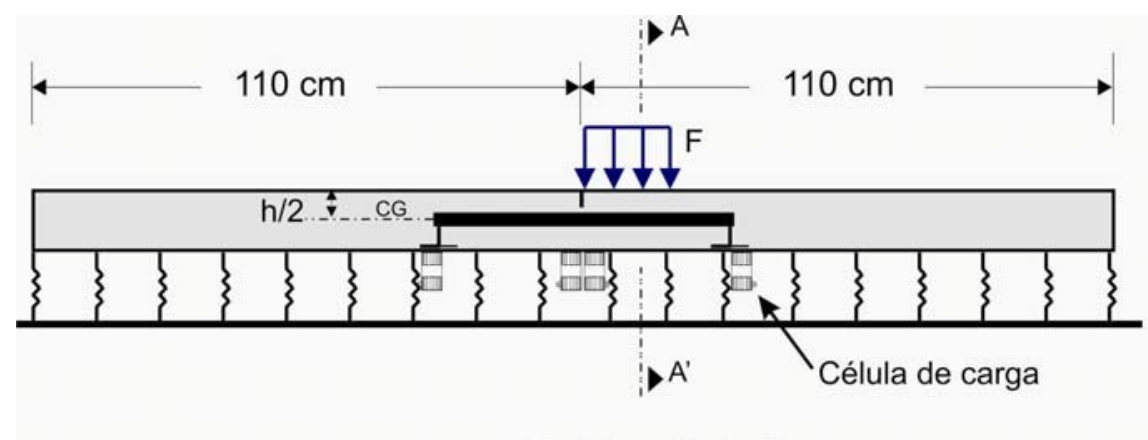

Corte Longitudinal

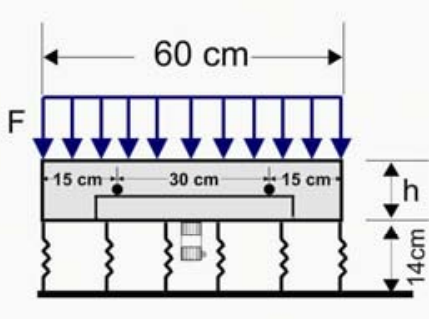

Corte Transversal Seção AA'

Figura 4.2 - Posicionamento do carregamento

\subsubsection{Dispositivos de transferência}

Os dispositivos de transferência metálicos estudados encontram-se na Tabela 4.3. 
Tabela 4.3 - Dispositivos de transferência de carga

\begin{tabular}{|c|c|c|c|}
\hline \multicolumn{3}{|c|}{ Dispositivos metálicos } \\
\hline $\begin{array}{c}\text { Barra de } \\
\text { transferência }\end{array}$ & Barra quadrada & Placa metálica & Disco metálico \\
\hline & & & \\
\hline & & &
\end{tabular}

As barras com seção transversal quadrada e circular são produzidas com aço de baixo teor de carbono, de acordo com a norma ASTM A36 (1997). É um aço carbono de resistência mecânica média, com um limite de escoamento estimado em $f_{y} \geq 250$ MPa e um limite de ruptura $f_{u}=400 \mathrm{MPa}$ a $550 \mathrm{MPa}$

Para a usinagem da placa metálica e do disco metálico foi utilizado aço tipo USISAC 41, com limite de escoamento estimado em $f_{y} \geq 300 \mathrm{MPa}$. Esse valor é especificado no Catálogo de Produtos da USIMINAS (2006). Os aços da série USISAC são de resistência mecânica média e foram desenvolvidos para utilização na construção civil em geral.

Neste estudo, optou-se por não considerar barras de transferência disponíveis comercialmente, por elas não atenderem o limite de escoamento adotado para as chapas. Essas barras de transferência são fabricadas em aço CA-25 e a resistência característica de escoamento é igual a 250MPa.

Para efeito de projeto, foram adotados os seguintes valores das propriedades mecânicas, para os aços relacionados: módulo de elasticidade tangente $E_{s}=205.000 \mathrm{MPa}$ e coeficiente de Poisson do aço estrutural $v_{a}=0,3$, conforme a NBR 8800 (2003).

Adotou-se para a barra de seção circular um diâmetro $\phi=12,5 \mathrm{~mm}$, encontrado em barras de transferência comercializadas. As dimensões da seção da barra quadrada foram obtidas mediante equivalência do momento de inércia da seção circular, conforme apresentado na eq.(4.3). 


$$
I_{C}=\frac{\pi \phi^{4}}{64}=I_{Q}=\frac{\ell_{Q}^{4}}{12}
$$

onde $I_{C}$ corresponde ao momento de inércia da barra circular, em $\mathrm{cm}^{4} ; I_{Q}$ é o momento de inércia da barra quadrada, em $\mathrm{cm}^{4}$; e $\ell_{Q}$ corresponde ao lado da seção quadrada.

Da mesma forma, para a placa metálica e o disco metálico foram feitas equivalências de momento de inércia das seções, tendo em vista que a placa metálica possui dimensões fixadas de $\ell_{P L}=11,5 \mathrm{~cm}$ e espessura $e=6 \mathrm{~mm}$, sugeridas por Walker e Holland (1998). A chapa metálica disponibilizada para o corte dos dispositivos listados possui espessura nominal de $e=6,3 \mathrm{~mm}$. As eqs.(4.4) e (4.5) apresentam a formulação proposta para as dimensões do disco metálico, sendo constante a espessura dos dois dispositivos:

$$
\begin{aligned}
& D=\ell_{P L} \cdot \sqrt{2} \\
& I_{P L}=I_{D}=\frac{D \cdot e^{3}}{12}
\end{aligned}
$$

onde $D$ é a diagonal da placa metálica ou o diâmetro do círculo circunscrito, Figura 4.3; $I_{P L}$ é o momento de inércia da placa metálica, em $\mathrm{cm}^{4} ; I_{D}$ é o momento de inércia do disco metálico, em $\mathrm{cm}^{4}$; $e$ corresponde à espessura do dispositivo, em $\mathrm{cm}$.

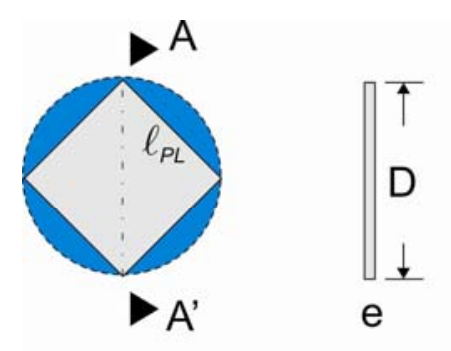

Corte AA'

Figura 4.3 - Correspondência dimensional 


\subsubsection{Materiais}

\section{A. Concreto}

Para o controle tecnológico do concreto, ensaios de determinação da resistência e de caracterização de materiais foram efetuados segundo a Associação Brasileira de Normas Técnicas (ABNT). Os ensaios foram realizados no Laboratório Carlos Campos, em Goiânia, e no Laboratório de Estruturas da EESC.

Os ensaios e os procedimentos obedeceram as normas da ABNT: abatimento do tronco de cone, NBR NM67 (1998); moldagem e cura de corpos-de-prova cilíndricos, NBR 5738 (2003); ensaios de compressão, NBR 5739 (2007); resistência à tração por compressão diametral, NBR 7222 (1994) e resistência à tração na flexão em corpos-de-prova prismáticos, NBR 12142 (1991).

O módulo de elasticidade estático secante do concreto $\left(E_{c}\right)$ foi determinado para uma tensão equivalente a $40 \%$ da tensão de ruptura do concreto, segundo a NBR 8522 (2003).

Utilizaram-se, em média, três corpos-de-prova cilíndricos, com 15cm de diâmetro por $30 \mathrm{~cm}$ de altura, para a determinação das resistências à compressão e à tração por compressão diametral e do módulo de elasticidade do concreto, nas idades de 7, 14, 21, 28 dias e no dia do ensaio. Os modelos foram ensaiados a partir do décimo quarto dia de idade, desde que se atingisse um valor de resistência próximo ao especificado.

Para a determinação da resistência do concreto à tração na flexão $\left(f_{c t, f}\right)$ foram utilizados dois corpos-de-prova prismáticos de $45 \mathrm{~cm} \times 15 \mathrm{~cm} \times 15 \mathrm{~cm}$, rompidos nas idades de 14 e 28 dias e no dia do ensaio. Os corpos-de-prova receberam carregamento aplicado perpendicularmente às suas faces superior e inferior, no terço médio do vão, sem excentricidade, conforme o método de ensaio da NBR 12142 (1991).

\section{B. Aço}

As barras em aço utilizadas na confecção dos dispositivos lineares eram do tipo ASTM A36 (1997), e os dispositivos em chapa foram usinados em aço do tipo USISAC 41. Ambos materiais metálicos foram ensaiados à tração até a ruptura, 
segundo o Anexo C da NBR 6892 (2002), com o propósito de se determinarem algumas propriedades mecânicas.

\subsubsection{Confecção dos modelos e dos corpos-de-prova}

A. Placa de concreto

Precedendo à concretagem dos modelos, foram confeccionadas oito fôrmas metálicas desmontáveis e reutilizáveis, apresentadas na Figura 4.4a, com dimensões internas de $220 \mathrm{~cm}$ x $60 \mathrm{~cm}$.

Barras roscadas rígidas em zincado branco, com diâmetro 12,5mm, foram cortadas para a confecção dos parafusos laterais ou de suspensão. Esses parafusos tinham comprimento total de $20 \mathrm{~cm}$ e foram posicionados a $h / 2$ da espessura do modelo, como apresentado na Figura 4.4b.

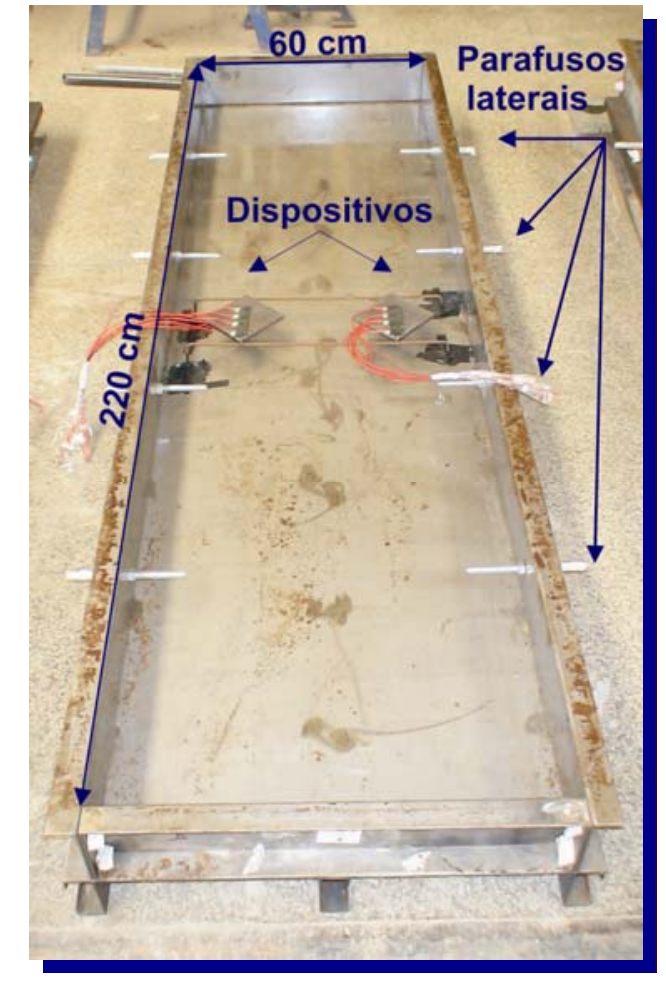

(a)

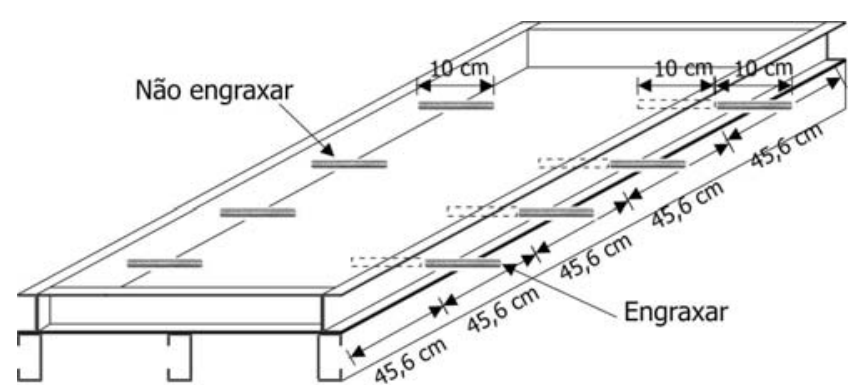

(b)

Figura 4.4 - Fôrmas metálicas: (a) dimensões internas; (b) parafusos de suspensão

Parafusos sextavados foram utilizados para o fechamento de todo o perímetro da fôrma e contaram com porcas borboletas. Este recurso permitiu a desmontagem da 
fôrma para ensaios posteriores. Os parafusos foram distribuídos a cada $38 \mathrm{~cm}$, ao longo das laterais, e a cada $20 \mathrm{~cm}$ na menor dimensão das fôrmas.

Para a execução das juntas moldadas, divisórias metálicas, apresentadas na Figura 4.5, foram confeccionadas com cantoneiras em L. Cada divisória tem comprimento total de $60 \mathrm{~cm}$ e alça para içamento em aço CA-50. A Figura 4.6 fornece o detalhamento das divisórias.

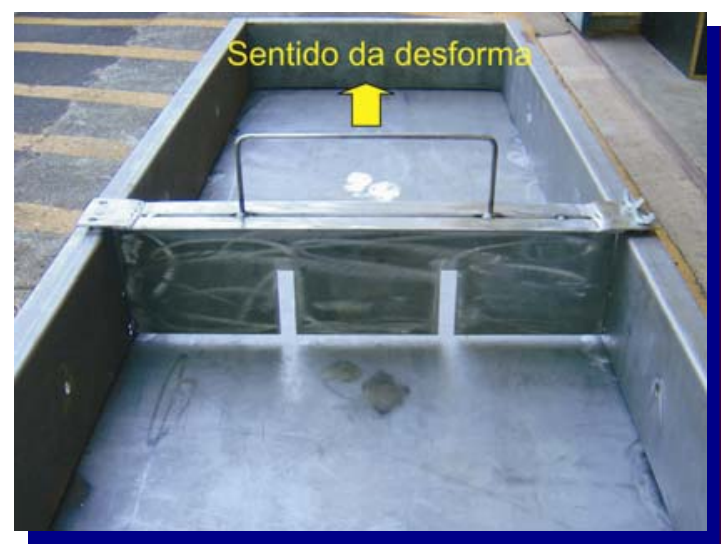

(a)

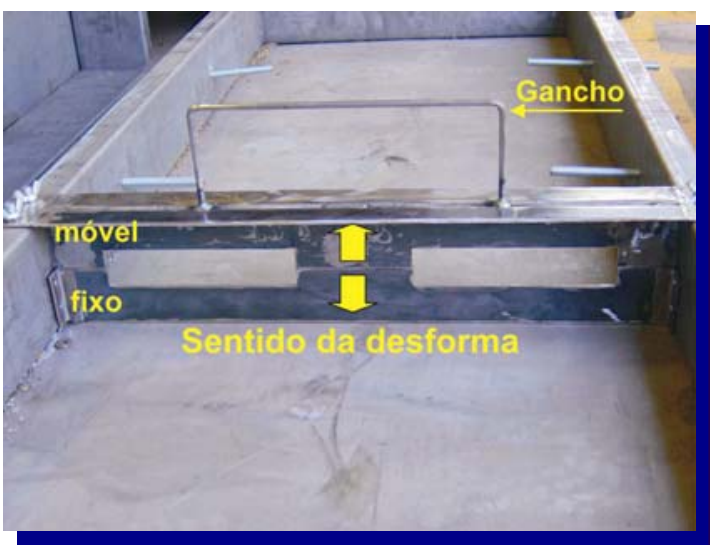

(b)

Figura 4.5 - Divisória para construção de junta moldada com dispositivo em: (a) barra; (b) chapa 


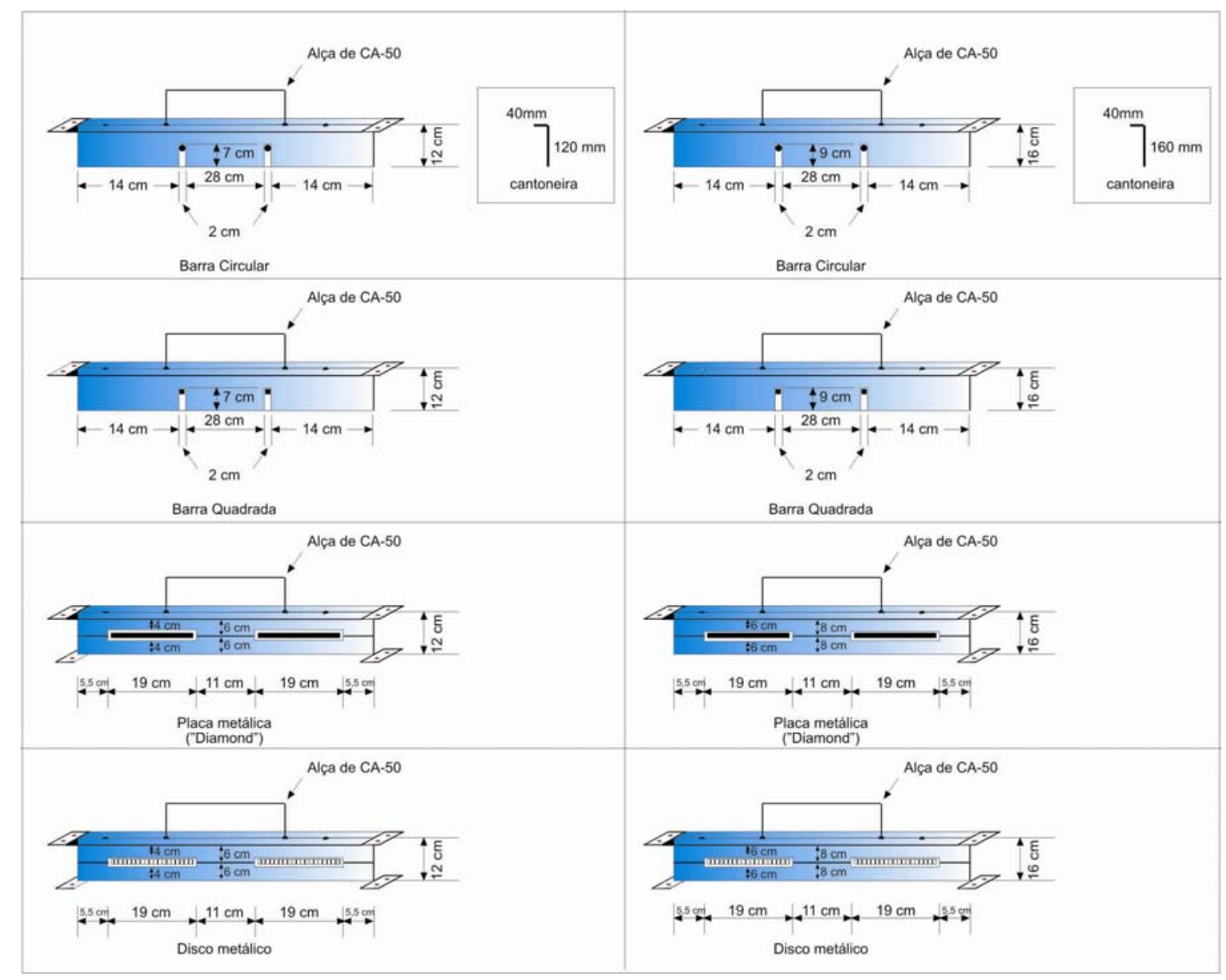

Figura 4.6 - Detalhe das divisórias utilizadas na confecção de junta moldada

Tanto a parte externa dos parafusos de suspensão e suas porcas sextavadas como o interior das fôrmas e as divisórias receberam uma demão de óleo mineral, para facilitar a desmoldagem.

O concreto, ao ser depositado nas fôrmas metálicas, foi adensado mecanicamente por vibrador de imersão, com mangote flexível e agulha cilíndrica. Na Figura 4.7a, visualiza-se o momento da concretagem, com o lançamento do material em ambos os lados do modelo com junta moldada. Na Figura 4.7b, pode-se observar, em detalhe, os filetes de madeira, com $6 \mathrm{~mm}$ de espessura, posicionados para aumentar a estanqueidade da fôrma e garantir a abertura da junta. É possivel também visualizar os espaçadores metálicos, que posicionaram os dispositivos a $h / 2$ da face inferior da fôrma metálica, e o espaçamento dos dispositivos de $30 \mathrm{~cm}$. 


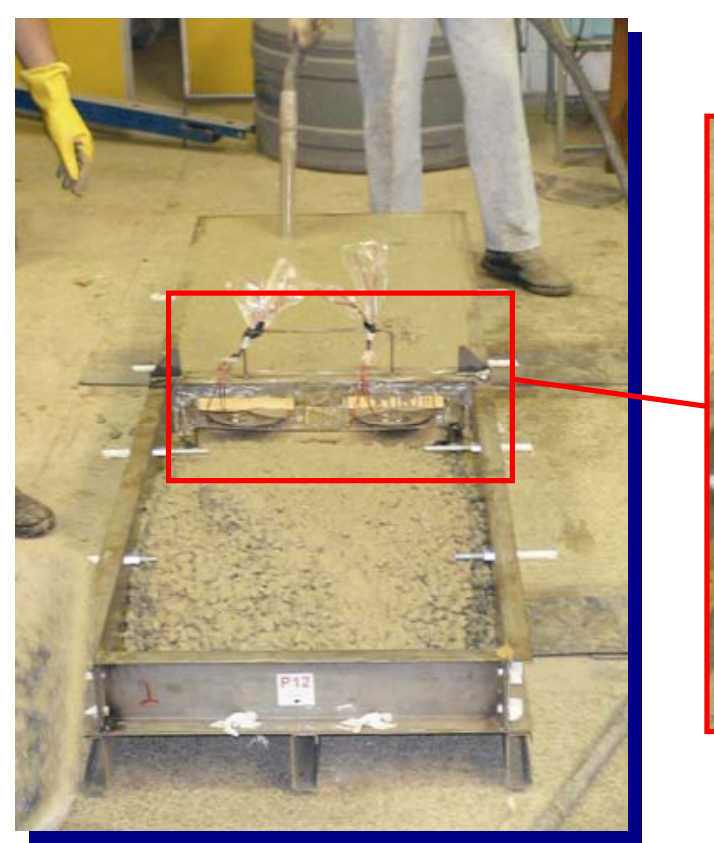

(a)

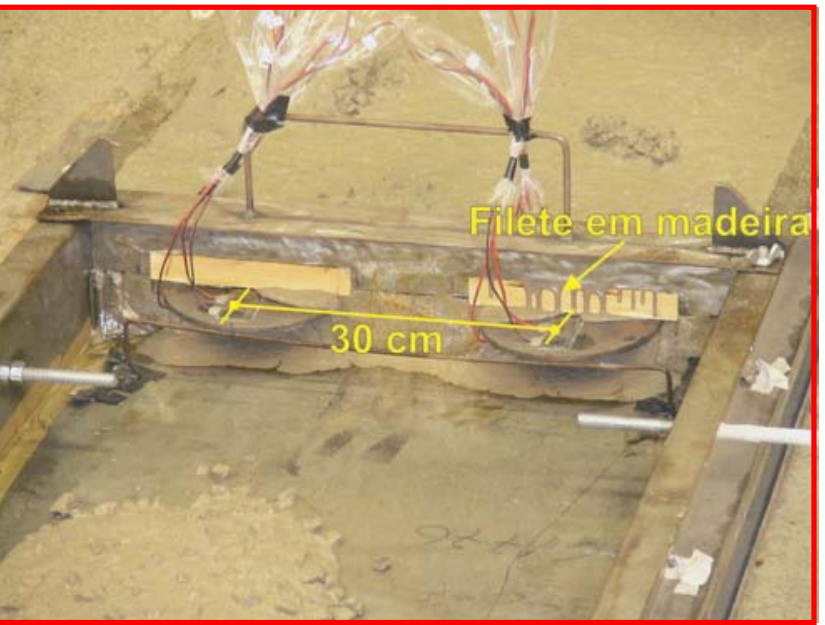

(b)

Figura 4.7 - Confecção das placas de concreto: (a) concretagem; (b) detalhe da divisória e espaçador metálico

As etapas para o acabamento das placas foram constituídas de: nivelamento e regularização da superfície, por meio de régua metálica plana; desempeno com prancha de metal; e alisamento com colher de pedreiro e brocha umedecida com água limpa. A Figura 4.8 apresenta o aspecto final, após a concretagem, para os modelos com juntas serradas e moldadas, respectivamente.

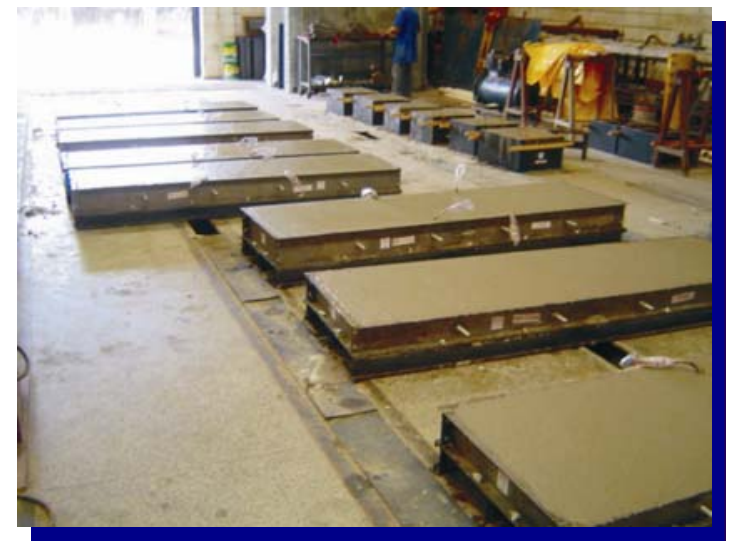

(a)

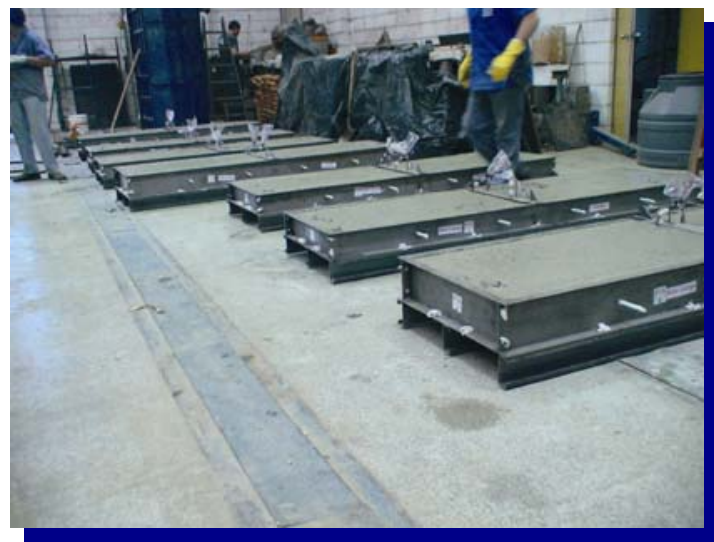

(b)

Figura 4.8 - Aspecto dos modelos após a concretagem: (a) junta serrada; (b) junta moldada

Todas as placas receberam cura úmida, por pelo menos três dias, a partir das primeiras quatro horas após a concretagem. Antecedendo aos ensaios, foi 
proporcionada uma secagem ao ar livre da superfície das placas, evitando assim o acúmulo de umidade nas regiões instrumentadas por extensômetros elétricos colados na face superior do concreto. Ao atingir uma resistência suficiente para a desforma, depois de no mínimo três dias, foram feitas as desmoldagens das fôrmas metálicas.

\section{B. Corpos-de-prova para cisalhamento duplo}

Para se determinar a resistência do sistema placa-junta por meio da associação entre o concreto e o dispositivo de transferência metálico, sem contudo levar em conta a resistência da fundação do pavimento, foram realizados ensaios de cisalhamento duplo. Foram moldados oito corpos-de-prova prismáticos, sem fissura pré-existente, como mostrados na Figura 4.9, na mesma concretagem em que foram feitos os modelos em placa com junta serrada para ensaio com carregamento estático. Estes corpos-de-prova não foram confeccionados para o ensaio preliminar.

Cada corpo-de-prova continha um dispositivo de transfêrencia em seu interior, para os quatro tipos estudados (barra circular, barra quadrada, placa metálica e disco metálico) e para as duas espessuras fixadas $(12 \mathrm{~cm}$ e $16 \mathrm{~cm})$.

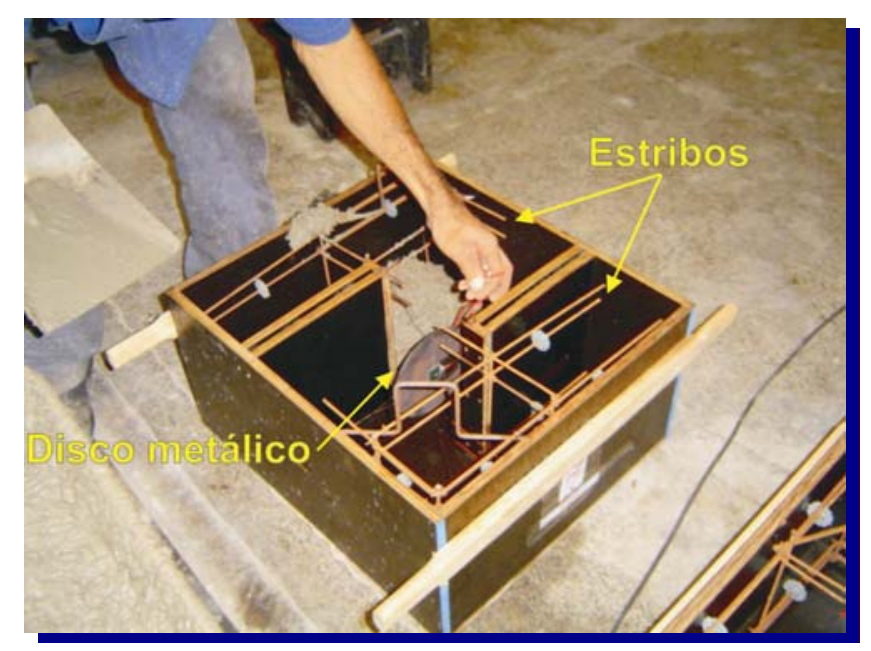

Figura 4.9 - Concretagem de corpo-de-prova para ensaio de cisalhamento duplo

As fôrmas em madeira para a moldagem dos corpos-de-prova prismáticos, Figura $4.10 \mathrm{a}$ e $4.10 \mathrm{~d}$, tinham medidas internas de $30 \mathrm{~cm} \times 50 \mathrm{~cm}$, respectivamente altura e largura. O comprimento da fôrma foi variável entre $44 \mathrm{~cm}$ e $56 \mathrm{~cm}$, segundo as espessuras das placas de concreto. Ganchos foram colocados em duas extremidades dos corpos-de-prova, para seu levantamento e transporte antes e após os ensaios. 
Os estribos utilizados serviram como armadura de montagem, do corpo-de-prova, como apresentado nas Figura 4.10b, 4.10c, 4.10e, 4.10f, e foram posicionados para levar os corpos-de-prova à ruptura ao longo do Plano Cortante. Foram confeccionados com barras de aço CA-50 e diâmetro nominal de 5mm. A Figura 4.11 apresenta o espaçamento adotado na montagem dos estribos, evitando a sua concentração na região intermediária, onde se encontra o dispositivo metálico.

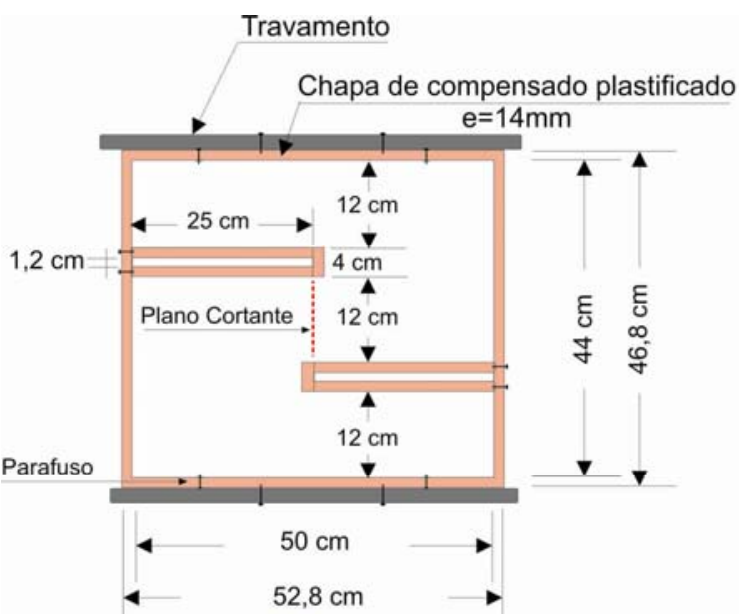

(a)

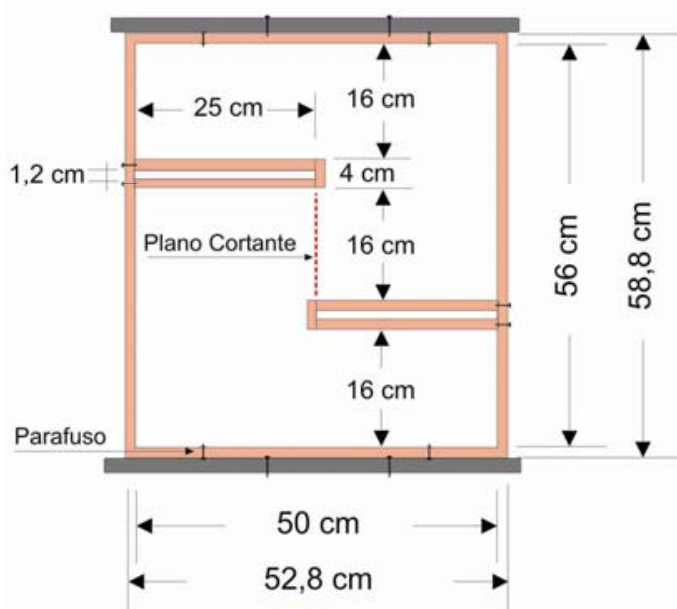

(d)

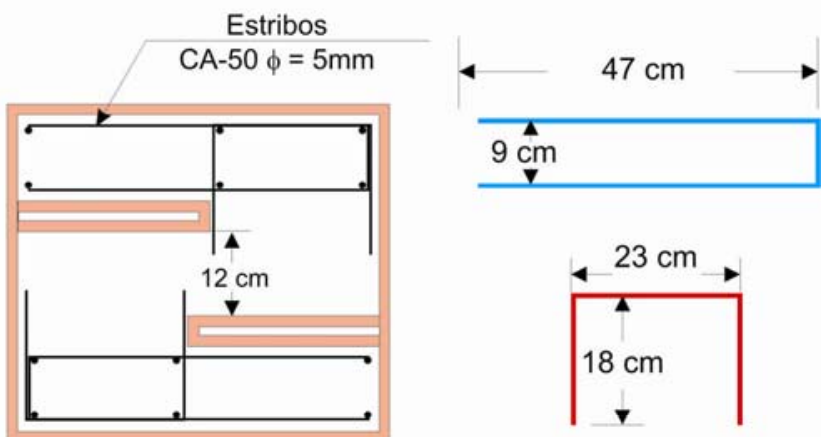

(b)

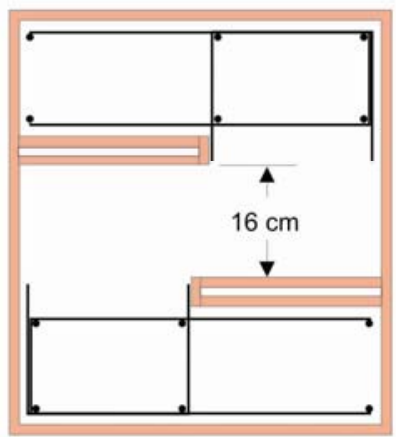

(e)

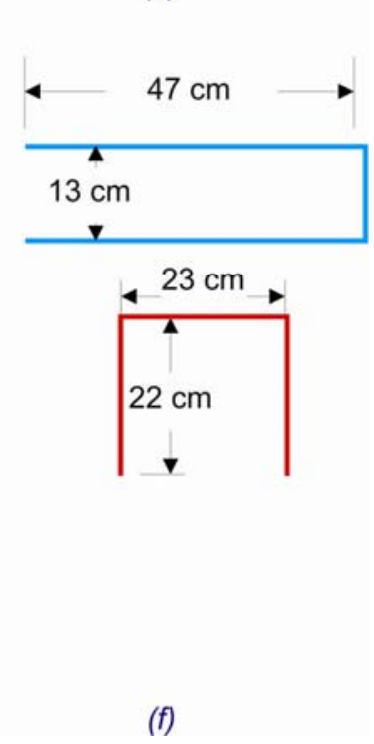

(c)

Figura 4.10 - Detalhamento da armadura e da fôrma em madeira para ensaio de cisalhamento duplo 


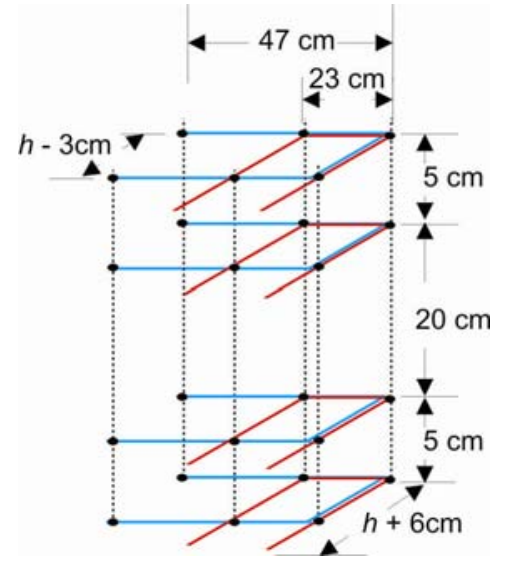

Figura 4.11 - Armadura de montagem dos estribos para ensaio de cisalhamento duplo

\subsubsection{Montagem dos ensaios}

A. Placa de concreto

Antecedendo aos ensaios estáticos e cíclicos, os modelos foram posicionados sobre uma base elástica, que fornecia um apoio uniforme e constante. Essa base foi previamente montada com 14 lençóis de borracha natural, como apresentado na Figura 4.13, com cerca de $1 \mathrm{~cm}$ de espessura cada. Alguns lençóis de borracha foram substituídos ao longo dos ensaios, para garantir uma maior uniformidade do coeficiente de recalque.

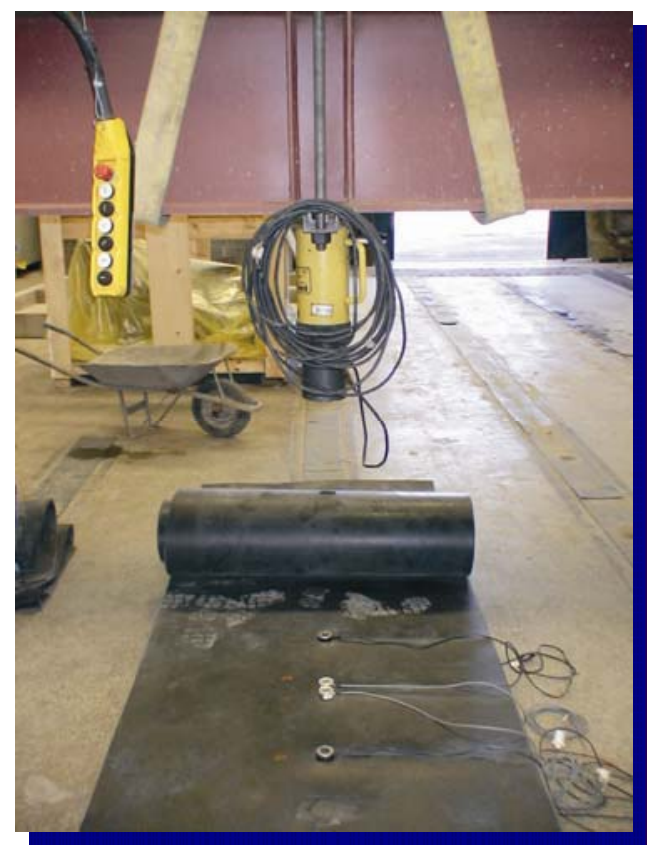

Figura 4.12 - Desenrolamento e posicionamento dos lençóis de borracha 
Os lençóis de borracha foram cobertos por lona plástica de $130 \mu \mathrm{m}$ de espessura, utilizada como material intermediário e deslizante entre a base elástica e as placas de concreto, Figura 4.13a. Uma fina camada de argamassa foi aplicada para assentamento dos modelos e regularização da superfície, conforme apresentado na Figura 4.13b.

Antes da retirada das fôrmas, os modelos foram cortados com serra de disco diamantado ou desmoldados na junta de construção. As Figura 4.14a e 4.14b apresentam respectivamente a desforma do modelo e seu içamento, através dos parafusos de suspenção, para posicionamento sobre a argamassa ainda em estado fresco.

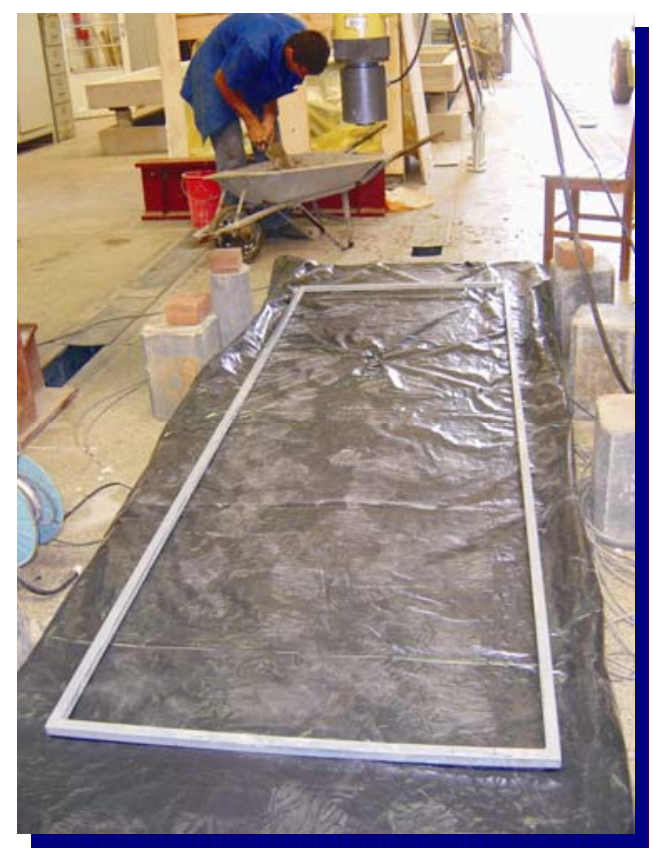

(a)

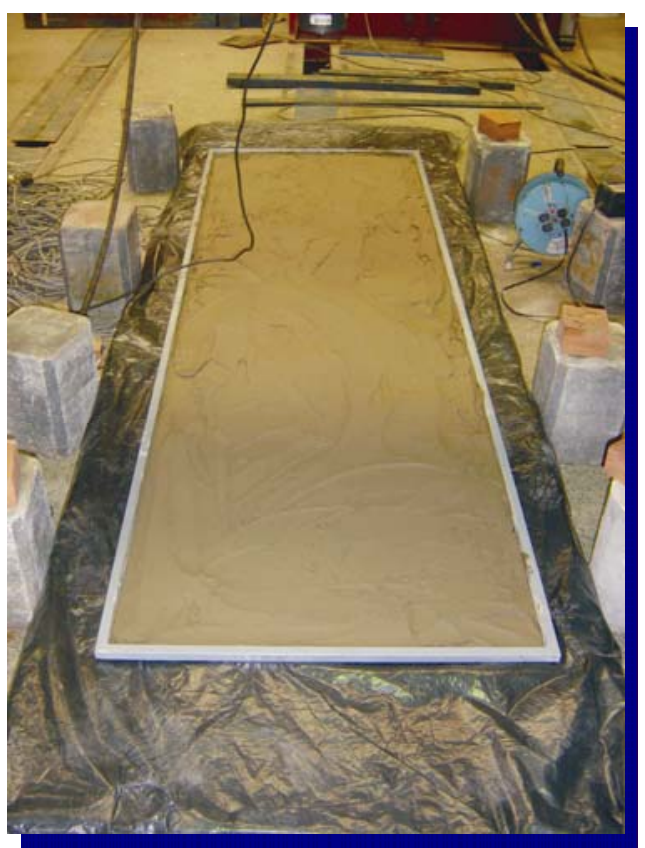

(b)

Figura 4.13 - Procedimento de montagem dos ensaios: (a) colocação de lona plástica; (b) aplicação de argamassa 


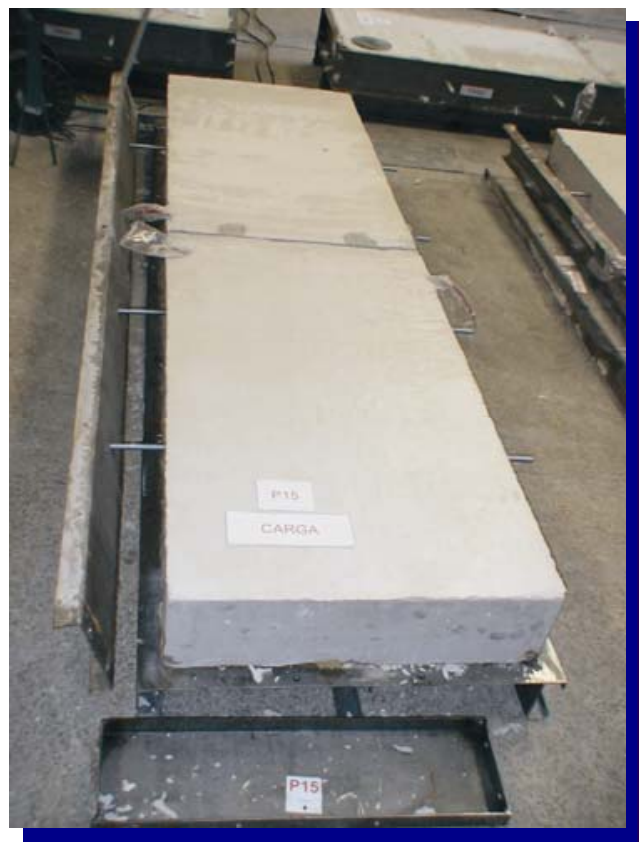

(a)

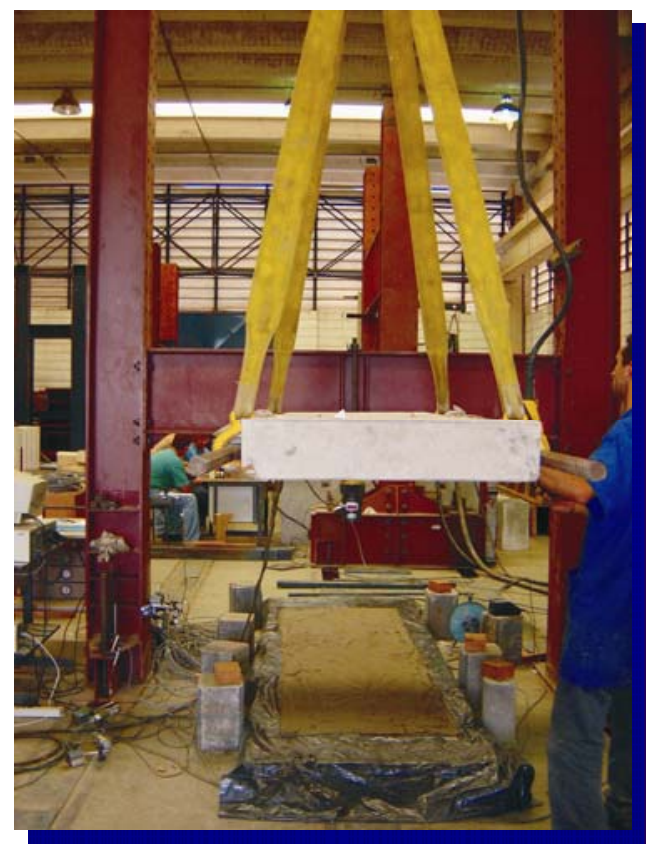

(b)

Figura 4.14 - Procedimento de montagem dos ensaios: (a) desfôrma do modelo; (b) içamento e posicionamento do modelo no canteiro de ensaio

\section{B. Corpos-de-prova para cisalhamento duplo}

Após 28 dias de idade, os corpos-de-prova utilizados na determinação da tensão de cisalhamento foram desformados, como apresentado na Figura 4.15.

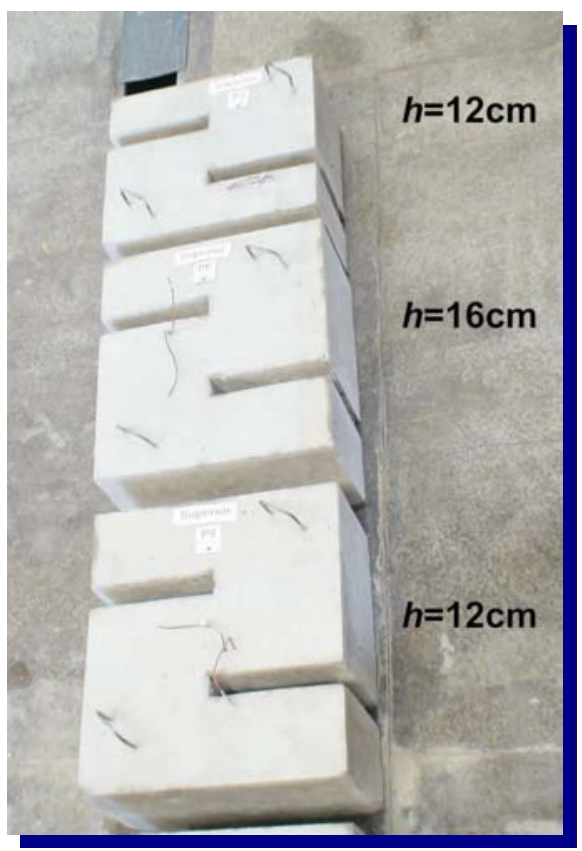

Figura 4.15 - Desfôrma de corpos-de-prova para cisalhamento duplo 


\subsubsection{Sistema de ensaio}

As forças de ruína dos modelos foram obtidas mediante leitura instrumental das células de carga. O instante da ruína foi verificado quando a força solicitante atingia a resistência do modelo sem dispositivo e, em seguida, ocorria uma diminuição da força. Nos modelos com dispositivo de transferência, o critério de interrupção considerava o escoamento ou a ocorrência de fechamento da junta

As forças foram aplicadas nas peças de concreto por meio de atuador hidráulico, e as leituras, feitas por sistema de aquisição de dados. O atuador hidráulico estava preso a uma viga metálica de reação, atirantada nos apoios, conforme apresentado na Figura 4.16. As forças eram transmitidas às placas de concreto por meio de viga metálica de distribuição, posicionada sobre um dos lados da junta. As placas de concreto estavam apoiadas na base elástica, que, por sua vez, estava em contato direto com a laje de reação. Detalhes dos sistemas de reação podem ser visualizados na Tabela 4.4.

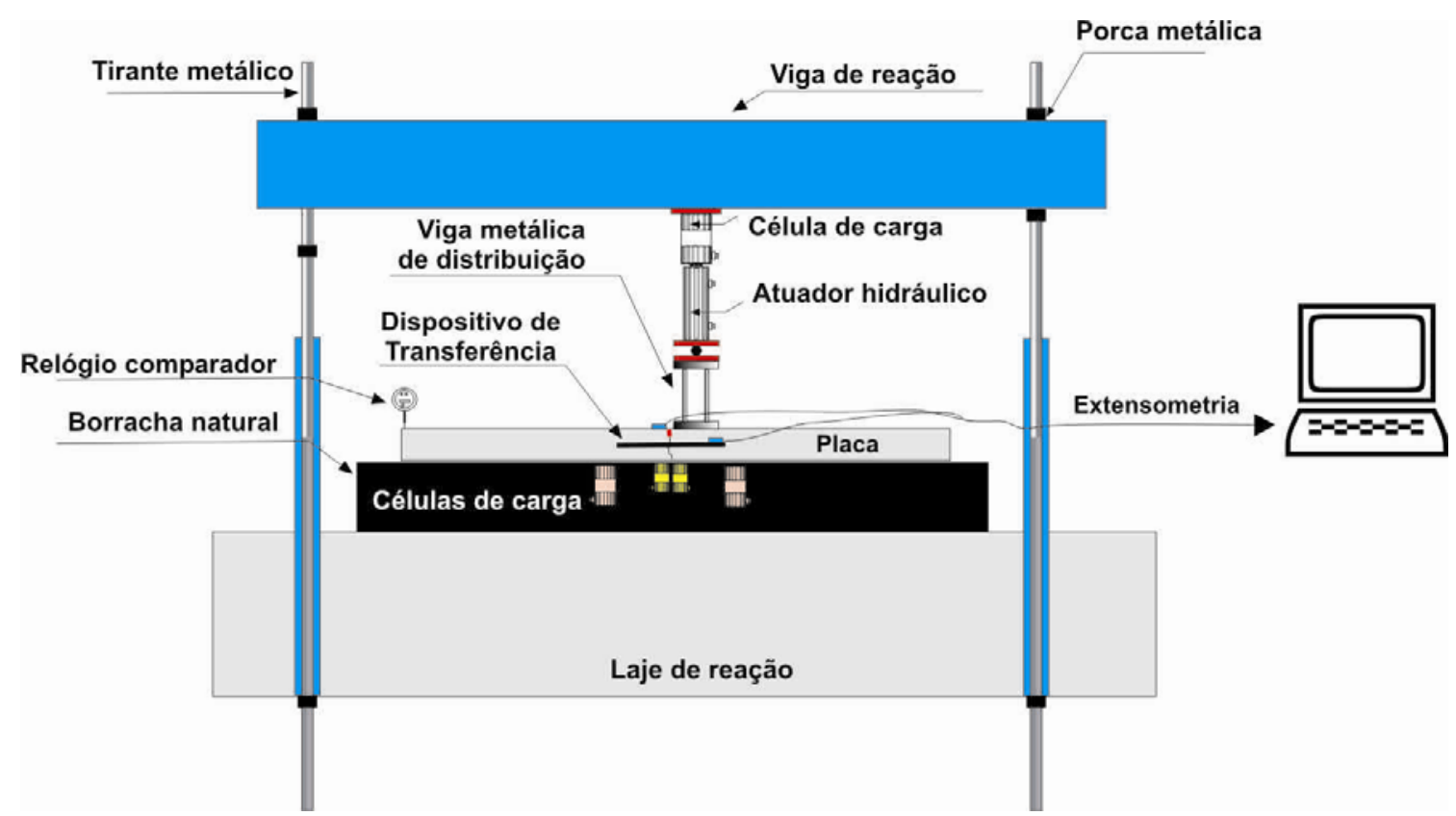

Figura 4.16 - Sistema de ensaio para carregamento estático e cíclico 
Tabela 4.4 - Detalhes dos sistemas de reação

\begin{tabular}{|c|c|c|}
\hline $\begin{array}{l}\text { Aparelhagem de } \\
\text { reação }\end{array}$ & Laboratório USP & Laboratório UFG \\
\hline Viga & Comprimento $=220 \mathrm{~cm}$ & Comprimento $=250 \mathrm{~cm}$ \\
\hline Coluna & $\begin{array}{l}\text { Colunas de } 441 \mathrm{~cm} \text { de altura e seção } \\
\text { transversal de } 25 \mathrm{~cm} \times 30 \mathrm{~cm}\end{array}$ & $\begin{array}{c}\text { Tirantes metálicos de } 300 \mathrm{~cm} \text { de altura } \\
\text { e } 4,5 \mathrm{~cm} \text { de diâmetro }\end{array}$ \\
\hline
\end{tabular}

A região de distribuição da carga aplicada na placa de concreto corresponde à área de contato do pneu de um veículo automotor sobre a superfície do pavimento, e foi adotada correspondente com $17 \mathrm{~cm}$ x $60 \mathrm{~cm}$. As dimensões da viga metálica de distribuição são apresentadas na Figura 4.17.

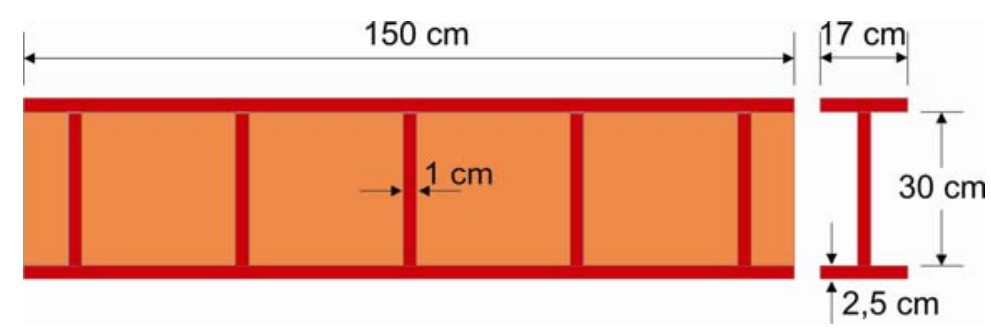

Figura 4.17 - Viga metálica de distribuição de força

No ensaio de cisalhamento duplo, realizado na Máquina Universal de Ensaios ServoHidráulica do Laboratório de Estruturas da EESC-USP, era aplicada uma força axial de compressão na região central dos corpos-de-prova, como apresentado na Figura 4.18a. Os modelos deveriam romper apenas por cisalhamento ao longo do plano paralelo à direção da força aplicada, em detalhe na Figura 4.18b. Chapas em aço de $30 \mathrm{~cm} \times 17 \mathrm{~cm}$, respectivamente comprimento e largura, e espessura de $3 \mathrm{~mm}$, foram posicionadas sobre o eixo do plano de corte. 


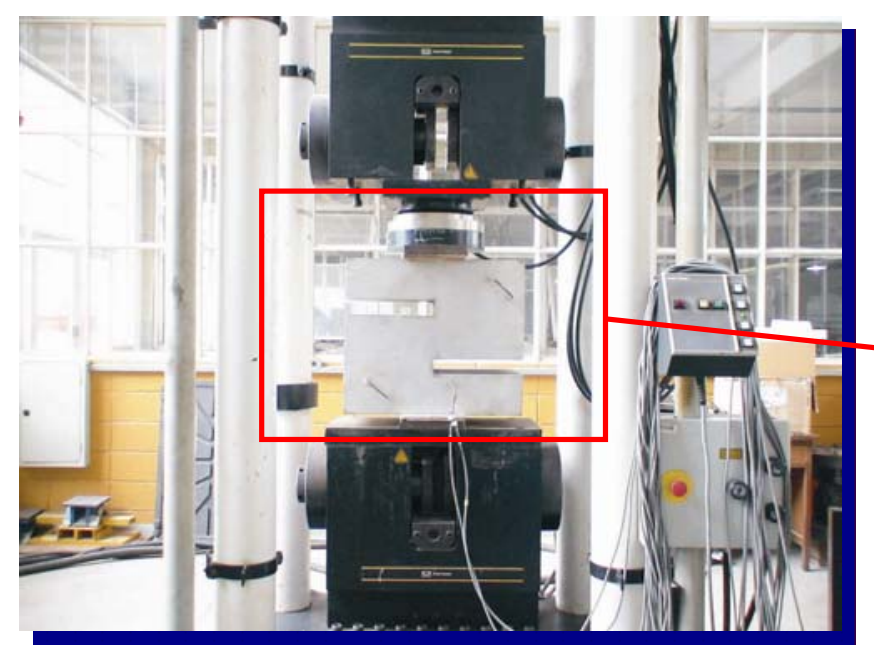

(a)

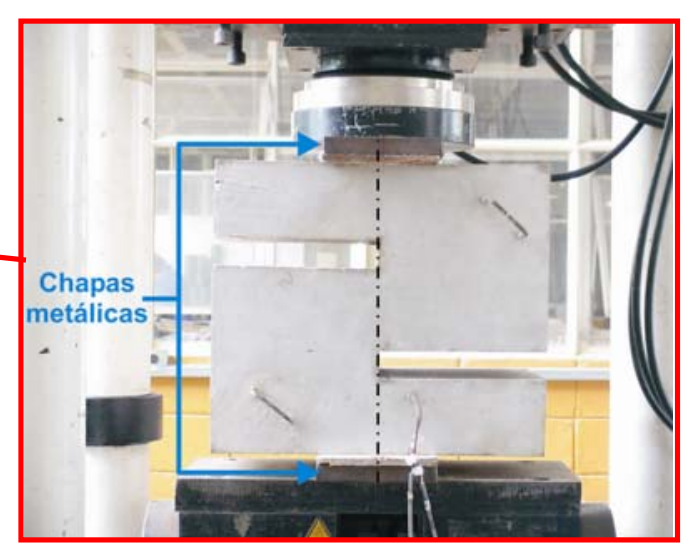

(b)

Figura 4.18 - Sistema de ensaio para cisalhamento duplo, no Laboratório de Estruturas da EESCUSP

\subsubsection{Instrumentação}

As leituras do carregamento aplicado pelo atuador hidráulico, dos deslocamentos verticais e das deformações, tanto da face superior do concreto como dos dispositivos metálicos, foram efetuadas simultaneamente, durante o processo de aplicação das forças. A instrumentação empregada nos ensaios contou com a utilização de: transdutores e relógios comparadores para a determinação dos deslocamentos verticais das faces da junta, do interior e das bordas das placas; extensômetros elétricos de resistência para a medição das deformações específicas no aço e no concreto; e células de carga, com indicador digital ou acopladas a um sistema de aquisição de dados.

No ensaio estático preliminar foi utilizado um sistema para aquisição de dados conectado a um microcomputador, formado por uma caixa de aquisição de dados com 16 canais, interligada a um terminal da National Instruments, modelo SCXI1001. O programa gráfico utilizado para a aquisição de dados foi o LabView versão 6.0, desenvolvido também pela National Instruments.

O sitema de aquisição utilizado nos ensaios estáticos, realizados no Laboratório de Estruturas da EESC-USP, foi o System 5000 da Vishay Measurements Group, modelos 5100, 5100A e 5100B, com 20 canais cada scanner. Para os ensaios cíclicos, foi utilizado o System 6000 da Vishay Measurements Group, com dois 
scanners modelo 6100 e um total de 26 canais de leitura dos dados. Ambos sistemas são habilitados à entrada de sensores como células de carga, transdutores de deslocamentos e extensômetros elétricos. O programa utilizado para a leitura de dados foi o StrainSmart, em versão Windows, também da Vishay Measurements Group. Este programa é capaz de ler dados, reduzi-los a formatos como "txt", apresentá-los no monitor e armazená-los.

As cargas submetidas às placas de concreto foram aplicadas de maneira gradual e crescente, até a ruína da peça. Para o ensaio estático preliminar, realizado no Laboratório de Estruturas da UFG, utilizou-se cilíndro hidráulico da marca Yellow Power, com capacidade de $300 \mathrm{kN}$, acionado por bomba hidráulica manual. Nos ensaios estáticos, realizados no Laboratório de Estruturas da EESC-USP foi empregado cilindro hidráulico da marca Enerpac, com capacidade para $500 \mathrm{kN}$, acionado por bomba hidráulica manual. Nos ensaios cíclicos (EESC-USP), foi utilizado atuador servo-hidráulico da marca Instron, com capacidade para 500kN e pistão de 150mm, assistido por bomba hidráulica de alta vazão e controlado por computador.

Para o ensaio de cisalhamento duplo, realizado no Laboratório de Estruturas da EESC-USP, foi utilizada a Máquina Universal Servo-Hidráulica da marca Instron. Este sistema é controlado digitalmente por computador, possui capacidade para $2500 \mathrm{kN}$ e espaço para ensaio de $400 \mathrm{~cm} \times 82,2 \mathrm{~cm} \times 51,4 \mathrm{~cm}$, respectivamente altura, comprimento e largura.

\section{A. Força aplicada}

A Figura 4.19 apresenta esquematicamente as posições das células de carga, em relação ao posicionamento do modelo. Para o ensaio preliminar, foi utilizada célula de carga tipo coluna (CEL5) da marca Kratos, com precisão de leitura, obtida pelo sistema eletrônico de aquisição de dados, da ordem de 0,01 kN e capacidade de $500 \mathrm{kN}$. De forma a medir as forças exercidas pela placa de concreto sobre a superfície da camada de borracha, foram instaladas inicialmente duas células de carga (CEL2 e CEL3), faceando a junta. Estas células de carga da marca Kratos apresentavam capacidade de $500 \mathrm{kN}$ e sistemas manuais, dotados de indicador eletrônico da mesma marca, acoplados a essas células de carga. 
Nas etapas posteriores, realizadas na EESC-USP, foram acrescentadas outras duas células de carga (CEL1 e CEL4), posicionadas junto às extremidades da barra circular, conforme visualizado na Figura 4.19b. As células CEL2 e CEL3 apresentam capacidade de $60 \mathrm{kN}$, diâmetro externo de $3 \mathrm{~cm}$, altura de $2 \mathrm{~cm}$ e são da marca Micro Sensores Industrial. As células CEL1 e CEL4 apresentam capacidade de 100kN, diâmetro externo de $4 \mathrm{~cm}$, altura de $10 \mathrm{~cm}$ e foram fabricadas no Laboratório de Estruturas da EESC-USP. A CEL5, para os ensaios estáticos e cíclicos era da marca Instron, acoplada ao atuador servo-hidráulico e com capacidade para 500kN.

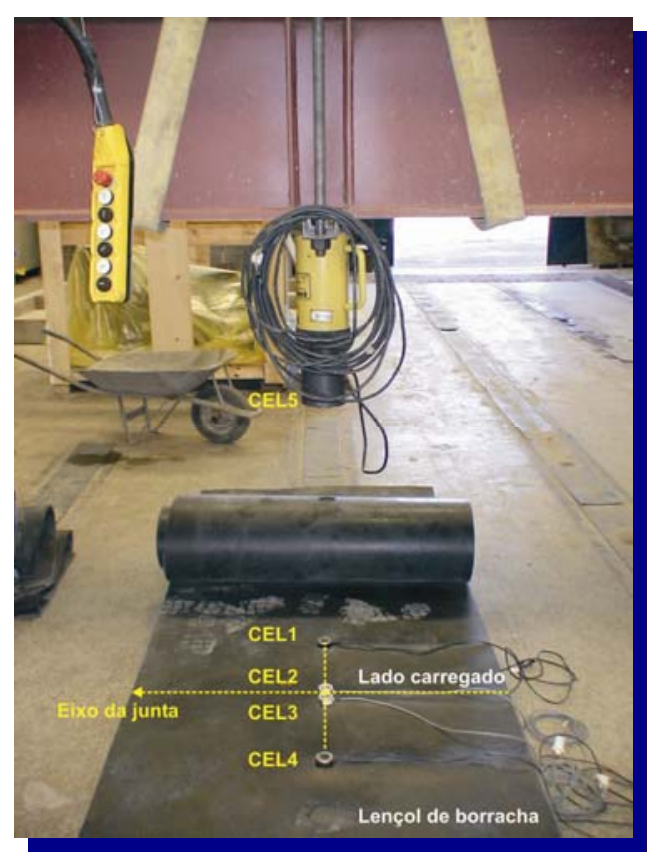

(a)

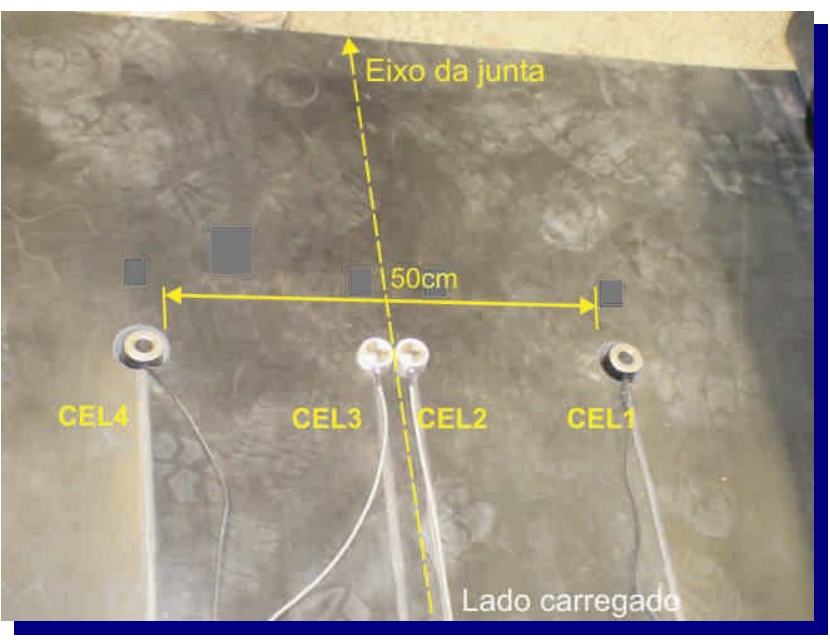

(b)

Figura 4.19 - Posicionamento das células de carga no interior dos lençóis de borracha: (a) vista longitudinal; (b) vista transversal

Nos ensaios cíclicos foi aplicado um pré-carregamento monotônico até a força de $12 \mathrm{kN}$ correspondente à carga de serviço, a uma velocidade de $\mathrm{v}=0,02 \mathrm{~mm} / \mathrm{s}$. Foi empregada a leitura de um dado por segundo, e em seguida descarregado.

Em seguida houve novo carregamento estático até 6,5kN, com emprego posterior de ciclos de carregamento em onda senoidal, com oscilação de $\pm 5,5 \mathrm{kN}$. Foram realizadas leituras de 500 dados por segundo, em 26 pontos instrumentados, conforme apresentado no Capítulo 6. 
A freqüência do carregamento foi de $6 \mathrm{~Hz}$, força máxima $\left(F_{\text {máx }}\right)$ de $12 \mathrm{kN}$ e força mínima $\left(F_{\min }\right)$ de $1,2 \mathrm{kN}$. A $F_{\mathrm{m} i ́ n}$ mantém um força mínima de compressão no modelo, necessária para se evitar tanto a perda de contato entre a placa e a fundação como solavancos no apoio rotulado e viga de distribuição. Posteriormente a força mínima sofreu pequena variação até atingir cerca de $2 \mathrm{kN}$, uma vez que o baixo carregamento de 1,2kN provocava movimentação dos apoios rotulados. Foram feitas leituras até 300.000 ciclos de carregamento, com exceção de JS16BCC, uma vez que houve término do expediente do laboratório.

Após o término dos ciclos de carregamento os modelos foram descarregados, e recarregados monotonicamente até a ruptura.

\section{B. Medidores de deslocamento}

Os deslocamentos foram medidos, em geral, ao longo do eixo central em $x$ e nas faces da junta das placas. A Figura 4.20 apresenta a disposição dos medidores de deslocamento nos modelos.

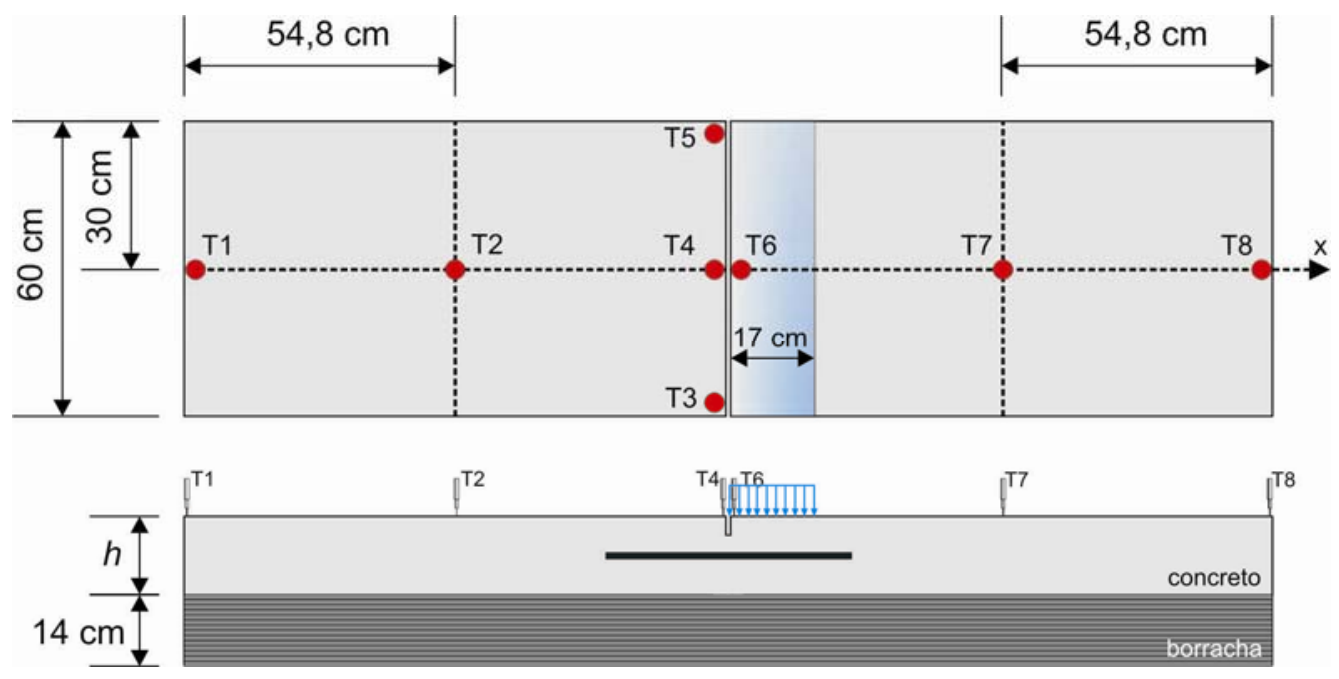

Figura 4.20 - Disposição sobre eixo x dos medidores de deslocamento nos modelos

Para a determinação dos deslocamentos transversais, utilizaram-se, para cada modelo, no mínimo oito medidores de deslocamento, como apresentado na Tabela 4.5. Os medidores de deslocamento foram posicionados na face superior das placas e convenientemente apoiados em suporte metálico. 
Tabela 4.5 - Medidores de deslocamento

\begin{tabular}{|c|c|c|c|}
\hline Medidor de deslocamento & Marca & $\begin{array}{c}\text { Precisão } \\
(\mathrm{mm})\end{array}$ & Laboratório \\
\hline Relógio comparador digital & Mitutoyo & 0,01 & UFG \\
\hline Transdutor de deslocamento & Kyowa & 0,001 & EESC-USP \\
\hline
\end{tabular}

A Figura 4.21 apresenta fotografias ilustrando o esquema de medição dos deslocamentos verticais para todas as placas.

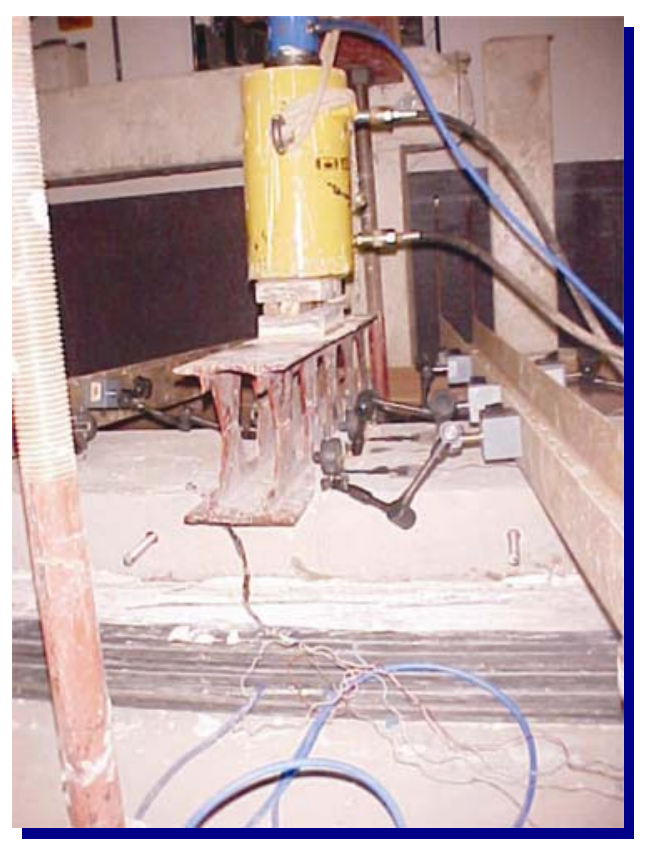

(a)

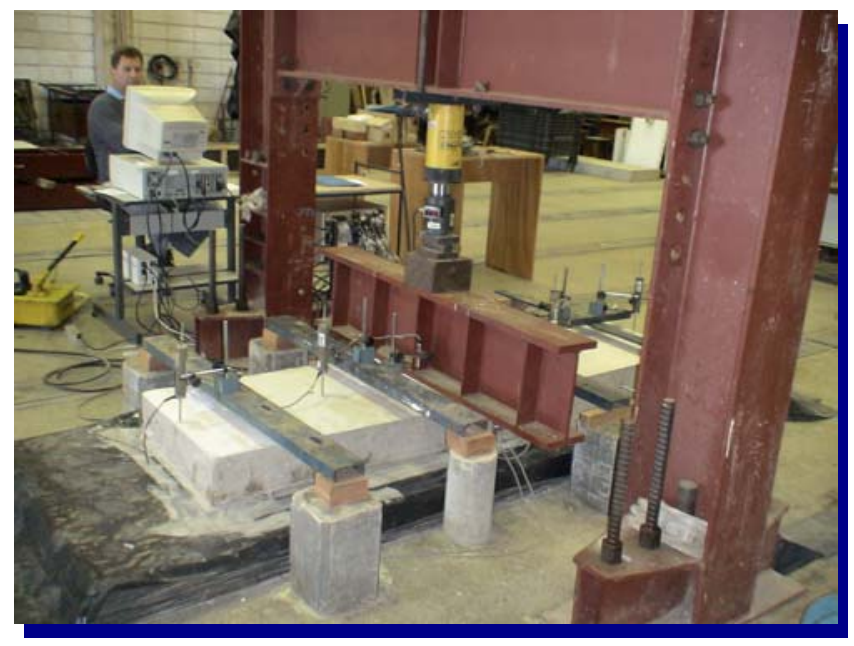

(b)

Figura 4.21 - Detalhe da medição do deslocamento vertical: (a) na vista lateral na junta (Laboratório de Estrutura da UFG); (b) na vista longitudinal (Laboratório de Estruturas da EESC-USP)

Transdutores de deslocamento, com cursos nominais de $20 \mathrm{~mm}$, foram utilizados em ensaios de cisalhamento duplo, mostrados na Figura 4.22, determinando 0 deslocamento sofrido pela região central onde passa o Plano Cortante. 


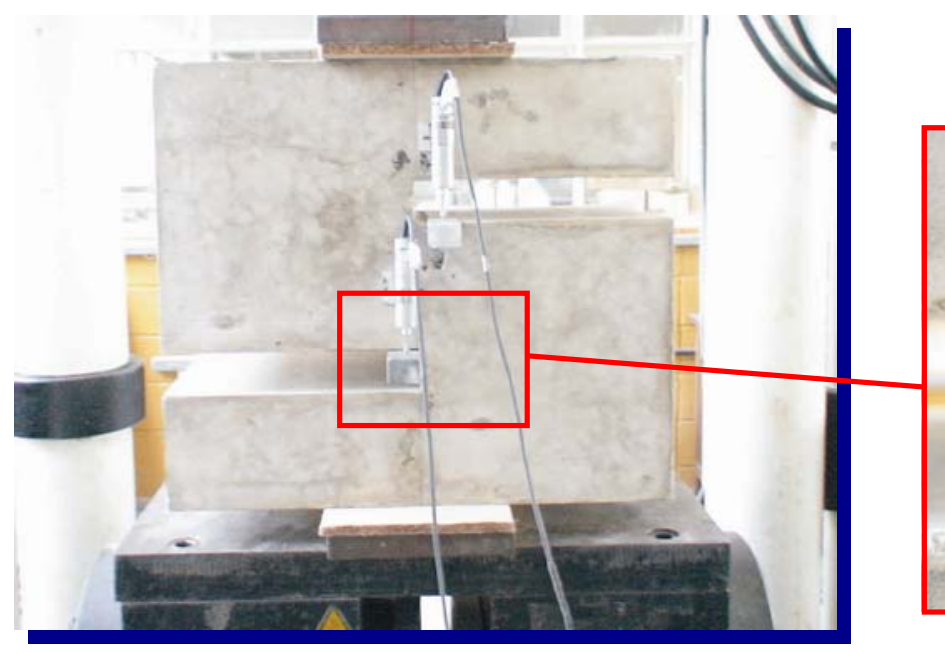

(a)

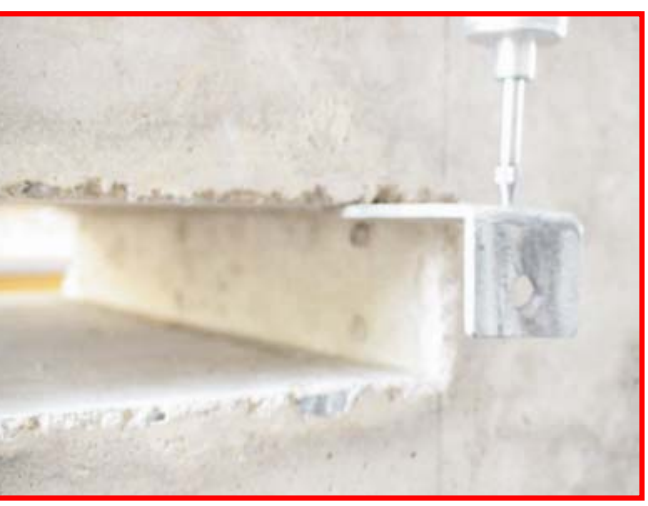

(b)

Figura 4.22 - Transdutor de deslocamento posicionado em ensaio de cisalhamento duplo

\section{Extensômetro elétrico}

As leituras das deformações específicas, tanto da superfície do concreto como das barras de aço, foram determinadas por extensômetros ligados a sistemas eletrônicos de aquisição de dados.

A conexão da instrumentação deu-se pela soldagem dos fios terminais de ligação dos extensômetros a fios condutores, conectando-os posteriormente aos aparelhos de medição, conforme apresentado nas Figura 4.23a e 4.23b.

Extensômetros elétricos do tipo "clip-gage" foram utilizados na determinação do Módulo de Elasticidade do concreto.

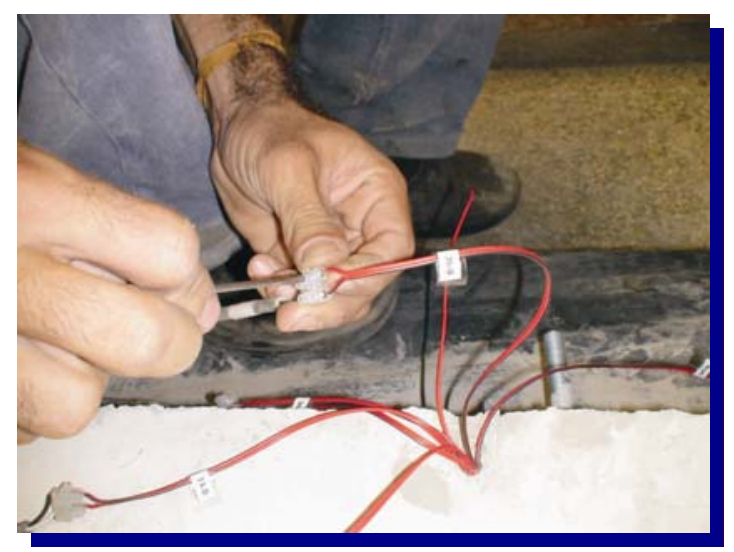

(a)

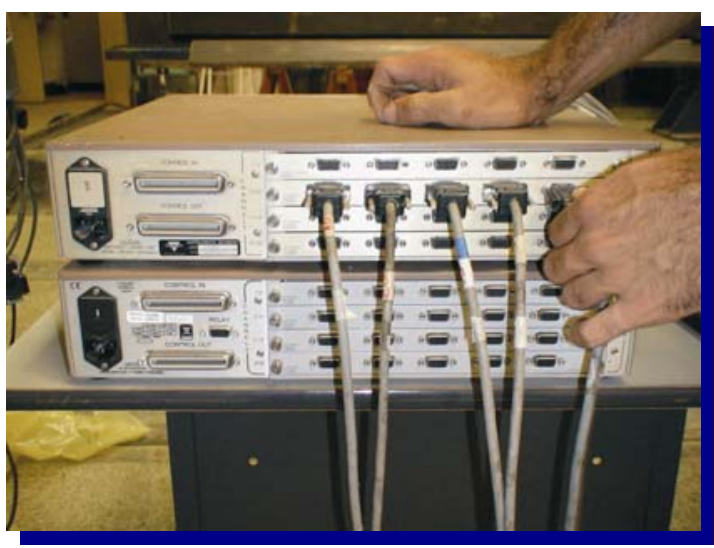

(b)

Figura 4.23 - (a) conexão dos fios condutores (b) conexão dos fios condutores ao aparelho de medição eletrônico. 
Extensômetros elétricos foram fixados nos dispositivos metálicos de transferência de carga, seguindo as recomendações do fabricante. A Tabela 4.6 fornece detalhes de seu posicionamento. Em alguns casos, houve diferenciação na instrumentação das barras do Lado Direito (LD) e do Lado Esquerdo (LE) do modelo, em virtude da simetria de alguns pontos e para evitar maior densidade de extensômetros, em algumas regiões dos dispositivos metálicos.

Extensômetros elétricos da marca Excel, tipo PA-06-125AA-120L, foram fixados nos dispositivos metálicos, para o ensaio preliminar. Para os ensaios posteriores, estáticos e cíclicos, foram utilizados extensômetros elétricos da marca Vishay MicroMeasurements, tipo L2A-06-125LW-120.

$\mathrm{Na}$ superfície de concreto, extensômetros elétricos foram colados, seguindo a orientação dos extensômetros fixados nos dispositivos metálicos, ou seja, na direção $x$. Em alguns modelos, foram adicionados extensômetros na direção y, como apresentado na Tabela 4.6. Foram utilizados extensômetros elétricos da marca Excel, tipo PA-06-250BA-120L, no Laboratório de Estruturas da UFG, e das marcas Vishay Micro-Measurements, tipo L2A-06-125LW-120, e Kyowa, tipo KFG-10-120C1-11 no Laboratório de Estruturas da EESC-USP. 
Tabela 4.6 - Detalhes da extensometria utilizada nos dispositivos de transferência

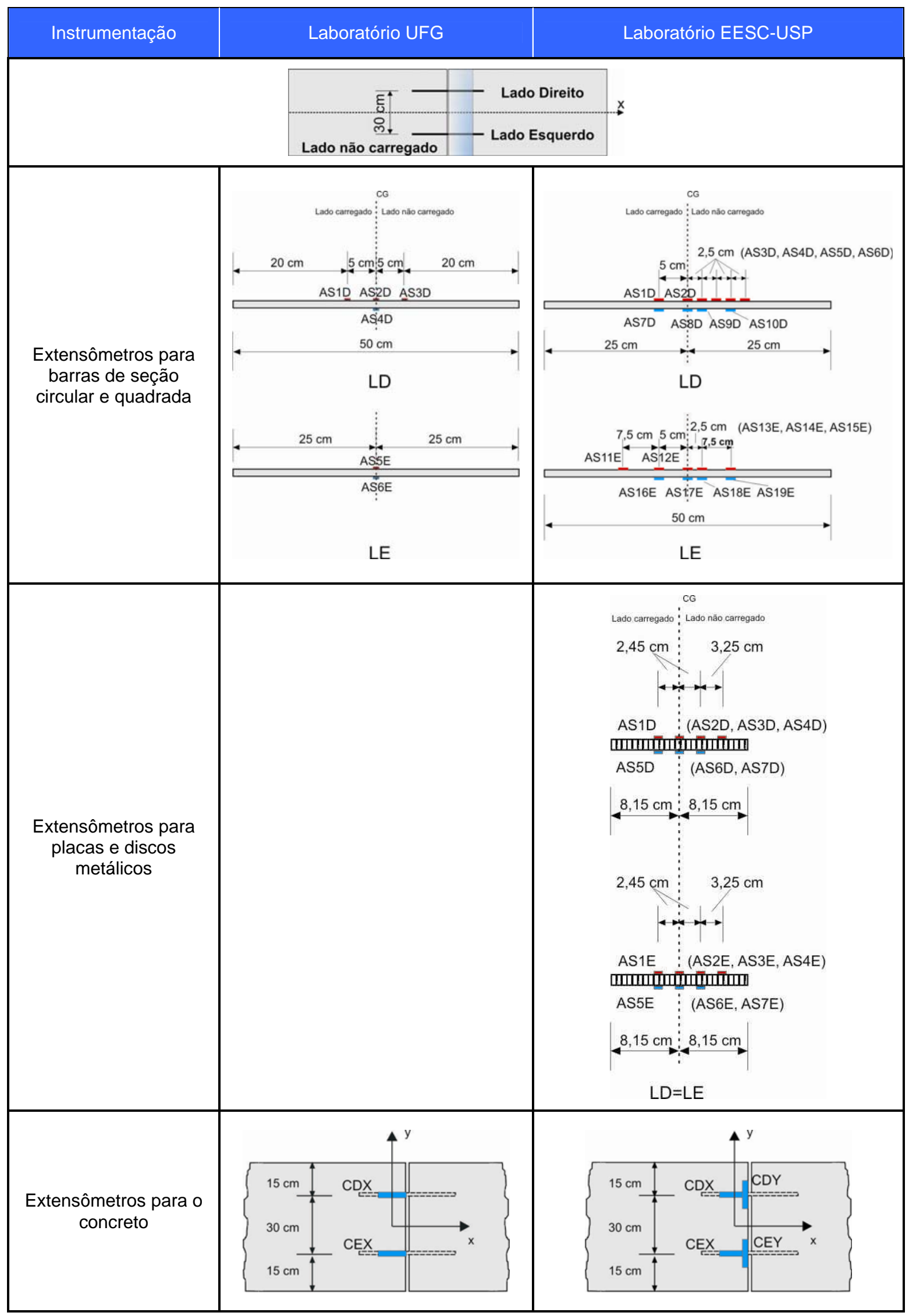


A Figura 4.24 e a Figura 4.25 apresentam respectivamente a superfície do concreto e os dispositivos colocados para determinação das deformações.

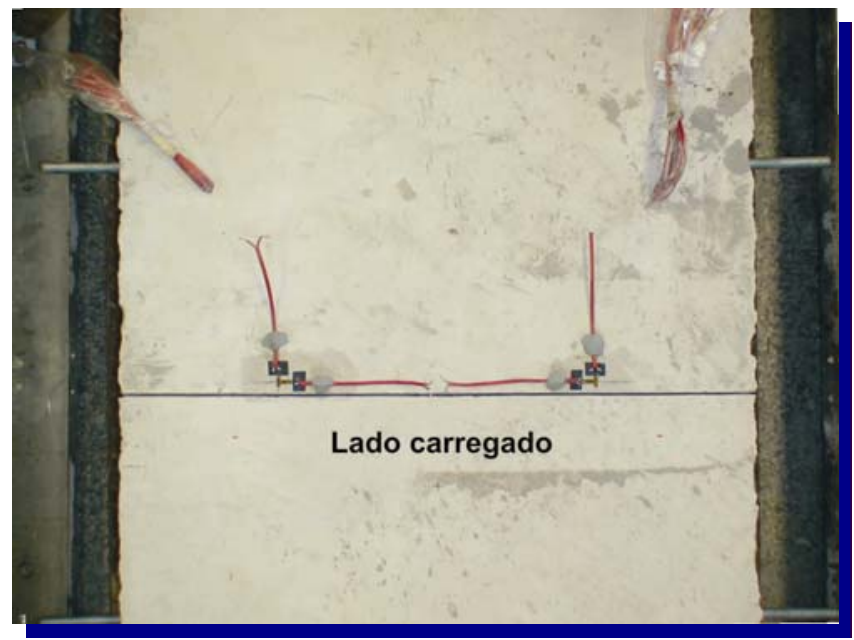

Figura 4.24 - Extensômetros elétricos fixados na superfície de concreto

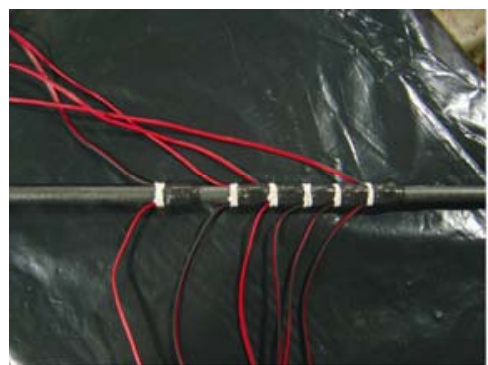

(a)

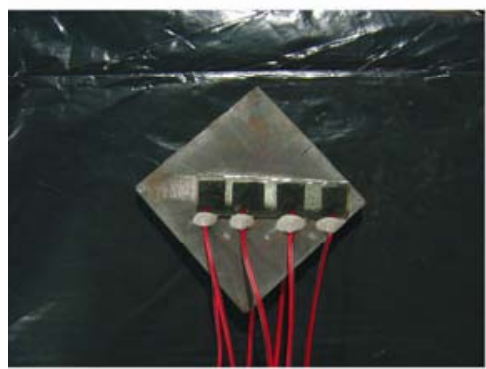

(c)

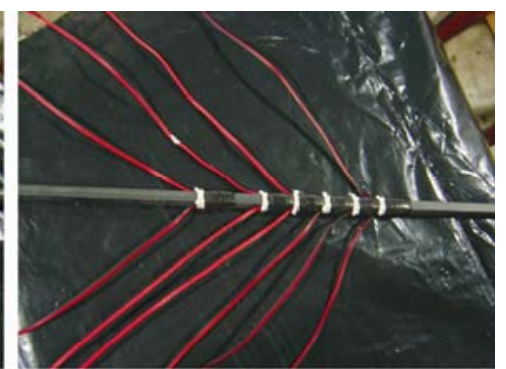

(b)

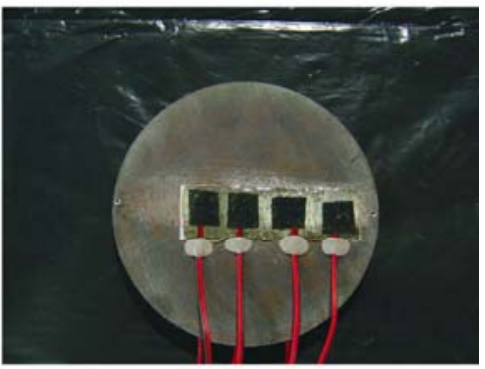

(d)

Figura 4.25 - Dispositivos metálicos instrumentados: (a) barra circular, (b) barra quadrada, (c) placa metálica, (d) disco metálico

No ensaio de cisalhamento duplo, foram utilizados dois extensômetros elétricos, colados na face superior e na inferior de cada dispositivo, no seu ponto central.

\subsection{ENSAIOS NA FUNDAÇÃO}

Ensaios realizados no Laboratório de Polímeros do Departamento de Materiais da UFSCar, para caracterização da borracha natural, indicaram propriedades, tais 
como: Dureza, Deformação Permanente à Compressão sob Deformação Constante e Compressão.

A dureza mede a resistência à penetração, e para materiais sólidos, é medida em escalas arbitrárias descritas no método ASTM D2240 (2005). As medições da dureza foram realizadas com o uso de um durômetro portátil analógico, marca Shore "A", Figura 4.26, com escalas graduadas de 0 a 100, fabricado pela The Shore Instruments \& MFG. O durômetro mede a resistência, tomada como a medida da dureza, à penetração de um pino pressionado contra o elastômero, pela ação de uma mola, sob carga padronizada. Um ponteiro move-se, através de uma escala, para mostrar a resistência à penetração. A escala Shore "A" é utilizada para os materiais macios, e as subseqüentes "B", "C" e "D", para materiais mais duros.

As leituras são efetuadas antes e após aquecimento em estufa, a uma temperatura padronizada de $70^{\circ} \mathrm{C}$, por 22 horas. Esses valores fornecem a variação da resistência à penetração, em condições adversas à borracha.

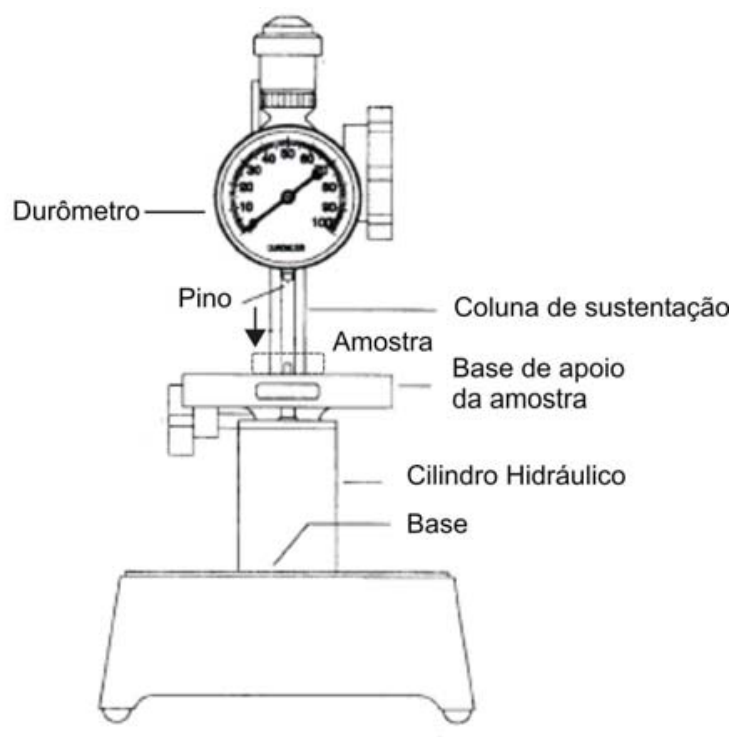

Figura 4.26 - Durômetro e suporte

A dureza dos lençóis de borracha, especificada em projeto, foi de 70 Shore A, com uma tolerância normalizada de \pm 5 Shore A. As características da borracha, fornecidas pelo fabricante, são apresentadas na Tabela 4.7 . 
Tabela 4.7 - Características da borracha especificada por fabricante

\begin{tabular}{|c|c|c|c|}
\hline Composto $^{[1]}$ & Polímero Básico & Cor & $\begin{array}{c}\text { Peso Específico } \\
\left(\mathrm{g} / \mathrm{cm}^{3}\right)\end{array}$ \\
\hline NR-1087 & Natural & Preta & 1,60 \\
\hline [1] Fabricado por ORION - Indústria de Artefatos de Borracha \\
\hline
\end{tabular}

As dimensões das amostras retiradas dos lençóis de borracha, segundo a ASTM D2240 (2005), são apresentadas na Figura 4.27. O diâmetro recomendado deve ser superior a $12 \mathrm{~mm}$, tendo sido adotado $D=25,4 \mathrm{~mm}$, para permitir um raio de pelo menos $6 \mathrm{~mm}$ para a penetração do pino sobre a superfície do elastômero, em até cinco pontos da superfície plana e paralela da borracha. A espessura $h$ da amostra corresponde à espessura do lençol de borracha natural adquirido, equivalente a aproximadamente $9,6 \mathrm{~mm}$.

Foram extraídas quatro amostras por lote, sendo que o lote 01 se refere aos lençóis de borracha adquiridos para ensaios realizados na UFG, e o lote 02, aos ensaios realizados na EESC-USP.

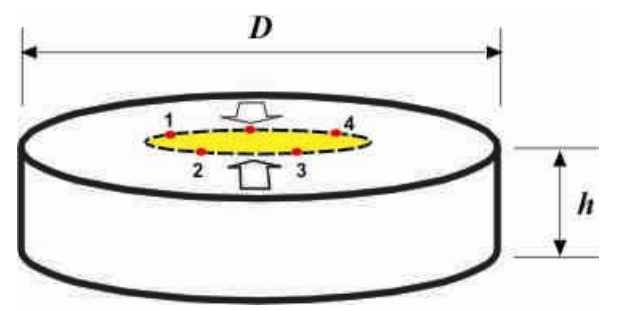

Figura 4.27 - Amostra de borracha

Como o ensaio de dureza é não-destrutivo, foram utilizadas as mesmas amostras para a realização do ensaio de Deformação Permanente à Compressão sob Deformação Constante.

O ensaio de Deformação Permanente à Compressão sob Deformação Constante, segundo a ASTM D395 (2003), é destinado a avaliar a capacidade de elastômeros conservarem suas propriedades elásticas, depois de ações prolongadas de tensões de compressão.

Este ensaio determina o grau de compressão sofrido por um determinado material, quando submetido a uma deformação permanente sob compressão. A deformação 
permanente é medida pelo decréscimo residual da espessura de uma amostra padrão, 30 minutos após ter sido removida de um aparelho de compressão, no qual tenha sido submetida a uma deformação previamente determinada, por um dado período de tempo, sob condições padronizadas. A normalização estabelece quatro amostras por lote de borracha.

Inicialmente, a espessura original é medida, e logo em seguida a amostra é colocada entre espaçadores com dimensões padronizadas, no aparelho de compressão apresentado na Figura 4.28. A amostra é comprimida a $25 \%$ de sua altura original, até atingir a espessura dos espaçadores, e colocada em uma estufa a uma temperatura de $70^{\circ} \mathrm{C}$, por 22 horas. Depois de retirada da estufa e resfriada à temperatura ambiente, a amostra é novamente medida com espessura final. A taxa de compressão $C$ na eq.(4.6) é expressa pela percentagem de perda na espessura.

$$
C=\left[\frac{t_{i}-t_{f}}{t_{i}-t_{e}}\right] \times 100
$$

onde $t_{i}$ é a espessura inicial, em $\mathrm{mm} ; t_{f}$ é a espessura final, em mm; e $t_{e}$ se refere à espessura do espaçador utilizado, em $\mathrm{mm}$.

O aparelho de compressão é feito por três placas metálicas rígidas e planas, e equipado com um sistema de espaçadores, que permite manter as placas paralelas, a distâncias previamente estabelecidas. 


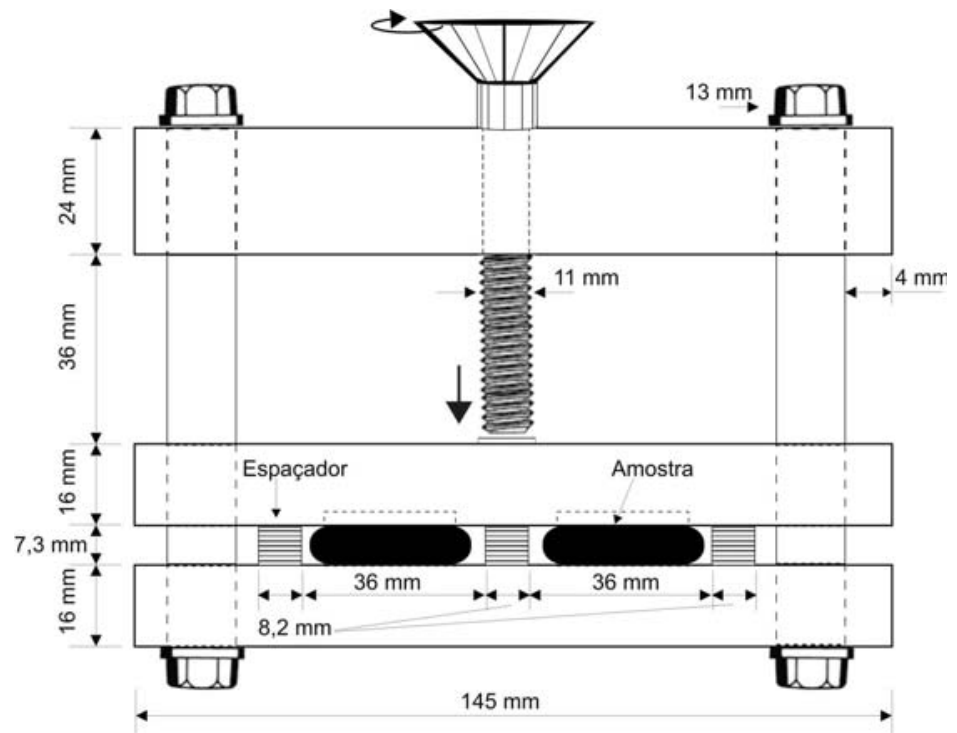

(a)

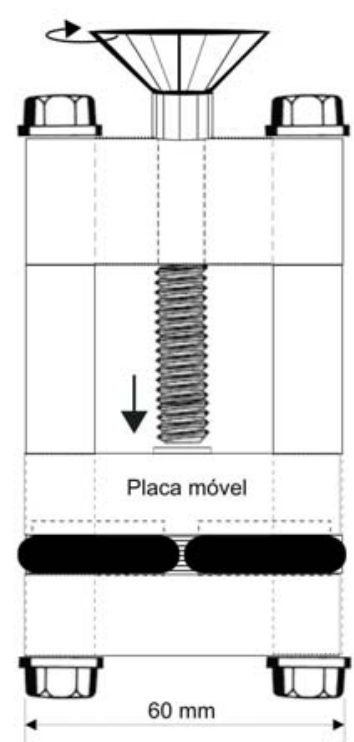

(b)

Figura 4.28 - Aparelho de Compressão: (a) Vista longitudinal; (b) Corte Transversal

No ensaio de compressão para a borracha, segundo a ASTM D 575 (1991), a tensão de compressão é medida pela força compressiva requerida, por unidade de área da seção reta inicial, para produzir uma determinada percentagem de deformação, normalmente de $5 \%, 10 \%$ e $20 \%$.

A norma estabelece uma velocidade de ensaio $12 \mathrm{~mm} / \mathrm{min}$, produzida por uma força $F$ sobre uma área $A$, até atingir a percentagem de deformação requerida de $40 \%$ $(0,40 \mathrm{~mm} / \mathrm{mm})$, para os ensaios. Curvas tensão de compressão imposta por deslocamentos verticais e/ou deformação foram obtidas para amostras.

As dimensões padronizadas das amostras são apresentadas na Tabela 4.8. Duas séries de ensaios foram efetuadas, variando o diâmetro adotado para as amostras. Este procedimento visou à verificação do comportamento da borracha para diferentes dimensões do corpo-de-prova, além de permitir uma melhor aproximação das condições laboratoriais, visto que os corpos-de-prova com diâmetro de 25,4mm, aproximadamente, e com mais de sete camadas de lençol de borracha, não permitiam a estabilidade adequada para a sua execução. Houve a necessidade do aumento do diâmetro, para melhoria da estabilidade no ensaio com 14 camadas. 
Tabela 4.8 - Dimensões das amostras de borracha

\begin{tabular}{|c|c|c|c|c|c|}
\hline \multirow{2}{*}{ Série } & Lote & $\begin{array}{c}\text { Espessura lençol } \\
\text { borracha } \\
(\mathrm{mm})\end{array}$ & $\begin{array}{c}\text { Diâmetro } \\
(\mathrm{mm})\end{array}$ & $\begin{array}{c}\text { Altura da amostra }{ }^{[1]} \\
h \\
(\mathrm{~mm})\end{array}$ & Obs.: \\
\hline \multirow{2}{*}{1} & 1 & 9,5 & 25,5 & 38,0 & $\begin{array}{c}\text { Amostra } \\
\text { confeccionada com } \\
\text { quatro camadas de } \\
\text { lençóis de borracha } \\
\text { sobrepostas }\end{array}$ \\
\cline { 2 - 5 } & 2 & 9,0 & 25,0 & 36,0 & $\begin{array}{c}\text { Amostra } \\
\text { confeccionada com } \\
\text { 14 camadas de } \\
\text { lençóis de borracha } \\
\text { sobrepostas }\end{array}$ \\
\cline { 2 - 4 } & 1 & 9,5 & 75,9 & 133 & 130,5 \\
\hline 1$]$ Valor médio lido com paquímetro & 9,3 & 75,6 &
\end{tabular}

Para o desenvolvimento deste ensaio mecânico foi utilizada uma Máquina Universal de ensaio de materiais, da marca Instron, modelo 5569, apresentada na Figura 4.29. Esse sistema pode ser equipado com uma grande variedade de sistemas de fixação, para ensaios de tração e de compressão. Com capacidade de $50 \mathrm{kN}$ e escala de velocidade de 0,001 - $500 \mathrm{~mm} / \mathrm{min}$, este equipamento é utilizado tipicamente em Metal, Papel, Plástico, Borracha, etc. A Figura 4.30 fornece detalhes das amostras ensaiadas e do procedimento experimental efetuado, com a aplicação da força comprimindo o material.

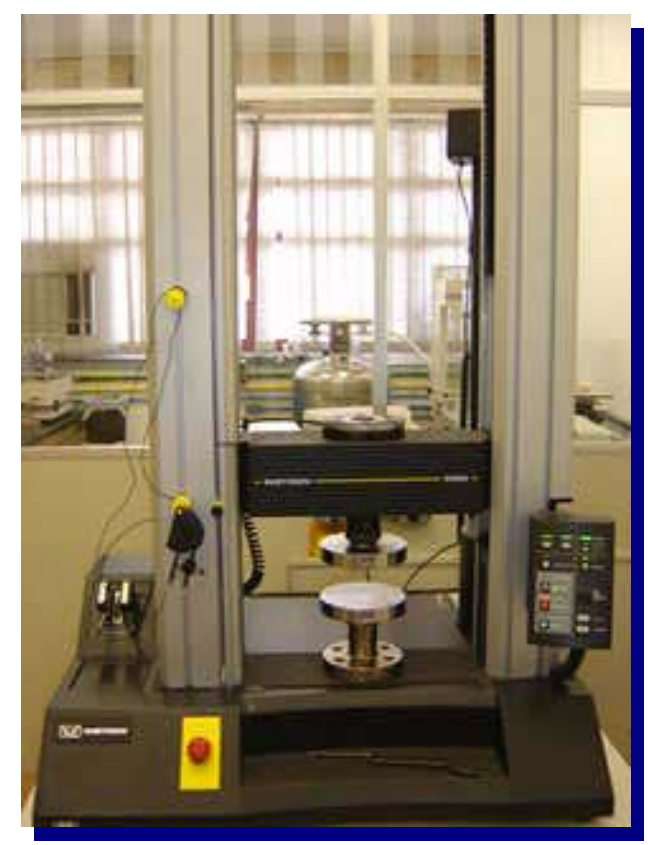

Figura 4.29 -Sistema de ensaio para compressão no Laboratório de Polímeros do Departamento de Materiais da UFSCar 


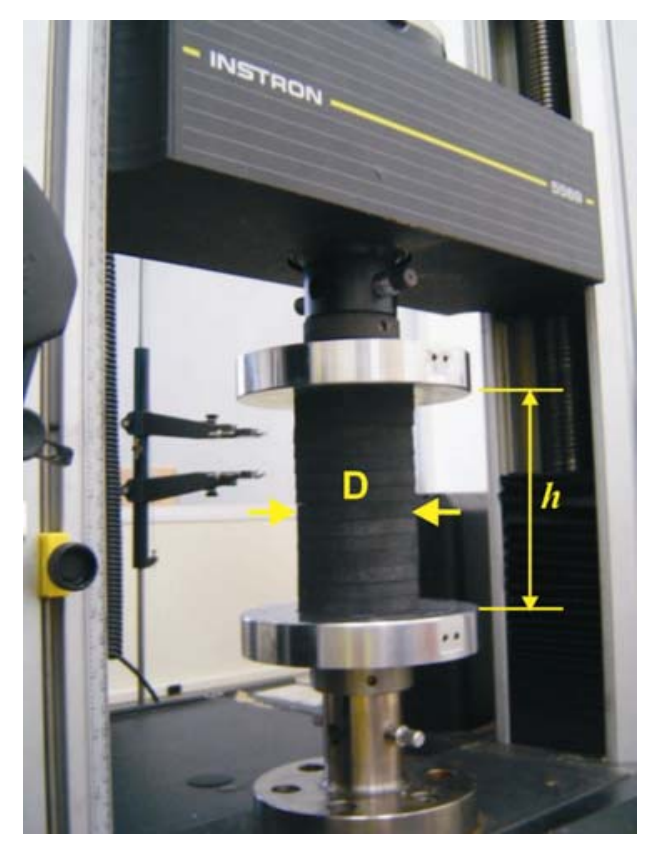

(a)

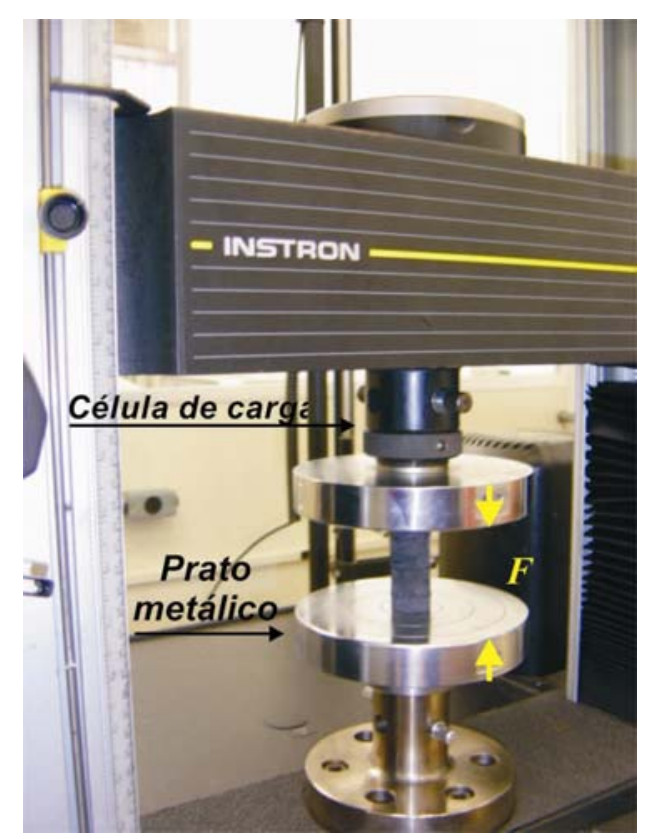

(b)

Figura 4.30 - Detalhe do ensaio: (a) dimensões; (b) configuração do ensaio

O subleito é o terreno sobre o qual se assentam as camadas do pavimento e que, em última análise, irá suportar as cargas atuantes nos pisos e nos pavimentos, sendo necessária uma investigação para determinar a sua capacidade de suporte.

Com o objetivo de controlar variações da capacidade de suporte da base após ensaios consecutivos, e torná-la a mais uniforme possível, foram feitas provas de carga em intervalos de ensaios estáticos e cíclicos, com substituição de alguns lençóis de borracha, quando julgada necessária. Os danos sofridos pelos lençóis de borracha localizados no topo da camada, devido aos ensaios e à queda de suporte registrada por variações do coeficiente de recalque, serviram de parâmetro para essas substituições.

A prova de carga estática, para a determinação do coeficiente de recalque da base da fundação de pavimentos rígidos, foi executada segundo os procedimentos estabelecidos pela Norma 35 do DNER (1989).

Para se obter a medida de resistência do solo ou capacidade de suporte, pode ser realizada uma prova de carga, determinada pelo módulo de reação de Westergaard ou coeficiente de recalque, expresso na eq. (2.6). 
O método correlaciona a pressão transmitida à fundação e a deformação vertical por ela sofrida, segundo o módulo de Westergaard. A curva pressão-deslocamento é obtida plotando-se, nas abscissas, os deslocamentos verticais após cada carregamento, e nas ordenadas, as pressões correspondentes. As pressões são transmitidas por uma placa de aço com diâmetro de $80 \mathrm{~cm}$ e rigidez suficiente para o trabalho a ser executado. O coeficiente de recalque é então obtido pela expressão:

$$
k=\frac{\sigma}{y}=\frac{\sigma_{0,127}-\sigma_{\frac{a d}{2}}}{y}
$$

onde $\sigma_{0,127}$ é a pressão correspondente ao deslocamento de $0,127 \mathrm{~cm} ; \sigma_{\frac{a d}{2}}$ é a metade da pressão de adensamento; $y$ é o deslocamento vertical correspondente a $0,127 \mathrm{~cm}$.

A pressão de adensamento origina-se da aplicação de carregamento, para um deslocamento vertical no intervalo de $0,25 \mathrm{~mm}$ a $0,50 \mathrm{~mm}$, ocasionando acomodação da placa de concreto. 


\section{CAPÍTULO 5}

SIMULAÇÕES NUMÉRICAS

Neste item são apresentadas as etapas de pré-processamento e solução da simulação numérica desenvolvida no Instituto Superior Técnico da Universidade Técnica de Lisboa (IST-UTL), Portugal, a partir de resultados experimentais do modelo PJS12BCM.

\subsection{INTRODUÇÃO}

A simulação numérica foi desenvolvida com o programa ANSYS 9.0, que utiliza o Método dos Elementos Finitos (MEF) para a modelagem de problemas de domínio finito de geometria quaisquer. O modelo de concreto leva em conta a fissuração, o comportamento pós-fissuração, o comportamento plástico na compressão e a presença de armadura. Também pode ser estabelecido um modelo de contato entre as superfícies da placa e da fundação, permitindo o descolamento entre as duas.

O ANSYS 9.0 possibilita a introdução de barras mergulhadas no elemento de concreto. Essas barras são elementos unidirecionais, que podem ser definidos um a um, ou embutidos em superfícies orientadas.

Esse programa constitui ferramenta poderosa, capaz de resolver uma grande variedade de problemas mecânicos, que incluem: análises estruturais estáticas e dinâmicas (ambas linear e não-linear), transferência de calor e líquido, assim como problemas acústicos e eletromagnéticos. Em geral, uma solução a partir do MEF pode ser particionada em três estágios:

- Pré-processamento: definição do problema.

- Solução: aplicação de carregamento, especificando carga pontual ou pressão; condições de contorno e resolução.

- Pós-processamento: processamento adicional e apresentação dos resultados, 
com lista dos deslocamentos nodais; forças e momentos nos elementos; diagramas de tensão e de deslocamentos.

\subsection{PRÉ-PROCESSAMENTO}

A definição do problema consiste em especificar o tipo do elemento (grau de liberdade, dimensionalidade 2D ou 3D); as propriedades do material (linear e não linear) e a geometria do modelo, com criação de áreas e volumes que configuram o projeto a ser analisado, segundo o fenômeno físico que está sendo considerado.

Os parâmetros de entrada de dados foram obtidos em experimentos laboratoriais executados no decorrer deste trabalho. A Tabela 5.1 apresenta os resultados obtidos no ensaio efetuado na placa PJS12BCM, dotada de barra de seção circular como dispositivo de transferência de carga.

Para modelar os pavimentos de concreto, são necessários elementos tridimensionais, que podem ser sólidos ou placas. Deve-se evitar o uso de elementos lineares triangulares ou tetraédricos, utilizados para a geração da malha, pois seria necessária uma malha muito refinada. Neste caso é mais aconselhável a utilização de elementos hexaédricos.

Tabela 5.1 - Parâmetros de projeto para modelagem da placa

\begin{tabular}{|c|c|c|}
\hline Parâmetros de Projeto & Placas $(\mathrm{P})$ & Unidade \\
\hline Comprimento da placa & 220 & $\mathrm{~cm}$ \\
\hline Largura da placa & 60 & $\mathrm{~cm}$ \\
\hline Espessura do pavimento $(\mathrm{h})$ & 12 & $\mathrm{~cm}$ \\
\hline Coeficiente de Poisson do concreto $(v)$ & 0,20 & - \\
\hline Resistência do concreto à tração na flexão $\left(f_{c t, f}\right)$ & 2,5 & $\mathrm{MPa}$ \\
\hline Resistência do concreto à compressão $\left(f_{c}\right)$ & 19,1 & $\mathrm{MPa}$ \\
\hline Módulo de Elasticidade do concreto $\left(E_{c}\right)$ & 23.400 & $\mathrm{MPa}$ \\
\hline Dispositivo de transferência: barra circular $(\phi)$ & 12,5 & $\mathrm{~mm}$ \\
\hline Resistência de escoamento das barras de aço $\left(f_{y}\right)$ & 301 & $\mathrm{MPa}$ \\
\hline Módulo de Elasticidade do aço $\left(E_{s}\right)$ & 163.508 & $\mathrm{MPa}$ \\
\hline Rigidez da mola $(\mathrm{K})$ & 345.662 & $\mathrm{~N} / \mathrm{m}$ \\
\hline
\end{tabular}




\subsubsection{Elementos finitos utilizados}

O modelo numérico desenvolvido foi elaborado com base em elementos prédefinidos, disponibilizados na biblioteca do ANSYS 9.0, os quais serão apresentados a seguir.

Inicialmente foi modelada uma placa de concreto simples com espessura de $12 \mathrm{~cm}$, sendo utilizado o elemento SOLID65. Esse elemento é utilizado na modelagem em 3D, para sólidos com ou sem armadura. O SOLID65 é capaz de considerar a fissuração na tração em três direções ortogonais, controlar as deformações plásticas e a ruptura do concreto à compressão. A geometria do SOLID65 é apresentada na Figura 5.1. O elemento é definido por oito nós, tendo três graus de liberdade em cada nó: translação nas direções nodais x, y e z.

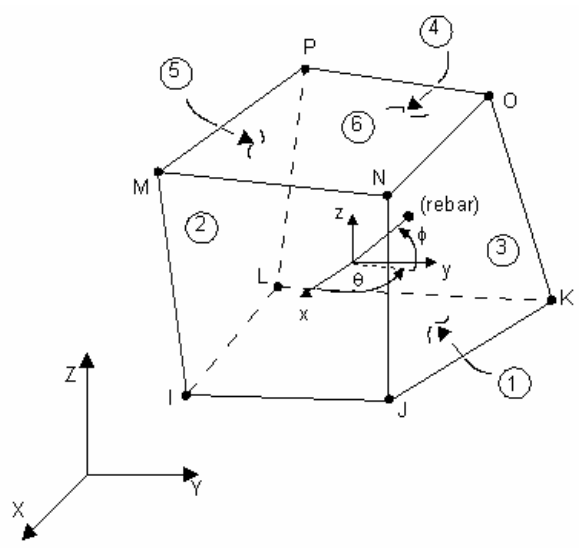

Figura 5.1 - Geometria do elemento SOLID65

A placa de concreto era dotada de duas barras de transferência de força, com seção circular de 12,5mm de diâmetro, inseridas a $h / 2$ da espessura do pavimento.

Os dispositivos de transferência metálicos foram modelados pelo elemento de barra LINK8. Esse elemento, visualizado na Figura 5.2, pode ser tracionado ou comprimido uniaxialmente, e possui três graus de liberdade em cada nó: translações nas direções x, y e z. No entanto, não são admitidos momentos no elemento, e sim grandes deslocamentos e plasticidade. O LINK8 é definido por dois nós, seção transversal, deformação inicial e propriedades do material. 


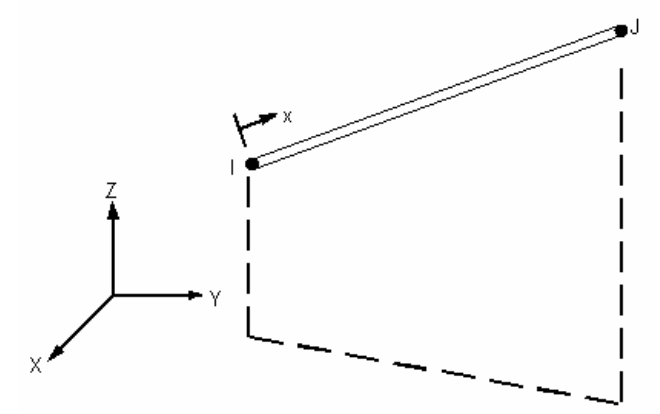

Figura 5.2 - Geometria do elemento LINK8

A base, formada por lençóis de borracha natural, foi modelada utilizando-se 0 elemento COMBIN14, apresentado na Figura 5.3.

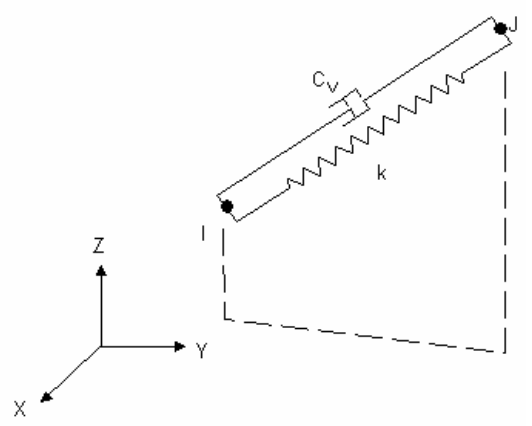

Figura 5.3 - Geometria do elemento COMBIN14

Este elemento de mola possui três graus de liberdade em cada nó: translações nas direções $x, y$ e $z$, não sendo considerados momentos fletores e torçores. A opção longitudinal da mola permite que o elemento seja tracionado ou comprimido axialmente em 1D, 2D ou 3D. O elemento de mola COMBIN14 não possui massa, e é definido por dois nós e uma constante de mola $\mathrm{k}$, em $\mathrm{N} / \mathrm{m}$.

Segundo Maggi (2004), se as molas forem acopladas aos nós da placa do pavimento, elas impedem que haja um descolamento entre este e o solo, produzindo resultados incorretos, Figura 5.4. Sendo assim, uma forma de modelar o solo por meio de molas, e permitir o descolamento entre pavimento e fundação, é introduzir outra placa, de pequena espessura e baixo módulo de elasticidade, tangente à face inferior da placa de concreto, denominada de placa tangente e, nesta sim, acoplar as molas que representam o solo. $\mathrm{O}$ modelo de contato é estabelecido entre essas duas placas.

O contato entre dois corpos deformáveis pode ser modelado usando contato com base em superfícies. Para definição do contato, é preciso determinar as faces dos 
elementos que potencialmente podem estar em contato, especificar quais superfícies interagem, e definir as propriedades mecânicas que governam o comportamento das superfícies.

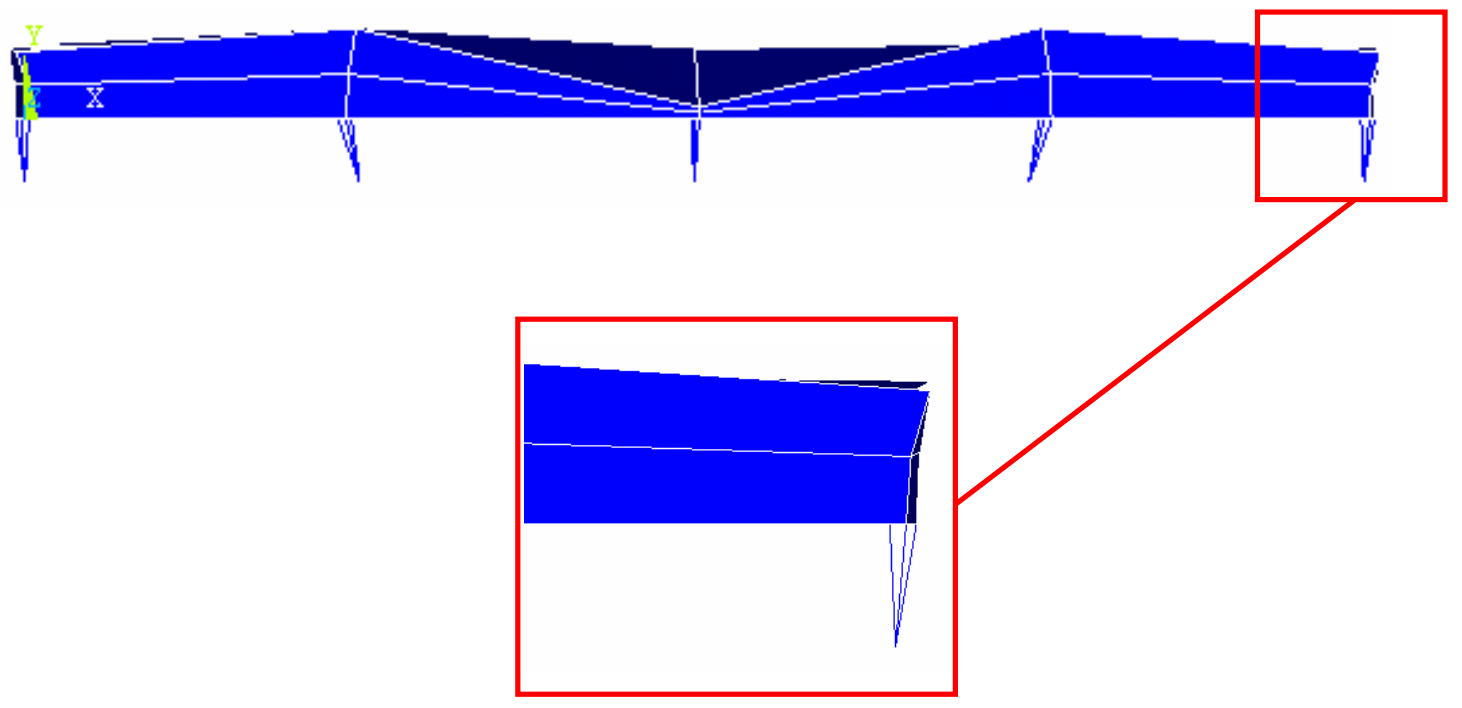

Figura 5.4 - Molas acopladas aos nós da placa com geração de resultados distorcidos

Em problemas envolvendo contato entre dois contornos ou um par de contato ("contact pair"), um dos contornos é convencionalmente denominado de Superfície Tangente (ST), discretizada por segmentos de elementos tangentes TARGET170. A outra superfície, denominada de Superfície de Contato (SC), é formada por elementos de superfície CONTA174, aplicados na análise estrutural em 3D. Para que ocorra um contato flexível-flexível, a ST e a SC serão sempre superfícies deformáveis.

O contato entre o par ocorrerá quando o elemento de superfície penetrar em um dos segmentos dos elementos tangentes, conforme apresentado na Figura 5.5. Os elementos de contato revestem os elementos sólidos que descrevem o limite de um corpo de deformável e entram potencialmente em contato com a superfície designada, definida pelo TARGE170. Esta superfície designada é discretizada por um jogo de segmentos de elementos designados, e é emparelhada com sua superfície de contato associada por constantes reais compartilhadas. 


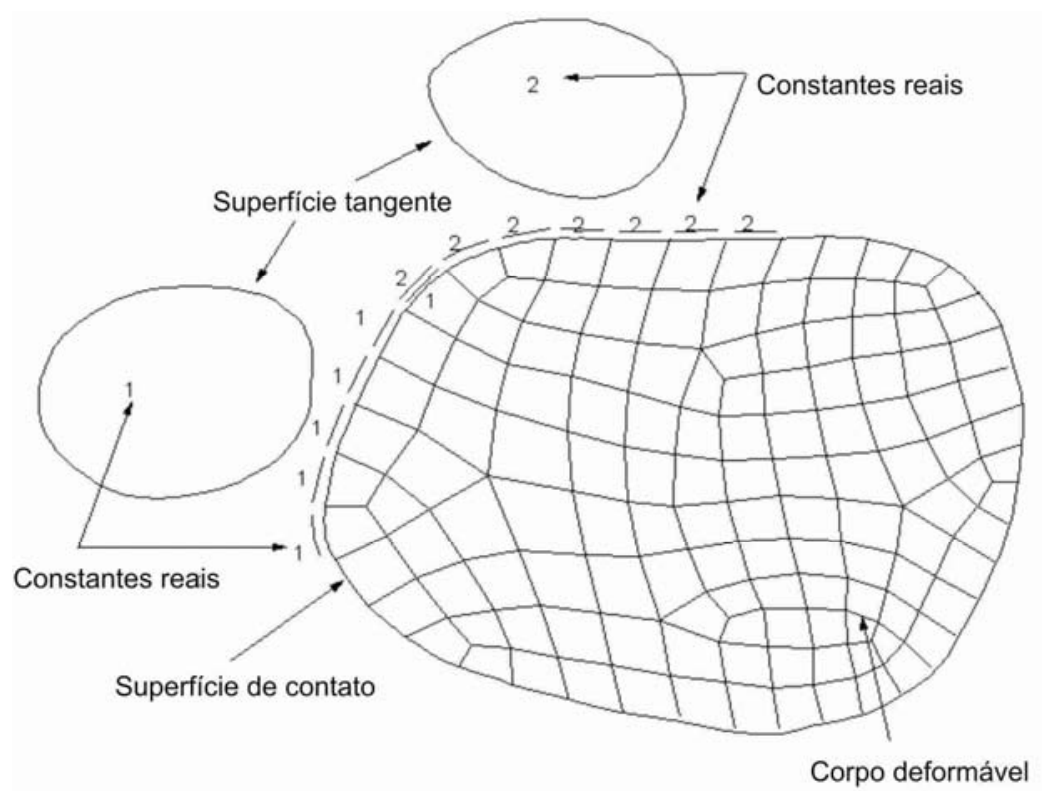

Figura 5.5 - Localização das regiões de contato

O elemento de contato CONTA174 é definido por oito nós, sendo que quatro são nós intermediários (Figura 5.6a). Os tipos de segmentos do elemento tangente TARGE170 (Figura 5.6b) são definidos por vários nós e geometrias variadas, como a triangular de três nós, a quadrilateral de quatro nós, a triangular de seis nós, a quadrilateral de oito nós, a cilíndrica, a cônica, a esférica e o nó piloto, que possui três graus de liberdade: rotações nas direções em x, y e z.

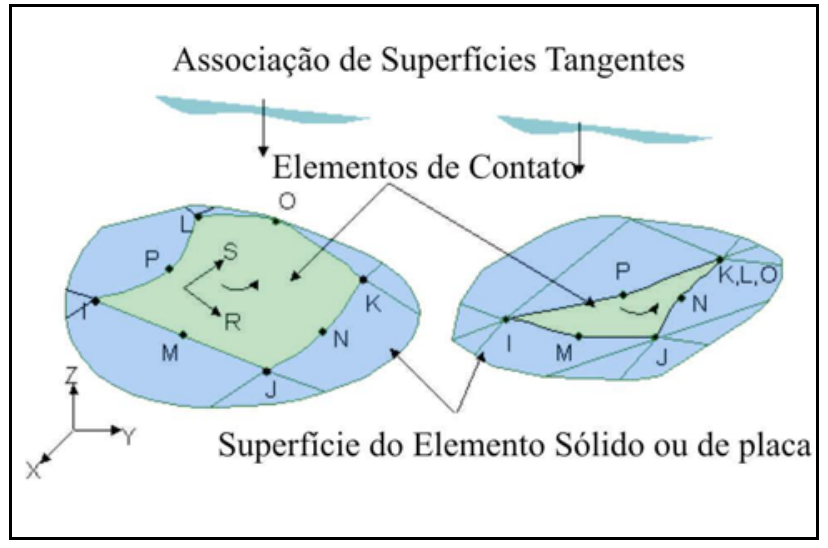

(a)

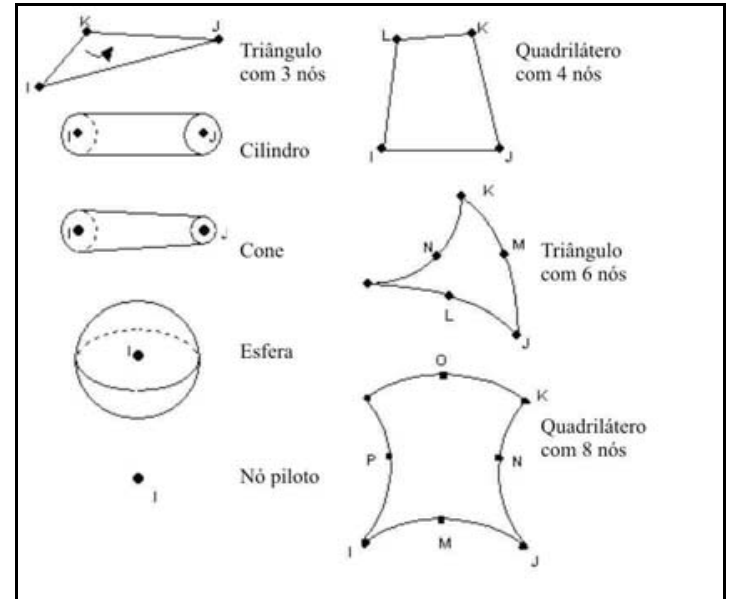

(b)

Figura 5.6 - Geometria dos elementos: (a) Elemento de contato CONTA174; (b) Elemento tangente TARGE170 


\subsubsection{Definição da malha de elementos finitos}

O modelo desenvolvido é constituído por quatro conjuntos de elementos, sendo eles a barra de transferência, a placa de concreto, o par de contato entre placa de concreto e placa tangente e a base elástica. Cada conjunto foi discretizado separadamente, porém de forma a coincidir os nós de cada um na sua interface, possibilitando o acoplamento entre tais conjuntos, realizado por meio desses nós.

Para a discretização da placa de concreto no sentido longitudinal (eixo x), mostrada na Figura 5.7, foi estabelecido um número de elementos na parte central que correspondesse à dimensão linear da barra circular, de forma que em cada nó referente à barra circular existisse um nó coincidente na placa. Nas extremidades da placa de concreto, adotou-se o mesmo número de elementos que na parte central.

No sentido vertical (eixo y), a placa de concreto foi discretizada de tal forma que permitisse que o seu centro geométrico coincidisse com o do dispositivo de transferência. No sentido transversal (eixo z), o critério obedecido foi do espaçamento entre os dispositivos.

A discretização da barra circular respeitou a concordância em relação à malha adotada para a placa de concreto, de forma a coincidir os nós desses grupos de elementos. 


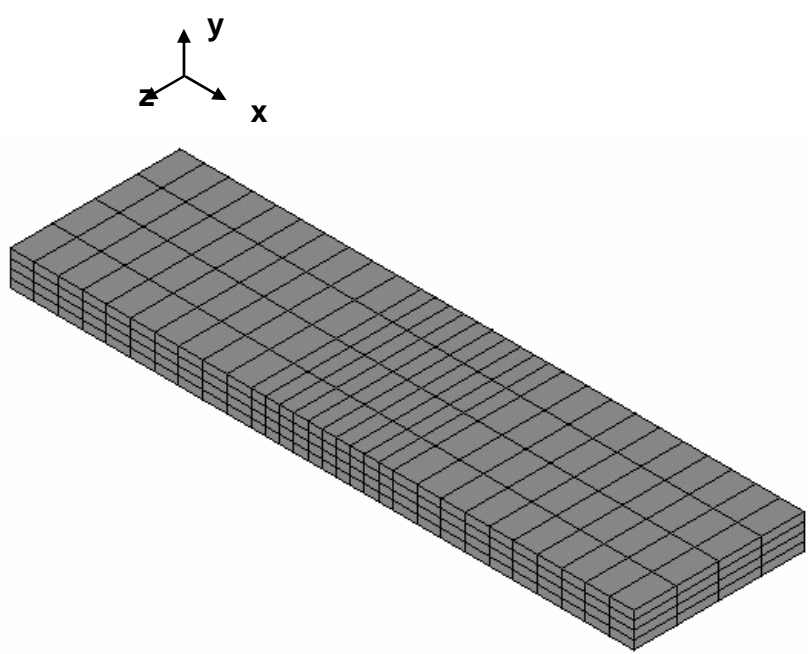

(a)

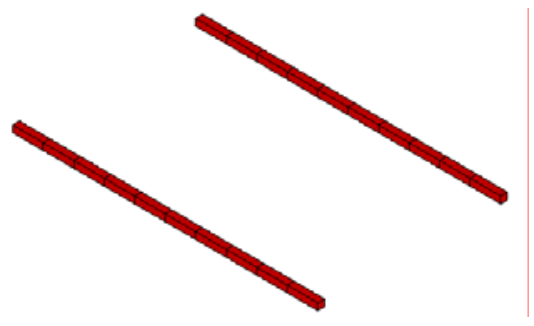

(b)

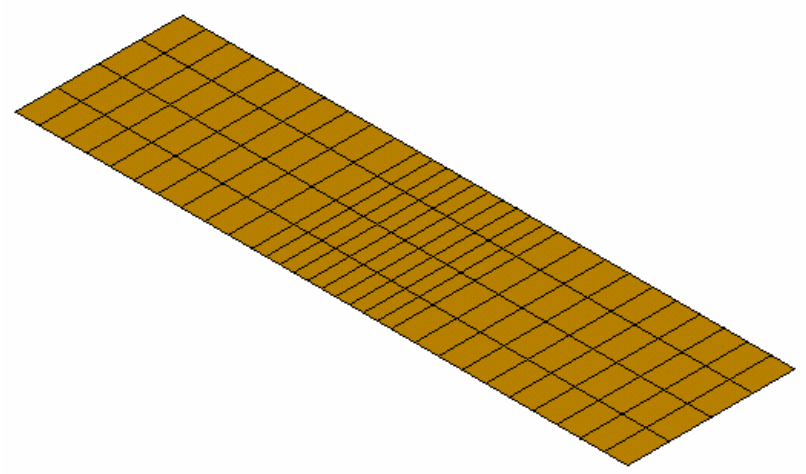

(c)

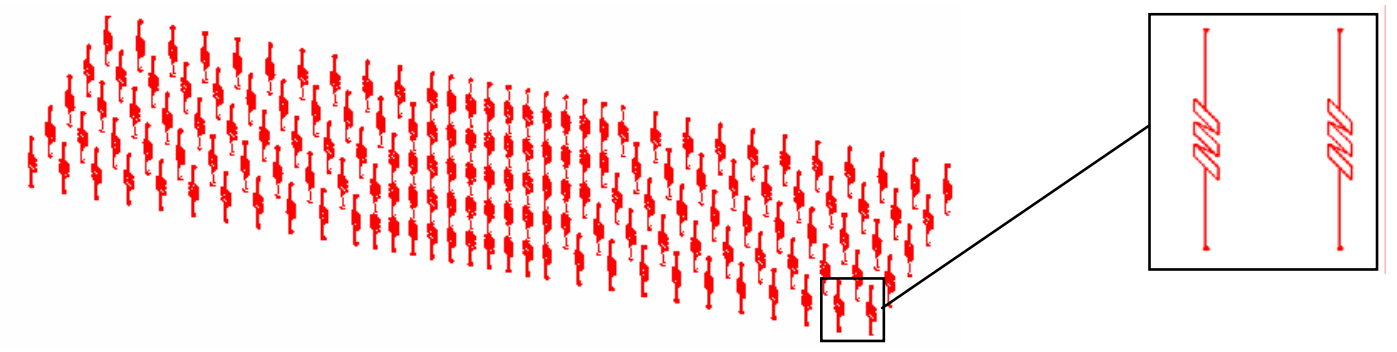

(d)

Figura 5.7 - Grupos de elementos finitos: (a) placa de concreto; (b) barra circular; (c) par de contato; (d) molas 


\subsubsection{Acoplamentos e vinculações}

Os grupos de elementos finitos, conforme mencionado, foram acoplados entre si por meio de nós coincidentes, de acordo com a Figura 5.8, e os procedimentos descritos a seguir:

- Placa de concreto / barra circular - foram compatibilizadas, por meio dos nós.

- Placa tangente / molas - aos nós da base da placa tangente foram acoplados elementos de mola, fixando as translações referentes aos eixos x e z. Aos nós finais do elemento de mola foram fixadas as translações nos eixos $x, y$ e $z$, conforme apresentado na Figura 5.8.

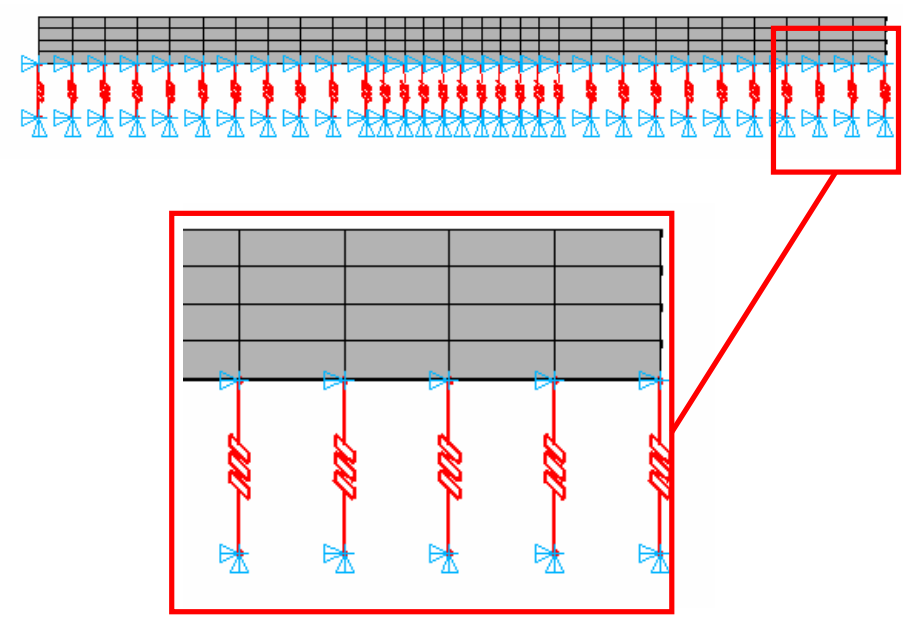

Figura 5.8 - Acoplamento entre grupo de elementos

\subsubsection{Relações constitutivas utilizadas}

A. Aço

Para as barras de transferência, adotou-se um modelo multilinear, com comportamento elastoplástico e encruamento linear isótropo, com base no critério de von Mises, conforme esquematiza a Figura 5.9. Neste caso, a expansão do intervalo elástico inicial de tensão, indicado no eixo das tensões, se dá simetricamente em relação ao seu centro e ocorre sempre que o passo implicar em evolução da deformação plástica. 


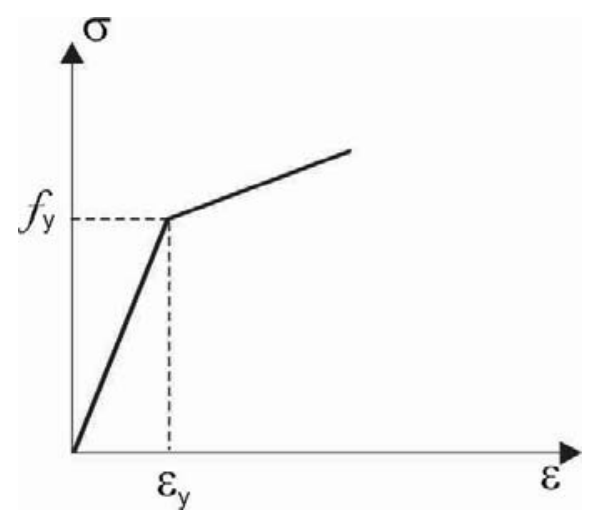

Figura 5.9 - Modelo constitutivo adotado para a barra circular

\section{B. Concreto}

O modelo constitutivo adotado na compressão foi do tipo multilinear, com encruamento isótropo usando von Mises, e a curva tensão-deformação utilizada, apresentada na eq.(5.1), é indicada na NBR 6118 (2003). O comportamento do concreto segue a relação a seguir:

$$
\sigma_{c}=f_{c} \cdot\left[1-\left(1-\frac{\varepsilon_{c}}{2 \%}\right)^{2}\right]
$$

Para tensões de compressão menores do que $0,5 f_{c}$, pode-se admitir uma relação linear entre tensões e deformações, conforme apresentado na Figura 5.10.

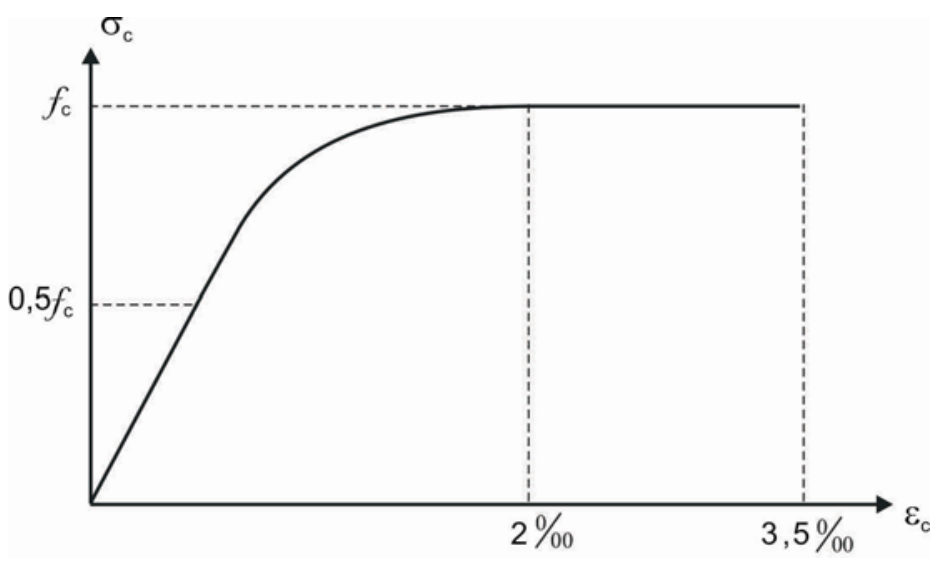

Figura 5.10 - Diagrama tensão-deformação segundo a NBR 6118 (2003)

O modelo do concreto referente à tração na flexão foi representado por meio do modelo concrete disponibilizado pelo ANSYS 9.0, que tem como base o modelo de Willian-Warnke e permite simular o concreto quando submetido a tensões de tração. 
Os parâmetros necessários para a utilização desse modelo são apresentados na Tabela 5.2. A resposta do concreto à compressão, disponibilizada pelo modelo concrete, foi desabilitada, estipulando-se para tanto, neste modelo, o $f_{c}$ igual a -1, conforme estudos realizados por Kotinda (2005). Desde modo evitou-se instabilidades numéricas ocorridas quando da utilização do modelo concrete de forma integral. Admitiu-se, nesse caso, o critério de plastificação de von Mises para o concreto sob compressão.

Tabela 5.2 - Parâmetros do modelo concrete pelo ANSYS 9.0

\begin{tabular}{|c|c|}
\hline Parâmetros & Denominação \\
\hline Coeficiente de transferência de cisalhamento para fissura aberta & ShrCF-Op \\
\hline Coeficiente de transferência de cisalhamento para fissura fechada & ShrCF-Cl \\
\hline Resistência uniaxial à tração & $f_{t}$ \\
\hline Resistência uniaxial à compressão & $f_{c}$ \\
\hline Estado de tensão hidrostática ambiente & $f_{c b}$ \\
\hline Resistência biaxial à compressão sob o estado de tensão hidrostático \\
ambiente & $\sigma_{h a}$ \\
\hline Coeficiente multiplicador de rigidez para condição fissurada na tração & $\mathrm{f}_{1}$ \\
\hline ambia uniaxial à compressão sob o estado de tensão hidrostático & $\mathrm{f}_{2}$ \\
\hline
\end{tabular}

Foram analisados 19 pares dos parâmetros ShrCF-Op e ShrCF-Cl de transferência de força vertical, para fissura aberta e fechada, consecutivamente, com valores indicados na Tabela 5.3. Valores próximos da unidade representam uma fissura rugosa, e valores próximos de zero, uma fissura lisa. 
Tabela 5.3 - Variação dos parâmetros ShrCF-Op e ShrCF-Cl

\begin{tabular}{|c|c|c|c|c|c|}
\hline Modelo & ShrCF-Op & ShrCF-Cl & Modelo & ShrCF-Op & ShrCF-Cl \\
\hline $\begin{array}{c}\text { PJS12BCM } \\
\text { FC1 }\end{array}$ & 0,5 & 0,95 & $\begin{array}{c}\text { PJS12BCM } \\
\text { FC11 }\end{array}$ & 0,7 & 0,9 \\
\hline $\begin{array}{c}\text { PJS12BCM } \\
\text { FC2 }\end{array}$ & 0,6 & 0,95 & $\begin{array}{c}\text { PJS12BCM } \\
\text { FC12 }\end{array}$ & 0,8 & 0,9 \\
\hline $\begin{array}{c}\text { PJS12BCM } \\
\text { FC3 }\end{array}$ & 0,7 & 0,95 & $\begin{array}{c}\text { PJS12BCM } \\
\text { FC13 }\end{array}$ & 0,7 & 0,8 \\
\hline $\begin{array}{c}\text { PJS12BCM } \\
\text { FC4 }\end{array}$ & 0,8 & 0,95 & $\begin{array}{c}\text { PJS12BCM } \\
\text { FC14 }\end{array}$ & 0,8 & 0,8 \\
\hline $\begin{array}{c}\text { PJS12BCM } \\
\text { FC5 }\end{array}$ & 0,9 & 0,95 & $\begin{array}{c}\text { PJS12BCM } \\
\text { FC15 }\end{array}$ & 0,4 & 0,85 \\
\hline $\begin{array}{c}\text { PJS12BCM } \\
\text { FC6 }\end{array}$ & 0,5 & 0,85 & $\begin{array}{c}\text { PJS12BCM } \\
\text { FC16 }\end{array}$ & 0,8 & 0,85 \\
\hline $\begin{array}{c}\text { PJS12BCM } \\
\text { FC7 }\end{array}$ & 0,6 & 0,85 & $\begin{array}{c}\text { PJS12BCM } \\
\text { FC17 }\end{array}$ & 0,8 & 0,9 \\
\hline $\begin{array}{c}\text { PJS12BCM } \\
\text { FC8 }\end{array}$ & 0,7 & 0,85 & $\begin{array}{c}\text { PJS12BCM } \\
\text { FC18 }\end{array}$ & 0,5 & 0,85 \\
\hline $\begin{array}{c}\text { PJS12BCM } \\
\text { FC9 }\end{array}$ & 0,8 & 0,85 & $\begin{array}{c}\text { PJS12BCM } \\
\text { FC19 }\end{array}$ & 0,8 & 0,8 \\
\hline $\begin{array}{c}\text { PJS12BCM } \\
\text { FC10 }\end{array}$ & 0,9 & 0,85 & - & - & - \\
\hline
\end{tabular}

Kotinda (2005) adotou para ShrCF-Op e ShrCF-Cl os valores 0,2 e 0,6 respectivamente. Canha (2004), em sua análise numérica desenvolvida para o caso da ligação pilar-fundação por meio cálice, verificou que valores de ShrCF-Op e ShrCF-Cl, respectivamente iguais a 0,9 e 0,95 representavam melhor o surgimento das fissuras rugosas, no modelo estudado. No entanto, verificou-se que, em ambos os estudos, esses valores não representavam o modelo considerado, e por isso foram feitas novas análises.

A Figura 5.11 fornece o gráfico para a variação dos parâmetros apresentados na Tabela 5.3, em que é possível observar que valores de ShrCF-Op equivalentes a 0,5 e 0,8 fornecem valores próximos para o deslocamento vertical do relógio comparador T1 (NÓ 148), no ensaio experimental para o modelo PJS12BCM - linha tracejada, correspondente ao lado não carregado. 


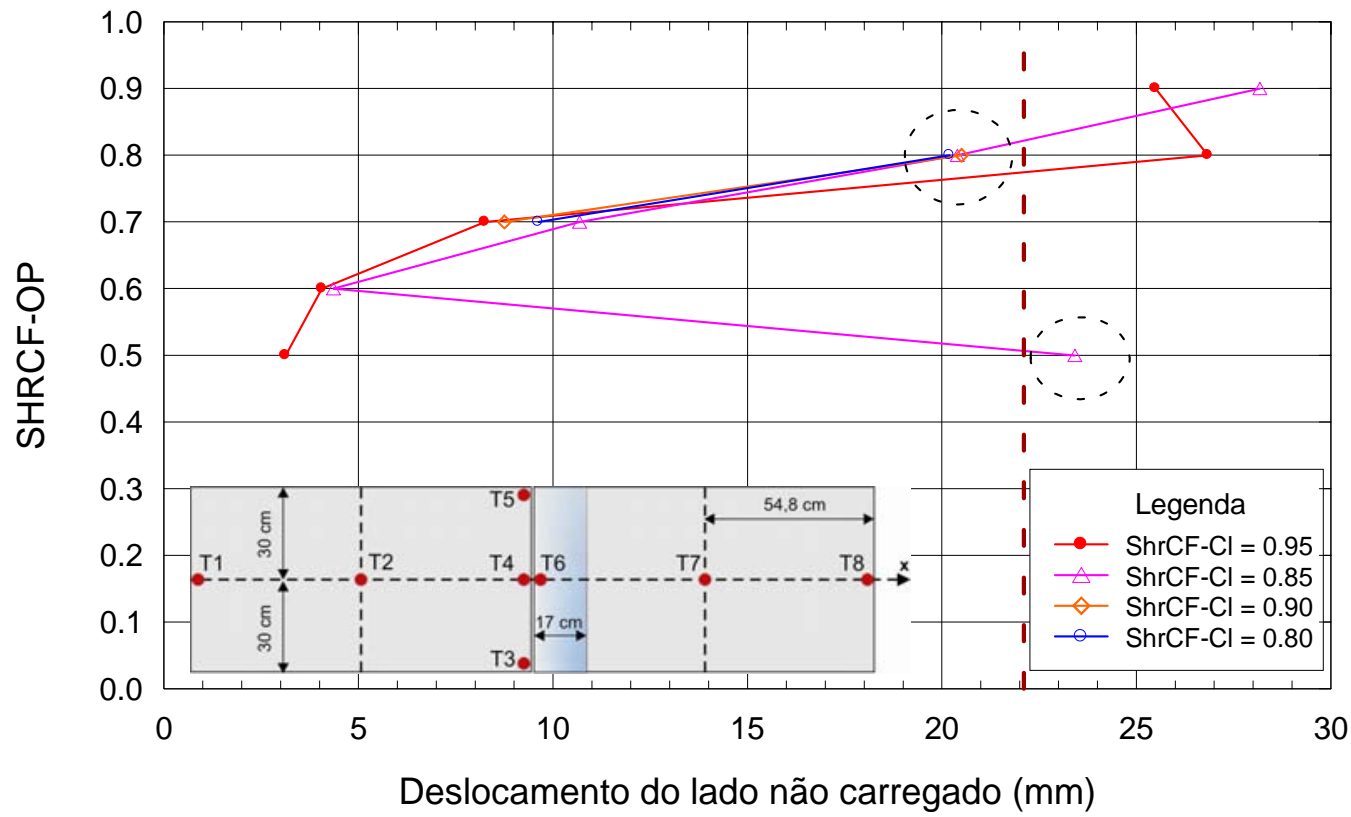

Figura 5.11 - Gráfico deslocamento do lado não carregado (nó 148) versus cisalhamento para fissura aberta

A Figura 5.12 fornece o gráfico para a variação dos parâmetros apresentados na Tabela 5.3, na qual é possível observar que valores de ShrCF-Op iguais a 0,5 e 0,8 fornecem resultados próximos para o deslocamento vertical T8 (NÓ 657), no ensaio experimental para o modelo PJS12BCM - linha tracejada, correspondente ao lado carregado.

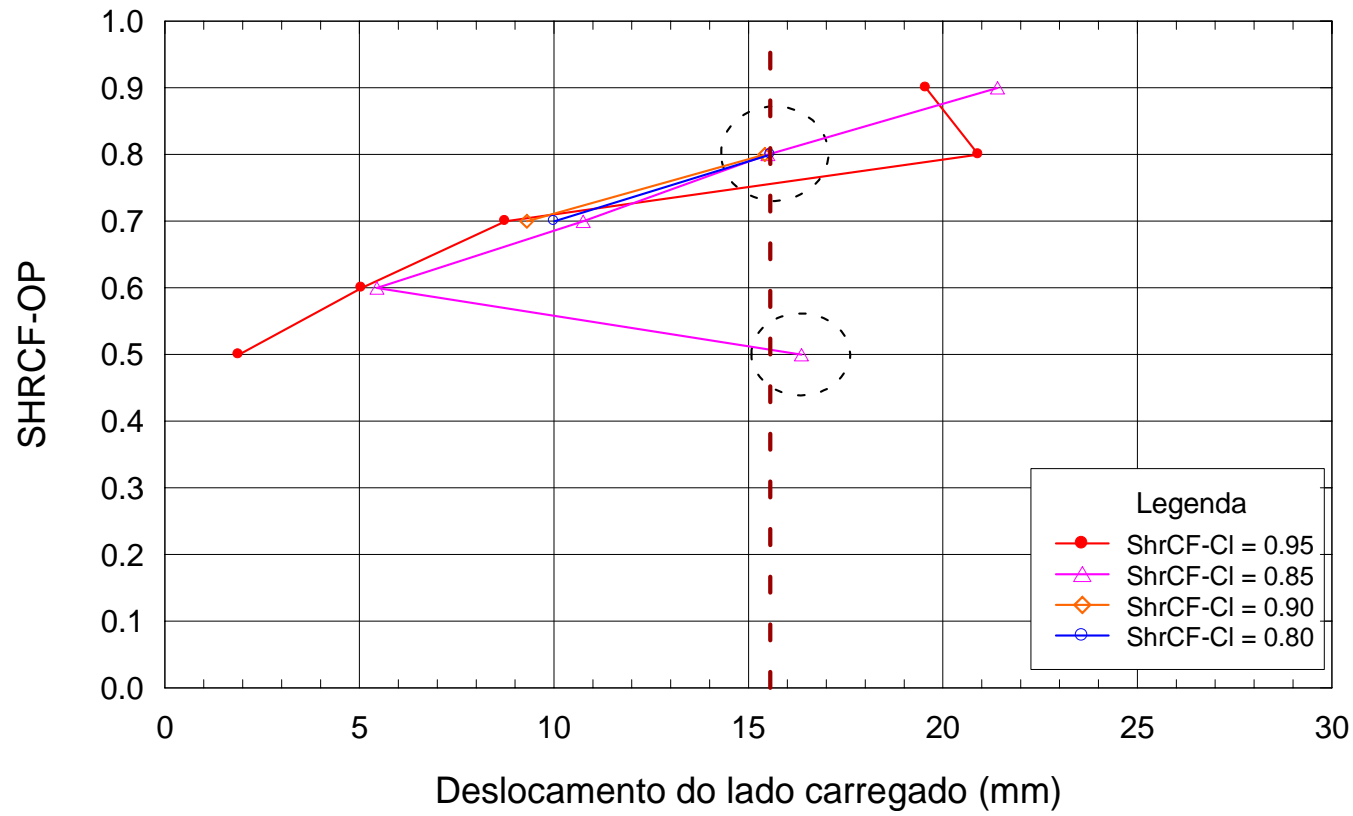

Figura 5.12 - Gráfico deslocamento do lado carregado (nó 657) versus cisalhamento para fissura aberta 
Tendo em vista que ShrCF-Op igual a 0,5 e ShrCF-Cl igual a 0,85 se aproximam mais dos valores experimentais, foram adotados na modelagem. Os últimos cinco parâmetros da Tabela 5.2 foram os pré-estabelecidos pelo ANSYS 9.0.

Devido à resistência do concreto à tração na flexão ser um parâmetro muito variável, foram feitas simulações com a variação deste valor em relação ao valor experimental encontrado, entre $15 \%$ e $50 \%$ acima. Conforme o gráfico apresentado na Figura 5.13, correspondente ao deslocamento vertical do bordo não carregado (T1) e ao nó 148 da malha de elementos finitos, verificou-se que para um $f_{c t, f}=4,5 \mathrm{MPa}$ os deslocamentos se aproximaram mais do valor experimental - linha cheia, além do inicio da fissuração ser o mais próximo do valor encontrado e correspondente a $50,35 \mathrm{kN}$.

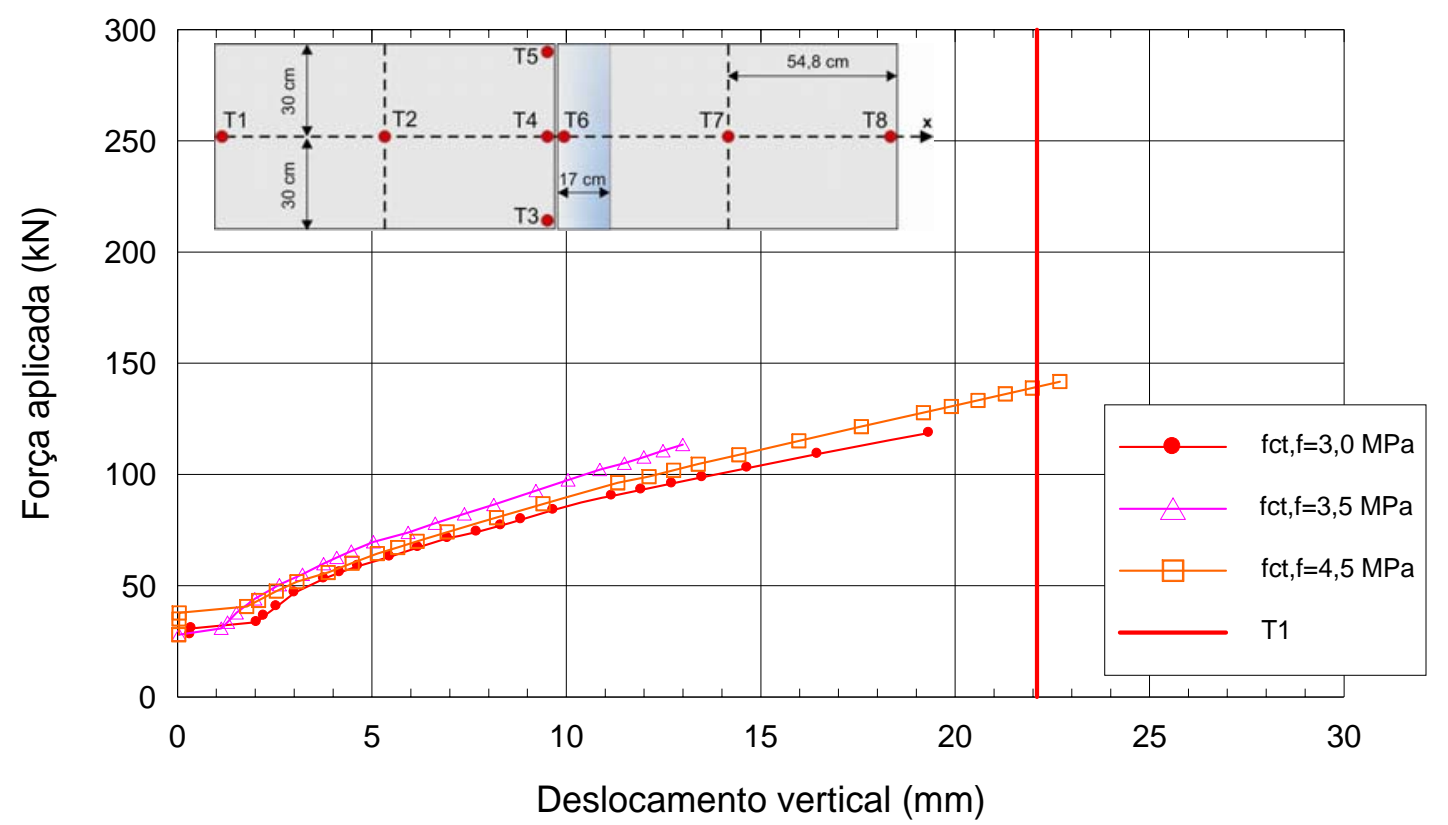

Figura 5.13 - Gráfico carga aplicada x deslocamento vertical

C. Par de contato na interface placa de concreto e placa tangente

Dentro das propriedades do par de contato, existe o coeficiente de atrito $\mu$ adimensional, que deve ser levado em conta, evitando assim o escorregamento entre as duas superfícies, conforme indicado na Figura 5.14. 


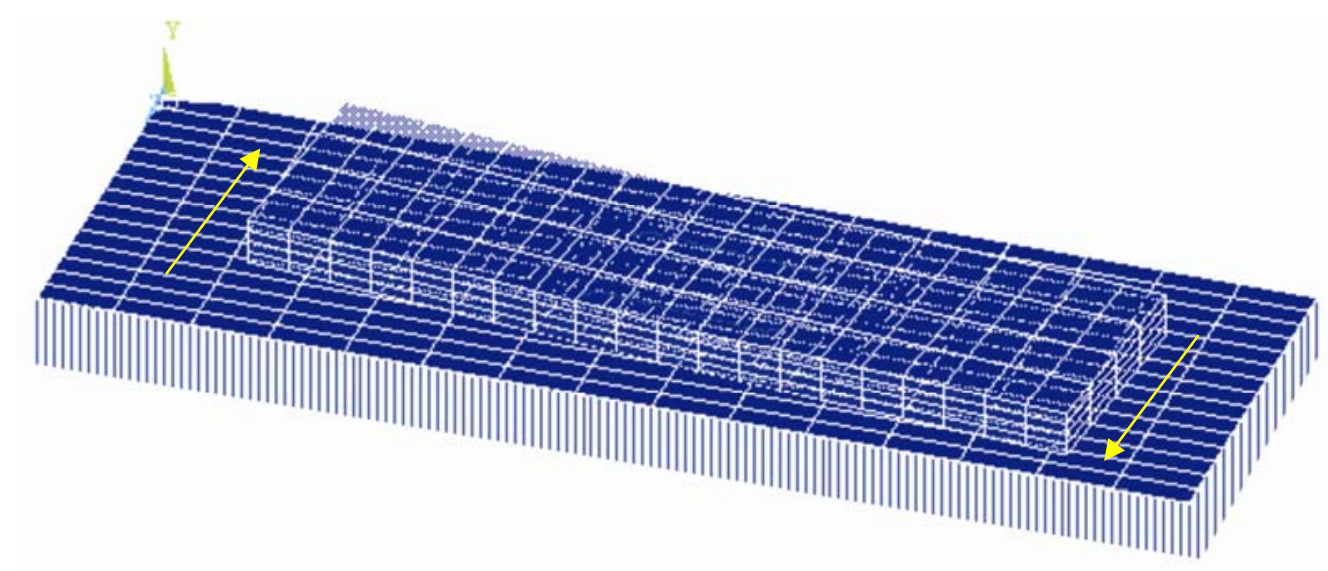

Figura 5.14 - Detalhe do escorregamento entre as duas superfícies para um $\mu$ igual a zero

Segundo Canha (2004), um valor padrão comumente adotado para o coeficiente de atrito $\mu$ na interface concreto-concreto é de 0,6. Já o DNIT (2005) sugere que o coeficiente de atrito entre a placa e a sub-base varie entre 1,5 e 2,0.

No modelo experimental, uma lona plástica foi posicionada entre a placa de concreto e a base do modelo, o que provocaria uma modificação no atrito do sistema.

Em virtude da possível interferência da lona plástica no que se refere ao atrito entre os elementos, foi feito um estudo da variação do coeficiente de atrito, podendo ser visualizado no gráfico coeficiente de atrito versus deslocamento vertical, na Figura 5.15. Verificou-se que tanto para a borda em que se aplicou a força (T8 e Nó 657) quanto para a borda não carregada (T1 e Nó 148), o coeficiente de atrito $\mu=0,3$ forneceu valores mais próximos dos obtidos experimentalmente. 


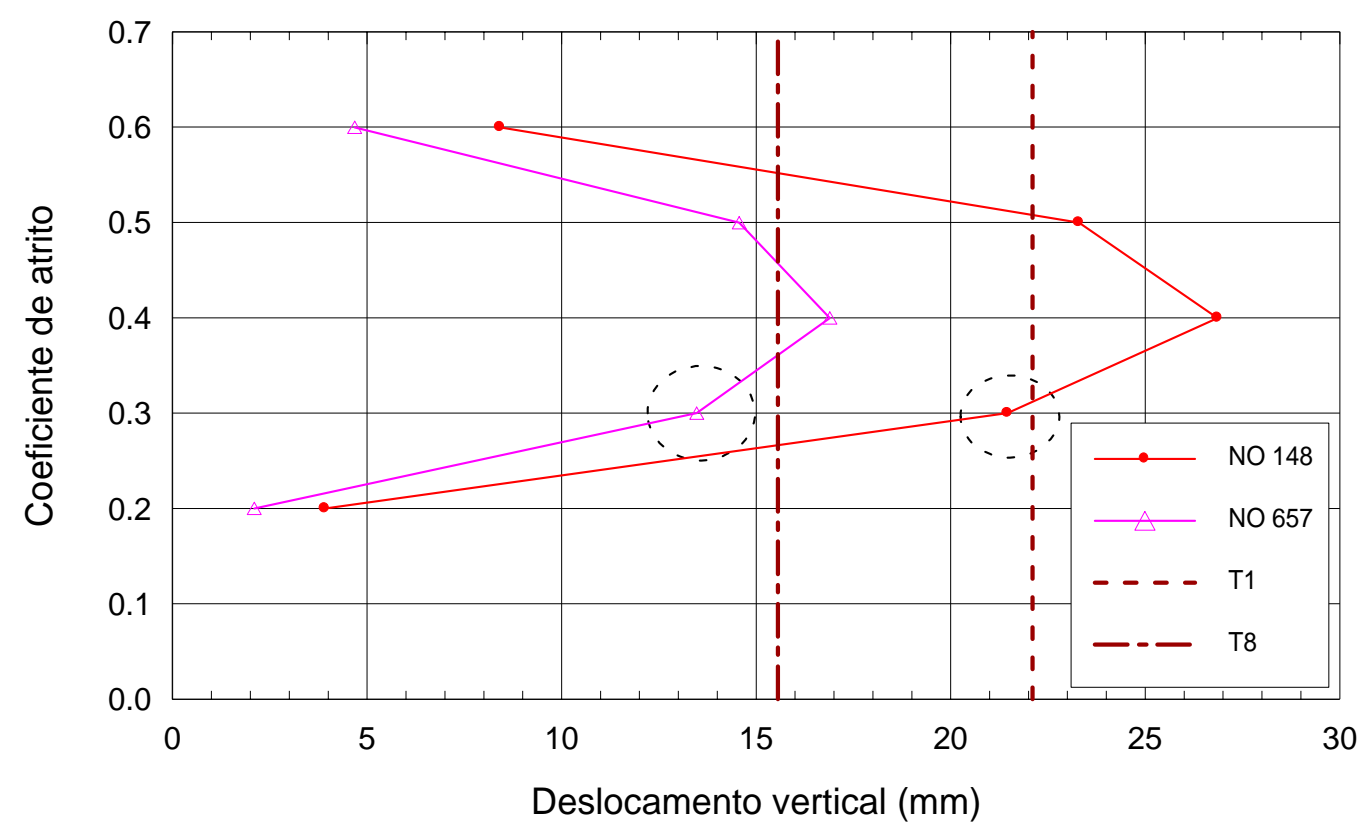

Figura 5.15 - Gráfico coeficiente de atrito x deslocamento vertical

Nas modelagens, foram utilizadas as constantes: FKN $=100$ ("constante real"), que define a rigidez normal do contato; $\mathrm{FTOLN}=0,1$, que representa a penetração máxima permitida; e $\tau_{\max }=10^{20}$ ("Taumax"), que corresponde à resistência de aderência, para análise do comportamento do contato.

Adotou-se para a placa tangente à de concreto um módulo de Elasticidade do concreto baixo, da ordem de $E_{c}=10^{5} \mathrm{~Pa}$.

\section{Base elástica}

A relação entre o coeficiente de recalque $k$ e a rigidez da mola $\mathrm{k}$ pode ser obtida pela expressão:

$$
\mathrm{k}=k \cdot A
$$

onde $A$ corresponde a área de contato do ensaio, em $\mathrm{mm}^{2}$; com $k$ em MPa/m.

Observou-se que, para os valores até então estudados de $k$ (vide Tabela 6.5), existia uma incoerência na modelagem numérica, ao se aplicar como constantes da mola $\mathrm{k}=8,3 \times 10^{7} \mathrm{~N} / \mathrm{m}$, para $k=162 \mathrm{MPa} / \mathrm{m}$, e $\mathrm{k}=3,45 \times 10^{5} \mathrm{~N} / \mathrm{m}$, para $k=82 \mathrm{MPa} / \mathrm{m}$. Sendo assim, para o estudo da rigidez da mola, foram verificados os valores apresentados no gráfico constante $\mathrm{k}$ da mola versus deslocamento vertical, 
apresentado na Figura 5.16. A constante da mola que mais se aproximou dos resultados experimentais foi $k=5 \times 10^{5} \mathrm{~N} / \mathrm{m}$. O nó 148 da malha corresponde ao relógio comparador na posição T1, enquanto que o nó 657 se refere a T8.

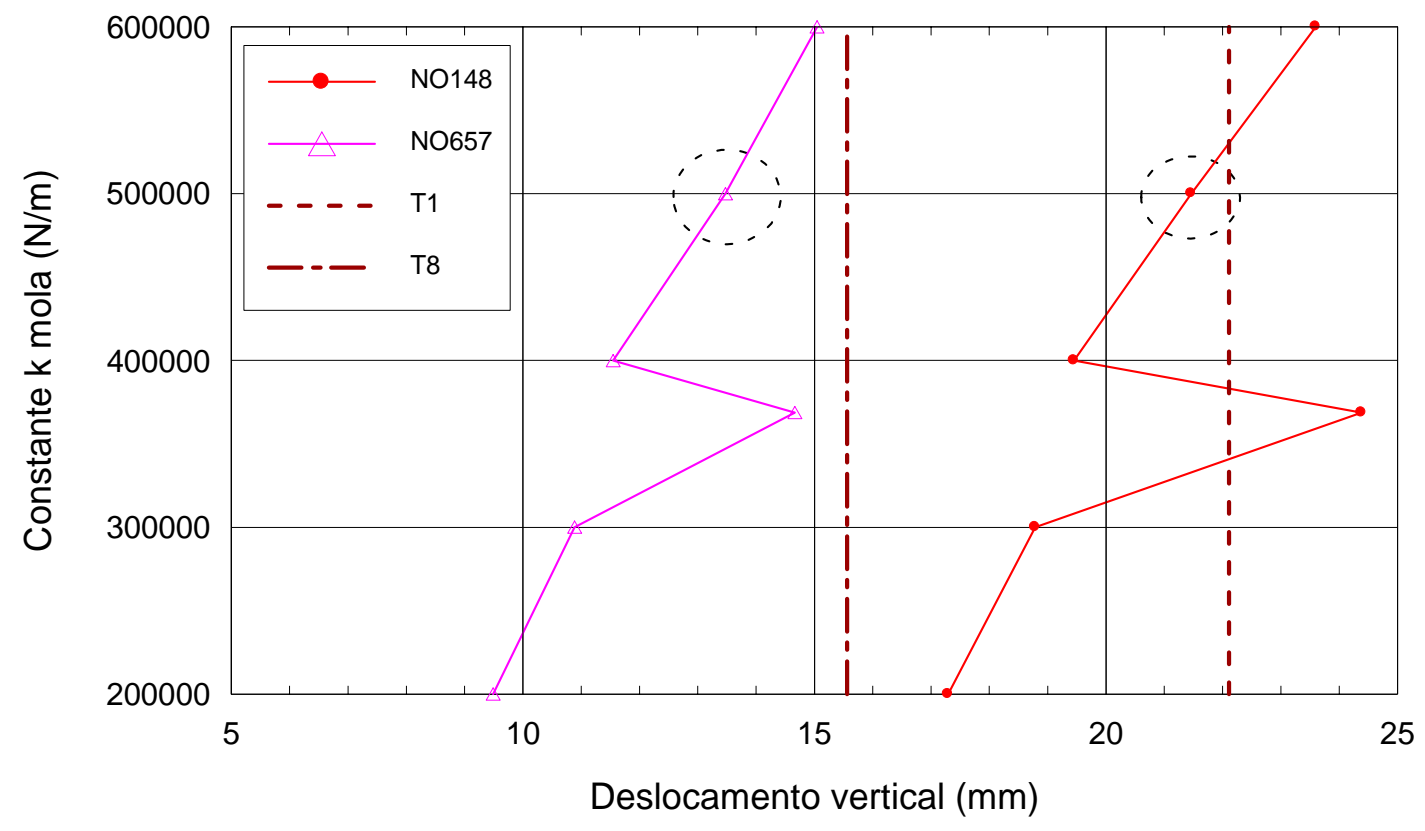

Figura 5.16 - Gráfico constante da mola x deslocamento vertical

\subsection{SOLUÇÃO}

O recurso estudado por Canha (2004), sobre a variação do valor numérico do módulo de elasticidade em relação ao obtido experimentalmente, corroborou para a implementação de curvas com a variação do módulo de elasticidade $E_{c}$ do concreto, apresentadas na Figura 5.17 e Figura 5.18. Observou-se que, para $2 E_{c}$, a curva ficou mais próxima da experimental, representada pelo modelo PJS12BCM, para ambas as bordas, carregada e não carregada. 


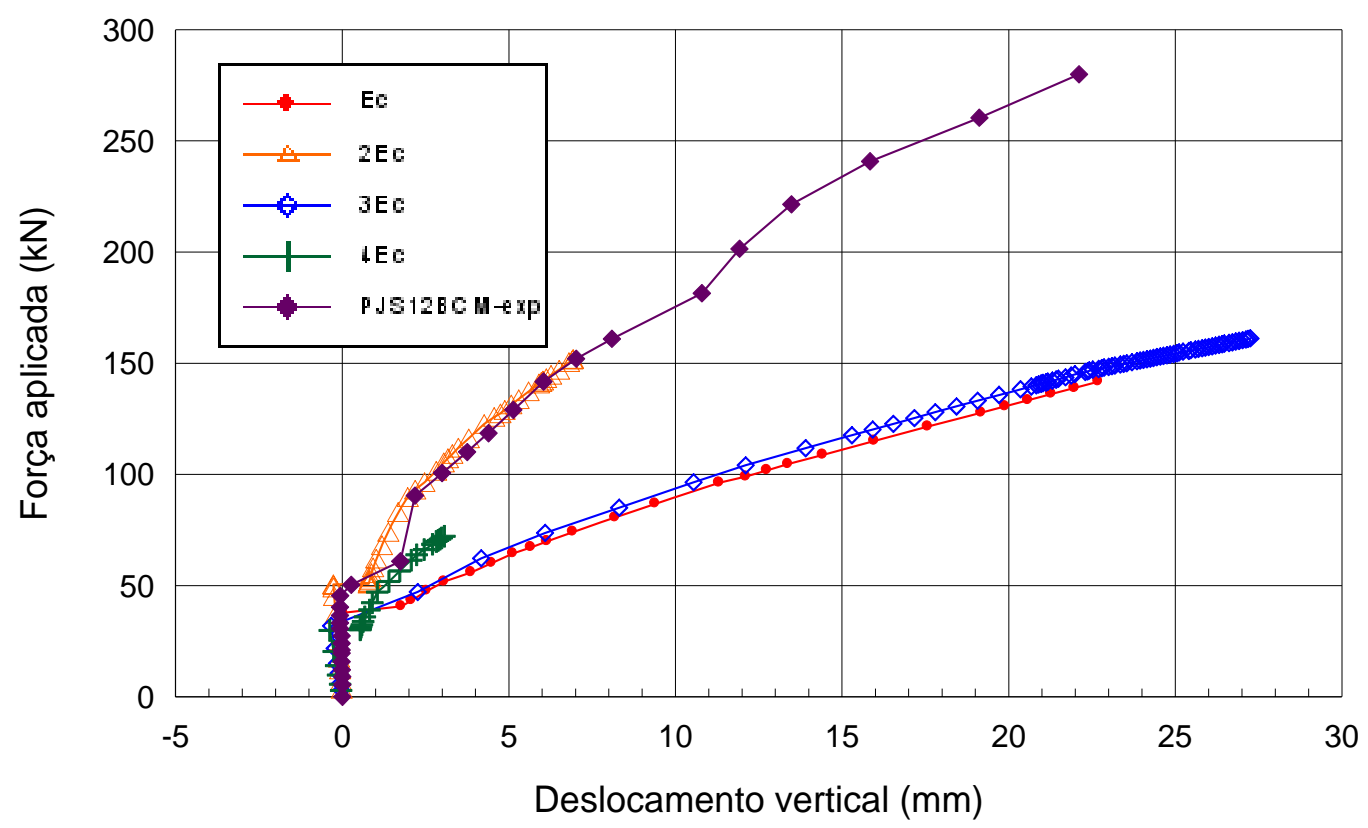

Figura 5.17 - Gráfico força aplicada versus deslocamento vertical (NO 148-T1)

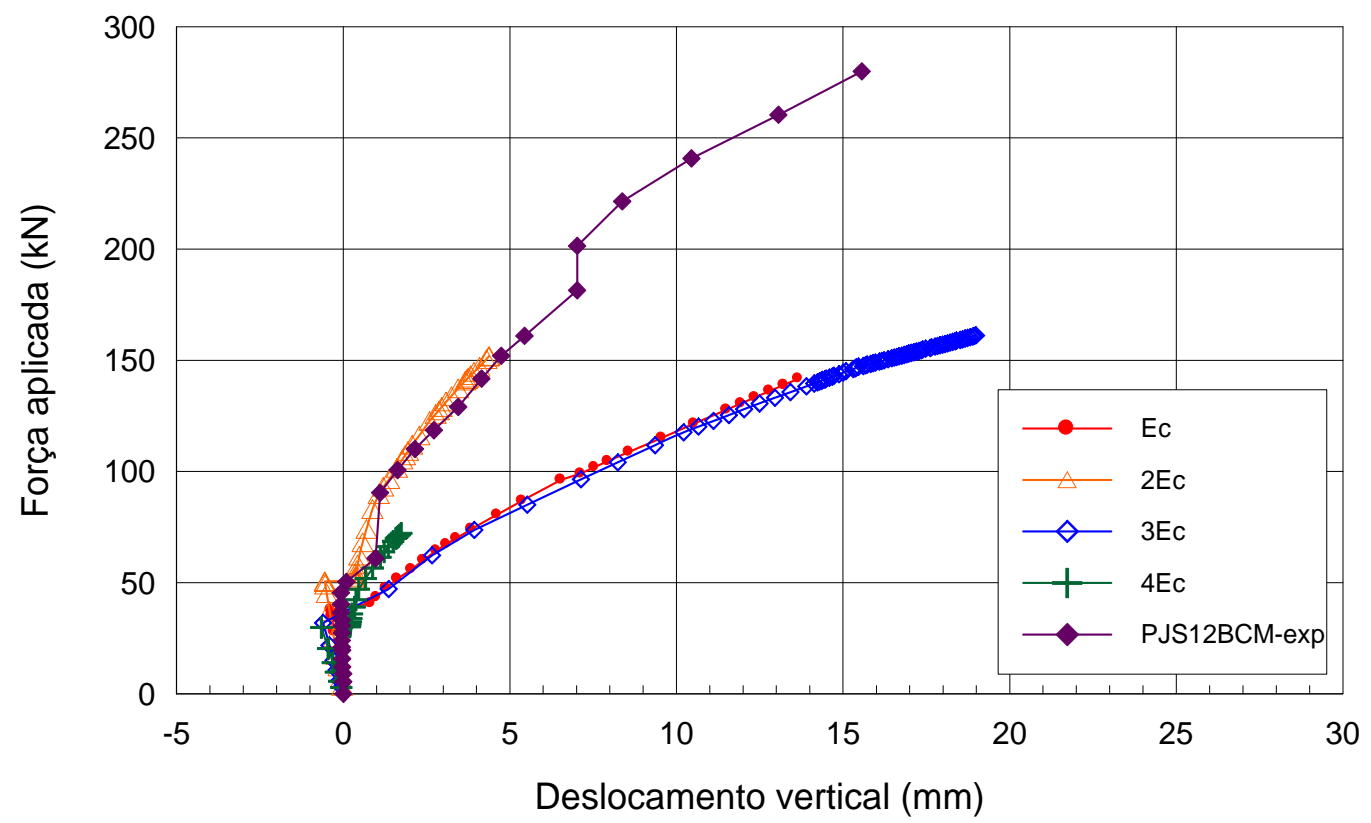

Figura 5.18 - Gráfico força aplicada versus deslocamento vertical (NO 657-T8)

O modelo desenvolvido apresentou resultados próximos aos obtidos experimentalmente. No entanto, atingiu a força última com valores abaixo do esperado, além de alterar significativamente os valores de $E_{c}$ e $\mathrm{k}$. Para que isto não ocorra, o perfil deformado da junta, obtido por curvas distância versus deslocamento vertical, em conjunto com a rigidez da fundação, para diferentes estágios de carregamento, deverão constituir dados para uma retroanálise. 


\section{CAPÍTULO 6}

\section{APRESENTAÇÃO DOS RESULTADOS}

Este capítulo apresenta os resultados obtidos nos ensaios realizados nas placas de concreto simples e na base elástica, além de descrever, resumidamente, os principais fatos ocorridos durante a realização desses ensaios.

Serão apresentados os resultados de caracterização dos materiais empregados na confecção dos modelos; geometria das placas; fissuração, cargas e modos de ruína; deslocamentos verticais; e deformações dos dispositivos de transferência e no concreto.

Os ensaios de caracterização dos materiais empregados no modelo preliminar foram realizados no Laboratório Carlos Campos e Laboratório de Materiais de Construção da Universidade Católica do Estado de Goiás (UCG), em parceria com a UFG. As características da borracha utilizada na fundação foram obtidas em ensaios realizados no Laboratório de Polímeros do Departamento de Materiais da Universidade Federal de São Carlos (UFSCar). Os demais ensaios foram realizados no Laboratório de Estruturas do Departamento de Engenharia de Estruturas da EESC-USP.

\subsection{PROPRIEDADE DOS MATERIAIS}

\subsubsection{Concreto}

O concreto utilizado na confecção das placas de concreto foi adquirido com uma previsão de resistência característica à compressão $\left(f_{c k}\right)$ de 20MPa (aos 28 dias). As características dos materiais utilizados e o traço do concreto foram de responsabilidade das empresas fornecedoras.

A Tabela 6.1 apresenta os resultados obtidos dos ensaios efetuados no concreto utilizado na confecção de todos os modelos. Essa tabela mostra a data do ensaio e a idade do modelo ensaiado, as resistências do concreto à compressão e à tração, 
para cada ensaio, e o módulo de elasticidade secante do concreto. Estes são valores em sua maior parte estimados, obtidos através de equações das curvas aproximadas, obtidas em gráficos resistência versus idade, para idades de 3, 7, 14, 21 e 28 dias. Isto se deve ao fato de que seriam necessários muitos corpos-de-prova para a determinação das resistências no dia de cada ensaio, dos trinta modelos ensaiados, o que inviabilizaria a confecção.

Tabela 6.1 - Propriedades mecânicas do concreto dos modelos

\begin{tabular}{|c|c|c|c|c|c|c|}
\hline Modelo & $\begin{array}{c}\text { Data do } \\
\text { ensaio }\end{array}$ & $\begin{array}{l}\text { Idade no } \\
\text { dia do } \\
\text { ensaio }\end{array}$ & $\begin{array}{c}\text { Resistência } \\
\text { do concreto } \\
\text { à } \\
\text { compressão } \\
f_{c}\end{array}$ & $\begin{array}{c}\text { Resistência do } \\
\text { concreto à } \\
\text { tração por } \\
\text { compressão } \\
\text { diametral } \\
f_{c t}\end{array}$ & $\begin{array}{l}\text { Resistência do } \\
\text { concreto à } \\
\text { tração na } \\
\text { flexão } \\
f_{c t, f}\end{array}$ & $\begin{array}{c}\text { Módulo de } \\
\text { elasticidade } \\
\text { do concreto } \\
E_{c}\end{array}$ \\
\hline & & dias & $\mathrm{MPa}$ & $\mathrm{MPa}$ & $\mathrm{MPa}$ & $\mathrm{MPa}$ \\
\hline PJS12BCM & $30 / 06 / 05$ & 17 & 19,4 & 2,1 & 3,1 & 23.400 \\
\hline JS12BCM & $12 / 02 / 07$ & 31 & 25,8 & 2,4 & 2,6 & 31.429 \\
\hline JS12BQM & $13 / 02 / 07$ & 32 & 25,9 & 2,4 & 2,6 & 31.173 \\
\hline JS12PMM & $13 / 02 / 07$ & 32 & 25,9 & 2,4 & 2,6 & 31.173 \\
\hline JS12DMM & $19 / 03 / 07$ & 24 & 23,4 & 2,0 & 2,3 & 29.053 \\
\hline JS16BCM & $27 / 02 / 07$ & 46 & 27,9 & 2,4 & 2,8 & 27.594 \\
\hline JS16BQM & $26 / 02 / 07$ & 45 & 26,3 & 2,4 & 2,7 & 27.849 \\
\hline JS16PMM & $21 / 03 / 07$ & 26 & 24,2 & 2,1 & 2,7 & 29.070 \\
\hline JS16DMM & $28 / 02 / 07$ & 47 & 28,0 & 2,4 & 2,7 & 27.338 \\
\hline JM12BCM & $28 / 11 / 06$ & 21 & 27,3 & 2,3 & 3,2 & 33.951 \\
\hline JM12BQM & 29/11/06 & 22 & 27,6 & 2,3 & 3,2 & 34.103 \\
\hline JM12PMM & 05/12/06 & 28 & 28,7 & 2,4 & 3,4 & 35.015 \\
\hline JM12DMM & $04 / 12 / 06$ & 27 & 28,7 & 2,4 & 3,4 & 34.863 \\
\hline JM16BCM & 01/12/06 & 24 & 28,2 & 2,3 & 3,3 & 34.407 \\
\hline JM16BQM & $04 / 12 / 06$ & 27 & 28,7 & 2,4 & 3,4 & 34.863 \\
\hline JM16PMM & $30 / 11 / 06$ & 23 & 27,9 & 2,3 & 3,3 & 34.255 \\
\hline JM16DMM & $06 / 12 / 06$ & 29 & 29,1 & 2,4 & 3,4 & 33.078 \\
\hline JS12SDM & $09 / 02 / 07$ & 28 & 25,4 & 2,4 & 2,6 & 32.196 \\
\hline JS16SDM & $12 / 02 / 07$ & 31 & 25,8 & 2,4 & 2,6 & 31.429 \\
\hline JS12BCC & $3 e 4 / 04 / 07$ & 38 e 39 & 26,9 & 2,3 & 3,2 & 29.171 \\
\hline JS12PMC & $16 \mathrm{e} 17 / 05 / 07$ & 110 e 111 & 31,4 & 2,3 & 3,2 & 30.639 \\
\hline JS12DMC & $18 / 6 / 2007$ & 102 & 29,3 & 2,1 & 2,7 & 30.094 \\
\hline JS16PMC & $26 \mathrm{e} 27 / 03 / 07$ & 31 e 32 & 25,8 & 2,2 & 2,6 & 29.112 \\
\hline
\end{tabular}


$\mathrm{Na}$ idade do ensaio, a resistência do concreto à compressão ficou entre 19,4MPa e 31,4MPa; a resistência à tração por compressão diametral do concreto, entre 2,0MPa e 2,4MPa, e a resistência à tração na flexão, entre 2,3MPa e 3,4MPa. Não foram encontrados ninhos de concretagem nos modelos ensaiados.

A Tabela 6.2 apresenta as propriedades mecânicas do concreto dos corpos-deprova para os ensaios de cisalhamento duplo. A resistência do concreto à compressão ficou entre 28,0MPa e 31,4MPa; a resistência à tração por compressão diametral, entre 2,3MPa e 2,4MPa, e a resistência à tração na flexão, entre 2,7MPa e 3,2MPa.

Tabela 6.2 - Propriedades mecânicas do concreto para os ensaios de cisalhamento duplo

\begin{tabular}{|c|c|c|c|c|c|c|}
\hline \multirow{2}{*}{ Modelo } & $\begin{array}{c}\text { Data do } \\
\text { ensaio }\end{array}$ & $\begin{array}{c}\text { Idade no } \\
\text { dia do } \\
\text { ensaio }\end{array}$ & $\begin{array}{c}\text { Resistência } \\
\text { do concreto } \\
\text { a } \\
\text { compressão } \\
f_{c}\end{array}$ & $\begin{array}{c}\text { Resistência do } \\
\text { concreto à } \\
\text { tração por } \\
\text { compressão } \\
\text { diametral } \\
f_{c t}\end{array}$ & $\begin{array}{c}\text { Resistência do } \\
\text { concreto à } \\
\text { tração na } \\
\text { flexão } \\
f_{c t, f}\end{array}$ & $\begin{array}{c}\text { Módulo de } \\
\text { elasticidade } \\
\text { do concreto } \\
E_{c}\end{array}$ \\
\cline { 3 - 7 } & dias & $\mathrm{MPa}$ & $\mathrm{MPa}$ & $\mathrm{MPa}$ & $\mathrm{MPa}$ \\
\hline CD-JS12BCM & $01 / 03 / 07$ & 48 & 28,0 & 2,4 & 2,7 & 27.338 \\
\hline CD-JS12BQM & $01 / 03 / 07$ & 48 & 28,0 & 2,4 & 2,7 & 27.338 \\
\hline CD-JS12PMM & $26 / 06 / 07$ & 123 & 31,4 & 2,3 & 3,2 & 30639 \\
\hline CD-JS16BCM & $01 / 03 / 07$ & 48 & 28,0 & 2,4 & 2,7 & 27.338 \\
\hline CD-JS16BQM & $01 / 03 / 07$ & 48 & 28,0 & 2,4 & 2,7 & 27.338 \\
\hline CD-JS16DMM & $26 / 06 / 07$ & 123 & 31,4 & 2,3 & 3,2 & 30639 \\
\hline
\end{tabular}

\subsubsection{Dispositivos de transferência}

Amostras dos aços empregados na confecção dos dispositivos de transferência metálicos foram ensaiadas à tração axial até a ruptura, segundo o Anexo C da NBR 6892 (2002), para a determinação das propriedades mecânicas. A Tabela 6.3 mostra os resultados médios dos corpos-de-prova ensaiados para a caracterização do aço. Verifica-se que a tensão média de escoamento dos aços utilizados é cerca de 334MPa.

Ensaios de tração, incluindo o lote de chapa metálica usinada (SAC-41; e=6,3 mm) para a confecção de todos os dispositivos de placa e disco metálicos da pesquisa, foram ensaiados no Laboratório de Materiais de Construção da UCG, através da 
máquina Emic DL, com capacidade de 30kN. Para as etapas posteriores, os ensaios dos novos lotes de barras circulares e quadradas (A-36) foram executados no Laboratório de Estruturas da EESC-USP, na Máquina Universal de ensaios mecânicos, servo-hidráulica, com capacidade de $2.500 \mathrm{kN}$.

Tabela 6.3 - Propriedades mecânicas dos dispositivos metálicos

\begin{tabular}{|c|c|c|c|c|c|c|}
\hline Aço & Dimensão & $\begin{array}{c}\text { Deformação } \\
\text { no } \\
\text { escoamento } \\
\varepsilon_{y}\end{array}$ & $\begin{array}{c}\text { Resistência } \\
\text { do aço ao } \\
\text { escoamento } \\
\sigma_{y}\end{array}$ & $\begin{array}{c}\text { Deformação } \\
\text { na ruptura } \\
\varepsilon_{u}\end{array}$ & $\begin{array}{c}\text { Resistência } \\
\text { última } \\
\sigma_{u}\end{array}$ & $\begin{array}{c}\text { Módulo de } \\
\text { elasticidade } \\
\text { do aço } \\
E_{s}\end{array}$ \\
\cline { 2 - 7 } & $\mathrm{mm}$ & $\mathrm{mm} / \mathrm{mm}$ & $\mathrm{MPa}$ & $\mathrm{mm} / \mathrm{mm}$ & $\mathrm{MPa}$ & $\mathrm{MPa}$ \\
\hline $\begin{array}{c}\text { Barra } \\
\text { Circular }\end{array}$ & $\phi 12,5$ & 0,0017 & 301 & 0,023 & 441 & 163.508 \\
\hline $\begin{array}{c}\text { Barra } \\
\text { Circular } \\
\begin{array}{c}\text { EESC- } \\
\text { USP) }\end{array}\end{array}$ & $\phi 12,5$ & 0,0016 & 303 & 0,017 & 410 & 190.943 \\
\hline $\begin{array}{c}\text { Barra } \\
\text { Quadrada } \\
\text { (EESC- } \\
\text { USP) }\end{array}$ & $\# 10,0$ & 0,0016 & 328 & 0,015 & 433 & 201.598 \\
\hline $\begin{array}{c}\text { Chapa } \\
\text { metálica }\end{array}$ & $e=6,3$ & 0,0013 & 382 & 0,0043 & 485 & 310.663 \\
\hline
\end{tabular}

A Figura 6.1 apresenta o gráfico tensão versus deformação do aço utilizado nos ensaios. 


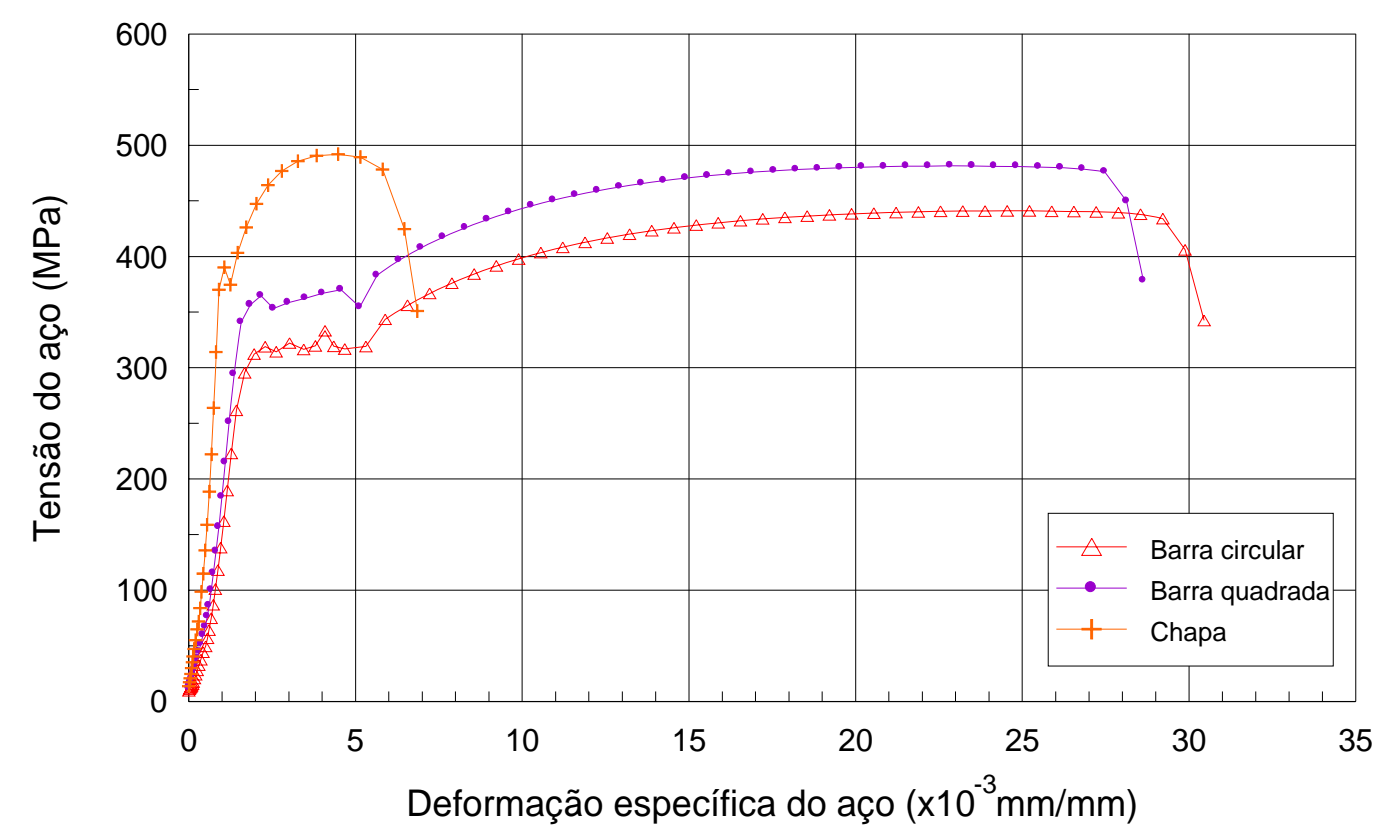

Figura 6.1 - Gráfico tensão do aço versus deformação para os dispositivos de transferência

\subsubsection{Camada de Borracha}

Amostras das borrachas empregadas na base dos modelos foram ensaiadas para a determinação das propriedades mecânicas: Dureza, Deformação Permanente à Compressão sob Deformação Constante e Compressão, segundo respectivamente a ASTM D2240 (2005), a ASTM D395 (2003) e a ASTM D 575 (2001).

Após a realização de cinco leituras em durômetro analógico sobre a face superior de cada amostra, foi feita uma média para a determinação de sua dureza, antes e depois de aquecida à temperatura de $70^{\circ} \mathrm{C}$ em estufa. O lote 1 corresponde às amostras 1.1 a 1.4, da borracha utilizada na UFG, e o lote 2 às amostras 1.5 a 1.8, da borracha adquirida para a etapa realizada na EESC-USP. A Figura 6.2 apresenta o gráfico dureza versus amostra da borracha, dos ensaios realizados no Laboratório de Polímeros do Departamento de Materiais da UFSCar.

Pode ser observada uma redução da dureza inicial $\left(D_{i}\right)$ em torno de $13 \%$, após seu aquecimento $\left(D_{f}\right)$, no entanto permanecendo no intervalo de tolerância permitida pela norma, de 5 Shore A. Isto indica que ambos os lotes, adquiridos em regiões diferentes do país, apresentaram a mesma propriedade de dureza. 


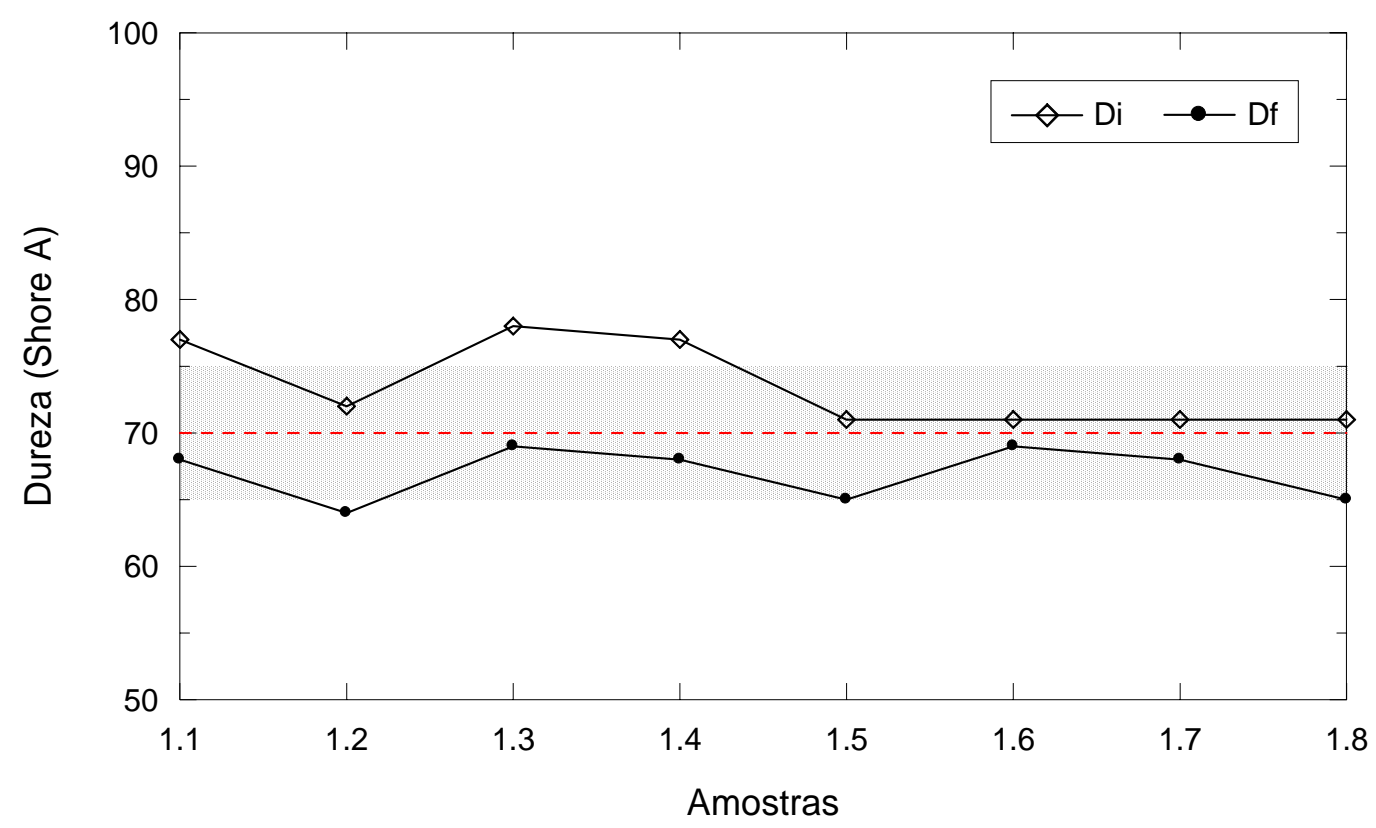

Figura 6.2 - Gráfico dureza versus amostra da borracha utilizada na fundação

As taxas de compressão $C$ das amostras para o ensaio de Deformação Permanente à Compressão sob Deformação Constante, segundo a ASTM D395 (2003), são apresentadas na Tabela 6.4. Com o limite máximo especificado pelo fabricante para a deformação permanente de compressão de 50\%, foi observado que os lotes de borracha adquiridos atenderam às especificações técnicas, com valores inferiores aos estabelecidos.

Tabela 6.4 - Taxa de compressão das amostras

\begin{tabular}{|c|c|c|c|c|c|c|c|c|}
\hline Características & \multicolumn{5}{|c|}{ Lote 1 } & \multicolumn{3}{c|}{ Lote 2 } \\
\hline Amostra & 1.1 & 1.2 & 1.3 & 1.4 & 1.5 & 1.6 & 1.7 & 1.8 \\
\hline $\begin{array}{c}\text { Taxa de } \\
\text { Compressão (\%) }\end{array}$ & 29 & 32 & 34 & 32 & 35 & 34 & 35 & 34 \\
\hline
\end{tabular}

A deformação sofrida pela amostra 1.5 provocou uma deformação máxima de 35\%, inferior à taxa de compressão, ou seja, os lençóis de borracha conservaram, de maneira geral, suas propriedades elásticas, depois de submetidas a tensões de compressão durante longo período.

Para a determinação das propriedades da borracha à compressão, foram feitos ensaios em amostras com diâmetros de 7,62mm com 14 camadas (vide Figura 
4.30), para um deslocamento de 12mm/min, segundo ASTM D 575 (2001). A Figura 6.3 fornece o gráfico tensão versus deslocamento vertical, para os dois lotes de borracha.

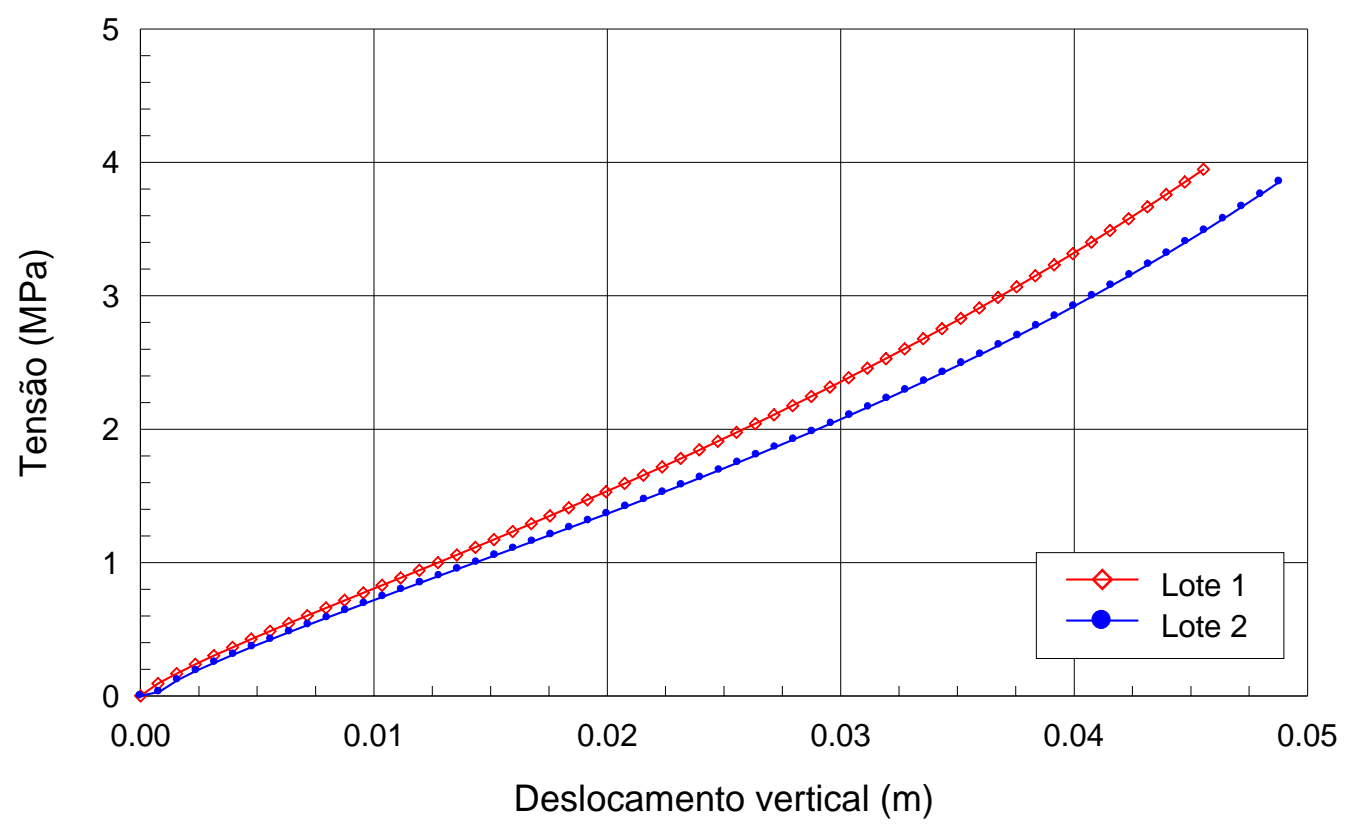

Figura 6.3 - Gráfico tensão versus deslocamento vertical da borracha

Ensaios na base elástica foram feitos para determinação do coeficiente de recalque $k$. Esses ensaios objetivaram apenas controlar variações da capacidade de suporte da base, após ensaios consecutivos, e torná-la a mais uniforme possível. Para tanto, foram feitas provas de carga em intervalos de ensaios estáticos e cíclicos, com algumas substituições de lençóis de borracha quando julgado necessário.

A determinação do $k$ da base empregou a metodologia do DNER (1989), com a qual, por meio de incrementos de força aplicada sobre uma placa metálica de $80 \mathrm{~cm}$ de diâmetro, determinaram-se os deslocamentos verticais. Alguns desses ensaios estáticos foram efetuados com deslocamento controlado, a uma taxa de 0,05mm/s, por meio de atuador servo-hidráulico ligado a um computador.

A plotagem do gráfico tensão versus deslocamento vertical é apresentada na Figura 6.4. Os valores positivos se referem à compressão. O ensaio inicial, realizado no Laboratório de Estruturas da EESC-USP, ocorreu no final do ano de 2006. Ensaios subsequentes foram efetuados intermediariamente aos testes nos modelos, com substituição dos dois lençóis de borracha da face superior da base, no dia 
22/02/2007. Essa primeira substituição visou o rearranjo da base, para acréscimo do valor $k$. Contudo, esse valor permaneceu praticamente o mesmo.

Em 21/03/2007(a), foram feitas novas leituras para avaliação do comportamento da borracha, depois que todos os ensaios estáticos foram realizados. Até então, não havia sido identificado modificações significativas no valor do $k$.

Prevendo uma queda maior no coeficiente de recalque, devido a danos progressivos e permanentes na borracha, ocasionados pelos ensaios cíclicos, foram substituídos, no dia 21/03/2007(b), mais quatro lençóis subjacentes, perfazendo um total de seis novos lençóis de borracha.

Em 25/06/2007 foram feitas leituras finais do coeficiente de recalque, após terem sido aplicados à base um valor superior a $10^{6}$ ciclos.

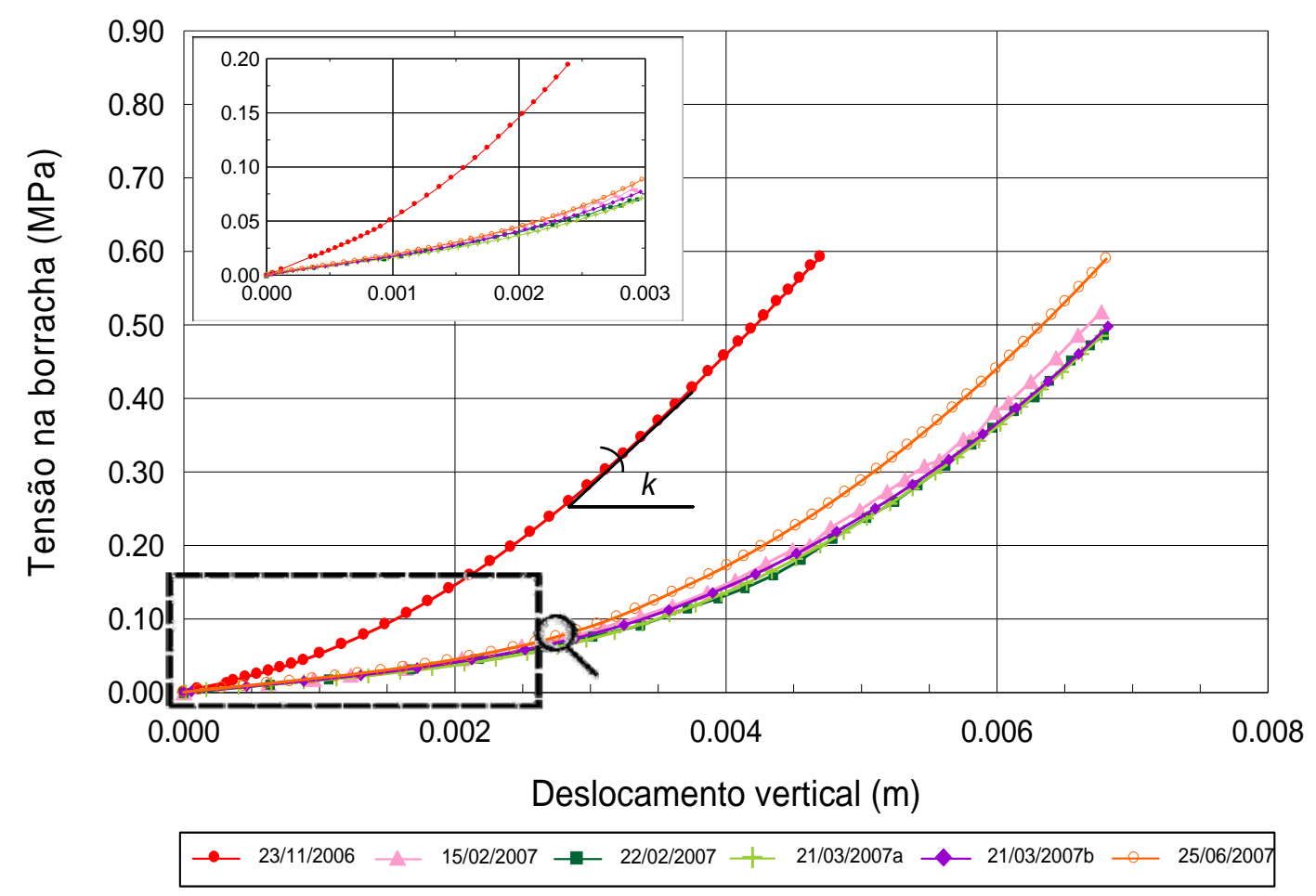

Figura 6.4- Gráfico pressão versus deslocamento da borracha, e em detalhe trechos parabólicos

Entendeu-se que a curva inicial representativa do polinômio, em detalhe na Figura 6.4, correspondeu à acomodação sofrida pela borracha a baixas pressões, eliminando temporariamente bolsões de ar existentes entre os lençóis. Estes bolsões criam espaços vazios e diminuem a aderência entre as faces dos lençóis, como visualizado na Figura 6.5, à esquerda. 


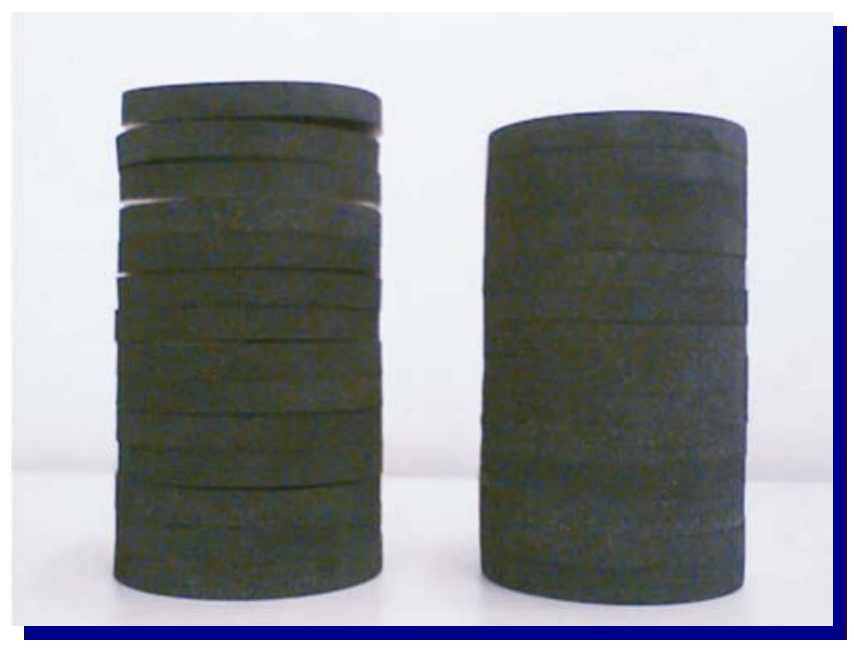

Figura 6.5 - Corpo-de-prova de borracha em estado inicial (esquerda) e depois de comprimido (direita)

Com a força aplicada diminuindo o ar circundante, verificou-se uma recuperação do coeficiente de recalque, com valores de deslocamentos verticais equivalentes aos máximos deslocamentos da junta, obtidos nos ensaios dos modelos. Portanto, a inclinação da reta tangente ao trecho retilíneo serviu de parâmetro para a determinação do $k$. A Tabela 6.5 fornece os resultados obtidos para o coeficiente de recalque.

Tabela 6.5 - Coeficiente de recalque da borracha

\begin{tabular}{|c|c|c|c|c|c|c|c|}
\hline \multirow{2}{*}{ Data } & UFG & \multicolumn{6}{|c|}{ EESC-USP } \\
\cline { 2 - 8 } & $13 / 05 / 05$ & $23 / 11 / 06$ & $15 / 02 / 07$ & $22 / 02 / 07$ & $21 / 03 / 07^{2}$ & $21 / 03 / 07 \mathrm{~b}$ & $25 / 06 / 07$ \\
\hline $\begin{array}{c}\text { Coeficiente de } \\
\text { recalque } k \\
(\mathrm{MPa} / \mathrm{m})\end{array}$ & 165 & 185 & 161 & 156 & 155 & 153 & 170 \\
\hline
\end{tabular}

Verificou-se que as leituras do dia 23/11/2006 diferem das demais, em virtude da modificação do valor $k$, havendo diminuição de $24 \mathrm{MPa} / \mathrm{m}$ entre o primeiro e o segundo ensaio. Essa variação possivelmente ocorreu pelo surgimento de deformações permanentes sofridas pela borracha. Vale ressaltar que a metodologia do DNER (1989) foi desenvolvida para solos e em ensaios no campo. 


\subsection{CISALHAMENTO DUPLO}

Para se determinar apenas a contribuição do modelo na rigidez do sistema placafundação sem a borracha, foram feitos ensaios em corpos-de-prova prismáticos dotados de dispositivos de transferência de esforços. A Tabela 6.6 apresenta a força cortante de fissuração $F_{\text {fiss }}$ e de ruína $F_{u}$, as relações entre estágios de força e variação na espessura, assim como a deformação $\varepsilon$ do dispositivo metálico, na ruptura do corpo-de-prova. Danos ocorridos nos corpos-de-prova CD-JS12DMM e CD-JS16PMM inviabilizaram seus ensaios.

A força de fissuração correspondeu em média a 15\% da força de ruína, com exceção de CD-JS12BQM. Verificou-se que na ruptura dos corpos-de-prova a deformação dos dispositivos foi inferior à deformação no escoamento, como visualizado na Tabela 6.3. O aumento de espessura aumentou mais significamente a força de ruína, para os corpos-de-prova com barra de seção quadrada.

Tabela 6.6 - Estágios do ensaio de cisalhamento duplo

\begin{tabular}{|c|c|c|c|c|c|c|}
\hline Corpo-de -prova & 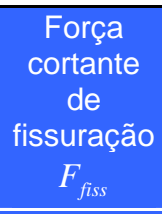 & $\begin{array}{l}\text { Força } \\
\text { cortante de } \\
\text { ruína } \\
F_{u}\end{array}$ & $\frac{F_{f}}{F_{u}}$ & $\frac{h_{16 \mathrm{~cm}}}{h_{12 \mathrm{~cm}}}$ & $\begin{array}{l}\text { Deformação do } \\
\text { dispositivo na } \\
\text { ruptura } \\
\varepsilon\end{array}$ & $\begin{array}{c}\text { Deformação } \\
\text { no } \\
\text { escoamento } \\
\varepsilon_{y}\end{array}$ \\
\hline & $\mathrm{kN}$ & $\mathrm{kN}$ & $\mathrm{kN} / \mathrm{kN}$ & $\mathrm{cm} / \mathrm{cm}$ & $\mathrm{mm} / \mathrm{mm}$ & $\mathrm{mm} / \mathrm{mm}$ \\
\hline CD-JS12BCM & 17,9 & 128,3 & 0,14 & \multirow{2}{*}{1,12} & 0,00052 & 0,0016 \\
\hline CD-JS16BCM & 17,7 & 143,1 & 0,12 & & 0,00086 & 0,0016 \\
\hline CD-JS12BQM & 39,9 & 105,6 & 0,38 & \multirow{2}{*}{1,52} & 0,00005 & 0,0013 \\
\hline CD-JS16BQM & 19,2 & 160,5 & 0,12 & & 0,00076 & 0,0016 \\
\hline CD-JS12PMM & 21,4 & 99,9 & 0,21 & & 0,00081 & 0,0016 \\
\hline CD-JS16DMM & 18,8 & 133,7 & 0,14 & & 0,00002 & 0,0013 \\
\hline
\end{tabular}

As Figura 6.6 e 6.7 apresentam gráficos força aplicada versus deformação específica do aço nas posições Esup e Einf, respectivamente. Observa-se que os dispositivos de transferência foram tracionados na porção central estudada.

Os dispositivos em barra (CD-JS12BCM, CD-JS12QCM, CD-JS16BCM, CDJS16QCM) sofreram deformações mais significativas, se comparados aos dispositivos em chapa (CD-JS12PMM, CD-JS16DMM), sem no entanto atingirem o limite de escoamento. 


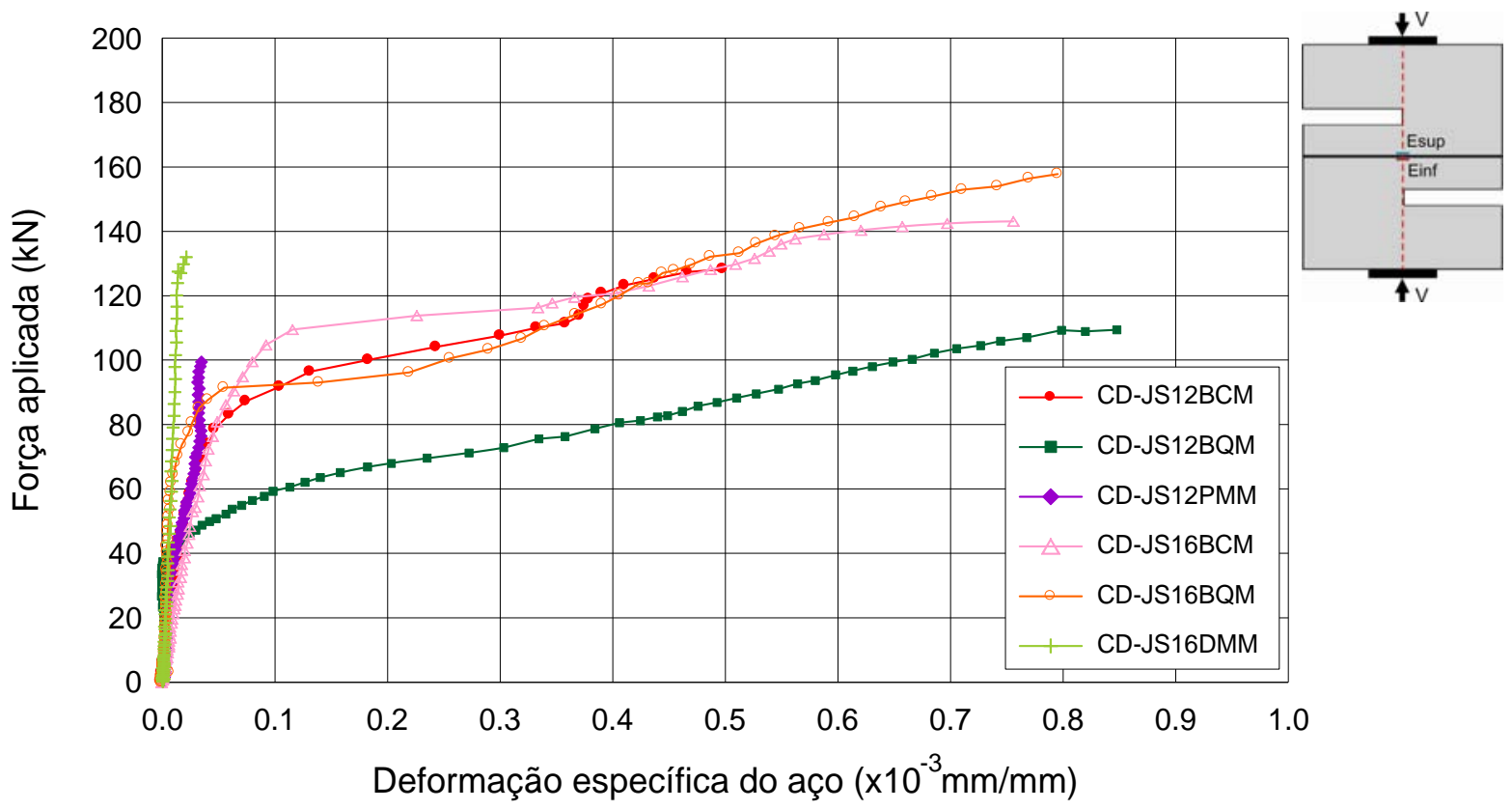

Figura 6.6 - Gráfico força aplicada versus deformação específica do aço em Esup

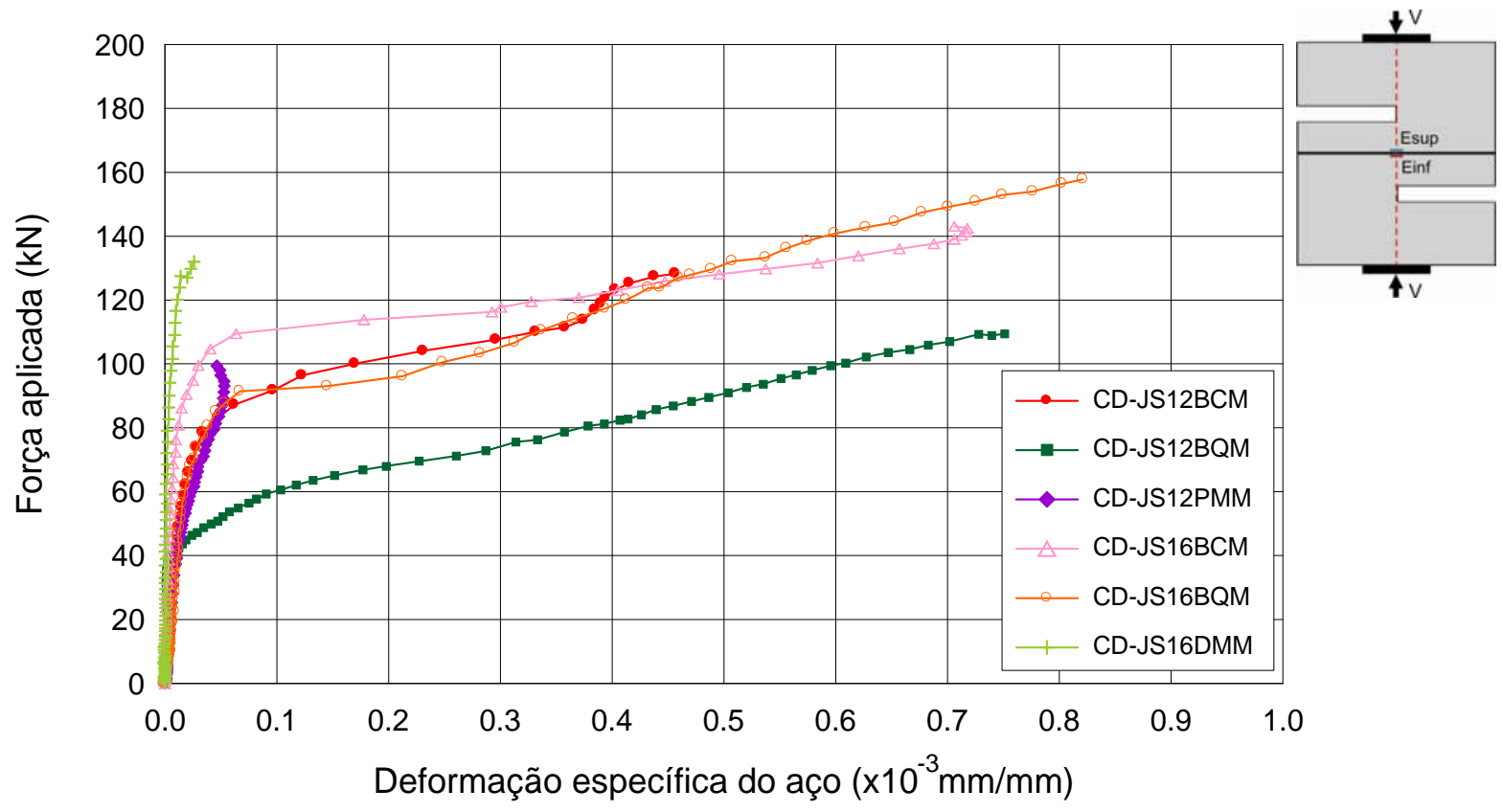

Figura 6.7 - Gráfico força aplicada versus deformação específica do aço em Einf

A configuração de ruptura dos corpos-de-prova dotados de dispositivos em barra é apresentada na Figura 6.9. Verficou-se que a ruptura ocorreu sobre o Plano Cortante, com surgimento de fissuração paralela ao seu eixo. Isto indica que o material, fora da zona de cisalhamento, foi confinado, evitando-se assim extensão de fissuras fora dessa zona. 


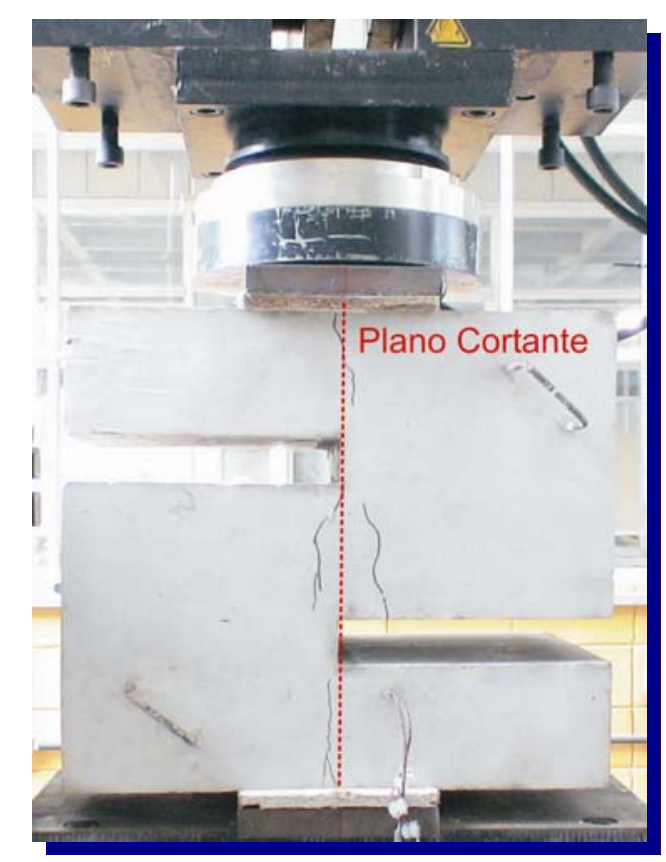

Figura 6. 8 - Configuração de ruptura sobre o Plano Cortante

Para o caso de corpos-de-prova dotados de dispositivos em chapa (placa e disco metálico) observou-se que a porção central do corpo-de-prova sofreu uma rotação $\theta$ no sentido anti-horário, como apresentado na Figura 6.9a. A inexistência de armadura que cortasse o plano de carga permitiu que a porção central rotacionasse de modo independente, quando solicitada pelo par de forças de compressão, produzindo tensões normais $\left(\sigma_{x^{\prime}}\right.$ e $\left.\sigma_{y^{\prime}}\right)$ e tensões de cisalhamento $\left(\tau_{x^{\prime} y^{\prime}}\right)$ rotacionadas em um ângulo $\theta$, Figura 6.9c. A fissuração decorrente ocorreu fora do Plano Cortante, com fissuras curvas e compreendidas entre as arestas dos dispositivos, como visualizado em detalhe na Figura 6.9d. Esta situação ocorre, segundo Wang e Bittencourt (1998), quando a zona de cisalhamento não é suficientemente confinada, desenvolvendo um estado de tensão misto (tração uniaxial e cisalhamento), com propagação da fissura em trajetória curva. 


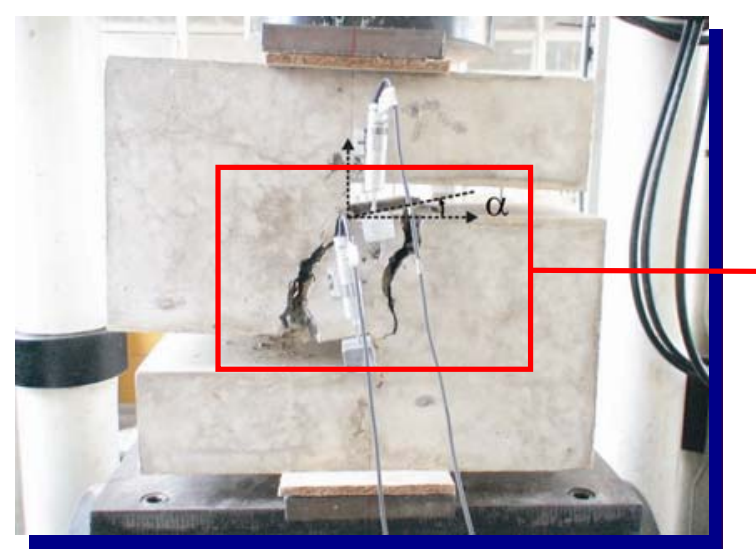

(a)

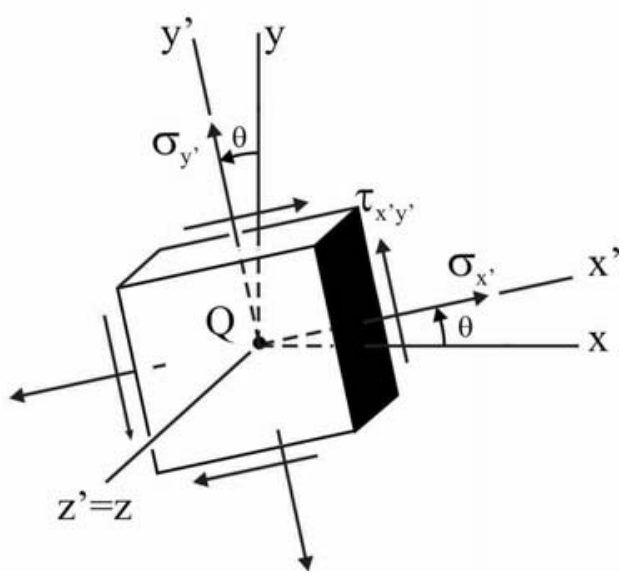

(c)

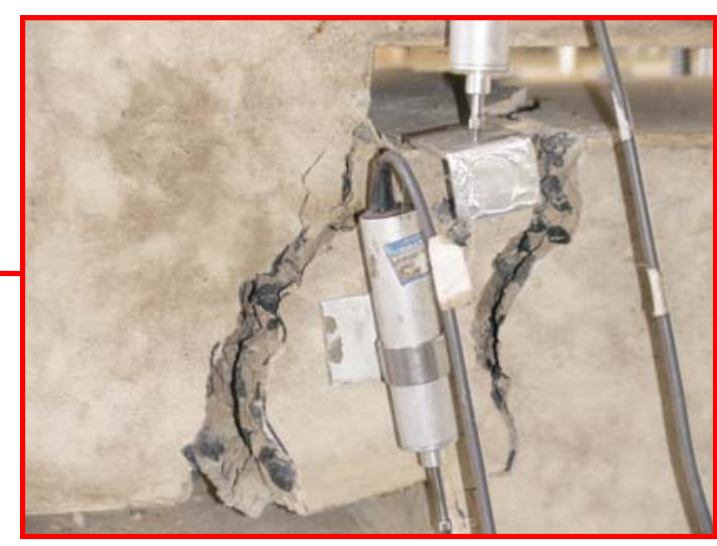

(b)

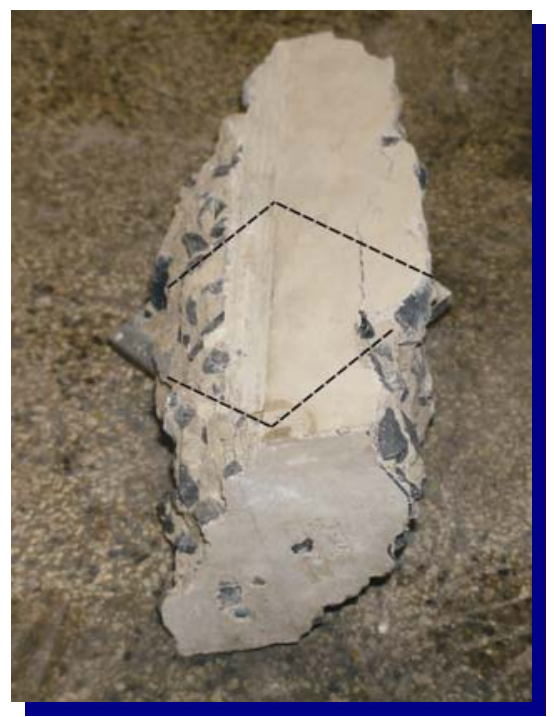

(d)

Figura 6.9 - Ensaio de cisalhamento duplo: (a) configuração pós-ruptura, (b) detalhe da rotação sofrida, (c) estado de tensão,(d) porção central extraída do corpo-de-prova

Os deslocamentos verticais nos corpos-de-prova CD-JS12PMM e CD-JS16DMM são apresentados na Figura 6.10 . 


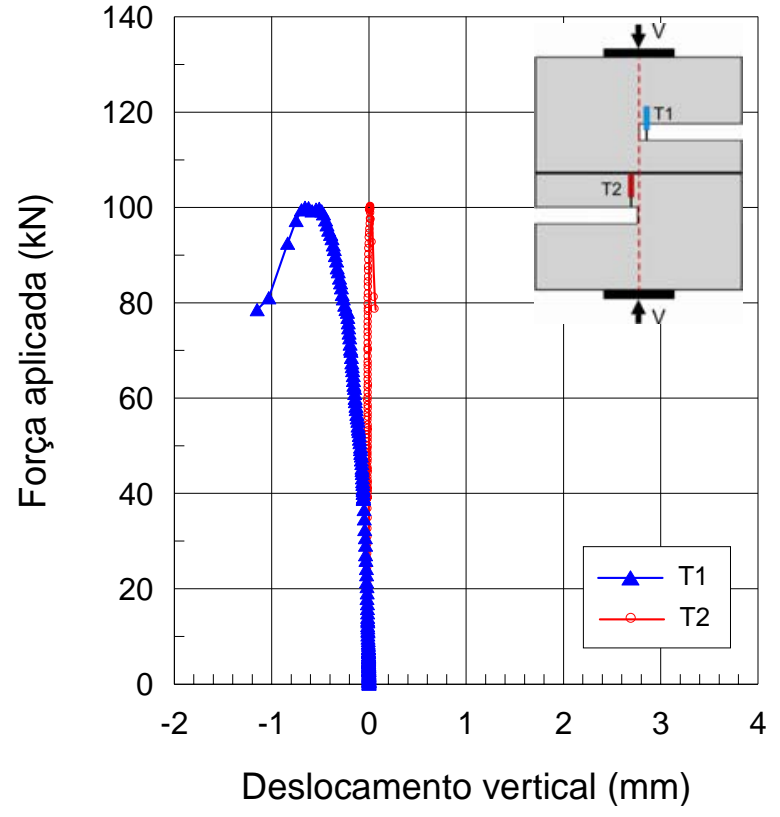

(a)

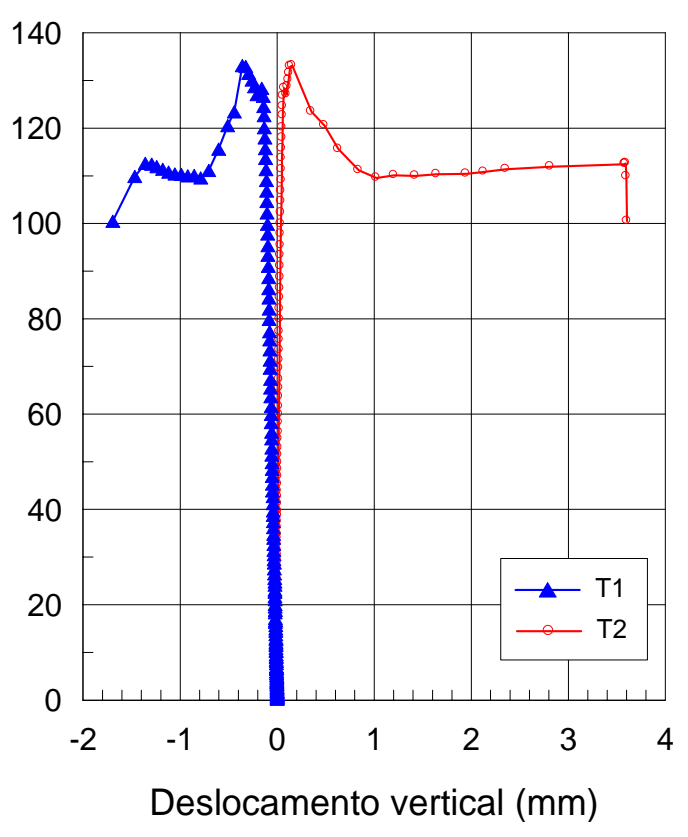

(b)

Figura 6.10 - Gráfico força aplicada versus deslocamento vertical em: (a)CD-SJ12PMM, (b) CDJS16DMM

\subsection{FISSURAÇÃO}

O mapeamento da fissuração nas faces superior e lateral dos modelos foi identificado e mensurado para elaboração dos desenhos esquemáticos mostrados neste item. Fotografias retratam detalhes da configuração pós-ruptura, como apresentado na Figura 6.11, e fornecem informações a respeito do processo gradativo e sequencial de formação de fissura, Figura 6.12. Não foram registrados esses dados, nos modelos preliminares. 


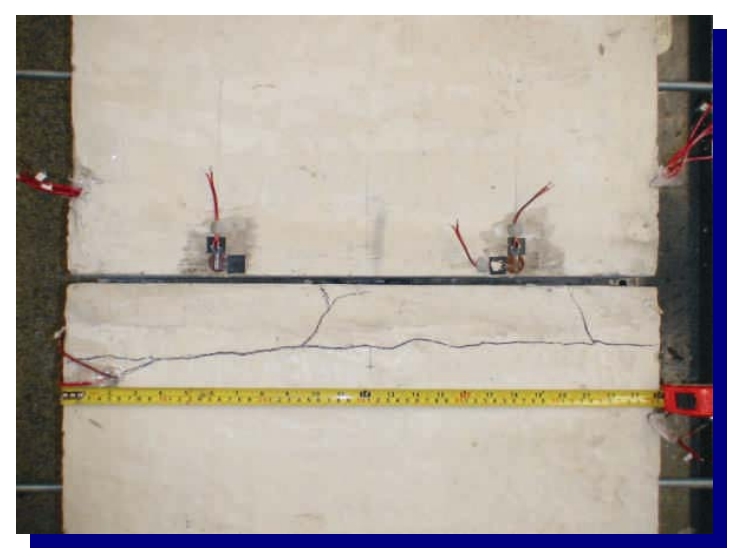

(a)

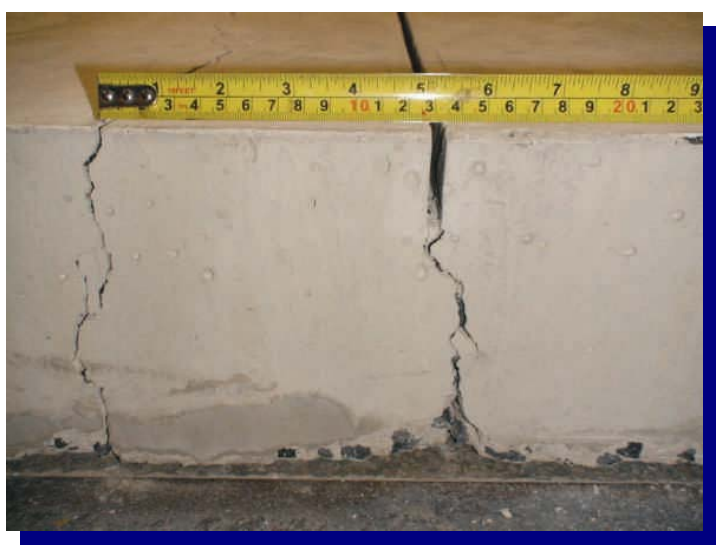

(b)

Figura 6.11 - Fotografias em escala para marcação de fissura: (a) vista superior, (b) vista lateral e força aplicada à esquerda da junta
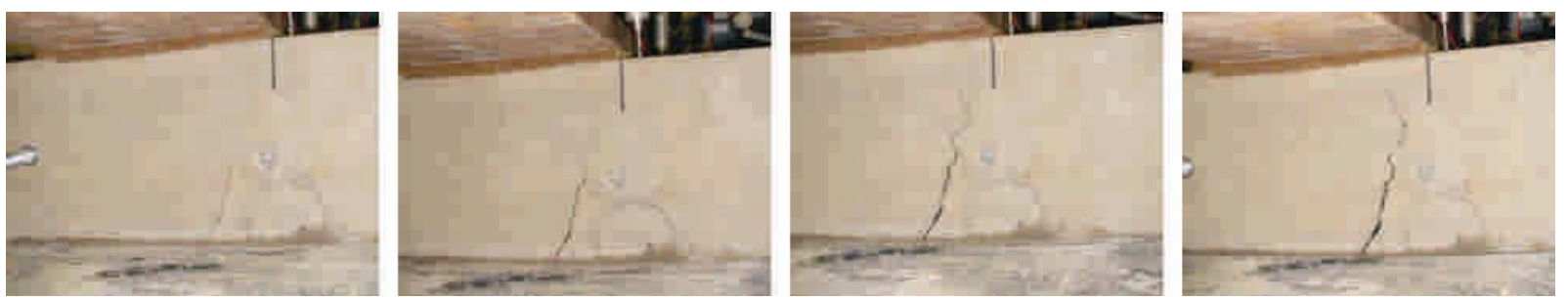

Figura 6.12 - Vista lateral da propagação da fissuração no modelo JS16SDM

Em geral, os modelos exibiram fissuras transversais inclinadas, alinhadas com as juntas das placas, sob a placa de distribuição de carga. Na vista lateral dos modelos com junta serrada, fissuras predominantemente coplanares e curvas se formaram, enquando que nos modelos com junta moldada, apareceram fissuras inclinadas.

\subsubsection{Modelos com junta serrada}

As Figura 6.13 e 6.14 apresentam esquematicamente, em vista lateral, a configuração de ruptura, respectivamente dos modelos: carregados monotonicamente com junta serrada e dispositivos, e com junta serrada sem dispositivos. A Figura 6.15 apresenta os modelos submetidos a carregamento cíclico.

As fissuras dos modelos com junta serrada surgiram inicialmente na face inferior da placa, sob o ponto de aplicação da força e paralela a junta, uma vez atingida a resistência do concreto à tração na flexão. Estas fissuras se propagaram, posteriormente, em direção à face superior da placa e/ou em direção à abertura da 
junta. O desenvolvimento da fissuração foi acompanhado apenas nas superfícies externas do modelo.

Foram detectados três tipos de fissuras formadas nos modelos:

- Fissura curva: surgida devido à insuficiência no confinamento do concreto, tendo sido provavelmente desenvolvido um estado de tensão do modo misto (compressão uniaxial e cisalhamento).

- Fissura inclinada: surgida devido à perda de resistência do concreto à tração na flexão.

- Fissura inclinada de separação: surgida devido à perda de resistência do concreto à tração na flexão e que leva à ruptura do modelo.

Como resultado de um processo de localização do dano numa certa região de pequena largura do meio, os modelos submetidos a carregamento cíclico apresentaram uma maior propagação das fissuras, se comparados aos similares submetidos a carregamento monotônico. A Figura 6.16 apresenta os estágios de fissuração para o modelo JS12DMC, sob carregamento estático, após ser submetido a 300.000 ciclos de carregamento. 


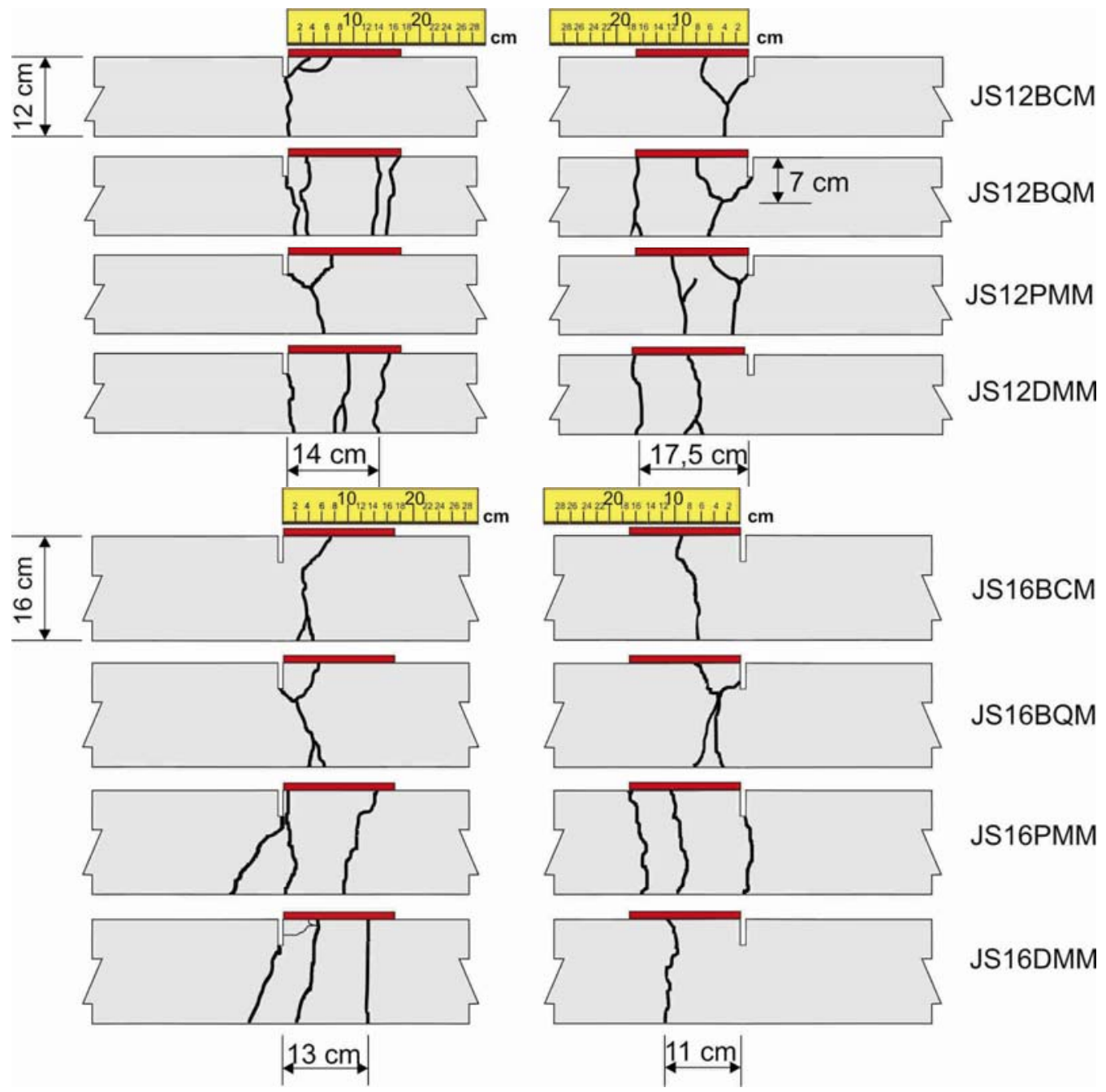

Figura 6.13 - Vista lateral dos modelos serrados, carregados monotonicamente e com dispositivos
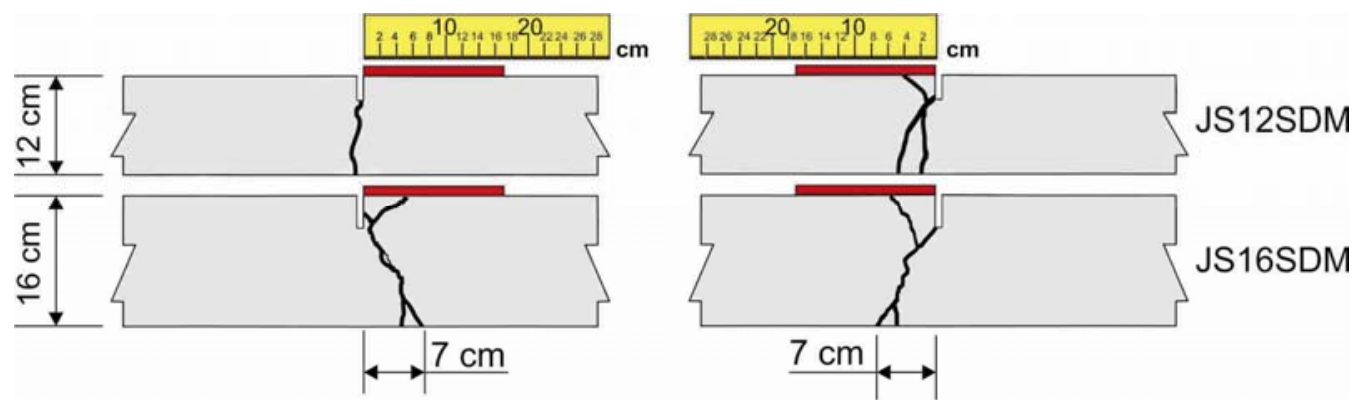

Figura 6.14 - Vista lateral dos modelos serrados, carregados monotonicamente e sem dispositivos 

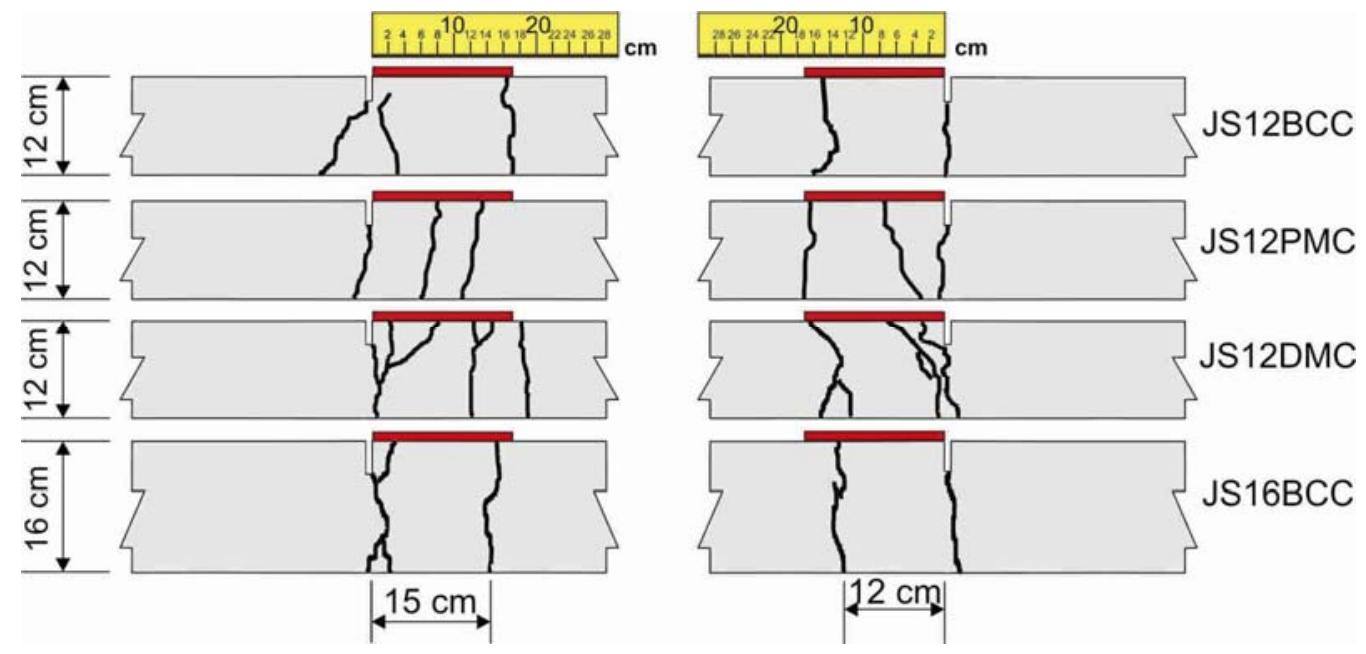

Figura 6.15 - Vista lateral dos modelos serrados, com carregamento cíclico e dispositivos
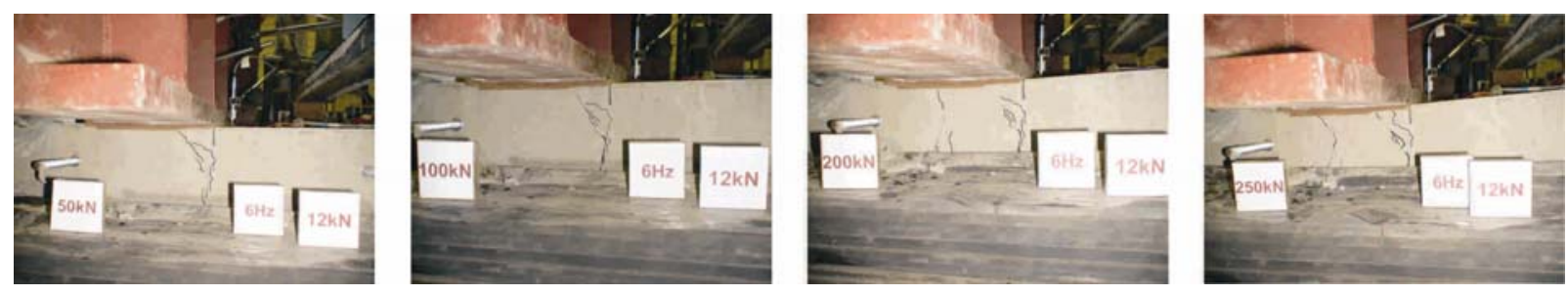

Figura 6.16 - Estágios de fissuração para o modelo JS12DMC em carregamento estático, após ser submetido a 300.000 ciclos de carregamento

\subsubsection{Modelos com junta moldada}

Nos modelos com junta moldada, a fissuração surgiu predominantemente sob a região carregada, partindo da face inferior no sentido da face superior, como apresentado na Figura 6.17.

Os modelos JM16BCM e JM16BQM apresentaram fechamento da junta, como visualizado, respectivamente, na Figura 6.19 e 6.20. Com o fechamento da junta, verificou-se uma deformação excessiva dos dispositivos em barra e de seções circular e quadrada, acima do limite de escoamento. O modelo JM16BQM não apresentou fissuração visual.

A compressão biaxial sob a placa de distribuição de carga e as tensões de esmagamento no modelo JM16DMM (Figura 6.20a e 6.20b) foram suficientes para fragmentar as faces da junta, como ocorrido nos experimentos realizados por Eddie, Shalaby e Rizkalla (2001) e apresentados nas Figuras 6.20c e 6.19d. 


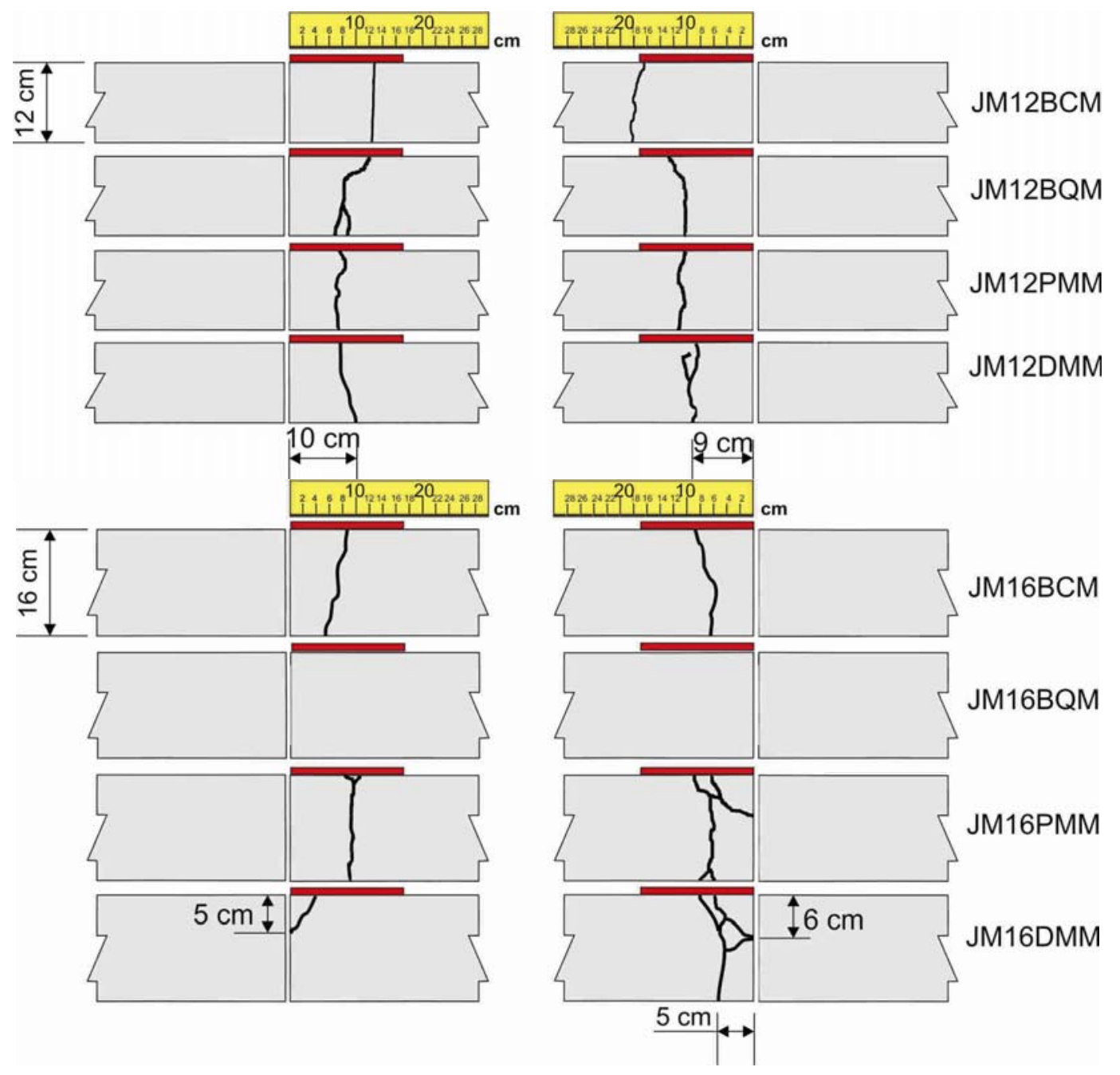

Figura 6.17 - Vista lateral dos modelos com juntas moldadas e com dispositivos, carregados monotonicamente 


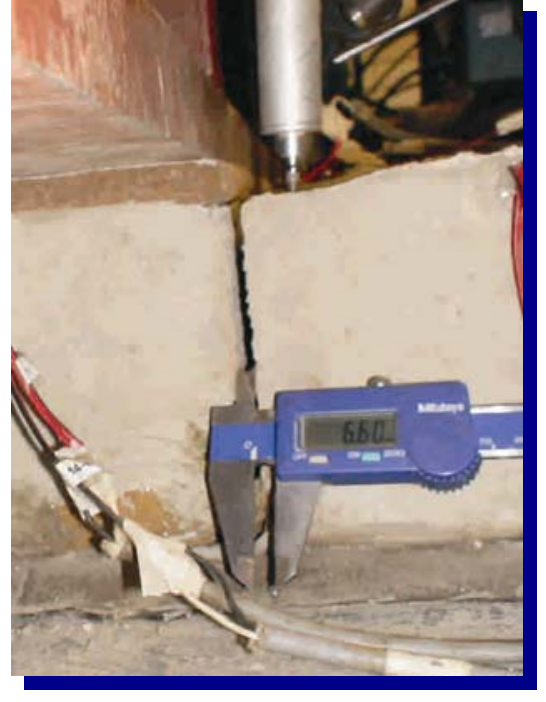

(a)

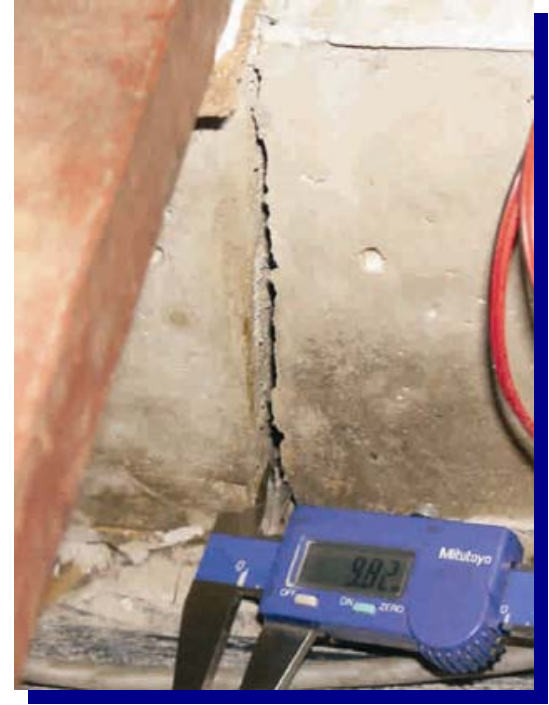

(b)

Figura 6.18 - Acompanhamento do fechamento da junta moldada no modelo JM16BCM, com paquímetro digital

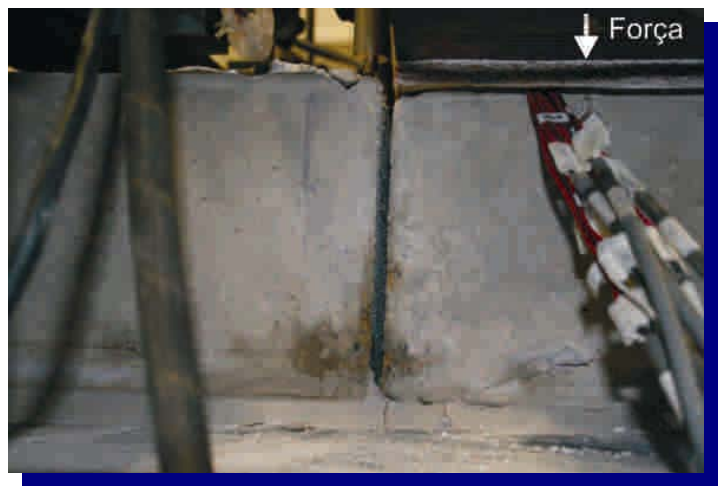

(a)

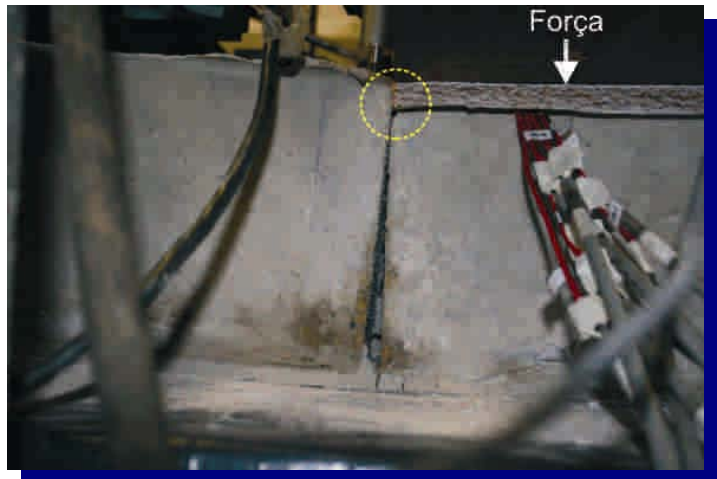

(b)

Figura 6.19 - Junta moldada do modelo JM16BQM: (a) abertura inicial, (b) fechamento da junta 


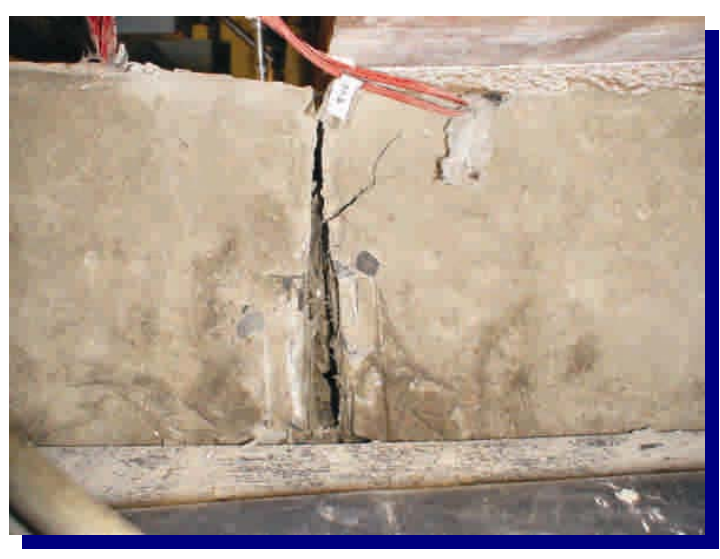

(a)

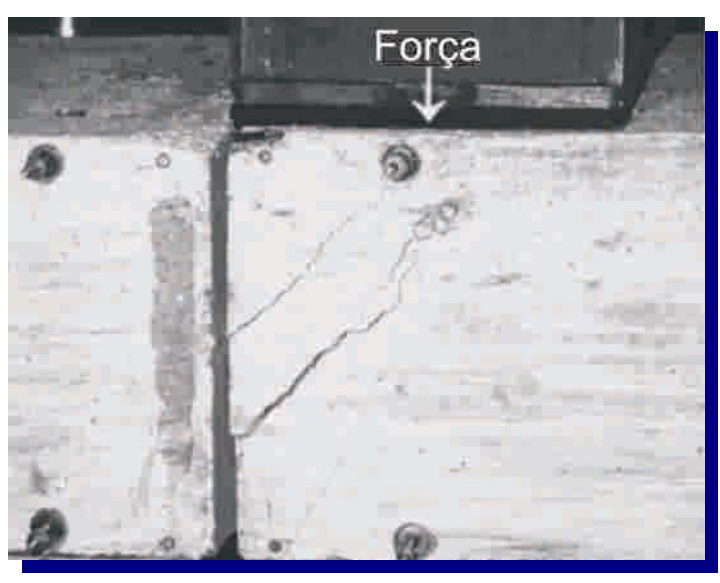

(c)

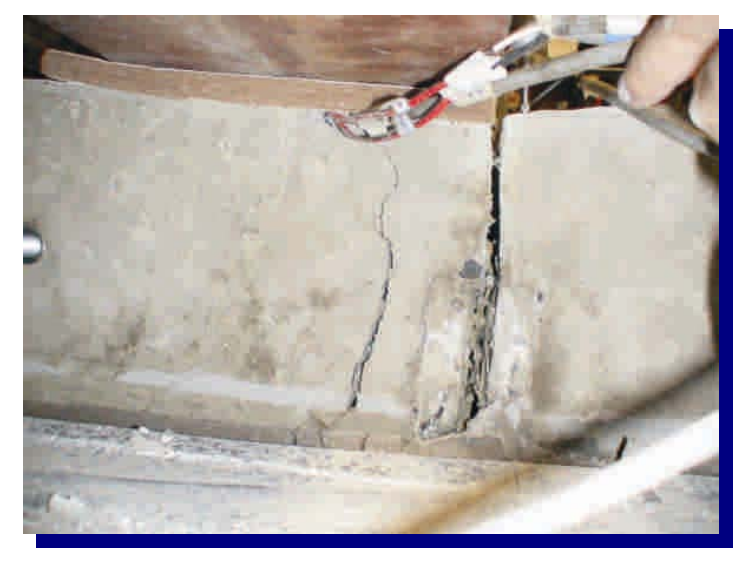

(b)

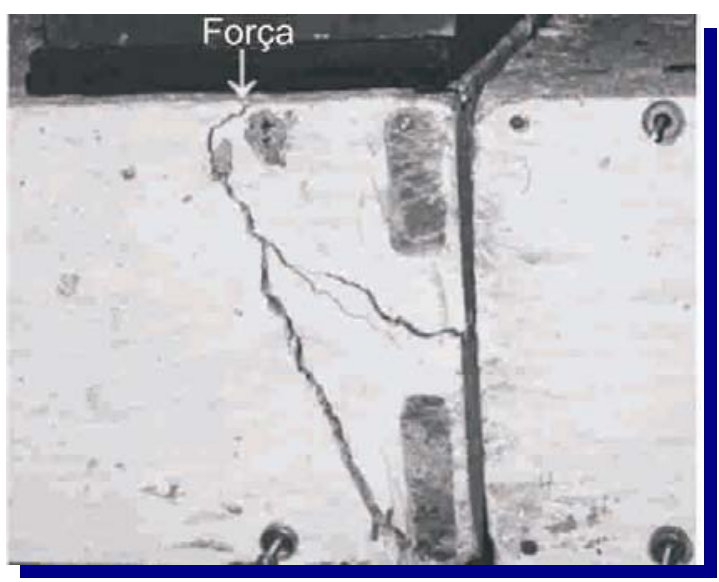

(d)

Figura 6.20 - Fissuração e esmagamento do concreto em ambos os lados do modelo(a)(b) Laboratório de Estruturas da EESC-USP, (c)(d) Fonte: Eddie, Shalaby e Rizkalla (2001)

\subsection{MODOS DE RUÍNA E CRITÉRIO DE PARADA DOS ENSAIOS}

\subsubsection{Modos de ruína}

Os modelos apresentaram modo de ruína devido predominantemente a forças de tração na flexão e ruptura do concreto à compressão, na fibra superior do modelo.

A ruptura do concreto à compressão é característica em peças submetidas à flexão, em que ocorre esmagamento do concreto e, em geral, escoamento da armadura, quando ela existir. Esse processo se originou com a rotação das placas em torno do eixo da junta, provocando seu fechamento. Este fechamento pode ou não ser acompanhado do esmagamento do concreto, nas proximidades das faces da junta. 
A extensometria inserida na região não carregada, não detectou a ruptura do concreto nos modelos JM16BCM e JM16BQM, únicos que tiveram fechamento da junta.

A ruptura ocasionada por forças de tração na flexão, nos modelos serrados e submetidos a carregamento monotônico, foi caracterizada pela formação de fissuras sob a junta. Para os modelos dotados de dispositivos em chapa (placa ou disco metálicos), verificou-se o surgimento de fissuras também sob a viga de distribuição de carga, a uma determinada distância da junta, causando separação de partes da placa.

Já era esperado o surgimento de fissura sob a junta, uma vez que esta é formada pela criação de uma seção enfraquecida na placa de concreto, direcionando e forçando a ocorrência de fissuração em locais previamente determinados.

A inexistência de armadura que cortasse o plano de carga dos modelos com dispositivo em chapa permitiu que a fissuração ocorresse também fora do Plano Cortante, com fissuras curvas e compreendidas entre as arestas dos dispositivos. Exepcionamente o modelo JS16BCM apresentou fissuração fora do alinhamento da junta.

A ruptura ocasionada por forças de tração na flexão, nos modelos serrados e submetidos a carregamento cíclico, foi caracterizada pela formação de fissuras, tanto na junta quanto sob a área carregada.

Não foi verificada a ruptura por fadiga, que é caracterizada pela ruptura de uma peça sob esforços repetidos a uma tensão inferior à resistência obtida em ensaios estáticos.

A ruptura ocasionada por forças de tração na flexão, nos modelos moldados, foi caracterizada pela formação de fissuras sob a área carregada, distantes da abertura da junta.

\subsubsection{Critério de parada dos ensaios}

Nos modelos serrados, sem dispositivos de transferência, a ruína era caracterizada pela diminuição dos deslocamentos verticais e separação das placas, determinando o fim do ensaio. 
Nos modelos serrados, com dispositivos de transferência, a parada do ensaio era adotada quando se percebia uma diminuição considerável na transferência de carga, com a perda de carga registrada pelas células sobre a junta e/ou pelos transdutores de deslocamentos, embora em vários casos o aço já tivesse escoado.

Nos modelos moldados, foram utilizados como critérios de parada o fechamento da junta, com levantamento excessivo das bordas das placas e perda de transferência de carga, registrada por queda nas leituras de força e de deslocamento.

A Tabela 6.7 apresenta um resumo dos critérios de parada adotados durante os ensaios e dos prováveis modos de ruptura dos modelos. 
Tabela 6.7 - Quadro resumo sobre ruptura

\begin{tabular}{|c|c|c|c|}
\hline Modelo & $\begin{array}{c}\text { Critério de parada do } \\
\text { ensaio }\end{array}$ & Modo de ruptura & Aplicação de carga \\
\hline PJS12BCM & 1 & 7 & \multirow{19}{*}{$\begin{array}{l}\text { Carregamento } \\
\text { monotônico }\end{array}$} \\
\hline JS12BCM & 1 & 7 & \\
\hline JS12BQM & 1 & 7 & \\
\hline JS12PMM & 4 & 7 & \\
\hline JS12DMM & 1 & 7 & \\
\hline JS16BCM & 4 & 7 & \\
\hline JS16BQM & 1 & 7 & \\
\hline JS16PMM & 1 & 7 & \\
\hline JS16DMM & 1 & 7 & \\
\hline JM12BCM & 2 & 7 & \\
\hline JM12BQM & 2 & 7 & \\
\hline JM12PMM & 2 & 7 & \\
\hline JM12DMM & 2 & 7 & \\
\hline JM16BCM & 5 & 8 & \\
\hline JM16BQM & 5 & 8 & \\
\hline JM16PMM & 2 & 7 & \\
\hline JM16DMM & 2 & 7 & \\
\hline JS12SDM & 6 & 7 & \\
\hline JS16SDM & 6 & 7 & \\
\hline JS12BCC & 4 & 7 & \multirow{4}{*}{ Carregamento cíclico } \\
\hline JS12PMC & 1 & 7 & \\
\hline JS12DMC & 1 & 7 & \\
\hline JS16BCC & 1 & 7 & \\
\hline \multicolumn{4}{|c|}{$\begin{array}{l}\text { [1] Queda registrada nas leituras das células de carga e dos transdutores; [2] Escoamento } \\
\text { do aço; [3] Queda nas leituras das células de carga; [4] Queda nas leituras dos } \\
\text { transdutores; [5] Fechamento da junta; [6] Separação das placas; [7] Ruptura do concreto à } \\
\text { tração; [8] Possível ruptura do concreto à compressão. }\end{array}$} \\
\hline
\end{tabular}

O modelo PJS12BCM apresentou queda nas leituras das células de carga, estabelecida como critério de parada para o ensaio.

Nos ensaios subsequentes, os modelos serrados JS12BCM, JS12BQM, JS12PMM, JS12DMM, JS16BCM, JS16BQM, JS16PMM, JS16DMM e JS12BCC apresentaram queda nas leituras das células de carga e/ou dos transdutores de deslocamento. No JS16BCC, não foi instalada extensometria, e por isso mesmo o critério estabelecido 
foi queda nas leituras das células de carga e dos transdutores de deslocamento. Os modelos JS12SDM e JS16SDM de concreto simples apresentaram separação visual das placas, além de queda nas leituras das células de carga e dos transdutores de deslocamento.

Para os modelos com junta moldada JM12BCM, JM12BQM, JM12PMM, JM12DMM, JM16PMM e JM16DMM, o carregamento foi cessado quando pelo menos seis extensômetros centrais, distantes do centro geométrico do dispositivo em até $5 \mathrm{~cm}$, seja na face superior seja na inferior e em pelo menos uma face, registraram escoamento do aço $\left(\varepsilon_{y}=0,0016\right)$. Esse critério se refere aos extensômetros: AS1D, AS2D, AS3D, AS4D, AS7D, AS8D, AS9D, AS12E, AS13E, AS14E, AS17E e AS12E. Em JM16BCM e JM16BQM, foi detectado fechamento da junta.

\subsection{FORÇAS E DESLOCAMENTOS}

Nos itens a seguir serão apresentadas as forças e os deslocamentos verticais sofridos pelos modelos dotados de juntas serradas e moldadas. O comportamento desses parâmetros será analisado por meio de gráficos e de tabelas comparativas, tanto na primeira fissura quanto na ruína, para ensaios estáticos e cíclicos.

\subsubsection{Juntas serradas - ensaio estático}

A força na fissuração no concreto $\left(F_{\text {fiss }}\right)$ foi obtida mediante a mudança na inclinação da curva do gráfico força aplicada versus deslocamento vertical. A deformação atingiu a de escoamento do aço na força $F_{y}$, quando pelo menos seis extensômetros centrais, distantes do centro geométrico do dispositivo em até $5 \mathrm{~cm}$, seja face superior seja na inferior, e em pelo menos uma face, registraram escoamento do aço $\left(\varepsilon_{y \phi}=\varepsilon_{y \#}=0,0016\right.$ e $\left.\varepsilon_{y, \text { chapa }}=0,0013\right)$. A força máxima $\left(F_{u}\right)$, admitida para os modelos dotados de junta serrada em ensaios estáticos, foi atingida quando ocorreram quedas nas leituras dos transdutores de deslocamentos e/ou das células de carga. A Tabela 6.8 apresenta um quadro resumo das forças, para os diferentes modelos. 
Tabela 6.8 - Quadro de forças - junta serrada e ensaio estático

\begin{tabular}{|c|c|c|c|}
\hline \multirow{2}{*}{ Modelo } & $\begin{array}{c}\text { Força de } \\
\text { fissuração } \\
F_{\text {fiss }}\end{array}$ & $\begin{array}{c}\text { Força no } \\
\text { escoamento } \\
F_{y}\end{array}$ & $\begin{array}{c}\text { Força cortante } \\
\text { máxima } \\
F_{u}\end{array}$ \\
\cline { 2 - 4 } & $\mathrm{kN}$ & $\mathrm{kN}$ & $\mathrm{kN}$ \\
\hline PJS12BCM & 50,35 & 129,0 & 280,0 \\
\hline JS12SDM & 15,99 & - & 34,04 \\
\hline JS16SDM & 30,17 & - & 76,45 \\
\hline JS12BCM & 10,19 & 81,23 & 100,40 \\
\hline JS16BCM & 43,09 & 92,84 & 172,24 \\
\hline JS12BQM & 16,05 & 47,93 & 106,78 \\
\hline JS16BQM & 38,88 & 104,84 & 189,54 \\
\hline JS12PMM & 22,26 & - & 74,17 \\
\hline JS16PMM & 23,88 & 132,58 & 134,59 \\
\hline JS12DMM & 22,57 & - & 237,91 \\
\hline JS16DMM & 33,01 & - & 274,41 \\
\hline
\end{tabular}

Verificou-se que para a espessura de $12 \mathrm{~cm}$, o modelo JS12BQM, dotado de dispositivo em barra de seção quadrada, apresentou uma força última superior cerca de $6 \%$ se comparada à do modelo com dispositivo de seção circular JS12BCM. Já o modelo JS12DMM apresentou uma força última cerca de 221\% superior à do JS12PMM. Para a espessura de $16 \mathrm{~cm}$, a força última do modelo JS16BQM foi superior cerca de 10\% em relação à do JS16BCM. O modelo JS16DMM apresentou uma força na ruptura superior da ordem de 104\% à do JS16PMM.

A força na fissuração, para os modelos dotados de discos metálicos, foi superior à dos modelos com placa metálica, da ordem de $1 \%$ e de $38 \%$, respectivamente, para as espessuras de $12 \mathrm{~cm}$ e de $16 \mathrm{~cm}$. Já nos modelos dotados de dispositivos em barra, não foi verificada uma similaridade no comportamento para diferentes espessuras. Para a espessura de $12 \mathrm{~cm}$, verificou-se que $F_{\text {fiss }}$ foi superior em JS12BQM, que atingiu a força de 16,05kN. Para a espessura de $16 \mathrm{~cm}$, verificou-se que $F_{\text {fiss }}$ foi superior em JS16BCM, que atingiu a força de 43,09kN.

Comparando-se o acréscimo na força última devido ao aumento da espessura dos modelos, pode ser avaliado que houve um aumento superior a $72 \%$ na força última, entre os modelos JS12BCM e JS16BCM, dotados de dispositivos em barra de seção 
circular. Já entre os modelos dotados de dispositivos em barra de seção quadrada, JS12BQM e JS16BQM, esse aumento foi da ordem de 78\%. Nos modelos com dispositivos em chapa metálica, JS12PMM e JS16PMM, o aumento na força última foi da ordem de $82 \%$, enquanto que para os modelos com disco metálico, JS12DMM e JS16DMM, foi superior a 15\%. Nos modelos de referência, ou seja, sem dispositivo de transferência de carga, JS16SDM apresentou uma força última cerca de 125\% superior à do JS12SDM.

O aumento da espessura dos modelos também proporcionou aumento em $F_{\text {fiss }}$. A força de fissuração do modelo JS16BCM foi 323\% superior em relação à JS12BCM, e cerca de 142\% entre JS16BQM e JS12BQM. Entre JS16PMM e JS12PMM, essa relação foi da ordem de 7\%; cerca de 46\% entre JS16DMM e JS12DMM, e de 89\% entre JS16SDM e JS12SDM.

A força relativa ao escoamento dos dispositivos em barra foi superior para a espessura de $16 \mathrm{~cm}$, se comparada à de $12 \mathrm{~cm}$. Entre os dispositivos de seção circular, esse aumento foi de 14\%, enquanto que, para os dispositivos de seção quadrada, o aumento foi de aproximadamente 119\%. Dos dispositivos em chapa, apenas JS16PMM apresentou escoamento das placas metálicas, seguido de ruptura.

O dispositivo em barra de seção circular demorou mais a escoar, se comparado ao de seção quadrada, embora $F_{u}$ tenha sido bastante próxima entre os modelos. $O$ modelo JS12BCM atingiu uma força no escoamento cerca de 70\% superior à do JS12BQM, enquanto que no JS16BQM ela foi cerca de $13 \%$ superior, em relação à do JS16BQM.

O ensaio preliminar referente ao modelo PJS12BCM apresentou força de fissuração equivalente a $50,4 \mathrm{kN}$, e força no momento da parada do ensaio igual a $280 \mathrm{kN}$, não tendo sido registrada queda nas leituras de toda a instrumentação. A força no escoamento foi registrada apenas no extensômetro AS3D (vide Tabela 4.6), igual a $129 \mathrm{kN}$.

A Tabela 6.8 apresenta um quadro resumo dos deslocamentos verticais máximos atingidos para os diferentes modelos. A Figura 6.21 indica o posicionamento dos transdutores de deslocamento e dos relógios comparadores dos modelos com juntas serrada e moldada. 
Tabela 6.9 - Quadro de deslocamentos máximos - junta serrada e ensaio estático

\begin{tabular}{|c|c|c|}
\hline \multirow{2}{*}{ Modelo } & $\begin{array}{c}\text { Deslocamento } \\
\text { vertical } \\
\text { T4 }\end{array}$ & $\begin{array}{c}\text { Deslocamento } \\
\text { vertical } \\
\text { T6 }\end{array}$ \\
\cline { 2 - 3 } & $\mathrm{mm}$ & $\mathrm{mm}$ \\
\hline PJS12BCM & 5,24 & 6,66 \\
\hline JS12SDM & 2,24 & 3,44 \\
\hline JS16SDM & 3,02 & 3,56 \\
\hline JS12BCM & 7,12 & 7,66 \\
\hline JS16BCM & 5,13 & 8,24 \\
\hline JS12BQM & 5,64 & 5,99 \\
\hline JS16BQM & 6,82 & 8,85 \\
\hline JS12PMM & 7,37 & 10,02 \\
\hline JS16PMM & 4,98 & 5,15 \\
\hline JS12DMM & 10,24 & 11,03 \\
\hline JS16DMM & 9,47 & 11,53 \\
\hline
\end{tabular}

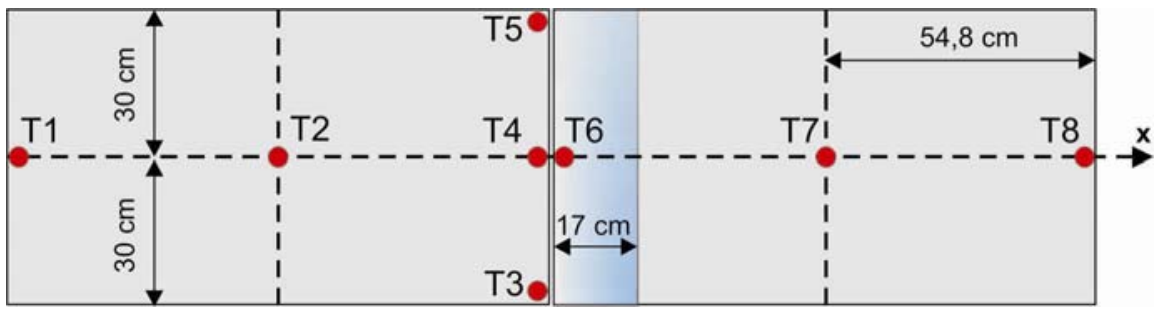

Figura 6.21 - Medidores de deslocamento

O transdutor de deslocamento T4 foi posicionado sobre a junta, no lado não carregado $d_{u}$ ("unload"). Já o transdutor de deslocamento T6 foi posicionado sobre a junta no lado carregado $d_{L}$ ("load"). Em geral, a média das leituras obtidas nos transdutores colocados ao longo do eixo paralelo ao da junta $(y)$ foi empregada na confecção dos gráficos. De maneira geral, o modelo com dispositivo em barra de seção circular sofreu maiores deslocamentos, se comparado ao de seção quadrada. Para os dispositivos em chapa, os modelos com disco metálico sofreram maiores deslocamentos, se comparados aos de placa metálica.

Com exceção de JS12SDM, JS16SDM, JS12BQM e JS16BQM, o aumento da espessura dos modelos provocou uma diminuição em seus deslocamentos centrais. 
Nos gráficos força aplicada versus deslocamento vertical apresentados nas Figuras 6.22 a 6.26, é possível visualizar os deslocamentos ocorridos na junta serrada e armada com dispositivos.

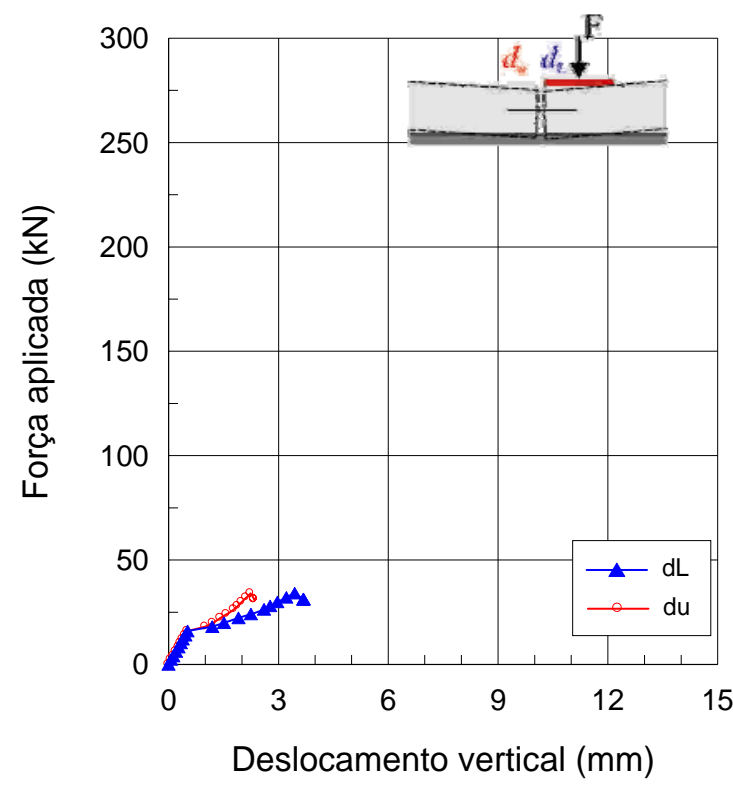

(a)

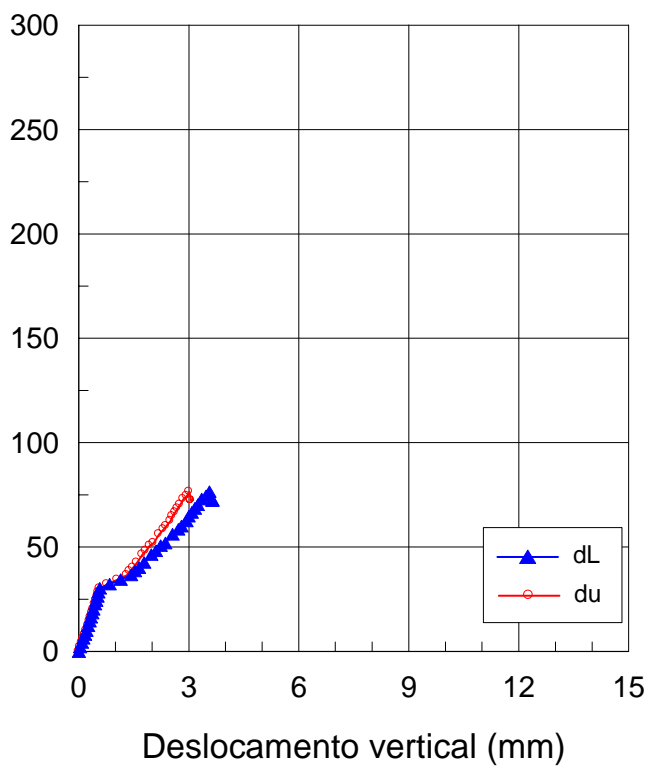

(b)

Figura 6.22 - Gráfico força aplicada versus deslocamento vertical: (a) JS12SDM; (b) JS16SDM

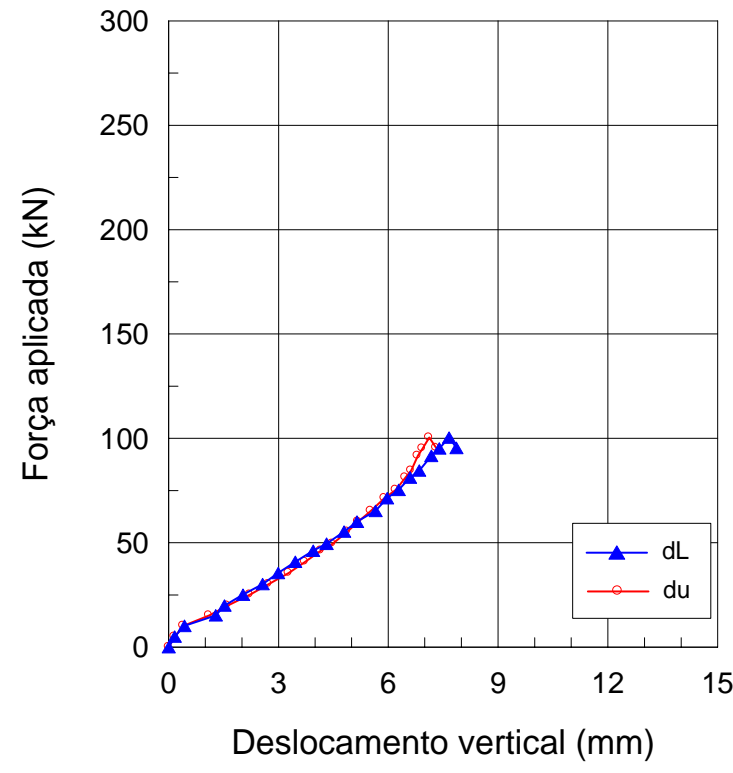

(a)

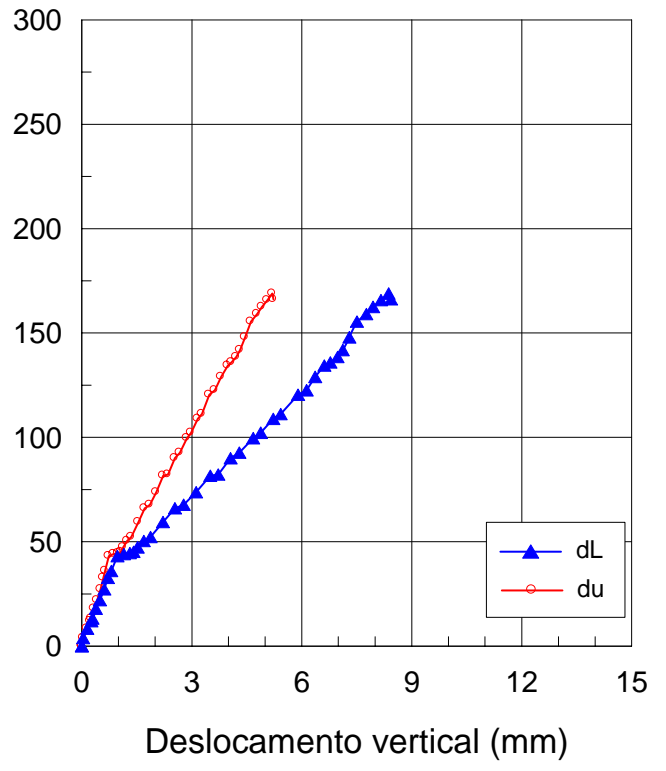

(b)

Figura 6.23 - Gráfico força aplicada versus deslocamento vertical: (a) JS12BCM; (b) JS16BCM 


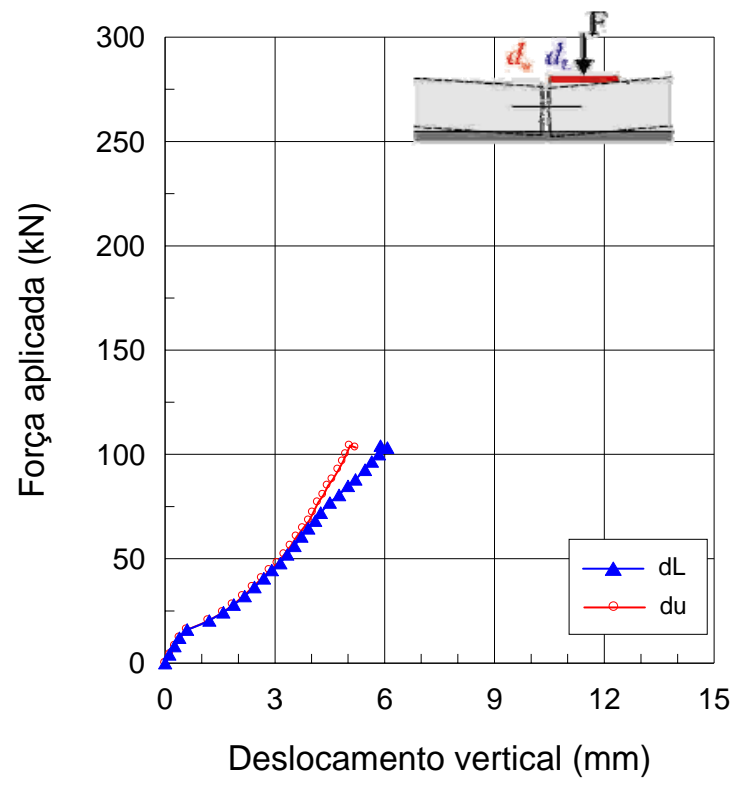

(a)

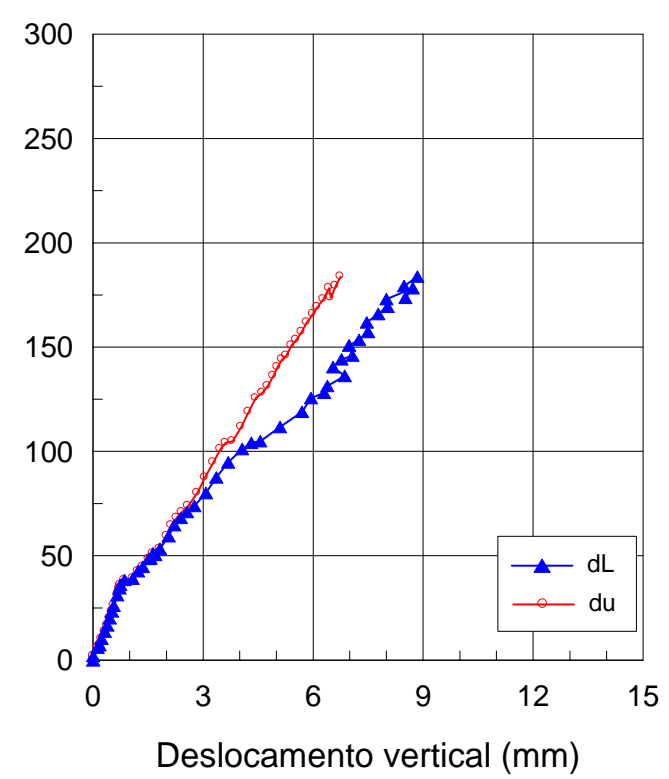

(b)

Figura 6.24 - Gráfico força aplicada versus deslocamento vertical: (a) JS12BQM; (b) JS16BQM

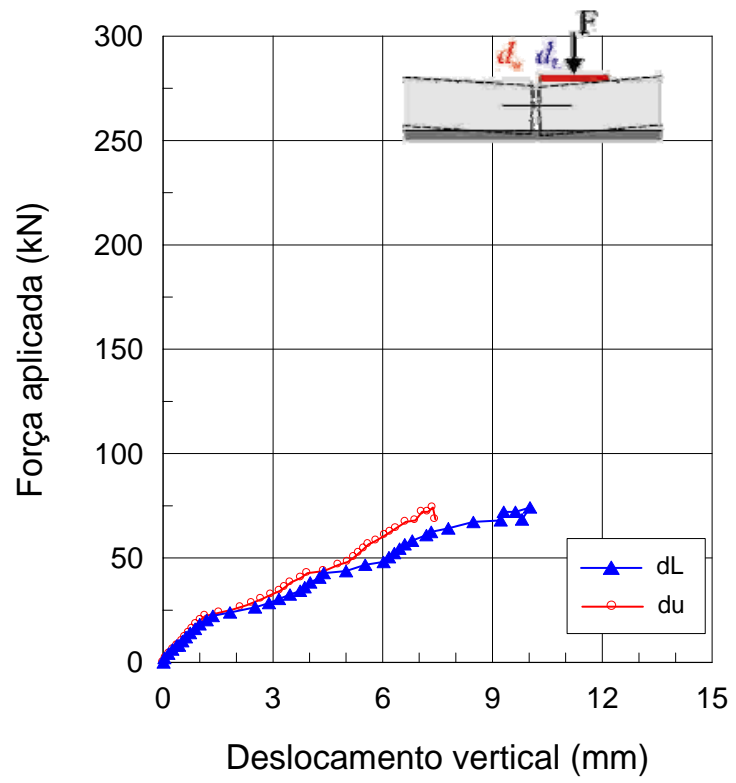

(a)

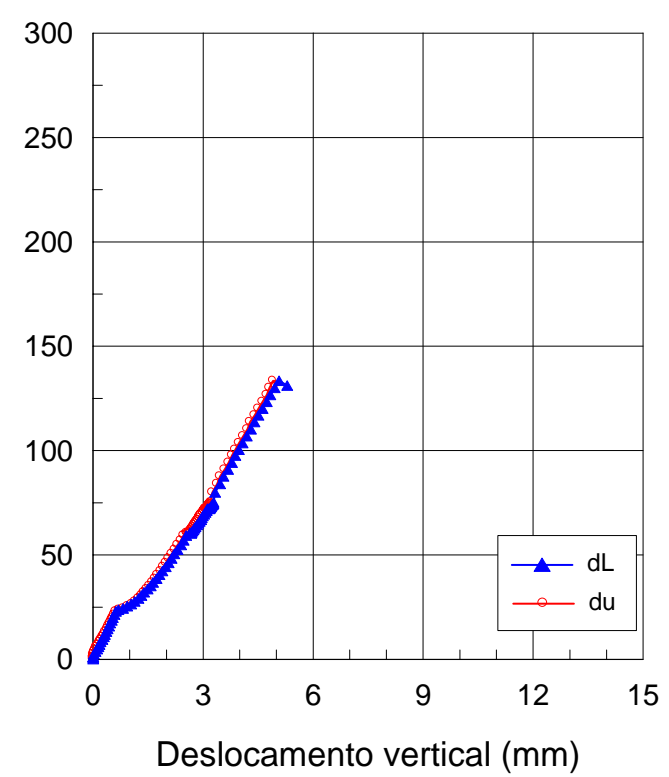

(b)

Figura 6.25 - Gráfico força aplicada versus deslocamento vertical: (a) JS12PMM; (b) JS16PMM 


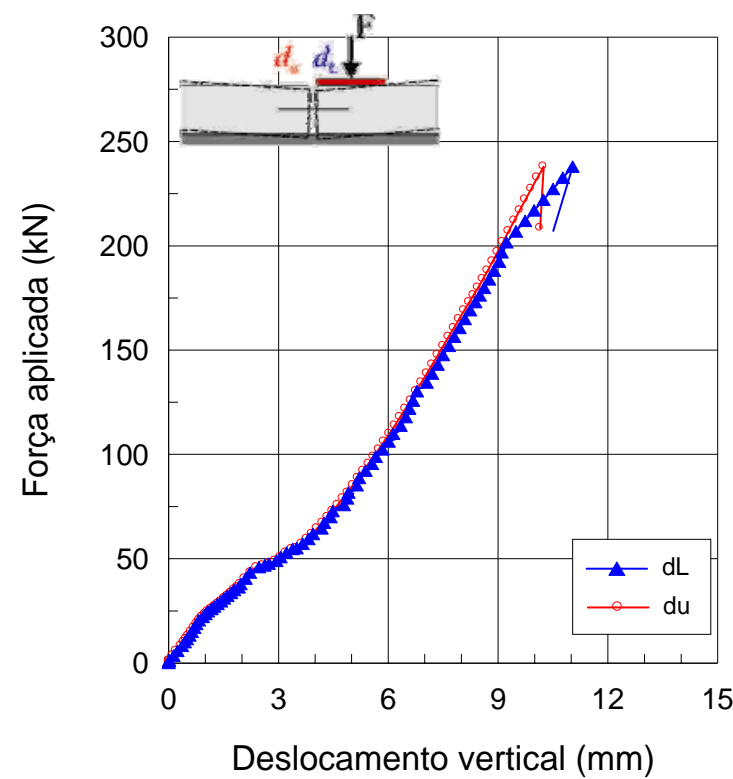

(a)

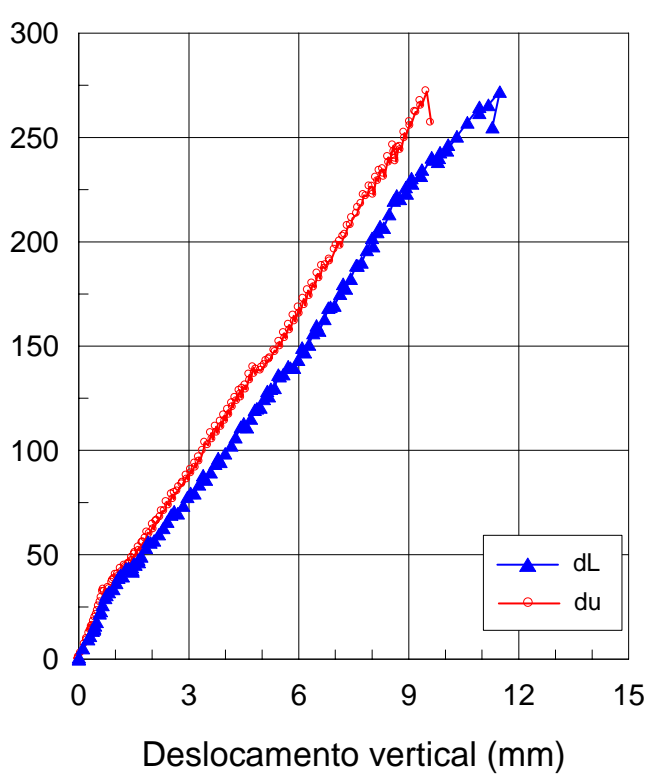

(b)

Figura 6.26 - Gráfico força aplicada versus deslocamento vertical: (a) JS12DMM; (b) JS16DMM

Nos modelos, foi verificada uma gradativa diferenciação entre $d_{u}$ e $d_{L}$, ocasionada pela diminuição na transferência de carga entre os lados da placa, à medida que se aproximava da ruptura.

As Figura 6.27 a 6.44 apresentam gráficos força aplicada versus força na célula de carga, provenientes da reação da fundação à força aplicada. Em geral, nos modelos, a célula de carga CEL1 apresentou leituras próximas de zero, com exceção no JS16PMM. Esse comportamento indica que houve levantamento excessivo do lado não carregado, capaz de diminuir o contato entre a face da placa neste ponto e a superfície da fundação.

As leituras da célula de carga CEL2 apresentaram valores inferiores aos da célula de carga CEL3. Até atingir a força de fissuração, ambas as células apresentaram leituras próximas de zero. $\mathrm{Na}$ ruptura, foi detectada uma mudança brusca nas leituras.

Os valores obtidos nas leituras da CEL4 apresentaram incoerência por danos ocorridos na célula, e por isso foram desconsiderados. 


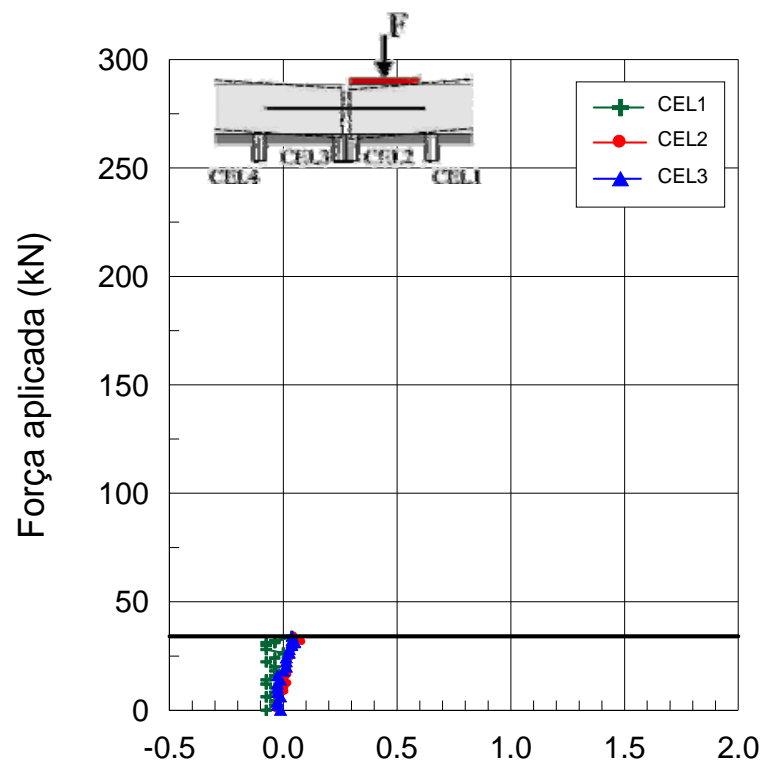

Força na célula de carga $(\mathrm{kN})$

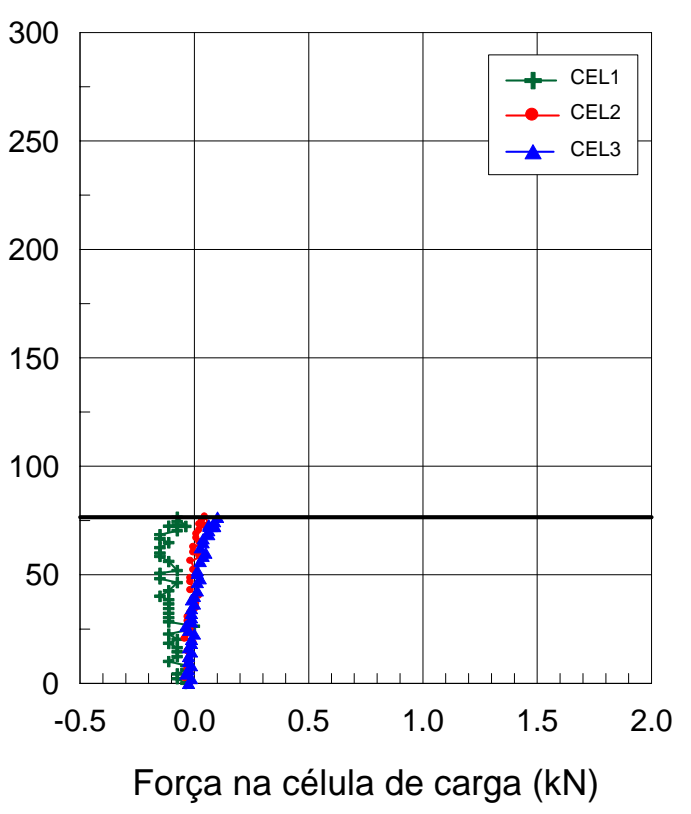

(b)

Figura 6.27 - Gráfico força aplicada versus força na célula de carga: (a) JS12SDM; (b) JS16SDM

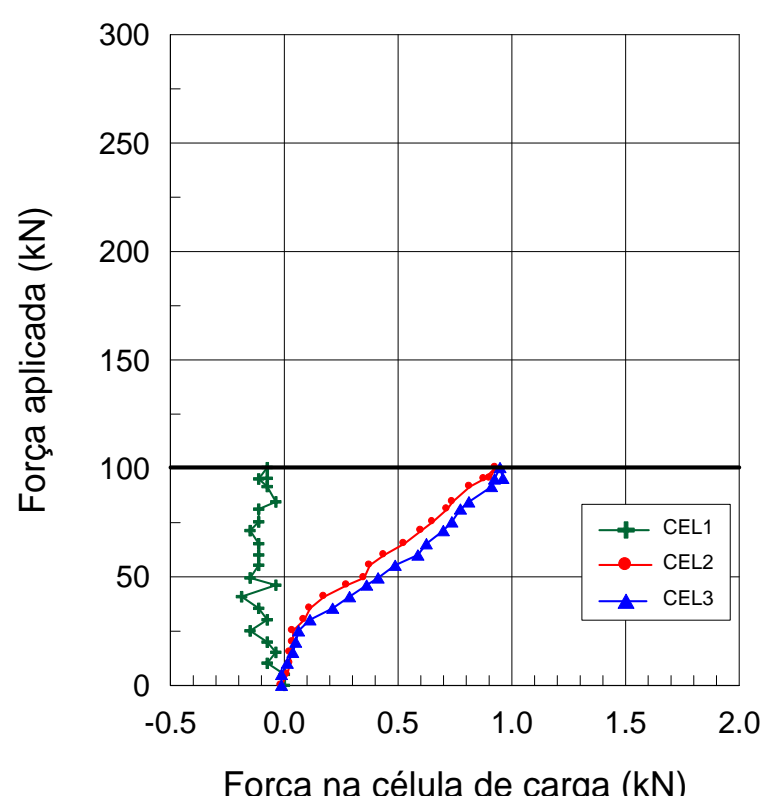

Força na célula de carga $(\mathrm{kN})$

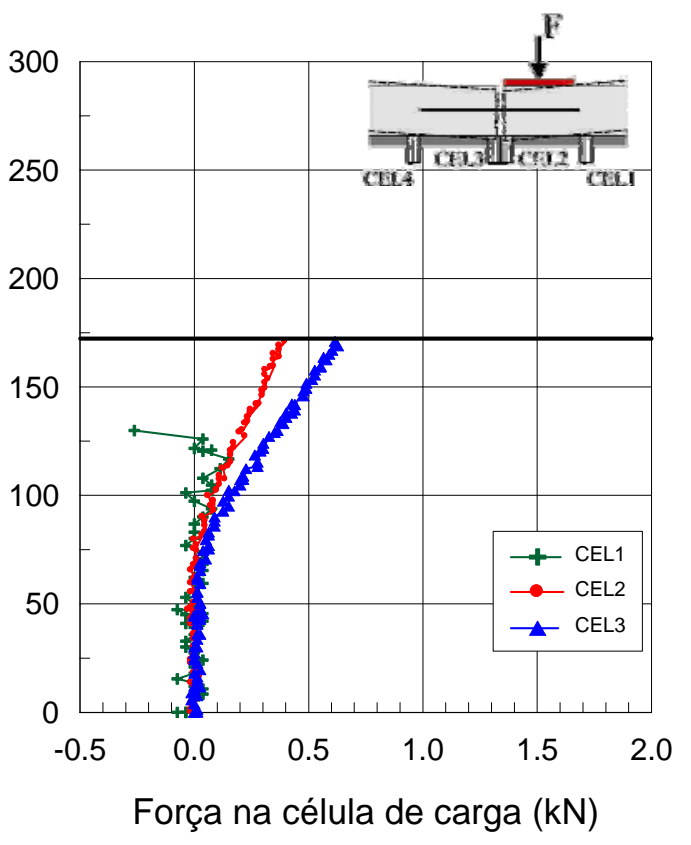

(b)

Figura 6.28 - Gráfico força aplicada versus força na célula de carga: (a) JS12BCM; (b) JS16BCM 


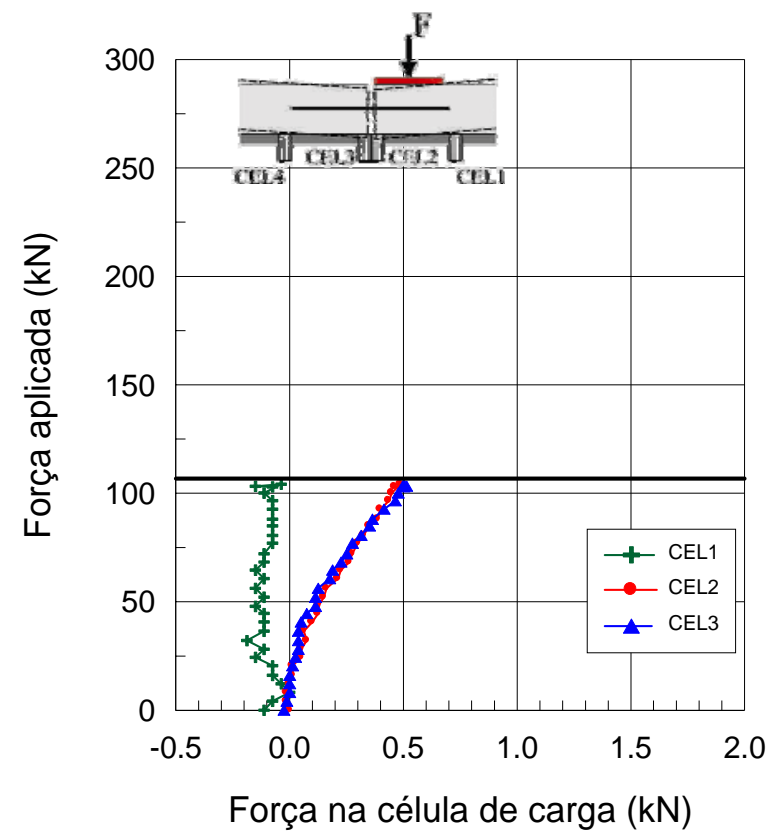

(a)

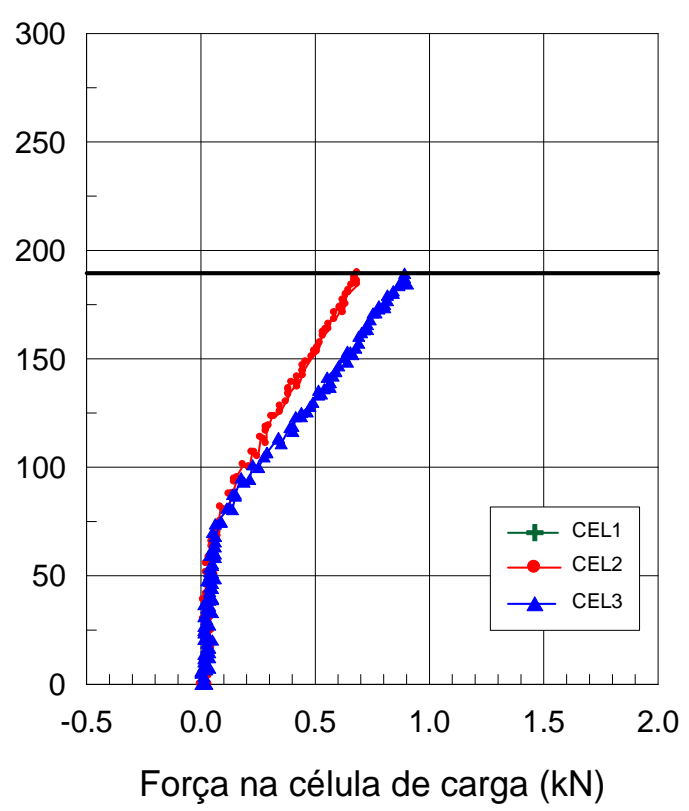

(b)

Figura 6.29 - Gráfico força aplicada versus força na célula de carga: (a) JS12BQM; (b) JS16BQM

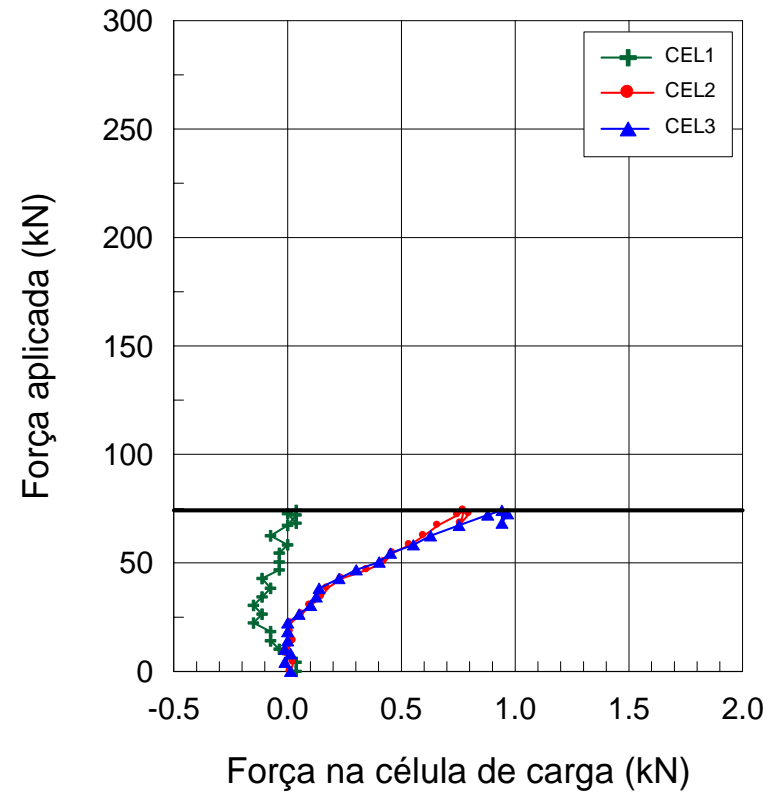

(a)

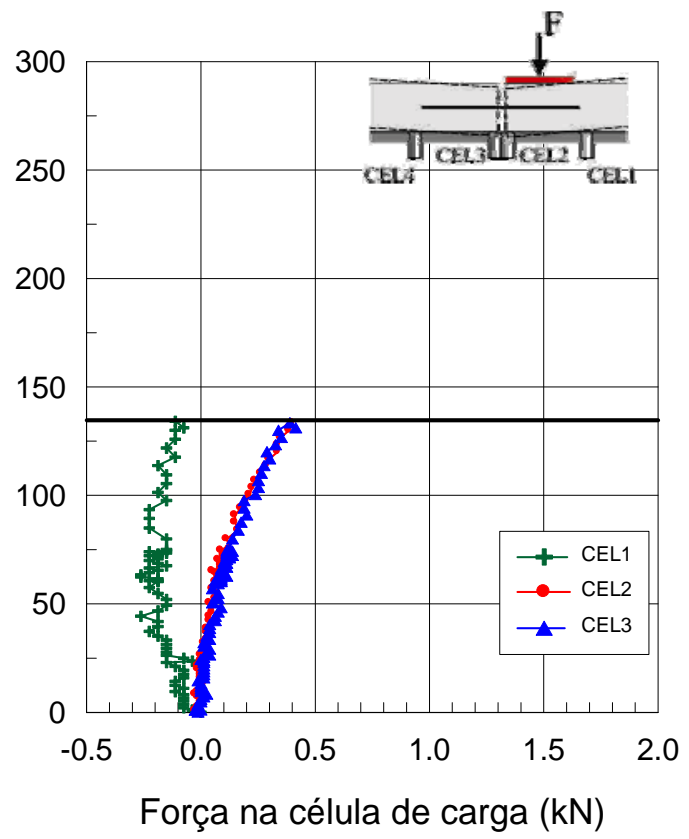

(b)

Figura 6.30 - Gráfico força aplicada versus força na célula de carga: (a) JS12PMM; (b) JS16PMM 


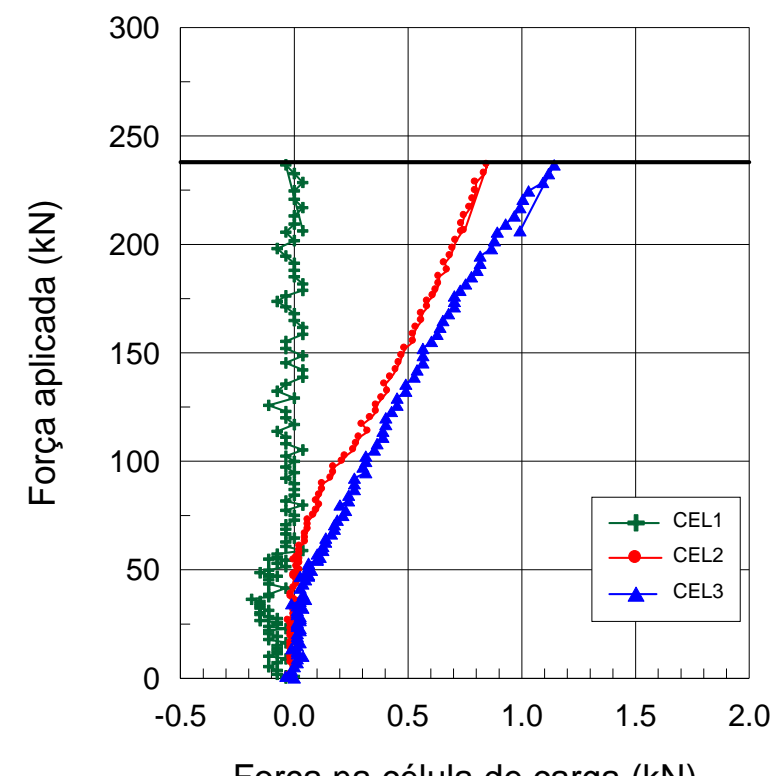

Força na célula de carga $(\mathrm{kN})$

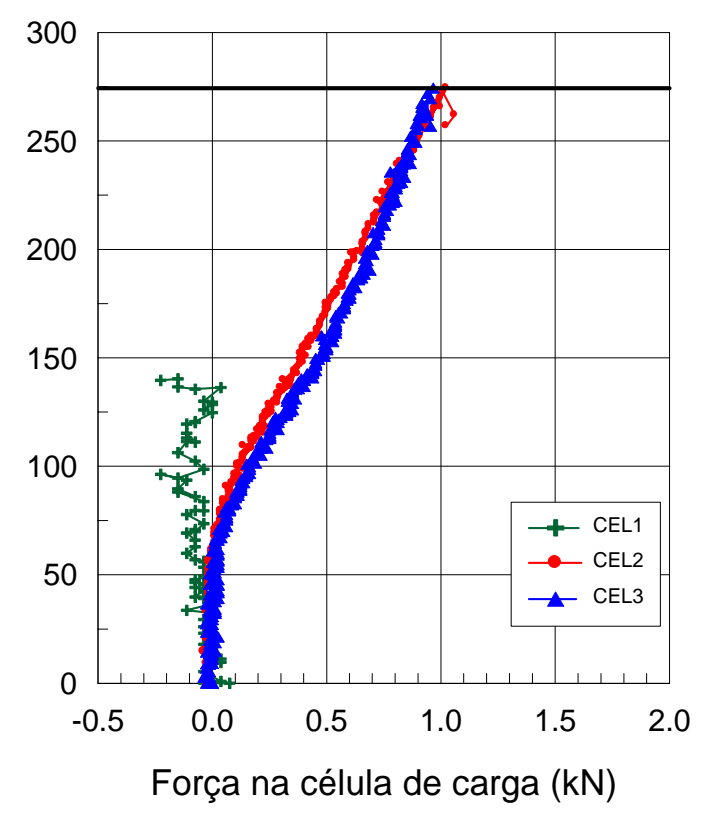

(b)

Figura 6.31 - Gráfico força aplicada versus força na célula de carga: (a) JS12DMM; (b) JS16DMM

Os gráficos da Figura 6.32 fornecem a relação força máxima lida pela célula de carga e espessura dos modelos. Nas células CEL2 e CEL3 os modelos em barra circular e placa metálica apresentaram diminuição na força com o aumento da espessura. Já os modelos com dispositivos em barra de seção quadrada, em chapa na forma de disco e o de referência apresentaram nas células aumento na reação da fundação com o aumento da espessura, com exceção de JS16BQM. Não foi encontrada uma relação entre o aumento na espessura dos modelos e a reação da fundação à força imposta. 

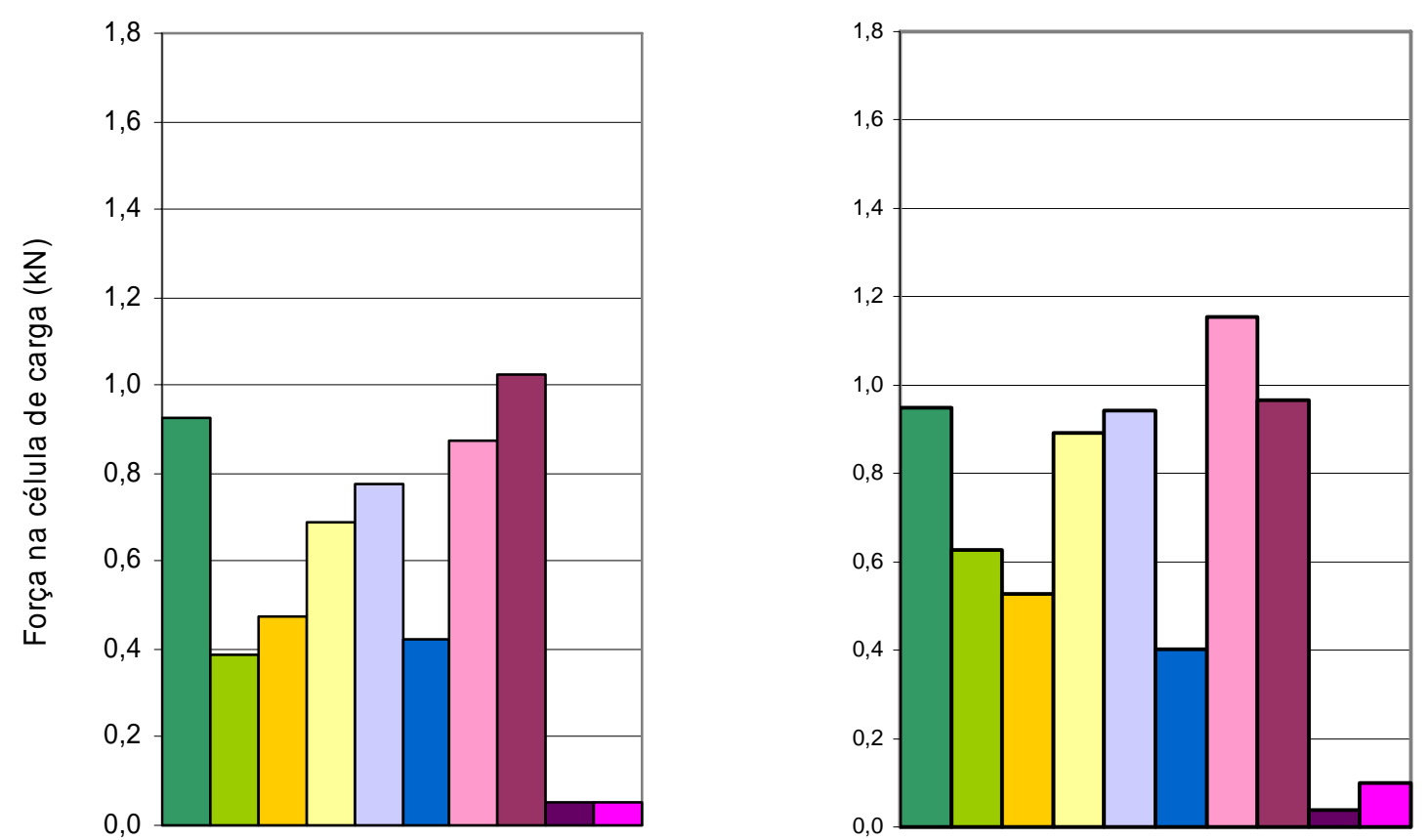

ロJS12BCM $\square J S 16 B C M \square J S 12 B Q M \square J S 16 B Q M \square J S 12 P M M \square J S 16 P M M \square J S 12 D M M \square J S 16 D M M \square J S 12 S D M \square J S 16 S D M$

(a)

(b)

Figura 6.32 - Relação entre espessura e reação na célula de carga: (a) CEL2; (b) CEL3

Os gráficos $\mathrm{F} / \mathrm{Fu}$ versus deslocamento vertical registrado no transdutor T4, das Figura 6.33 e 6.34, apresentam o comportamento dos modelos entre si para vários estágios de carregamento. Para os dispositivos em barra, é possivel verificar que todos os modelos se comportaram de maneira semelhante, do início do carregamento até atingir $F_{\text {fiss }}$. Após este valor e até atingir $60 \%$ de $F_{u}$, os modelos com espessura de $12 \mathrm{~cm}$ tiveram maiores deslocamentos. Entre $60 \%$ e $100 \%$ de $F_{u}$, o modelo JS16BQM apresentou maiores deslocamentos.

Para os dispositivos em chapa, é possível verificar que JS12DMM e JS16DMM apresentaram deslocamentos maiores que os de JS12PMM e JS16PMM. Em relação ao aumento da espessura, os modelos com $12 \mathrm{~cm}$ tiveram deslocamentos maiores, se comparados aos de $16 \mathrm{~cm}$. 


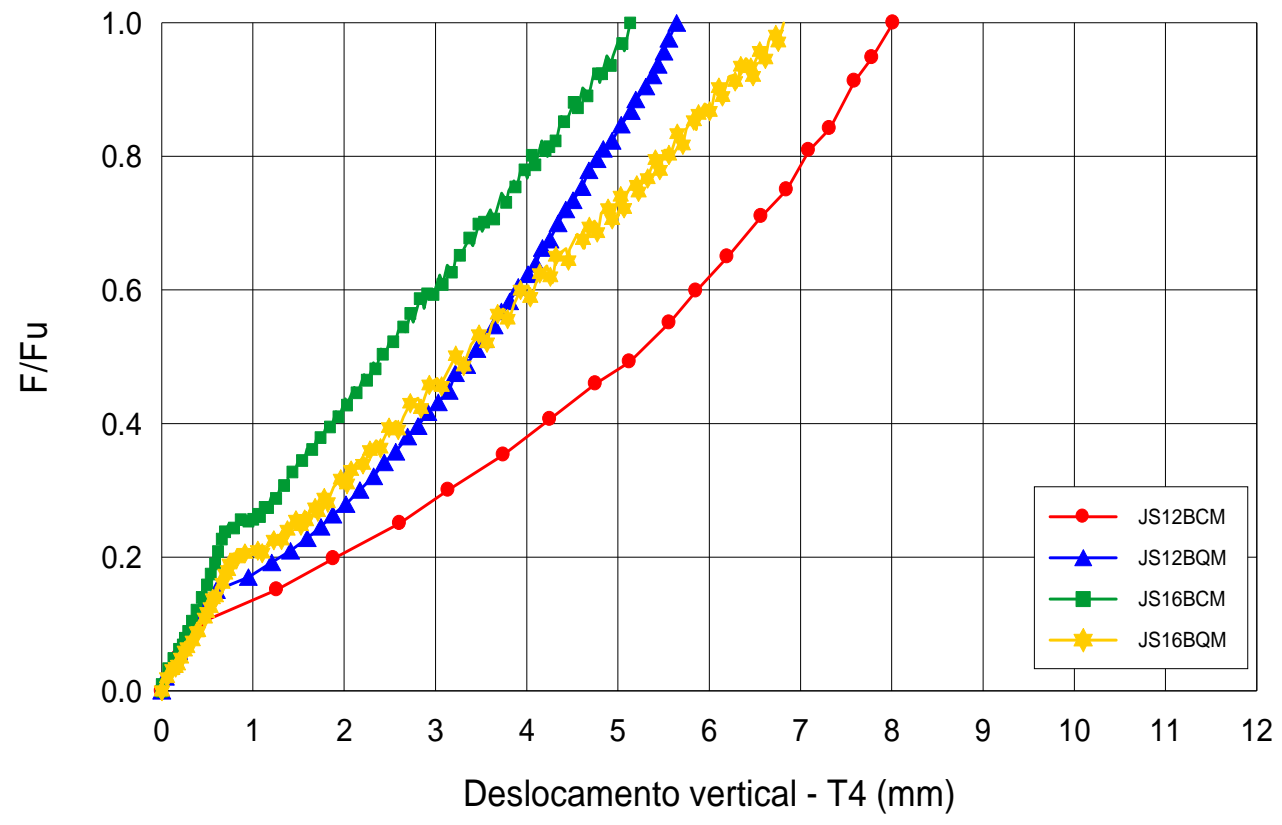

Figura 6.33 - Gráfico F/Fu versus deslocamento vertical em T4 - barra

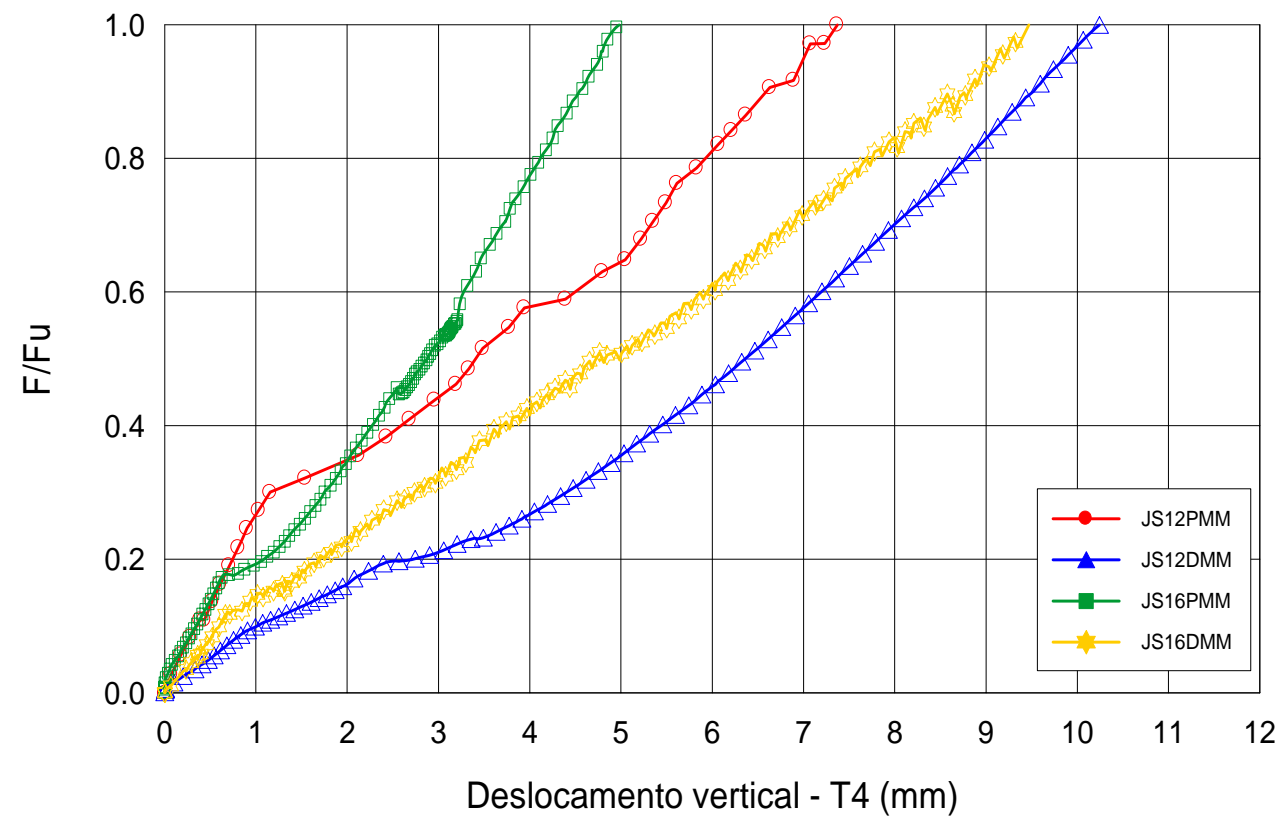

Figura 6.34 - Gráfico F/Fu versus deslocamento vertical em T4 - chapa

\subsubsection{Juntas serradas - ensaio cíclico}

Os modelos ensaiados com carregamento cíclico foram: JS12BCC, JS12PMC, JS12DMC e JS16BCC. Não foram detectadas fissuras durante a aplicação dos ciclos de carregamento, a uma frequência de $6 \mathrm{~Hz}$, força máxima de $12 \mathrm{kN}$ e mínima 
entre $1,2 \mathrm{kN}$ e $2,0 \mathrm{kN}$. A força mínima $F_{\text {mín }}$ correspondeu inicialmente a cerca de $10 \%$ da força máxima $F_{\text {máx }}$, durante os cíclos de carregamento.

A Tabela 6.10 apresenta o número de ciclos empregados por modelo ensaiado. Algumas interrupções foram registradas ao longo dos ensaios, em virtude de problemas no sistema de aquisição de dados ou da movimentação dos apoios rotulados, o que foi corrigido com o aumento da força mínima.

Tabela 6.10 - Resumo dos ensaios cíclicos

\begin{tabular}{|c|c|c|c|c|}
\hline \multirow{2}{*}{ Modelo } & $F_{\text {máx }}$ & $F_{\min }$ & $F_{\text {máx }}-F_{\text {min }}$ & \multirow{2}{*}{$\begin{array}{l}\text { Pontos de parada } \\
\quad N^{\circ} \text { ciclos }\end{array}$} \\
\hline & $\mathrm{kN}$ & $\mathrm{kN}$ & kN & \\
\hline JS16BCC & 12 & 1,2 & 10,8 & 100.000 \\
\hline JS12BCC & 12 & 1,2 & 10,8 & $\begin{array}{c}58.300 / 89.000 / 122.000 / \\
230.000 / 277.000 / 300.000\end{array}$ \\
\hline \multirow{2}{*}{ JS12PMC } & 12 & 1,2 & 10,8 & $10.000 / 17.900$ \\
\hline & 12 & 2 & 10 & $113.500 / 300.000$ \\
\hline JS12DMC & 12 & 2 & 10 & 300.000 \\
\hline
\end{tabular}

A Figura 6.35 fornece o posicionamento dos transdutores de deslocamento vertical, para os modelos ensaiados com carregamento repetido.

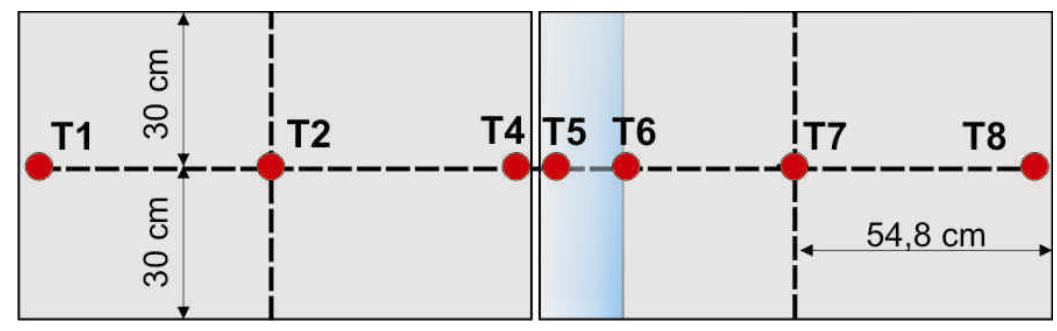

Figura 6.35 - Medidores de deslocamento vertical em ensaios cíclicos

A Figura 6.36 apresenta o gráfico generalizado do deslocamento vertical da junta do lado carregado (T5) versus tempo, durante os ciclos de carregamento do programa experimental. Foram capturados, no intervalo de um segundo, 500 dados plotados nas curvas, com seis pulsos de carga, para a frequência de $6 \mathrm{~Hz}$. Durante os ciclos de carregamento, a amplitude, indicada como a medida escalar não negativa da magnitude de oscilação de uma onda, permaneceu constante e próxima a 0,2mm. 


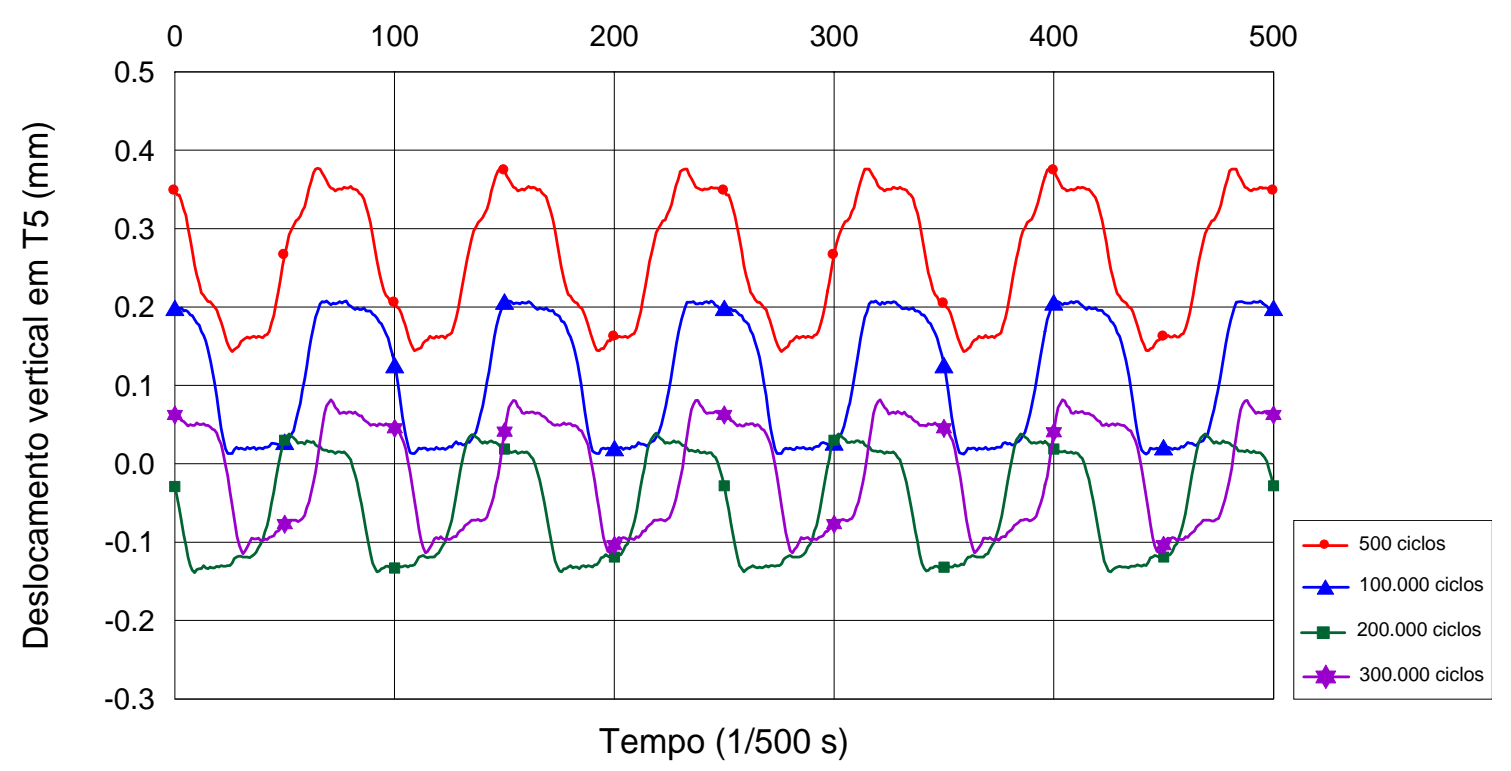

Figura 6.36 - Deslocamento vertical da junta em T5 versus tempo, para carga de serviço de $12 \mathrm{kN}$

O gráfico da Figura 6.37 apresenta os deslocamentos máximos medidos durante 0 pré-carregamento e após 300.000 ciclos de carregamento repetido. Em todos os modelos, foi detectada uma significativa diferença depois do número de ciclos de carregamento, verificando que, após a repetição do carregamento, os deslocamentos foram menores do que medidos inicialmente. Isto parece ter ocorrido devido a uma variação do módulo de elasticidade do concreto. O aumento dos esforços cortantes no dispositivo, devido à fissuração do concreto, pode também ter provocado uma mudança no momento de inércia da barra, resultando em uma menor medida dos deslocamentos.

Não houve nenhum indício de desgaste ou de dano na barra. Os dispositivos metálicos foram pouco solicitados, durante a carga de serviço imposta e até os 300.000 ciclos aplicados, como apresentado no item 6.6.2B. 


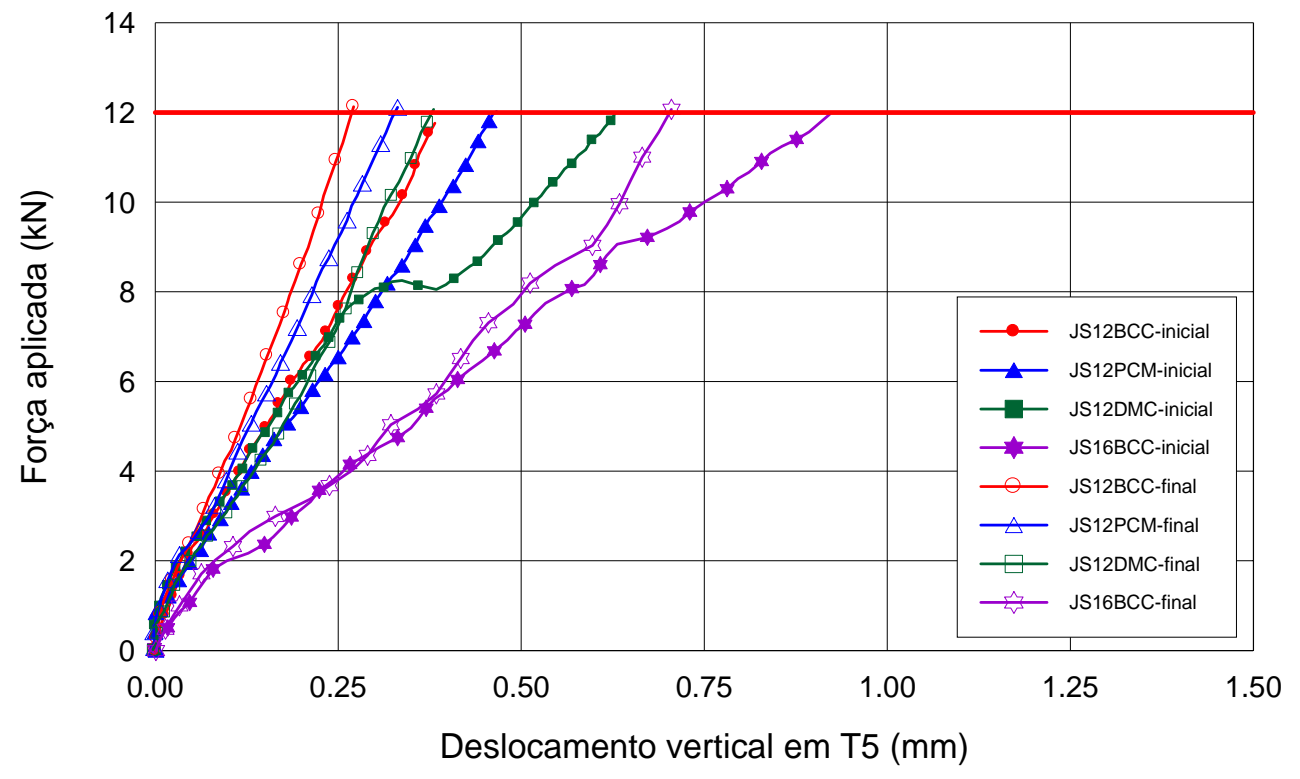

Figura 6.37 - Gráfico força aplicada versus deslocamento em T5, antes e depois de 300.000 ciclos

O gradual incremento dos deslocamentos verticais com a aplicação dos ciclos de carregamento é apresentado nas Figuras 6.38 e 6.39. Foi verificado que na região da junta, onde os transdutores tinham uma melhor aproximação, não foi registrada uma significativa variação nos deslocamentos verticais. Entre 50.000 ciclos e 200.000 ciclos, ocorreram algumas discrepâncias nos valores lidos em T1.

O modelo JS16BCC apresentou a maior relação entre os deslocamentos, para o mesmo número de ciclos (100.000; T4=0,116mm; T5=0,504mm), se comparado a JS12BCC (100.000; T4=0,165mm; T5=0,167mm), sendo que sua força última foi cerca de $121 \%$ superior. Isto sugere que a espessura maior eleva a força última do modelo, às custas de uma maior deslocabilidade da região armada da junta, ou seja, diminui a transferência de carga entre os lados da junta. 


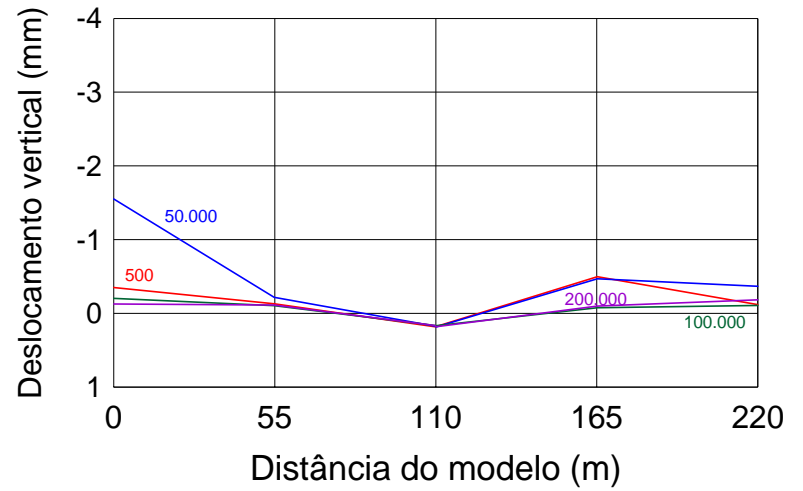

(a)

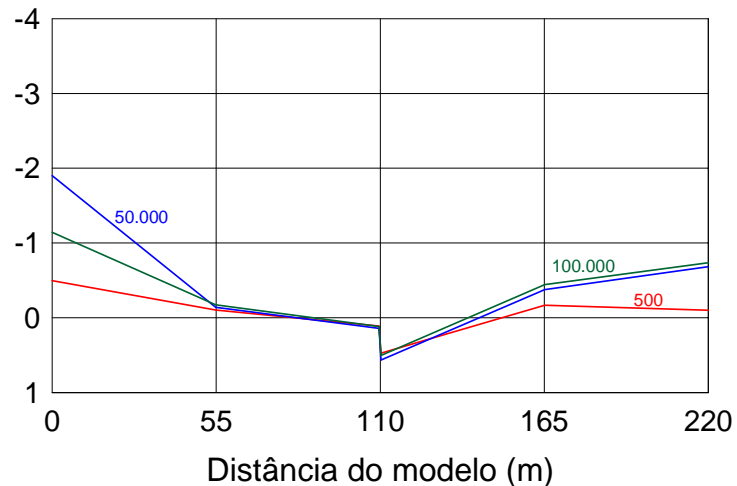

(b)

Figura 6.38 - Gráfico deslocamento vertical versus distância: (a) JS12BCC;(b) JS16BCC

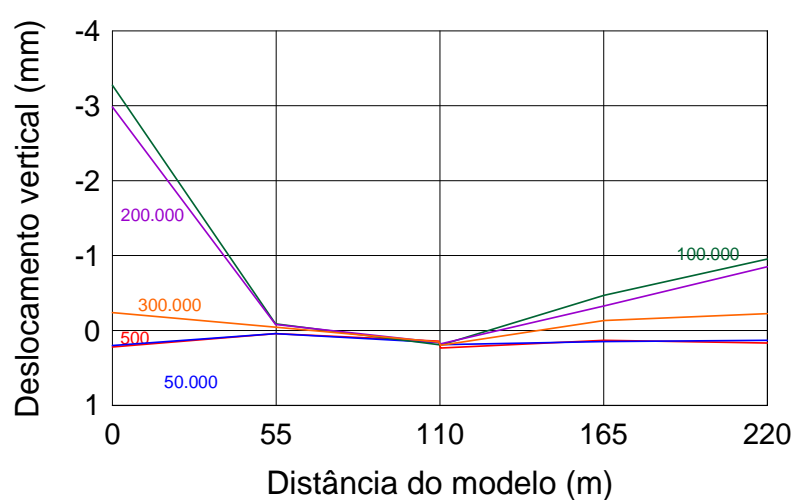

(a)

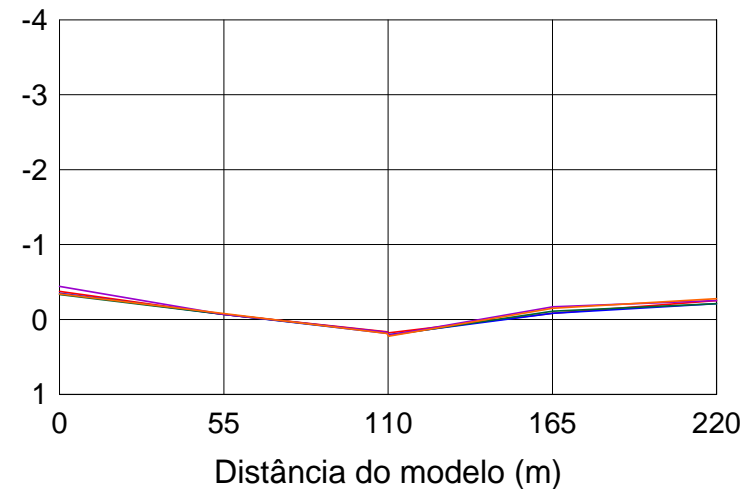

(b)

Figura 6.39 - Gráfico deslocamento vertical versus distância: (a) JS12PMC;(b) JS16DMC

A Figura 6.40 fornece o gráfico deslocamento vertical versus distância ao longo do eixo x, para 100.000 ciclos de carregamento. O modelo com dispositivo de placa metálica apresentou os maiores deslocamentos verticais das bordas. Para a espessura de $12 \mathrm{~cm}$, o maior deslocamento em T5 foi registrado em JS12DMC, igual a 0,211 mm. O aumento da espessura em JS16BCC permitiu maiores deslocamentos na região da junta armada, visto que $T 5$ foi equivalente a $0,504 \mathrm{~mm}$, enquanto que em JS12BCC foi de $0,167 \mathrm{~mm}$. 


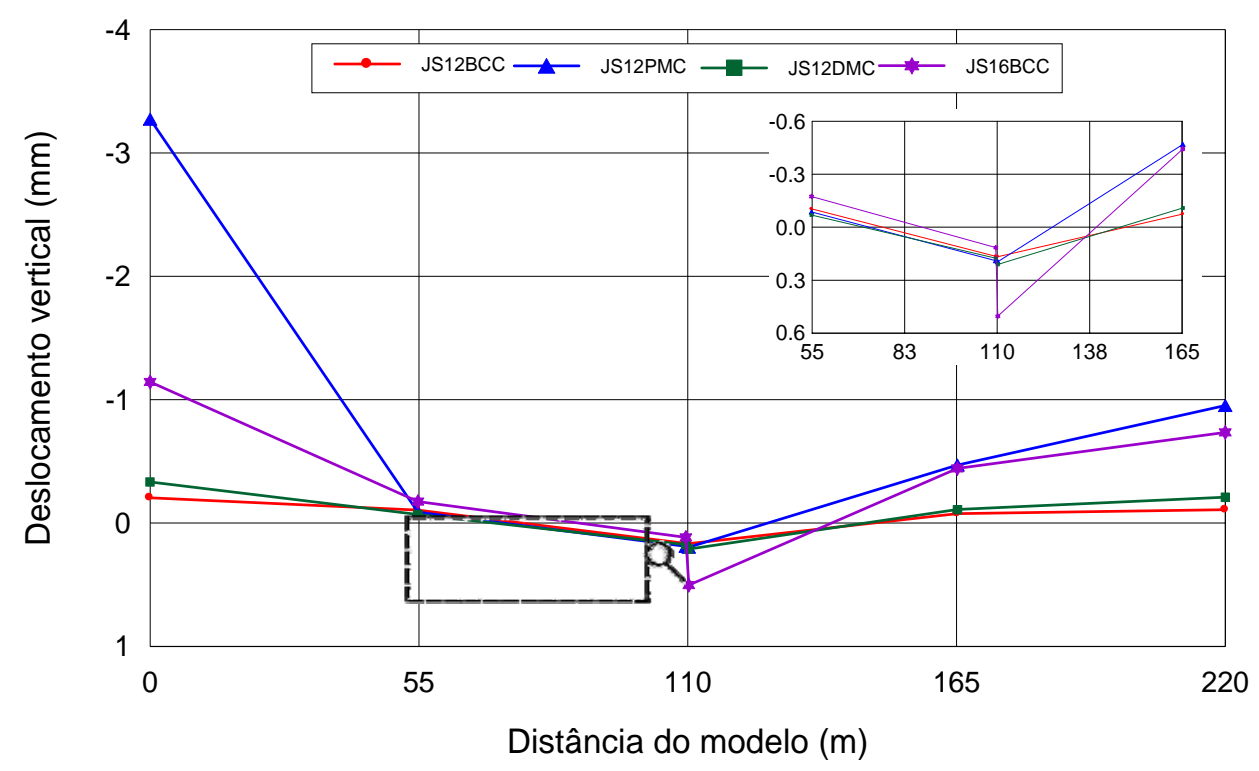

Figura 6.40 - Gráfico deslocamento vertical versus distância - 100.000 ciclos

A Figura 6.41 fornece o gráfico deslocamento vertical versus distância ao longo do eixo x, para 200.000 ciclos de carregamento. A diferença entre os deslocamentos verticais em T4, em JS12PMC e JS12DMC, até 100.000 ciclos, era de $8 \%$, cujos deslocamentos eram, respectivamente, 0,190mm e 0,176mm. Acima de 200.000 ciclos de carregamento e até 300.000 ciclos, esta diferença se inverteu, com deslocamentos maiores em JS12DMC, e ficou entre $8 \%$ e $21 \%$ respectivamente. Nestes intervalos, os valores de T4 para JS12DMC foram iguais a 0,171mm e $187 \mathrm{~mm}$, e para JS12PMC, $0,159 \mathrm{~mm}$ e $0,155 \mathrm{~mm}$. No transdutor T5, os deslocamentos do modelo com disco metálico foram maiores em relação com chapa metálica entre 8\% e 19\%, aumentando com o número de ciclos.

Até 200.000 ciclos de carregamento, os deslocamentos das bordas dos modelos (T1 e T8) foram significantemente maiores em JS12PMC, se comparados aos relativos a JS12DMC. Em T1, no modelo JS12PMC, para 100.000 ciclos e 200.000 ciclos, foram, respectivamente, $-3,275 \mathrm{~mm}$ e $-2,985 \mathrm{~mm}$, e no JS12DMC, respectivamente, $0,332 \mathrm{~mm}$ e $-0,443 \mathrm{~mm}$. Aos 300.000 ciclos, ocorreu uma sensível queda das amplitudes em T1 no modelo JS12PMC, equivalente a $-0,239 \mathrm{~mm}$, enquanto que no JS12DMC, foi de $-0,341 \mathrm{~mm}$.

Os deslocamentos na região da junta para os três dispositivos, barra de seção circular $(T 5=0,165 \mathrm{~mm})$, placa metálica $(T 5=0,159 \mathrm{~mm})$ e disco metálico (T5=0,171mm), permaneceram bastante próximos até 200.000 ciclos, uma vez que 
acima desta leitura ocorreram problemas na aquisição dos dados dos transdutores em JS12BCC. O dispositivo em barra e o disco metálico se comportaram de maneira similar, apesar da força última no dispositivo metálico ter sido 30\% superior.

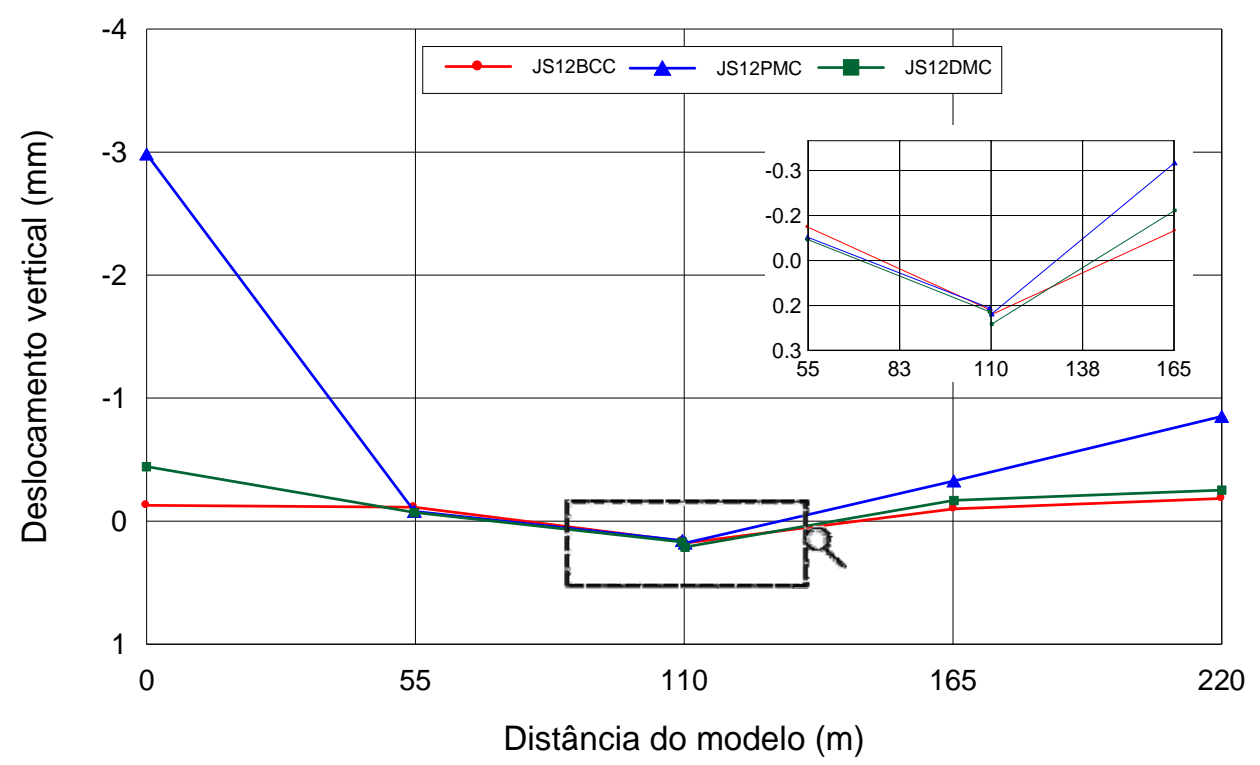

Figura 6.41 - Gráfico deslocamento vertical versus distância - 300.000 ciclos

Com o término dos ciclos de carregamento, os modelos foram levados até a ruptura, como apresentado na Figura 6.42. O modelo JS12BCC apresentou a primeira fissura quando atingiu a força de $17,93 \mathrm{kN}$, e atingiu a força máxima na ruptura em $97,69 \mathrm{kN}$. O modelo JS12PMC iniciou a fissuração com $23,23 \mathrm{kN}$, e sua força máxima na ruptura foi $100,75 \mathrm{kN}$. O modelo JS12DMC apresentou a primeira fissura quando atingiu a força de $17,44 \mathrm{kN}$, e sua ruptura foi detectada com a força de $128,21 \mathrm{kN}$. O modelo JS16BCC, com espessura de $16 \mathrm{~cm}$, teve força de fissuração em $30,32 \mathrm{kN}$, e força de ruptura igual a $215,85 \mathrm{kN}$. 


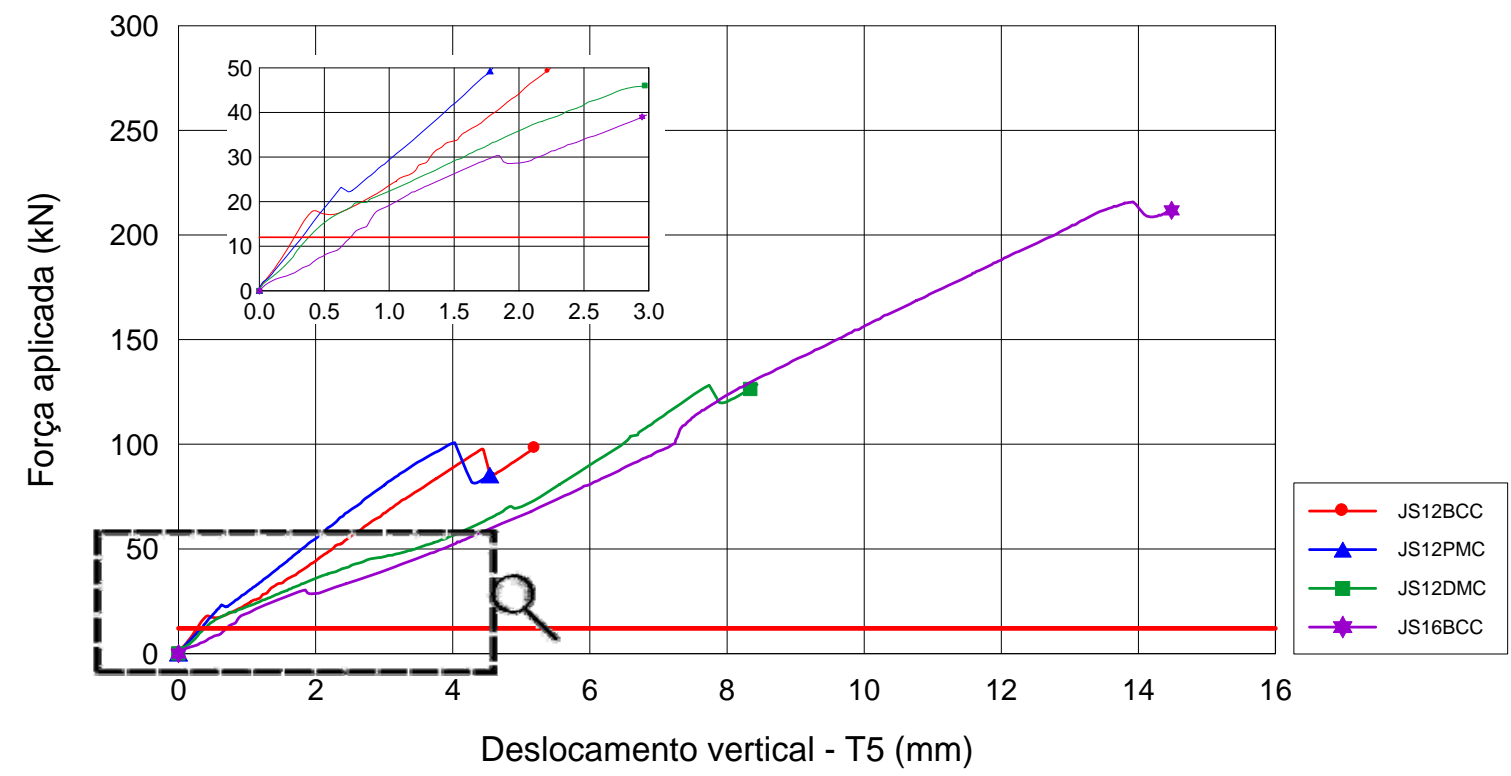

Figura 6.42 - Gráfico força aplicada versus deslocamento vertical em T5 - ensaios cíclicos

A Tabela 6.11 apresenta um resumo das forças para todos os modelos, após a repetição dos ciclos. Em geral, a $F_{\text {fiss }}$ correspondeu a menos de $20 \%$ do valor de $F_{u}$, para todos os modelos. Seu valor médio correspondeu a $F_{\text {fiss }}=19,5 \mathrm{kN}$ para modelos com espessura de $12 \mathrm{~cm}$.

Tabela 6.11 - Quadro de forças - junta serrada e ensaio cíclico

\begin{tabular}{|c|c|c|c|c|}
\hline \multirow{2}{*}{ Modelo } & $\begin{array}{c}\text { Força de } \\
\text { fissuração } \\
F_{\text {fiss }}\end{array}$ & $\begin{array}{c}\text { Força no } \\
\text { escoamento } \\
F_{y}\end{array}$ & $\begin{array}{c}\text { Força cortante } \\
\text { máxima } \\
F_{u}\end{array}$ & $\begin{array}{c}F_{\text {fiss }} \\
F_{u}\end{array}$ \\
\cline { 2 - 5 } & $\mathrm{kN}$ & $\mathrm{kN}$ & $\mathrm{kN}$ & $\%$ \\
\hline JS12BCC & 17,93 & 53,90 & 97,69 & 18 \\
\hline JS16BCC & 30,32 & $*$ & 215,85 & 14 \\
\hline JS12PMC & 23,23 & - & 100,75 & 23 \\
\hline JS12DMC & 17,44 & - & 128,21 & 14 \\
\hline *Modelo não instrumentado com extensômetro elétrico para aço \\
\hline
\end{tabular}

Dos modelos instrumentados, apenas JS12BCC apresentou $F_{y}$. A deformação no dispositivo atingiu a de escoamento do aço quando os extensômetros registraram escoamento $\left(\varepsilon_{y \phi}=\varepsilon_{y \#}=0,0016\right.$ e $\left.\varepsilon_{y, \text { chapa }}=0,0013\right)$. O modelo com barra instrumentado JS12BCC contou com os extensômetros AS1D, AS2D, AS3D, AS4D, 
AS7D, AS8D, AS11E, AS12E, AS13E e AS14E, em função do número disponível de canais do sistema de aquisição de dados. O modelo JS16BCC não foi instrumentado, visto ter sido ele o ensaio de referência para cargas repetidas. Os modelos com chapa contaram com os seguintes extensômetros: AS1D, AS2D, AS3D, AS4D, AS 5D, AS6D, AS7D, AS1E, AS2E e AS3E.

A Tabela 6.12 apresenta um quadro resumo dos deslocamentos verticais máximos atingidos para os diferentes modelos.

Tabela 6.12 - Quadro de deslocamentos máximos - junta serrada e ensaio cíclico

\begin{tabular}{|c|c|c|}
\hline \multirow{2}{*}{ Modelo } & $\begin{array}{c}\text { Deslocamento } \\
\text { vertical } \\
\text { T4 }\end{array}$ & $\begin{array}{c}\text { Deslocamento } \\
\text { vertical } \\
\text { T5 }\end{array}$ \\
\cline { 2 - 3 } & $\mathrm{mm}$ & $\mathrm{mm}$ \\
\hline JS12BCC & 4,72 & 4,87 \\
\hline JS16BCC & 8,41 & 13,88 \\
\hline JS12PMC & 3,86 & 4,02 \\
\hline JS12DMC & 6,43 & 7,74 \\
\hline
\end{tabular}

O transdutor de deslocamento T4 foi posicionado sobre a junta, no lado não carregado $d_{u}$ ("unload"). Já o transdutor de deslocamento T5 foi posicionado sobre a junta no lado carregado $d_{L}$ ("load"). De maneira geral, o modelo com disco metálico sofreu maiores deslocamentos se comparado aos de mesma espessura.

As Figura 6.43 a 6.44 apresentam gráficos força aplicada versus força na célula de carga provenientes da reação da fundação. Em geral, nos modelos, a célula de carga CEL1 apresentou leituras próximas de zero. Este comportamento, assim como nos ensaios estáticos, indica que houve levantamento excessivo do lado não carregado. Durante os ciclos de carregamento, não foram verificadas mudanças bruscas nas leituras da células de carga.

A célula de carga CEL2 apresentou valores inferiores aos da célula CEL3, com exceção no JS12BCC. Neste modelo, verificou-se que tanto o deslocamento vertical em T5 quanto a reação da fundação em CEL2, ambos do lado carregado, foram maiores do que em T4 e CEL3. As leituras em CEL2, no modelo JS12PMC, não foram obtidas por problemas ocorridos na célula, que foi substituida nos ensaios subsequentes. 


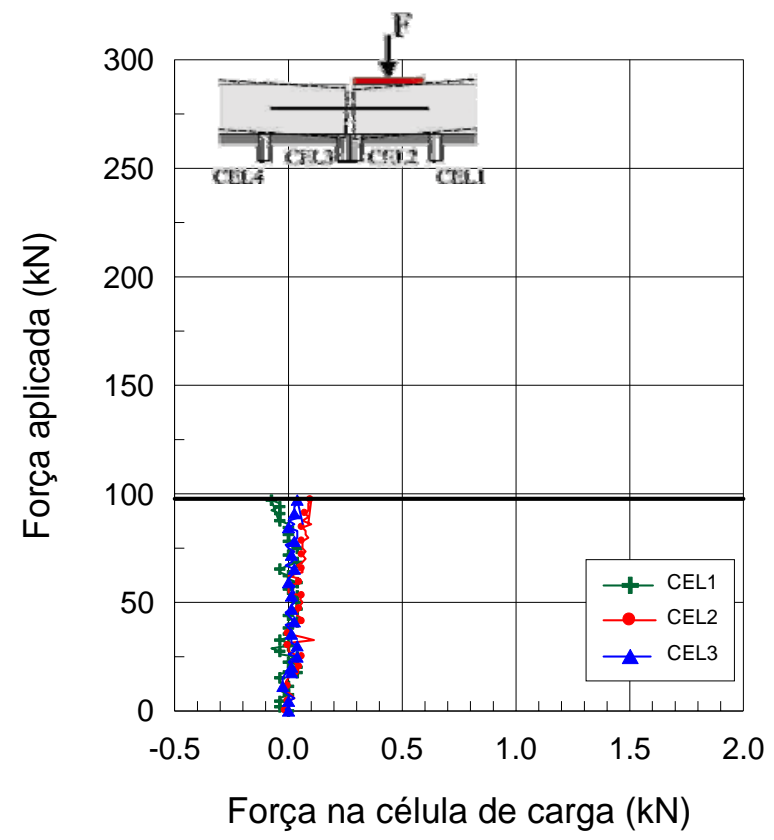

(a)

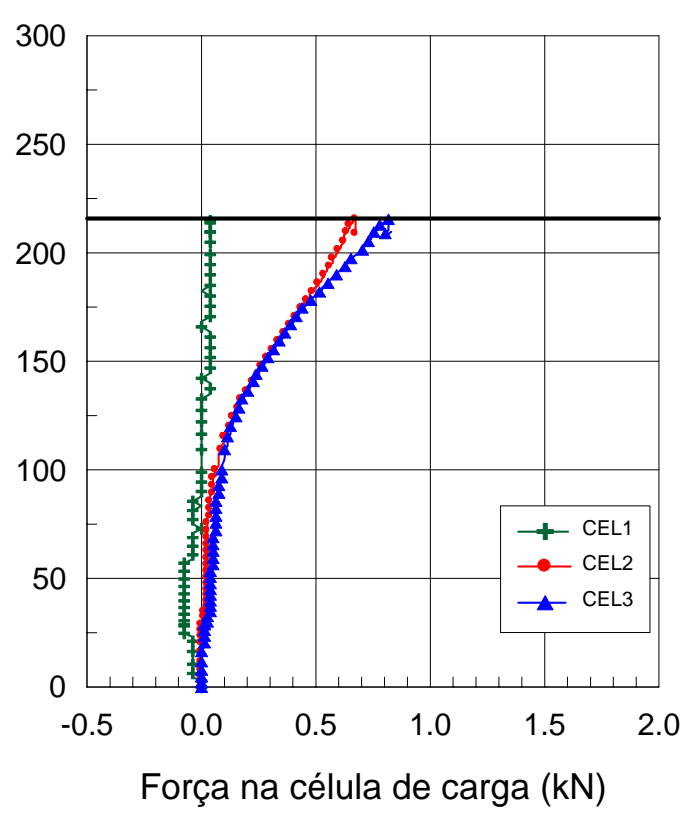

(b)

Figura 6.43 - Gráfico força aplicada versus força na célula de carga: (a) JS12BCC; (b) JS16BCC

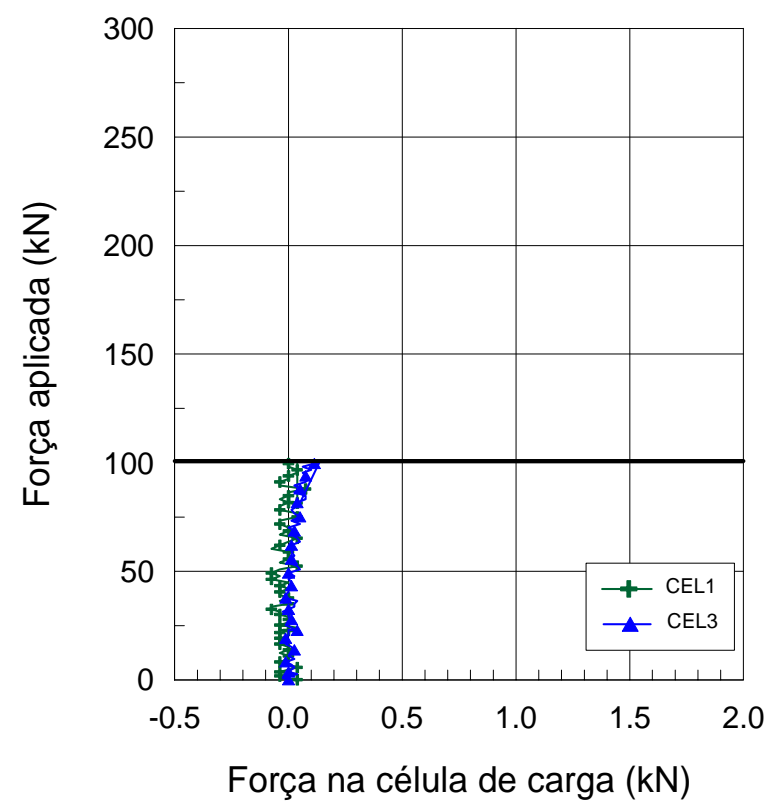

(a)

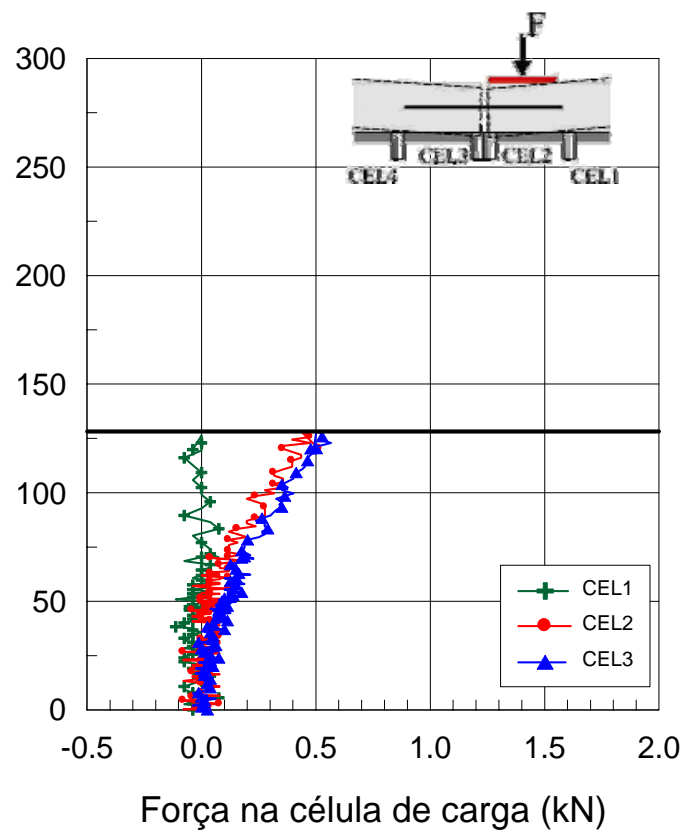

(b)

Figura 6.44 - Gráfico força aplicada versus força na célula de carga: (a) JS12PMC; (b) JS12DMC

Os gráficos F/Fu versus deslocamento vertical registrado no transdutor T4, da Figura 6.45, apresentam o comportamento dos modelos para vários estágios de carregamento. Para os dispositivos em barra, é possivel verificar que todos os 
modelos se comportaram de maneira semelhante no início do carregamento, até atingir $F_{\text {fiss }}$. Acima de $20 \%$ de $F_{u}$, o modelo com espessura de $16 \mathrm{~cm}$ teve maiores deslocamentos. Para os dispositivos em chapa, é possível verificar que JS12DMC apresentou deslocamentos maiores em relação aos de JS12PMC. Até cerca de 60\% de $F_{u}$, os modelos JS12DMC e JS16BCC se comportaram de maneira semelhante.

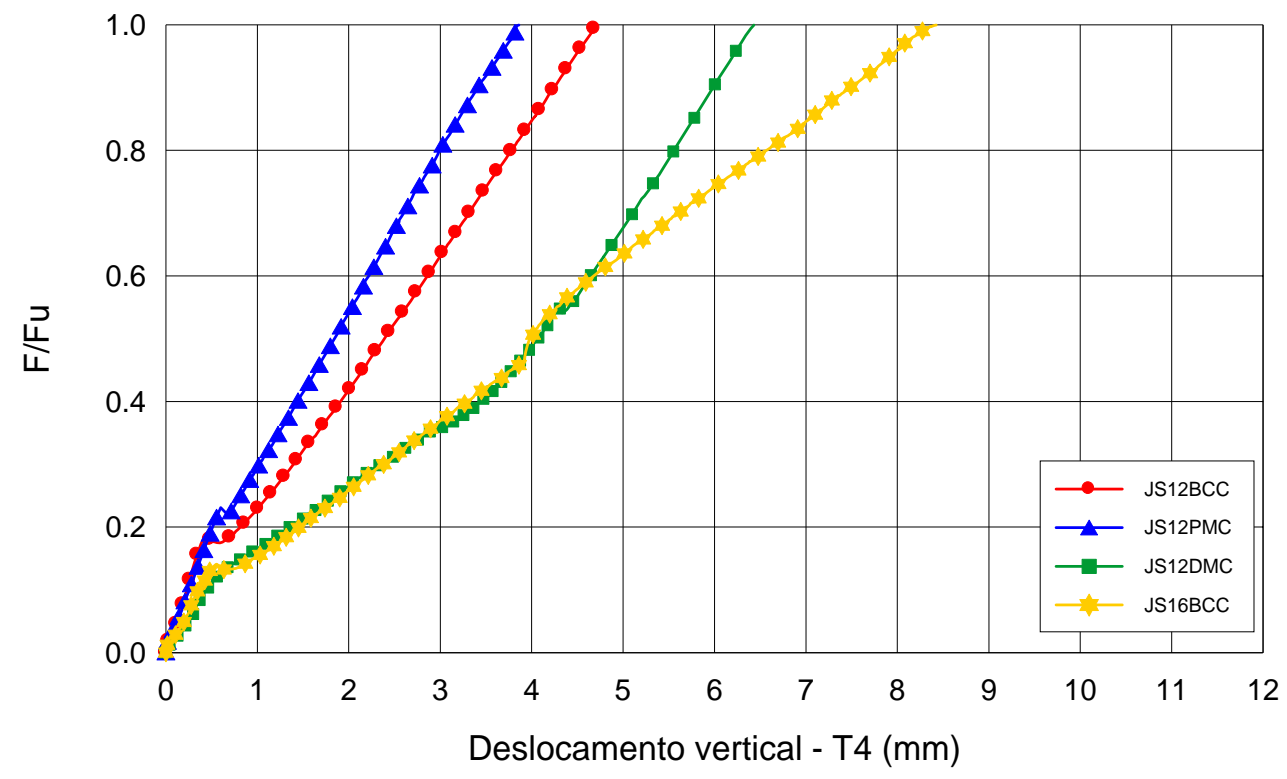

Figura 6.45 - Gráfico F/Fu versus deslocamento vertical em T4 - ensaio cíclico

\subsubsection{Juntas moldadas}

A força máxima $\left(F_{u}\right)$ admitida para os modelos dotados de junta moldada foi atingida no momento em que a deformação no dispositivo atingiu a deformação de escoamento do aço $\left(F_{y}\right)$. A Tabela 6.13 apresenta um quadro resumo das forças e dos deslocamentos máximos atingidos para os diferentes modelos. Os deslocamentos verticais foram considerados positivos quando ocorreram na direção e no sentido da força aplicada. 
Tabela 6.13 - Quadro de força e deslocamentos - junta moldada

\begin{tabular}{|c|c|c|c|}
\hline \multirow{2}{*}{ Modelo } & $\begin{array}{c}\text { Força cortante } \\
\text { máxima } \\
F_{u}=F_{y}\end{array}$ & $\begin{array}{c}\text { Deslocamento } \\
\text { vertical } \\
\mathrm{T} 4\end{array}$ & $\begin{array}{c}\text { Deslocamento } \\
\text { vertical } \\
\mathrm{T} 6\end{array}$ \\
\cline { 2 - 4 } & $\mathrm{kN}$ & $\mathrm{mm}$ & $\mathrm{mm}$ \\
\hline JM12BCM & 80,2 & 2,50 & 3,40 \\
\hline JM16BCM & 101,0 & 2,70 & 3,67 \\
\hline JM12BQM & 86,1 & 3,17 & 4,87 \\
\hline JM16BQM & 100,6 & 2,43 & 3,46 \\
\hline JM12PMM & 89,9 & 4,97 & - \\
\hline JM16PMM & 170,3 & 6,69 & 9,94 \\
\hline JM12DMM & 75,2 & 7,69 & 9,32 \\
\hline JM16DMM & 170,0 & 7,95 & 11,99 \\
\hline
\end{tabular}

Verificou-se que para a espessura de $12 \mathrm{~cm}$ o modelo JM12BQM, dotado de dispositivo em barra de seção quadrada, apresentou uma força de ruína cerca de $8 \%$ superior, se comparada à do modelo com dispositivo de seção circular JM12BCM. Já o modelo JM12PMM apresentou uma força de ruína cerca de 20\% superior à de JM12DMM.

Para a espessura de $16 \mathrm{~cm}$, não foram detectadas variações sensíveis na força de ruína entre os modelos JM16BCM e JM16BQM, e entre JM16PMM e JM16DMM.

Comparando-se o acréscimo na força de ruína devido ao aumento da espessura dos modelos, nota-se que houve um aumento superior a $25 \%$ na força de ruína entre os modelos JM12BCM e JM16BCM, dotados barras de seção circular. Já entre os modelos com barras de seção quadrada, JM12BQM e JM16BQM, esse aumento foi da ordem de 17\%. Nos modelos com chapas metálicas, JM12PMM e JM16PMM, o aumento na força de ruína foi da ordem de $90 \%$, enquanto que para os modelos com discos metálicos, JM12DMM e JM16DMM ,foi superior a 120\%.

O transdutor de deslocamento T4 foi posicionado sobre a junta, no lado não carregado $d_{u}$ ("unload"). Já o transdutor de deslocamento T6 foi posicionado sobre a junta no lado carregado $d_{L}$ ("load"). Em JM12PMM, não foram obtidas as leituras, por problemas no transdutor. De maneira geral, foi verificada maior deslocabilidade 
dos modelos com espessura de $16 \mathrm{~cm}$, se comparados aos de espessura inferior, com exceção de JM16BQM.

Nos gráficos força aplicada versus deslocamento vertical, apresentados nas Figuras 6.46 a 6.49, é possível visualizar os deslocamentos ocorridos na junta moldada e armada com dispositivos. Foram detectadas quedas nas leituras das células de carga antes do escoamento dos dispositivos ( $\varepsilon_{y \phi}=\varepsilon_{y \#}=0,0016$ e $\varepsilon_{y, \text { chapa }}=0,0013$ ) apenas em JM12DMM, com 35,3kN. No restante dos modelos, verificou-se uma gradativa diferenciação entre $d_{u}$ e $d_{L}$, ocasionada pela diminuição na transferência de carga entre os lados da placa, à medida que o dispositivo se aproximava do escoamento.

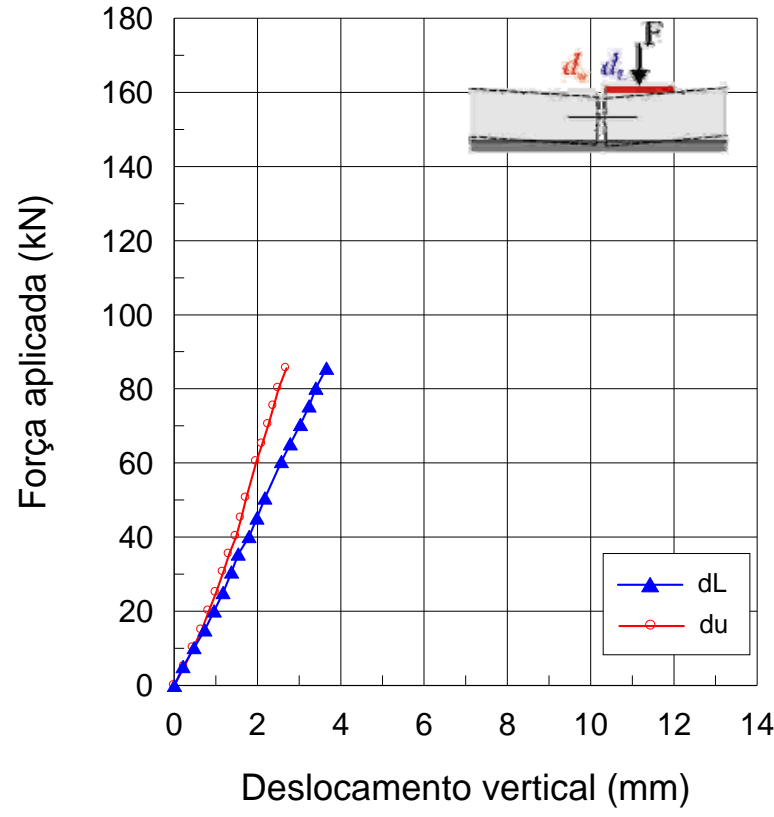

(a)

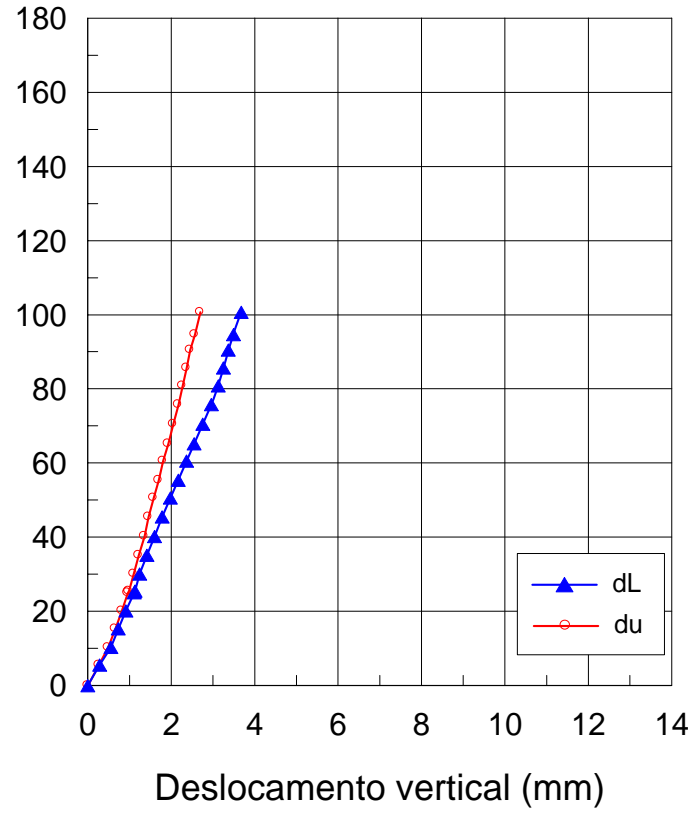

(b)

Figura 6.46- Gráfico força aplicada versus deslocamento vertical: (a) JM12BCM; (b) JM16BCM 


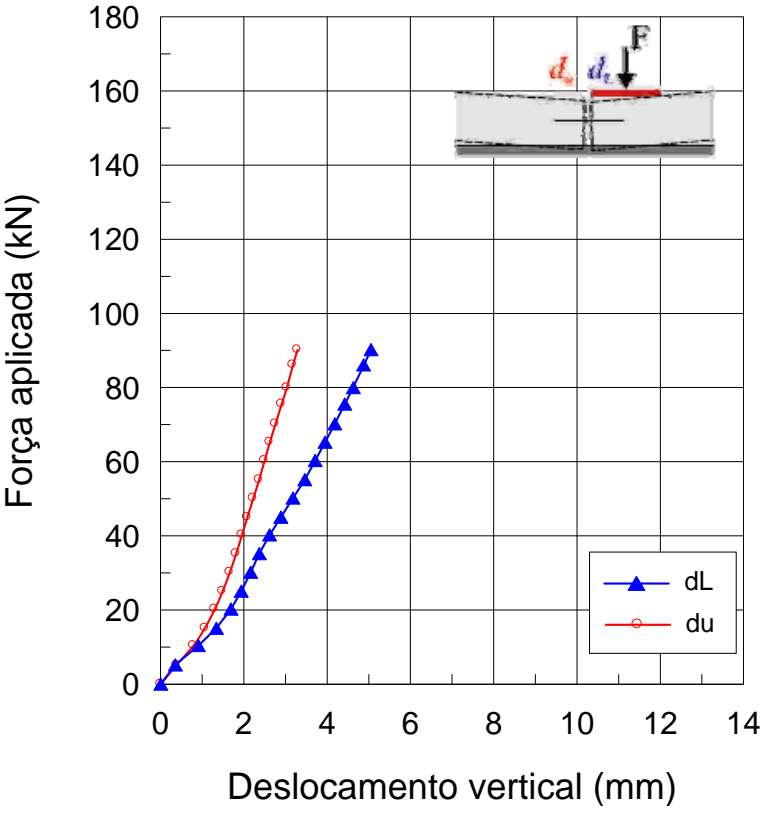

(a)

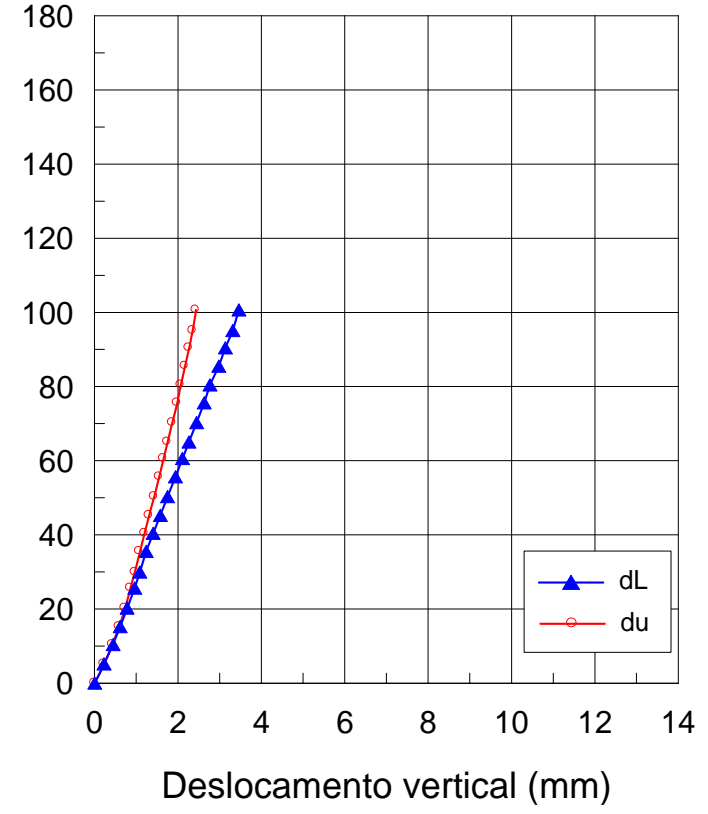

(b)

Figura 6.47- Gráfico força aplicada versus deslocamento vertical: (a) JM12BQM; (b) JM16BQM

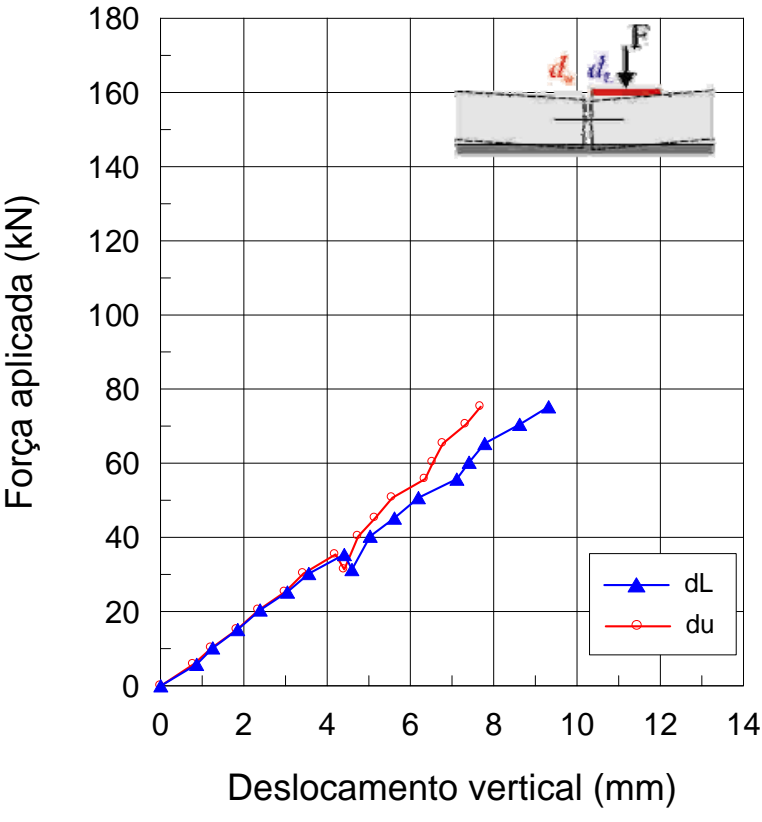

(a)

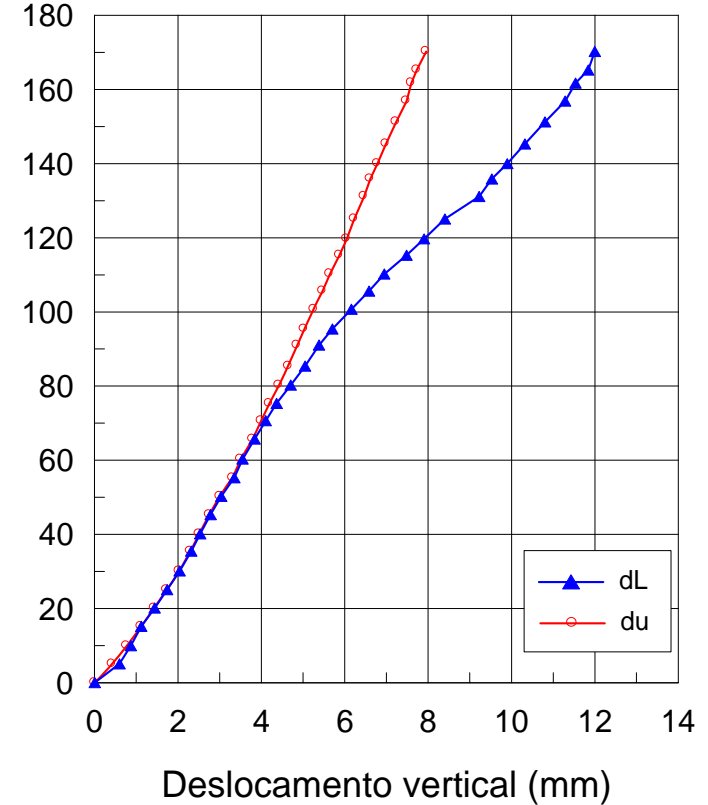

(b)

Figura 6.48- Gráfico força aplicada versus deslocamento vertical: (a) JM12DMM; (b) JM16DMM 


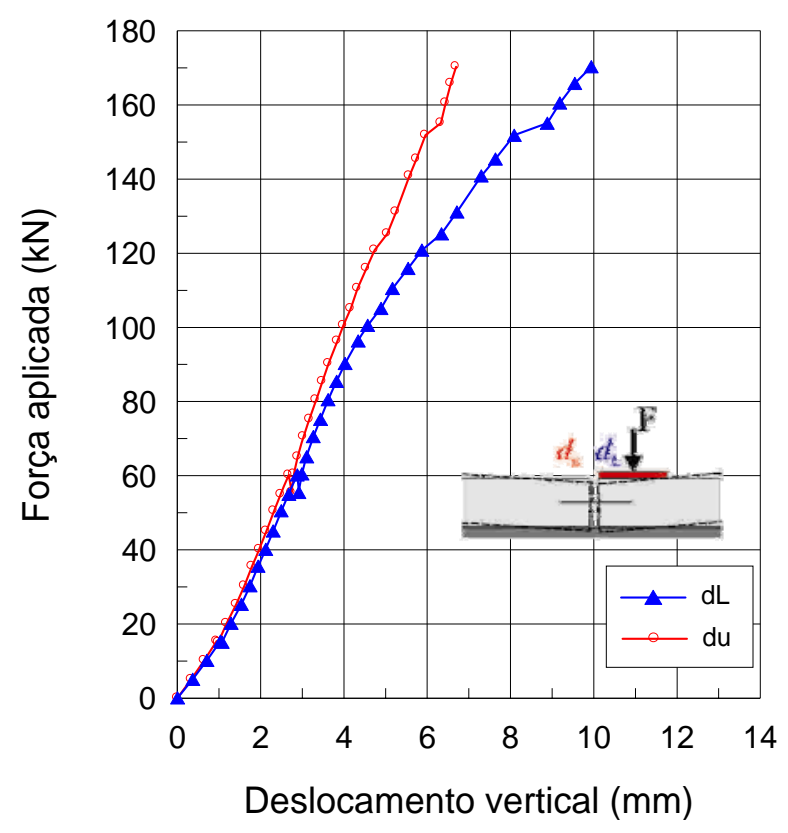

Figura 6. 49 - Gráfico força aplicada versus deslocamento vertical em JM16PMM

As Figura 6.50 a 6.53 apresentam gráficos força aplicada versus força na célula de carga, provenientes da reação da fundação. Em todos os modelos dotados de junta moldada, a célula de carga CEL1 apresentou leituras próximas de zero. Este comportamento indica que os deslocamentos na borda, do lado não carregado, foram suficentes para reduzir o contato entre a face da placa neste ponto e a superfície da fundação. Ruídos, provenientes da resolução da célula de carga para baixos carregamentos, originaram trechos denteados nos gráficos.

As leituras da célula de carga CEL2, nos modelos JM12BCM, JM12BQM, JM16BCM e JM16BQM, apresentaram valores inferiores aos da célula CEL3. No escoamento dos dispositivos em barra, não foram detectadas mudanças bruscas na inclinação da curva relativa à CEL2.

Já nos modelos JM12PMM, JM12DMM, JM16PMM e JM16DMM, dotados de dispositivos em chapa, verificou-se uma inversão nos valores da CEL2 em relação aos da CEL3, ou seja, as leituras obtidas na CEL2 foram ligeiramente maiores do que na CEL3. No entanto, foi detectado razoável paralelismo na inclinação das curvas relativas à CEL2 e à CEL3, nesses modelos. 


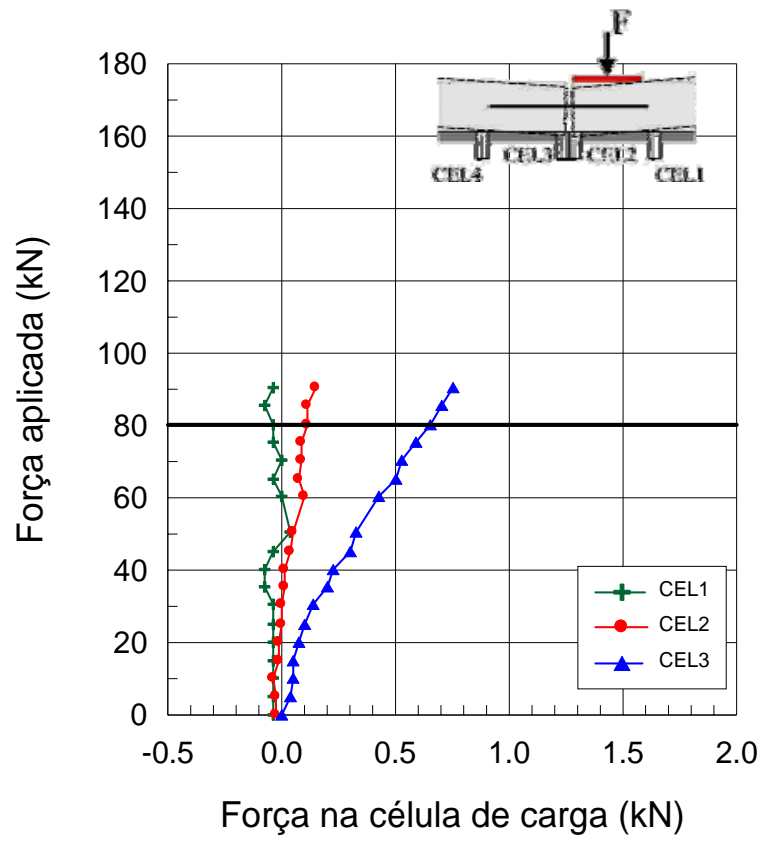

(a)

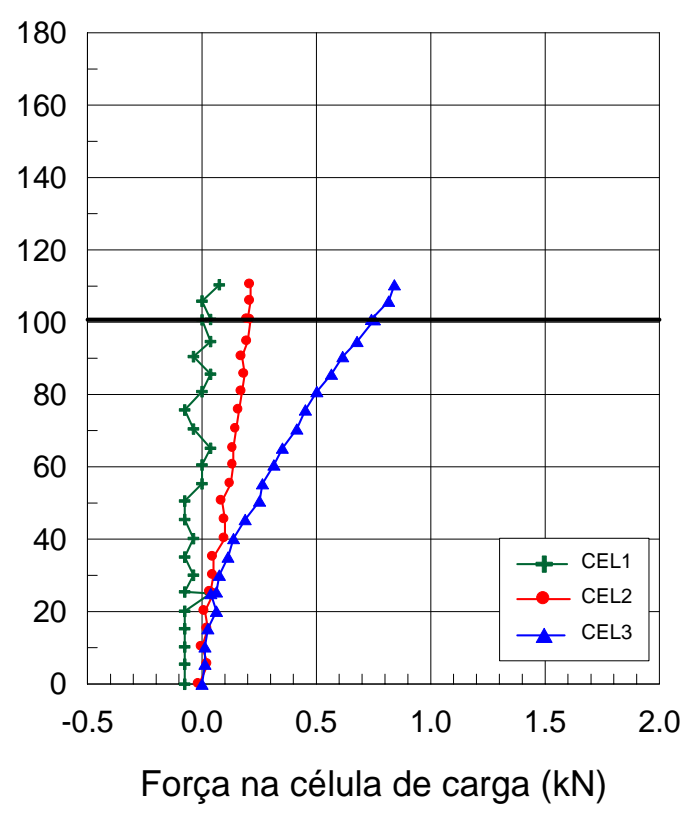

(b)

Figura 6.50- Gráfico força aplicada versus força na célula de carga: (a) JM12BCM; (b) JM16BCM

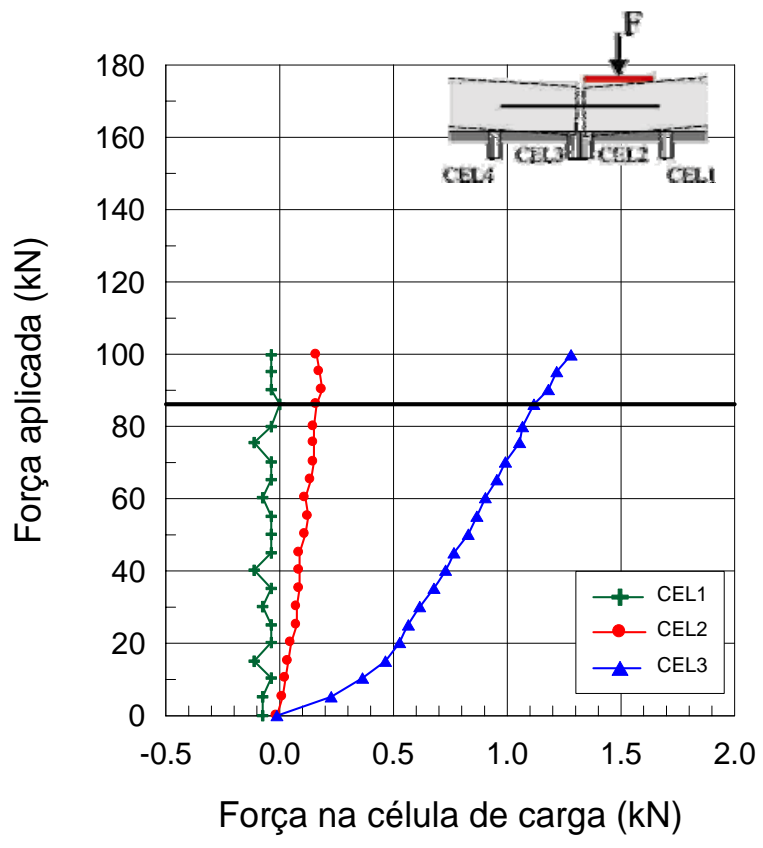

(a)

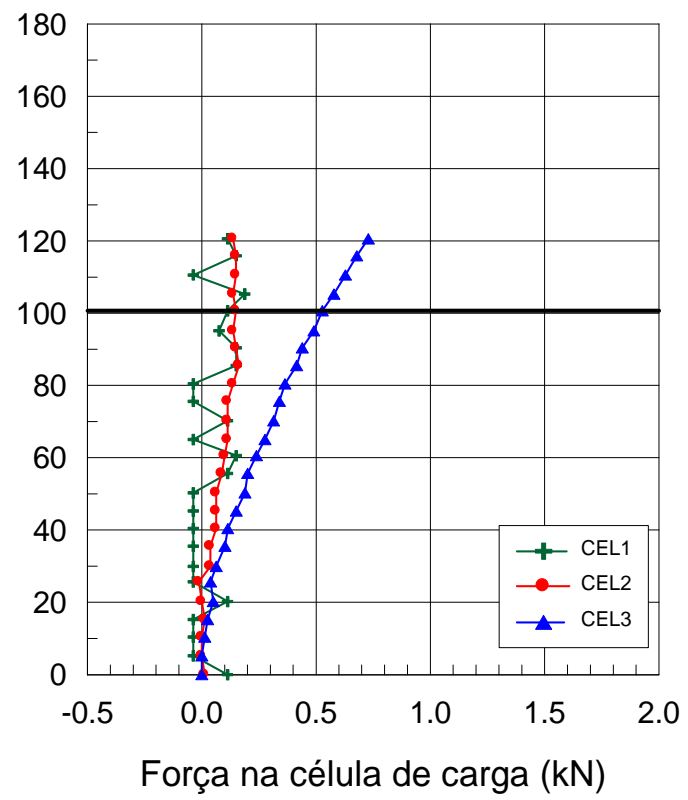

(b)

Figura 6.51- Gráfico força aplicada versus força na célula de carga: (a) JM12BQM; (b) JM16BQM 


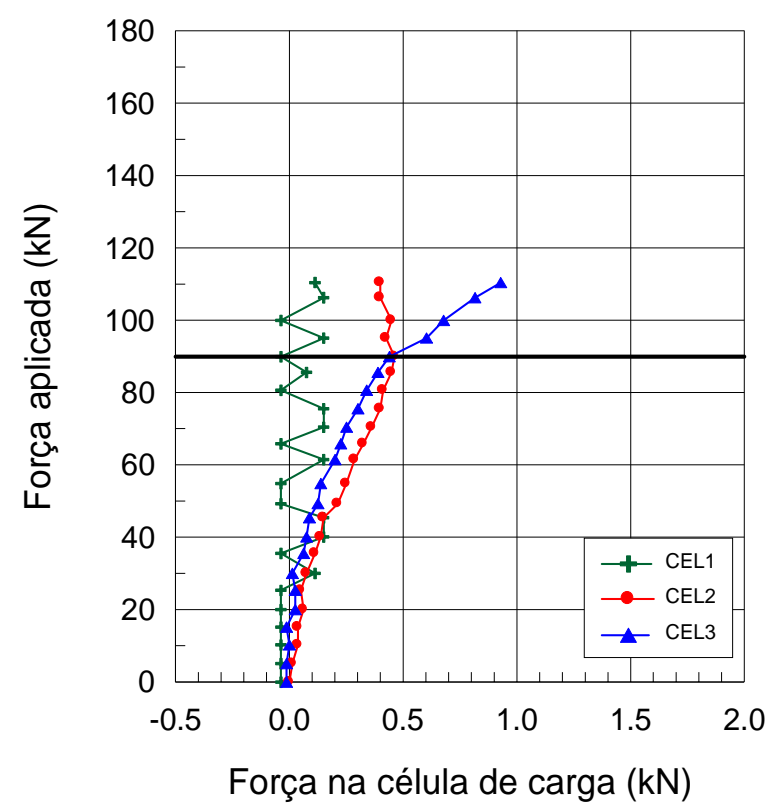

(a)

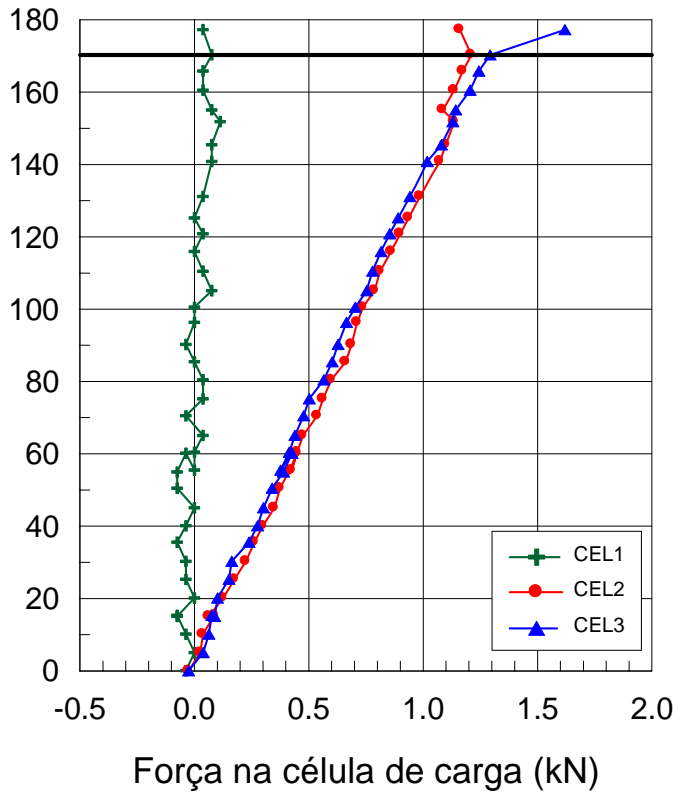

(b)

Figura 6.52- Gráfico força aplicada versus força na célula de carga: (a) JM12PMM; (b) JM16PMM

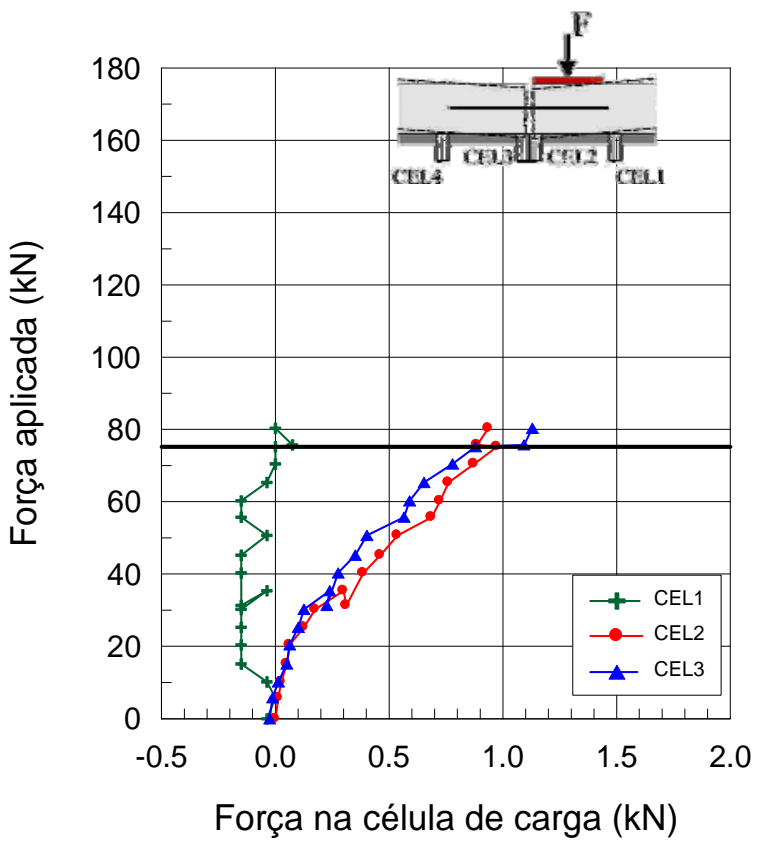

(a)

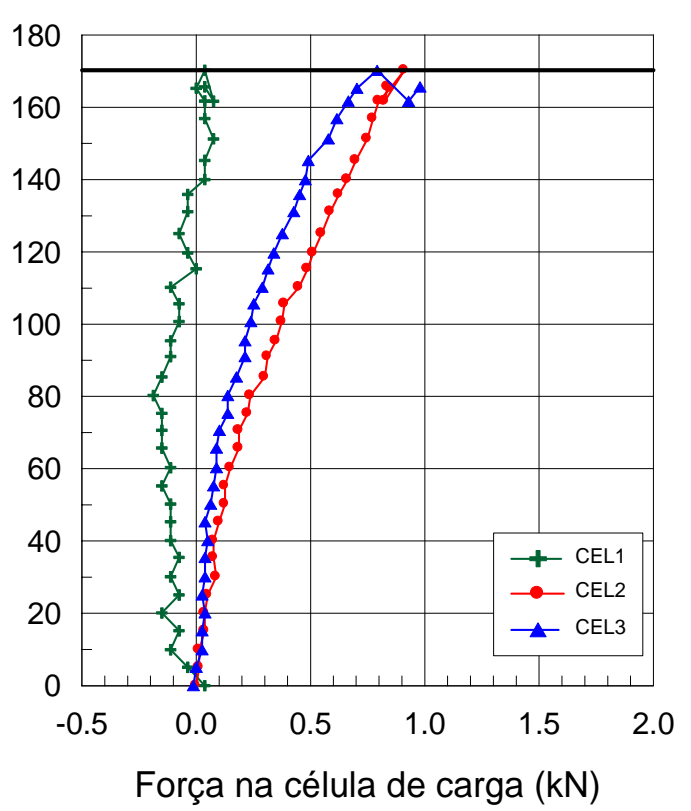

(b)

Figura 6.53- Gráfico força aplicada versus força na célula de carga: (a) JM12DMM; (b) JM16DMM 
Os gráficos da Figura 6.54 fornecem a relação força máxima na célula de carga e espessura dos modelos. Nas células CEL2 e CEL3, os modelos com barra circular e placa metálica apresentaram aumento da força com o aumento da espessura.

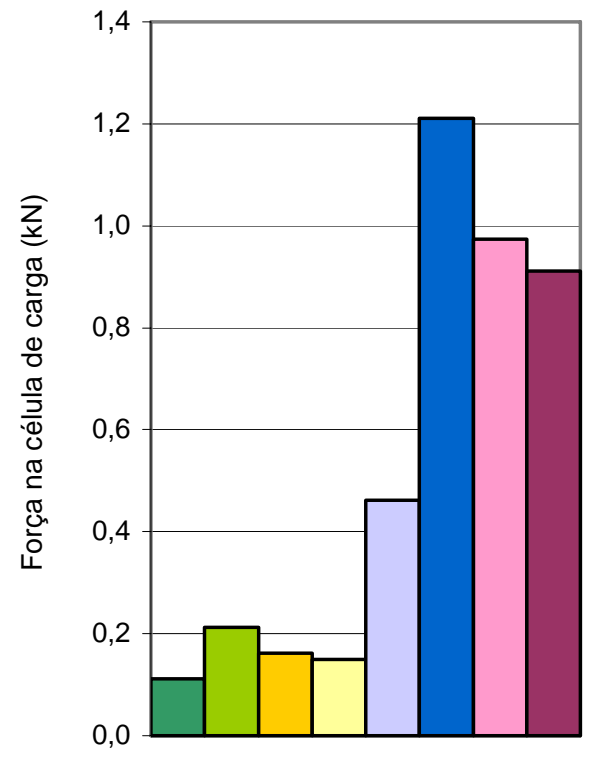

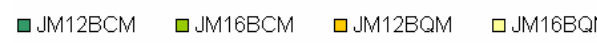

(a)

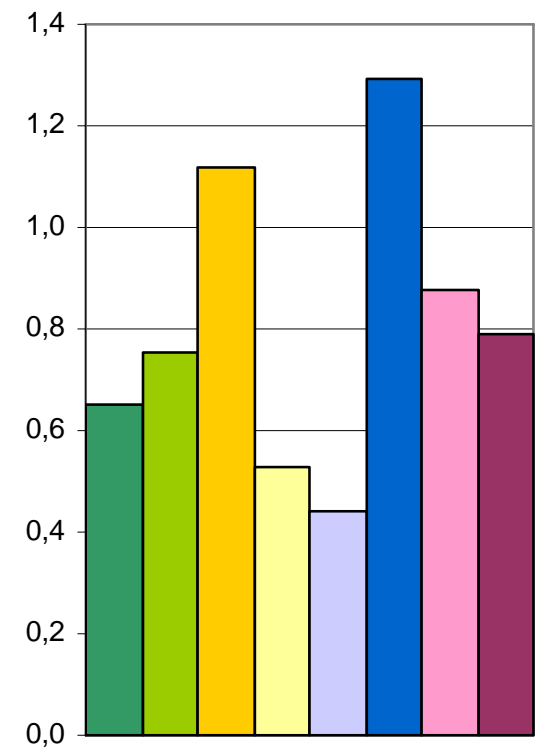

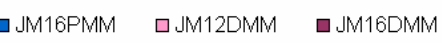

Figura 6.54 - Relação entre espessura e reação na célula de carga: (a) CEL2; (b) CEL3

Os gráficos $\mathrm{F} / \mathrm{Fu}$ versus deslocamento vertical registrado no transdutor T4 das Figura 6.55 e 6.56 apresentam o comportamento dos modelos para vários estágios de carregamento. Para os dispositivos em barra, é possivel verificar que todos os modelos se comportaram de maneira semelhante, desde o início do carregamento. Após $20 \%$ de $F_{u}$, as curvas mudam sua inclinação, que permanece igual até a ruptura do modelo. O modelo JM12BQM apresentou os maiores deslocamentos, seguido de JM16BCM.

Para os dispositivos em chapa, é possível verificar que JM12DMM e JM16DMM se comportaram de maneira semelhante, uma vez que os deslocamentos finais foram respectivamente de 7,61mm e 7,81mm. Em JM12DMM ocorreu uma perturbação na carga de 35,3kN e em JM16PMM, na de 60,2kN, provavelmente devido ao início do 
escoamento indicado pelo extensômetro AS2D central. O modelo JM16PMM apresentou maiores deslocamentos, se comparados aos de JM12PMM.

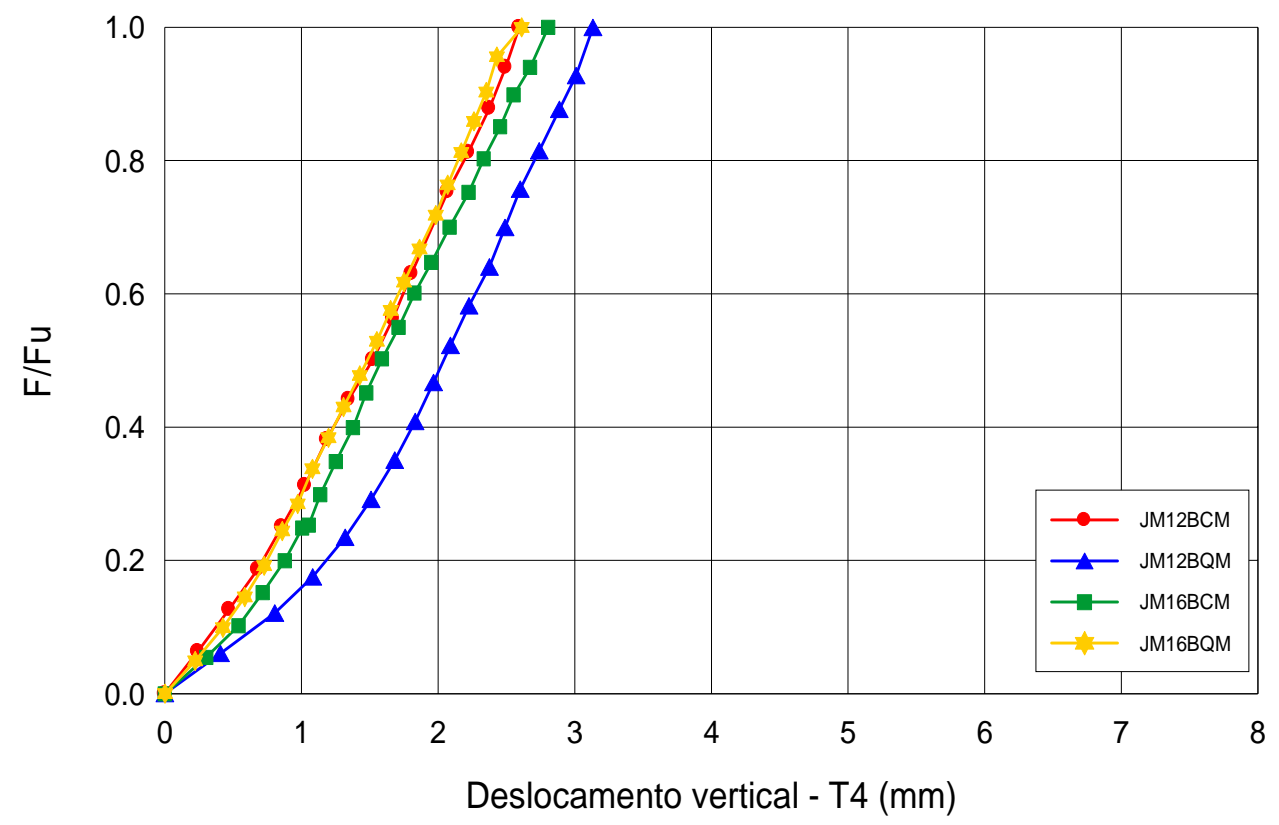

Figura 6.55 - Gráfico F/Fu versus deslocamento vertical em T4 - barra

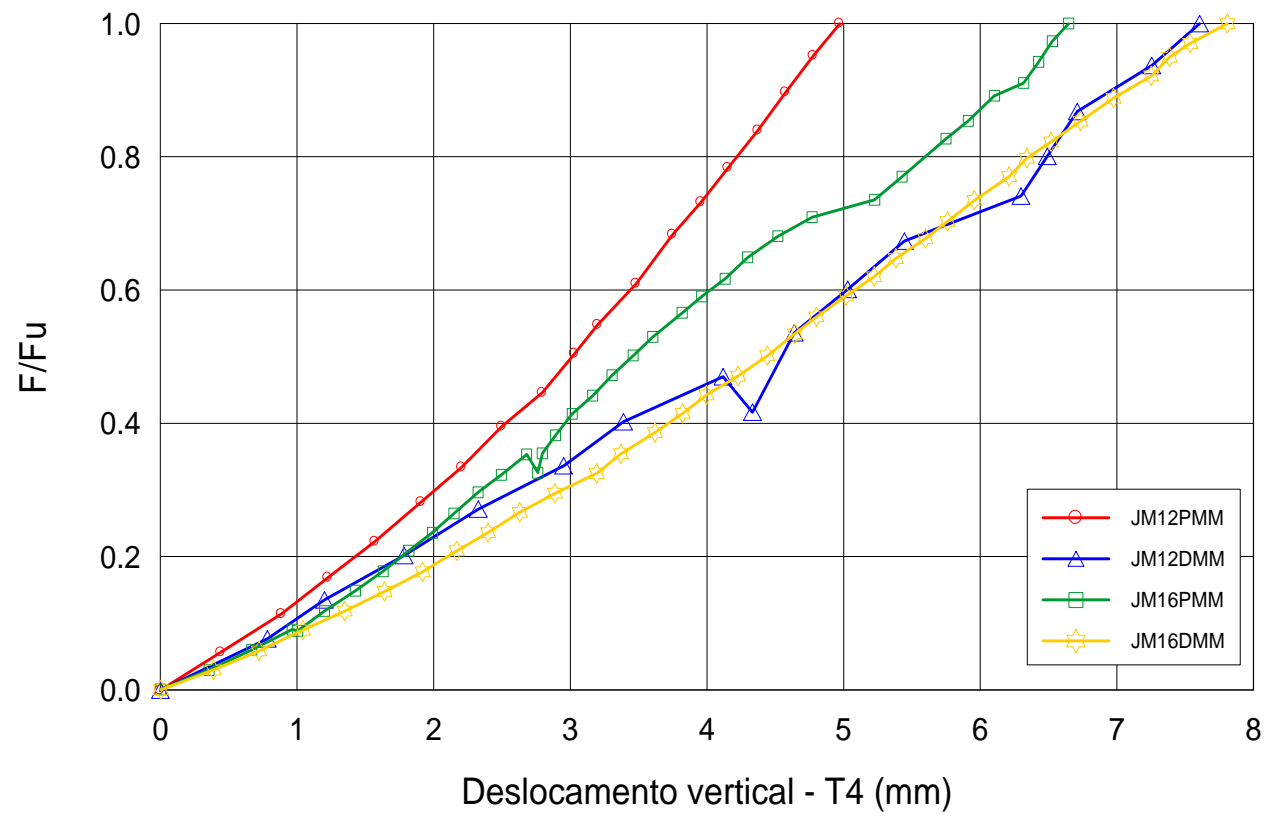

Figura 6.56 - Gráfico F/Fu versus deslocamento vertical em T4 - chapa

As leituras dos deslocamentos verticais foram realizadas em vários estágios de carregamento, por meio de transdutores posicionados como apresentado na Figura 6.57 . 


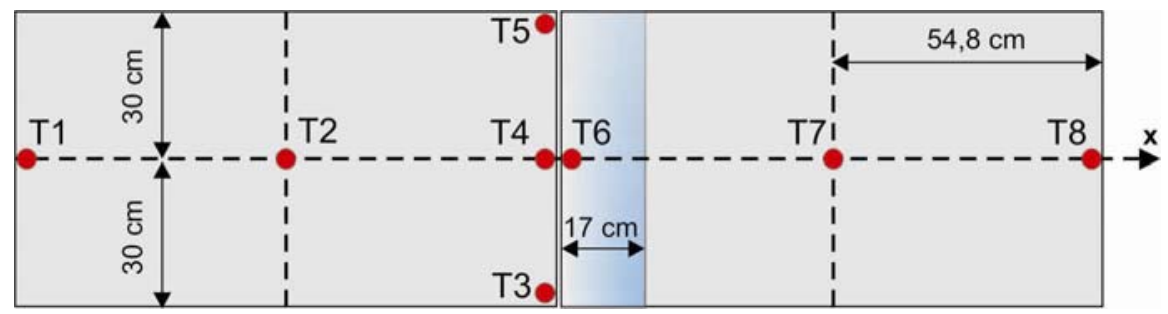

Figura 6.57 - Transdutores de deslocamento

A Figura 6.58 fornece o gráfico deslocamento vertical versus distância, generalizado do comportamento dos modelos ao longo do eixo x. O sentido positivo considerado é para baixo, seguindo o sentido da força aplicada. A borda do lado não carregado, em T1, apresentou os maiores deslocamentos, seguido de T2. Já do lado carregado, em T7, os deslocamentos foram menores.

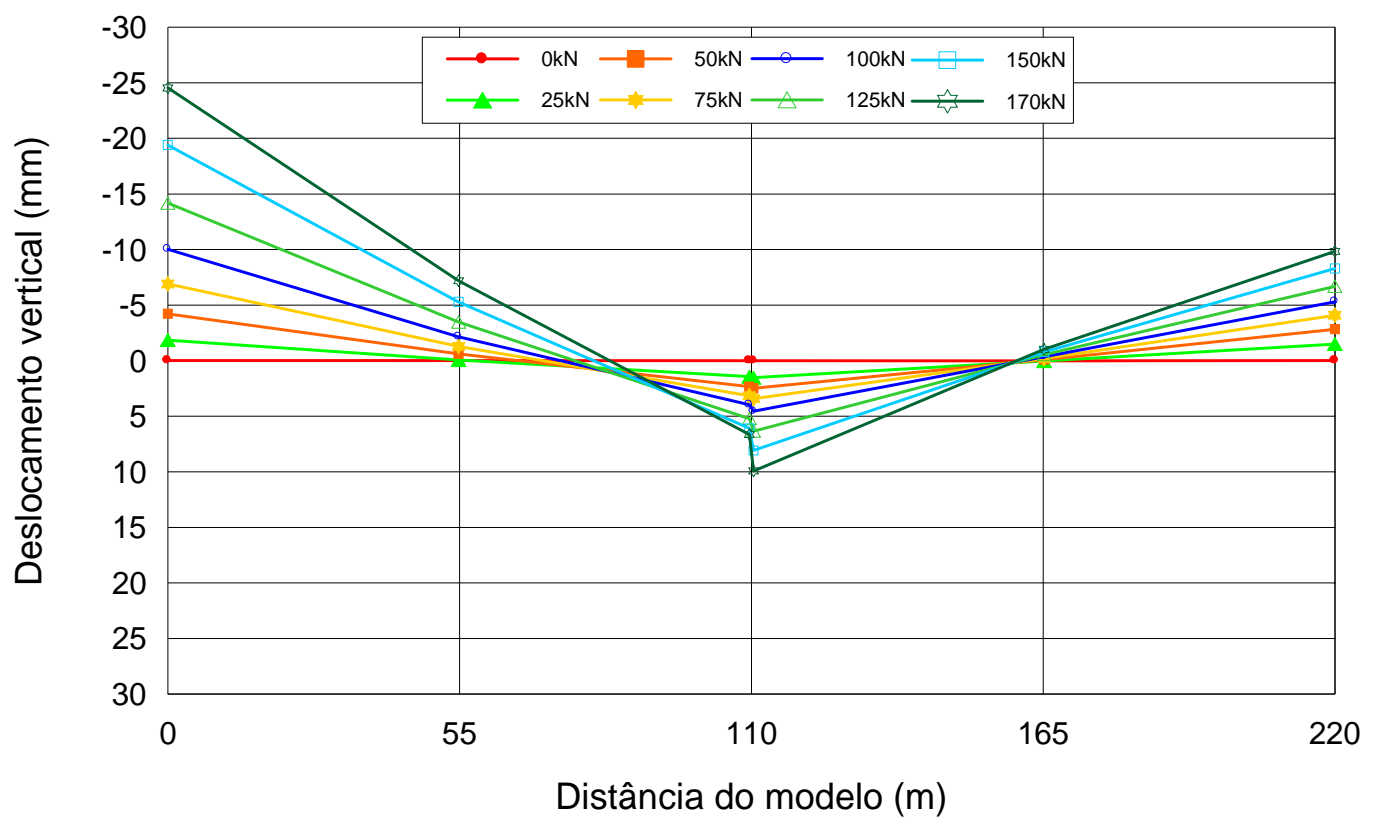

Figura 6.58 - Gráfico deslocamento vertical versus distância, do modelo JM16PMM

\subsection{EXTENSOMETRIA}

Neste item serão apresentados os resultados obtidos na leitura dos extensômetros elétricos de resistência empregados na superfície de concreto dos modelos e nos dispositivos metálicos de transferência de carga. 


\subsubsection{Deformação no concreto}

A extensometria fixada no concreto foi posicionada como apresentado na Figura 6.59. O limite de deformação empregado, segundo a NBR 6118 (2003), para o encurtamento último do concreto na compressão por flexão foi de $\varepsilon_{c u}=-3,5 \times 10^{-3} \mathrm{~mm} / \mathrm{mm}$, enquanto que seu alongamento foi de $\varepsilon_{c t}=0,15 \times 10^{-3} \mathrm{~mm} / \mathrm{mm}$.

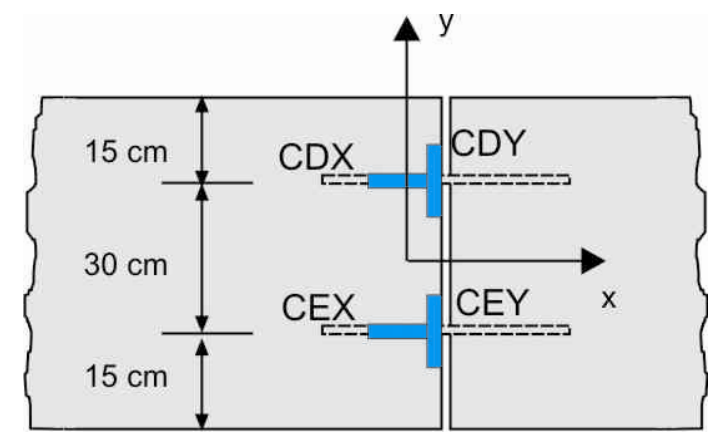

Figura 6.59 - Extensômetro no concreto

\section{A. Juntas serradas - ensaio estático}

Os gráficos força aplicada versus deformação específica do concreto, apresentados na Figura 6.60, referem-se aos modelos sem dispositivo de transferência. Verificouse que os extensômetros posicionados ao longo do eixo $x$ (CDX e CEX) e eixo $y$ paralelo à junta (CDY e CEY) apresentaram leituras próximas de zero. 


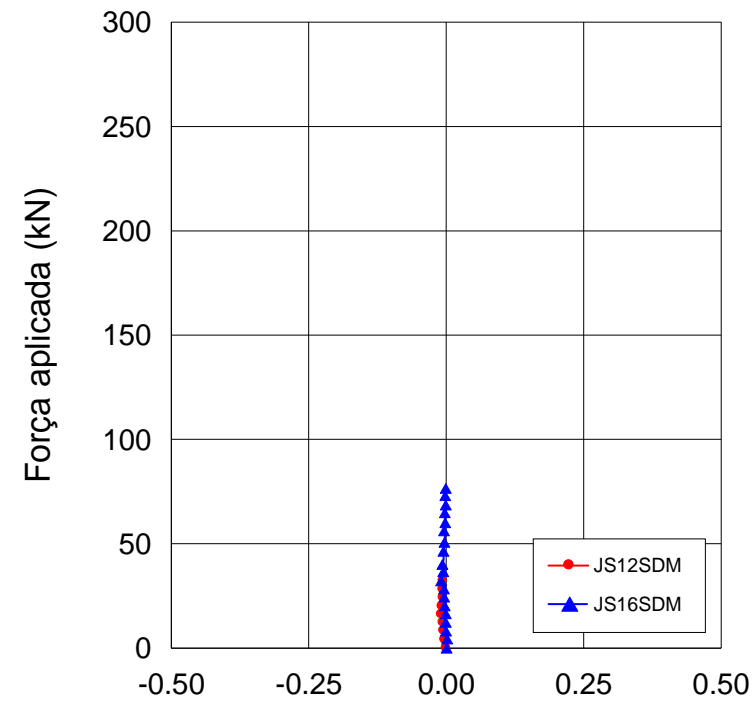

Deformação do concreto $\left(10^{-3} \mathrm{~mm} / \mathrm{mm}\right)$

(a)

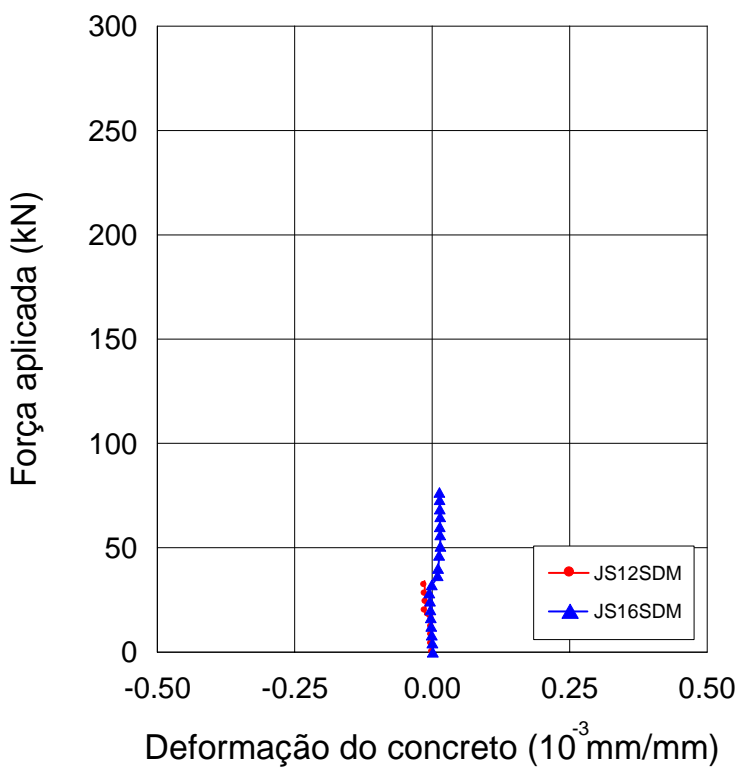

(c)

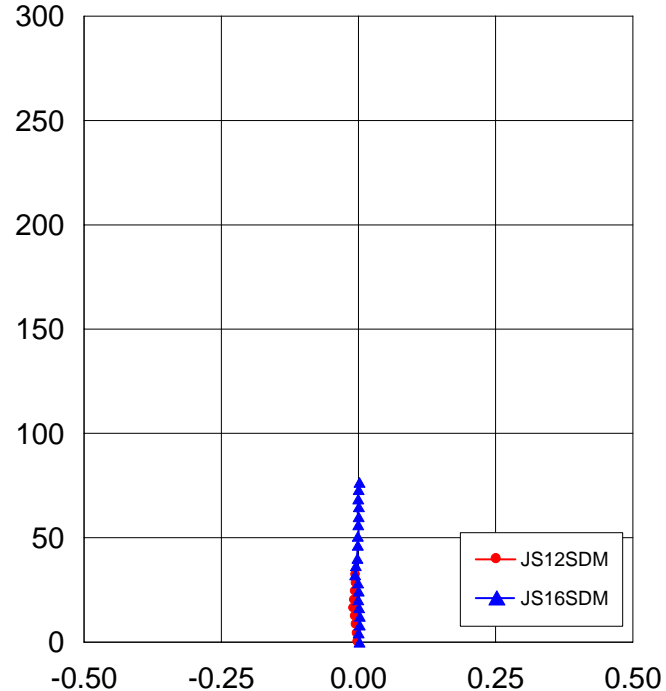

Deformação do concreto $\left(10^{-3} \mathrm{~mm} / \mathrm{mm}\right)$

(b)

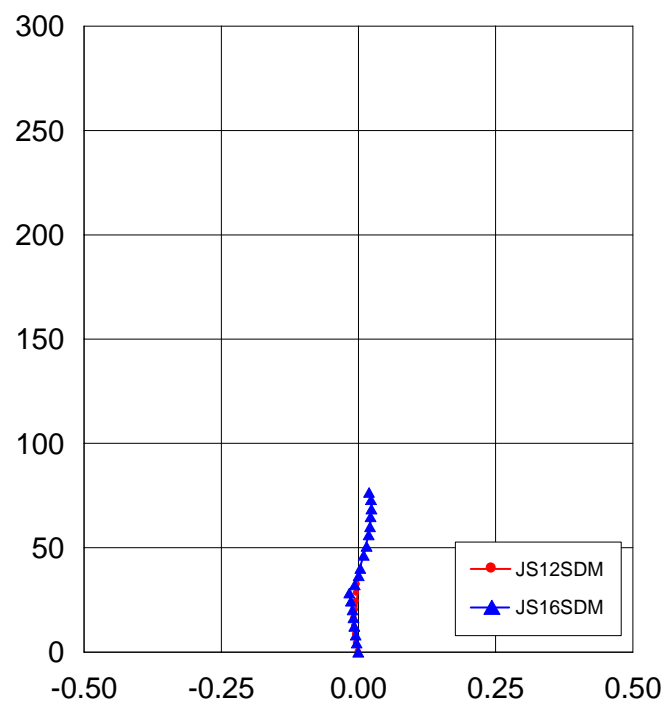

Deformação do concreto $\left(10^{-3} \mathrm{~mm} / \mathrm{mm}\right)$

(d)

Figura 6.60 - Gráfico força aplicada versus deformação específica do concreto, em modelos de referência, nos extensômetros: (a) CDY; (b) CEY; (c) CDX; (d) CEX

$\mathrm{Na}$ Figura 6.61, ao longo do eixo $y$, foram registradas leituras apenas em JS12BQM. Em $x$, foram registradas leituras em JS12BCM e JS16BQM. Em geral, os extensômetros colados na superfície de concreto dos modelos dotados de dispostitivos em barra apresentaram leituras inferiores ao limite de deformação na compressão. 


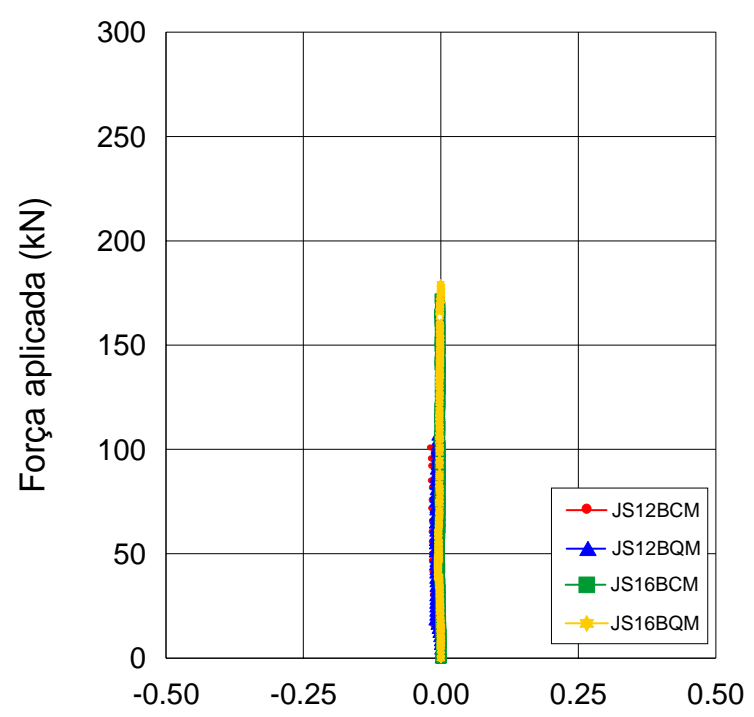

Deformação do concreto $\left(10^{-3} \mathrm{~mm} / \mathrm{mm}\right)$

(a)

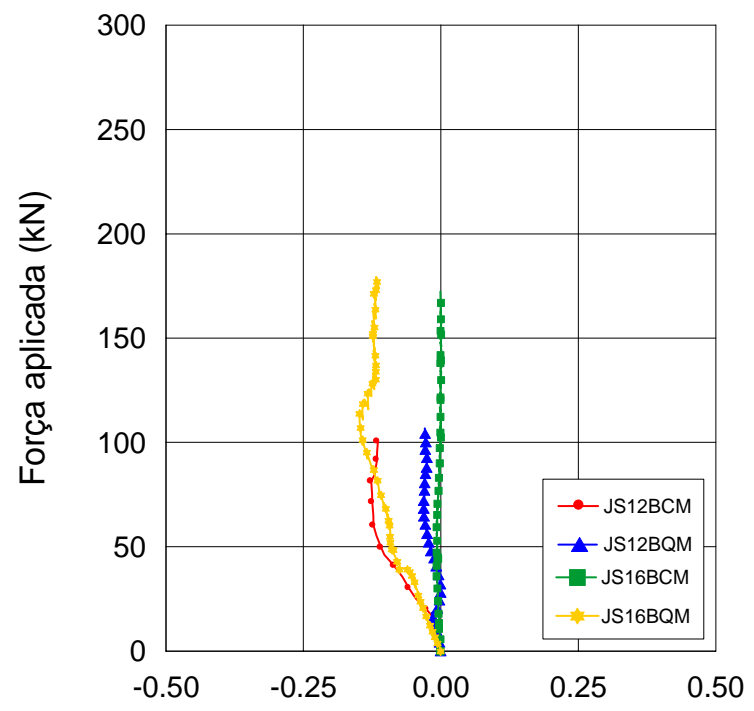

Deformação do concreto $\left(10^{-3} \mathrm{~mm} / \mathrm{mm}\right)$

(c)

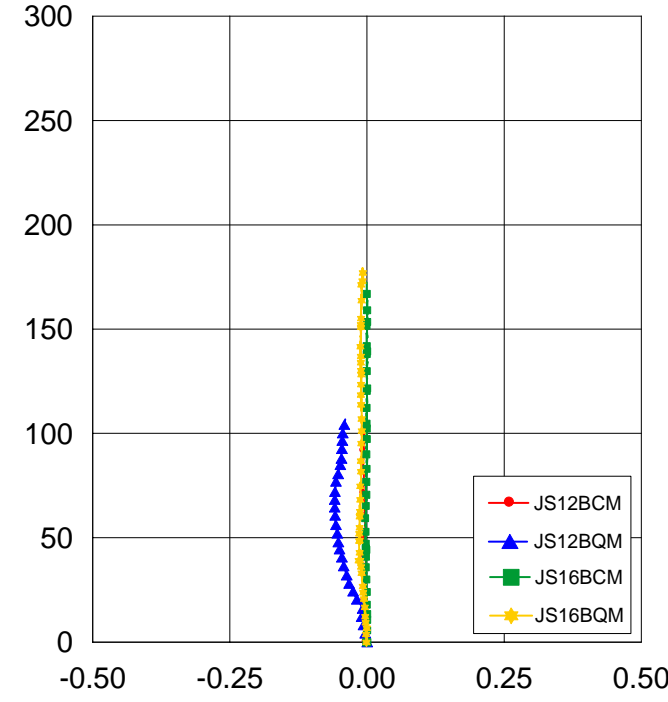

Deformação do concreto $\left(10^{-3} \mathrm{~mm} / \mathrm{mm}\right)$

(b)

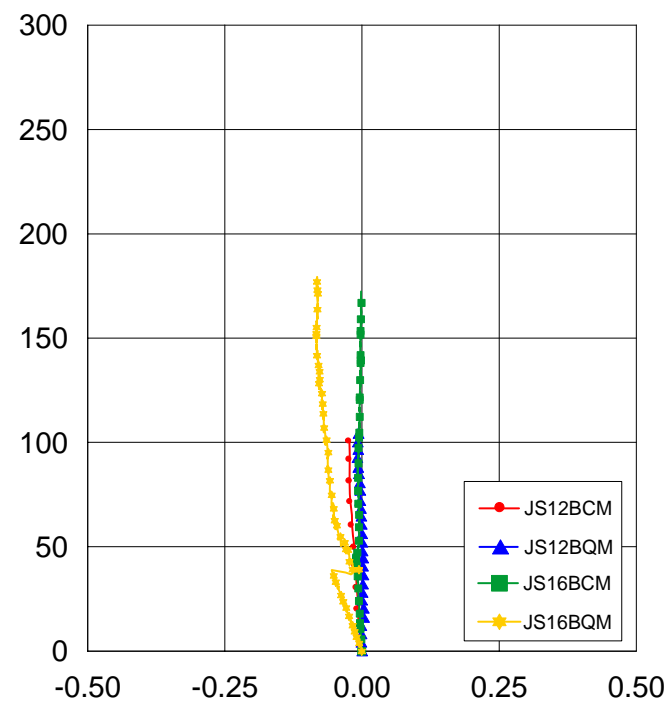

Deformação do concreto $\left(10^{-3} \mathrm{~mm} / \mathrm{mm}\right)$

(d)

Figura 6.61 - Gráfico força aplicada versus deformação específica do concreto, em modelos com dispositivo em barra, nos extensômetros: (a) CDY; (b) CEY; (c) CDX; (d) CEX

Na Figura 6.62, ao longo do eixo $y$, foram registradas leituras apenas em JS12DMM e JS16DMM. Em $x$, foram registradas leituras inferiores ao limite de deformação na compressão, em todos os modelos dotados de dispostitivos em chapa. 


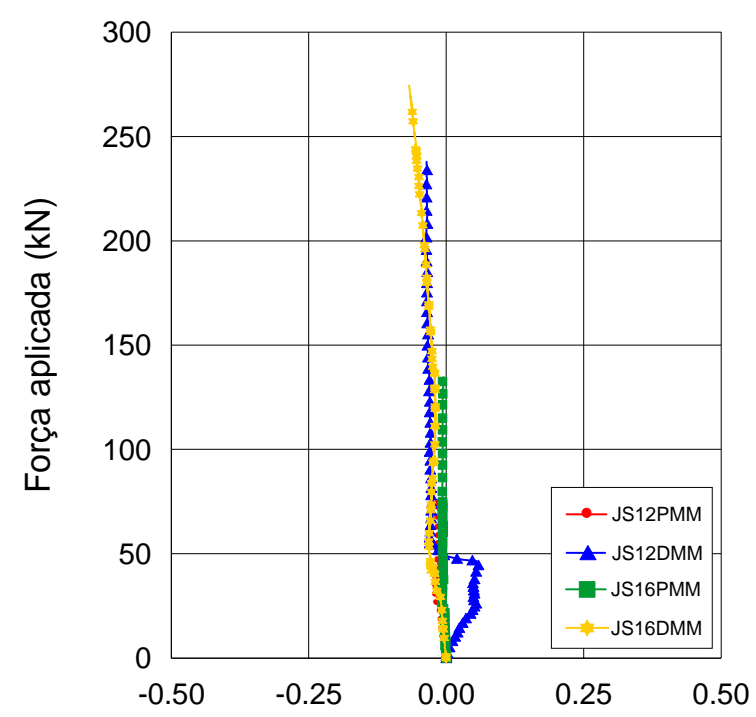

Deformação do concreto $\left(10^{-3} \mathrm{~mm} / \mathrm{mm}\right)$

(a)

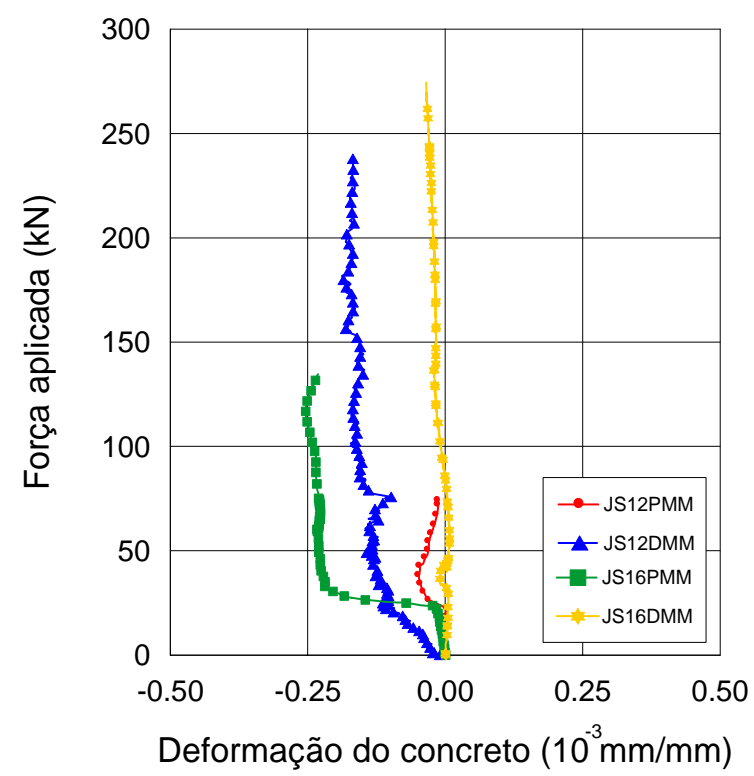

(c)

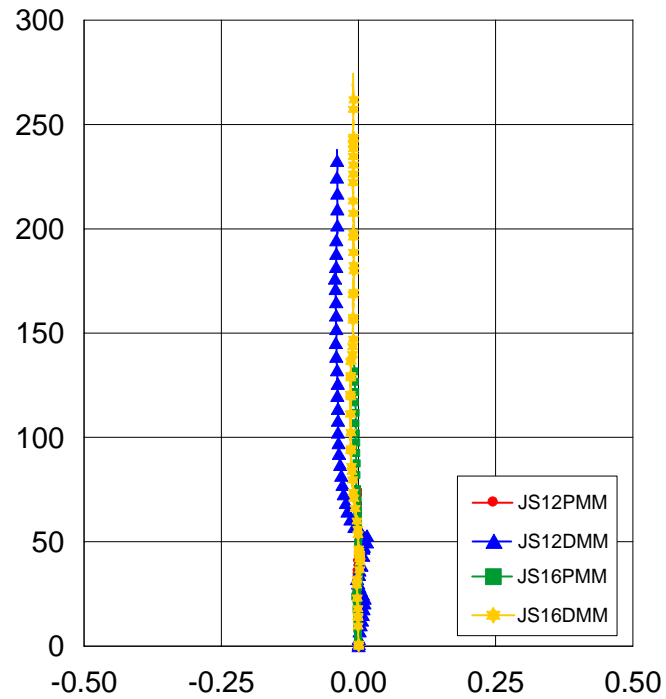

Deformação do concreto $\left(10^{-3} \mathrm{~mm} / \mathrm{mm}\right)$

(b)

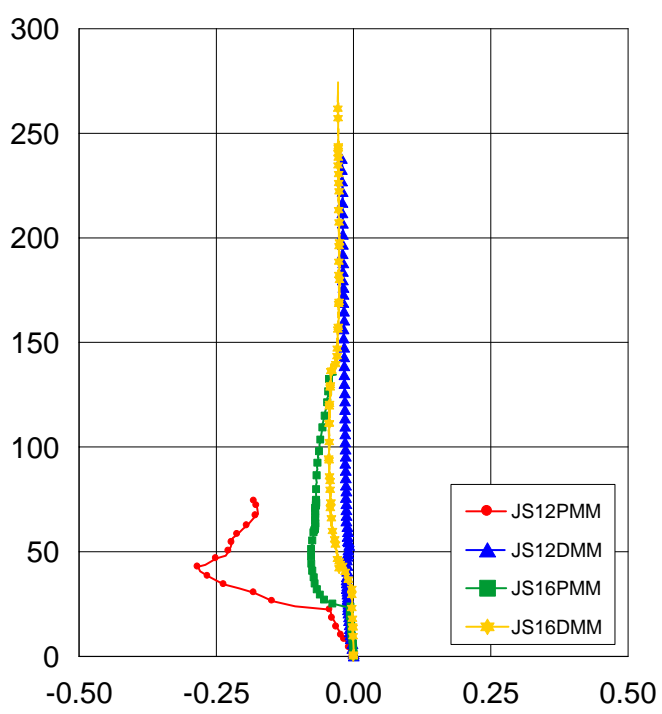

Deformação do concreto $\left(10^{-3} \mathrm{~mm} / \mathrm{mm}\right)$

(d)

Figura 6.62 - Gráfico força aplicada versus deformação específica do concreto, em modelos com dispositivo em chapa, nos extensômetros: (a) CDY; (b) CEY; (c) CDX; (d) CEX

B. Juntas serradas - ensaio cíclico

Os gráficos força aplicada versus deformação específica do concreto, apresentados nas Figuras 6.63 e 6.64, referem-se aos modelos JS12BCC, JS12PMC e JS12DMC. Foram colados extensômetros no concreto apenas no eixo $x$. Verificou-se que os 
extensômetros apresentaram leituras próximas de zero, com exceção no JS12DMC. Para este modelo, as deformações do concreto foram inferiores ao limite estabelecido para compressão.

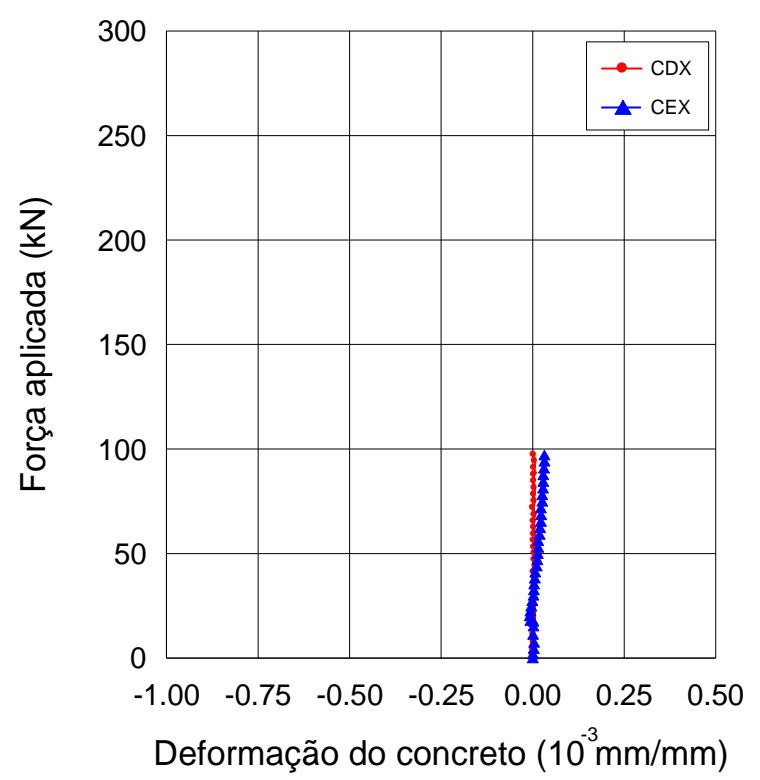

Figura 6.63 - Gráfico força aplicada versus deformação específica do concreto em JS12BCC

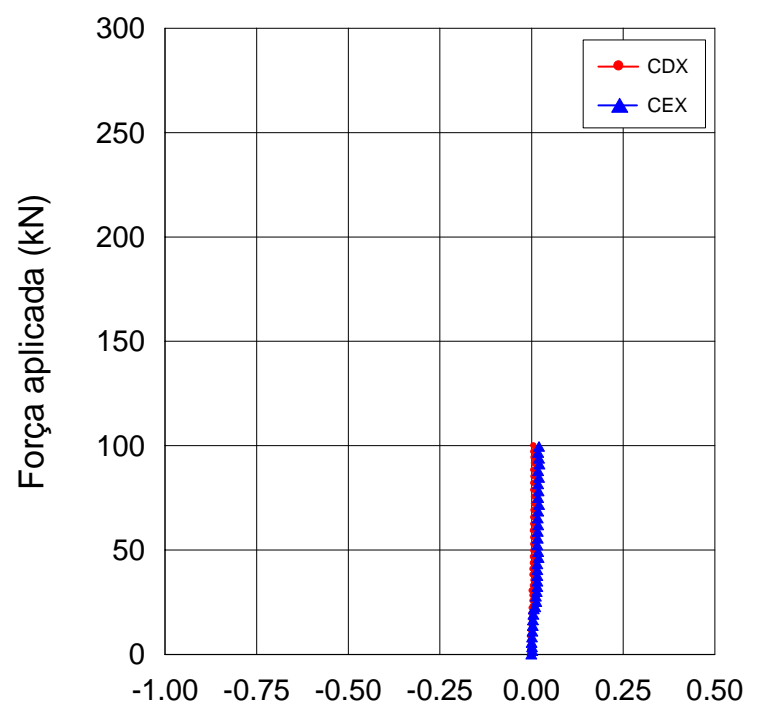

Deformação do concreto $\left(10^{-3} \mathrm{~mm} / \mathrm{mm}\right)$

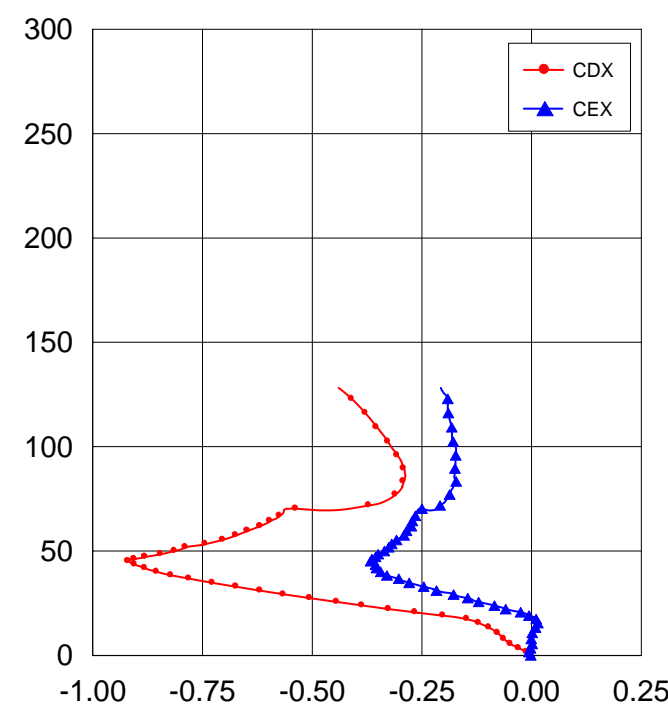

Deformação do concreto $\left(10^{-3} \mathrm{~mm} / \mathrm{mm}\right)$

(a)

(b)

Figura 6. 64 - Gráfico força aplicada versus deformação específica do concreto em: (a) JS12PMC; (b) JS12DMC 
C. Juntas moldadas

Os gráficos força aplicada versus deformação específica do concreto, apresentados na Figura 6.65, referem-se aos modelos com dispositivo em barra.

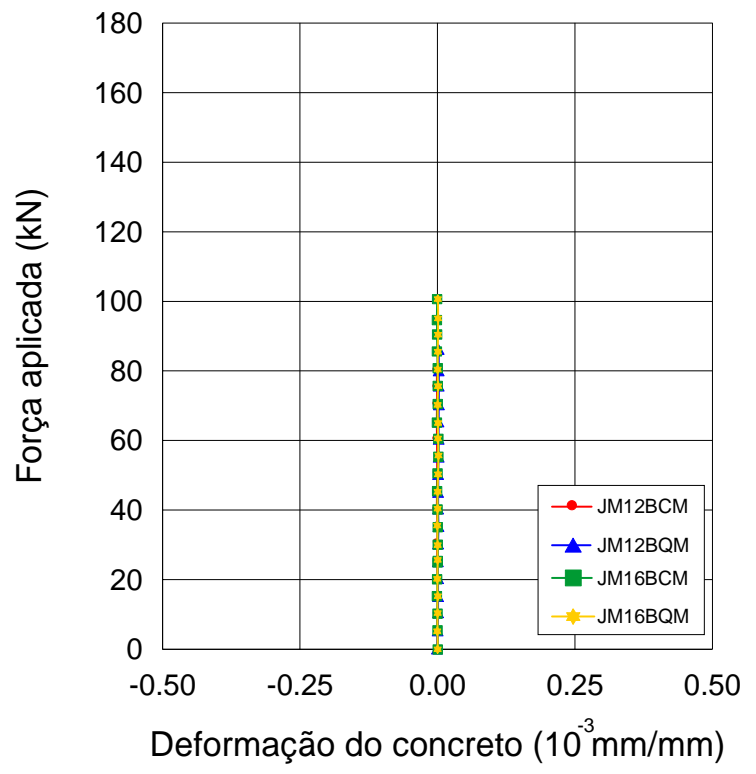

(a)

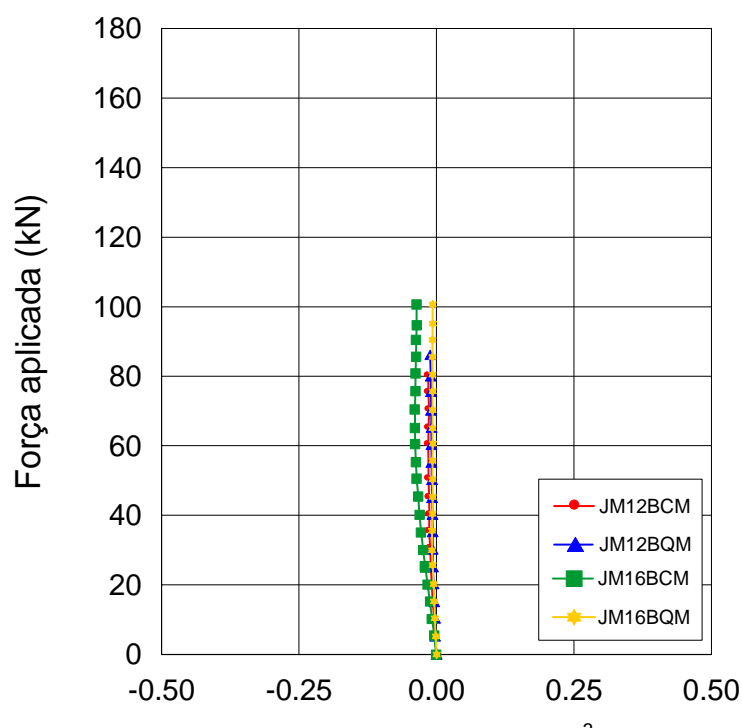

Deformação do concreto $\left(10^{-3} \mathrm{~mm} / \mathrm{mm}\right)$

(c)

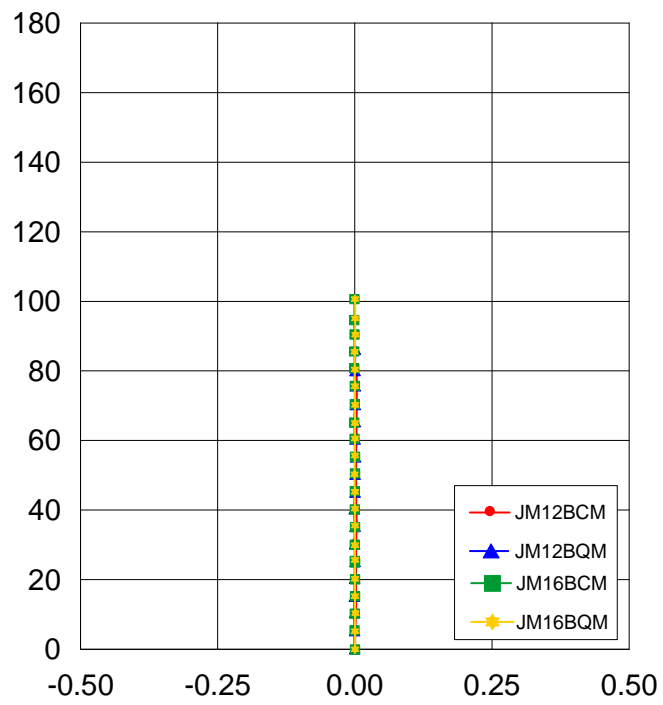

Deformação do concreto $\left(10^{-3} \mathrm{~mm} / \mathrm{mm}\right)$

(b)

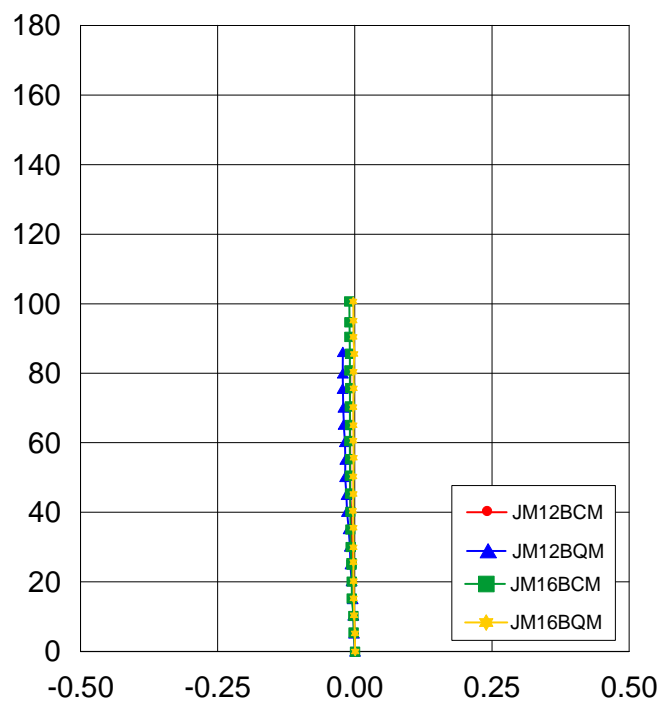

Deformação do concreto $\left(10^{-3} \mathrm{~mm} / \mathrm{mm}\right)$

(d)

Figura 6.65 - Gráfico força aplicada versus deformação específica do concreto, em modelos com dispositivo em barra, nos extensômetros: (a) CDY; (b) CEY; (c) CDX; (d) CEX 
Verificou-se que os extensômetros posicionados ao longo do eixo $y$ e paralelos à junta (CDY e CEY) apresentaram leituras próximas de zero. Da mesma forma, os extensômetros em $x$ (CDX e CEX) apresentaram leituras inferiores ao limite de deformação, não tendo sido detectado o provável esmagamento sofrido pelos modelos JM16BCM e JM16BQM.

Os gráficos força aplicada versus deformação específica do concreto, apresentados na Figura 6.66, referem-se aos modelos com dispositivo em chapa. Verificou-se que, ao longo do eixo $y$, os extensômetros apresentaram leituras proximas de zero, com exceção de JM16DMM. Para o eixo $x$, foram registradas leituras de compressão em CDX, sem no entanto atingir o limite de deformação. 


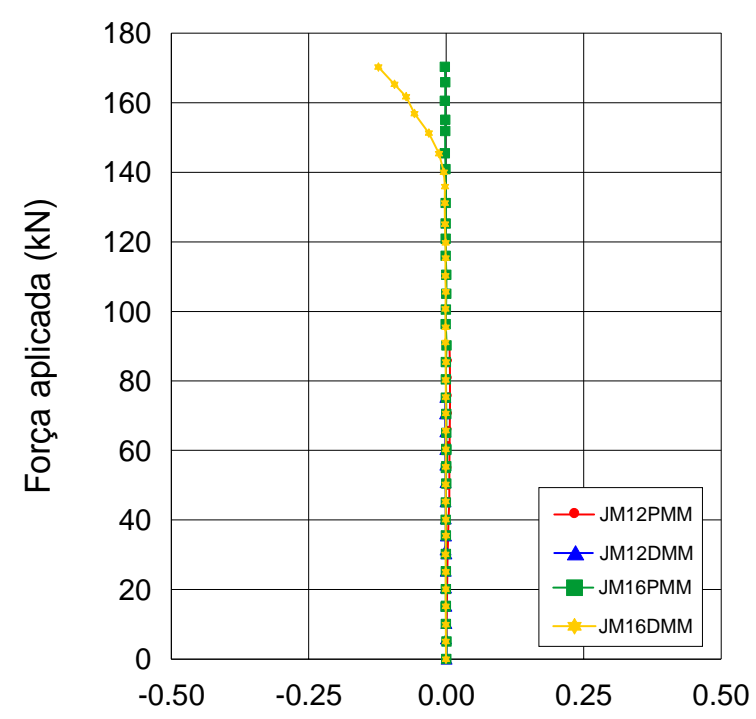

Deformação do concreto $\left(10^{-3} \mathrm{~mm} / \mathrm{mm}\right)$

(a)

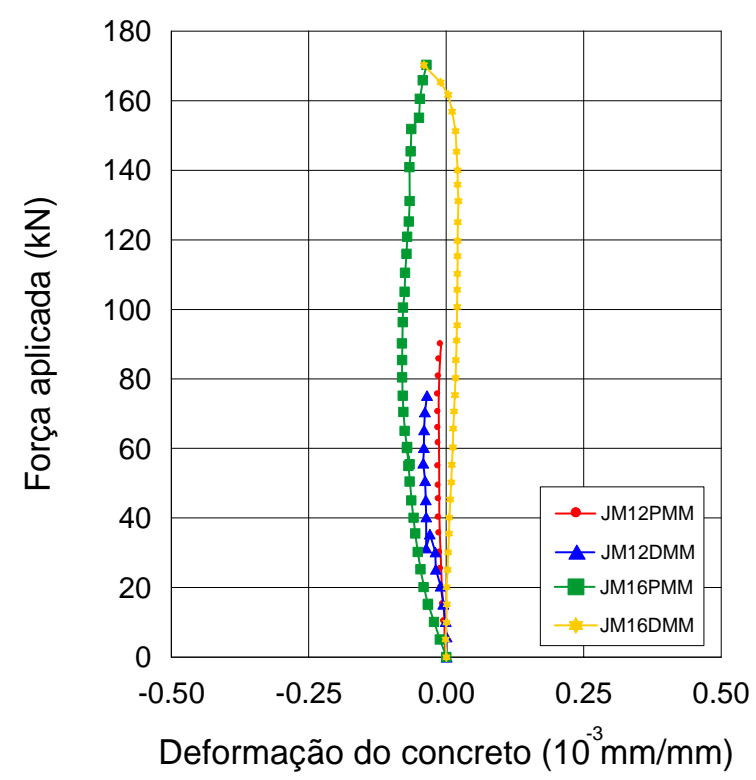

(c)

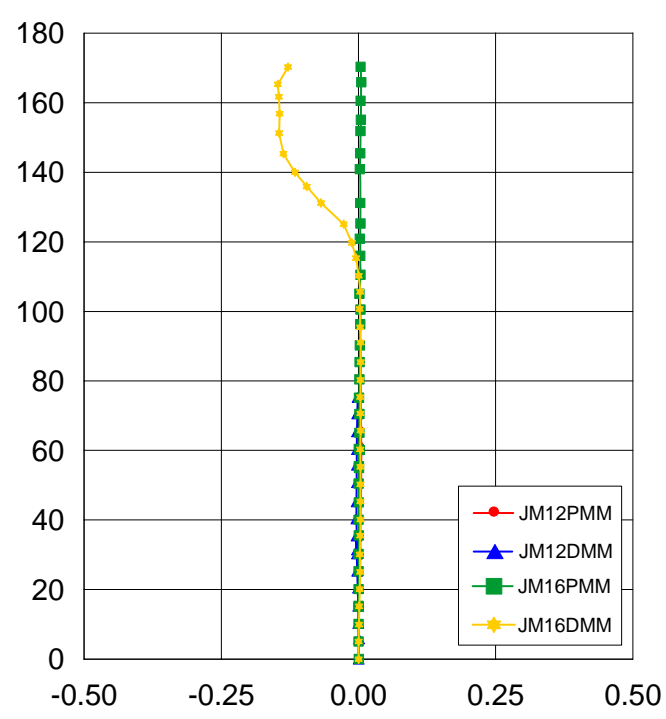

Deformação do concreto $\left(10^{-3} \mathrm{~mm} / \mathrm{mm}\right)$

(b)

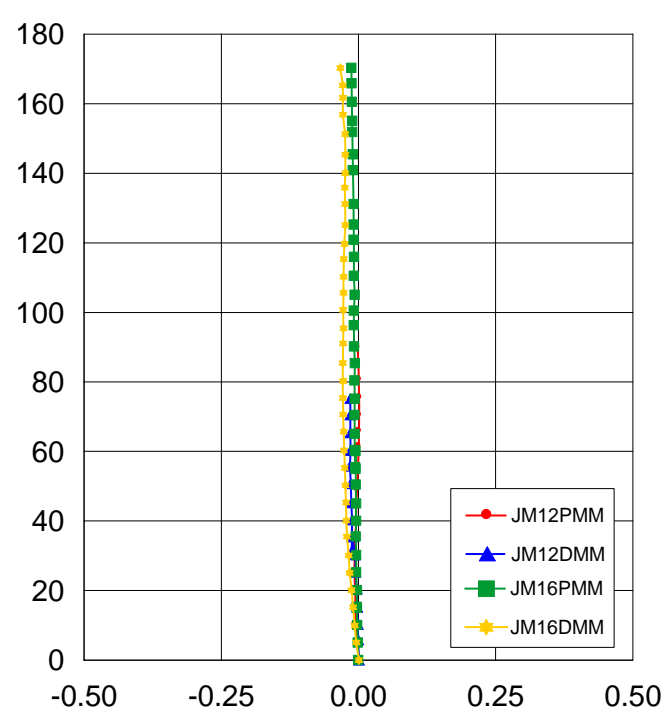

Deformação do concreto $\left(10^{-3} \mathrm{~mm} / \mathrm{mm}\right)$

(d)

Figura 6.66 - Gráfico força aplicada versus deformação específica do concreto, em modelos com dispositivo em chapa, nos extensômetros: (a) CDY; (b) CEY; (c) CDX; (d) CEX

\subsubsection{Deformação no aço}

Neste item serão apresentados os resultados obtidos na leitura da extensometria nos modelos dotados de junta serrada e carregamentos estático e cíclico, e junta moldada com carregamento estático. Todos os dispositivos de transferência foram 
instrumentados nas faces superior e inferior, ao longo do eixo $x$, como apresentado na Tabela 4.6. O posicionamento da extensometria tentou abranger pelo menos $30 \%$ do comprimento efetivo do dispositivo, varrendo a região que apresentava as maiores deformações, ou seja, sob o carregamento.

A. Junta serrada - ensaio estático

O gráfico força aplicada versus deformação, apresentado na Figura 6.67, fornece o comportamento generalizado dos dispositivos em barra.

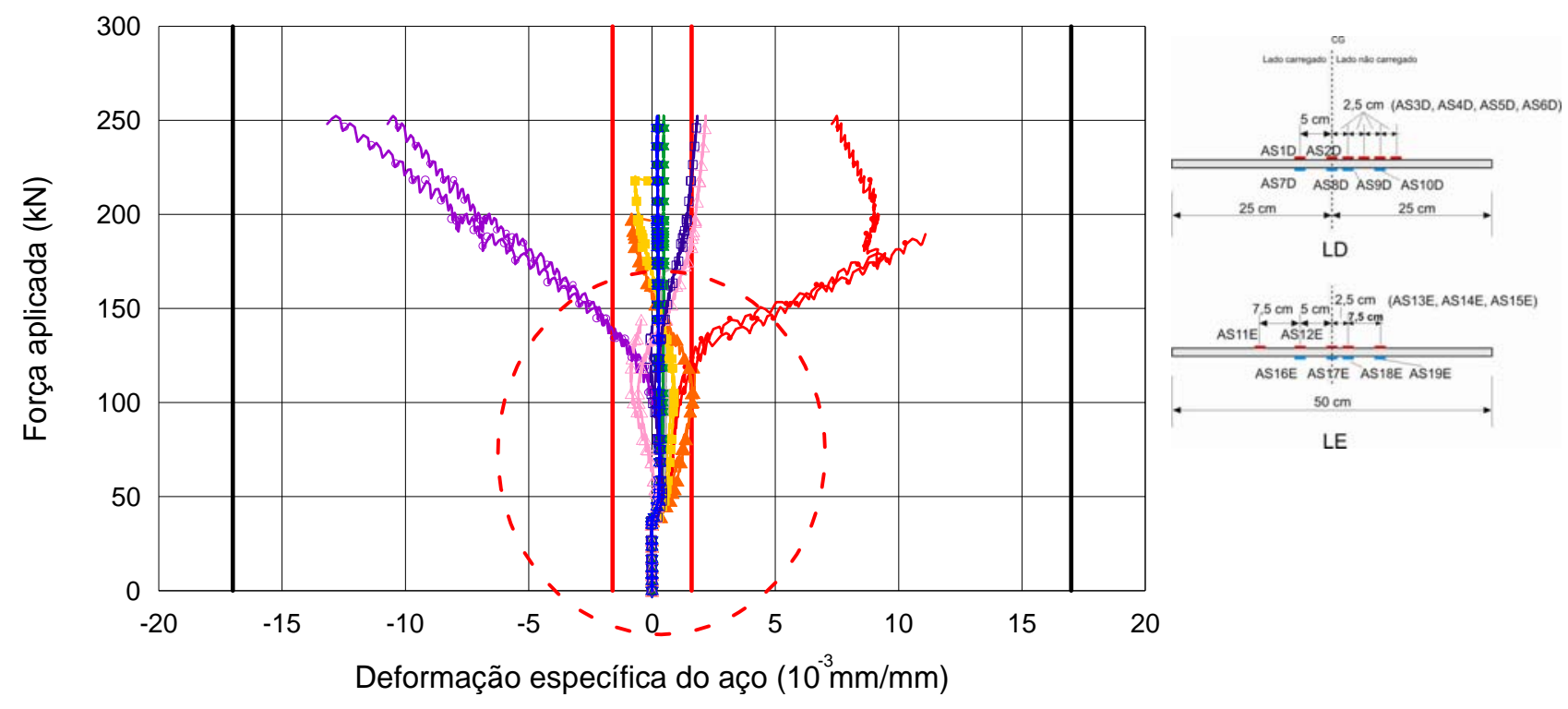

(a)

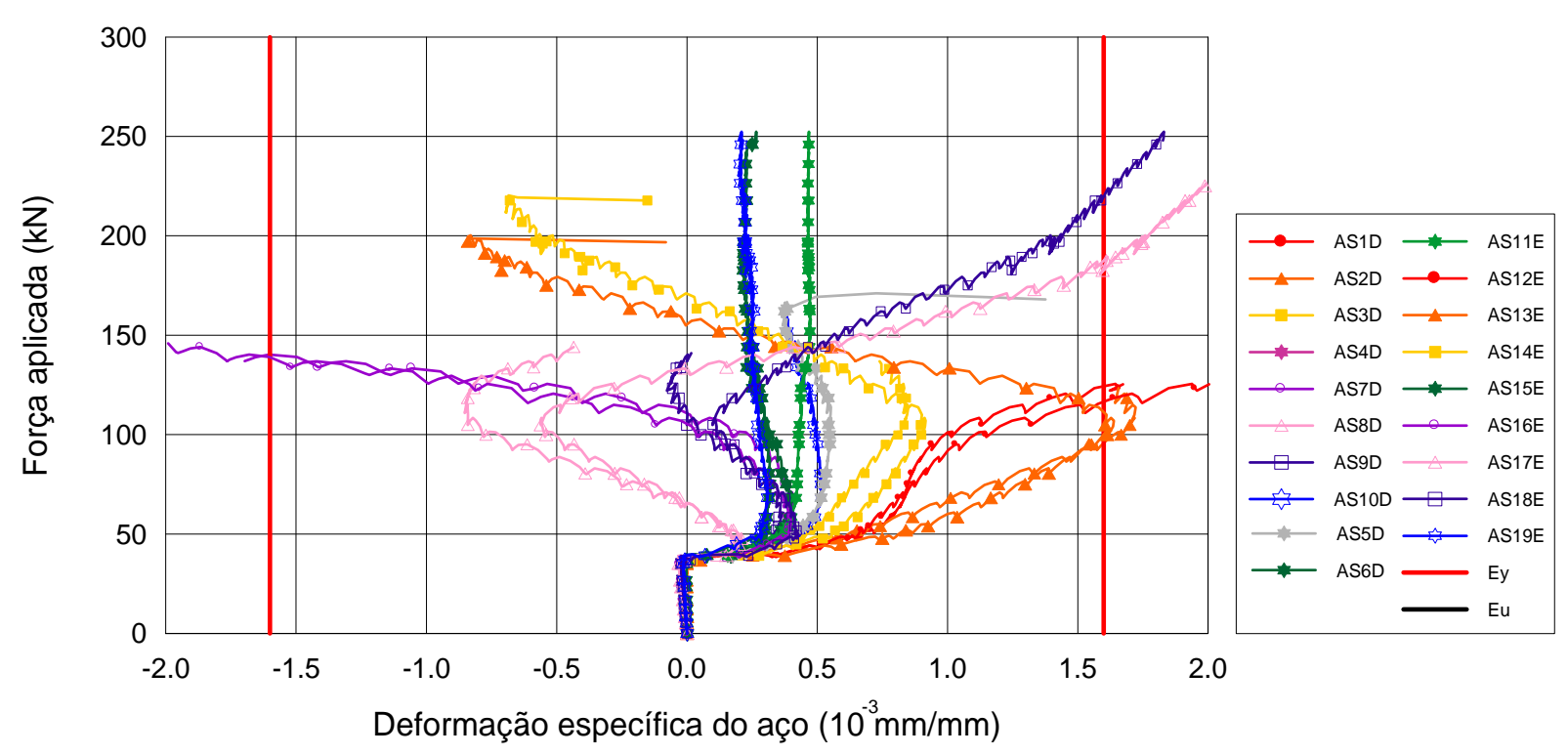

(b)

Figura 6.67 - Gráfico força aplicada versus deformação em JS16BQM: (a) total; (b) detalhe 
Para o caso de dispositivos em barra, os gráficos força aplicada versus deformação, apresentados nas Figuras 6.68 a 6.74, referem-se aos modelos JS12BCM, JS12BQM, JS16BCM e JS16BQM. Verificou-se que as barras do lado esquerdo (LE) comportaram-se, em geral, de maneira semelhante às das do lado direito (LD), e por isso foram plotados gráficos generalizados do comportamento de ambas as barras. O limite de escoamento empregado foi de $\varepsilon_{y \phi}=\varepsilon_{y \#}=0,0016$.

Até atingir $F_{\text {fiss }}$, a extensometria apresentou leituras próximas de zero. Geralmente, o dispositivo em barra com seção circular apresentou maiores deformações, verificadas em AS1D, AS2D e AS3D, apesar das forças máximas $F_{u}$ serem próximas em JS12BCM e JS12BQM, e em JS16BCM e JS16BQM.

As maiores deformações, que levaram ao escoamento do aço, foram verificadas em AS3D, a cerca de $4,7 \mathrm{~cm}$ da face da junta. A região central do dispositivo com barra (AS2D) na junta apresentou deformações inferiores, porém próximas à de escoamento. Após a fissuração do concreto, o início da ruína dos modelos surgiu em AS3D seguido de AS2D.

A uma distância de $10 \mathrm{~cm}$ da abertura da junta e no lado carregado, em AS6D, foram verificadas deformações devidas a esforços de tração inferiores aos de escoamento. Em AS11E, posicionado a $10 \mathrm{~cm}$ da abertura da junta e do lado não carregado, foram obtidas deformações de tração, que levaram ao escoamento do aço apenas em JS12BCM. Em AS4D e AS5D, foram obtidas leituras positivas de tração inferiores às de escoamento. 


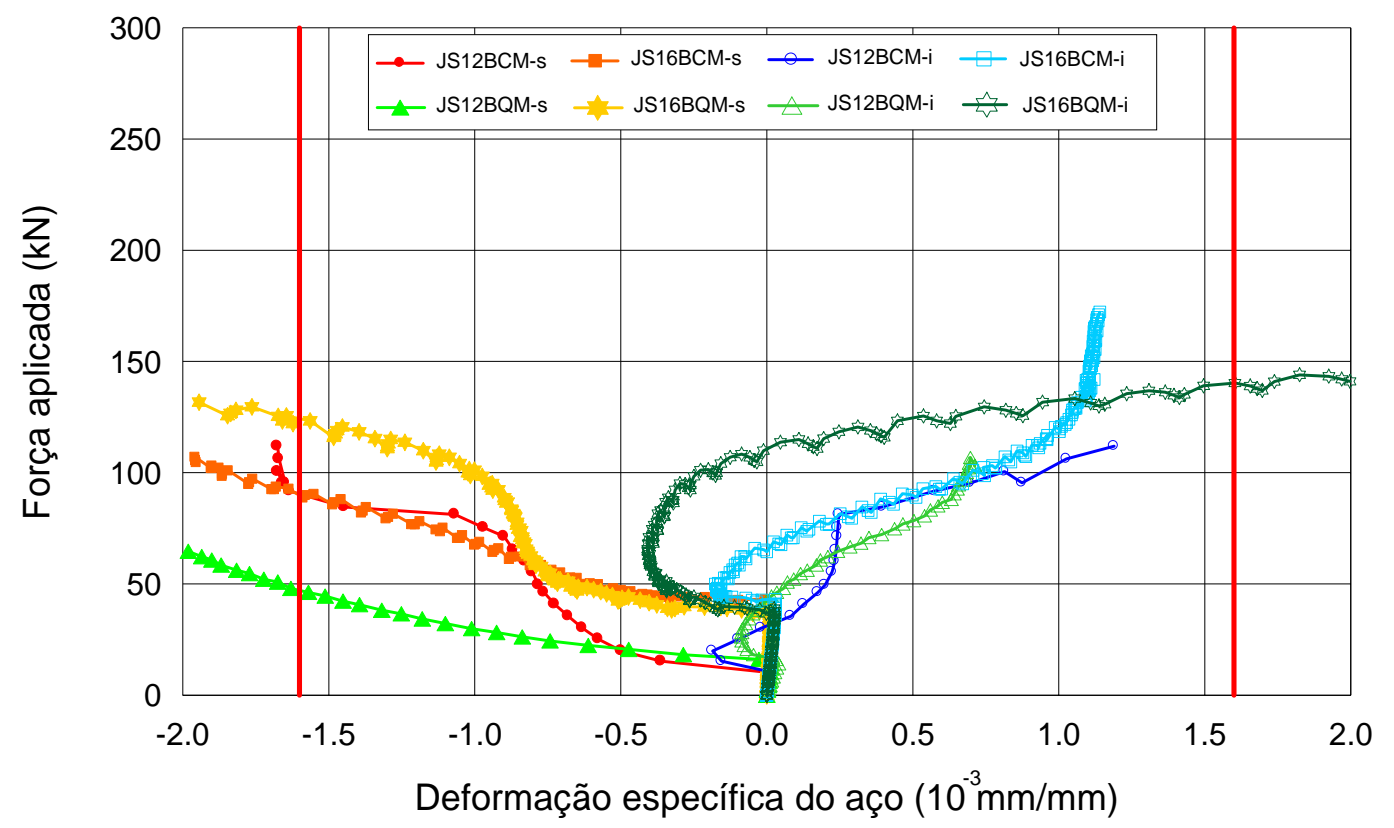

Figura 6.68 - Gráfico força aplicada versus deformação em AS1D e AS7D

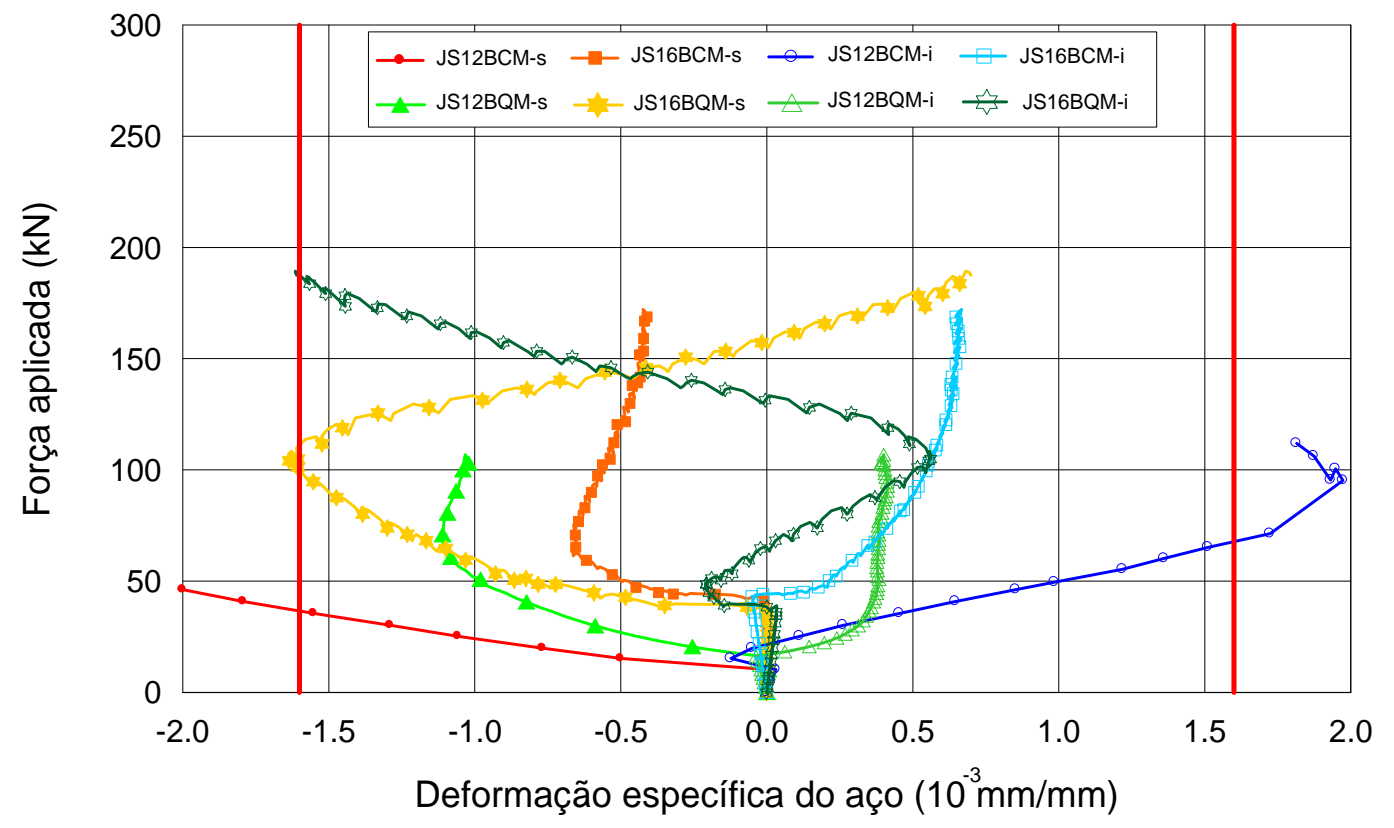

Figura 6.69 - Gráfico força aplicada versus deformação em AS2D e AS8D 


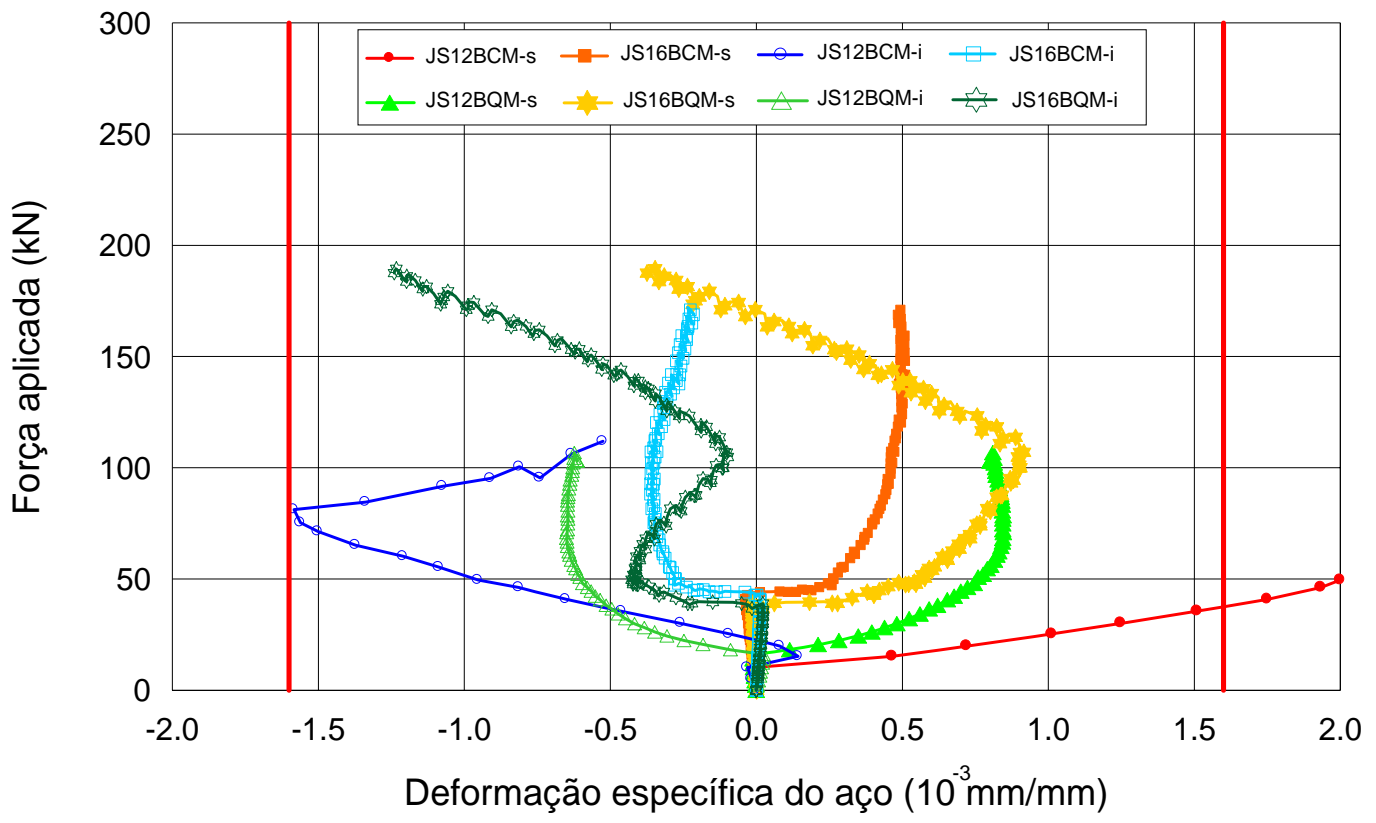

Figura 6.70 - Gráfico força aplicada versus deformação em AS3D e AS9D

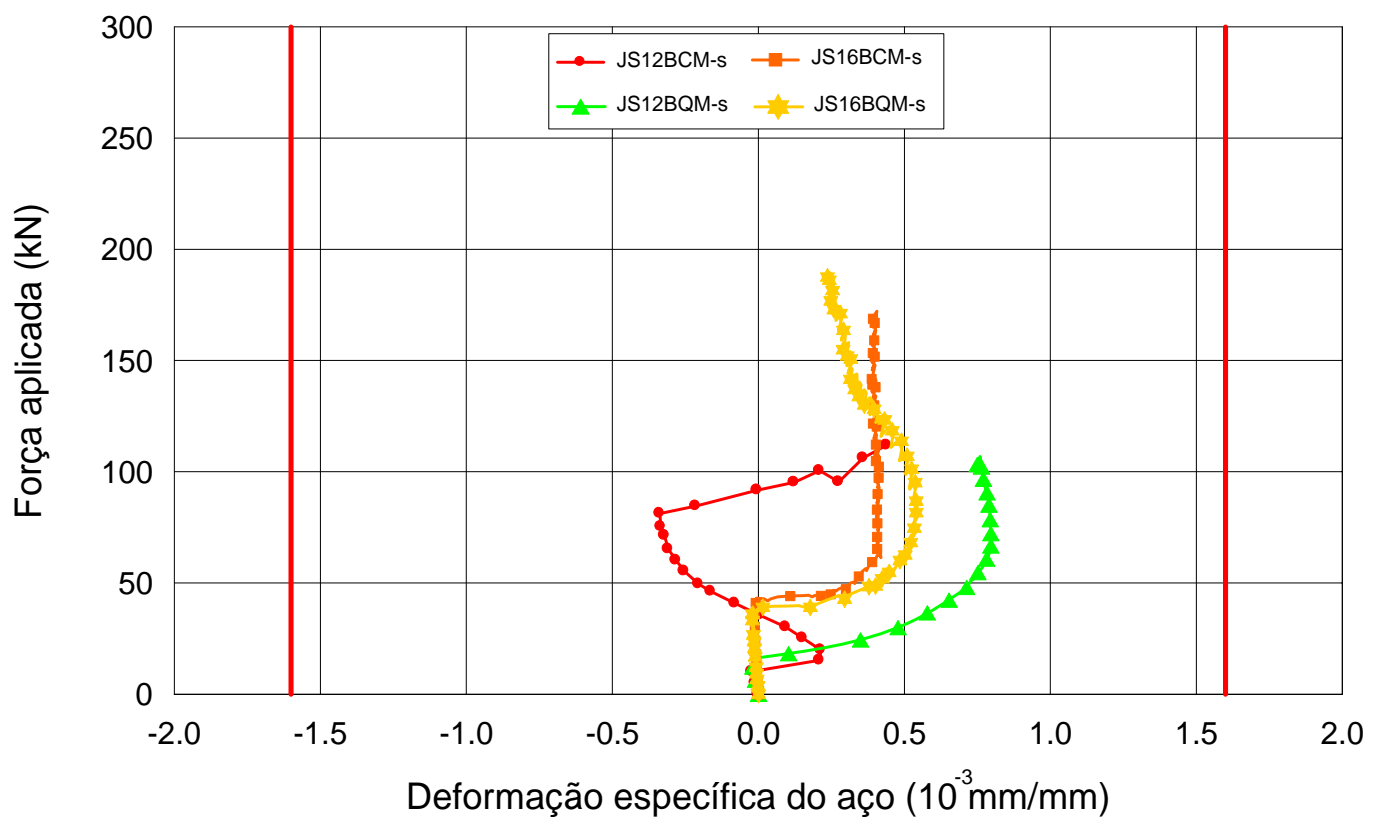

Figura 6.71 - Gráfico força aplicada versus deformação em AS4D 


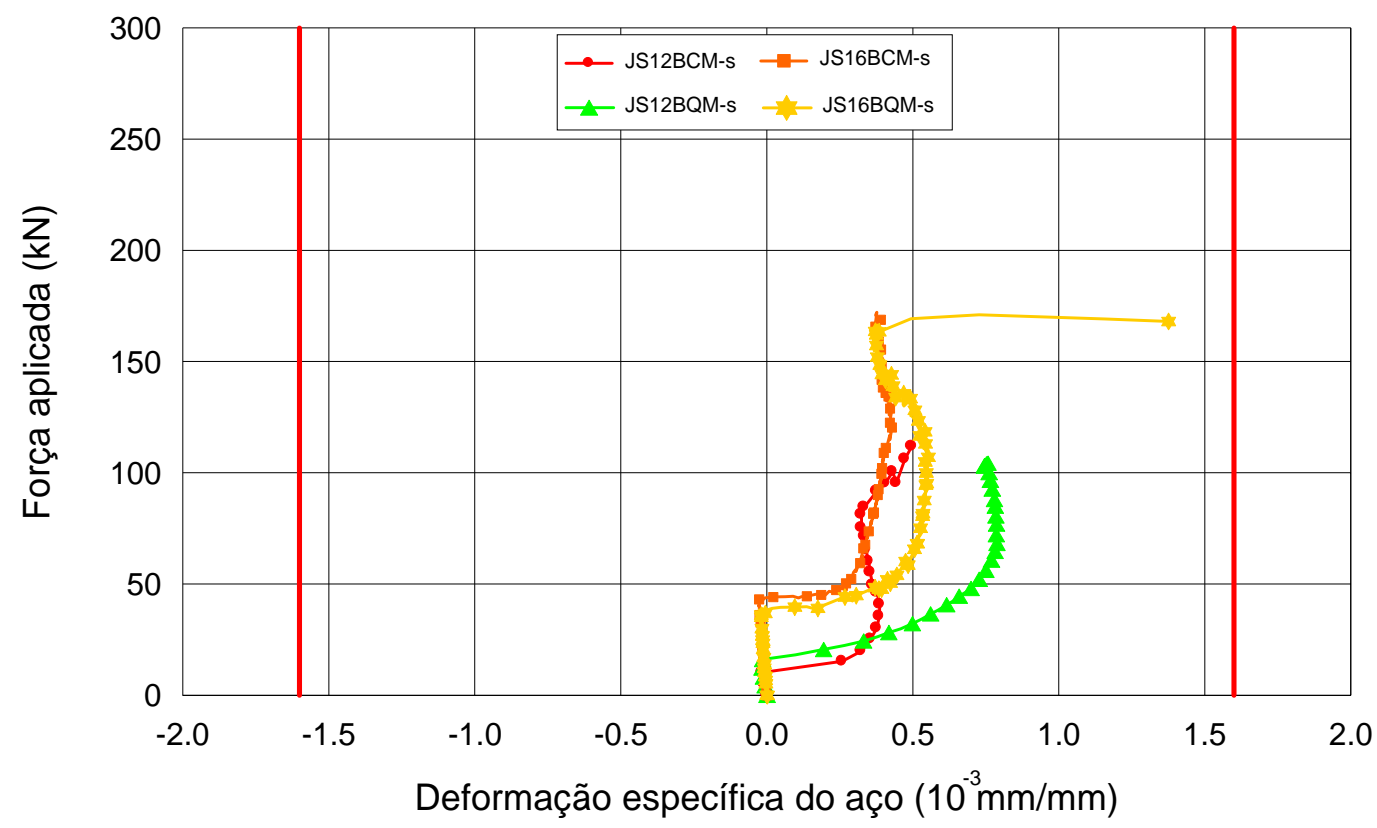

Figura 6.72 - Gráfico força aplicada versus deformação em AS5D

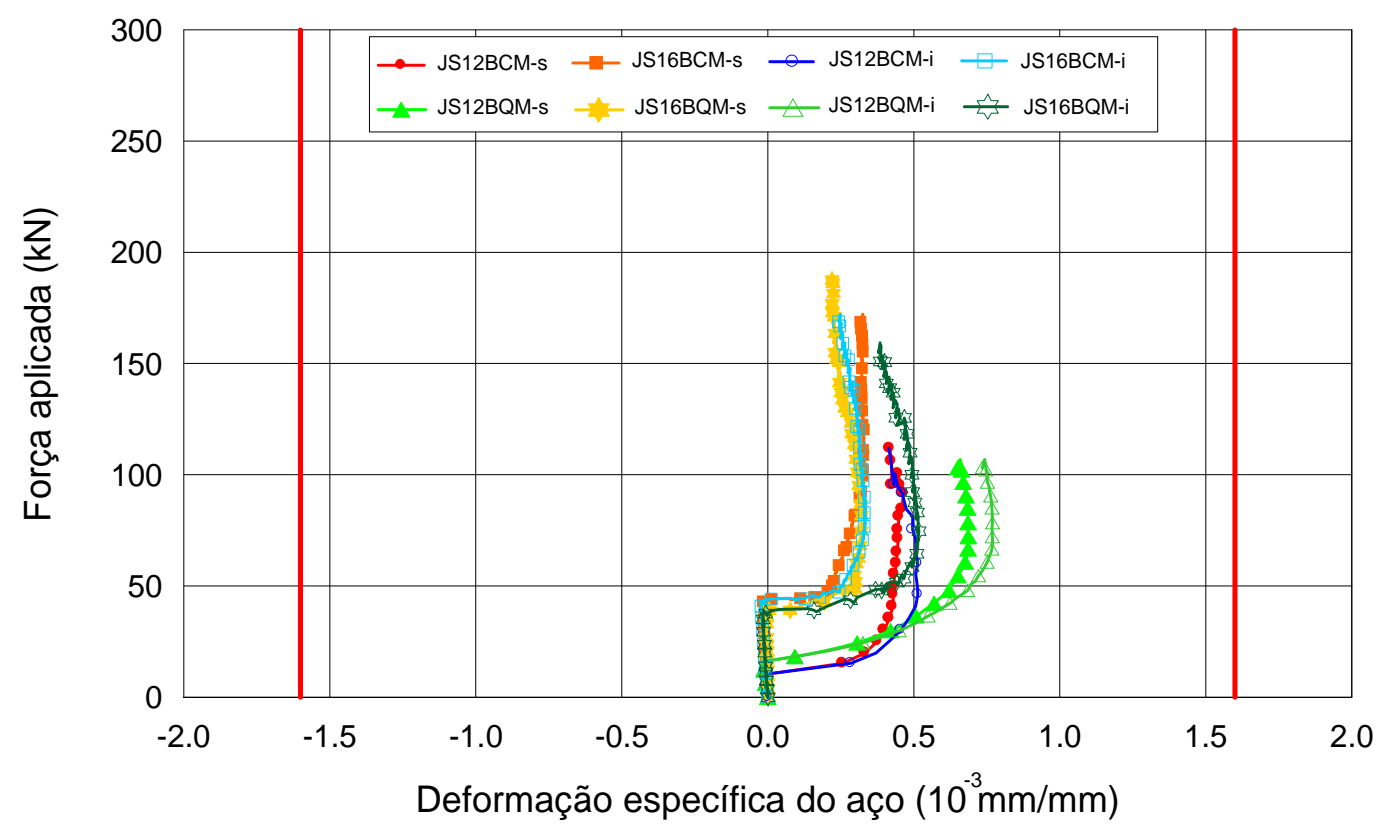

Figura 6.73 - Gráfico força aplicada versus deformação em AS6D e AS10D 


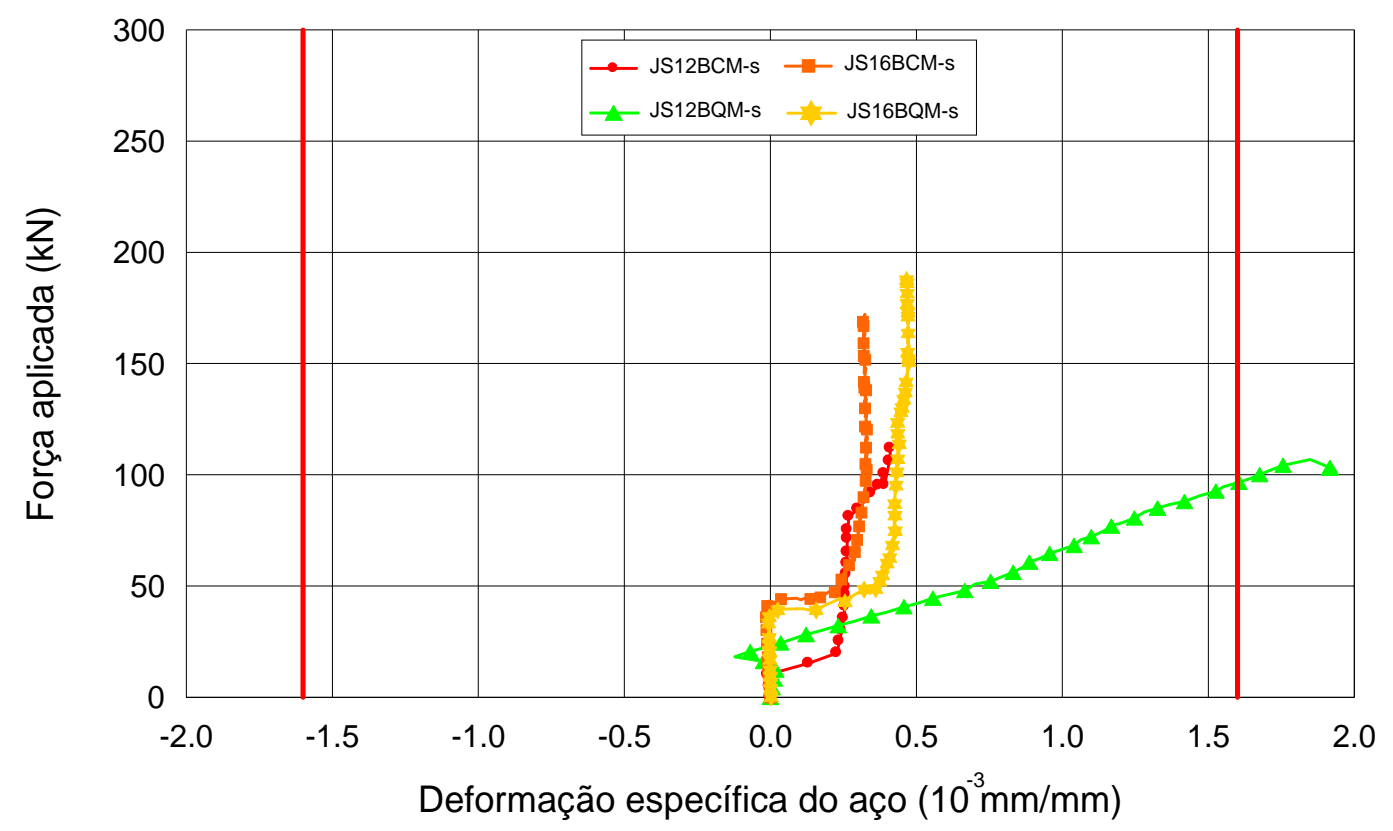

Figura 6.74 - Gráfico força aplicada versus deformação em AS11E

O gráfico $F / F_{u}$ versus deformação, apresentado na Figura 6.75, fornece a relação entre os estágios de carregamento e as deformações sofridas pelos dispositivos em barra, em um ponto deformável, AS1D. Verificou-se que os quatro modelos, JS12BCM, JS12BQM, JS16BCM e JS16BQM, apresentaram leituras diferentes de zero, com o início da fissuração do concreto. Até $60 \%$ de $F_{u}$, os modelos apresentaram comportamento semelhante. A partir desse ponto, em JS16BQM ocorreu deformação excessiva do dispositivo, levando-o quase ao colapso $\left(\varepsilon_{u}=0,017 \mathrm{~mm} / \mathrm{mm}\right)$. De maneira geral, o aumento da espessura permitiu que, para um mesmo estágio no carregamento, os modelos com espessura de $16 \mathrm{~cm}$ tivessem maior deformabilidade, sem no entanto chegar a $\varepsilon_{u}$. O desempenho da barra de seção circular, em relação à de seção quadrada, nesse ponto, foi basicamente o mesmo, em termos de deformações. 


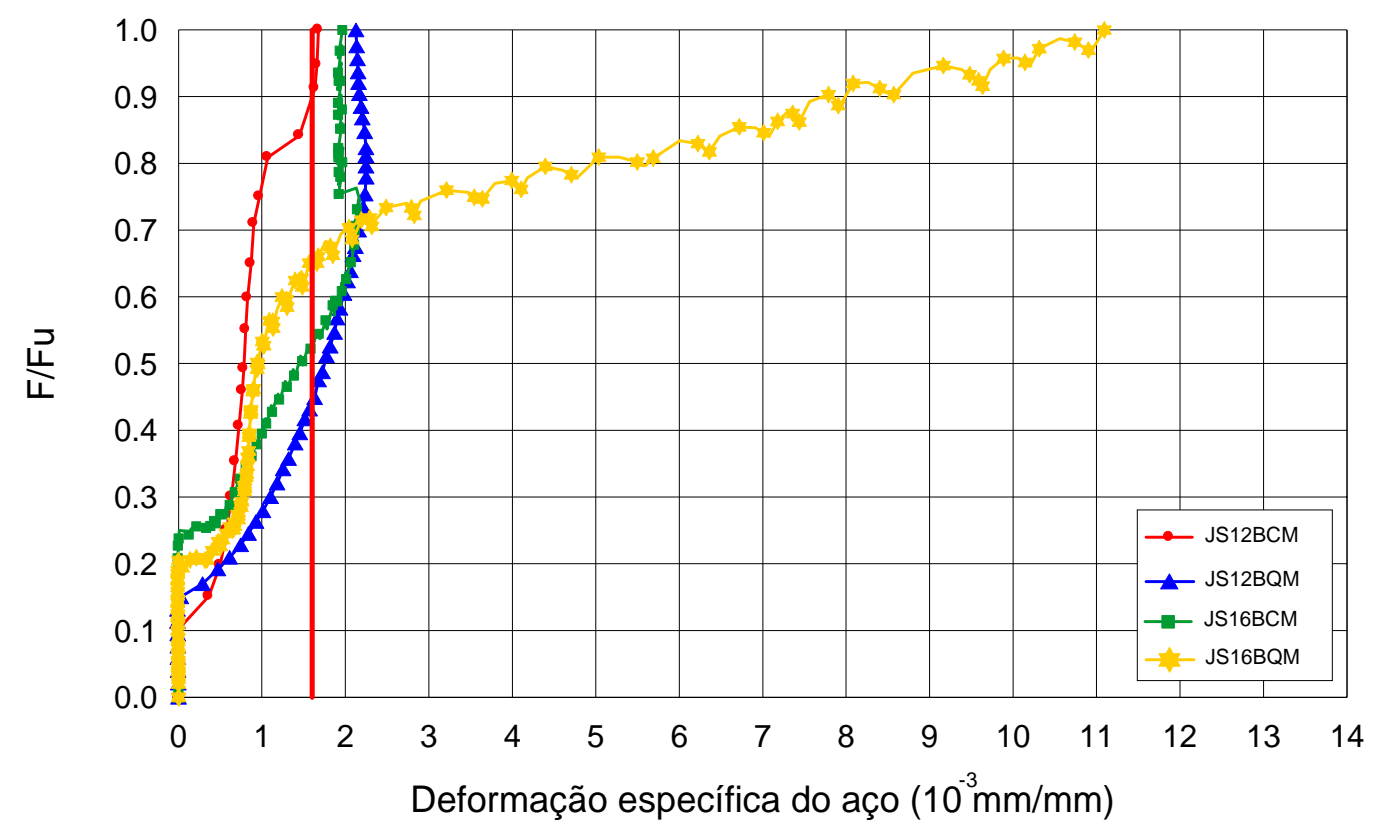

Figura 6.75 - Gráfico F/Fu versus deformação em AS1D - barra

O gráfico força aplicada versus deformação, apresentado na Figura 6.76a, fornece o comportamento generalizado dos dispositivos em chapa e, na Figura 6.76b, um detalhe desse comportamento. 

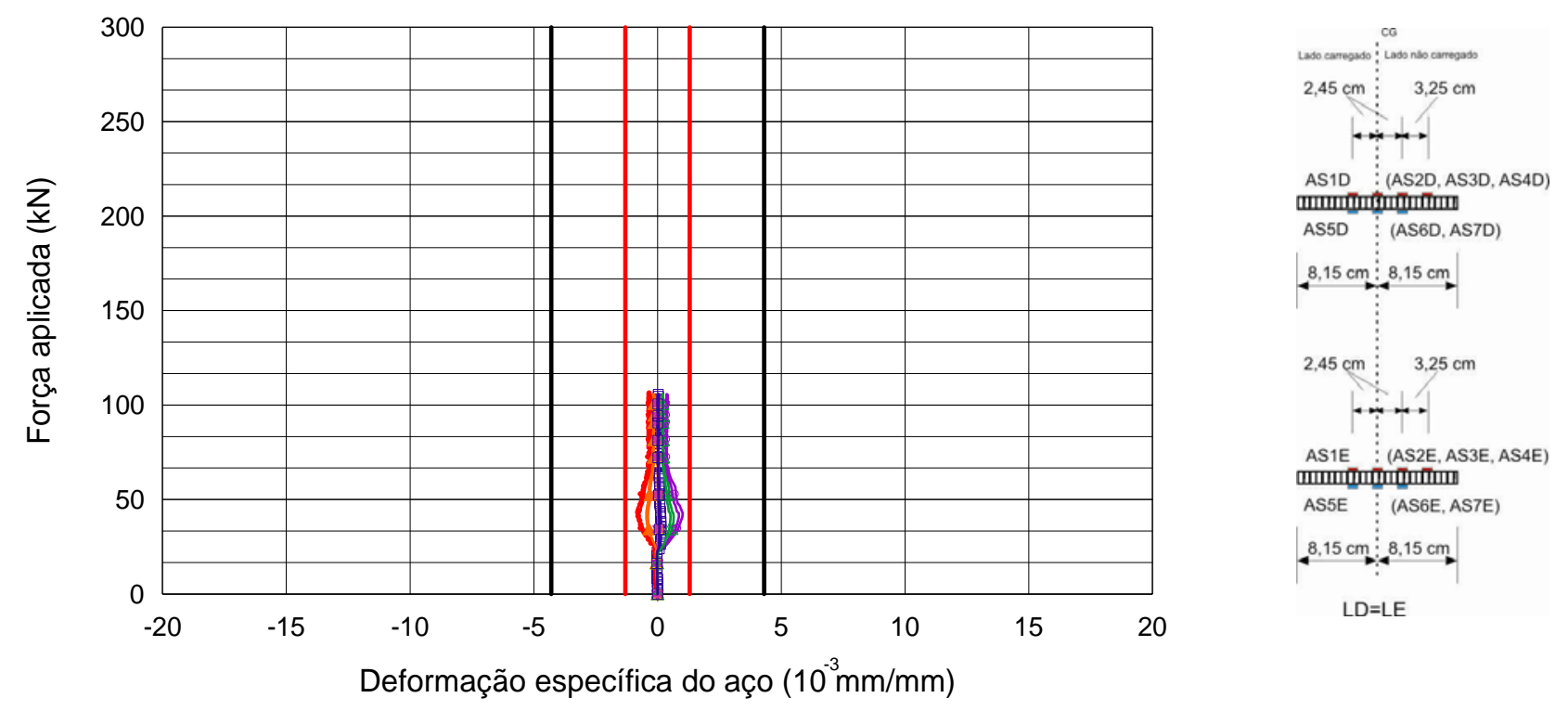

(a)

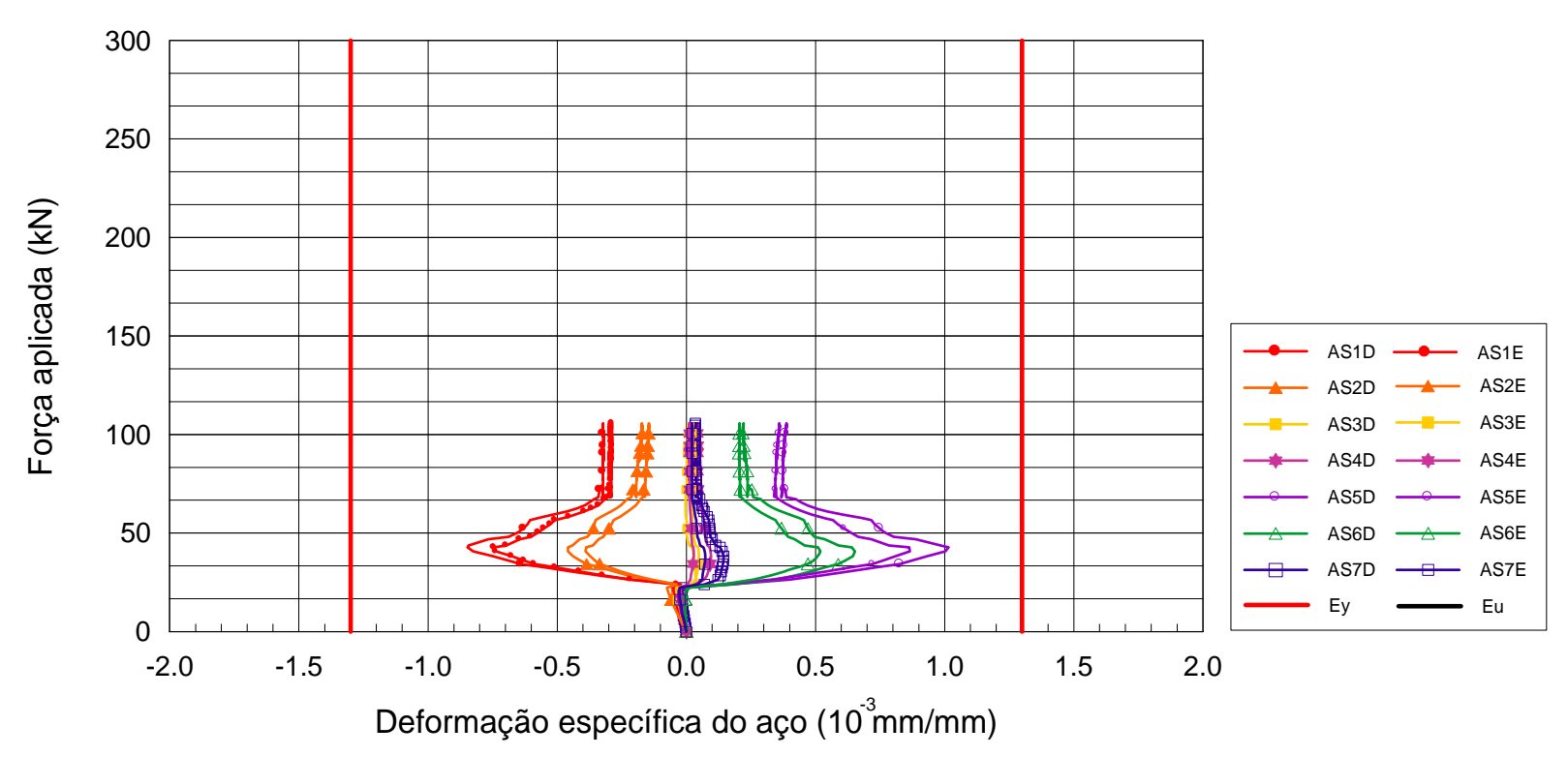

(b)

Figura 6.76 - Gráfico força aplicada versus deformação em JS16DMM: (a) total; (b) detalhe

Para o caso de dispositivos em chapa, os gráficos força aplicada versus deformação, apresentados nas Figuras 6.77 a 6.80, referem-se aos modelos JS12PMM, JS12DMM, JS16PMM e JS16DMM. Gráficos generalizados do comportamento dos dispositivos em chapa, do lado esquerdo (LE) e do lado direito (LD), foram plotados, uma vez que se comportaram de maneira semelhante. O limite de escoamento empregado foi de $\varepsilon_{y, \text { chapa }}=0,0013 \mathrm{~mm} / \mathrm{mm}$ (linha vermelha). 
Nos dispositivos em chapa, as maiores deformações aconteceram a cerca de $2,15 \mathrm{~cm}$ da face da junta, em AS1D, seguido de AS2D, posicionado na região central do dispositivo. No entanto, essas deformações foram inferiores ao limite de escoamento, com exceção de JS16PMM, em AS2D. Tendo iniciado o processo de fissuração do concreto, os dispositivos sofreram, de maneira geral, um aumento das deformações para pequenos acréscimos de carga, até $50 \mathrm{kN}$. Após esta carga, ocorreu um decréscimo e posterior estabilização das deformações, até a ruptura do modelo.

Em AS3D, apenas o modelo JS16PMM apresentou deformações que levaram ao escoamento da placa metálica. Em AS4D, a uma distância de $5,7 \mathrm{~cm}$ do eixo da junta e no lado não carregado foram verificadas deformações devidas a esforços de tração, próximas de zero, em JS12PMM, JS12DMM e JS16DMM.

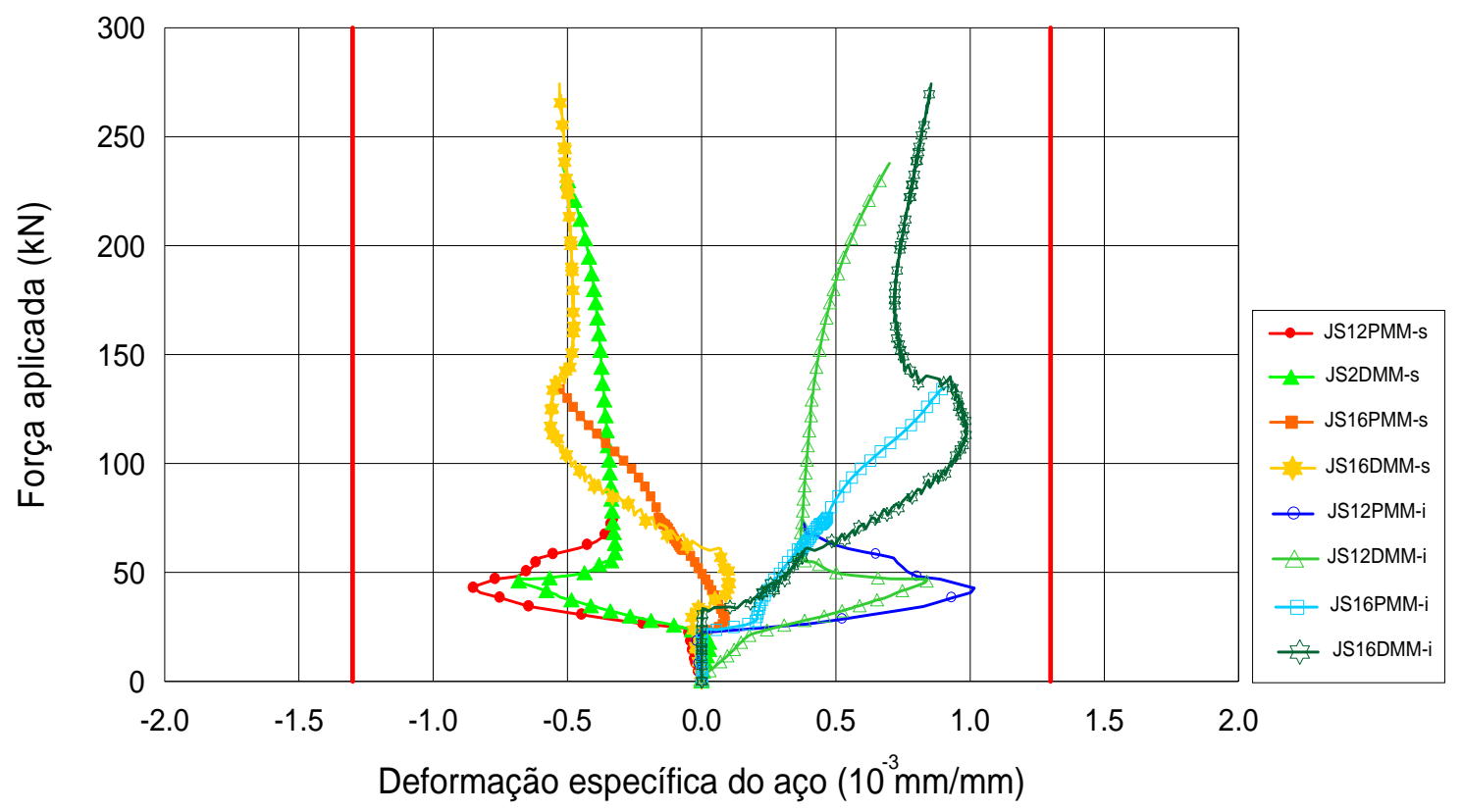

Figura 6.77 - Gráfico força aplicada versus deformação, em AS1D e AS5D 


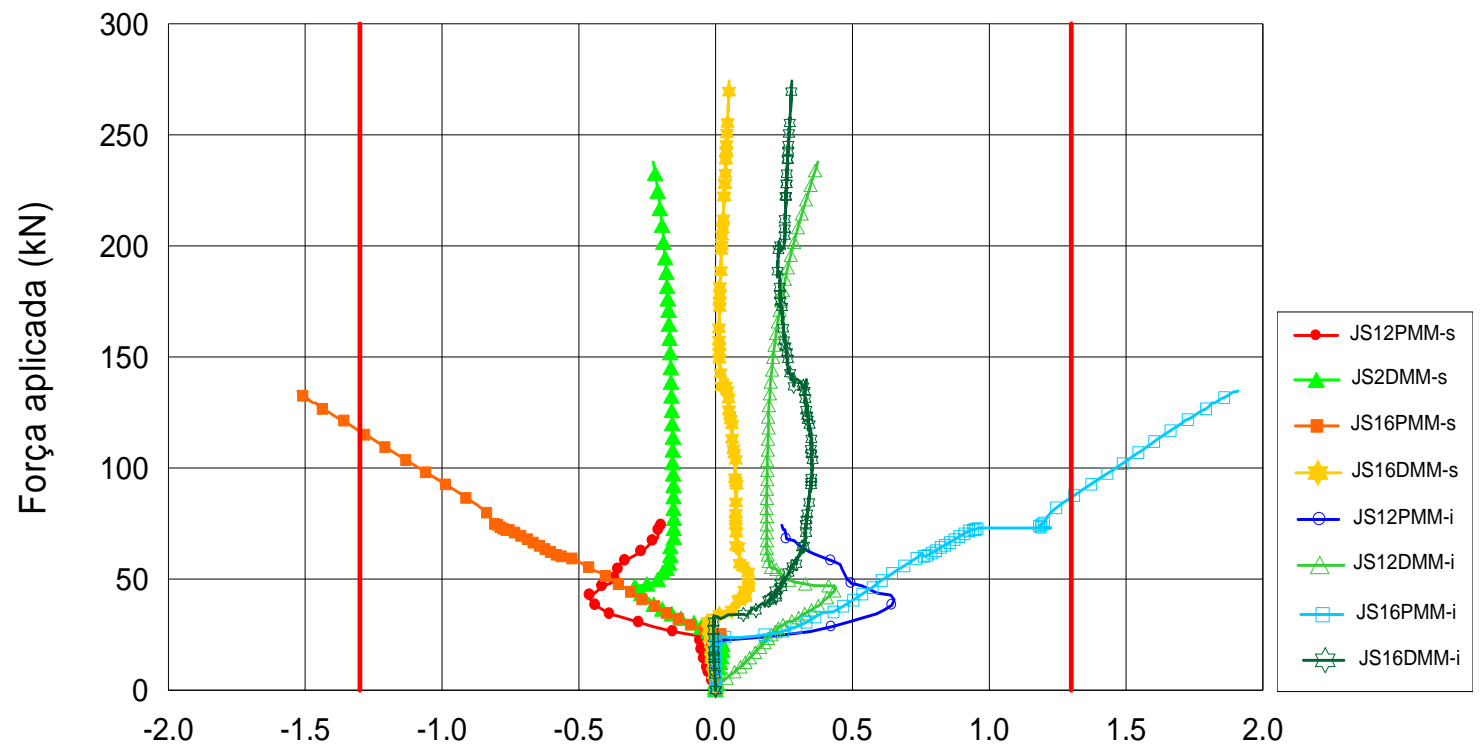

Deformação específica do aço $\left(10^{-3} \mathrm{~mm} / \mathrm{mm}\right)$

Figura 6.78 - Gráfico força aplicada versus deformação, em AS2D e AS6D

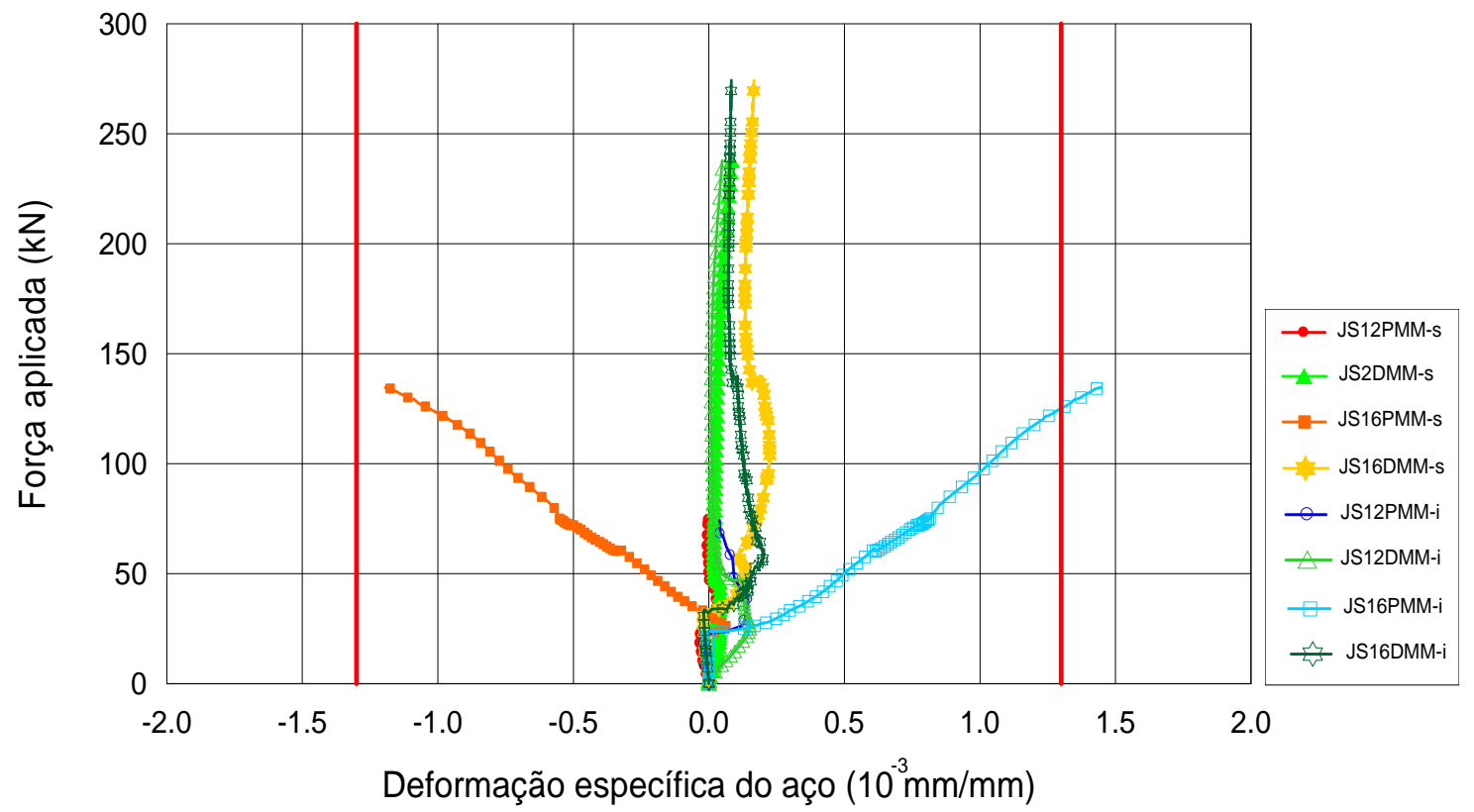

Figura 6.79 - Gráfico força aplicada versus deformação, em AS3D e AS7D 


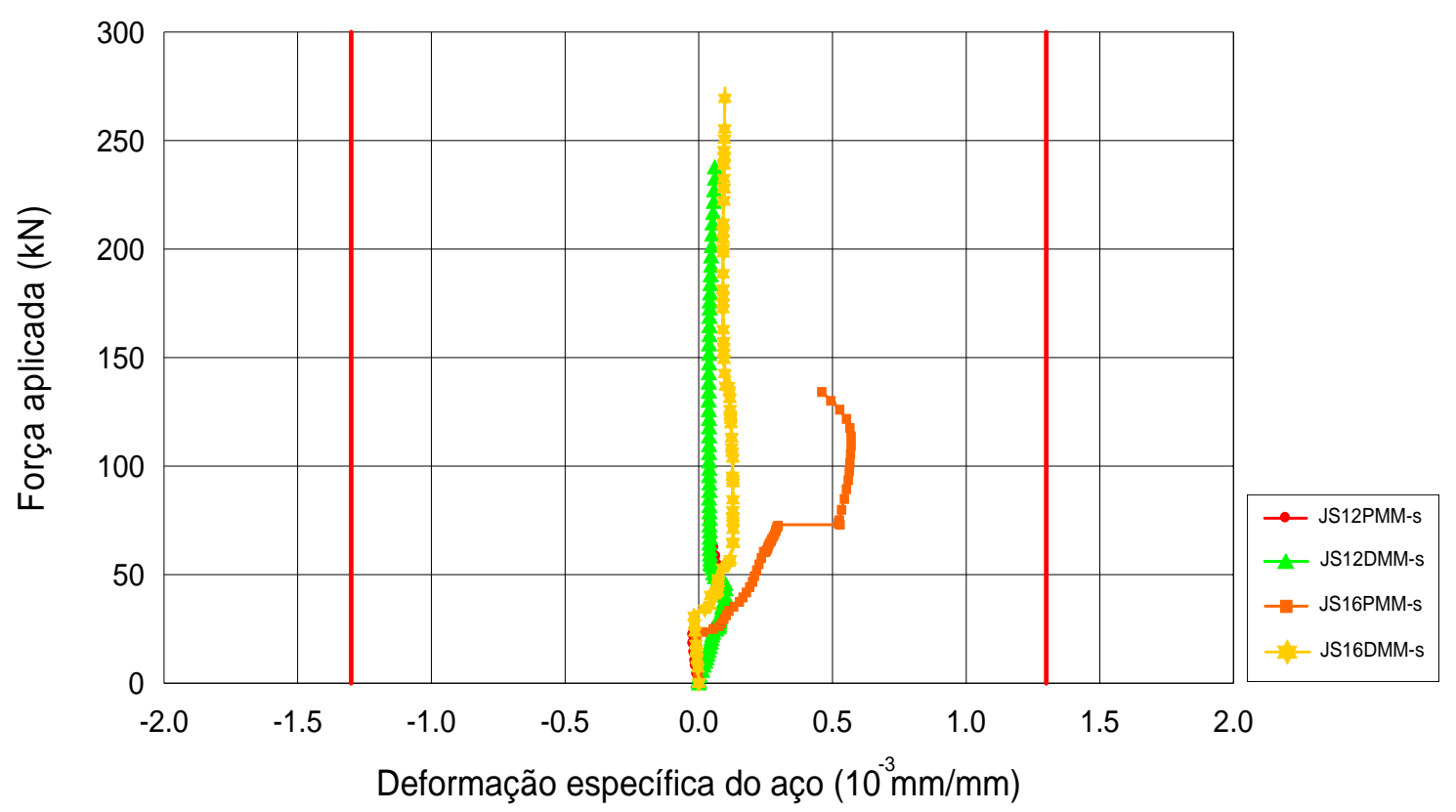

Figura 6.80 - Gráfico força aplicada versus deformação, em AS4D

O gráfico $F / F_{u}$ versus deformação, apresentado na Figura 6.81, fornece a relação entre os estágios de carregamento e as deformações sofridas pelos dispositivos em chapa em um ponto deformável, AS1D. Até atingir $F_{\text {fiss }}$, os quatro modelos, JS12PMM, JS12DMM, JS16PMM e JS16DMM, apresentaram leituras próximas de zero. Acima de $F_{\text {fiss }}$, os modelos não apresentaram acentuada variação no comportamento. De maneira geral, o aumento da espessura não teve grande influência na deformabilidade dos dispositivos. 


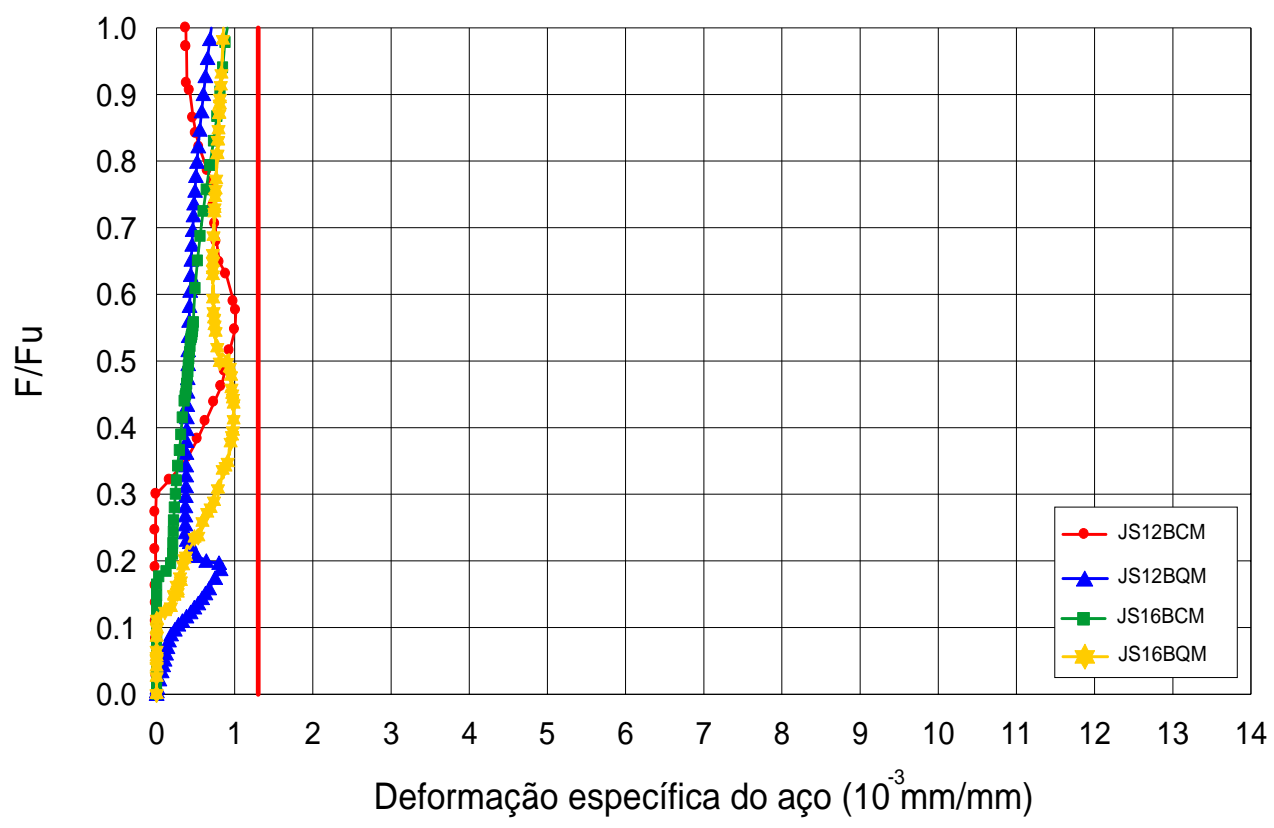

Figura 6.81 - Gráfico F/Fu versus deformação, em AS1D - chapa

B. Junta serrada - ensaio cíclico

Os gráficos força aplicada versus deformação específica do aço, apresentados nas Figuras 6.82 e 6.83, fornecem as leituras obtidas no primeiro carregamento estático, até $12 \mathrm{kN}$, aplicado nos modelos JS12BCC, JS12PMC e JS12DMC. O modelo JS16BCC não teve instrumentação nos dispositivos. As deformações encontradas estiveram bem abaixo dos limites de escoamento: $\varepsilon_{y \phi}=1,6 \times 10^{-3} \mathrm{~mm} / \mathrm{mm}$ e $\varepsilon_{y, \text { chapa }}=1,3 \times 10^{-3} \mathrm{~mm} / \mathrm{mm}$. 


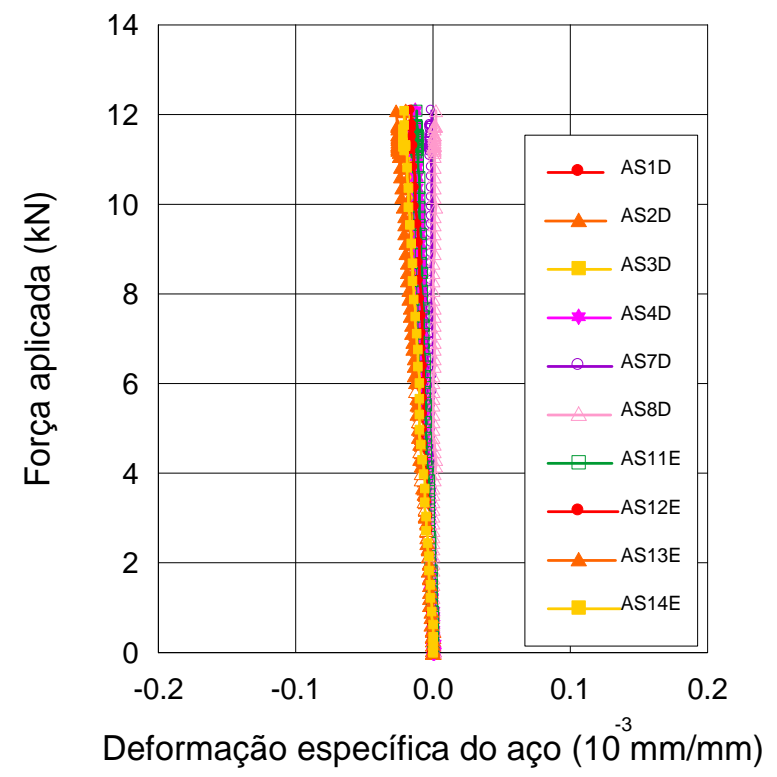

Figura 6.82 - Gráfico força aplicada versus deformação, em JS12BCC
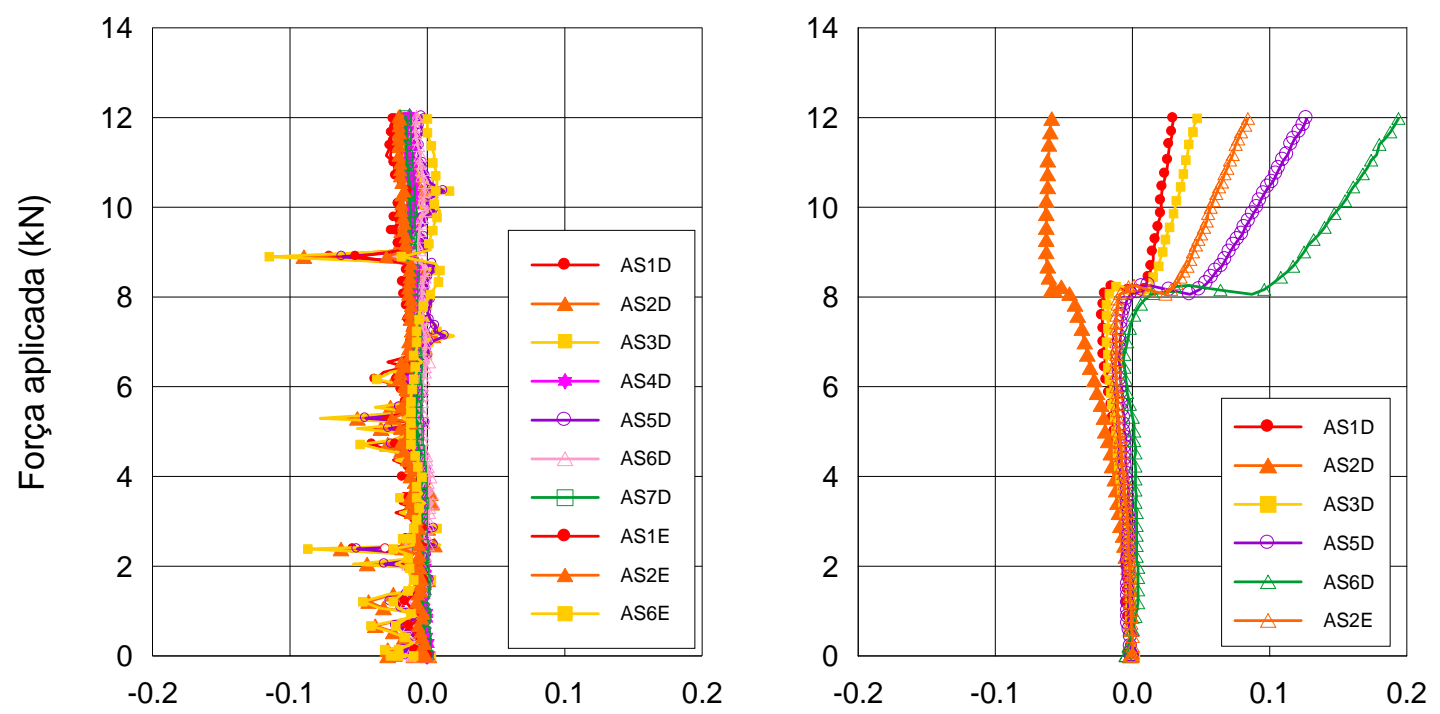

Deformação específica do aço $\left(10^{-3} \mathrm{~mm} / \mathrm{mm}\right)$ Deformação específica do aço $\left(10^{-3} \mathrm{~mm} / \mathrm{mm}\right)$

(a)

(b)

Figura 6.83 - Gráfico força aplicada versus deformação, em: (a) JS12PMC; (b) JS12DMC

Durante os ciclos de carregamento, correram baixas alterações nas amplitudes das deformações do dispositivo em barra, em média da ordem de $0,019 \times 10^{-3} \mathrm{~mm} / \mathrm{mm}$, como apresentado na Figura 6.84. O extensômetro elétrico apresentado refere-se a AS3D, cuja deformação específica foi a máxima verificada. 


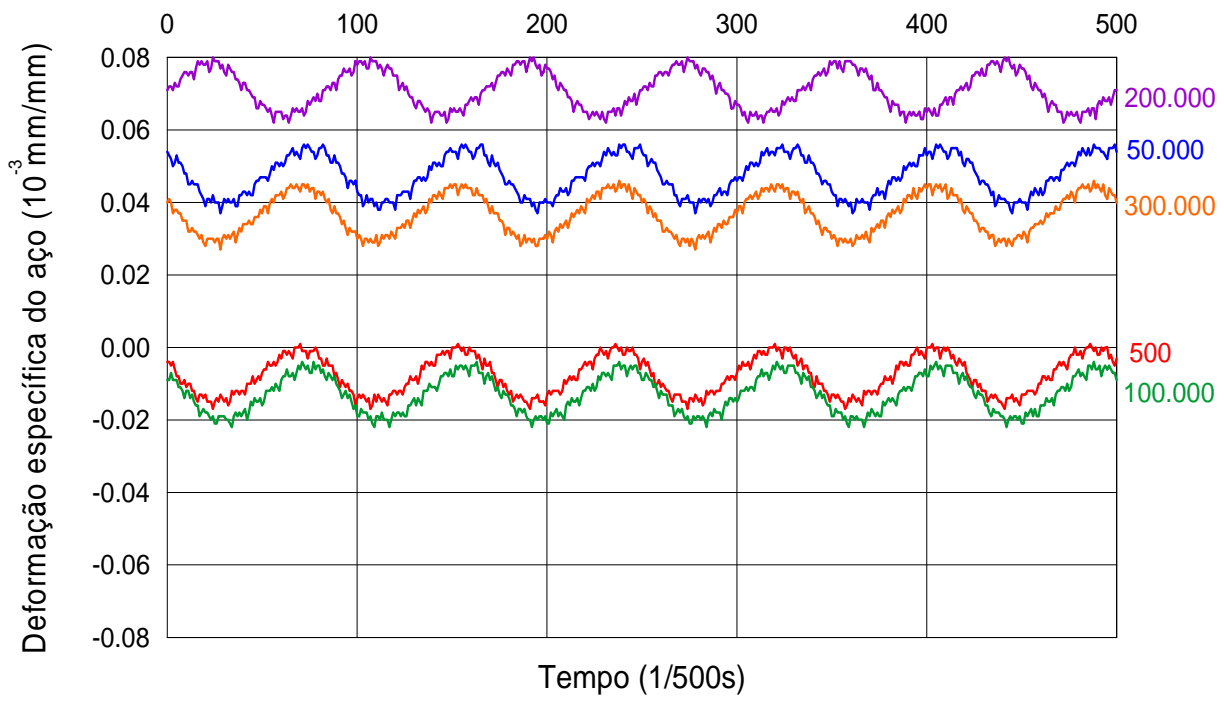

Figura 6.84 - Deformação em AS3D versus tempo, para carga de serviço de $12 \mathrm{kN}$ - modelo JS12BCC

As baixas alterações nas amplitudes também ocorreram nas deformações dos dispositivos em chapa. As amplitudes em média foram da ordem de 0,028 $\times 10^{-3} \mathrm{~mm} / \mathrm{mm}$, para JS12PMC, e 0,019 $\times 10^{-3} \mathrm{~mm} / \mathrm{mm}$, para JS12DMC, como apresentado nas Figuras 6.85 e 6.86. O extensômetro elétrico apresentado refere-se a AS1D, cuja deformação específica foi a máxima observada. Alguns ruídos foram detectados nas leituras obtidas, surgindo picos de deformações que foram descartados no cálculo da amplitude.

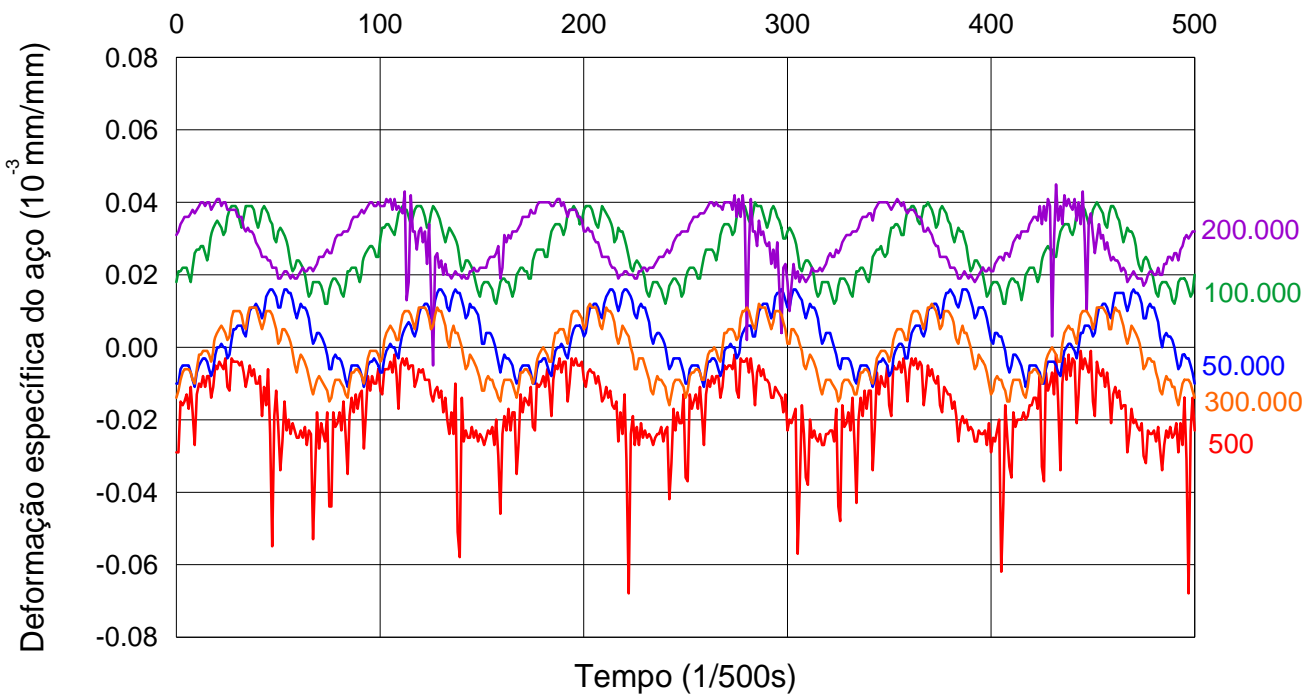

Figura 6.85 - Deformação em AS1D versus tempo, para carga de serviço de $12 \mathrm{kN}$ - modelo JS12PMC 


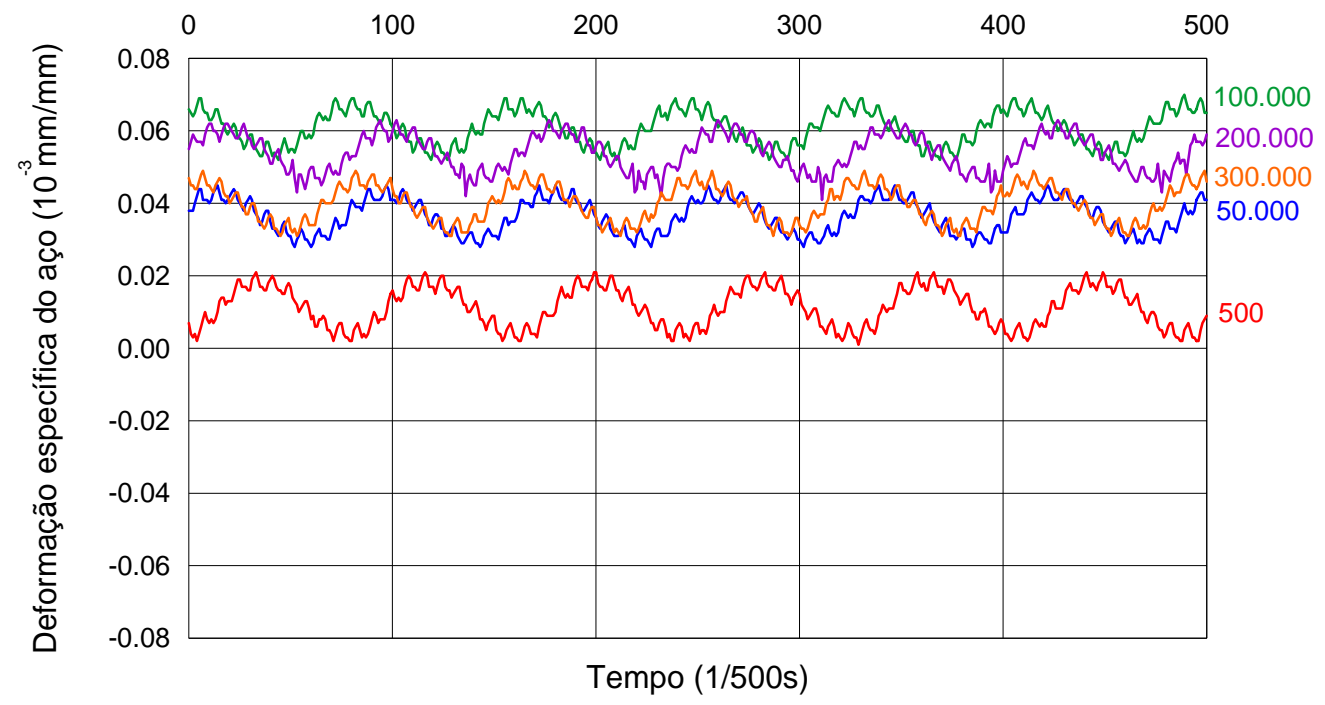

Figura 6.86 - Deformação em AS1D versus tempo, para carga de serviço de $12 \mathrm{kN}$ - modelo JS12DMC

Os gráficos anteriores sugerem que, para o carregamento de serviço imposto, e até os 300.000 ciclos aplicados, os dispositivos metálicos são pouco solicitados, e suas deformações máximas não ultrapassam 2,5\% do limite de escoamento adotado.

Após a aplicação dos ciclos (leitura final), não foram verificadas alterações importantes nas deformações dadas pela extensometria (leitura inicial) dos modelos, até a força de $12 \mathrm{kN}$, como apresentado na Tabela 6.14.

Tabela 6.14 - Resumo das deformações dos dispositivos para carga de serviço de $12 \mathrm{kN}$

\begin{tabular}{|c|c|c|c|c|c|}
\hline Modelo & \multicolumn{5}{|c|}{ Extensômetro elétrico $\left(\times 10^{-3} \mathrm{~mm} / \mathrm{mm}\right)^{*}$} \\
\hline \multirow{3}{*}{ JS12BCC } & Leitura & AS1D & AS2D & AS3D & AS4D \\
\cline { 2 - 6 } & Inicial & $-0,015$ & $-0,020$ & $-0,017$ & $-0,013$ \\
\cline { 2 - 6 } & Final & $-0,015$ & $-0,021$ & $-0,020$ & $-0,014$ \\
\hline \multirow{3}{*}{ JS12PMC } & Leitura & AS1D & AS2D & AS3D & AS4D \\
\cline { 2 - 6 } & Inicial & $-0,026$ & $-0,020$ & $-0,012$ & $-0,013$ \\
\cline { 2 - 6 } & Final & $-0,025$ & $-0,023$ & $-0,014$ & $-0,014$ \\
\hline \multirow{3}{*}{ JS12DMC } & Leitura & AS1D & AS2D & AS3D & AS5D \\
\cline { 2 - 6 } & Inicial & 0,030 & $-0,059$ & 0,047 & 0,127 \\
\cline { 2 - 6 } & Final & 0,009 & $-0,012$ & 0,019 & 0,083 \\
\hline * Maiores deformações verificadas & & \\
\hline
\end{tabular}


C. Junta moldada

O gráfico força aplicada versus deformação, apresentado na Figura 6.87, fornece o comportamento generalizado dos dispositivos em barra.

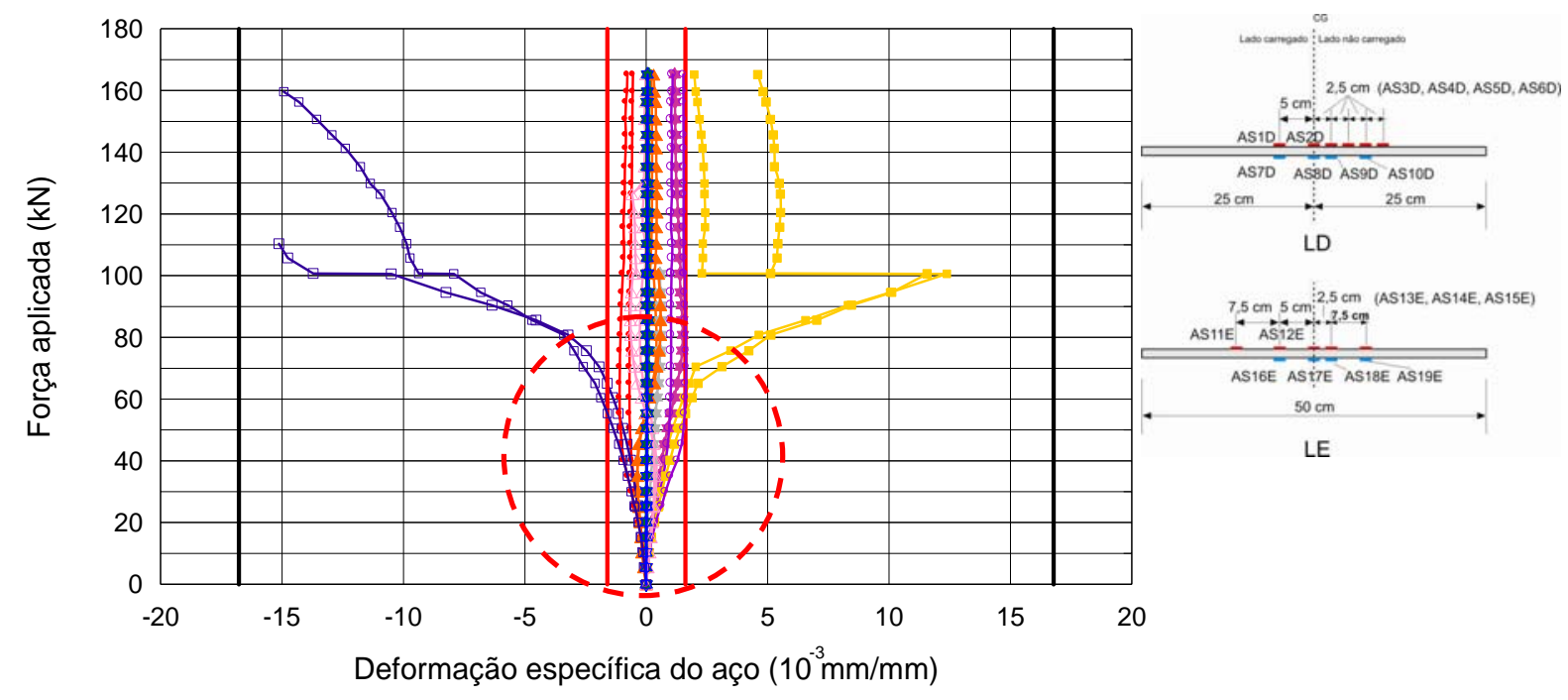

(a)

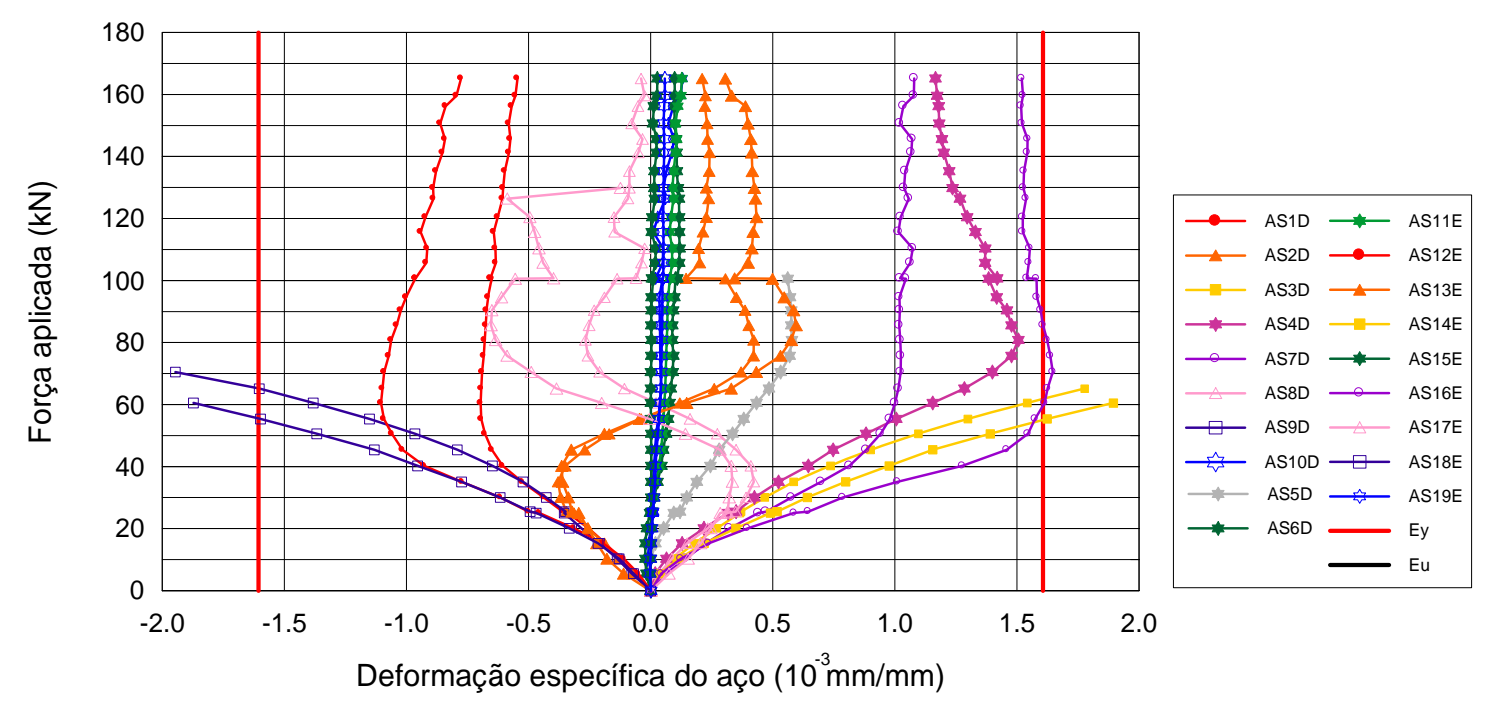

(b)

Figura 6.87 - Gráfico força aplicada versus deformação em JM16BCM: (a) total; (b) detalhe

Para o caso de dispositivos em barra, os gráficos força aplicada versus deformação, apresentados nas Figuras 6.88 a 6.94, referem-se aos modelos JM12BCM, JM12BQM, JM16BCM e JM16BQM. Verificou-se que as barras do lado esquerdo (LE) comportaram-se de maneira semelhante à das do lado direito (LD), e por isso 
foram plotados gráficos generalizados do comportamento de ambas as barras. $\mathrm{O}$ limite de escoamento empregado foi de $\varepsilon_{y \phi}=\varepsilon_{y \#}=0,0016$.

Apesar da força máxima $F_{u}$ ser próxima para JM12BCM e JM12BQM, e para JM16BCM e JM16BQM, os modelos com barra de seção circular apresentaram deformações maiores em AS1D, AS4D e AS5D.

A região central do dispositivo em barra (AS2D) não apresentou as maiores deformações, embora estivesse localizada na junta. As deformações no escoamento do aço foram verificadas em AS3D, a cerca de $2,2 \mathrm{~cm}$ da face da junta, assinalando que os modelos entravam em ruína muito antes de surgir escoamento no centro.

A uma distância de $10 \mathrm{~cm}$ da abertura da junta, tanto do lado carregado, em AS6D, quanto do lado não carregado, em AS11E, foram verificadas deformações próximas a zero, devidas aos esforços de tração. Em AS4D e AS5D, as deformações devidas aos esforços de tração foram inferiores às de escoamento.

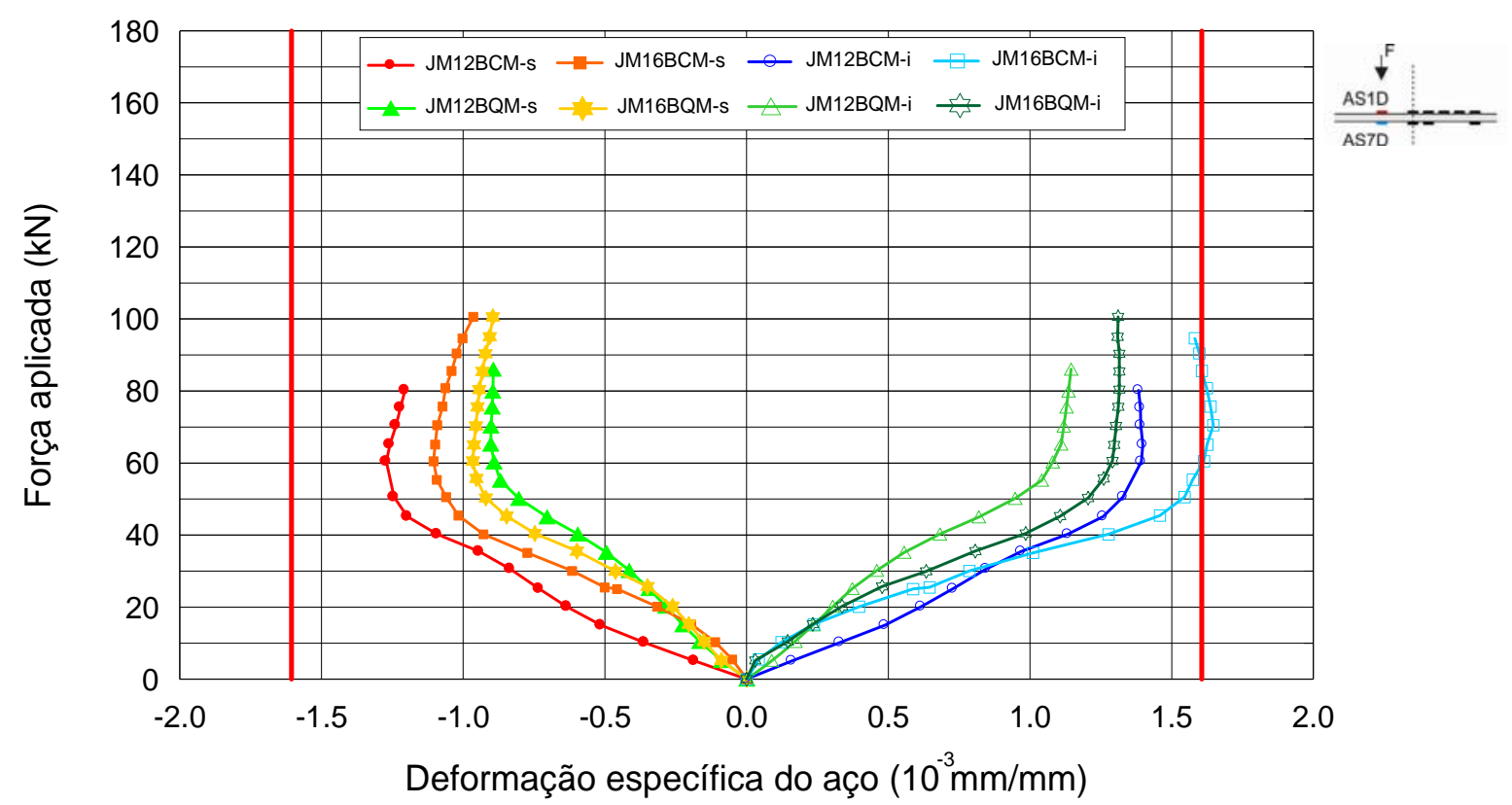

Figura 6.88 - Gráfico força aplicada versus deformação, em AS1D e AS7D 


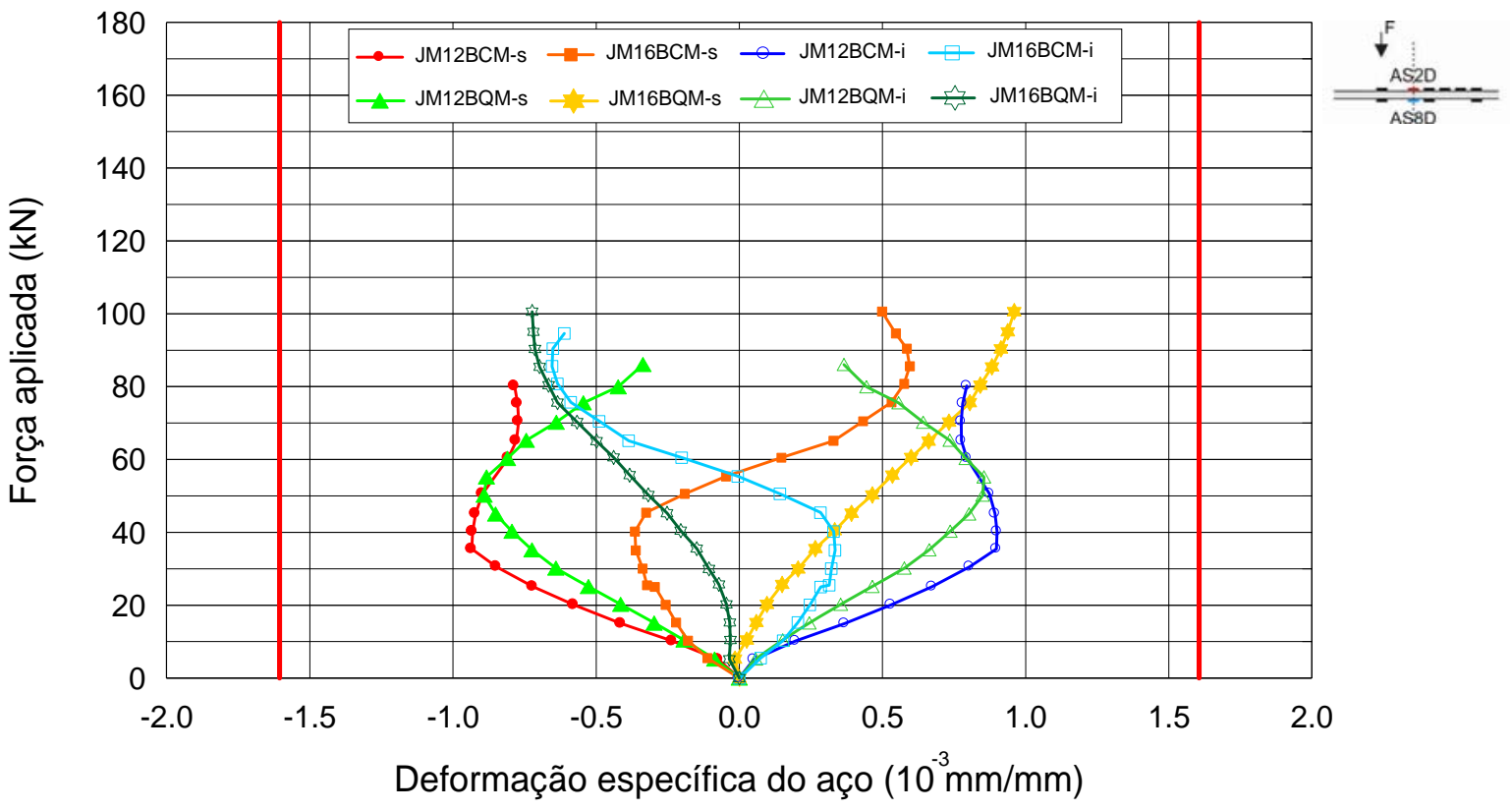

Figura 6.89 - Gráfico força aplicada versus deformação, em AS2D e AS8D

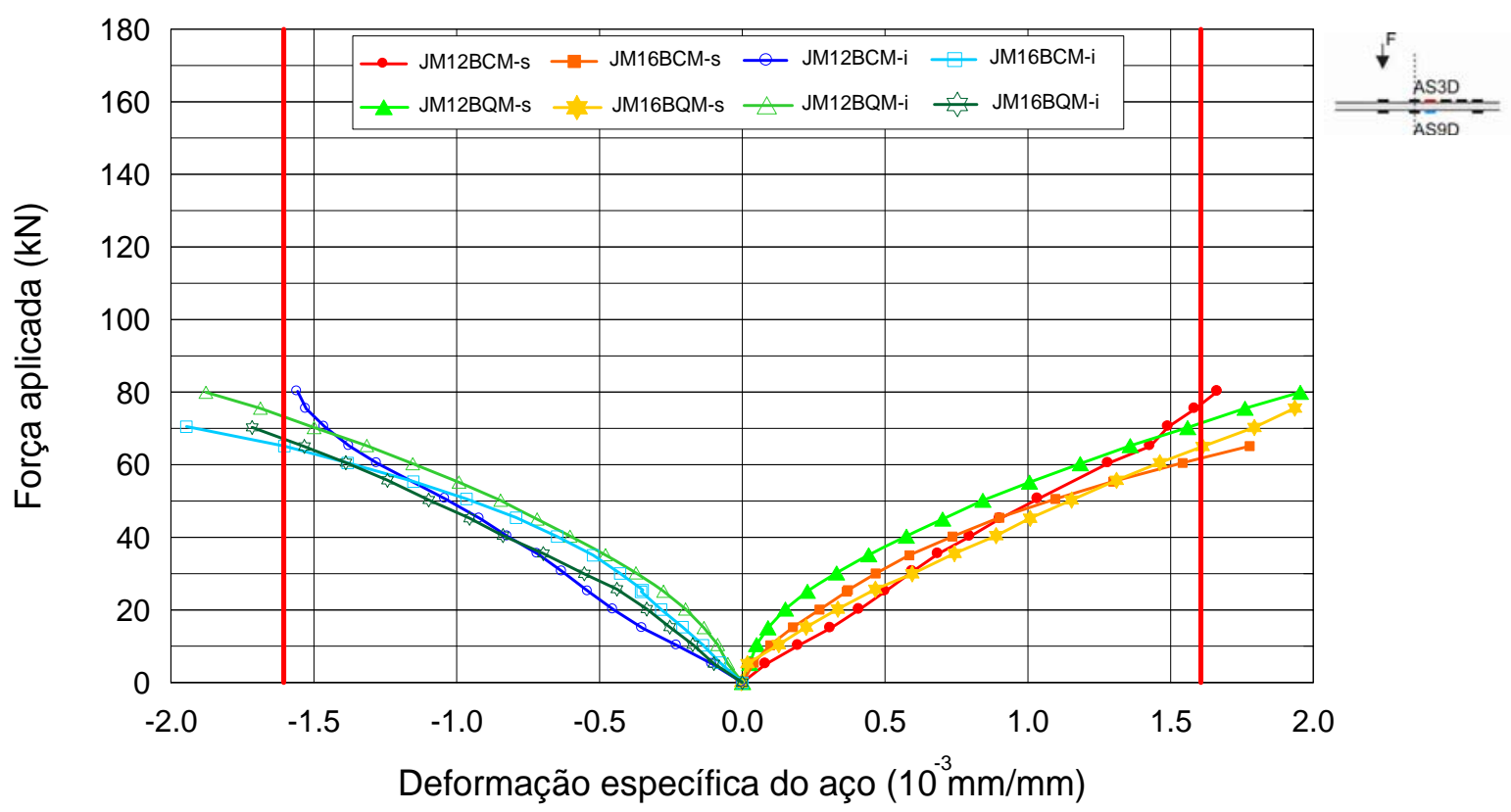

Figura 6.90 - Gráfico força aplicada versus deformação, em AS3D e AS9D 


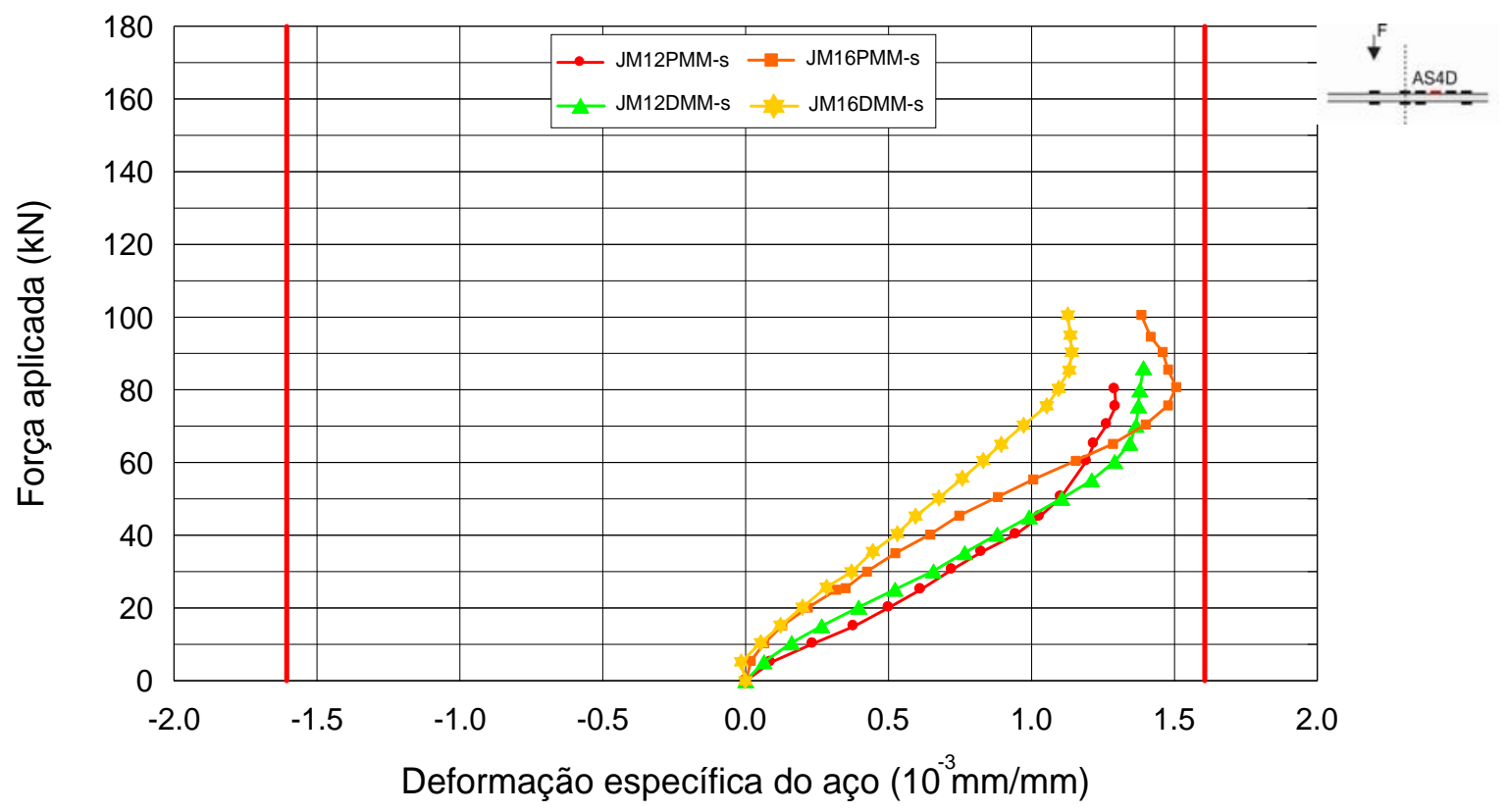

Figura 6.91 - Gráfico força aplicada versus deformação, em AS4D

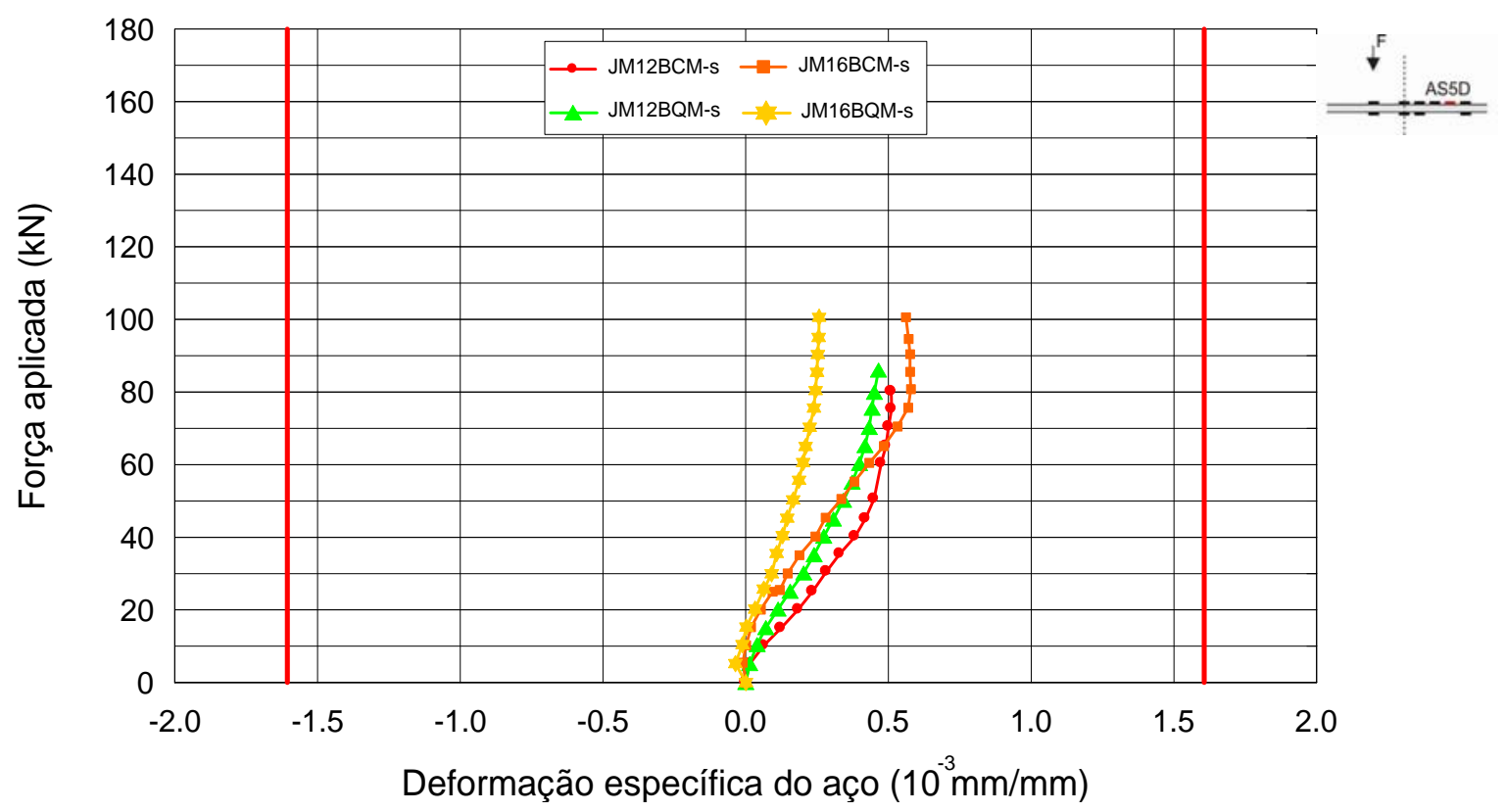

Figura 6.92 - Gráfico força aplicada versus deformação, em AS5D 


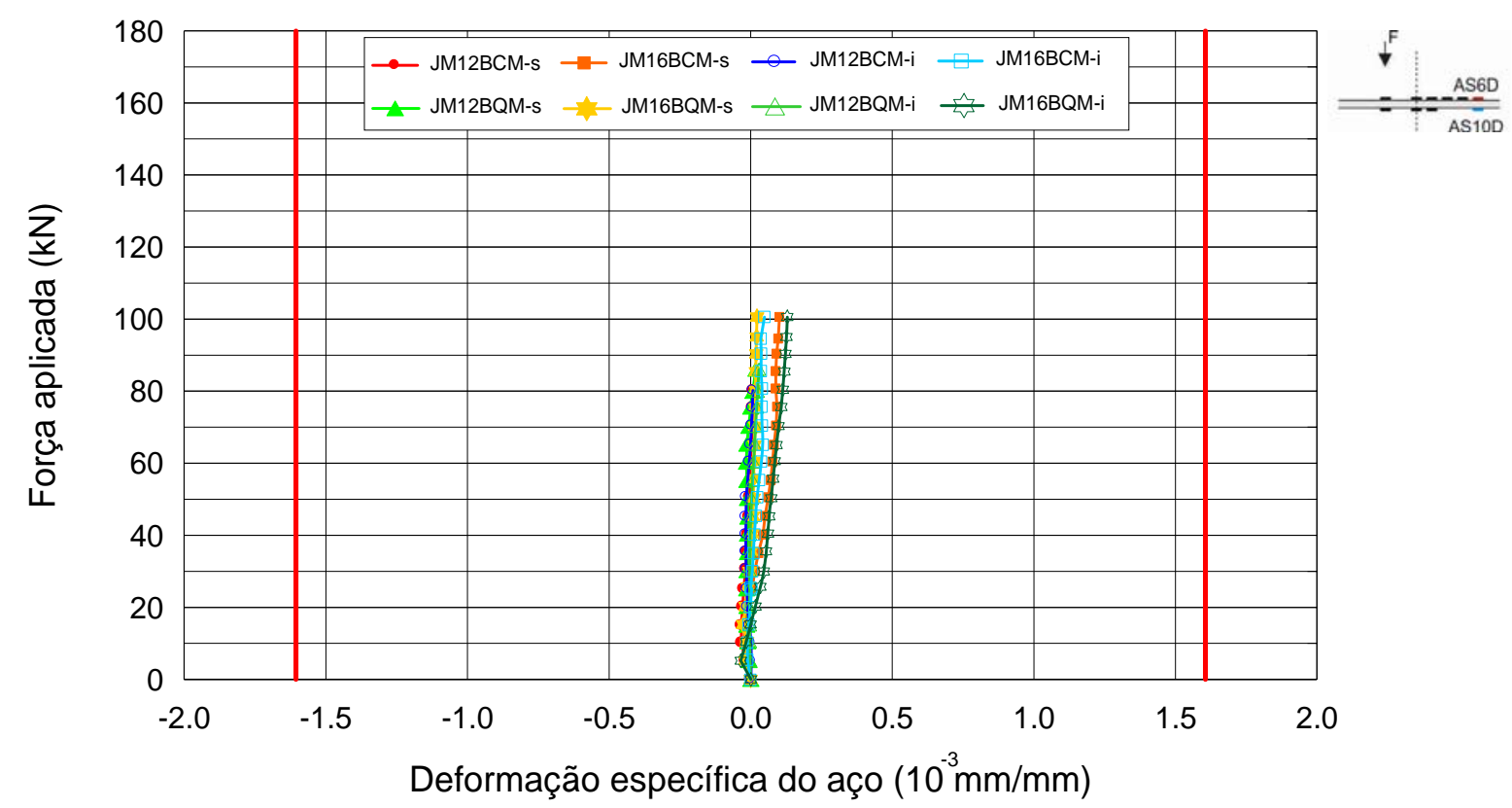

Figura 6.93 - Gráfico força aplicada versus deformação, em AS6D e AS10D

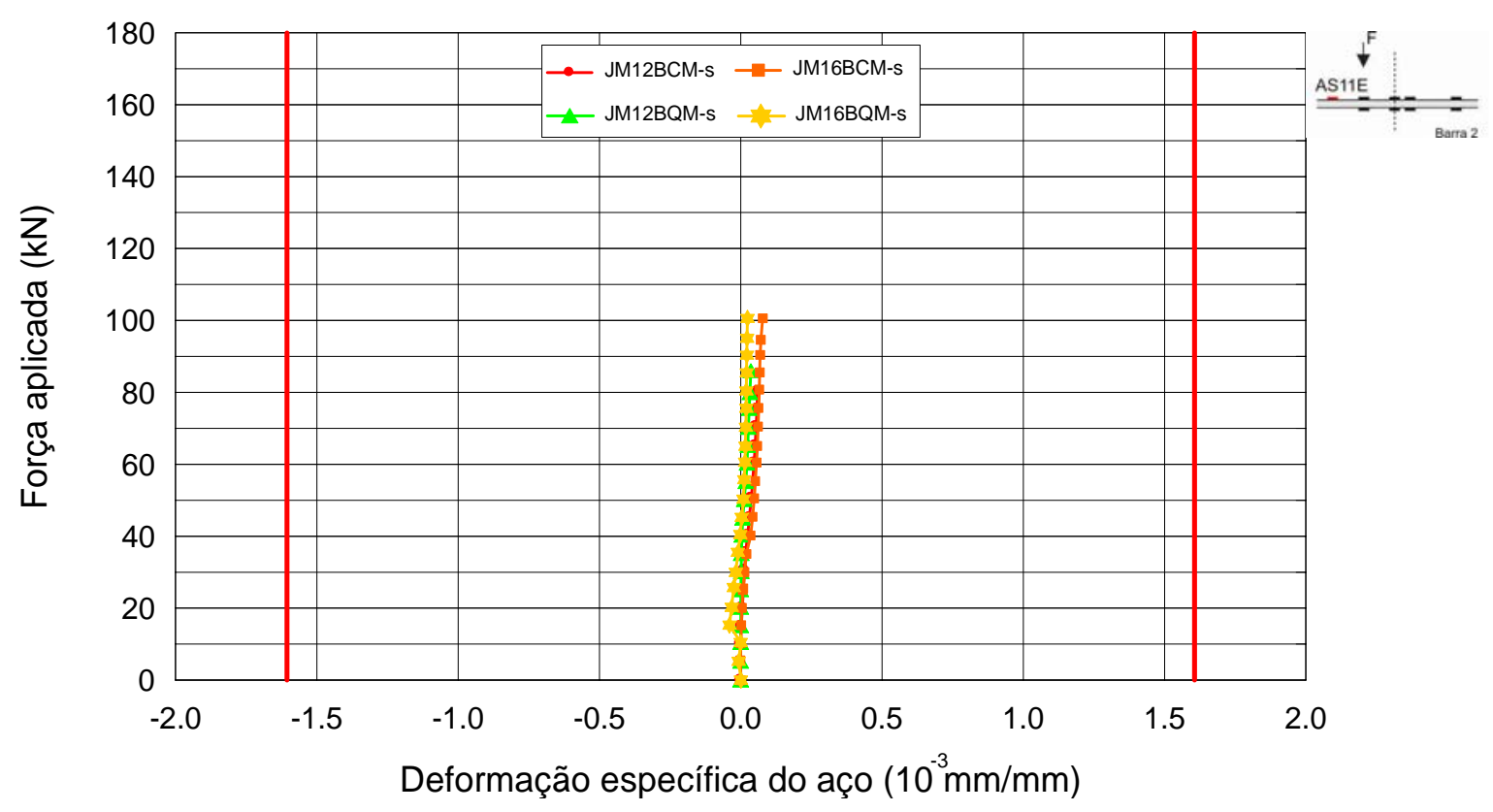

Figura 6.94 - Gráfico força aplicada versus deformação, em AS11E

O gráfico $F / F_{u}$ versus deformação, apresentado na Figura 6.95, fornece a relação entre os estágios de carregamento e as deformações sofridas pelos dispositivos em barra em um ponto deformável, AS3D. Verifica-se que os quatro modelos, JM12BCM, JM12BQM, JM16BCM e JM16BQM, apresentaram leituras ainda no início da aplicação da força, indicando que os dispositivos foram solicitados. Até $70 \%$ de $F_{u}$, os modelos apresentaram o mesmo comportamento. A partir deste ponto, em JM12BQM ocorreu deformação excessiva do dispositivo, levando-o quase ao 
colapso $\left(\varepsilon_{u}=0,017 \mathrm{~mm} / \mathrm{mm}\right.$ ). De maneira geral, o aumento da espessura permitiu que, para um mesmo estágio no carregamento, os modelos com espessura de $16 \mathrm{~cm}$ tivessem uma maior deformabilidade, sem no entanto chegar a $\varepsilon_{u}$. O desempenho da barra de seção circular, em relação ao da de seção quadrada, neste ponto, foi basicamente o mesmo, em termos de deformações.

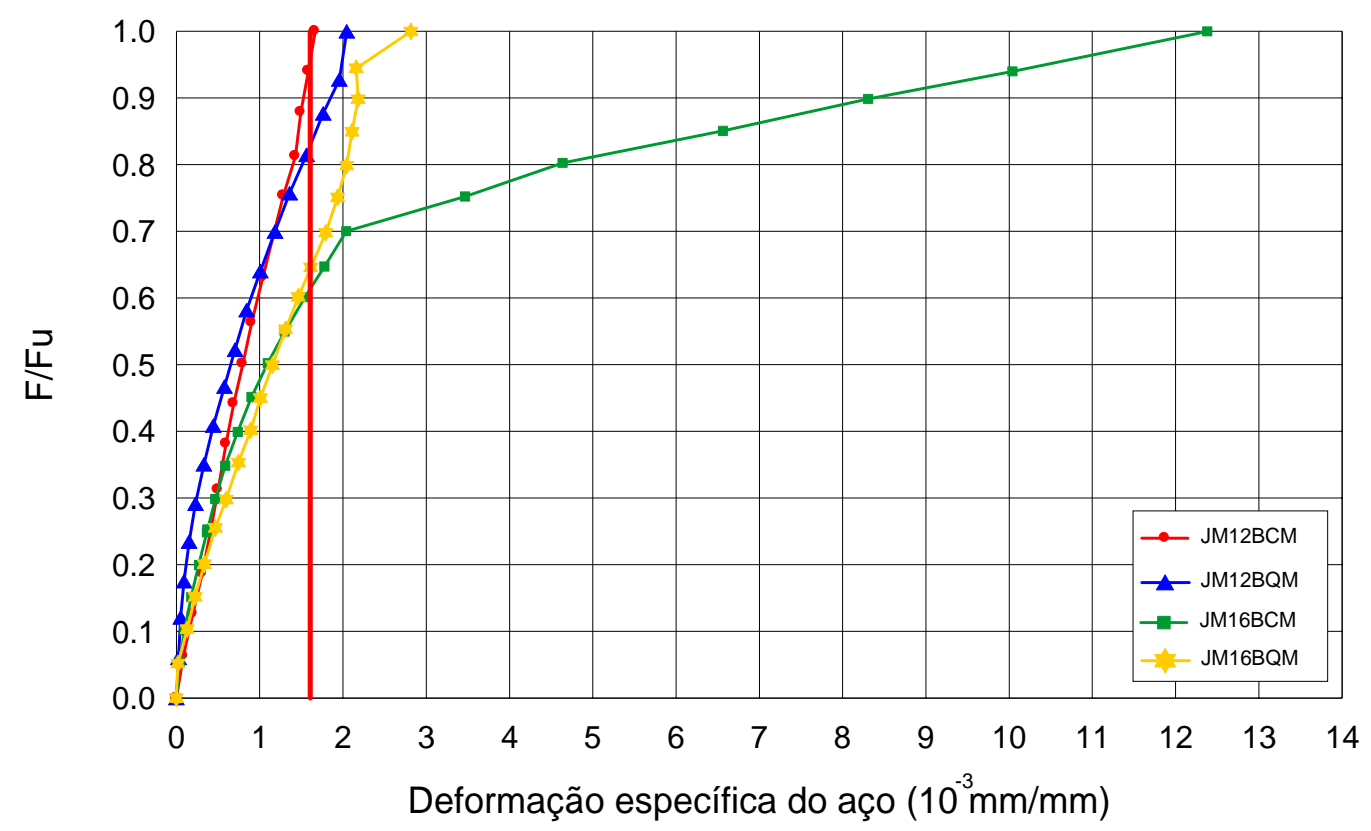

Figura 6.95 - Gráfico F/Fu versus deformação, em AS3D - barra

O gráfico força aplicada versus deformação, apresentado na Figura 6.96a, fornece 0 comportamento generalizado dos dispositivos em barra. Na Figura 6.96b tem-se um detalhe desse comportamento. 

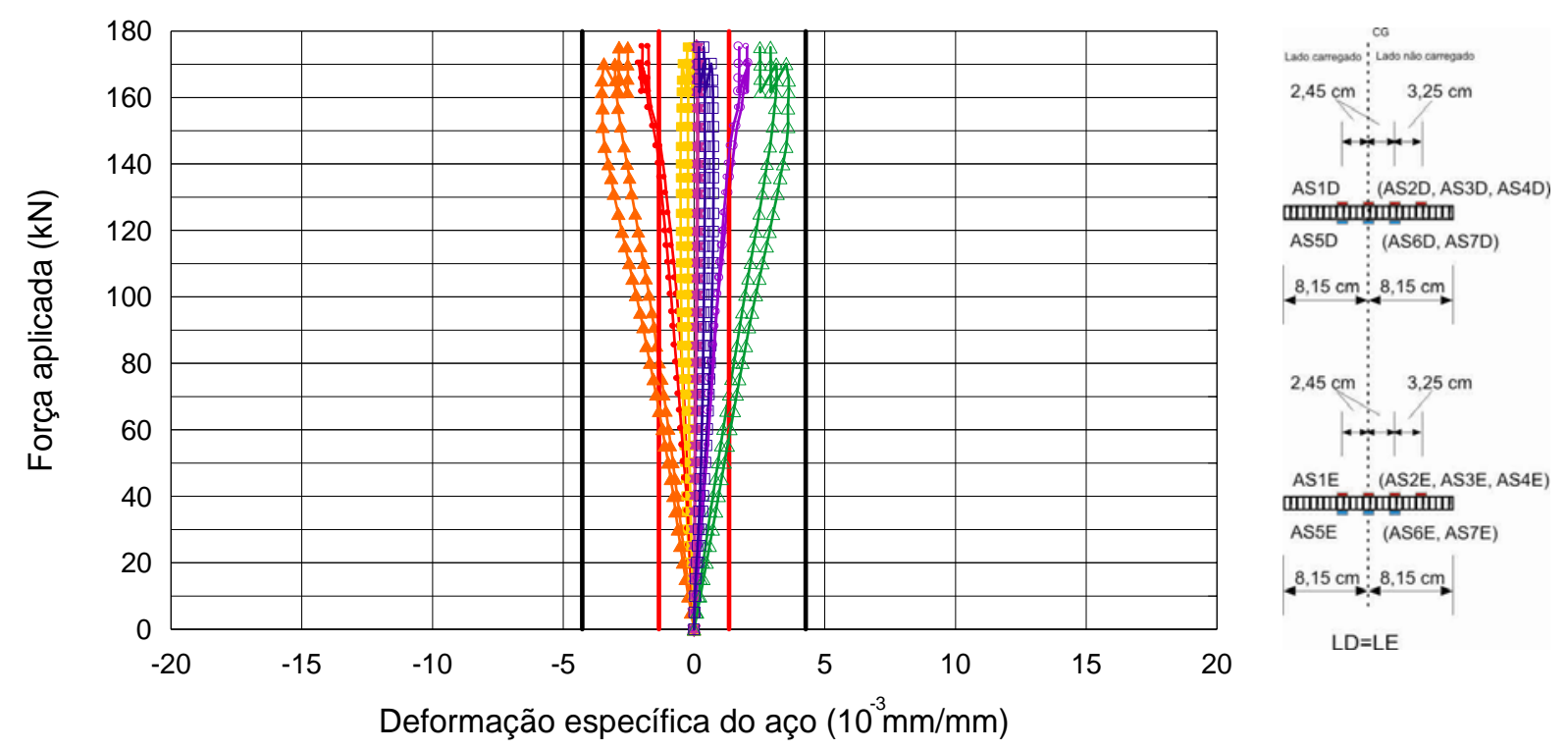

AS1D (AS2D, AS3D, ASA

AS5D $($ AS6D, AS7D)

$8,15 \mathrm{~cm}, 8,15 \mathrm{~cm}$

$2,45 \mathrm{~cm} \quad 3,25 \mathrm{~cm}$

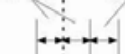

AS1E $\quad$ (AS2E, AS3E, AS4E)

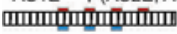

AS5E $\quad$ (AS6E, AS7E)

$8.15 \mathrm{~cm}: 8.15 \mathrm{~cm}$

$\mathrm{LD}=\mathrm{LE}$

(a)

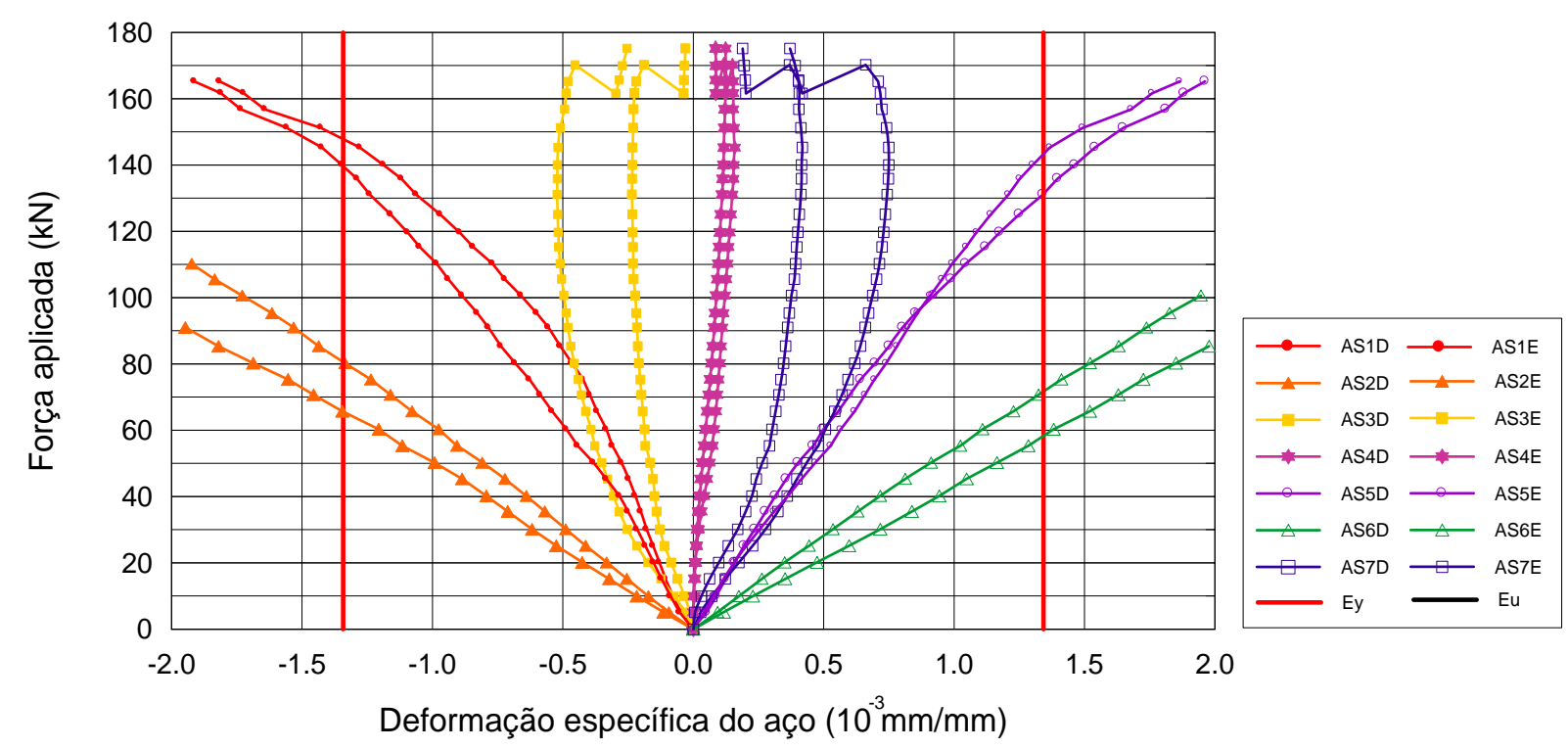

(b)

Figura 6.96 - Gráfico força aplicada versus deformação, em: JM16DMM (a) total; (b) detalhe

Para o caso de dispositivos em chapa, os gráficos força aplicada versus deformação, apresentados nas Figuras 6.97 a 6.100, referem-se aos modelos JM12PMM, JM12DMM, JM16PMM e JM16DMM. Verificou-se que os dispositivos em chapa, do lado esquerdo (LE), comportaram-se de maneira semelhante no lado direito (LD), e por isso foram plotados gráficos generalizados do comportamento dos dispositivos, em ambos os lados. O limite de escoamento empregado foi de $\varepsilon_{\text {y,chapa }}=0,0013 \mathrm{~mm} / \mathrm{mm}$. 
Nos dispositivos em chapa, os modelos com espessura de $12 \mathrm{~cm}$ apresentaram as maiores deformações, em AS1D e AS2D.

A região central do dispositivo em chapa (AS2D) apresentou as maiores deformações, que levaram ao escoamento dos dispositivos, diferentemente do que ocorreu nos modelos serrados. Essas deformações no aço também foram verificadas em AS1D, a cerca de $2,15 \mathrm{~cm}$ da face da junta e do lado carregado, nos modelos JM12DMM e JM12PMM.

A uma distância de $5,7 \mathrm{~cm}$ do eixo da junta e no lado não carregado, em AS4D, foram verificadas deformações próximas de zero, devidas a esforços de tração. Em AS3D, posicionado a $2,45 \mathrm{~cm}$ do eixo da junta, foram obtidas deformações menores do que o limite de escoamento do aço.

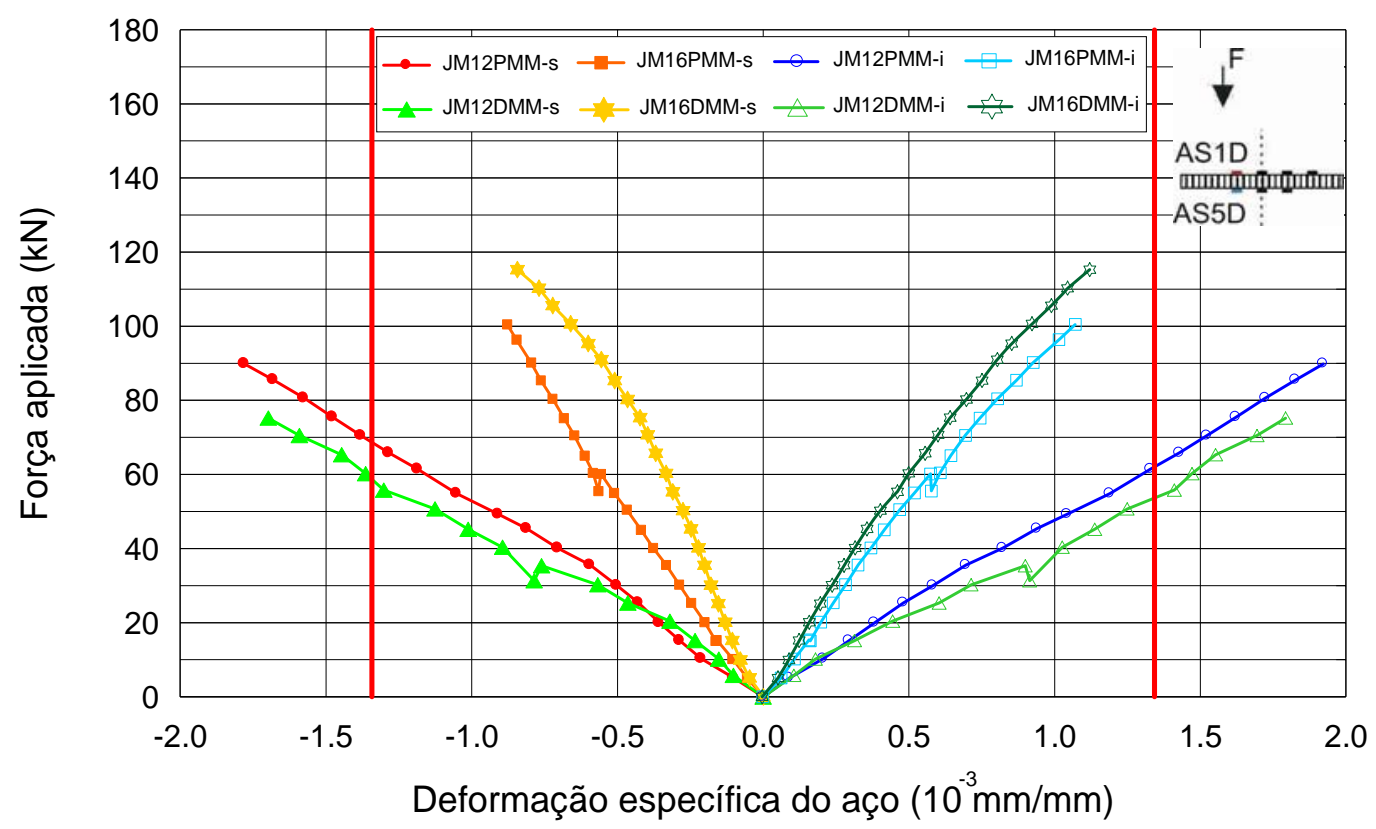

Figura 6.97 - Gráfico força aplicada versus deformação, em AS1D e AS5D 


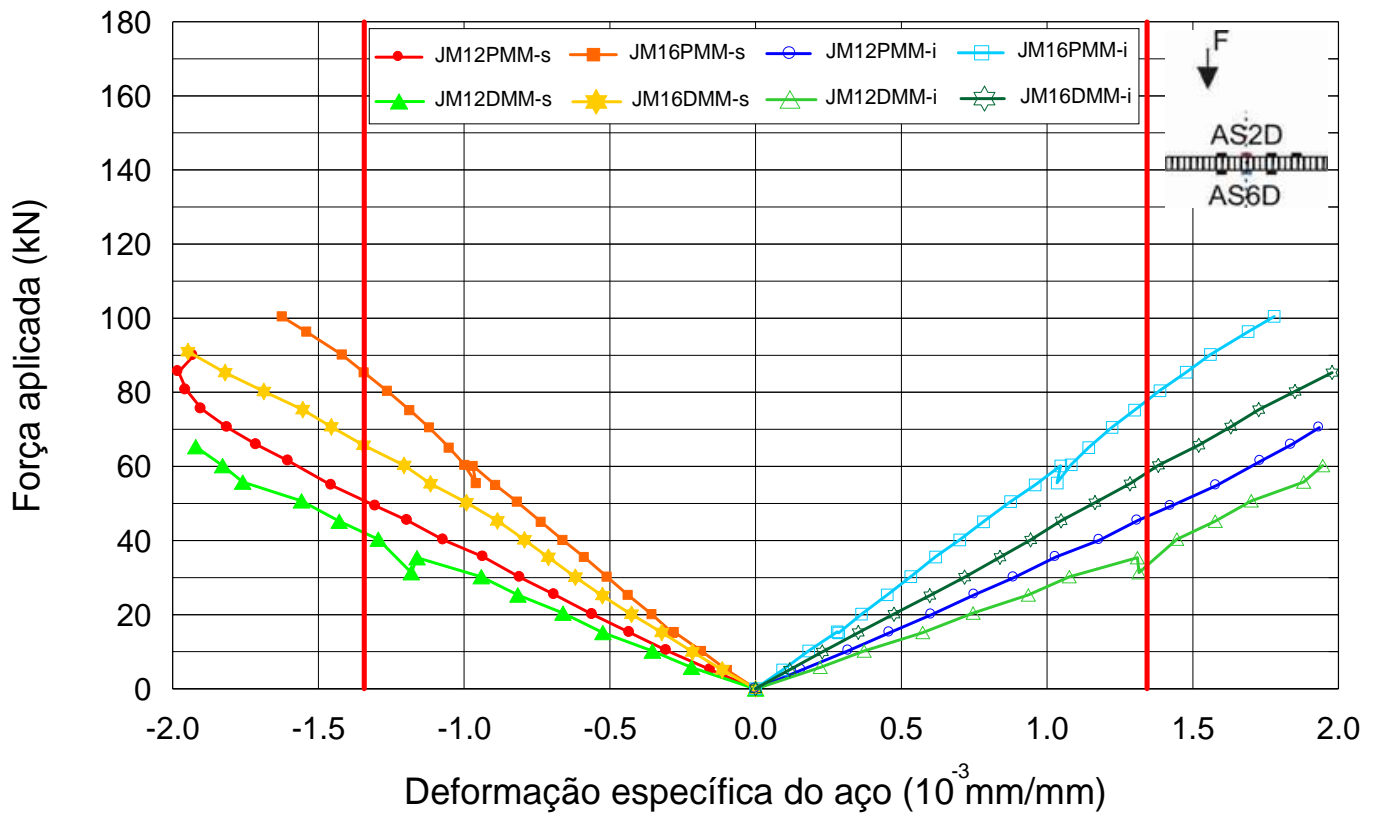

Figura 6.98 - Gráfico força aplicada versus deformação, em AS2D e AS6D

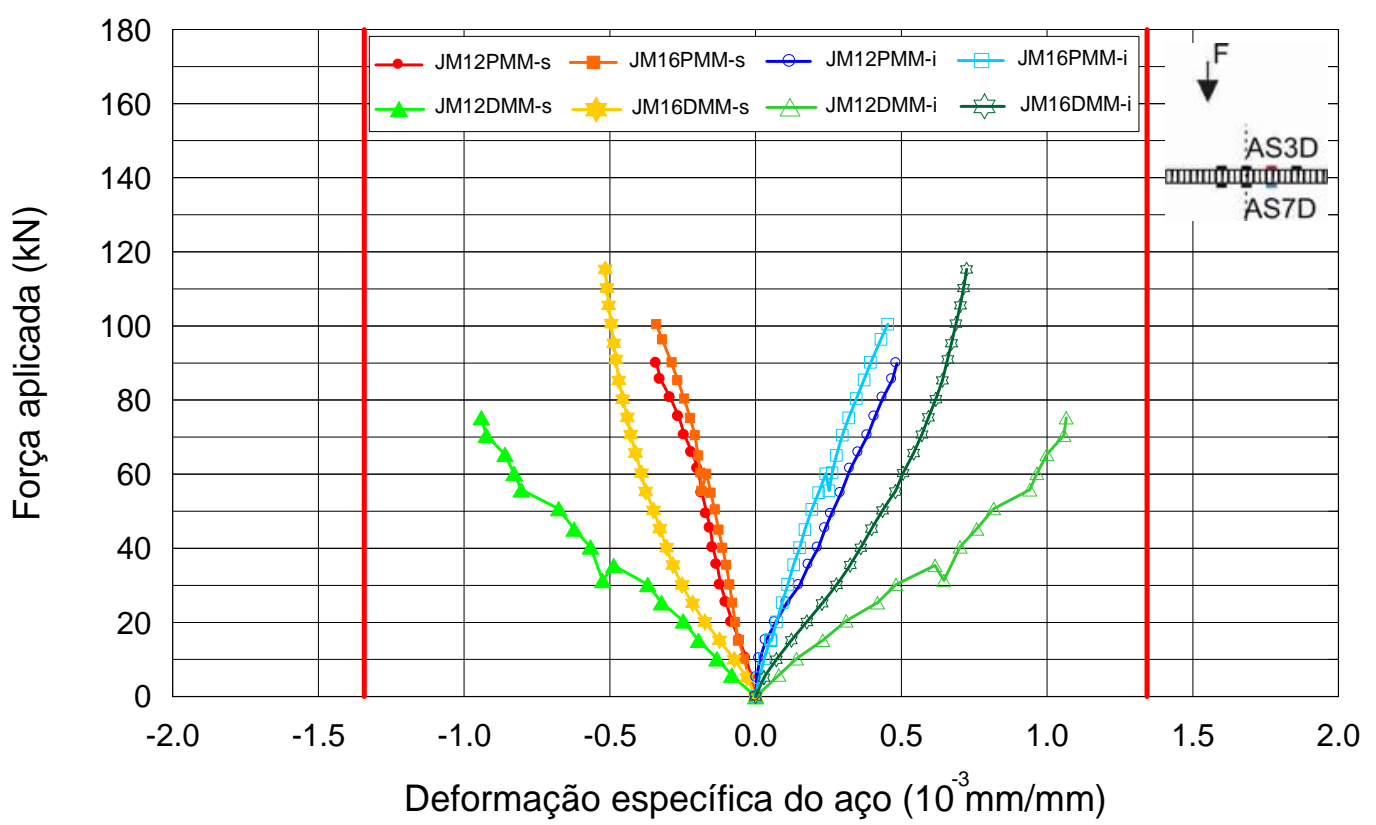

Figura 6.99 - Gráfico força aplicada versus deformação, em AS3D e AS7D 


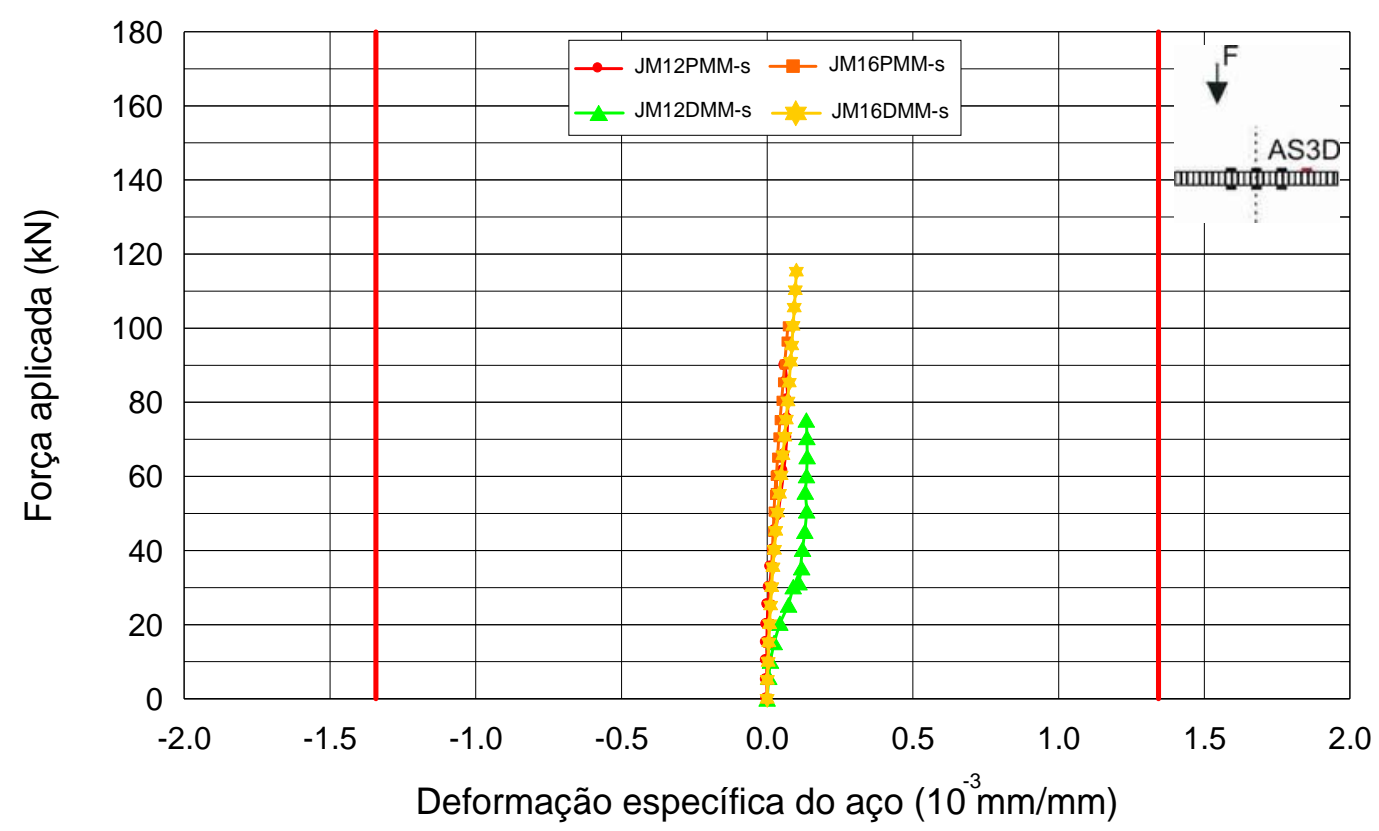

Figura 6.100 - Gráfico força aplicada versus deformação, em AS4D

O gráfico $F / F_{u}$ versus deformação apresentado na Figura 6.101, fornece a relação entre os estágios de carregamento e as deformações sofridas pelos dispositivos em chapa em um ponto deformável, AS3D. Verifica-se que os quatro modelos, JM12PMM, JM12DMM, JM16PMM e JM16DMM, apresentaram leituras ainda no início da aplicação da força, indicando que os dispositivos foram solicitados. Até $70 \%$ de $F_{u}$ os modelos apresentaram o mesmo comportamento, com exceção de JM16PMM. A partir desse ponto, em JM16DMM, as deformações foram maiores, sem no entanto chegar a $\varepsilon_{u}$. De maneira geral, o aumento da espessura até o escoamento do dispositivo não teve influência na sua deformabilidade. Ou seja, para um mesmo estágio no carregamento, os modelos se comportaram de maneira semelhante, em termos de deformações. 


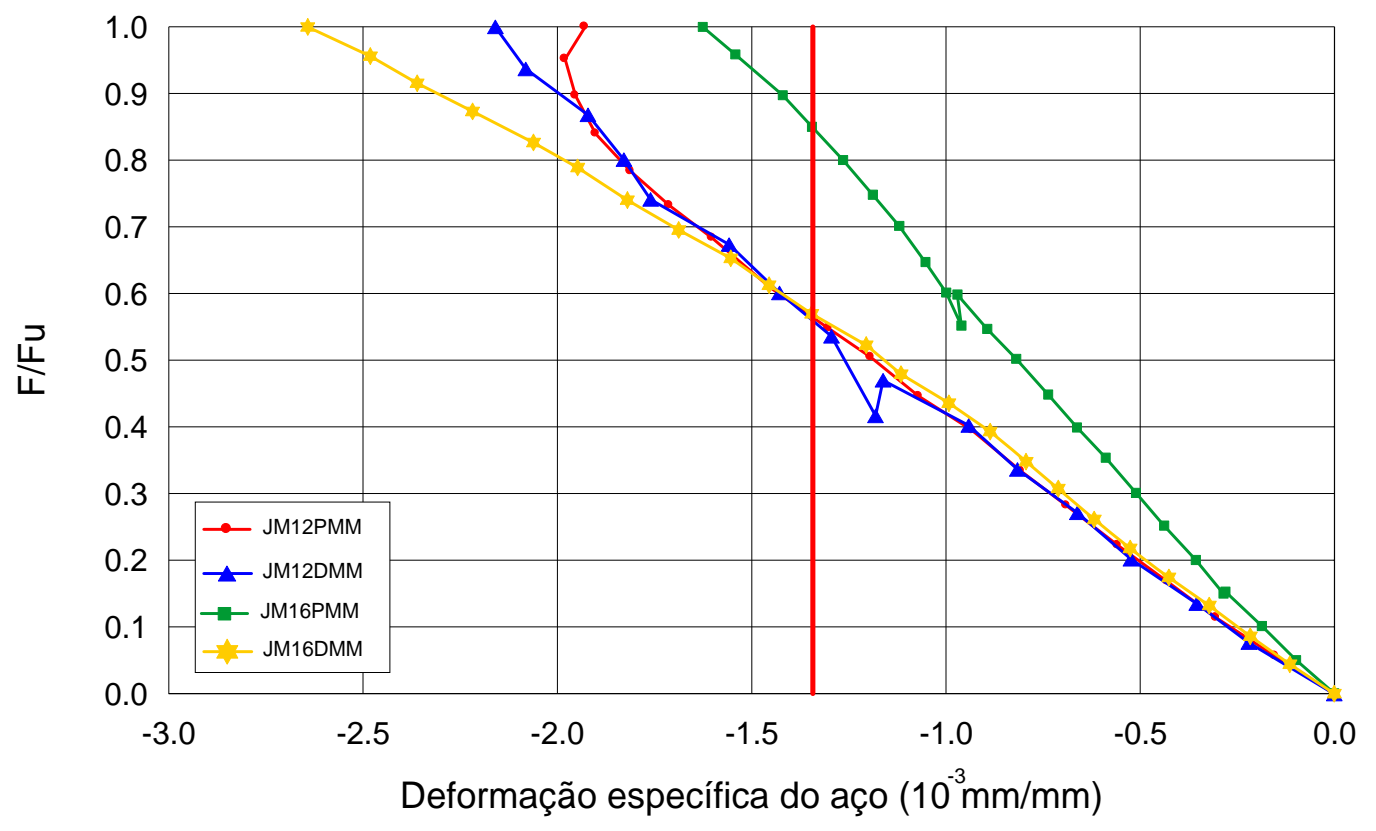

Figura 6.101 - Gráfico F/Fu versus deformação, em AS3D - chapa 


\section{CAPÍTULO 7}

\section{ANÁLISE DOS RESULTADOS}

Este capítulo apresenta a análise dos resultados obtidos nos ensaios das placas de concreto simples. Considerações a respeito do emprego de corpos-de-prova submetidos a cisalhamento duplo na análise de juntas armadas, eficiência, forças e deslocamentos verticais dos modelos e custos unitários dos dispositivos metálicos foram realizadas.

\subsection{PLACAS VERSUS CORPOS-DE-PROVA PRISMÁTICOS}

Com o objetivo de se determinar apenas a contribuição do modelo na rigidez do sistema placa-fundação sem a borracha, foram feitos ensaios em corpos-de-prova prismáticos dotados de dispositivos de transferência de carga. A Tabela 7.1 apresenta um resumo das forças, para os corpos-de-prova e os modelos ensaiados.

Analisando inicialmente a força de fissuração, pôde ser verificado que apenas JS12PMM (J = junta; $\mathbf{S}=$ serrada; espessura em $\mathbf{c m}$; $\mathbf{P M}=$ placa metálica; $\mathbf{M}=$ ensaio monotônico) apresentou coerência nos valores obtidos, com a relação entre $F_{\text {fiss }}$, no modelo e no corpo-de-prova, próximo a um.

As forças últimas, obtidas na ruptura das peças, foram próximas, com exceção de JS16DMM, tendo este modelo apresentado fissuração fora do plano de corte. O comportamento semelhante dos corpos-de-prova com os modelos, na ruptura, sugere seu emprego na previsão de forças últimas, quando não forem utilizados outros recursos teóricos. 
Tabela 7.1 - Resumo da forças para corpos-de-prova em cisalhamento duplo e placas

\begin{tabular}{|c|c|c|c|c|c|c|c|}
\hline \multirow{2}{*}{$\begin{array}{c}\text { Corpo-de - } \\
\text { prova }\end{array}$} & $\begin{array}{c}\text { Força de } \\
\text { fissuração } \\
F_{\text {fiss }}\end{array}$ & $\begin{array}{c}\text { Força } \\
\text { última } \\
F_{u}\end{array}$ & \multirow{2}{*}{ Modelo } & $\begin{array}{c}\text { Força de } \\
\text { fissuração } \\
F_{\text {fiss }}\end{array}$ & $\begin{array}{c}\text { Força } \\
\text { última } \\
F_{u}\end{array}$ & $\frac{F_{\text {fis }, \text { cp }}}{F_{\text {fiss,md }}}$ & $\frac{F_{u, c p}}{F_{u, m d}}$ \\
\cline { 2 - 3 } & $\mathrm{kN}$ & $\mathrm{kN}$ & & $\mathrm{kN}$ & $\mathrm{kN}$ & $\mathrm{kN} / \mathrm{kN}$ & $\mathrm{kN} / \mathrm{kN}$ \\
\hline CD-JS12BCM & 17,9 & 128,3 & JS12BCM & 10,19 & 100,40 & 1,8 & 1,3 \\
\hline CD-JS16BCM & 17,7 & 143,1 & JS16BCM & 43,09 & 172,24 & 0,4 & 0,8 \\
\hline CD-JS12BQM & 39,9 & 105,6 & JS12BQM & 16,05 & 106,78 & 2,5 & 1,0 \\
\hline CD-JS16BQM & 19,2 & 160,5 & JS16BQM & 38,88 & 189,54 & 0,5 & 0,8 \\
\hline CD-JS12PMM & 21,4 & 99,9 & JS12PMM & 22,26 & 74,17 & 1,0 & 1,3 \\
\hline CD-JS16DMM & 18,8 & 133,7 & JS16DMM & 33,01 & 274,41 & 0,6 & 0,5 \\
\hline
\end{tabular}

\subsection{EFICIÊNCIA DAS JUNTAS}

O parâmetro da eficiência das juntas proposto pela ACPA (1991) foi utilizado na verificação do comportamento das juntas armadas, e seu limite, especificado de $75 \%$, foi tracejado por linha vermelha nos gráficos a seguir.

Os gráficos apresentados nas Figura 7.1 e 7.2 fornecem a eficiência das juntas armadas com dispositivos metálicos, submetidas a carregamento estático. Para os modelos dotados de dispositivos em barra, verificou-se uma queda progressiva da eficiência à medida que os dispositivos foram solicitados, após a fissuração do concreto. No modelo JS16BCM, verificou-se uma queda brusca da eficiência, provavelmente por problemas surgidos na leitura de um dos transdutores sobre a junta, uma vez que o comportamento fugiu ao padrão corrente. Defeitos de execução do modelo, que poderiam explicar esse comportamento imprevisto, foram investigados e descartados, entre os quais: ninhos de concretagem, espaçamento incorreto dos dispositivos de transferência ou profundidade irregular do corte da junta.

Para a espessura de $12 \mathrm{~cm}$, a barra com seção circular apresentou melhor eficiência na transferência de carga, cerca de 96\%, enquanto JS12BQM apresentou eficiência de $92 \%$. A diferença na força de ruptura entre os modelos foi cerca de $6 \%$. Pode-se concluir que ambos os dispositivos apresentaram, durante os ensaios estáticos, um comportamento bastante similar em termos de eficiência. 


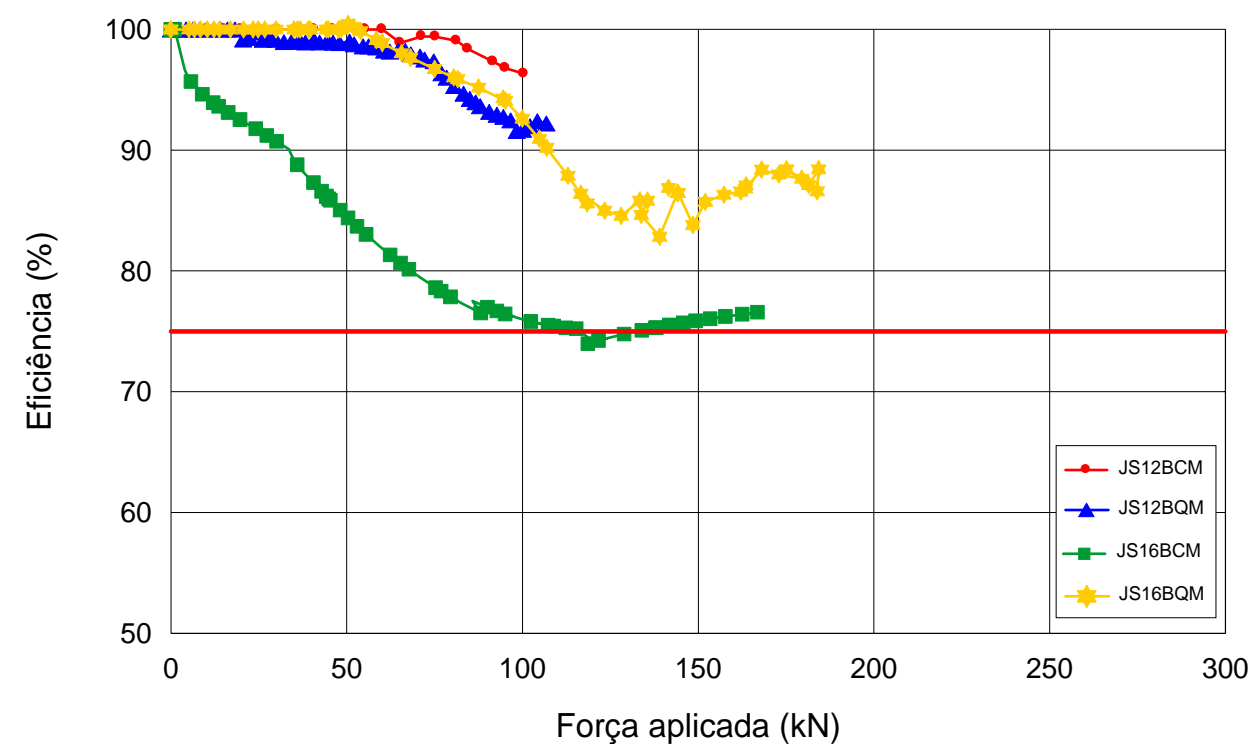

Figura 7.1 - Eficiência da junta serrada para dispositivos em barra

Para os modelos dotados de dispositivos em chapa (Figura 7.2) também foi verificada uma queda progressiva da eficiência do sistema para cargas superiores a $F_{\text {fiss }}$. O disco metálico apresentou uma eficiência superior em ambas as espessuras, se comparado à placa metálica introduzida na junta.

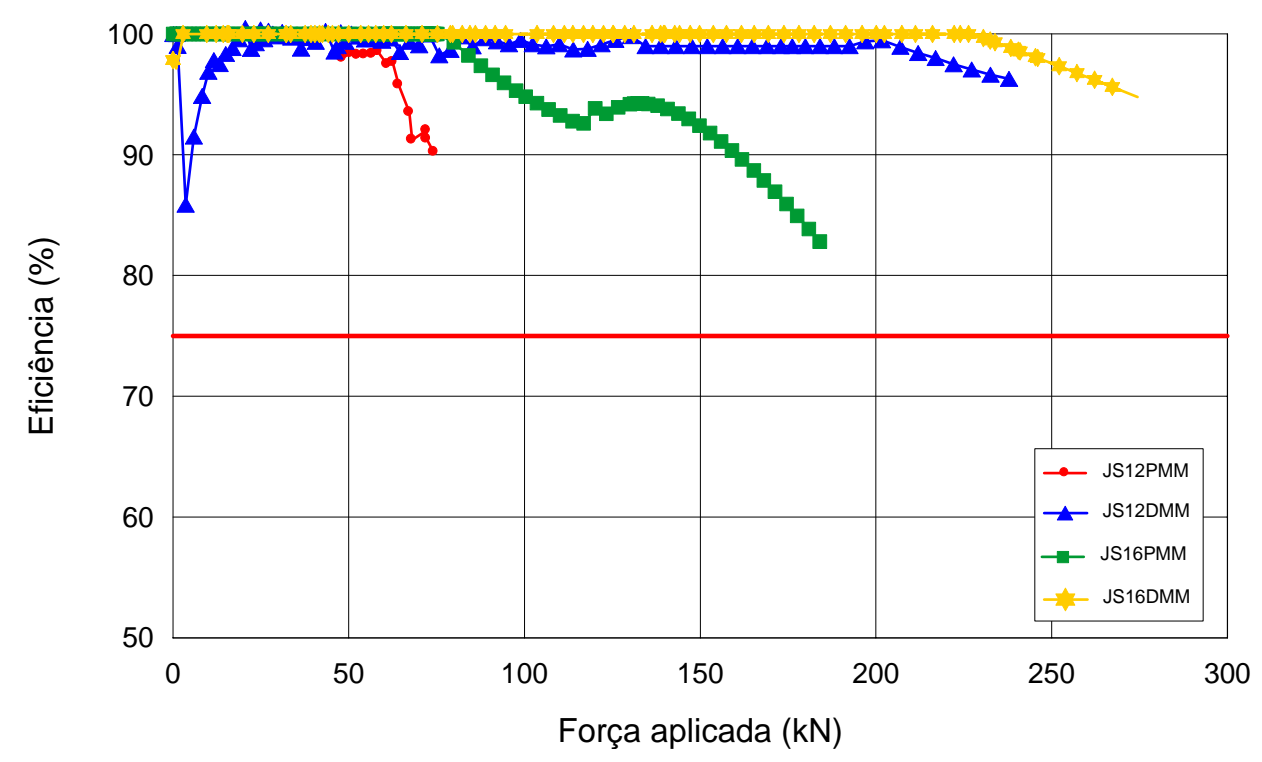

Figura 7.2 - Eficiência da junta serrada para dispositivos em chapa

Os modelos dotados de junta moldada apresentaram, desde o início do carregamento, queda progressiva da eficiência, como apresentado nas Figura 7.3 e 7.4. Assim como nas juntas serradas, nas moldadas, para a espessura de $12 \mathrm{~cm}$, a 
barra de seção circular apresentou maior eficiência (85\%), se comparada à da de seção quadrada (79\%). Para a espessura de $16 \mathrm{~cm}$, a eficiência de ambas se aproximou a 80\%, ao atingirem a força última. Os dispositivos em chapa dos modelos JM16PMM e JM16DMM apresentaram comportamento bastante similar, com eficiência final próxima a $80 \%$.

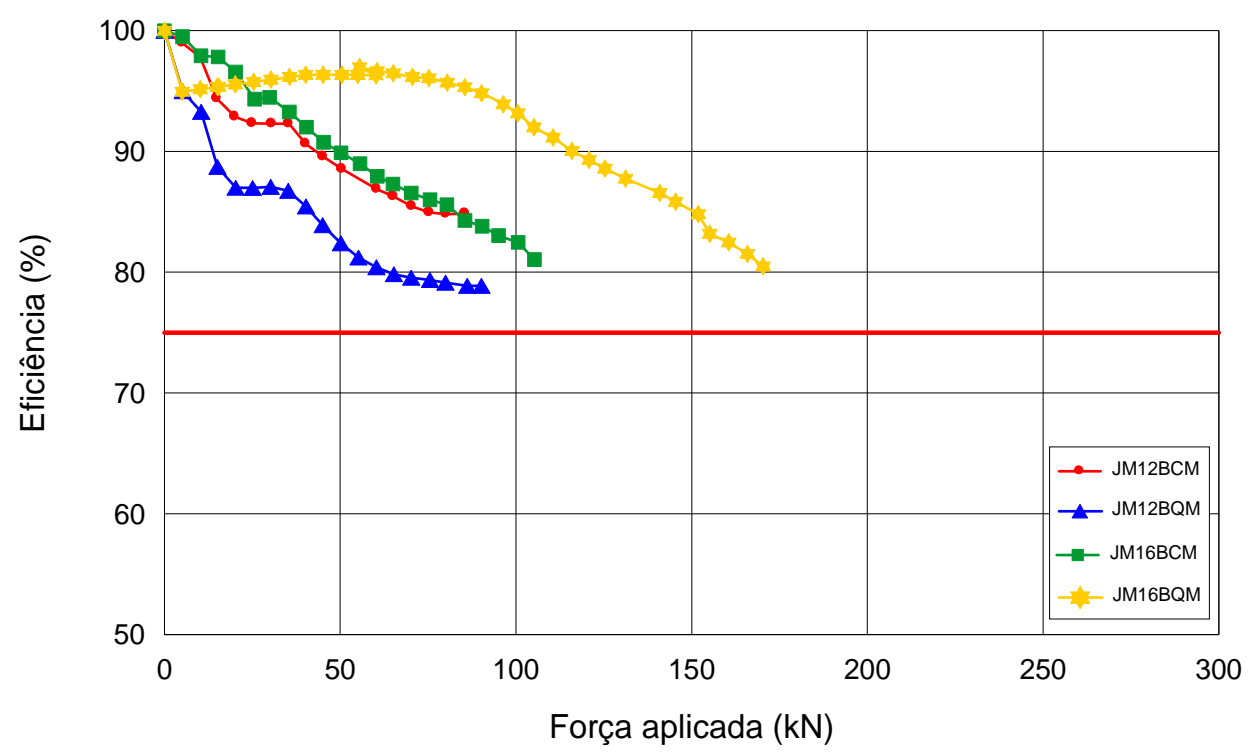

Figura 7.3 - Eficiência da junta moldada para dispositivos em barra

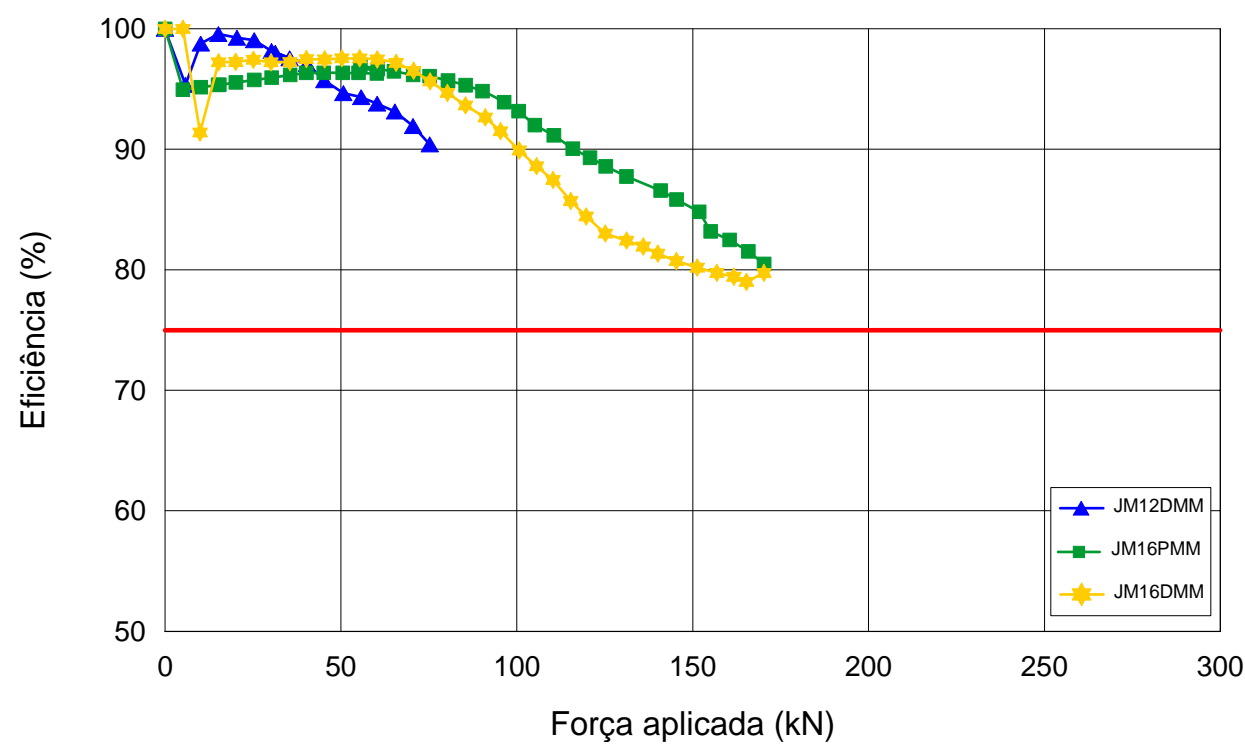

Figura 7.4 - Eficiência da junta moldada para dispositivos em chapa

As juntas moldadas apresentaram menor eficiência em relação às juntas serradas, desde o início do carregamento, como visualizado nas Figura 7.5 e 7.6. 


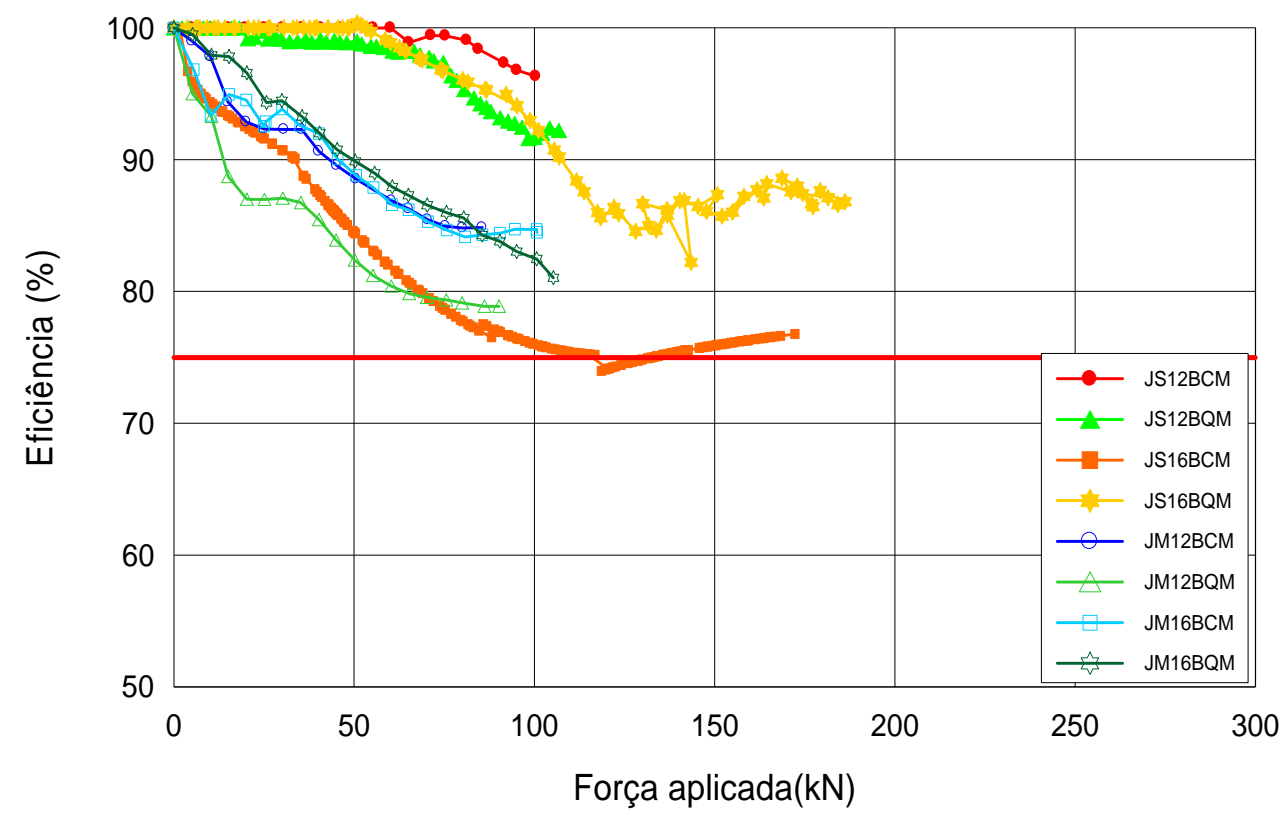

Figura 7.5 - Eficiência da junta para dispositivos em barra

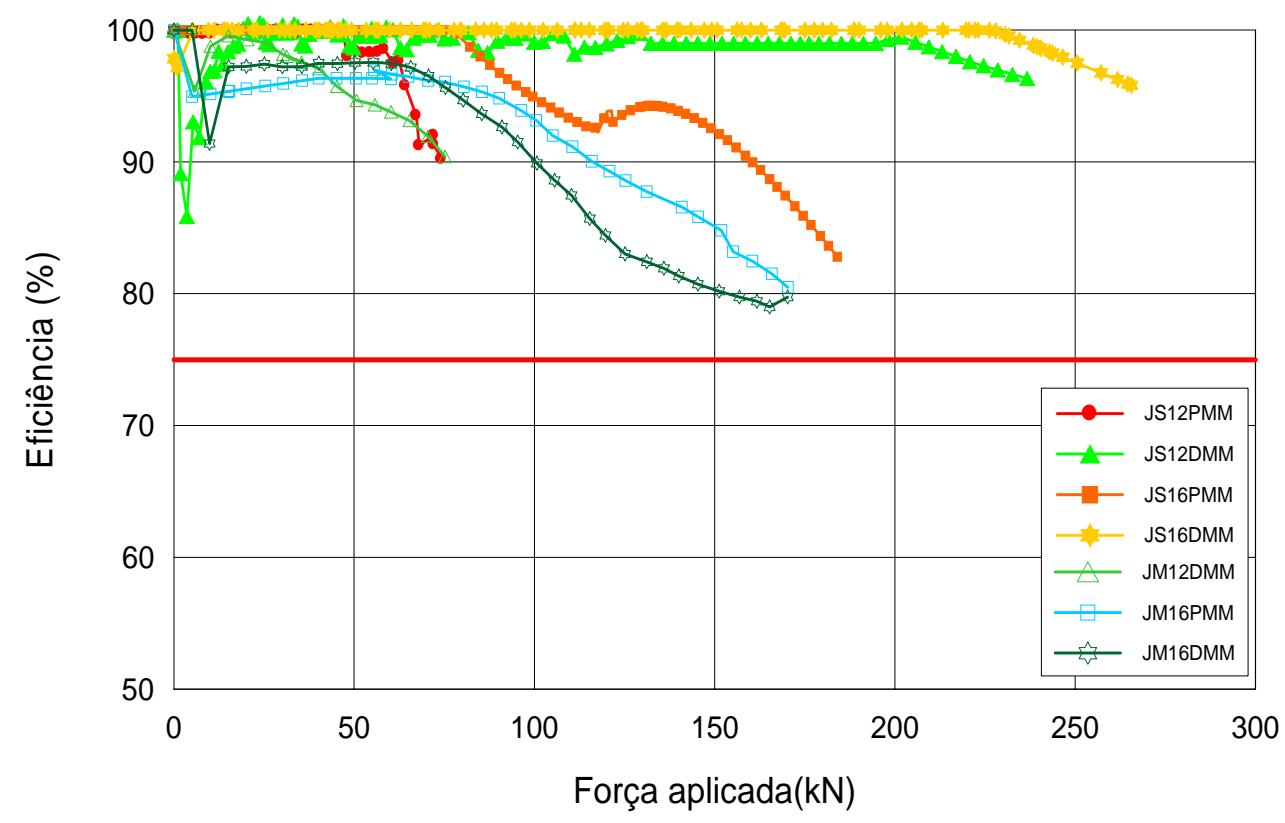

Figura 7.6 - Eficiência da junta para dispositivos em chapa

Nas Figura 7.7 e 7.8 são apresentadas as eficiências dos modelos submetidos a carregamento repetido. O acréscimo da espessura em JS16BCC aumentou sua força de ruptura $(215,85 \mathrm{kN})$, se comparado a JS12BCC $(97,69 \mathrm{kN})$. Este aumento da força provocou uma maior solicitação do dispositivo em barra de seção circular, que levou à diminuição de sua eficiência, a partir de $175 \mathrm{kN}$ até a ruptura. No entanto, 
esta perda não pode ser considerada expressiva, já que a eficiência permaneceu na ordem de $90 \%$.

Após os ciclos de carga em JS12PMC e JS12DMC, as eficiências na ruptura foram respectivamente de 98\% e 91\%. Os maiores deslocamentos do lado carregado (T5) de JS12DMC levaram à diminuição de sua eficiência, a partir de 46,75kN. No entanto, a diferença entre as eficiências, da ordem de 7\%, é inferior à diferença entre as forças últimas atingidas, de 128,21kN para JS12DMC, superior a 27\%, em relação à JS12PMC.

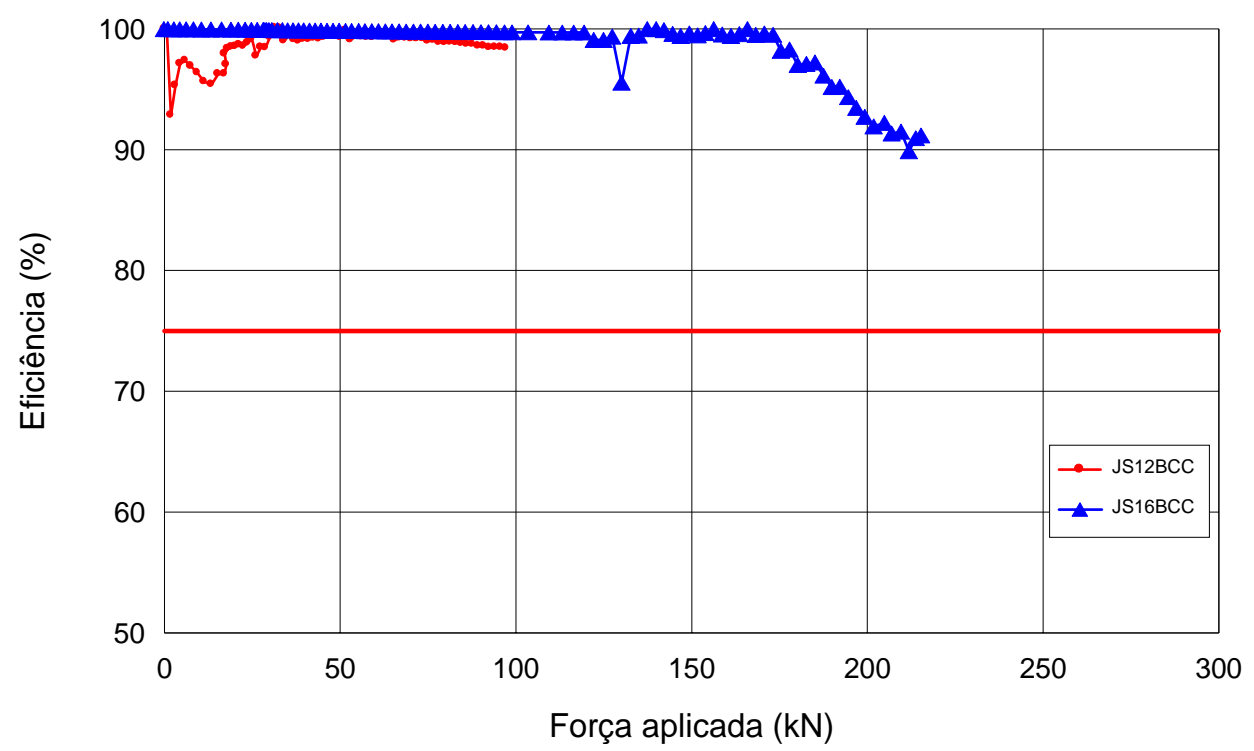

Figura 7.7 - Eficiência da junta serrada para dispositivos em barra - cíclico

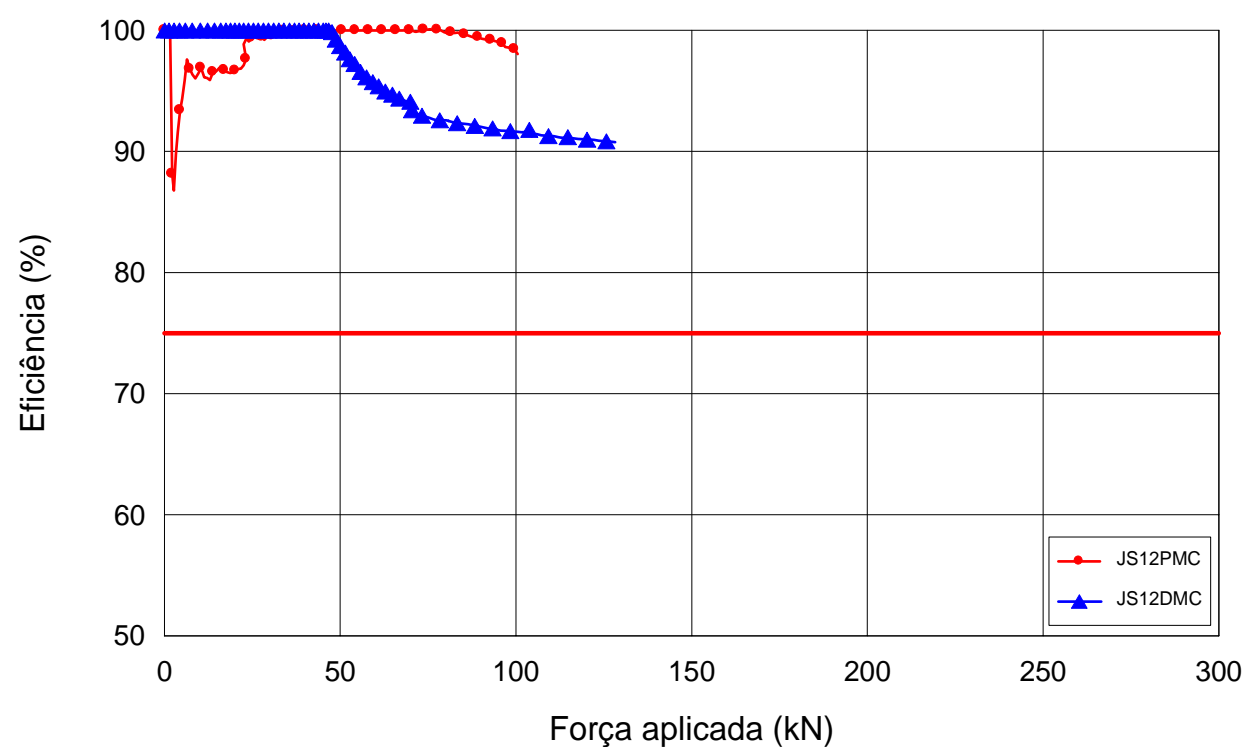

Figura 7.8 - Eficiência da junta serrada para dispositivos em chapa - cíclico 
Com o intuito de comparar o desempenho dos dispositivos, foi traçado o gráfico da eficiência na Figura 7.9. Os modelos JS12BCC e JS12PMC apresentaram comportamento bastante similar, apesar de apresentarem dispositivos de transferência diferenciados, em termos de taxa de armadura e de comprimento de embutimento.

O modelo JS12DMC atingiu sua força última com valores superiores aos das demais, mantendo sua eficiência em torno de 90\%. Em situação de serviço, provavelmente por acomodação do sistema e escorregamentos iniciais dos dispositivos, JS12BCC e JS12PMC tiveram queda da eficiência e posterior estabilização, enquanto JS12DMC permaneceu com valores em torno de 100\%, acima de $F_{\text {fiss }}$, durante todo o período.

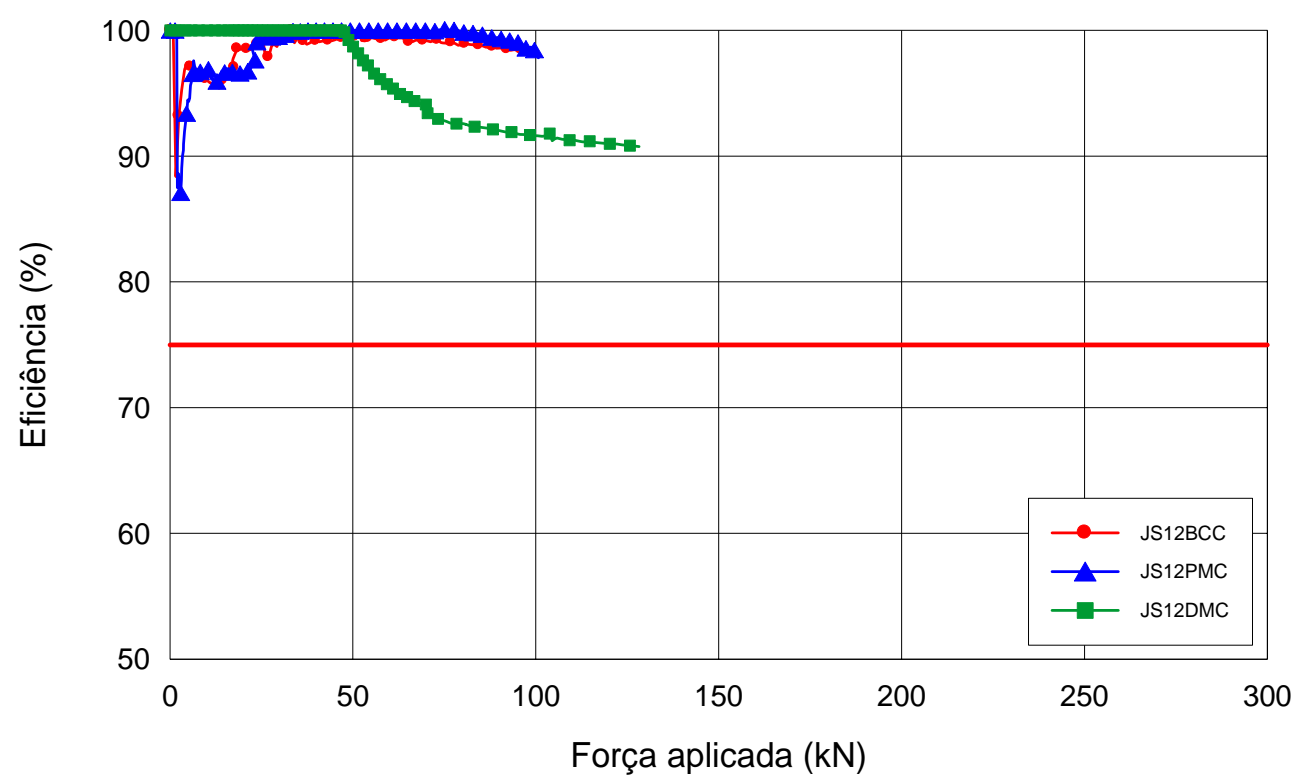

Figura 7.9 - Eficiência da junta serrada para dispositivos

\subsection{FORÇAS E DESLOCAMENTOS}

A Figura 7.10 fornece o gráfico $F / F_{u}$ versus deslocamento vertical em T4, para todos os modelos com junta serrada. Os dispositivos em forma de disco apresentaram os maiores deslocamentos, em função da porcentagem de força última empregada. Os modelos com espessura de $12 \mathrm{~cm}$, com placas e discos metálicos, foram mais deslocáveis que aqueles com espessura de $16 \mathrm{~cm}$. Para o 
restante dos modelos, não foi possível estabelecer um padrão para os deslocamentos verticais obtidos.

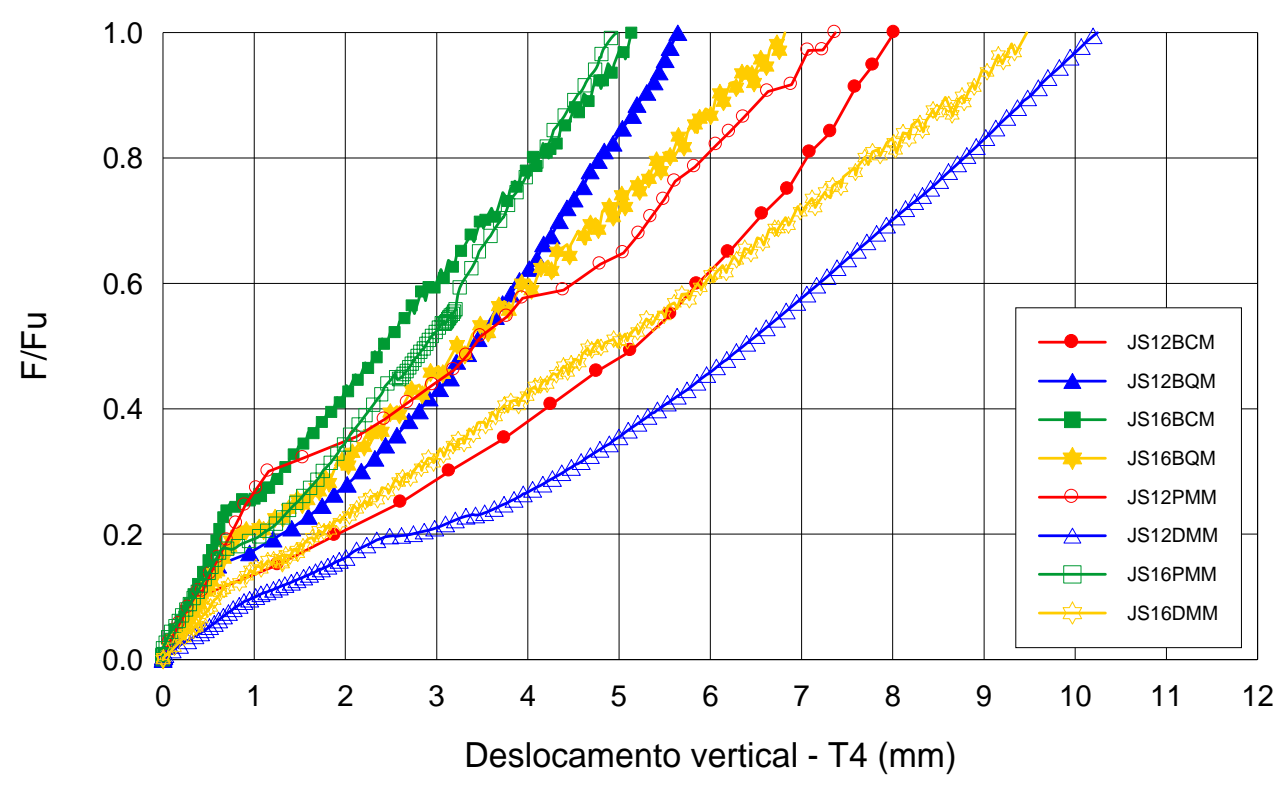

Figura 7.10 - Gráfico $F / F_{u}$ versus deslocamento vertical em $T 4$ - junta serrada

A Figura 7.11 fornece o gráfico $F / F_{u}$ versus deslocamento vertical em T4 para todos os modelos com junta moldada. É visível a maior deslocabilidade dos dispositivos em chapa, e em termos de conforto, essas variações dos deslocamentos das juntas, acima de $F_{\text {fiss }}$, com a passagem do tráfego, pouco são detectadas pelos usuários. 


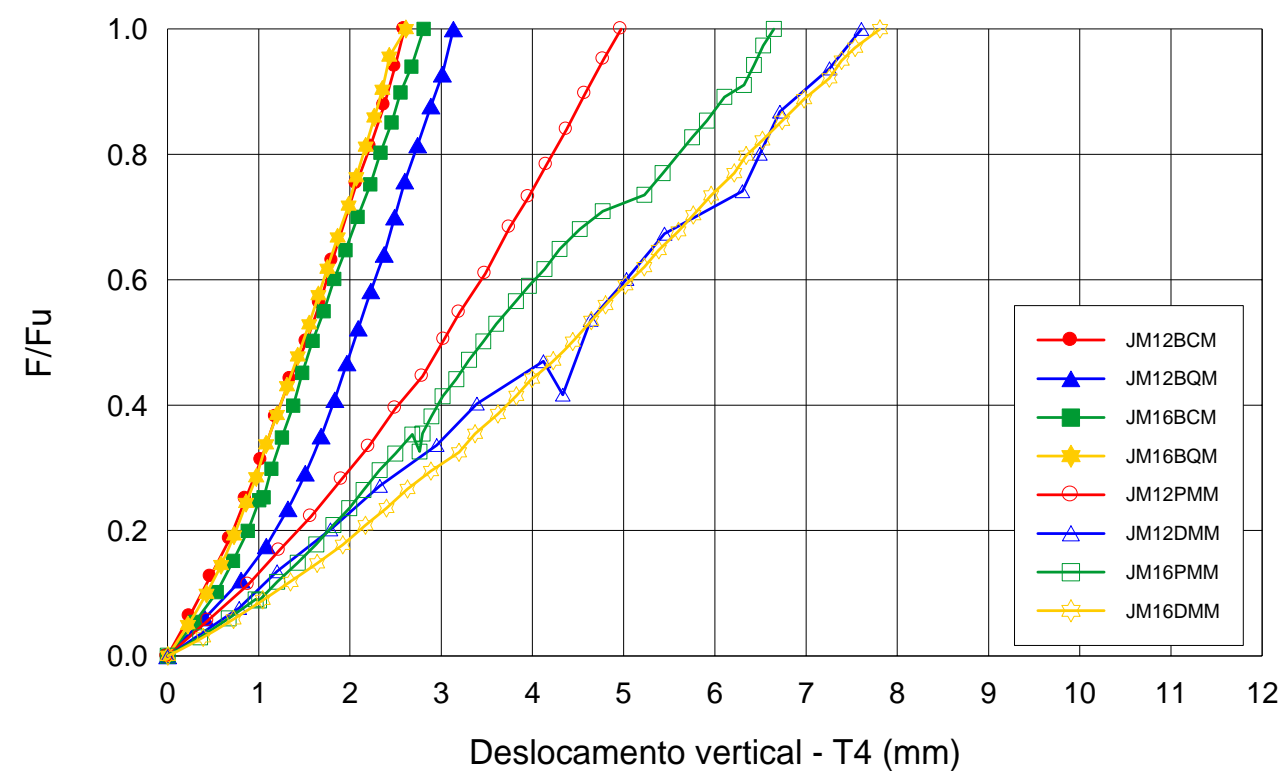

Figura 7.11 - Gráfico $F / F_{u}$ versus deslocamento vertical em T4 - junta moldada

Para um mesmo estágio de carregamento, os modelos com dispositivos em chapa se comportaram de maneira semelhante, em termos de deformações, nos pontos instrumentados. No entanto, os cantos do dispositivo em chapa metálica provavelmente formam pontos de concentração de tensões, que surgem tanto pelo aumento no valor das tensões atuantes, causado pela diminuição da área resistente, como também pela perturbação que a descontinuidade causa. A concentração de tensões resultará na fissuração do núcleo de concreto localizado nessa região, e sua posterior propagação. Essa fissuração propagada, iniciada nos cantos, levará o modelo à ruptura com força inferior à do modelo com dispositivo em forma de disco.

A tipologia da junta pode influenciar na carga de ruptura da peça, uma vez que a presença de concreto abaixo do dispositivo causa variação na rigidez vertical do conjunto, conhecida como interação concreto-barra, dada pela eq.(2.21). A porção de concreto existente abaixo da junta promove uma contribuição no somatório de forças, devida à resistência do concreto, que possibilita que a junta serrada atinja o colapso com forças superiores às das juntas moldadas.

A Tabela 7.2 apresenta as forças últimas para os modelos submetidos a carregamento monotônico. Vale ressaltar que a força última dos modelos com junta moldada era atingida quando os extensômetros, localizados na região central do dispositivo, registravam deformações de escoamento. Variações na resistência do concreto e diminuição da capacidade resistente da fundação, medida pelo 
coeficiente de recalque, podem justificar as variações registradas nas forças de escoamento alcançadas pelos modelos.

Tabela 7.2 - Resumo das forças últimas para juntas serradas e moldadas

\begin{tabular}{|c|c|c|c|c|}
\hline \multirow[t]{2}{*}{ Modelo } & $\begin{array}{c}\text { Força no } \\
\text { escoamento } \\
F_{y}\end{array}$ & $\begin{array}{c}\text { Força última } \\
F_{u}\end{array}$ & \multirow[t]{2}{*}{ Modelo } & $\begin{array}{l}\text { Força última } \\
\qquad F_{u}=F_{y}\end{array}$ \\
\hline & $\mathrm{kN}$ & $\mathrm{kN}$ & & $\mathrm{kN}$ \\
\hline JS12BCM & 81,23 & 100,40 & JM12BCM & 80,2 \\
\hline JS16BCM & 92,84 & 172,24 & JM16BCM & 101,0 \\
\hline JS12BQM & 47,93 & 106,78 & JM12BQM & 86,1 \\
\hline JS16BQM & 104,84 & 189,54 & JM16BQM & 100,6 \\
\hline JS12PMM & - & 74,17 & JM12PMM & 89,9 \\
\hline JS16PMM & 132,58 & 134,59 & JM16PMM & 170,3 \\
\hline JS12DMM & - & 237,91 & JM12DMM & 75,2 \\
\hline JS16DMM & - & 274,41 & JM16DMM & 170,0 \\
\hline
\end{tabular}

Os modelos de referência, JS12SDM e JS16SDM, atingiram a ruptura nas forças de $34,04 \mathrm{kN}$ e $76,45 \mathrm{kN}$, respectivamente. Esses valores foram ambos inferiores às forças últimas dos modelos dotados de dispositivos metálicos para transferência de carregamento.

A comparação entre os resultados obtidos nos ensaios estáticos e cíclicos é apresentada na Tabela 7.3. Para a força de fissuração, apenas JS12PM_ apresentou valores próximos, com $F_{\text {fiss }}$ superior $4,4 \%$ no ensaio cíclico. Em JS16BC_ e JS12DM_, a diferença foi superior a 20\%, e, em ambos os casos, foi maior para os ensaios estáticos. Em JS16BC_ e JS12PM_ a força última no ensaio cíclico ficou entre 25\% e 36\% maior do que no ensaio estático. Em JS12DM_, foi verificada uma queda em torno de $46 \%$ com o emprego dos ciclos de carregamento, se comparada aos valores estáticos. $O F_{u}$ emJS12BC_ foi praticamente o mesmo, com variação de $3 \%$ nos valores estático e cíclico.

Conclui-se desta forma que os ciclos empregados provocaram uma diminuição de $F_{\text {fiss }}$ em parte dos modelos, mas não provocou a diminuição da capacidade resistente das peças, com exceção de JS12DM. 
Tabela 7.3 - Forças em ensaios estáticos e cíclicos

\begin{tabular}{|c|c|c|c|c|}
\hline \multirow{2}{*}{ Modelo } & \multicolumn{2}{|c|}{$\begin{array}{c}\text { Força de fissuração } \\
F_{\text {fiss }}\end{array}$} & \multicolumn{2}{c|}{ Força última } \\
& $F_{u}$ \\
\cline { 2 - 5 } & estático & cíclico* $^{*}$ & estático & cíclico* $^{*}$ \\
\hline JS12BC_ & 10,19 & 17,93 & 100,40 & 97,69 \\
\hline JS16BC_ & 43,09 & 30,32 & 172,24 & 215,85 \\
\hline JS12PM_ & 22,26 & 23,23 & 74,17 & 100,75 \\
\hline JS12DM_ & 22,57 & 17,44 & 237,91 & 128,21 \\
\hline *Após ciclos de carregamento & & \\
\hline
\end{tabular}

Os gráficos força aplicada versus força na célula de carga CEL3, apresentados nas Figura 7.12 e 7.11, fornecem as curvas das forças obtidas em diferentes estágios de carregamento e até a ruptura, para modelos serrados e moldados, em ensaios estáticos. A célula de carga CEL3 estava posicionada do lado não carregado da junta.

Os modelos com dispositivos em barra de seção circular e em disco metálico apresentaram as menores reações, em função da espessura de $16 \mathrm{~cm}$, para um mesmo carregamento. Já os dispositivos de seção quadrada apresentaram as menores reações, em função da tipologia da junta, no caso junta serrada. As reações da fundação nos modelos com dispositivo em placa metálica não apresentaram um comportamento uniforme. 


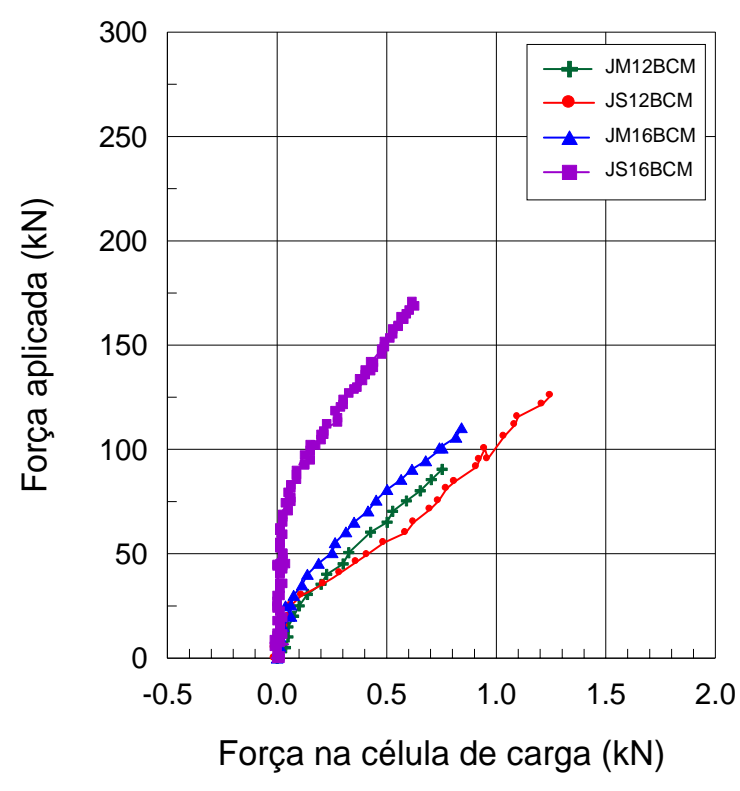

(a)

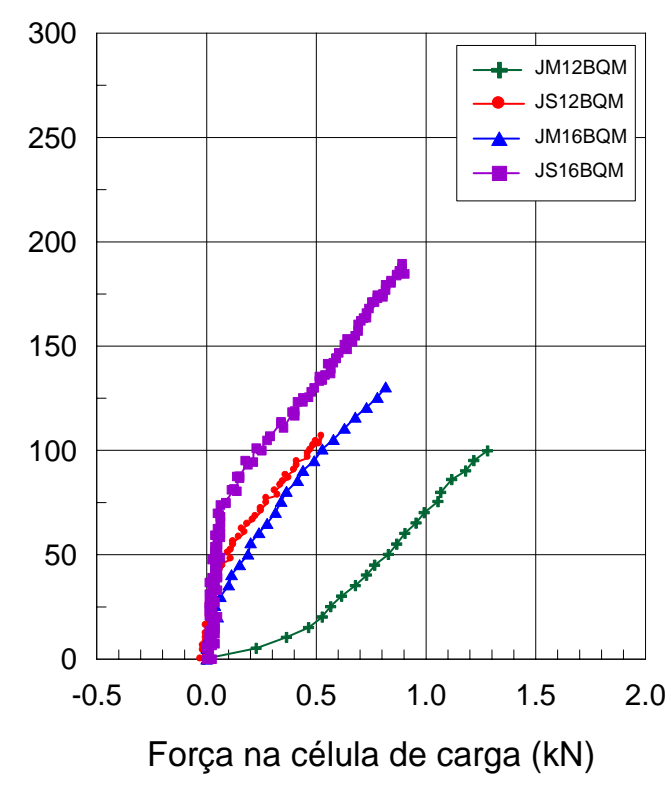

(b)

Figura 7.12 - Gráfico força aplicada versus força em CEL3: (a) barra circular; (b) barra quadrada

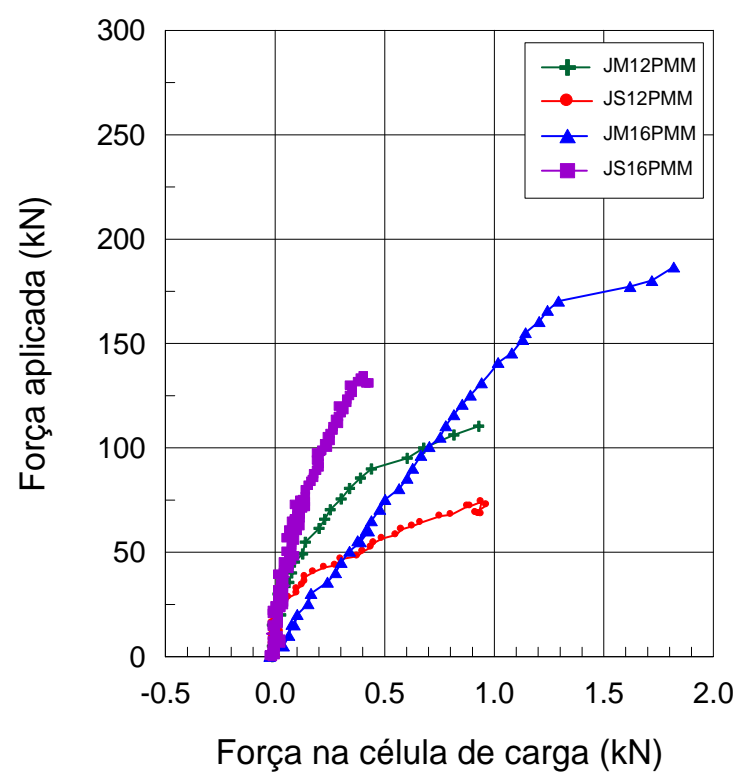

(a)

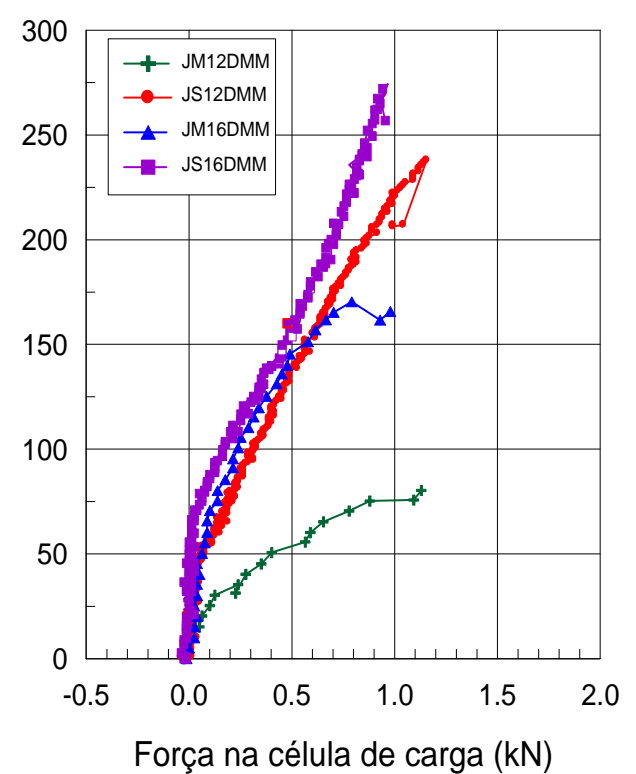

(b)

Figura 7.13 - Gráfico força aplicada versus força em CEL3: (a) placa metálica; (b) disco metálico

A Tabela 7.4 fornece os valores dos deslocamentos verticais no lado carregado, obtidos pela formulação de Westergaard (1928), na eq. (2.10). Uma breve comparação com os experimentos executados em laboratório é apresentada. 
Tabela 7.4 - Relação entre deslocamentos teóricos e experimentais

\begin{tabular}{|c|c|c|c|c|c|c|c|c|}
\hline Modelo & $\begin{array}{c}\text { Módulo de } \\
\text { elasticidade } \\
\text { do concreto } \\
E_{c}\end{array}$ & $\begin{array}{c}\text { Coeficiente } \\
\text { de } \\
\text { recalque }\end{array}$ & Espessura & $\begin{array}{l}\text { raio de } \\
\text { rigidez } \\
\text { relativa }\end{array}$ & $\begin{array}{l}\text { Força } \\
\text { última }\end{array}$ & $\begin{array}{c}\text { yteo }^{[1]} \\
\text { Westergaard } \\
(1928)\end{array}$ & $\mathrm{Y}_{\exp }$ & $y_{\text {teo }} / y_{\exp }$ \\
\hline & $\mathrm{MPa}$ & $\mathrm{MPa} / \mathrm{m}$ & $\mathrm{m}$ & $\mathrm{m}$ & $\mathrm{kN}$ & $\mathrm{mm}$ & $\mathrm{mm}$ & $\mathrm{mm} / \mathrm{mm}$ \\
\hline PJS12BCM & 23.400 & 165 & 0,12 & 0,38 & 280,00 & 2,28 & 6,66 & 0,34 \\
\hline JS12BCM & 31.429 & 185 & 0,12 & 0,40 & 100,40 & 0,70 & 7,86 & 0,09 \\
\hline JS12BQM & 31.173 & 185 & 0,12 & 0,40 & \begin{tabular}{|l|}
106,78 \\
\end{tabular} & 0,75 & 6,07 & 0,12 \\
\hline JS12PMM & 31.173 & 185 & 0,12 & 0,40 & 74,17 & 0,52 & 9,80 & 0,05 \\
\hline JS12DMM & 29.053 & 156 & 0,12 & 0,41 & 237,91 & 1,93 & 11,03 & 0,18 \\
\hline JS16BCM & 27.594 & 156 & 0,16 & 0,50 & 172,24 & 1,11 & 10,03 & 0,11 \\
\hline JS16BQM & 27.849 & 156 & 0,16 & 0,50 & 189,54 & 1,22 & 8,85 & 0,14 \\
\hline JS16PMM & 29.070 & 155 & 0,16 & 0,51 & \begin{tabular}{|l|}
134,59 \\
\end{tabular} & 0,86 & 5,15 & 0,17 \\
\hline JS16DMM & 27.338 & 156 & 0,16 & 0,50 & 274,41 & 1,78 & 11,53 & 0,15 \\
\hline JM12BCM & 33.951 & 185 & 0,12 & 0,41 & 80,15 & 0,55 & 3,40 & 0,16 \\
\hline JM12BQM & 34.103 & 185 & 0,12 & 0,41 & 86,12 & 0,59 & 4,87 & 0,12 \\
\hline JM12PMM & 35.015 & 185 & 0,12 & 0,41 & 89,88 & 0,61 & - & \\
\hline JM12DMM & 34.863 & 185 & 0,12 & 0,41 & 75,19 & 0,51 & 9,32 & 0,06 \\
\hline JM16BCM & 34.407 & 185 & 0,16 & 0,50 & \begin{tabular}{|l|}
100,63 \\
\end{tabular} & 0,54 & 3,67 & 0,15 \\
\hline JM16BQM & 34.863 & 185 & 0,16 & 0,51 & 100,63 & 0,54 & 3,46 & 0,16 \\
\hline JM16PMM & 34.255 & 185 & 0,16 & 0,50 & |170,30 & 0,91 & 9,94 & 0,09 \\
\hline JM16DMM & 33.078 & 185 & 0,16 & 0,50 & 170,02 & 0,92 & 11,99 & 0,08 \\
\hline JS12SDM & 32.196 & 185 & 0,12 & 0,40 & 34,04 & 0,24 & 3,44 & 0,07 \\
\hline JS16SDM & 31.429 & 185 & 0,16 & 0,49 & 76,45 & 0,42 & 3,56 & 0,12 \\
\hline JS12BCC & 29.171 & 153 & 0,12 & 0,41 & 97,70 & 0,80 & 4,43 & 0,18 \\
\hline JS12PMC & 30.639 & 153 & 0,12 & 0,41 & \begin{tabular}{|l|}
100,75 \\
\end{tabular} & 0,82 & 4,03 & 0,20 \\
\hline JS12DMC & 30.094 & 153 & 0,12 & 0,41 & 128,21 & 1,05 & 7,74 & 0,14 \\
\hline JS16PMC & 29.112 & 153 & 0,16 & 0,51 & 215,85 & 1,39 & 13,88 & 0,10 \\
\hline
\end{tabular}

A metodologia segundo Westergaard (1928), empregada para a determinação dos deslocamentos verticais, apresentou resultados com grande dispersão em relação aos deslocamentos obtidos experimentalmente. Os resultados teóricos subestimam os deslocamentos verticais obtidos, independentemente do tipo de junta empregada. 


\subsection{REAÇÕES DE APOIO}

Com o objetivo de verificar a transferência de forças em cada lado da junta foram calculadas as resultantes da reação na fundação, sugerida por Fleury (2006) em seu estudo de transferência de esforços em juntas armadas.

O cálculo das resultantes experimentais $R_{L}$ e $R_{u}$ foi realizado a partir das leituras obtidas nas células de carga CEL2 e CEL3, respectivamente, considerando a linearidade das tensões.

$$
\begin{aligned}
& R_{u}=c \cdot C_{u} \cdot L_{u} \\
& R_{L}=c \cdot C_{L} \cdot L_{L}
\end{aligned}
$$

onde $R_{u}$ é a resultante experimental do lado não carregado; $C_{u}$ é a leitura na célula de carga do lado não carregado (CEL3); $L_{u}$ é o comprimento de parte da placa apoiada na fundação do lado não carregado; $R_{L}$ é a resultante experimental do lado carregado; $C_{L}$ é a leitura na célula de carga do lado carregado (CEL2); $L_{L}$ é o comprimento de parte da placa apoiada na fundação do lado carregado; e $c$ é a constante referente à forma de distribuição da resultante e igual a $1 / 2$ para reação triangular.

Dividindo-se $R_{u}$ por $R_{L}$ e rearranjando os termos, tem-se que:

$$
\frac{R_{u}}{C_{u} \cdot L_{u}}=\frac{R_{L}}{C_{L} \cdot L_{L}}
$$

Através do equilíbrio de forças na direção vertical, e desprezando o peso próprio das placas, tem-se que:

$$
R_{u}+R_{L}=F
$$

onde $F$ é a força aplicada.

Para a determinação de $L_{u}$ e $L_{L}$ foram utilizados os deslocamentos verticais obtidos pelos transdutores, como apresentado na Figura 7.14. Por semelhança de triângulo, 
e sendo conhecidos T1, T4 $\left(d_{u}\right)$, T6 $\left(d_{L}\right)$ e T8, determinou-se o comprimento da porção da placa apoiada na fundação, para cada intensidade de força requerida.

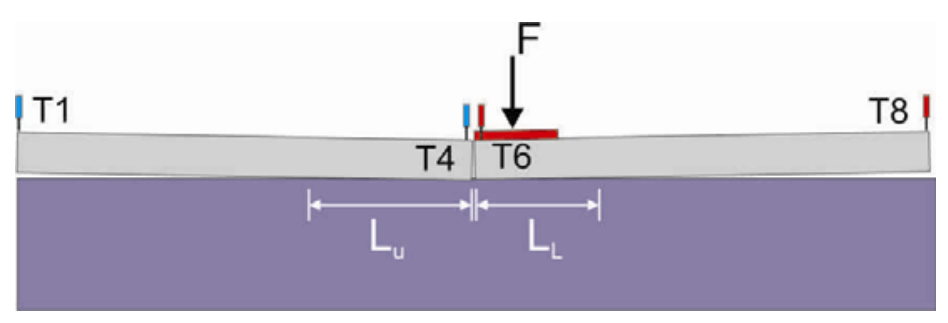

Figura 7.14 - Configuração deformada dos modelos

O primeiro cálculo das resultantes teóricas $R_{u, t e o}$ e $R_{L, t e o}$ considerou a reação da fundação triangular, como apresentada na Figura 7.15.

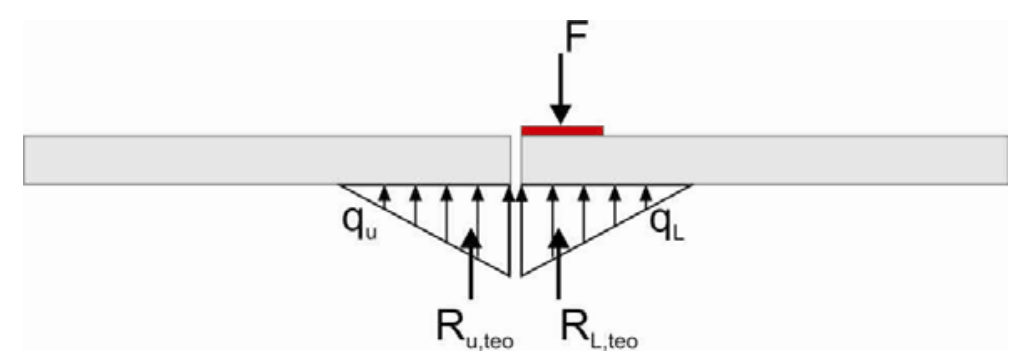

Figura 7.15 - Forças atuantes consideradas para reação triangular

A eq.(7.5) fornece a relação entre as resultantes e as reações da fundação.

$$
\frac{R_{u, \text { teo }}}{q_{u} \cdot L_{u}}=\frac{R_{L, \text { teo }}}{q_{L} \cdot L_{L}}
$$

onde $q$ é a reação da fundação.

Westergaard (1926) propôs que a reação da fundação por unidade de área para qualquer ponto dado é igual à constante $k$ multiplicada pelo deslocamento vertical de qualquer ponto, como visualizado na eq.(7.6). Assume-se que $k$ é constante para cada ponto, independentemente do deslocamento. 


$$
q=k \cdot d
$$

onde $k$ é o coeficiente de recalque ou módulo de Westergaard; $d$ é o deslocamento vertical, obtido pela leitura de transdutor posicionado na junta.

Substituindo a eq.(7.6) em eq. (7.5) tem-se que:

$$
\frac{R_{u, t e o}}{k \cdot d_{u} \cdot L_{u}}=\frac{R_{L, t e o}}{k \cdot d_{L} \cdot L_{L}}
$$

Eliminando os termos comuns, $k$, obtém-se:

$$
\frac{R_{u, t e o}}{d_{u} \cdot L_{u}}=\frac{R_{L, t e o}}{d_{L} \cdot L_{L}}
$$

O segundo cálculo das resultantes teóricas $R_{u, t e o}$ e $R_{L, t e o}$ considerou a reação da fundação como parabólica, como apresentado na Figura 7.16.

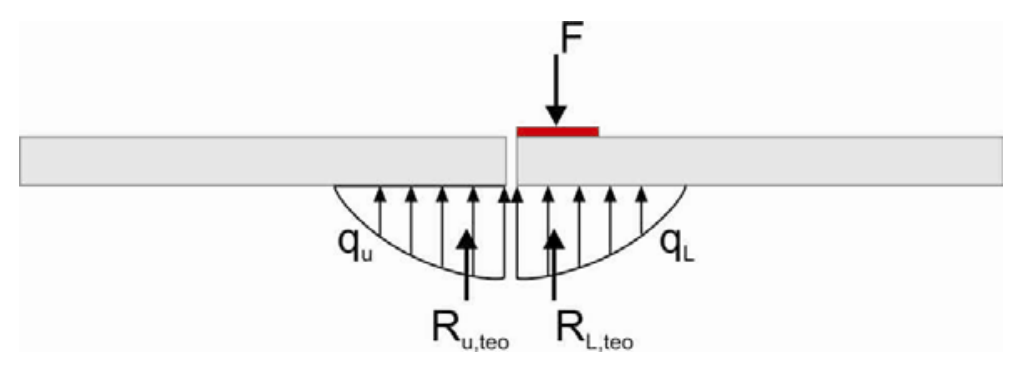

Figura 7.16 - Forças atuantes consideradas para reação parabólica

Considerando-se a reação parabólica, tem-se que:

$$
\frac{R_{u, t e o}}{d_{u}{ }^{2} \cdot L_{u}}=\frac{R_{L, t e o}}{d_{L}^{2} \cdot L_{L}}
$$

Nos dois métodos teóricos foi considerado que:

$$
R_{u, \text { teo }}+R_{L, t e o}=F
$$


As reações resultantes da fundação, teóricas e experimentais, na ruptura, são apresentadas na Tabela 7.5. A célula CEL2 de JS12PMC e o transdutor T6 em JM12PMM apresentaram problemas, inviabilizando o cálculo das resultantes nos dois modelos.

Os métodos teóricos apresentaram boa proximidade entre as resultantes apenas para as juntas serradas, com distribuição de tensão aproximadamente triangular. Nas juntas moldadas, para a mesma distribuição, os resultados não foram bons para a resultante do lado não carregado $R_{u, t e o}$. A distribuição de tensão aproximadamente parabólica permitiu bons resultados para os dois tipos de junta. O Apêndice A apresenta um exemplo de cálculo para determinação das resultantes. 
Tabela 7.5 - Resultantes teóricas e experimentais da fundação

\begin{tabular}{|c|c|c|c|c|c|c|c|c|c|c|}
\hline \multirow[b]{2}{*}{ Modelo } & \multicolumn{2}{|c|}{ Experimental } & \multicolumn{4}{|c|}{ Teórico $1^{\circ}$ método } & \multicolumn{4}{|c|}{ Teórico $2^{\circ}$ método } \\
\hline & $R_{u}$ & $R_{L}$ & $R_{u, \text { teo }}$ & $R_{L, \text { teo }}$ & $\frac{R_{u \text {,teo }}}{R_{u}}$ & $\frac{R_{L, \text { teo }}}{R_{L}}$ & $R_{u, \text { teo }}$ & $R_{L, \text { teo }}$ & $\frac{R_{u, t e o}}{R_{u}}$ & $\frac{R_{L, \text { teo }}}{R_{L}}$ \\
\hline JS12BCM & 35,80 & 64,60 & 34,60 & 65,80 & 0,94 & 1,03 & 32,96 & 67,44 & 0,90 & 1,06 \\
\hline JS12BQM & 36,72 & 70,06 & 35,52 & 71,26 & 0,85 & 1,10 & 31,92 & 74,86 & 0,76 & 1,16 \\
\hline JS12PMM & 22,77 & 51,40 & 21,06 & 53,11 & 0,72 & 1,19 & 16,74 & 57,43 & 0,57 & 1,28 \\
\hline JS12DMM & 42,91 & 195,00 & 50,60 & 187,31 & 0,77 & 1,09 & 47,71 & 190,20 & 0,72 & 1,11 \\
\hline JS16BCM & 54,99 & 117,25 & 55,39 & 116,85 & 0,58 & 1,52 & 39,27 & 132,97 & 0,41 & 1,72 \\
\hline JS16BQM & 57,93 & 131,61 & 57,93 & 131,61 & 0,72 & 1,21 & 47,98 & 141,56 & 0,59 & 1,30 \\
\hline JS16PMM & 29,52 & 105,07 & 27,53 & 107,06 & 1,02 & 1,00 & 26,79 & 107,80 & 0,99 & 1,00 \\
\hline JS16DMM & 88,01 & 186,40 & 73,58 & 200,83 & 0,90 & 1,04 & 63,49 & 210,92 & 0,78 & 1,09 \\
\hline JM12BCM & 7,49 & 72,71 & 24,53 & 55,67 & 0,39 & 3,11 & 19,65 & 60,55 & 0,32 & 3,38 \\
\hline JM12BQM & 6,58 & 79,52 & 23,30 & 62,80 & 0,34 & 3,59 & 16,76 & 69,34 & 0,24 & 3,96 \\
\hline JM12PMM & - & - & - & - & - & - & - & - & - & - \\
\hline JM12DMM & 28,11 & 47,09 & 23,14 & 52,06 & 0,94 & 1,03 & 20,18 & 55,02 & 0,82 & 1,09 \\
\hline JM16BCM & 15,07 & 85,93 & 31,71 & 69,29 & 0,46 & 2,20 & 25,42 & 75,58 & 0,37 & 2,40 \\
\hline JM16BQM & 12,41 & 88,19 & 25,95 & 74,65 & 0,41 & 2,04 & 19,73 & 80,87 & 0,31 & 2,21 \\
\hline JM16PMM & 48,57 & 121,73 & 37,98 & 132,32 & 0,71 & 1,13 & 27,59 & 142,71 & 0,52 & 1,22 \\
\hline JM16DMM & 61,57 & 108,43 & 41,87 & 128,13 & 0,82 & 1,08 & 30,28 & 139,72 & 0,59 & 1,17 \\
\hline JS12SDM & 15,26 & 18,78 & 9,70 & 24,34 & 0,90 & 1,05 & 7,00 & 27,04 & 0,65 & 1,16 \\
\hline JS16SDM & 16,99 & 59,46 & 25,05 & 51,40 & 0,61 & 1,45 & 22,35 & 54,10 & 0,55 & 1,53 \\
\hline JS12BCC & 57,22 & 40,47 & 50,39 & 47,30 & 1,54 & 0,73 & 51,94 & 45,75 & 1,59 & 0,70 \\
\hline JS12PMC & - & - & 49,29 & 51,46 & - & - & 48,20 & 52,55 & - & - \\
\hline JS12DMC & 43,09 & 85,12 & 58,19 & 70,02 & 0,85 & 1,18 & 52,38 & 75,83 & 0,76 & 1,27 \\
\hline JS16BCC & 51,61 & 164,24 & 81,42 & 134,43 & 0,69 & 1,38 & 57,93 & 157,92 & 0,49 & 1,62 \\
\hline
\end{tabular}

*Resultados em kN 
A Tabela 7.6 fornece a relação entre a força última e a resultante da reação do lado não carregado, seja teórica e experimental.

Tabela 7.6 - Forças transmitidas no lado não carregado da junta

\begin{tabular}{|c|c|c|c|c|}
\hline & & Experimental & Teórico $1^{\circ}$ método & Teórico $2^{\circ}$ método \\
\hline Modelo & $F_{u}$ & $\frac{R_{u}}{F_{u}}$ & $\frac{R_{u, \text { teo }}}{F_{u}}$ & $\frac{R_{u, \text { teo }}}{F_{u}}$ \\
\hline JS12BCM & 100,4 & 0,37 & 0,34 & 0,33 \\
\hline JS12BQM & 106,78 & 0,39 & 0,33 & 0,30 \\
\hline JS12PMM & 74,17 & 0,40 & 0,28 & 0,23 \\
\hline JS12DMM & 237,91 & 0,28 & 0,21 & 0,20 \\
\hline JS16BCM & 172,24 & 0,55 & 0,32 & 0,23 \\
\hline JS16BQM & 189,54 & 0,43 & 0,31 & 0,25 \\
\hline JS16PMM & 134,59 & 0,20 & 0,20 & 0,20 \\
\hline JS16DMM & 274,41 & 0,30 & 0,27 & 0,23 \\
\hline JM12BCM & 80,2 & 0,78 & 0,31 & 0,25 \\
\hline JM12BQM & 86,1 & 0,80 & 0,27 & 0,19 \\
\hline JM12PMM & 89,9 & - & - & - \\
\hline JM12DMM & 75,2 & 0,33 & 0,31 & 0,27 \\
\hline JM16BCM & 101 & 0,69 & 0,31 & 0,25 \\
\hline JM16BQM & 100,6 & 0,64 & 0,26 & 0,20 \\
\hline JM16PMM & 170,3 & 0,31 & 0,22 & 0,16 \\
\hline JM16DMM & 170 & 0,30 & 0,25 & 0,18 \\
\hline JS12SDM & 34,04 & 0,32 & 0,28 & 0,21 \\
\hline JS16SDM & 76,45 & 0,54 & 0,33 & 0,29 \\
\hline JS12BCC & 97,69 & 0,34 & 0,52 & 0,53 \\
\hline JS12PMC & 100,75 & - & 0,49 & 0,48 \\
\hline JS12DMC & 128,21 & 0,54 & 0,45 & 0,41 \\
\hline JS16BCC & 215,85 & 0,55 & 0,38 & 0,27 \\
\hline
\end{tabular}


Westergaard (1928) concluiu que cada lado da junta transmitiria $\frac{P}{2}$ para barras ativas na transferência, ou seja, 0,50 F. As reações do lado não carregado, apresentadas na Tabela 7.6, são equivalentes, em média, a 0,34 F . 


\section{CAPÍTULO 8}

\section{CONCLUSÕES E RECOMENDAÇÕES}

O objetivo desta tese de doutorado é o estudo do comportamento estrutural de juntas transversais de pavimentos de concreto simples, quando submetidas a carregamentos monotônico e repetido, em um dos lados da junta. Os modelos ensaiados para carregamento repetido foram avaliados sob carga de serviço.

Foram analisadas juntas serradas e moldadas, por meio de ensaios experimentais, avaliando a influência de alguns parâmetros na resposta do pavimento às solicitações.

Em sua totalidade, foram confeccionados 23 modelos em concreto simples, que simulavam frações de uma pista trafegável de pavimento de concreto. Essas partes, compostas por duas placas justapostas, eram interligadas por dispositivos que serviam de pontos de transferência de esforços, posicionados sob o lugar de junção desses elementos: a junta. Os modelos foram apoiados em solo deformável, simulado por camadas de borracha natural.

A análise dos resultados baseou-se nas relações força aplicada versus deslocamento vertical, força aplicada versus deformação, eficiência e F/Fu versus deslocamento vertical.

\subsection{CONCLUSÕES}

As principais conclusões advindas desta pesquisa são destacadas a seguir.

- Os dispositivos com barra em modelos serrados apresentaram, durante os ensaios estáticos, um comportamento bastante similar em termos de eficiência. O disco metálico apresentou uma eficiência superior para ambas as espessuras, se comparado à placa metálica introduzida na junta.

- Após o emprego dos ciclos de carregamento, nos ensaios estáticos subseqüentes, a barra circular e a placa metálica apresentaram um comportamento similar, 
embora apresentassem taxa de armadura e comprimento de embutimento diferentes. Já entre os modelos com barra circular e espessuras de $12 \mathrm{~cm}$ e $16 \mathrm{~cm}$, verificou-se uma diferença inexpressível na eficiência, se comparada ao ganho na resistência proporcionada pelo aumento da espessura.

- Os modelos com juntas moldadas apresentaram, desde o início do carregamento, queda progressiva da eficiência, devido à solicitação empreendida no dispositivo. Os dispositivos em chapa apresentaram comportamento bastante similar, com eficiência final próxima a $80 \%$. Para a espessura de $12 \mathrm{~cm}$, a barra de seção circular apresentou maior eficiência, se comparada à de seção quadrada. Para a espessura de $16 \mathrm{~cm}$, a eficiência de ambas se aproximou a $80 \%$, ao atingirem a força última.

- As juntas moldadas apresentaram menores eficiências e forças últimas, em relação às juntas serradas, desde o início do carregamento.

- Em geral, o disco metálico proporcionou forças últimas e deslocamentos verticais superiores aos dos demais tipos de dispositivos, sem, no entanto caracterizar perda substancial em sua eficiência. Ao contrário, em situação de serviço e acima de $F_{\text {fiss }}$, o modelo JS12DMC permaneceu com valores acima de $95 \%$, chegando a $100 \%$.

- A concentração de tensões nos cantos dos dispositivos em placa metálica resultou na fissuração do núcleo de concreto localizado nessa região, e sua posterior propagação. Essa fissuração propagada, iniciada nos cantos, levou o modelo à ruptura com força inferior à do modelo com dispositivo em forma de disco.

- As reações máximas verificadas com as células de carga posicionadas no interior da camada de borracha representaram menos de $2 \%$ das forças últimas atingidas. Em geral a célula de carga CEL1 apresentou leituras próximas a zero. Este comportamento indica que houve levantamento excessivo do lado não carregado, capaz de diminuir o contato entre a face da placa, neste ponto, e a superfície da fundação. O início do escoamento em pontos dos dispositivos pôde ser detectado com a mudança de inclinação na curva força aplicada versus força na célula de carga.

- O concreto que envolve a região central do dispositivo em chapa (chapa metálica e disco metálico) provocou uma mudança da localização das maiores 
deformações. Como a área envolvida por concreto nos dispositivos em barra é menor, não foram detectadas mudanças nas regiões de deformações máximas, uma vez que todas, em geral, foram lidas em AS3D. Para as juntas serradas, as maiores deformações, que levaram ao escoamento do aço, foram verificadas em AS3D, cerca de $4,7 \mathrm{~cm}$ da face da junta. A região central do dispositivo em barra (AS2D) na junta apresentou deformações inferiores, porém próximas ao escoamento. Após a fissuração do concreto o início da ruína dos modelos surgiu em AS3D seguido de AS2D. Para as juntas moldadas, a região central do dispositivo em barra (AS2D) não apresentou as maiores deformações, embora estivesse localizada na junta. As deformações no escoamento do aço foram verificadas em AS3D, cerca de $2,2 \mathrm{~cm}$ da face da junta, assinalando que os modelos entravam em ruína muito antes de surgir escoamento no centro.

- Os modelos apresentaram modo de ruína devido predominantemente a forças de tração na flexão e ruptura do concreto à compressão na fibra superior do modelo.

- Em geral, os modelos exibiram fissuras transversais inclinadas, alinhadas com as juntas das placas, sob a placa de distribuição de carga. Na vista lateral dos modelos com junta serrada, fissuras predominantemente coplanares e curvas se formaram, enquanto que nos modelos com junta moldada, foram verificadas fissuras inclinadas. Após o emprego dos ciclos de carregamento, na etapa estática monotônica, foi verificada uma maior propagação das fissuras sob o ponto de aplicação da força, evidenciando maiores danos nas faces laterais dos modelos.

- De maneira geral, o acréscimo na espessura do pavimento aumenta sua capacidade resistente, para os dois tipos de junta. No entanto, para a mesma área da seção transversal do dispositivo, este aumento da espessura leva a uma maior solicitação do dispositivo. Em conseqüência, verifica-se uma queda maior da eficiência do sistema. Para que isto seja evitado, é necessário um aumento dessa área de aço, de maneira a aumentar a eficiência do conjunto com o aumento da espessura.

- Não foram verificados danos por fadiga, nos modelos submetidos até 300.000 ciclos de carregamento. $\mathrm{O}$ aumento do número de ciclos, com valores acima de $10^{6}$ ciclos, poderia fornecer mais informações a respeito de danos ou queda da resistência e da eficiência do sistema. Infelizmente, os ensaios com maior número 
de ciclos de carregamento não puderam ser feitos, por falta de disponibilidade no cronograma do Laboratório.

- Os ciclos de carregamento empregados provocaram uma diminuição de $F_{\text {fiss }}$ em parte dos modelos, mas não provocou a diminuição da capacidade resistente das peças.

- O emprego dos corpos-de-prova prismáticos, submetidos a cisalhamento duplo, pode ser sugerido como referência no comportamento de juntas serradas e na previsão de forças últimas, quando não existirem outros parâmetros para sua determinação.

- Westergaard (1928) concluiu que cada lado da junta transmitiria $\frac{P}{2}$ para barras ativas na transferência, ou seja, 0,50 F. As reações verificadas no estudo foram equivalentes, em média, a $0,28 F$.

- O modelo numérico desenvolvido apresentou resultados próximos aos obtidos experimentalmente. No entanto, atingiu a força última com valores abaixo do esperado, além de alterar significativamente os valores de $E_{c}$ e $\mathrm{k}$. Para que isto não ocorra, o perfil deformado da junta, obtido por curvas distância versus deslocamento vertical, em conjunto com a rigidez da fundação, para diferentes estágios de carregamento, deverão constituir dados para uma retroanálise.

\subsection{RECOMENDAÇÕES}

As juntas moldadas devem ser empregadas apenas em situações em que o emprego da junta serrada não seja possível, visto que a eficiência das juntas moldadas é inferior e sua suscetibilidade ao colapso, maior.

Recomenda-se empregar a junta armada em no lugar da junta sem dispositivo, para se obter maior vida útil do pavimento, com menos patologias associadas ao aspecto estrutural, como fissuras, surgidas principalmente devido a forças de tração na flexão, e grande deslocabilidade da junta. Esta deslocabilidade pode provocar o surgimento de escalonamento entre as placas.

Sugere-se empregar a extensometria na superfície de concreto em pontos distantes da abertura da junta, já que nesta região, e principalmente no eixo y (paralelo ao 
eixo da junta), as leituras foram próximas de zero. Já nos dispositivos metálicos, o estudo pode ser realizado na região central, em até cerca de $5 \mathrm{~cm}$ de cada lado do centro. Pontos mais distantes apresentam leituras inferiores às do limite de escoamento adotado, e geralmente, próximas de zero.

O disco metálico, em função dos dados coletados, apresentou o melhor desempenho em relação aos demais, e é sugerido como o dispositivo de transferência preferencial para se obter uma maior eficiência do sistema. A barra de seção circular pode ser empregada sem grandes prejuízos na deslocabilidade da junta, porém sem apresentar os mesmos benefícios relativos a eficiência, forças aplicadas ou deformações.

\subsection{SUGESTÕES PARA TRABALHOS FUTUROS}

Com a finalidade de melhorar o conhecimento a respeito do comportamento das juntas em placas de concreto para pavimentação, algumas sugestões de pesquisas são apresentadas a seguir.

- Estudar uma relação baseada na área de aço do dispositivo, capaz de promover o aumento da eficiência do conjunto, ao ser aumentada a espessura do modelo.

- Considerar o conforto do usuário ao trafegar nas pistas, tendo como parâmetro os deslocamentos da junta, segundo a metodologia da AASHTO (1993).

- Avaliar o parâmetro eficiência na transferência de carga segundo as reações da fundação ao carregamento imposto, diferentemente do empregado, que era segundo os deslocamentos obtidos.

- Empregar um maior número de ciclos de carregamento, para identificação de fadiga nos modelos e eventuais patologias decorrentes.

- Sugere-se ainda que os estudos subseqüentes desenvolvam modelos apoiados em fundação dotada de diferentes camadas, sejam elas base, sub-base e camada rígida, variando-se a espessura do revestimento. Além disso, realizar controle laboratorial da base de argamassa utilizada para o assentamento das placas.

- Utilizar os espaçadores dos dispositivos, em forma de treliça, para verificação de sua influência no comportamento do sistema. 
- Propor um conjunto de equações que simulem o comportamento das juntas submetidas a carregamentos verticais monotônico e cíclico, para placas de concreto simples (modelagem);

- Realizar estudo paramétrico, utilizando modelos numéricos, variando a espessura da placa; posicionamento, número, seção transversal e dimensão dos dispositivos de transferência, resultando em uma maior amostragem do comportamento do pavimento, a um custo menor que aquele obtido apenas por ensaios laboratoriais.

- Realizar análise numérica empregando-se elementos shell para modelar o dispositivo em chapa no interior da matriz de concreto, e utilizar elementos em barra para discretizar os dispositivos lineares.

- Realizar estudo em modelos de verdadeira grandeza, como pistas experimentais, para se obter informações importantes a respeito do comportamento do pavimento, em virtude da mudança na mecânica do sistema de forças e das variações do clima. 


\section{BIBLIOGRAFIA}

AMERICAN ASSOCIATION OF STATE HIGHWAY AND TRANSPORTATION OFFICIALS - AASHTO (1993). Guide for design of pavement structures. Washington, DC.

AMERICAN CONCRETE PAVEMENT ASSOCIATION - ACPA (1991). Design and construction of joints for concrete highways (ISO60-01P). Concrete Paving Technology, Portland Cement Association.

ASSOCIAÇÃO BRASILEIRA DE NORMAS TÉCNICAS. NBR 5738:2003. Concreto Procedimento para moldagem e cura de corpos-de-prova. Rio de Janeiro.

ASSOCIAÇÃO BRASILEIRA DE NORMAS TÉCNICAS. NBR 5739:2007. Concreto Ensaio de compressão de corpos-de-prova cilíndricos. Rio de Janeiro.

ASSOCIAÇÃO BRASILEIRA DE NORMAS TÉCNICAS. NBR 7222:1994. Argamassa e concreto - Determinação da resistência à tração por compressão diametral de corpos-de-prova cilíndricos. Rio de Janeiro.

ASSOCIAÇÃO BRASILEIRA DE NORMAS TÉCNICAS. NBR 8522:2003. Concreto Determinação dos módulos estáticos de elasticidade e de deformação e da curva tensão-deformação. Rio de Janeiro.

ASSOCIAÇÃO BRASILEIRA DE NORMAS TÉCNICAS. NBR 8800:1986. Projeto e execução de estruturas de aço e de estruturas mistas aço-concreto de edifícios: Procedimento. Rio de Janeiro.

ASSOCIAÇÃO BRASILEIRA DE NORMAS TÉCNICAS. NBR 12142:1991. Concreto - Determinação da resistência à tração na flexão em corpos-de-prova prismáticos. Rio de Janeiro.

ASSOCIAÇÃO BRASILEIRA DE NORMAS TÉCNICAS. NBR 6118:2003. Projeto de estruturas de concreto: Procedimento. Rio de Janeiro. 
ASSOCIAÇÃO BRASILEIRA DE NORMAS TÉCNICAS. NBR 6892:2002. Materiais metálicos - Ensaio de tração à temperatura ambiente. Rio de Janeiro.

ASSOCIAÇÃO BRASILEIRA DE NORMAS TÉCNICAS. NBR NM67:1998. Concreto - Determinação da consistência pelo abatimento do tronco de cone. Rio de Janeiro.

AMERICAN SOCIETY FOR TESTING AND MATERIALS - ASTM A36:1997. Standard Specification for Carbon Structural Steel.

AMERICAN SOCIETY FOR TESTING AND MATERIALS - ASTM D575:2001. Standard Test Method for Rubber Property in Compression.

AMERICAN SOCIETY FOR TESTING AND MATERIALS - ASTM D395:2003 Standard Test Method for Rubber Property - Compression Set.

AMERICAN SOCIETY FOR TESTING AND MATERIALS - ASTM D2240:2005. Standard Test Method for Rubber Property - durometer hardness.

AZIZ, N.; JALALIFAR, H. Reinforced fully grouted rock joints with doublé shear apparatus (DSA). Research project. University of Wollongong. 2p. Disponível em: $<$ http://www.uow.edu.au/eng/research/aseacm/doubleshearbolts.pdf> Acesso em: 1 jun. 2007.

BALBO, J. T. (1999). Contribuição à análise estrutural de reforços com camadas ultradelgadas de concreto de cimento Portland sobre pavimentos asfálticos. Tese (livre-docência), Escola Politécnica da Universidade de São Paulo, São Paulo.

BRADBURY, R. D. (1932). Design of joints in concrete pavements. Highway Research Board, Proceedings, n.12, p.105-141.

BUCH, N.; ZOLLINGER, D. G. (1996). Development of dowel looseness prediction model for jointed concrete pavements. Transportation Research Record, v.1525, p.21-27.

BURMISTER, D. M. (1943). The theory of stresses and displacements in layered systems and applications to the design of airport runways. Highway Research Board, Proceedings, p.126-148. 
CANHA, R. M. (2004). Estudo teórico-experimental da ligação pilar-fundação por meio de cálice em estruturas de concreto pré-moldado. Tese (Doutorado) Escola de Engenharia de São Carlos, Universidade de São Paulo, São Carlos.

CERVO, T. C. (2004). Estudo da resistência à fadiga de concreto de cimento portland para pavimentação. São Paulo. Tese (doutorado) - Escola Politécnica da Universidade de São Paulo, São Paulo.

CHANNAKESHAVA, C.; BARZEGAR, F.; VOYIADJIS, G. Z. (1993). Nonlinear FE analysis of plain concrete pavements with doweled joints. Journal of Transportation Engineering, v.119, n.5, p. 763-781, Sep-Oct.

COLLEY, B.; HUMPHREY, H. (1967). Aggregate interlock at joints in concrete pavements. Highway Research Record, n.189, p.18.

DANLEY CONSTRUCTION PRODUCTS (2000). Jointing system in concrete structures. Disponível em: <http://www.danley.com.au/rnd.html>. Acesso em: 20 jun. 2006.

DAVIDS, W. G; TURKIYYAH, G. M.; MAHONEY, J. P. (1998). EverFE - Rigid pavement three-dimensional finite element analysis tool. Transportation Research Record, v.1629, p.41-49.

DAVIDS, W. G; MAHONEY, J. P. (1999). Experimental verification of rigid pavement joint load transfer modeling with EverFE. Transportation Research Record, v.1684, p.81-89.

DEPARTAMENTO NACIONAL DE ESTRADAS DE RODAGEM - DNER (1997). Glossário de termos técnicos rodoviários. Rio de Janeiro, p.296, publ. 700/100.

DEPARTAMENTO NACIONAL DE ESTRADAS DE RODAGEM - DNER (1989). Manual de pavimentos rígidos: projeto e dimensionamento, operação e conservação - norma 35. Rio de Janeiro, v.2, p.365.

DEPARTAMENTO NACIONAL DE INFRA-ESTRUTURA DE TRANSPORTES DNIT (2005). Manual de pavimentos rígidos. 2.ed. Rio de Janeiro, p.234. 
DEPARTAMENTO NACIONAL DE INFRA-ESTRUTURA DE TRANSPORTES DNIT 061 (2004). Pavimento rígido - defeitos nos pavimentos rígidos terminologia.

EDDI, D.; SHALABY, A.; RIZKALLA, S. (2001). Glass fiber reinforced polymer dowels for concrete pavements. ACI Structural Journal, p.201-206, Mar-Apr.

FLEURY, R. C. G. (2006). Estudo experimental de mecanismos de transferência de esforços em juntas de pavimentos rígidos. Dissertação (Mestrado) - Escola de Engenharia, Universidade Federal de Goiás, Goiás.

FREMONT, W. O. (1940). Discussion of "Design of dowels in transverse joints of concrete pavements", por B. F. Friberg. American Society of Civil Engineers (ASCE), Transactions, n.105, p.1102-1111.

FRIBERG, B. F. (1940). Design of dowels in transverse joints of concrete pavements. American Society of Civil Engineers (ASCE), Transactions, n.2081, p.1076-1116.

FRIBERG, B. F. (1938). Load and deflection characteristics of dowels in transverse joints of concrete pavements. Highway Research Board, Proceedings, v.18, p.140161.

GRINTER, L. E. (1940). Discussion of "Design of dowels in transverse joints of concrete pavements", por B. F. Friberg. American Society of Civil Engineers (ASCE), Transactions, n.105, p.1096-1101.

GULYAS, R. (2006). O dilema das placas de concreto: problemas de empenamento. Revista PI - Pisos Industriais, Reggenza Editorial, Biblioteca Técnica.

GUO, H.; SHERWOOD, J. A.; SNYDER, M. B. (1995). Component dowel-bar model for load transfer systems in PCC pavements. Journal of Transportation Engineering, ASCE, v.121, n.3, p.289-298, May-June.

HOFBECK, J. A.; IBRAHIM, I. O.; MATTOCK, A. H. (1969). Shear transfer in reinforced concrete. ACI Structural Journal, p.119-128, fev.

HUANG, Y. H.; WANG, S. T. (1973). Finite-element analysis of concrete slabs and its implications for rigid pavement design. Highway Research Record, n.466, p.55-69. 
IOANNIDES, A. M.; KOROVESIS, G. T. (1992). Analysis and design of doweled slabon-grade pavement systems. Journal of Transportation Engineering, v.118, n.6, p.745-768, Nov-Dec.

KOTINDA, T. I. (2005). Modelagem numérica de vigas mistas aço-concreto simplesmente apoiadas: ênfase ao estudo da interface laje-viga. Dissertação (Mestrado) - Escola de Engenharia de São Carlos, Universidade de São Paulo, São Paulo.

MAGGI, P. L. O. (2004). Comportamento de pavimentos de concreto estruturalmente armados sob carregamentos estáticos e repetidos. Tese (Doutorado) - Escola de Engenharia de São Carlos, Universidade de São Paulo, São Paulo.

MANNAVA, S. S.; BUSH, T. D.; KUKRETI, A. R. (1999). Load deflection behavior of smooth dowels. ACI Structural Journal, p.891-898, Nov-Dec.

MATTOCK, A. H.; HAWKINS, N. M. (1972). Shear transfer in reinforced concrete recent research. PCI Journal, p.55-75, Mar-Apr.

MURISON, S.; SHALABY, A.; MUFTI, A. (2004). Laboratory evaluation of concretefilled GFRP dowels in jointed concrete pavements. In: Annual Conference of the Transportation Association of Canada. Quebec.

MURISSON, S.; SHALABY, A.; MUFTI, A. (2002). Modeling of concrete pavement dowel-slab interaction. In: Transportation Specialty Conference of the Canadian Society for Civil Engineering, 4. Canada.

PITTA, M. R. (1998). Estudo Técnico - ET 22: Selagem de juntas em pavimentos de concreto. Associação Brasileira de Cimento Portland (ABCP), São Paulo.

PNA Construction Technologies (1). Disponível em: <http://www.pnainc.com/products/diamond_dowel/>. Acesso em: 18 jun. 2006.

PORTLAND CEMENT ASSOCIATION - PCA (1984). Thickness design for concrete highway and street pavements. EB109.01P, Illinois, EUA, p.47. 
SCARPAS, A.; EHROLA, E.; JUDYCKI, J. (1994). Simulation of load transfer across joints in RC pavements. In: International Workshop on the Design and Evaluation of Concrete Pavements, 3. p.249-258.

SEVERI, A. A. (2002). Estudo dos gradientes térmicos em pavimentos de concreto de cimento portland no ambiente Tropical. São Paulo. Tese (doutorado) - Escola Politécnica da Universidade de São Paulo, São Paulo.

SHAW L.; SHAW R. (2005). Disk plate concrete dowel system - claims. Disp. em: <http://www1.uspto.gov/web/patents/patog/week40/OG/html/1311-/US0692646320061003.html>. Acesso em: 15 abr. 2007.

SILVA, P. D. E. (2001). Estudo do reforço de concreto de cimento (Whitetopping) na pista circular experimental do Instituto de Pesquisas Rodoviárias. Tese (doutorado) - Universidade Federal do Rio de Janeiro, COPPE, Rio de Janeiro.

TELLER, L. W.; CASHELL, H. D. (1958). Performance of doweled joints under repetitive loading. Public Roads, v.30, n.1, p.1-24.

TELLER, L.W.; SUTHERLAND, E.C. (1935). The structural design of concrete pavements. Part I - A description of the investigation. Public Roads, v.16, n.8 e 9.

TERTULIANO, G. (2005). Avaliação experimental de mecanismos de transferência de esforços cisalhantes em juntas de pavimentos rígidos. Dissertação (mestrado) - Universidade Federal de Goiás.

TIMOSHENKO, P.; LESSELL, J. (1925). Applied elasticity. Westinghouse Technical Night School Press.

USIMINAS (2006). Catálogo de Produtos: Chapas Grossas, estrutural para construção civil. Disponível em: <http://www.usiminas.com.br/produtos/>. Acesso em: 14 jun. 2006.

WALKER, W. W.; HOLLAND, J. A. Plate dowels for slabs on ground. PNA Construction and Technologies. Disponível em: <http://www.pnainc.com/articles/platedowel.pdf>. Acesso em: 11 set. 2004. 
WANG, T. K., BITTENCOURT, T. N. (1998). Identificação de processos de fraturamento no concreto estrutural. Escola Politécnica da Universidade de São Paulo, Boletim Técnico, BT/PEF-9801, ISSN 0103-9822. Disponível em: <http://www.Imc.ep.usp.br/people/tbitten/gmec/publicacoes.htm\#boletins>. Acesso em: 17 set 2007.

WESTERGAARD, H. M. (1926). Stress in concrete pavements of airfields. Public Roads, v.7, p. 25-35, Apr.

WESTERGAARD, H. M. (1927). Analysis of stresses in concrete pavements due to variations of temperature. Proceedings of Highway Research Board, v.6, Washington, D. C., p.205-218.

WESTERGAARD, H. M. (1928). Spacing of dowels. In: Annual Meeting, 8. Proceedings of Highway Research Board, p.154-158.

YU, H. T.; TAYABJI, S. D. (2007). The need for improved specifications on dowel bar placement tolerance In: Annual Meeting, 86. Proceedings of Transportation Research Board, Washington, DC, Jan. 


\section{APÊNDICE A \\ EXEMPLO DE CÁLCULO}

Este item apresenta um exemplo do cálculo feito para as resultantes da fundação. Os cálculos foram feitos para a placa JS12BCM na força última de 100,4kN.

\section{A.1 CÁlCULO DO COMPRIMENTO L}

Para a determinação de $L_{u}$ e $L_{L}$ foram utilizados os deslocamentos verticais obtidos pelos transdutores, como apresentado na Figura A.1.

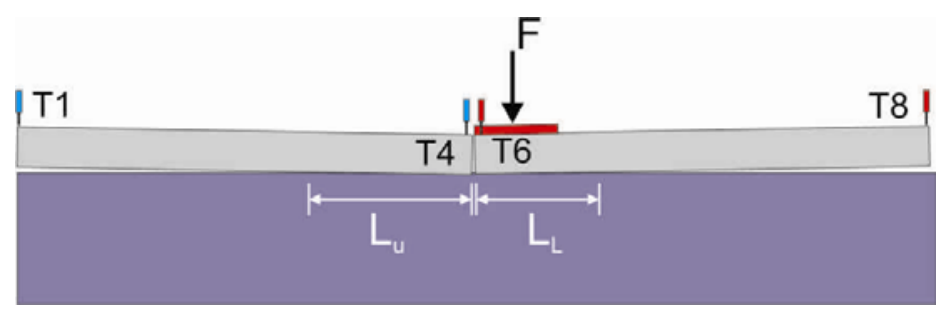

Figura A.1 - Configuração deformada dos modelos

A Tabela A.1 apresenta os resultados experimentais do modelo JS12BCM.

Tabela A.1 - Resultados do modelo JS12BCM - deslocamentos

\begin{tabular}{|c|c|c|c|c|c|}
\hline \multirow{2}{*}{ Modelo } & $F_{u}$ & $\mathrm{~T} 1$ & $\mathrm{~T} 8$ & $\mathrm{~T} 4\left(d_{u}\right)$ & $\mathrm{T} 6\left(d_{L}\right)$ \\
\cline { 2 - 6 } & $\mathrm{kN}$ & $\mathrm{mm}$ & $\mathrm{mm}$ & $\mathrm{mm}$ & $\mathrm{mm}$ \\
\hline JS12BCM & 100,4 & $-20,67$ & $-9,26$ & 7,12 & 7,66 \\
\hline
\end{tabular}

$L_{u}=\frac{d_{u} \cdot 110}{d_{u}-T 1}=\frac{7,12 \cdot 110}{7,12-(-20,67)} \therefore 28,18 \mathrm{~cm}$

$L_{L}=\frac{d_{L} \cdot 110}{d_{L}-T 8}=\frac{7,66 \cdot 110}{7,66-(-9,26)} \therefore 49,79 \mathrm{~cm}$ 


\section{A.2 CÁlCULO DA RESULTANTE EXPERIMENTAL}

A Tabela A.2 apresenta as leituras obtidas pelas células de carga do modelo JS12BCM.

Tabela A.2 - Resultados do modelo JS12BCM - células de carga

\begin{tabular}{|c|c|c|c|c|c|}
\hline \multirow{2}{*}{ Modelo } & $F_{u}$ & $L_{u}$ & $L_{L}$ & $C_{u}$ & $C_{L}$ \\
\cline { 2 - 6 } & $\mathrm{kN}$ & $\mathrm{cm}$ & $\mathrm{cm}$ & $\mathrm{kN}$ & $\mathrm{kN}$ \\
\hline JS12BCM & 100,4 & 28,18 & 49,79 & 0,95 & 0,93 \\
\hline
\end{tabular}

$R_{u}+R_{L}=F$

$\frac{R_{u}}{C_{u} \cdot L_{u}}=\frac{R_{L}}{C_{L} \cdot L_{L}} \quad \longrightarrow \quad R_{L}=R_{u} \cdot \frac{C_{L} \cdot L_{L}}{C_{u} \cdot L_{u}}(2)$

Substituindo (2) em (1):

$$
\begin{aligned}
& \left.R_{u}+R_{u} \cdot \frac{C_{L} \cdot L_{L}}{C_{u} \cdot L_{u}}=F \quad \longrightarrow R_{u}\left(\frac{C_{L} \cdot L_{L}}{C_{u} \cdot L_{u}}+1\right)=F \quad \longrightarrow \quad R_{u}=\frac{F}{\left(\frac{C_{L} \cdot L_{L}}{C_{u} \cdot L_{u}}\right)}\right) \\
& R_{u}=\frac{100,4}{\left(\frac{0,93 \cdot 49,79}{0,95 \cdot 28,18}+1\right)} \quad \longrightarrow \quad R_{u}=36,78 \mathrm{kN} \\
& R_{L}=F-R_{u} \longrightarrow R_{L}=100,40-35,80 \quad \longrightarrow \quad R_{L}=63,61 \mathrm{kN}
\end{aligned}
$$




\section{A.3 CÁlCULO DA RESULTANTE TEÓRICA PELO $1^{\circ}$ MÉTODO}

O primeiro cálculo das resultantes teóricas $R_{u, t e o}$ e $R_{L, t e o}$ considerou a reação da fundação como sendo triangular, como apresentado na Figura A.2.

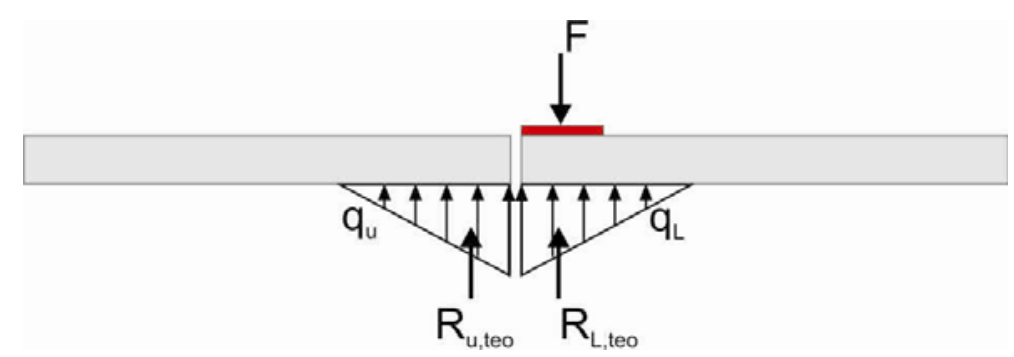

Figura A.2 - Forças atuantes consideradas para reação triangular

$\frac{R_{L, \text { teo }}}{d_{L} \cdot L_{L}}=\frac{R_{u, \text { teo }}}{d_{u} \cdot L_{u}} \quad \longrightarrow \quad R_{L, \text { teo }}=R_{u, \text { teo }} \cdot\left(\frac{d_{L} \cdot L_{L}}{d_{u} \cdot L_{u}}\right)$

$R_{L, \text { teo }}+R_{u, \text { teo }}=F \quad \longrightarrow \quad R_{u, \text { teo }} \cdot\left(\frac{d_{L} \cdot L_{L}}{d_{u} \cdot L_{u}}\right)+R_{u, \text { teo }}=F \longrightarrow R_{u, \text { teo }}=\frac{F}{\frac{d_{L} \cdot L_{L}}{d_{u} \cdot L_{u}}+1}$

$R_{u, t e o}=\frac{100,40}{\frac{7,66 \cdot 49,79}{7,12 \cdot 28,18}+1}=34,60 \mathrm{kN}$

$R_{L, \text { teo }}=F-R_{u, \text { teo }} \quad \longrightarrow \quad R_{L, \text { teo }}=65,80 \mathrm{kN}$

\section{A.4 CÁlCULO DA RESULTANTE TEÓRICA PELO $2^{\circ}$ MÉTODO}

O segundo cálculo das resultantes teóricas $R_{u, t e o}$ e $R_{L, t e o}$ considerou a reação da fundação como parabólica, como apresentado na Figura A.3 


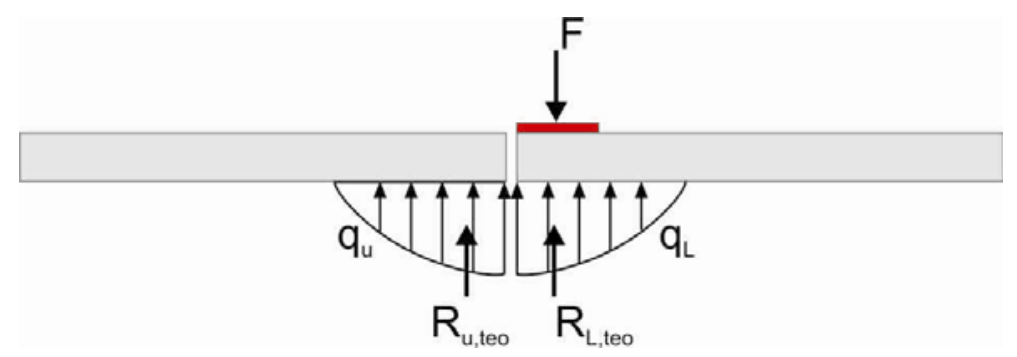

Figura A.3 - Forças atuantes consideradas para reação parabólica

$\frac{R_{L, \text { teo }}}{d_{L}^{2} \cdot L_{L}}=\frac{R_{u, t e o}}{d_{u}^{2} \cdot L_{u}} \quad \longrightarrow \quad R_{L, t e o}=R_{u, t e o} \cdot\left(\frac{d_{L}^{2} \cdot L_{L}}{d_{u}^{2} \cdot L_{u}}\right)$

$R_{u, \text { teo }}+R_{L, \text { teo }}=F \longrightarrow R_{u, \text { teo }}+R_{u, \text { teo }} \cdot\left(\frac{d_{L}^{2} \cdot L_{L}}{d_{u}^{2} \cdot L_{u}}\right)=F \quad \longrightarrow \quad R_{u, \text { teo }}=\frac{F}{\frac{d_{L}^{2} \cdot L_{L}}{d_{u}^{2} \cdot L_{u}}+1}$

$R_{u, \text { teo }}=\frac{100,40}{\frac{7,66^{2} \cdot 49,79}{7,12^{2} \cdot 28,18}+1}=32,96 \mathrm{kN}$

$R_{L, \text { teo }}=F-R_{\text {u,teo }} \quad \longrightarrow \quad R_{L, \text { teo }}=67,44 \mathrm{kN}$

A Tabela A.3 apresenta os resultados experimentais dos modelos e as variáveis encontradas. 
Tabela A.3 - Resultados experimentais para o cálculo das resultantes de forças na fundação

\begin{tabular}{|c|c|c|c|c|c|c|c|c|c|}
\hline & $F_{u}$ & $\mathrm{~T} 1$ & T8 & ${ }_{\mathrm{T} 4}\left(d_{u}\right)$ & ${ }_{\mathrm{T}}\left(d_{L}\right)$ & $L_{u}$ & $L_{L}$ & $\left.{ }_{\mathrm{C} 2(} C_{L}\right)$ & ${ }_{\text {C3}}\left(C_{u}\right)$ \\
\hline & $\mathrm{kN}$ & $\mathrm{mm}$ & $\mathrm{mm}$ & $\mathrm{mm}$ & $\mathrm{mm}$ & $\mathrm{cm}$ & $\mathrm{cm}$ & $\mathrm{kN}$ & $\mathrm{kN}$ \\
\hline JS12BCM & 100,40 & $-20,67$ & $-9,26$ & 7,12 & 7,66 & 28,18 & 49,79 & 0,93 & 0,95 \\
\hline JS12BQM & 106,78 & $-12,43$ & $-5,97$ & 5,13 & 5,99 & 32,12 & 55,12 & 0,47 & 0,53 \\
\hline JS12PMM & 74,17 & $-21,27$ & $-10,97$ & 7,37 & 10,02 & 28,31 & 52,50 & 0,77 & 0,94 \\
\hline JS12DMM & 237,91 & $-52,68$ & $-8,69$ & 10,24 & 11,03 & 17,91 & 61,54 & 0,87 & 1,16 \\
\hline JS16BCM & 172,24 & $-9,67$ & $-9,84$ & 5,13 & 8,24 & 38,15 & 50,14 & 0,39 & 0,63 \\
\hline JS16BQM & 189,54 & $-23,01$ & $-13,28$ & 6,82 & 8,85 & 25,14 & 43,99 & 0,69 & 0,89 \\
\hline JS16PMM & 134,59 & $-10,76$ & 0,82 & 4,98 & 5,15 & 34,80 & 130,81 & 0,42 & 0,40 \\
\hline JS16DMM & 274,41 & $-38,24$ & $-14,38$ & 9,47 & 11,53 & 21,84 & 48,95 & 1,02 & 0,97 \\
\hline JM12BCM & 80,20 & $-8,91$ & $-5,87$ & 2,50 & 3,40 & 24,13 & 40,33 & 0,11 & 0,65 \\
\hline JM12BQM & 86,10 & $-9,10$ & $-5,86$ & 3,17 & 4,87 & 28,45 & 49,96 & 0,16 & 1,12 \\
\hline JM12PMM & 89,90 & $-21,53$ & $-5,73$ & 4,97 & - & 20,63 & - & 0,46 & 0,44 \\
\hline JM12DMM & 75,20 & $-15,94$ & $-6,12$ & 7,69 & 9,32 & 35,79 & 66,42 & 0,97 & 0,88 \\
\hline JM16BCM & 101,00 & $-10,38$ & $-7,41$ & 2,70 & 3,67 & 22,71 & 36,47 & 0,21 & 0,75 \\
\hline JM16BQM & 100,60 & $-10,41$ & $-5,60$ & 2,43 & 3,46 & 20,81 & 42,00 & 0,15 & 0,53 \\
\hline JM16PMM & 170,30 & $-24,56$ & $-9,84$ & 6,69 & 9,94 & 23,56 & 55,28 & 1,21 & 1,29 \\
\hline JM16DMM & 170,00 & $-23,96$ & $-11,73$ & 7,95 & 11,99 & 27,41 & 55,62 & 0,91 & 0,79 \\
\hline JS12SDM & 34,04 & $-3,10$ & $-1,59$ & 2,24 & 3,44 & 46,16 & 75,31 & 0,05 & 0,04 \\
\hline JS16SDM & 76,45 & $-5,98$ & $-2,54$ & 3,02 & 3,56 & 36,91 & 64,23 & 0,05 & 0,10 \\
\hline JS12BCC & 97,69 & $-10,92$ & $-6,03$ & 4,72 & 4,43 & 33,17 & 46,55 & 0,13 & 0,06 \\
\hline JS12PMC & 100,75 & $-9,19$ & $-3,70$ & 3,86 & 4,03 & 32,53 & 57,36 & - & 0,14 \\
\hline JS12DMC & 128,21 & $-24,16$ & $-13,76$ & 6,43 & 7,74 & 23,12 & 39,59 & 0,44 & 0,50 \\
\hline JS16BCC & 215,85 & $-34,68$ & $-13,23$ & 8,41 & 13,88 & 21,46 & 56,33 & 0,67 & 0,82 \\
\hline
\end{tabular}




\section{APÊNDICE B}

\section{RESULTADOS EXPERIMENTAIS}

Neste item são apresentados resultados experimentais de forma mais detalhada. As Tabelas B.1 a B.4 apresentam as leituras das células de carga para os modelos dotados de juntas moldadas. As Tabelas B.5 a B.8, para aqueles com apresentam as leituras das células de carga para os modelos dotados de juntas serradas.

Trechos das Tabelas AN.5 a AN.8 foram extraídos, em virtude do grande número de dados.

Tabela B.1 - Forças nas células de carga (kN) - junta moldada

\begin{tabular}{|c|c|c|c|c|c|c|c|}
\hline \multicolumn{5}{|c|}{ JM12BCM } & \multicolumn{4}{|c|}{ JM12BQM } \\
\hline$F$ & CEL1 & CEL2 & CEL3 & $F$ & CEL1 & CEL2 & CEL3 \\
\hline 0,00 & $-0,04$ & $-0,02$ & 0,00 & 0,00 & $-0,08$ & $-0,01$ & $-0,01$ \\
\hline 5,07 & $-0,04$ & $-0,02$ & 0,04 & 5,18 & $-0,08$ & 0,01 & 0,23 \\
\hline 10,13 & $-0,04$ & $-0,04$ & 0,05 & 10,42 & $-0,04$ & 0,02 & 0,36 \\
\hline 14,97 & $-0,04$ & $-0,01$ & 0,05 & 15,08 & $-0,11$ & 0,04 & 0,46 \\
\hline 20,09 & $-0,04$ & $-0,01$ & 0,08 & 20,21 & $-0,04$ & 0,05 & 0,53 \\
\hline 25,05 & $-0,04$ & 0,00 & 0,10 & 25,10 & $-0,04$ & 0,07 & 0,56 \\
\hline 30,57 & $-0,04$ & 0,00 & 0,14 & 30,17 & $-0,08$ & 0,07 & 0,62 \\
\hline 35,41 & $-0,08$ & 0,01 & 0,20 & 35,18 & $-0,04$ & 0,09 & 0,68 \\
\hline 40,19 & $-0,08$ & 0,01 & 0,23 & 40,24 & $-0,11$ & 0,09 & 0,73 \\
\hline 45,14 & $-0,04$ & 0,04 & 0,30 & 45,03 & $-0,04$ & 0,09 & 0,77 \\
\hline 50,55 & 0,04 & 0,05 & 0,33 & 50,15 & $-0,04$ & 0,11 & 0,83 \\
\hline 60,39 & 0,00 & 0,10 & 0,43 & 55,16 & $-0,04$ & 0,12 & 0,87 \\
\hline 65,12 & $-0,04$ & 0,07 & 0,50 & 60,28 & $-0,08$ & 0,11 & 0,90 \\
\hline 70,41 & 0,00 & 0,09 & 0,53 & 65,23 & $-0,04$ & 0,14 & 0,95 \\
\hline 75,36 & $-0,04$ & 0,09 & 0,59 & 70,18 & $-0,04$ & 0,15 & 0,99 \\
\hline 80,15 & $-0,04$ & 0,11 & 0,65 & 75,54 & $-0,11$ & 0,15 & 1,05 \\
\hline 85,55 & $-0,08$ & 0,11 & 0,70 & 79,92 & $-0,04$ & 0,15 & 1,07 \\
\hline 90,45 & $-0,04$ & 0,15 & 0,75 & 86,12 & 0,00 & 0,16 & 1,12 \\
\hline & & & & 90,16 & $-0,04$ & 0,19 & 1,18 \\
\hline & & & & 95,12 & $-0,04$ & 0,17 & 1,22 \\
\hline & & & & 99,78 & $-0,04$ & 0,16 & 1,28 \\
\hline
\end{tabular}


Tabela B.2 - Forças nas células de carga (kN) - junta moldada

\begin{tabular}{|c|c|c|c|c|c|c|c|}
\hline \multicolumn{7}{|c|}{ JM12PMM } & \multicolumn{4}{c|}{ JM12DMM } \\
\hline$F$ & CEL1 & CEL2 & CEL3 & $F$ & CEL1 & CEL2 & CEL3 \\
\hline$-0,06$ & $-0,04$ & 0,00 & $-0,01$ & $-0,06$ & $-0,04$ & 0,00 & $-0,03$ \\
\hline 5,07 & $-0,04$ & 0,01 & $-0,01$ & 5,75 & 0,00 & 0,01 & $-0,01$ \\
\hline 10,25 & $-0,04$ & 0,04 & 0,00 & 10,13 & $-0,04$ & 0,02 & 0,01 \\
\hline 15,14 & $-0,04$ & 0,04 & $-0,01$ & 15,14 & $-0,15$ & 0,05 & 0,05 \\
\hline 19,98 & $-0,04$ & 0,06 & 0,03 & 20,38 & $-0,15$ & 0,06 & 0,06 \\
\hline 25,33 & $-0,04$ & 0,05 & 0,03 & 25,27 & $-0,15$ & 0,12 & 0,10 \\
\hline 30,00 & 0,11 & 0,07 & 0,01 & 30,23 & $-0,15$ & 0,17 & 0,13 \\
\hline 35,52 & $-0,04$ & 0,11 & 0,06 & 35,35 & $-0,04$ & 0,30 & 0,24 \\
\hline 40,07 & 0,15 & 0,14 & 0,08 & 31,31 & $-0,15$ & 0,31 & 0,23 \\
\hline 45,37 & 0,15 & 0,15 & 0,09 & 40,30 & $-0,15$ & 0,39 & 0,28 \\
\hline 49,24 & $-0,04$ & 0,21 & 0,13 & 45,20 & $-0,15$ & 0,46 & 0,35 \\
\hline 54,82 & $-0,04$ & 0,25 & 0,14 & 50,66 & $-0,04$ & 0,54 & 0,40 \\
\hline 61,42 & 0,15 & 0,29 & 0,20 & 55,73 & $-0,15$ & 0,69 & 0,56 \\
\hline 65,80 & $-0,04$ & 0,32 & 0,23 & 60,22 & $-0,15$ & 0,72 & 0,59 \\
\hline 70,41 & 0,15 & 0,36 & 0,25 & 65,29 & $-0,04$ & 0,76 & 0,65 \\
\hline 75,48 & 0,15 & 0,40 & 0,30 & 70,47 & 0,00 & 0,87 & 0,78 \\
\hline 80,60 & $-0,04$ & 0,41 & 0,34 & 75,19 & 0,00 & 0,97 & 0,88 \\
\hline 85,55 & 0,08 & 0,45 & 0,39 & 75,71 & 0,08 & 0,89 & 1,09 \\
\hline 89,88 & $-0,04$ & 0,46 & 0,44 & 80,26 & 0,00 & 0,94 & 1,13 \\
\hline 95,00 & 0,15 & 0,42 & 0,60 & & & & \\
\hline 99,90 & $-0,04$ & 0,45 & 0,68 & & & & \\
\hline 106,15 & 0,15 & 0,40 & 0,82 & & & & \\
\hline 110,42 & 0,11 & 0,40 & 0,93 & & & & \\
\hline
\end{tabular}


Tabela B.3 - Forças nas células de carga $(\mathrm{kN})$ - junta moldada

\begin{tabular}{|c|c|c|c|c|c|c|c|}
\hline \multicolumn{7}{|c|}{ JM16BCM } & \multicolumn{4}{|c|}{ JM16BQM } \\
\hline$F$ & CEL1 & CEL2 & CEL3 & $F$ & CEL1 & CEL2 & CEL3 \\
\hline$-0,06$ & $-0,08$ & $-0,01$ & 0,00 & 0,00 & 0,11 & 0,01 & 0,00 \\
\hline 5,46 & $-0,08$ & 0,02 & 0,01 & 5,18 & $-0,04$ & 0,00 & 0,00 \\
\hline 10,25 & $-0,08$ & 0,00 & 0,01 & 10,42 & $-0,04$ & 0,00 & 0,01 \\
\hline 15,26 & $-0,08$ & 0,02 & 0,03 & 15,26 & $-0,04$ & 0,01 & 0,03 \\
\hline 20,09 & $-0,08$ & 0,01 & 0,06 & 20,21 & 0,11 & 0,00 & 0,05 \\
\hline 24,99 & 0,04 & 0,05 & 0,04 & 25,67 & $-0,04$ & $-0,01$ & 0,04 \\
\hline 25,44 & $-0,08$ & 0,04 & 0,06 & 29,94 & $-0,04$ & 0,04 & 0,06 \\
\hline 30,05 & $-0,04$ & 0,05 & 0,08 & 35,52 & $-0,04$ & 0,04 & 0,10 \\
\hline 35,06 & $-0,08$ & 0,05 & 0,11 & 40,41 & $-0,04$ & 0,06 & 0,11 \\
\hline 40,19 & $-0,04$ & 0,10 & 0,14 & 45,25 & $-0,04$ & 0,06 & 0,15 \\
\hline 45,42 & $-0,08$ & 0,10 & 0,19 & 50,26 & $-0,04$ & 0,06 & 0,19 \\
\hline 50,55 & $-0,08$ & 0,09 & 0,25 & 55,67 & 0,11 & 0,09 & 0,20 \\
\hline 55,33 & 0,00 & 0,12 & 0,26 & 60,56 & 0,15 & 0,10 & 0,24 \\
\hline 60,51 & 0,00 & 0,14 & 0,31 & 65,00 & $-0,04$ & 0,11 & 0,28 \\
\hline 65,12 & 0,04 & 0,14 & 0,35 & 70,24 & 0,11 & 0,11 & 0,31 \\
\hline 70,47 & $-0,04$ & 0,15 & 0,41 & 75,59 & $-0,04$ & 0,11 & 0,34 \\
\hline 75,71 & $-0,08$ & 0,16 & 0,45 & 80,37 & $-0,04$ & 0,14 & 0,36 \\
\hline 80,77 & 0,00 & 0,17 & 0,50 & 85,50 & 0,15 & 0,16 & 0,41 \\
\hline 85,61 & 0,04 & 0,19 & 0,56 & 90,39 & 0,15 & 0,15 & 0,44 \\
\hline 90,45 & $-0,04$ & 0,17 & 0,62 & 95,06 & 0,08 & 0,14 & 0,49 \\
\hline 94,60 & 0,04 & 0,20 & 0,68 & 100,63 & 0,11 & 0,15 & 0,53 \\
\hline 100,98 & 0,00 & 0,21 & 0,75 & 105,24 & 0,19 & 0,14 & 0,58 \\
\hline 100,75 & 0,04 & 0,20 & 0,74 & 110,59 & $-0,04$ & 0,15 & 0,63 \\
\hline 105,76 & 0,00 & 0,21 & 0,82 & 115,89 & 0,15 & 0,15 & 0,68 \\
\hline 110,37 & 0,08 & 0,21 & 0,84 & 120,56 & 0,11 & 0,14 & 0,73 \\
\hline
\end{tabular}


Tabela B.4 - Forças nas células de carga (kN) - junta moldada

\begin{tabular}{|c|c|c|c|c|c|c|c|}
\hline \multicolumn{4}{|c|}{ JM16PMM } & \multicolumn{4}{|c|}{ JM16DMM } \\
\hline$F$ & CEL1 & CEL2 & CEL3 & $F$ & CEL1 & CEL2 & CEL3 \\
\hline 0,06 & $-0,04$ & $-0,02$ & $-0,03$ & 0,00 & 0,04 & 0,00 & $-0,01$ \\
\hline 5,07 & 0,00 & 0,02 & 0,04 & 5,07 & $-0,04$ & 0,01 & 0,00 \\
\hline 10,19 & $-0,04$ & 0,04 & 0,06 & 9,90 & $-0,11$ & 0,01 & 0,03 \\
\hline 15,37 & $-0,08$ & 0,09 & 0,08 & 15,20 & $-0,08$ & 0,04 & 0,03 \\
\hline 15,08 & $-0,08$ & 0,06 & 0,09 & 20,09 & $-0,15$ & 0,04 & 0,04 \\
\hline 20,15 & 0,00 & 0,12 & 0,10 & 25,10 & $-0,08$ & 0,05 & 0,03 \\
\hline 25,33 & $-0,04$ & 0,17 & 0,15 & 30,11 & $-0,11$ & 0,09 & 0,04 \\
\hline 30,28 & $-0,04$ & 0,22 & 0,16 & 35,46 & $-0,08$ & 0,07 & 0,04 \\
\hline 35,58 & $-0,08$ & 0,26 & 0,24 & 40,13 & $-0,11$ & 0,07 & 0,05 \\
\hline 40,13 & $-0,04$ & 0,30 & 0,28 & 45,31 & $-0,11$ & 0,10 & 0,04 \\
\hline 45,08 & 0,00 & 0,35 & 0,30 & 50,20 & $-0,11$ & 0,12 & 0,06 \\
\hline 50,49 & $-0,08$ & 0,37 & 0,34 & 55,27 & $-0,15$ & 0,12 & 0,08 \\
\hline 54,99 & $-0,08$ & 0,41 & 0,39 & 60,28 & $-0,11$ & 0,15 & 0,09 \\
\hline 60,17 & $-0,04$ & 0,45 & 0,43 & 65,69 & $-0,15$ & 0,19 & 0,09 \\
\hline 55,50 & 0,00 & 0,42 & 0,38 & 70,64 & $-0,15$ & 0,19 & 0,10 \\
\hline 60,45 & 0,00 & 0,45 & 0,41 & 75,31 & $-0,15$ & 0,22 & 0,14 \\
\hline 65,06 & 0,04 & 0,47 & 0,44 & 80,20 & $-0,19$ & 0,24 & 0,14 \\
\hline 70,53 & $-0,04$ & 0,54 & 0,48 & 85,38 & $-0,15$ & 0,30 & 0,18 \\
\hline 75,19 & 0,04 & 0,56 & 0,50 & 91,02 & $-0,11$ & 0,31 & 0,21 \\
\hline 80,43 & 0,04 & 0,60 & 0,56 & 95,34 & $-0,11$ & 0,35 & 0,21 \\
\hline 85,44 & 0,00 & 0,66 & 0,60 & 100,69 & $-0,08$ & 0,37 & 0,24 \\
\hline 90,22 & $-0,04$ & 0,69 & 0,63 & 105,58 & $-0,08$ & 0,39 & 0,25 \\
\hline 96,37 & 0,00 & 0,71 & 0,67 & 110,25 & $-0,11$ & 0,45 & 0,29 \\
\hline 100,52 & 0,00 & 0,74 & 0,70 & 115,32 & 0,00 & 0,49 & 0,31 \\
\hline 105,07 & 0,08 & 0,79 & 0,75 & 119,70 & $-0,04$ & 0,51 & 0,34 \\
\hline 110,54 & 0,04 & 0,81 & 0,78 & 125,11 & $-0,08$ & 0,55 & 0,38 \\
\hline 115,94 & 0,00 & 0,86 & 0,82 & 131,14 & $-0,04$ & 0,59 & 0,43 \\
\hline 120,84 & 0,04 & 0,90 & 0,85 & 135,87 & $-0,04$ & 0,62 & 0,45 \\
\hline 125,28 & 0,00 & 0,94 & 0,89 & 140,02 & 0,04 & 0,66 & 0,48 \\
\hline 131,14 & 0,04 & 0,99 & 0,94 & 145,32 & 0,04 & 0,70 & 0,49 \\
\hline 140,88 & 0,08 & 1,07 & 1,02 & 151,24 & 0,08 & 0,75 & 0,58 \\
\hline 145,43 & 0,08 & 1,10 & 1,08 & 156,87 & 0,04 & 0,77 & 0,62 \\
\hline 151,86 & 0,11 & 1,14 & 1,13 & 161,71 & 0,04 & 0,80 & 0,67 \\
\hline 155,11 & 0,08 & 1,09 & 1,14 & 165,24 & 0,00 & 0,85 & 0,70 \\
\hline 160,51 & 0,04 & 1,14 & 1,21 & 170,02 & 0,04 & 0,91 & 0,79 \\
\hline 165,81 & 0,04 & 1,17 & 1,24 & 161,65 & 0,08 & 0,82 & 0,93 \\
\hline 170,30 & 0,08 & 1,21 & 1,29 & 165,64 & 0,04 & 0,84 & 0,98 \\
\hline 177,25 & 0,04 & 1,16 & 1,62 & & & & \\
\hline 180,15 & 0,11 & 1,14 & 1,72 & & & & \\
\hline 186,70 & 0,00 & 1,21 & 1,82 & & & & \\
\hline
\end{tabular}


Tabela B.5 - Forças nas células de carga (kN) - junta serrada

\begin{tabular}{|c|c|c|c|c|c|c|c|}
\hline \multicolumn{4}{|c|}{ JS12BCM } & \multicolumn{4}{|c|}{ JS12BQM } \\
\hline$F$ & CEL1 & CEL2 & CEL3 & $F$ & CEL1 & CEL2 & CEL3 \\
\hline$-0,06$ & 0,00 & $-0,01$ & $-0,01$ & 0,00 & $-0,11$ & 0,00 & $-0,03$ \\
\hline 5,01 & 0,00 & 0,01 & $-0,01$ & 2,22 & 0,04 & $-0,01$ & 0,00 \\
\hline 10,19 & $-0,08$ & 0,03 & 0,01 & 4,21 & $-0,08$ & $-0,01$ & $-0,01$ \\
\hline 15,20 & $-0,04$ & 0,03 & 0,04 & 6,32 & $-0,04$ & $-0,01$ & $-0,01$ \\
\hline 19,87 & $-0,08$ & 0,04 & 0,05 & 8,14 & 0,00 & $-0,01$ & 0,00 \\
\hline 25,16 & $-0,15$ & 0,04 & 0,06 & 10,13 & $-0,08$ & 0,01 & 0,00 \\
\hline 30,17 & $-0,08$ & 0,09 & 0,11 & 12,12 & $-0,04$ & 0,00 & 0,00 \\
\hline 35,46 & $-0,11$ & 0,11 & 0,21 & 14,06 & $-0,08$ & 0,01 & 0,01 \\
\hline 40,81 & $-0,19$ & 0,18 & 0,29 & 16,05 & $-0,08$ & 0,01 & 0,00 \\
\hline 46,16 & $-0,04$ & 0,28 & 0,36 & 18,16 & $-0,11$ & 0,01 & 0,03 \\
\hline 49,46 & $-0,15$ & 0,35 & 0,41 & 20,49 & $-0,08$ & 0,01 & 0,01 \\
\hline 55,33 & $-0,11$ & 0,38 & 0,49 & 22,37 & $-0,08$ & 0,05 & 0,04 \\
\hline 60,11 & $-0,11$ & 0,44 & 0,59 & 24,36 & $-0,15$ & 0,05 & 0,03 \\
\hline 65,23 & $-0,11$ & 0,53 & 0,62 & 26,18 & $-0,11$ & 0,05 & 0,01 \\
\hline 71,32 & $-0,15$ & 0,60 & 0,70 & 28,12 & $-0,11$ & 0,05 & 0,04 \\
\hline 75,31 & $-0,11$ & 0,65 & 0,74 & 29,83 & $-0,08$ & 0,06 & 0,04 \\
\hline 81,23 & $-0,11$ & 0,72 & 0,77 & 32,10 & $-0,19$ & 0,07 & 0,04 \\
\hline 84,53 & $-0,04$ & 0,74 & 0,81 & 34,27 & $-0,15$ & 0,06 & 0,05 \\
\hline 91,64 & $-0,08$ & 0,82 & 0,91 & 36,49 & $-0,11$ & 0,06 & 0,04 \\
\hline 95,17 & $-0,11$ & 0,88 & 0,92 & 38,19 & $\begin{array}{l}-0,08 \\
\end{array}$ & 0,09 & 0,05 \\
\hline 100,40 & $-0,08$ & 0,93 & 0,95 & 40,64 & $-0,11$ & 0,10 & 0,05 \\
\hline 95,40 & $-0,08$ & 0,90 & 0,96 & 42,29 & $-0,15$ & 0,10 & 0,06 \\
\hline 106,15 & $-0,08$ & 1,07 & 1,04 & 44,51 & $-0,11$ & 0,12 & 0,08 \\
\hline 111,85 & $-0,04$ & 1,14 & 1,09 & 46,11 & $-0,11$ & 0,12 & 0,08 \\
\hline 115,60 & $-0,11$ & 1,21 & 1,10 & 47,93 & $-0,15$ & 0,12 & 0,11 \\
\hline 121,58 & $-0,08$ & 1,27 & 1,21 & 50,77 & $-0,08$ & 0,14 & 0,10 \\
\hline 125,79 & $-0,04$ & 1,32 & 1,25 & 52,08 & $-0,11$ & 0,15 & 0,11 \\
\hline & & & & 54,64 & $\begin{array}{l}-0,08 \\
\end{array}$ & 0,17 & 0,13 \\
\hline & & & & 56,18 & $-0,15$ & 0,16 & 0,13 \\
\hline & & & & 58,40 & $-0,11$ & 0,19 & 0,15 \\
\hline & & & & 60,68 & $-0,11$ & 0,21 & 0,18 \\
\hline & & & & 62,27 & $\begin{array}{l}-0,08 \\
\end{array}$ & 0,19 & 0,16 \\
\hline & & & & 64,61 & $-0,15$ & 0,22 & 0,19 \\
\hline & & & & 66,60 & $-0,08$ & 0,24 & 0,21 \\
\hline & & & & 92,67 & $-0,08$ & 0,40 & 0,41 \\
\hline & & & & 94,55 & $-0,04$ & 0,42 & 0,41 \\
\hline & & & & 96,60 & $-0,08$ & 0,44 & 0,46 \\
\hline & & & & 98,36 & $-0,11$ & 0,45 & 0,46 \\
\hline & & & & 100,06 & $-0,11$ & 0,45 & 0,48 \\
\hline & & & & 102,17 & $\begin{array}{l}-0,08 \\
\end{array}$ & 0,46 & 0,49 \\
\hline & & & & 104,22 & $-0,04$ & 0,49 & 0,50 \\
\hline & & & & 106,78 & $-0,04$ & 0,47 & 0,53 \\
\hline & & & & 103,19 & $-0,15$ & 0,50 & 0,51 \\
\hline & & & & 102,97 & $\begin{array}{l}-0,04 \\
\end{array}$ & 0,46 & 0,51 \\
\hline & & & & 102,91 & $-0,08$ & 0,46 & 0,50 \\
\hline
\end{tabular}


Tabela B.6 - Forças nas células de carga (kN) - junta serrada

\begin{tabular}{|c|c|c|c|c|c|c|c|}
\hline \multicolumn{4}{|c|}{ JS12PMM } & \multicolumn{4}{|c|}{ JS12DMM } \\
\hline$F$ & CEL1 & CEL2 & CEL3 & $F$ & CEL1 & CEL2 & CEL3 \\
\hline$-0,06$ & 0,04 & 0,01 & 0,01 & 0,09 & $-0,04$ & $-0,04$ & 0,00 \\
\hline 2,05 & 0,04 & 0,01 & $-0,01$ & 0,38 & $-0,04$ & $-0,04$ & 0,00 \\
\hline 4,21 & 0,04 & 0,02 & $-0,01$ & 0,66 & 0,00 & 0,00 & 0,00 \\
\hline 6,15 & $-0,04$ & 0,00 & $-0,01$ & 0,84 & 0,00 & 0,00 & $-0,04$ \\
\hline 8,08 & 0,00 & 0,00 & 0,01 & 1,04 & $-0,04$ & $-0,04$ & $-0,03$ \\
\hline 8,08 & 0,00 & 0,01 & $-0,01$ & 10,07 & $-0,11$ & $-0,11$ & 0,04 \\
\hline 10,13 & $-0,04$ & 0,00 & $-0,01$ & 10,41 & $-0,04$ & $-0,04$ & 0,00 \\
\hline 12,07 & $-0,04$ & 0,01 & 0,03 & 10,84 & 0,00 & 0,00 & 0,01 \\
\hline 14,12 & $-0,08$ & 0,02 & 0,00 & 20,13 & $-0,08$ & $-0,08$ & 0,03 \\
\hline 16,11 & 0,04 & 0,01 & $-0,01$ & 20,54 & $-0,11$ & $-0,11$ & 0,01 \\
\hline 18,27 & $-0,08$ & 0,01 & 0,00 & 30,22 & $-0,15$ & $-0,15$ & 0,01 \\
\hline 20,26 & $-0,08$ & 0,02 & 0,01 & 30,60 & $-0,11$ & $-0,11$ & 0,03 \\
\hline 22,26 & $-0,15$ & 0,01 & 0,00 & 40,58 & $-0,11$ & $-0,11$ & 0,03 \\
\hline 23,85 & $-0,19$ & 0,02 & 0,04 & 41,55 & $-0,04$ & $-0,04$ & 0,03 \\
\hline 26,35 & $-0,11$ & 0,06 & 0,05 & 50,22 & $-0,08$ & $-0,08$ & 0,08 \\
\hline 28,40 & $-0,15$ & 0,09 & 0,06 & 50,71 & $-0,11$ & $-0,11$ & 0,08 \\
\hline 30,40 & $-0,15$ & 0,10 & 0,10 & 60,22 & $-0,11$ & $-0,11$ & 0,15 \\
\hline 32,50 & $-0,11$ & 0,11 & 0,10 & 60,72 & $-0,04$ & $-0,04$ & 0,13 \\
\hline 34,27 & $-0,11$ & 0,15 & 0,13 & 70,02 & 0,00 & 0,00 & 0,16 \\
\hline 35,97 & $-0,23$ & 0,15 & 0,14 & 70,79 & $-0,04$ & $-0,04$ & 0,18 \\
\hline 38,25 & $-0,08$ & 0,17 & 0,14 & 80,38 & $-0,04$ & $-0,04$ & 0,23 \\
\hline 40,59 & $-0,08$ & 0,21 & 0,18 & 81,14 & $-0,08$ & $-0,08$ & 0,23 \\
\hline 42,75 & $-0,11$ & 0,24 & 0,23 & 81,75 & $-0,04$ & $-0,04$ & 0,24 \\
\hline 43,72 & $-0,11$ & 0,30 & 0,28 & 90,48 & 0,04 & 0,04 & 0,25 \\
\hline 46,79 & $-0,04$ & 0,35 & 0,30 & 91,35 & $-0,04$ & $-0,04$ & 0,26 \\
\hline 48,10 & $-0,04$ & 0,36 & 0,38 & 100,55 & $-0,04$ & $-0,04$ & 0,33 \\
\hline 50,38 & $-0,04$ & 0,42 & 0,40 & 101,49 & 0,04 & 0,04 & 0,33 \\
\hline 52,37 & 0,00 & 0,42 & 0,44 & 120,87 & $-0,04$ & $-0,04$ & 0,41 \\
\hline 54,42 & $-0,04$ & 0,46 & 0,45 & 121,90 & 0,00 & 0,00 & 0,41 \\
\hline 56,58 & 0,00 & 0,50 & 0,49 & 149,85 & $-0,04$ & $-0,04$ & 0,56 \\
\hline 58,29 & 0,00 & 0,54 & 0,55 & 150,91 & 0,00 & 0,00 & 0,58 \\
\hline 60,91 & $-0,04$ & 0,55 & 0,58 & 180,80 & $-0,04$ & $-0,04$ & 0,74 \\
\hline 62,44 & $-0,08$ & 0,60 & 0,63 & 181,81 & 0,04 & 0,04 & 0,75 \\
\hline 64,15 & 0,11 & 0,61 & 0,67 & 200,61 & $-0,04$ & $-0,04$ & 0,87 \\
\hline 67,22 & 0,00 & 0,66 & 0,75 & 201,74 & 0,00 & 0,00 & 0,88 \\
\hline 68,02 & 0,04 & 0,67 & 0,80 & 220,85 & 0,00 & 0,00 & 1,00 \\
\hline 72,06 & 0,04 & 0,75 & 0,88 & 235,36 & 0,04 & 0,04 & 1,13 \\
\hline 72,12 & 0,08 & 0,75 & 0,89 & 236,69 & $-0,04$ & $-0,04$ & 1,14 \\
\hline 74,17 & 0,04 & 0,77 & 0,94 & 237,91 & $-0,04$ & $-0,04$ & 1,16 \\
\hline 68,42 & 0,00 & 0,79 & 0,93 & 207,19 & 0,04 & 0,04 & 1,04 \\
\hline 68,31 & 0,04 & 0,76 & 0,94 & 206,33 & 0,04 & 0,04 & 0,99 \\
\hline 68,93 & 0,04 & 0,79 & 0,92 & 207,10 & $-0,04$ & $-0,04$ & 0,99 \\
\hline
\end{tabular}


Tabela B.7 - Forças nas células de carga $(\mathrm{kN})$ - junta serrada

\begin{tabular}{|c|c|c|c|c|c|c|}
\hline \multicolumn{4}{|c|}{ JS16BCM } & \multicolumn{3}{|c|}{ JS16BQM } \\
\hline$F$ & CEL1 & CEL2 & CEL3 & $F$ & CEL2 & CEL3 \\
\hline 0,00 & $-0,04$ & 0,00 & 0,00 & 0,00 & 0,02 & 0,00 \\
\hline 1,08 & $-0,04$ & $-0,01$ & 0,01 & $-0,06$ & 0,00 & 0,03 \\
\hline 1,59 & 0,00 & 0,00 & 0,03 & 1,99 & 0,02 & 0,03 \\
\hline 3,87 & 0,00 & $-0,01$ & 0,00 & 3,70 & 0,04 & 0,01 \\
\hline 5,12 & 0,04 & $-0,01$ & 0,00 & 3,47 & 0,04 & 0,03 \\
\hline 5,69 & 0,00 & 0,01 & $-0,01$ & 5,12 & 0,02 & 0,00 \\
\hline 8,94 & 0,04 & 0,00 & $-0,01$ & 5,98 & 0,02 & 0,01 \\
\hline 10,02 & 0,04 & 0,00 & 0,00 & 20,09 & 0,05 & 0,03 \\
\hline 10,70 & 0,04 & 0,01 & 0,00 & 20,61 & 0,04 & 0,01 \\
\hline 30,11 & $-0,04$ & 0,00 & 0,00 & 38,99 & 0,04 & 0,04 \\
\hline 30,23 & 0,00 & $-0,01$ & $-0,01$ & 38,37 & 0,04 & 0,03 \\
\hline 30,05 & 0,04 & 0,00 & 0,01 & 39,05 & 0,04 & 0,05 \\
\hline 40,98 & $-0,04$ & 0,01 & 0,01 & 40,64 & 0,05 & 0,04 \\
\hline 43,09 & $-0,04$ & 0,00 & 0,03 & 51,17 & 0,04 & 0,05 \\
\hline 42,81 & 0,04 & $-0,01$ & 0,03 & 51,86 & 0,05 & 0,04 \\
\hline 50,38 & $-0,04$ & 0,00 & 0,03 & 70,92 & 0,06 & 0,08 \\
\hline 49,64 & 0,00 & 0,01 & 0,01 & 69,90 & 0,07 & 0,05 \\
\hline 50,09 & $-0,04$ & 0,00 & 0,03 & 68,82 & 0,09 & 0,06 \\
\hline 62,39 & 0,00 & 0,01 & 0,01 & 92,21 & 0,16 & 0,18 \\
\hline 62,22 & 0,00 & 0,01 & 0,01 & 95,12 & 0,16 & 0,18 \\
\hline 61,30 & 0,08 & 0,00 & 0,01 & 105,47 & 0,22 & 0,29 \\
\hline 70,70 & 0,04 & 0,01 & 0,05 & 104,84 & 0,25 & 0,28 \\
\hline 70,75 & 0,00 & 0,04 & 0,03 & 150,78 & 0,49 & 0,63 \\
\hline 84,64 & 0,08 & 0,04 & 0,08 & 149,70 & 0,49 & 0,63 \\
\hline 83,05 & 0,00 & 0,05 & 0,06 & 148,45 & 0,46 & 0,64 \\
\hline 101,14 & $-0,04$ & 0,10 & 0,16 & 179,41 & 0,64 & 0,82 \\
\hline 99,61 & 0,04 & 0,06 & 0,15 & 178,33 & 0,61 & 0,83 \\
\hline 98,65 & $-0,04$ & 0,10 & 0,15 & 176,85 & 0,62 & 0,82 \\
\hline 102,34 & 0,08 & 0,10 & 0,15 & 175,83 & 0,62 & 0,82 \\
\hline 112,30 & 0,11 & 0,12 & 0,23 & 184,25 & 0,69 & 0,87 \\
\hline 150,33 & $-33,76$ & 0,29 & 0,49 & 187,10 & 0,69 & 0,87 \\
\hline 149,24 & $-33,76$ & 0,31 & 0,49 & 186,13 & 0,67 & 0,88 \\
\hline 161,25 & $-33,80$ & 0,36 & 0,56 & 184,76 & 0,67 & 0,88 \\
\hline 163,59 & $-33,76$ & 0,37 & 0,56 & 183,80 & 0,66 & 0,87 \\
\hline 168,26 & $-33,80$ & 0,36 & 0,63 & 184,14 & 0,66 & 0,87 \\
\hline 166,89 & $-33,76$ & 0,37 & 0,60 & 189,54 & 0,69 & 0,89 \\
\hline 165,69 & $-33,83$ & 0,37 & 0,60 & 188,86 & 0,67 & 0,90 \\
\hline 165,01 & $-33,80$ & 0,35 & 0,59 & 187,55 & 0,67 & 0,89 \\
\hline 172,24 & $-33,83$ & 0,39 & 0,63 & 186,53 & 0,69 & 0,90 \\
\hline 170,99 & $-33,76$ & 0,40 & 0,62 & 185,67 & 0,69 & 0,89 \\
\hline 169,85 & $-33,76$ & 0,39 & 0,62 & 185,05 & 0,67 & 0,89 \\
\hline 168,88 & $-33,80$ & 0,37 & 0,63 & 184,54 & 0,67 & 0,90 \\
\hline
\end{tabular}


Tabela B.8 - Forças nas células de carga (kN) - junta serrada

\begin{tabular}{|c|c|c|c|c|c|c|c|}
\hline \multicolumn{4}{|c|}{ JS16PMM } & \multicolumn{4}{|c|}{ JS16DMM } \\
\hline$F$ & CEL1 & CEL2 & CEL3 & $F$ & CEL1 & CEL2 & CEL3 \\
\hline 0,06 & 0,00 & $-0,01$ & $-0,01$ & 0,00 & $-0,04$ & $-0,01$ & $-0,01$ \\
\hline 0,23 & $-0,04$ & $-0,01$ & $-0,03$ & 0,00 & 0,04 & $-0,02$ & 0,00 \\
\hline 6,84 & $-0,08$ & $-0,01$ & 0,00 & 20,43 & 0,00 & $-0,02$ & 0,00 \\
\hline 7,16 & $-0,08$ & $-0,01$ & 0,01 & 19,75 & $-0,08$ & $-0,01$ & $-0,01$ \\
\hline 7,45 & $-0,08$ & $-0,04$ & $-0,03$ & 22,03 & 0,00 & $-0,01$ & 0,00 \\
\hline 7,78 & $-0,04$ & 0,00 & $-0,01$ & 21,23 & $-0,08$ & $-0,01$ & 0,03 \\
\hline 8,06 & $-0,08$ & 0,01 & 0,00 & 23,51 & $-0,04$ & 0,00 & $-0,03$ \\
\hline 8,33 & $-0,04$ & $-0,02$ & 0,03 & 23,00 & $-0,04$ & 0,01 & 0,01 \\
\hline 8,64 & $-0,08$ & $-0,04$ & $-0,03$ & 24,87 & 0,00 & 0,00 & $-0,01$ \\
\hline 8,96 & $-0,04$ & $-0,01$ & 0,01 & 25,22 & $-0,04$ & $-0,02$ & 0,00 \\
\hline 9,22 & $-0,11$ & $-0,01$ & $-0,01$ & 26,01 & $-0,04$ & $-0,01$ & $-0,01$ \\
\hline 9,51 & $-0,11$ & $-0,01$ & 0,00 & 27,09 & $-0,04$ & $-0,01$ & 0,00 \\
\hline 13,23 & $-0,11$ & 0,01 & 0,00 & 33,47 & $-0,08$ & $-0,01$ & $-0,01$ \\
\hline 13,51 & $-0,11$ & 0,00 & $-0,01$ & 36,66 & 0,00 & $-0,01$ & $-0,01$ \\
\hline 13,86 & $-0,15$ & 0,00 & 0,00 & 36,60 & 0,00 & 0,00 & $-0,03$ \\
\hline 20,39 & $-0,11$ & 0,02 & 0,00 & 43,55 & $-0,08$ & $-0,01$ & 0,01 \\
\hline 20,74 & $-0,11$ & 0,00 & $-0,01$ & 43,20 & $-0,11$ & 0,00 & 0,01 \\
\hline 25,23 & $-0,15$ & 0,00 & 0,00 & 50,49 & $-0,04$ & 0,01 & $-0,01$ \\
\hline 25,44 & $-0,11$ & 0,01 & 0,01 & 49,98 & $-0,08$ & $-0,01$ & 0,00 \\
\hline 37,34 & $-0,23$ & 0,04 & 0,05 & 74,62 & $-0,04$ & 0,04 & 0,05 \\
\hline 37,75 & $-0,19$ & 0,02 & 0,04 & 73,49 & $-0,04$ & 0,04 & 0,05 \\
\hline 38,15 & $-0,19$ & 0,02 & 0,06 & 72,69 & $-0,08$ & 0,02 & 0,05 \\
\hline 38,62 & $-0,19$ & 0,02 & 0,04 & 78,89 & $-0,04$ & 0,04 & 0,05 \\
\hline 38,98 & $-0,19$ & 0,02 & 0,04 & 77,70 & $-0,11$ & 0,04 & 0,06 \\
\hline 39,51 & $-0,19$ & 0,02 & 0,01 & 76,56 & $-0,08$ & 0,05 & 0,06 \\
\hline 40,03 & $-0,23$ & 0,02 & 0,04 & 76,16 & $-0,08$ & 0,05 & 0,06 \\
\hline 40,49 & $-0,15$ & 0,05 & 0,04 & 79,58 & $-0,08$ & 0,04 & 0,08 \\
\hline 40,96 & $-0,26$ & 0,02 & 0,05 & 81,45 & $-0,08$ & 0,07 & 0,06 \\
\hline 41,26 & $-0,19$ & 0,02 & 0,04 & 80,32 & $-0,11$ & 0,05 & 0,08 \\
\hline 56,95 & $-0,26$ & 0,05 & 0,05 & 108,26 & $-0,08$ & 0,16 & 0,20 \\
\hline 57,55 & $-0,23$ & 0,05 & 0,09 & 106,32 & $-0,15$ & 0,15 & 0,20 \\
\hline 58,22 & $-0,15$ & 0,05 & 0,08 & 105,13 & $-0,08$ & 0,14 & 0,21 \\
\hline 58,66 & $-0,19$ & 0,06 & 0,06 & 108,32 & $-0,11$ & 0,17 & 0,21 \\
\hline 66,25 & $-0,23$ & 0,07 & 0,08 & 137,86 & $-0,23$ & 0,32 & 0,38 \\
\hline 72,12 & $-0,11$ & 0,10 & 0,13 & 161,71 & $-33,91$ & 0,46 & 0,51 \\
\hline 72,15 & $-0,23$ & 0,10 & 0,13 & 162,96 & $-33,91$ & 0,46 & 0,54 \\
\hline 132,58 & $-0,15$ & 0,37 & 0,38 & 245,27 & $-33,91$ & 0,89 & 0,85 \\
\hline 133,43 & $-0,11$ & 0,40 & 0,39 & 267,30 & $-33,91$ & 0,99 & 0,92 \\
\hline 134,20 & $-0,11$ & 0,42 & 0,39 & 265,65 & $-33,87$ & 1,00 & 0,92 \\
\hline 134,59 & $-0,08$ & 0,42 & 0,40 & 264,97 & $-33,87$ & 0,97 & 0,93 \\
\hline 132,05 & $-0,04$ & 0,42 & 0,41 & 274,41 & $-33,91$ & 1,02 & 0,97 \\
\hline 131,16 & $-0,08$ & 0,39 & 0,41 & 271,97 & $-33,91$ & 1,01 & 0,94 \\
\hline 131,15 & $-0,04$ & 0,40 & 0,43 & 261,95 & $-33,98$ & 1,06 & 0,94 \\
\hline 131,18 & $-0,08$ & 0,41 & 0,43 & 256,88 & $-33,91$ & 1,02 & 0,95 \\
\hline
\end{tabular}

